UNIVERSIDAD PDLITÉCNICA DE VALENCIA

FACLLTAD DE BELLAS ARTES

DEPARTAMENTO DE COMUNICACIÓN AUDIDVISUALL

DICUMENTACIÓN E HISTTRIA DEL ARTE

TÍTULD DEL PRDGRAMA: MLISLCA

\title{
ESTUDIO DE LOS MÉTODOS \\ DE SOLFEO ESPAÑOLES \\ EN EL SIGLO XIX \\ Y PRINCIPIOS DEL XX
}

TESIS DOCTORAL

Autor: ROBERTO LORAS VILLALONGA

DIRIGIDA POR: DR. D. JOAQUÍN ARNAU AMO

DR. D. MANUEL PÉREZ GIL

Mayo 2008 


\section{$\underline{\text { Resumen (Abstract) }}$}

El presente estudio es un análisis de los métodos de solfeo existentes en el periodo que va desde principios del siglo XIX hasta 1920, de autores exclusivamente españoles. El trabajo tiene varios apartados: una declaración de intenciones en cuanto a objetivos y metodología; una ligera exposición de antecedentes en la enseñanza de esta disciplina; el cuerpo central en el que se han analizado a 37 autores, que representan un total de 70 libros o partes de métodos, en los que se examinan pormenorizadamente los contenidos pedagógicos de ellos, la idoneidad de su planteamiento y su efectividad práctica, comparándolos con los escasos programas de la asignatura existentes en la época, para distinguir si los contenidos respondían a un plan preexistente o a iniciativas personales; y también contrastándolos con los modernos principios pedagógicos. Le sigue a este grueso de la tesis un estudio comparativo de todos los métodos en cuanto a sus contenidos, para al fin llegar a una conclusión sobre los textos de enseñanza en la época estudiada.

Se completa el trabajo con un apéndice en el que se hace referencia a las lecciones de solfeo a 2 y 3 voces de Salvador Giner, descubiertas, recopiladas, arregladas y editadas por el autor de esta tesis, que aunque no constituyen un método, sí son lecciones solfísticas de ese período. Éstas se analizan deslindadamente en todos sus aspectos rítmicos, melódicos, motívicos, armónicos y formales, llegando así mismo a deducciones. También el apéndice contiene el facsímil de las portadas de todos los métodos y de algunos otros documentos de interés.

El present estudi és una anàlisi dels mètodes de solfeig existents en el període que va des de principis del segle XIX fins a 1920, d'autors exclusivament espanyols. El treball té diversos apartats: una declaració d'intencions quant a objectius i metodologia; una lleugera exposició d'antecedents en l'ensenyança d'esta disciplina; el cos central en què s'han analitzat a 37 autors, que representen un total de 70 llibres o parts de mètodes, en els que s'examinen detalladament els continguts pedagògics d'ells, la idoneïtat del seu plantejament i la seua efectivitat pràctica, comparant-los amb els pocs programes de l'assignatura existents en l'època, per a distingir si els continguts responien a un pla preexistent o a iniciatives personals; i també contrastant-los amb els moderns principis pedagògics. Li segueix a este gros de la tesi un estudi comparatiu de tots els mètodes quant als seus continguts, per a la fi arribar a una conclusió sobre els textos d'ensenyança en l'època estudiada.

Es completa el treball amb un apèndix en què es fa referència a les lliçons de solfeig a 2 i 3 veus de Salvador Giner, descobertes, recopilades, arreglades i editades per l'autor d'esta tesi, que encara que no és un mètode, sí que són lliçons solfístiques d'eixe període. Aquestes s'analitzen delimitadament en tots els seus aspectes rítmics, melòdics, motívics, harmònics i formals, arribant així mateix a deduccions. També l'apèndix conté el facsímil de les portades de tots els mètodes i d'alguns altres documents d'interès. 
The present study consists of an analysis of the contents in the existing methods of "solfeo" in the period that goes since the beginning of the XIX century until 1920, from Spanish authors exclusively.

After the declaration of objectives and methodology, the state of the question is exposed analyzing the antecedents in the teaching of this discipline. The central body of the work, in which 37 authors have been analyzed, those which represent a total of 70 books or parts of methods, consists in a detailed examination of their pedagogical contents, the suitability of their exposition and their practical effectiveness, comparing them with the little existing programs of this subject at that period, to distinguish, through this comparative methodology, if the contents responded to a pre-existing plan or to personal initiatives; and also to contrast them with the modern pedagogical principles with the intention of investigating their degree of use in our time. This thickness of the thesis is followed by a comparative study of all the methods as for their contents, to reach a conclusion on different texts from education of the "solfeo" at the studied time.

The work is completed with several appendices; one referenced to the 2 and 3 voices lessons of "solfeo" of Salvador Giner, discovered, compiled, arranged and published by the author of this thesis, which, although they do not constitute a method, they are, really, lessons of that period. These are analyzed separately in all rhythmical, melodic, motive, harmonic and formal aspects, reaching deductions likewise. In other appendices, facsimiles of the covers of all the methods and some other documents of interest are shown. 


\section{AGRADECIMIENTOS}

A mis directores:

Dr. D. Joaquín Arnau Amo por sus sabios consejos y su atención siempre amable, provechosa y estimulante.

Dr. D. Manuel Pérez Gil no sólo por su enorme y valiosa ayuda, también por su aportación bibliográfica y su formidable implicación en la elaboración de esta tesis.

Al Dr. D. José $\mathrm{M}^{\mathrm{a}}$ Vives Ramiro, compañero y amigo, quien me dio la idea de investigar a Giner y posteriormente hacer el estudio de los métodos de solfeo de su época.

A los también compañeros y amigos, D. Vicente Sanjosé Huguet y Dr. D. Vicente Sanjosé López, quienes me sugirieron el comparar los métodos analizados con programas existentes de enseñanza de la asignatura en la época tratada. Y en especial a este último por su inestimable y generosa ayuda.

Al personal de las Bibliotecas de Valencia, Cataluña y Madrid; Conservatorios Superiores de Valencia y Madrid; y Servicio de Bibliotecas y Documentación de la Universidad de Valencia. 


\section{LISTA DE ABREVIATURAS, FUENTES Y TIPOGRAFÍAS EMPLEADAS}

Times New Roman 18 puntos = rotulación puntos de la tesis

Times New Roman 14 puntos = encabezados de apartados

Times New Roman 12 puntos $=$ texto del cuerpo

Times New Roman 10 puntos = notas al pie

Times New Roman 12 puntos cursiva = citas literales

Times New Roman 11 puntos y mayor margen = citas literales largas

Arial 11 puntos $=$ encabezamientos de página

\footnotetext{
Abreviaturas:

p. = página

pp. = páginas
} 


\section{ÍNDICE DE LA TESIS}

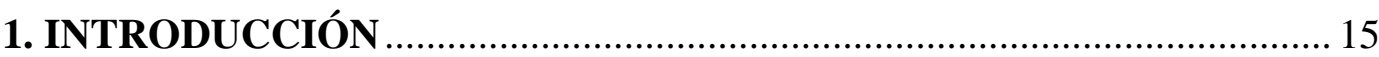

1.1. Tema de estudio y organización del trabajo ........................................ 17

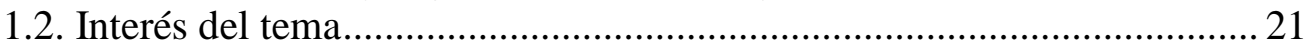

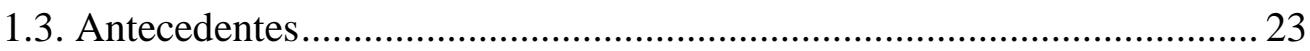

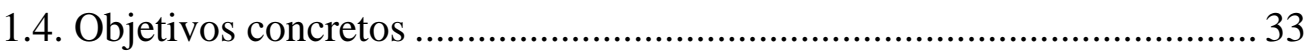

1.5. Antecedentes históricos en la enseñanza de la solmización y el solfeo, y sistemas de enseñanza aplicados al lenguaje musical ............................ 35

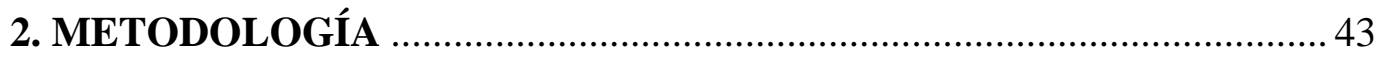

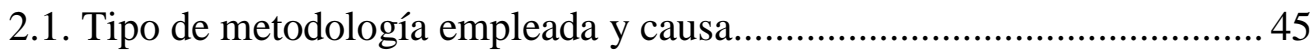

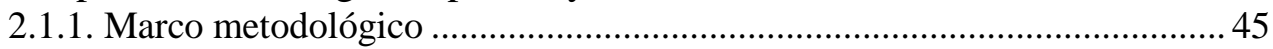

2.1.2. Definición de la unidad de análisis ................................................................. 46

2.1.3. Técnicas y procedimientos de recolección de la información ........................46

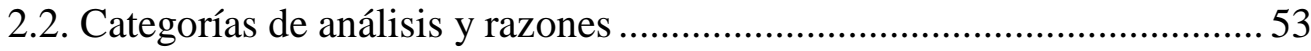

2.2.1. El instrumento registrador .....................................................................5 53

2.2.2. Criterios personales y de algunos autores sobre la conducción de la asignatura, que sirven para la valoración posterior de cada método ...........54

2.3. Criterios para la valoración de las categorías ..........................................63

2.3.1. Elementos de comparación y evaluación de los métodos...............................63

2.3.2. Parámetros y gradaciones de los distintos elementos musicales que consideramos óptimos en el proceso de enseñanza/aprendizaje .................. 74

2.4. Patrones de comparación y valoración .................................................. 85

2.4.1. Patrones secuenciados de los programas del RCSMM................................. 85

2.4.2. Secuencias de contenidos que consideramos idóneas con los procedimientos actuales de enseñanza/aprendizaje del solfeo .................... 93

2.4.3. Patrones de valoración para la inferencia final de los datos ........................97

2.4.4. Materiales a analizar .............................................................................. 101

\section{ESTUDIO DE LOS DISTINTOS MÉTODOS DE SOLFEO, ORDENADOS CRONOLÓGICAMENTE Y DIVIDIDOS EN CUATRO BLOQUES.. 103}

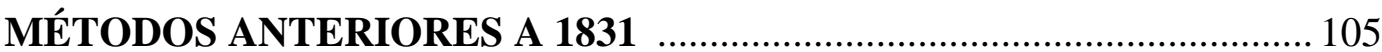

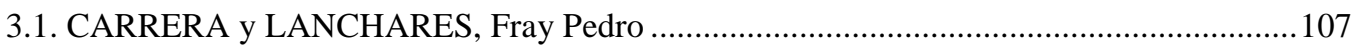

3.1.1. Descripción detallada del método........................................................................... 107

3.1.2. Valoración de la efectividad del método y de su aportación a la enseñanza ..................114

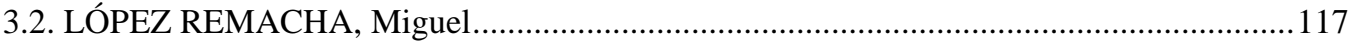

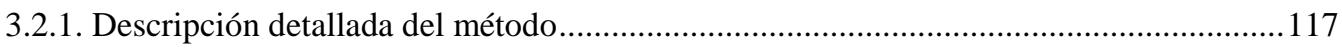

3.2.2. Valoración de la efectividad del método y de su aportación a la enseñanza ..................124

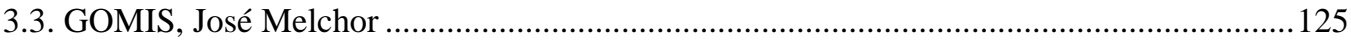

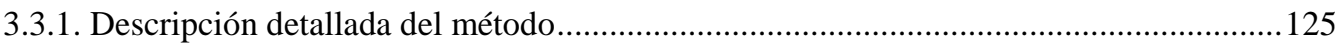

3.3.2. Valoración de la efectividad del método y de su aportación a la enseñanza ...................131 


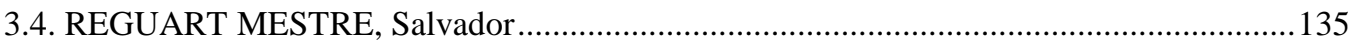

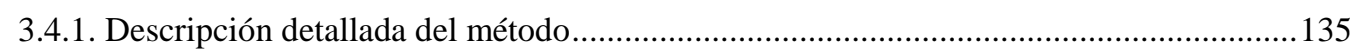

3.4.2. Valoración de la efectividad del método y de su aportación a la enseñanza ....................138

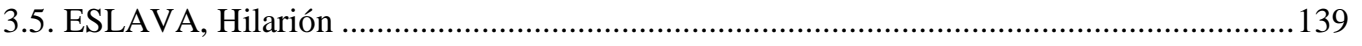

3.5.1. Descripción detallada del método..............................................................................141

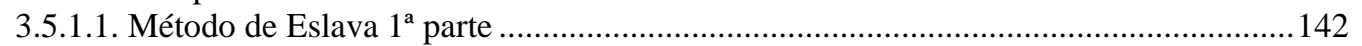

3.5.1.2. Método de Eslava $2^{\mathrm{a}}$ parte ..................................................................... 150

3.5.1.3. Método de Eslava $3^{\mathrm{a}}$ parte ..................................................................... 158

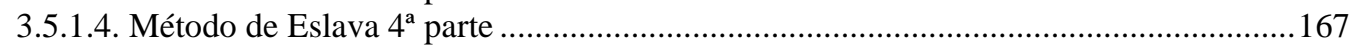

3.5.2. Valoración de la efectividad del método y de su aportación a la enseñanza ...................172

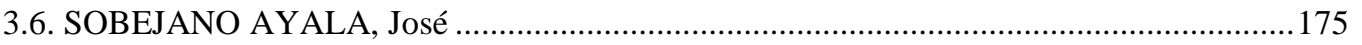

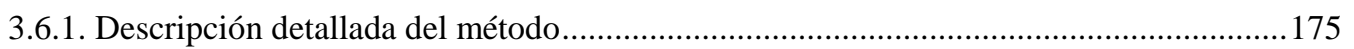

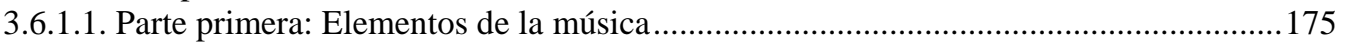

3.6.1.2. Parte segunda: Lecciones con sostenidos y bemoles ..................................................178

3.6.1.3. Parte tercera: Lecciones por las llaves restantes .......................................................179

3.6.2. Valoración de la efectividad del método y de su aportación a la enseñanza ...................180

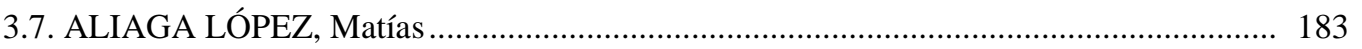

3.7.1. Descripción detallada del método......................................................................................183

3.7.2. Valoración de la efectividad del método y de su aportación a la enseñanza ...................191

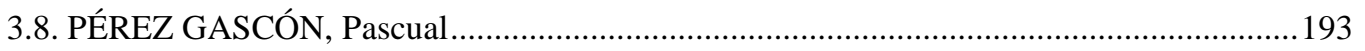

Principios de solfeo y canto

3.8.1. Descripción detallada del método.................................................................................194

3.8.2. Valoración de la efectividad del método y de su aportación a la enseñanza ....................203

Método de solfeo y principios de canto

3.8.3. Descripción detallada del método.................................................................................204

3.8.4. Valoración de la efectividad del método y de su aportación a la enseñanza ................ 220

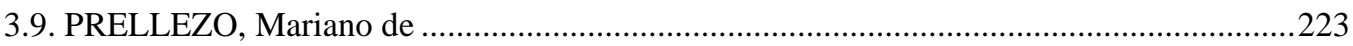

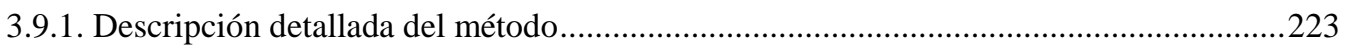

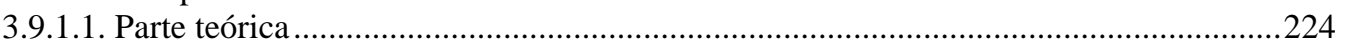

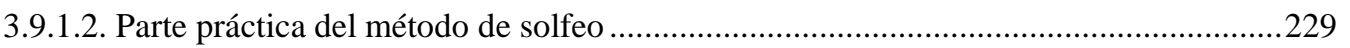

3.9.2. Valoración de la efectividad del método y de su aportación a la enseñanza ...................231

3.10. VALERO PERIS, José y ROMERO, Antonio................................................................233

3.10.1. Descripción detallada del método........................................................................234

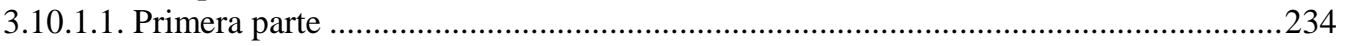

3.10.1.2. Segunda parte ...................................................................................................2239

3.10.2. Valoración de la efectividad del método y de su aportación a la enseñanza ............. 243

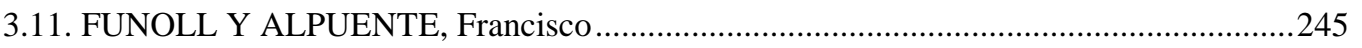

3.11.1. Descripción detallada del método................................................................................245

3.11.2. Valoración de la efectividad del método y de su aportación a la enseñanza ................252

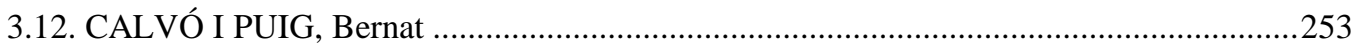

3.12.1. Descripción detallada del método..........................................................................253

3.12.2. Valoración de la efectividad del método y de su aportación a la enseñanza ...............260 


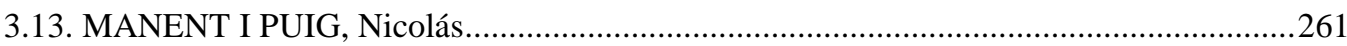

3.13.1. Descripción detallada del método.......................................................................... 261

3.13.2. Valoración de la efectividad del método y de su aportación a la enseñanza ................265

MÉTODOS POSTERIORES A 1861 ............................................................. 267

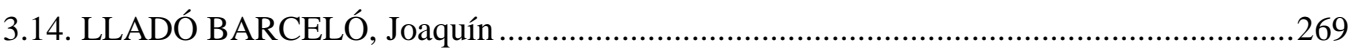

Método analítico para el estudio del solfeo

3.14.1. Descripción detallada del método........................................................................269

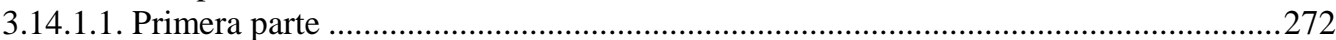

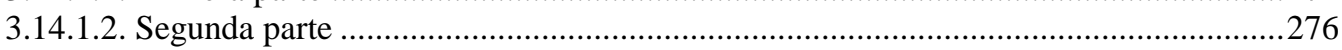

3.14.2. Valoración de la efectividad del método y de su aportación a la enseñanza ...............2278

Método de solfeo analítico, fácil y conciso ......................................................................279

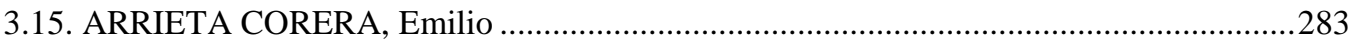

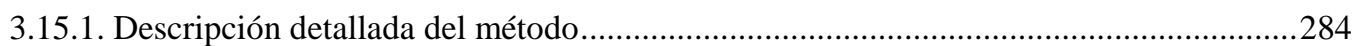

SEGUNDO AÑO........................................................28

3.15.2. Descripción detallada de este segundo año.............................................................289

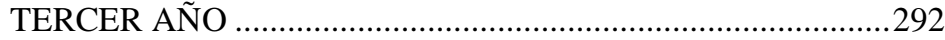

3.15.3. Descripción detallada de este tercer año..................................................................293

PRIMER LIBRO DE CONCURSOS ....................................298

3.15.4. Descripción detallada de este libro .......................................................................299

3.15.5. Valoración de la efectividad del método y de su aportación a la enseñanza .................302

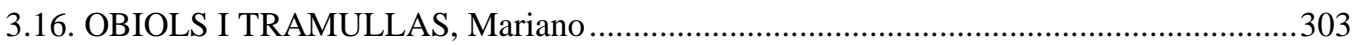

3.16.1. Descripción detallada del método...........................................................................303

3.16.2. Valoración de la efectividad del método y de su aportación a la enseñanza .................310

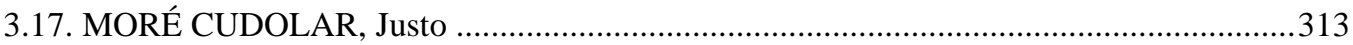

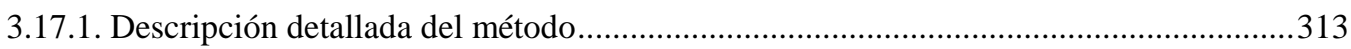

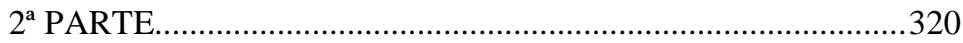

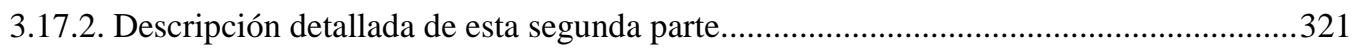

$3^{\circ}$ PARTE ...................................................................... 330

3.17.3. Descripción detallada de esta tercera parte............................................................. 331

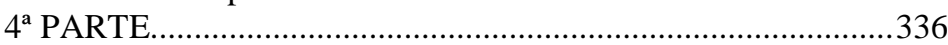

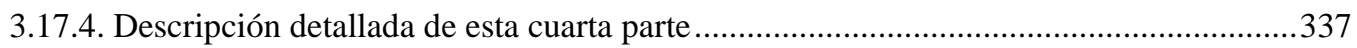

3.17.5. Valoración de la efectividad del método y su aportación a la enseñanza ......................342

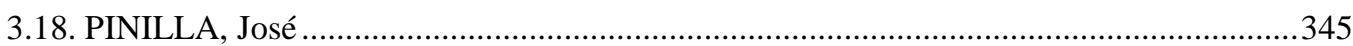

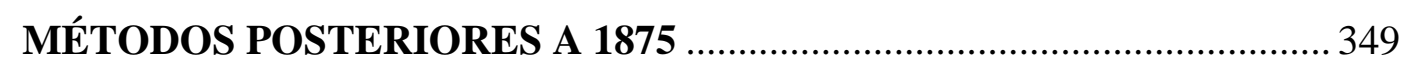

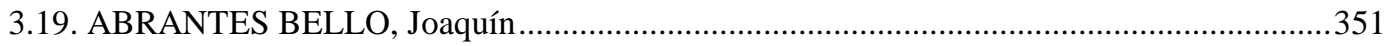

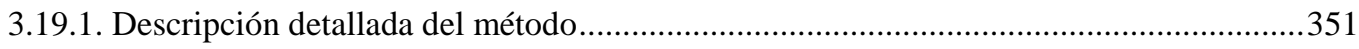

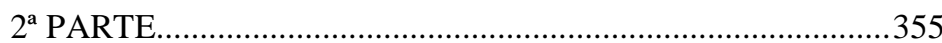

3.19.2. Descripción detallada de esta segunda parte............................................................ 355

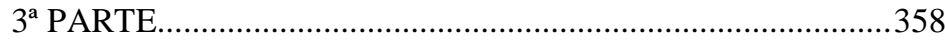

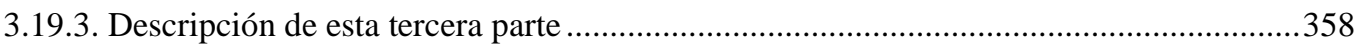

3.19.4. Valoración de la efectividad del método y de su aportación a la enseñanza ...................358 


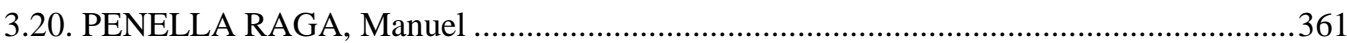

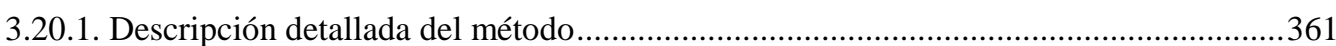

3.20.2. Valoración de la efectividad del método y de su aportación a la enseñanza ................364

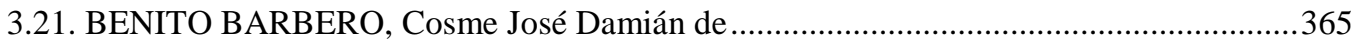

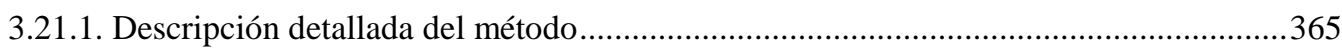

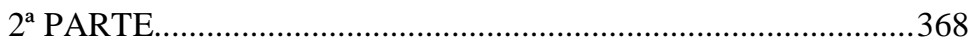

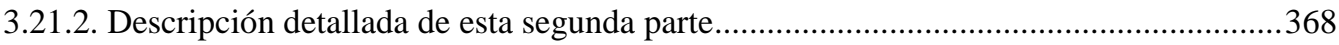

3.21.3. Valoración de la efectividad del método y de su aportación a la enseñanza .................369

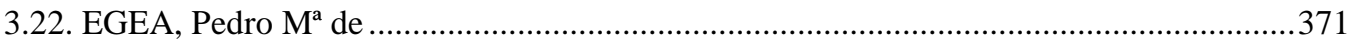

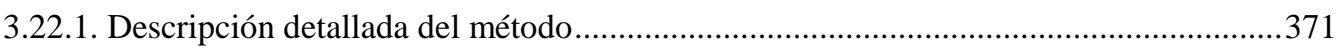

3.22.2. Valoración de la efectividad del método y de su aportación a la enseñanza .................375

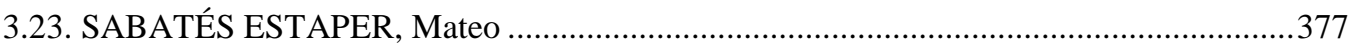

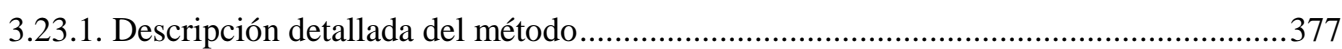

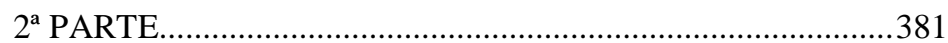

3.23.2. Descripción detallada de esta segunda parte............................................................ 381

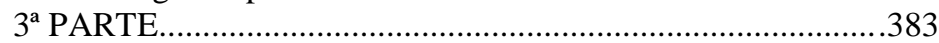

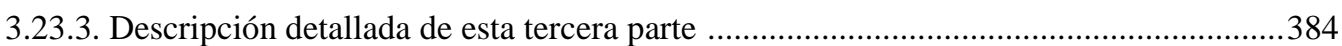

3.23.4. Valoración de la efectividad del método y de su aportación a la enseñanza ............. 385

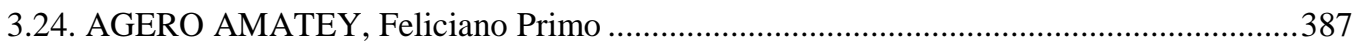

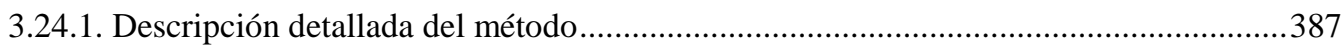

$2^{\mathrm{a}}$ PARTE....................................................................... 390

3.24.2. Descripción detallada de esta segunda parte........................................................ 391

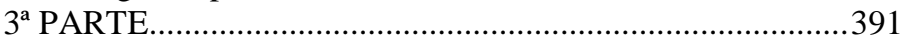

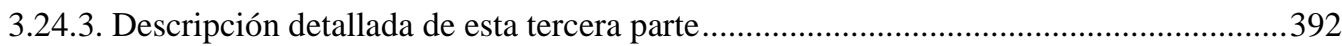

3.24.4. Valoración de la efectividad del método y de su aportación a la enseñanza .................393

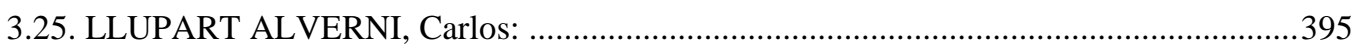

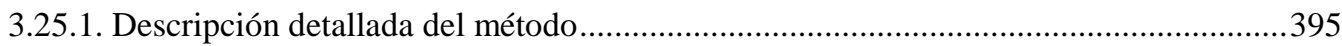

3.25.2. Valoración de la efectividad del método y de su aportación a la enseñanza .................404

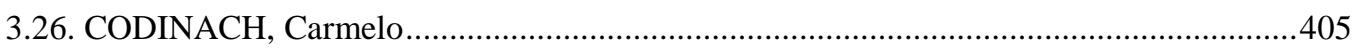

3.26.1. Descripción detallada del método..........................................................................405

3.26.2. Valoración de la efectividad del método y de su aportación a la enseñanza .................408

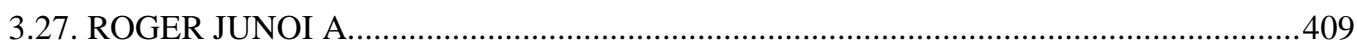

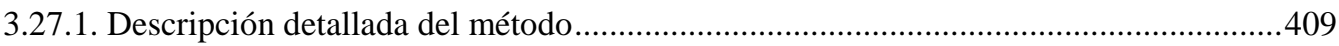

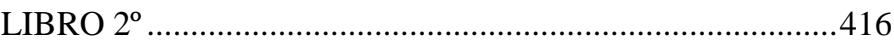

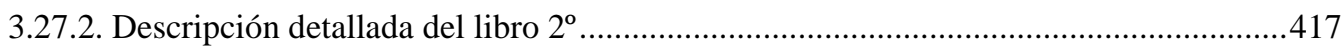

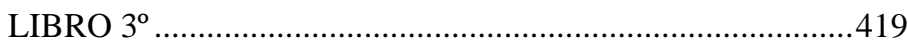

3.27.3. Descripción detallada del libro $3^{\circ}$.........................................................................419

3.27.4. Valoración de la efectividad del método y de su aportación a la enseñanza ................422

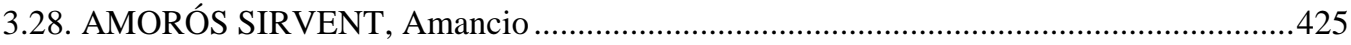

Elementos de solfeo

3.28.1. Descripción detallada del método.............................................................................425

3.28.2. Valoración de la efectividad del método y de su aportación a la enseñanza .................430

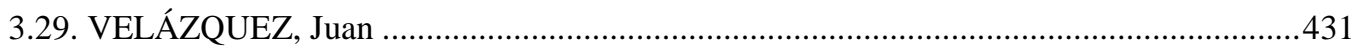

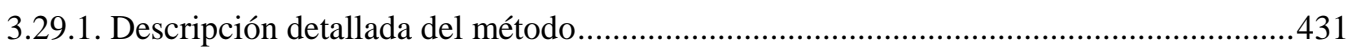

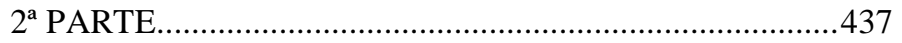




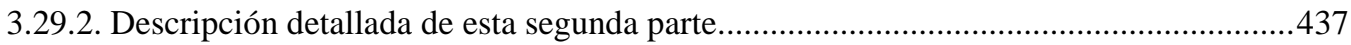

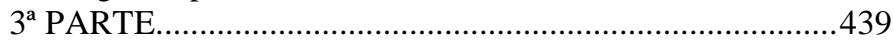

3.29.3. Descripción detallada de esta tercera parte..............................................................440

3.29.4. Valoración de la efectividad del método y de su aportación a la enseñanza .................441

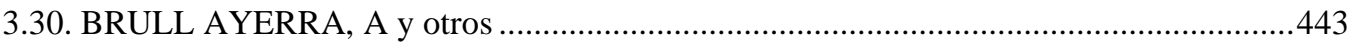

3.30.1. Descripción detallada del método..............................................................................444

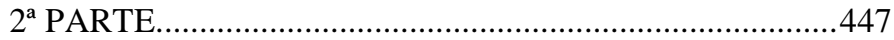

3.30.2. Descripción detallada de esta segunda parte...........................................................448

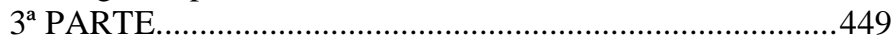

3.30.3. Descripción detallada de esta tercera parte................................................................450

3.30.4. Valoración de la efectividad del método y de su aportación a la enseñanza .................450

3.31. PARDÁS Y FONT, Primitivo ……........................................................................... 453

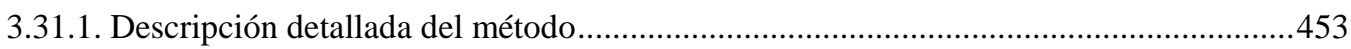

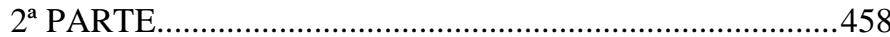

3.31.2. Descripción detallada de esta segunda parte...............................................................458

3.31.3. Valoración de la efectividad del método y de su aportación a la enseñanza .................459

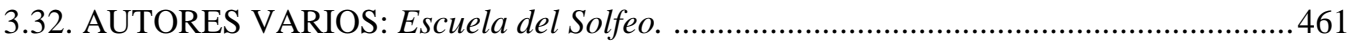

3.32.1. Descripción detallada del método..............................................................................461

LIBRO II................................................................ 472

3.32.2. Descripción detallada de este libro II ..................................................................... 473

3.32.3. Valoración de la efectividad del método y de su aportación a la enseñanza ............... 477

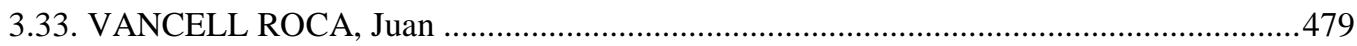

3.33.1. Descripción detallada del método.............................................................................479

3.33.2. Valoración de la efectividad del método y de su aportación a la enseñanza ............... 487

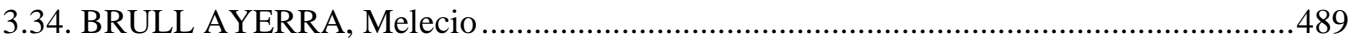

3.34.1. Descripción detallada del método..............................................................................489

3.34.2. Valoración de la efectividad del método y de su aportación a la enseñanza .................. 492

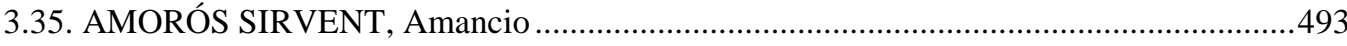

Lecciones manuscritas graduadas

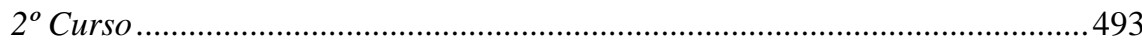

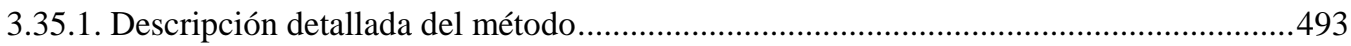

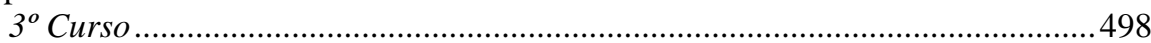

3.35.2. Descripción detallada del método tercer curso ......................................................498

3.35.3. Valoración de la efectividad del método y de su aportación a la enseñanza .................502

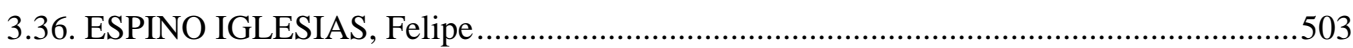

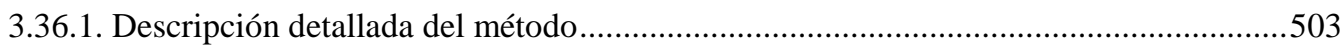

3.36.2. Valoración de la efectividad del método y de su aportación a la enseñanza .................507

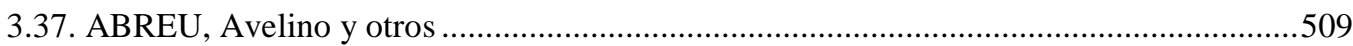

$2^{\circ}$ Curso

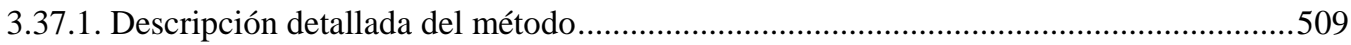

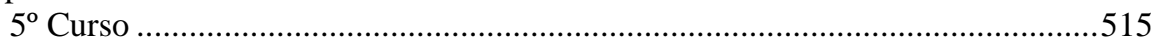

3.37.2. Descripción detallada del $5^{\circ}$ curso .......................................................................516

3.37.3. Valoración de la efectividad del método y de su aportación a la enseñanza ................519

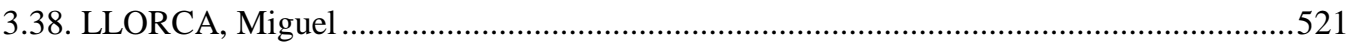

3.38.1. Descripción detallada del método .......................................................................521

3.38.2. Valoración de la efectividad del método y de su aportación a la enseñanza.............524 


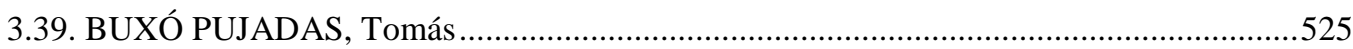

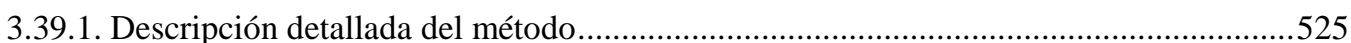

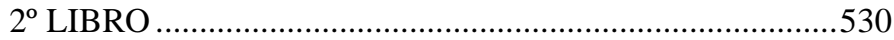

3.39.2. Descripción detallada de este segundo libro..........................................................531

$3^{\circ}$ LIBRO …….........................................................5 535

3.39.3. Descripción detallada de este tercer libro ..............................................................536

3.39.4. Valoración de la efectividad del método y de su aportación a la enseñanza .................539

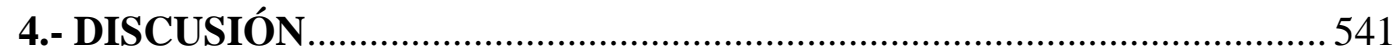

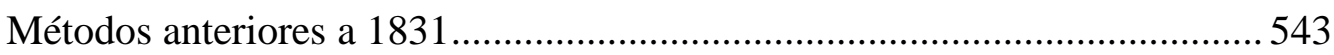

Métodos posteriores a la fundación del RCSMM …………………………....545

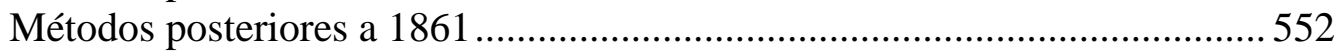

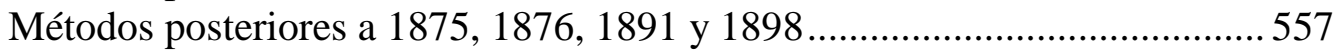

5.- CONCLUSIONES.- Inferencias sobre los datos...................... 579

Estudio comparativo de las analogías y contrastes entre todos los métodos.

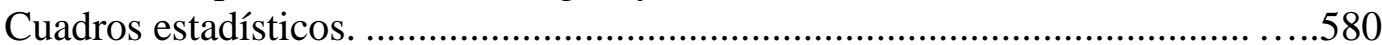

5.1. Claves empleadas y orden didáctico.............................................................58

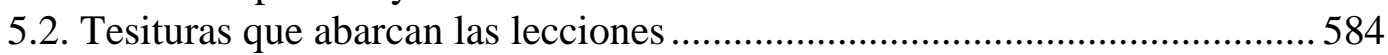

5.3. Tonalidades y modalidades que emplean .......................................................58 586

5.4. Compases que enseñan y que utilizan para comenzar la enseñanza..............587

5.5. Dificultades métricas que estudian y secuencia …………………………......58

5.6. Métodos que contemplan las notas de adorno ............................................... 591

5.7. Dificultades melódicas y ejercicios de entonación..........................................596

5.7.1. Interválica: Métodos que incluyen ejercicios de entonación.................... 597

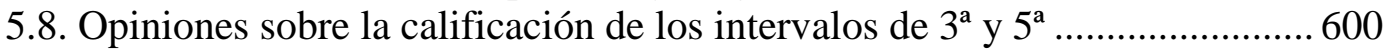

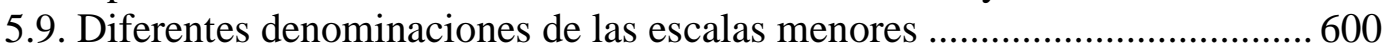

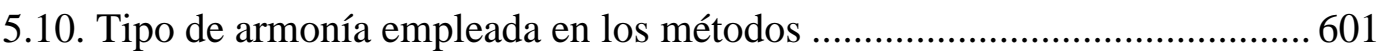

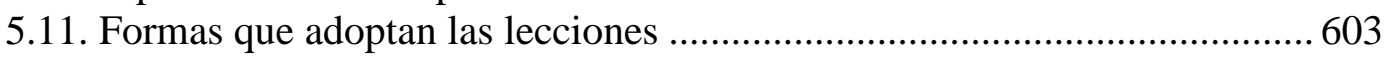

5.12. Cantidad de lecciones que tienen introducción, codas o intermedios

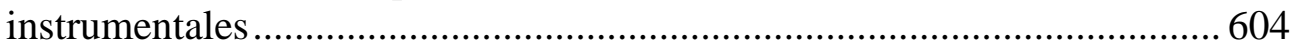

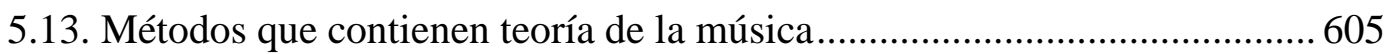

5.14 Aspectos curiosos encontrados en algunos métodos ....................................... 606

5.15. Métodos que se hicieron para la enseñanza profesional de la música, y métodos que no se hicieron con ese fin .................................................... 610

5.16. Consideraciones sobre la utilidad que, a nuestro juicio, pudieron tener

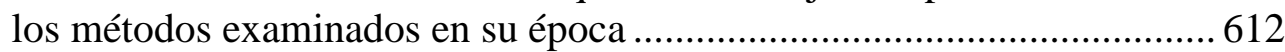

5.17. Consideraciones sobre la utilidad actual de los métodos examinados ..... 614

6.- CONCLUSIONES DEFINITIVAS Y RECOMENDACIONES ............621

7.- BIBLIOGRAFÍA 
APÉNDICE (en soporte CD)

A. LAS LECCIONES DE SOLFEO DE SALVADOR GINER

1. Reseña histórica del autor

2. Edición de los manuscritos de sus lecciones de solfeo a 2 y 3 voces

3. Análisis de cada una de las lecciones

4. Estudio comparativo de todas las lecciones

B. DOCUMENTOS DE INTERÉS Y PORTADAS DE LOS MÉTODOS 
- 1 -

INTRODUCCIÓN 


\subsection{TEMA DE ESTUDIO Y ORGANIZACIÓN DEL TRABAJO}

El propósito de nuestra investigación ha sido recopilar la mayor parte de métodos de enseñanza del solfeo, de autores españoles, durante el siglo XIX y primer tercio del XX, analizarlos pormenorizadamente, exponerlos de la forma más clarificadora posible, recabar opiniones profesionales sobre su valía, indagar la causa que a cada autor le llevó a organizar su método de la manera que lo hizo, establecer comparaciones y diferencias entre ellos, y llegar a conclusiones sobre su adecuación y vigencia.

Habiendo encontrado en el Archivo del Conservatorio Superior de Música "Joaquín Rodrigo" de Valencia partituras manuscritas, o partes de algunas de ellas, de lecciones de solfeo a 2 y 3 voces del gran compositor valenciano Salvador Giner Vidal, nos pusimos a la tarea de agrupar las distintas voces, partes de piano y armonium en una sola partitura, elaborar el acompañamiento de piano en las lecciones o fragmentos que no los había, y posteriormente editarlas como libro complementario y formativo, no sólo en la enseñanza del solfeo, sino también en la de la armonía y el análisis.

Siendo especialista y profesional de la enseñanza del Lenguaje Musical, nos sobrevino la idea de averiguar qué métodos había, o se utilizaron en España, en el aprendizaje de esta disciplina en la época en que vivió el compositor y pedagogo aludido, y comparar las estructuras musicales y didácticas de las lecciones de los distintos autores de esa época con las de Giner. A la postre esa comparación no se lleva a cabo, al no constituir las lecciones de solfeo de Giner un método ni una metodología, sino una recopilación de lecciones que él hacía como cierre a las Audiciones de alumnos del Conservatorio de Valencia; sí se exponen (en el apéndice de esta tesis) análisis diversos de ellas y conclusiones del hecho de comparar entre sí todas estas lecciones.

Eso nos llevó a indagar, y descubrir, que hubo muchos métodos en esos años desde comienzos del siglo XIX, por ello decidimos delimitar el presente estudio analítico desde principios del XIX hasta 1920, fechas, un poco expandidas, de la vida de Salvador Giner

Comparándolos con las metodologías actuales, hemos efectuado un examen de cada uno de los métodos o libros de la enseñanza del solfeo encontrados entre los autores de la época señalada en España, desde 1805 hasta 1920, analizando su metodología, su utilidad, aportación y circunscripción a los planes de estudios, o programas vigentes en el momento, materias que abarcan, y objetivos que pretendían cubrir. 
Introducción.

1.1. Tema de estudio y organización del trabajo

Tras comentarios y reflexiones sobre esta enseñanza en cualquiera de sus vertientes y la metodología seguida, hacemos un estudio descriptivo y comparativo de cada método y sus partes, si las tiene, exponiendo esquemáticamente la cantidad de lecciones que componen el método, la extensión máxima y mínima que tienen, tesituras entre las que se desenvuelven, qué claves enseñan, las tonalidades y compases que se practican con ellos, el grado de sencillez o complejidad de las dificultades métrico - rítmicas que afrontan; igualmente con las dificultades de entonación y la forma en que van enseñando la interválica. También el estilo armónico que ha empleado el compositor, si es que las lecciones llevan acompañamiento de piano, de lo cual muchos métodos carecen, las formas en que se estructuran las lecciones y algunas otras particularidades. Aspectos estos que, creemos, son los que interesan a un pedagogo del solfeo cuando decide qué método va a utilizar en sus clases.

Terminado este esquema de información general, hacemos una explicación detallada de las distintas partes, capítulos y epígrafes por los que van pasando cada uno de los métodos, con comentarios y observaciones sobre la manera de aplicar la enseñanza de cada uno de los signos, de la teoría (si la contienen), de abordar la enseñanza de la entonación, el orden de aparición de las claves y otros signos, curiosidades y cuanto vemos de interesante reflejar. O sea, describimos conceptos solfísticos, técnicas que afrontan y objetivos que pueden alcanzarse. Se cierra la inspección de cada uno de los libros con la valoración de la efectividad del método y de su aportación a la enseñanza.

En capítulo de la discusión, cotejamos cada método, o sus partes, con los pocos programas que hubo en el momento y con los objetivos que, a nuestro parecer y a la visión actual de la pedagogía, serían de desear, con el fin de llegar a conclusiones de si su estructura respondía a algún programa de los existentes en el momento, o por el contrario estaban confeccionados siguiendo un programa totalmente libre, caprichoso, arbitrario o perfectamente estructurado a pesar de no obedecer a ningún programa oficial; si responderían en la actualidad a las modernas tendencias pedagógicas; y en fin si pudieron tener mucha o poca difusión en su época y/o posteriores.

Continuamos tratando de llegar a unas conclusiones sobre la enseñanza de esta disciplina, y en base a la cuantificación metodológica que describiremos más adelante, comparamos las distintas obras pedagógicas entre si con el fin de extraer aspectos positivos y negativos del estado de la enseñanza en esa época, a lo que añadimos curiosidades encontradas en algunos métodos, opiniones de los autores de esa época sobre la calificación de los intervalos de $4^{\mathrm{a}}$ y $5^{\mathrm{a}}$, denominaciones de las escalas menores, opiniones 
dispares sobre clases e interpretación de las notas de adorno y cualquier cosa que hemos creído interesante resaltar o informar.

Y concluimos con las deducciones a que nos llevan los cotejos anteriores.

Esto en cuanto al cuerpo de la tesis.

En soporte de "compact disc", hay un apéndice dividido en 2 partes:

La primera contiene la relación de las lecciones de solfeo de Salvador Giner. En ella se encuentra la referencia biográfica, la cita a las dichas lecciones, un análisis intenso de cada una de ellas, formal, armónico, rítmico, melódico, motívico, etc. y un estudio comparativo entre ellas.

La segunda parte del apéndice, contiene facsímiles de todas las portadas de los métodos analizados, páginas de algunos de ellos que por diversos motivos hemos creído interesante mostrar, y algunos otros documentos de la época considerada. 
Introducción.

1.1. Tema de estudio y organización del trabajo 


\subsection{INTERÉS DEL TEMA}

Esta tesis encuentra su justificación en la necesidad de mejorar tanto la calidad de la metodología con la cual se está enseñando el solfeo como la calidad y cantidad del aprendizaje referidas al desarrollo de habilidades y competencias que los estudiantes están recibiendo.

No hemos encontrado ningún estudio similar sobre los planteamientos pedagógicos de los métodos para la enseñanza del solfeo, y aunque lo que nos llevó en un principio a desarrollar este análisis fuera otro objetivo, el de comparar métodos del siglo XIX con nuestra publicación de las lecciones de Giner, vista la cantidad de métodos que existieron, se desarrolló nuestra curiosidad por ver cómo eran, cómo planteaban las cuestiones pedagógicas, de qué manera trataban de enseñar una disciplina fundamental en los estudio musicales.

Nuestra labor no se centra en el proceso enseñanza/aprendizaje, sino que intenta, desde una metodología más descriptiva, relacionar las fuentes del conocimiento (métodos de solfeo) con la formación musical que estos ofrecen, sus orientaciones metodológicas y sus programaciones de actividades para el logro del objetivo de sus métodos. En ningún momento se estudia en este trabajo el nivel de formación que estas publicaciones consiguieron transmitir a los sujetos pacientes, a los aprendices. Es por tanto, un análisis que recae sobre la bondad o no de los planteamientos del profesorado autor de dichas publicaciones.

Reputamos, modestamente, de gran interés esta memoria por acercar al lector, o al estudioso, al panorama de la enseñanza musical básica en los siglos pasados, justamente cuando comenzaba a andar, de una manera más o menos reglada, esta instrucción.

Este trabajo es fundamentalmente descriptivo y de análisis musical, ya que analiza exhaustiva y críticamente cada uno de los 70 libros pertenecientes a más de 30 autores, detallando sus contenidos, que constituye el capítulo más voluminoso de esta tesis.

Creemos que nuestra tesis marca un punto de arranque y establece un modo de analizar la cuestión pedagógica de una materia que, dentro de la enseñanza de la música, nunca ha sido especialmente objeto de gran atención.

Una vez efectuada nuestra exploración, dejamos el camino abierto para que, posteriores estudiosos, profundicen aun más en puntos que hayan quedado olvidados o re- 
Introducción.

1.2. Interés del tema

legados, y sobre todo, para que continúen avanzando en el conocimiento de un período histórico que puso las bases de los procesos de aprendizaje de las generaciones musicales posteriores y en otros periodos ulteriores. 


\subsection{ANTECEDENTES}

En la reciente historia de la investigación musicológica en nuestro país, están surgiendo estudios y tesis muy valiosas que aportan nuevas luces sobre la situación musical que vivió España a lo largo del s. XIX. Tesis doctorales como las de Celsa Alonso (Alonso, 1992), Vicente Galbis López (Galbis, 1998), Manuel Sancho García (Sancho García, 2003), Ana Fontestad Piles (Fontestad, 2005), y otros, han estudiado diferentes facetas del arte musical en el s. XIX. En referencia al tema que nos ocupa, el estudio de las formas de enseñanza/aprendizaje del solfeo a través del análisis de los diferentes métodos aparecidos durante el s. XIX y principios del s. XX, hemos podido constatar entre los trabajos doctorales un vacío importante en los estudios relativos a la manera en que se enseñaba el solfeo en el siglo XIX, sus metodologías y su repercusión en el proceso de enseñanza/aprendizaje; los procedimientos, materias que trataban, su ensambladura con los programas vigentes en el momento, concordancia con principios pedagógicos, etc., sobre todo en lo que hace referencia a la enseñanza de la música dirigida a futuros profesionales. Sí hay, en cambio, investigaciones sobre la idoneidad de la enseñanza de la música en la escuela, de las distintas metodologías, la proyección que han tenido, etc., pero no, como decimos, sobre los distintos métodos que fueron editándose a lo largo del XIX y primeros años del XX dedicados por completo al estudio de la materia denominada solfeo.

\section{ESTUDIO DE PRECIADO}

El primer estudio más concreto sobre los métodos de solfeo en el siglo XIX es el artículo de Dionisio Preciado, doctor en musicología, profesor superior de composición y licenciado en canto gregoriano, titulado "Don Hilarión Eslava y su Método completo de solfeo" (Preciado, 1978).

Sin duda fue esta monografía de Dionisio Preciado sobre D. Hilarión Eslava y su método de solfeo la que ha tratado con más profundidad el tema que nosotros pretendemos, con esta tesis, desarrollar ampliamente, abarcando una gran cantidad de autores españoles que publicaron métodos de enseñanza del solfeo.

Este artículo está dividido en tres partes; la primera habla en general de Eslava y sus diversos métodos pedagógicos; en la segunda hay un amplio listado de métodos de solfeo del siglo XIX, con comentarios, más o menos amplios, de su contenido e impor- 
Introducción.

1.3. Antecedentes

tancia que tuvieron; la tercera parte es un pequeño análisis del Método completo de solfeo.

Centrándonos en la segunda parte, Dionisio Preciado (op. citada) inventaría y comenta, más o menos extensamente, los siguientes libros dedicados a la enseñanza de la materia que nos ocupa, ordenados cronológicamente.

Nosotros los dividiremos en 4 grupos por coherencia con lo que antecede y lo que sigue:

\section{PRIMER GRUPO}

Métodos referidos por Preciado, y algunos también por Gómez Amat (Gómez Amat, 1984), que están ampliamente analizados en esta tesis:

Los de Carrera Lanchares, López Remacha, Melchor Gomis, Reguart Mestre, Sobejano Ayala, Aliaga, Pérez Gascón, Prellezo, Valero y Romero, Lladó, Calvó Puig, Manent, Moré y Gil, Brull y otros, Arrieta, y Amorós. (Preciado, 1978, pp. 233 a 245).

SEGUNDO GRUPO

Métodos citados por ambos (Preciado y Gómez Amat, op. citadas) que no tratamos en esta tesis por ser, según ellos mismos, teorías de la música, o contener otras cuestiones musicales, pero no especificamente lecciones de solfeo:

LIDÓN, José, organista del Palacio Real, maestro de la Capilla Real y rector del Real Colegio de niños cantores: Demostración de los primeros rudimentos de la música. Sus caracteres, valor y oficios de ellos, según el estilo moderno, [Madrid, ca. 1805]. Es una teoría de 14 folios de extensión, manuscritos, con breves ejemplos; los 3 últimos folios recogen las escalas de UT en $1^{\mathrm{a}}, 2^{\mathrm{a}}$ y $3^{\mathrm{a}}$; la de FA en $2^{\mathrm{a}}$ y la de SOL en $2^{\mathrm{a}}$. Todavía utiliza la nomenclatura antigua en las figuras de nota, y a los reguladores les llama "crecientes y decrecientes".

BIOSCA, Ramón: Breve resumen de la forma y efecto de los caracteres musicales, para uso de los principiantes, dispuesto en verso, Madrid, 1807. Son 8 folios manuscritos, sin ejemplos, de la teoría más elemental, y como figura en su título, está redactado en verso. 
Introducción.

1.3. Antecedentes

MORETTI, Federico, italiano, brigadier y guitarrista: Gramática razonada musical, compuesta en forma de diálogo para los principiantes. Madrid, 1821. Sistema uniclave o ensayo sobre unificar las claves de la música, sujetándose a una sola escala... Madrid, 1824. La primera es una teoría para principiantes y la segunda un sistema para facilitar la escritura solfística.

BALLESTER DE BELMONTE, Tomás: El porqué de la música o sea, primeros elementos del noble arte de la música y método fácil que contiene la teórica y práctica del canto de órgano y un compendio o breve explicación fundamental del canto llano y canto figurado, Barcelona 1824. Es un tratado de canto gregoriano.

CAPLAROLS Y MARUÑS, Pedro Pablo, profesor de piano y danza: El maestro y discípulo de música. Método breve y fácil de elementos generales de música, útiles y necesarios a todos los que quieran aprender este bello arte, arreglados al estilo moderno, con definiciones claras y fundamentales y copiosidad de ejemplos para mayor ilustración, Barcelona, 1825. Es una teoría de 32 páginas en forma dialogada. (libro revisado)

MARTÍ, Francisco de Paula, el gran taquígrafo valenciano, a quien Gómez Amat llama (quizás por un error de imprenta) Martín, compuso en 1827 un tratado de taquigrafía musical denominado: Taquigrafía de la música o arte de escribirla sin usar del pentagrama con igual exactitud que por el método usual, pudiéndose copiar por su medio una sonata o una aria mientras se toca o canta, por...editada por su hijo Ángel Ramón Martí, Madrid 1833. Es un tratadillo de 13 páginas y 5 láminas de taquigrafía musical, siendo la última una canción con acompañamiento de piano como resumen. Es un invento que no ha tenido ninguna trascendencia por su inoperatividad. (También cita Preciado otros dos métodos de este estilo: Método teórico - práctico de taquigrafía musical, inventado y escrito para compositores y enseñanza en los conservatorios y escuelas de música, Madrid 1895, dedicado a la Infanta Isabel de Borbón por su autor Serafín Ramón Guas Ezcurdia, y otro de Gabriel Abreu: Sistema de escribir la música en puntos de relieve, con real privilegio de invención, dedicado a los ciegos, Madrid 1856).

ROCA Y BISBAL, Juan Bautista: Gramática musical dividida en catorce lecciones. Obra utilísima para los que quieren aprender la música; resumen para los que 
Introducción.

1.3. Antecedentes

la saben e introducción para todos los métodos, Barcelona 1837. Es una teoría muy superficial. ${ }^{1}$ (libro revisado)

FRONTERA DE VALLDEMOSA, Francisco, cantante bajo, maestro de canto de la reina Isabel II, profesor en el Conservatorio de Madrid: Equinotación musical o sea, nuevo sistema musical de llaves (sin variar su figura) por el cual desaparece su actual complicación y se facilita la inteligencia de toda la música escrita a dos o más partes, la de las grandes particiones y el arte de transportar para los acompañamientos, Madrid, 1858. Es un tratado para reducir todas las claves a la única de Sol en $2^{\text {a }}$; no tuvo ningún éxito.

(Todos ellos en Preciado, op. citada, pp. 232 a 241)

\section{TERCER GRUPO}

Métodos que cita Dionisio Preciado, y no Gómez Amat, (op. citadas) que no están incluidos en el presente estudio por ser libros de teoría de la música exclusivamente (según él describe):

SÁNCHEZ DE MADRID, Joaquín: Juegos músicos o método de enseñanza mutua, para aprender la ciencia música en la parte teórica, dividida en dos partes, Cádiz, 1823. Sistema de la unión de la música especulativa con la teórica y la práctica, Cádiz, 1823. Nuevo sistema música - teórico - físico - matemático, Cádiz, 1842. Como sus títulos anuncian, son tratados teóricos y de juegos musicales.

MARTÍNEZ DEL ROMERO, A: Elementos generales de la música, Madrid, s. f. Explica Preciado que después de las explicaciones teóricas y ejemplos se incorpora un método de solfeo llamado Gran método de solfeo o nueva escuela de música, que no contiene lecciones del autor, sino de compositores franceses como Fétis, Garaudé o Gomis. Se encuentra en la Universidad de Las Palmas de Gran Canaria.

ROMERO Y ANDÍA, Antonio, profesor de clarinete, inventor del sistema Romero: Gramática musical o sea, teoría general de la música, aprobada y adoptada por

\footnotetext{
${ }^{1}$ Esa es la opinión de Preciado, que coincide con la nuestra, a lo que añadimos que es confuso y desordenado-
} 
Introducción.

1.3. Antecedentes

el Real Conservatorio de Música y Declamación de Madrid, dedicad a su ViceProtector, el Excmo. Sr. D. Ventura de la Vega, Madrid, 1857. Son 36 páginas de teoría más 7 láminas plegables con música.

PINILLA Y PASCUAL, José, logroñés, nacido en 1837, discípulo de Eslava y catedrático numerario de solfeo en el Conservatorio de Madrid: Teoría completa del solfeo, Madrid, s. f. Fue obra de texto en el Conservatorio de Madrid donde fue profesor. Escribió también Egercicios [sic] de entonación y medida aplicables a todos los métodos de solfeo, Madrid, Bonifacio Eslava, s. f. que son ejercicios para el ritmo y la entonación por separado y después juntas las dos dificultades, sin acompañamiento. Algo complementario a cualquier otro método. (Estos sí incluidos en el presente estudio, punto 3, por tratarse de ejercicios solfísticos y no teoría).

GALIANA, Miguel, de Onteniente, profesor de canto y armonía en el Conservatorio de Madrid: Prontuario teórico - práctico, dispuesto en forma de diálogo para mayor facilidad, Madrid, 1856. Teoría en forma dialogada o catecismo musical.

BONET VALLVERDÚ, Ramón: Método práctico de música vocal, destinado a los colegiales de primera y segunda enseñanza, Tarragona, ca. 1865. Es el único de este grupo no teórico, pero tampoco es un método de solfeo, sino un manual para estudiantes no de música.

GIL Y NAVARRO, José: Nuevo sistema de notación musical bajo la supresión de los sostenidos, bemoles y becuadros y llaves y la reducción de tonos, Madrid 1863. Se publicó por entregas a partir de ese año, y desató polémicas entre su autor y los señores Eslava, Arrieta, Hernando y Valldemosa, incluso con demandas por injurias a su autor.

PEDRELL, Felipe: Gramática o manual expositivo de la teoría del solfeo en forma de diálogo, Barcelona, 1872. Es clarísimo que es un tratado teórico, que tuvo tres ediciones, y en cada una de ellas se fue aumentando los contenidos. 
Introducción.

1.3. Antecedentes

CUARTO GRUPO

Métodos que cita Dionisio Preciado que son de solfeo, pero cuya ubicación, si es que en algún sitio están, nos es desconocida:

SALDONI, Baltasar: Nuevo método de solfeo y canto [ca. 1830] y Veinticuatro vocalizaciones [1837?]. Fue el primer método de solfeo utilizado en el Conservatorio de Madrid. Las veinticuatro vocalizaciones que, dice la obra, son para contralto o para bajo, se guardan en la Biblioteca del Conservatorio de París.

SORIANO FUERTES, Indalecio: Método de solfeo, manuscrito sin lugar ni fecha. Tiene 38 folios pequeños y apaisados, con acompañamiento de bajo cifrado. La mayor parte de lecciones en clave de Sol y las últimas en clave de Fa en $4^{\mathrm{a}}$. Están las armaduras posibles y no se tratan los compases de amalgama.

SORIANO FUERTES, Mariano, hijo del anterior y profesor del Conservatorio de Madrid: Método breve de solfeo o nueva escuela de música, Madrid, 1843.

CALVO, Julián, murciano, organista y compositor: Método de solfeo, s. 1., s. f. (Todos ellos en Preciado, op. citada, pp. 236 a 242)

También, en una parte de la tesis doctoral de Ana Fontestad Piles se comentan algunos de los métodos de solfeo del s. XIX, pero ciñéndose a los compositores valencianos, como son: Pascual Pérez Gascón, del que hace una larga historia de su trayectoria pedagógica y de las vicisitudes que tuvo que pasar para publicar, y poner de texto sus métodos de solfeo; José Melchor Gomis, y Amancio Amorós Sirvent. Los tres aquí, en su momento son analizados. También cita algunas teorías del solfeo como: Teoría general del solfeo escrita en forma de diálogo e ilustrada con ejemplos de Antonio Marco Benlloch, Valencia, Sánchez - Ferris, 1900? Teoría de la música, Valencia, J. Peydró, 1879 y Teoría del solfeo, Valencia, J. Peydró, 1897, ambas de Manuel Coronado Cervera. (Fontestad, 2005, pp. 115 a 400)

\section{ESTUDIO DE GÓMEZ AMAT}

El segundo estudio que cabe reseñar es el de Carlos Gómez Amat (Gómez Amat, 1984). En su capítulo XXI "Teóricos y tratadistas. La enseñanza musical” hace 
un pequeño inventario de los métodos de solfeo en el siglo XIX, en España, pero sin analizar su contenido, idoneidad, o eficacia.

Sí contiene, en cambio, un ilustrativo paseo por la enseñanza de la música de la época en nuestro país, que merece dedicarle aquí unos cuantos párrafos.

En el siglo XIX la música es el arte más popular socialmente en el mundo civilizado, proliferan las orquestas y los solistas, el teatro musical apasiona; los conciertos públicos facilitan el contacto de todas las clases sociales con la música. Y por ello florece la teoría de la música, como consecuencia del estudio de las obras, y hay una demanda de educación musical. España, aunque distanciada de Europa en la cultura musical, tampoco escapa a ese auge de la música, y aparecen numerosos tratados y métodos para su enseñanza. Y opina Gómez Amat:

Como es natural, las obras didácticas y teóricas están íntimamente relacionadas con la música que se produce en su mismo tiempo, y en gran parte, tienen mucho que ver con modas pasajeras. Los tratados decimonónicos han perdido su verdadera vigencia hace mucho tiempo, pero no por ello dejan de interesarnos desde un punto de vista histórico y estético. ${ }^{2}$

Los tratados fueron varios y variados, desde algunos serios, con método y verdaderamente útiles, hasta librillos y folletos para hacer sencillo el estudio de la música, fundándose muchos en el beneficioso influjo del estudio de la música en la juventud.

Como ejemplo de librillo, pone Gómez Amat, uno publicado en Madrid en 1878 titulado Prontuario de lectura y música de doña Rosario Zapater de Otal, que era una cartilla para aprender a leer y también algunos principios de música. (p. 247)

Destaca entre todos los autores decimonónicos a Hilarión Eslava y su Método completo de solfeo, comentando que la permanencia de ese y otros métodos suyos en los centros de enseñanza musical, no se debe tan sólo a su bondad, sino a no haber sabido sustituirlos otros autores, excepto por algunos mamotretos franceses que tampoco se pueden poner como modelo de avance técnico o estético. ${ }^{3}$ Alaba su originalidad (aunque afirma tener un fundamento en las obras de Reicha y Fétis), la organización sistemática de los conocimientos y la eficacia.

Contrapone a la figura equilibrada y eficaz de Eslava, la del brigadier José Joaquín de Virués y Spínola, con su libro de La Geneuphonia o generación de la biensonancia música, publicada en Madrid en 1831 y dedicada a la reina María Cristina, adoptado como texto en el Conservatorio de Madrid. Aunque no es un método de sol-

\footnotetext{
${ }^{2}$ IBÍDEM, p. 247.
} 
Introducción.

1.3. Antecedentes

feo, sino de composición, cambió totalmente la terminología musical e hizo un sistema matemático y filosófico, inventando términos como "politonogamismo", "base tipométrica" o "tipómetro meloarmónico".

Y luego cita, entremezclados con tratados de otras asignaturas, algunos de los métodos de solfeo publicados en ese siglo:

Melopea o Instituciones teórico - prácticas del solfeo, del buen gusto, del canto y de la armonía, para perfeccionar un buen músico y cantor, de Miguel López Remacha.

Curso completo de música teórica - práctica por un método nuevo, sencillo y claro de Mariano de Prellezo, obra opuesta a los preceptos didácticos de Eslava y que produjo controversias entre ambos.

Método de solfeo y de canto por José Melchor Gomis.

Los métodos de Salvador Reguart, Pérez Gascón, Pedro Carrera, Antonio Romero, destacando también el Método de solfeo de Justo Moré y Juan Gil. Todos ellos ampliamente analizados y comentados en este estudio.

Y otros cuantos, no desarrollados aquí, por diversos motivos, como un método elemental de Mateo Pérez de Albéniz (1802).

Sistema uniclave (Madrid 1824) del militar y guitarrista Federico Moretti.

Los métodos de Pedro Pablo Caplarols (1825).

José Lidón.

Ramón Biosca, Elementos prácticos de canto llano y figurado (Madrid 1827).

Joaquín García Castañer, que fue maestro de la iglesia de San Juan Bautista en Valencia.

Uno curioso Taquigrafía de la música, inventada por don Francisco Martín ${ }^{4}$ y publicada por su hijo don Ángel (Madrid 1833).

Escuela elemental del noble arte de la música y canto (Barcelona 1834) de Manuel Camps y Castellví, tenor de la Real Capilla y capellán de las Descalzas Reales.

La Gramática musical de Juan Roca y Bisbal (1837).

El por qué de la música de Tomás Ballester.

Y también otro especial titulado Equinotación o Nuevo sistema musical de llaves (sin variar su figura), por el cual desaparece su actual complicación, y se facilita la

\footnotetext{
${ }^{3}$ IBÍDEM, P. 249
} 
inteligencia de toda música (Madrid 1858) cuyo autor es Francisco Frontera de Valldemosa, profesor de Isabel II y más tarde de la emperatriz Eugenia de Montijo.

También los dedicados al canto llano como los de Daniel Travería (1804), Joaquín Gil (1820), fray Juan Rodó, Vicente Pérez Martínez, Martínez Dávila (1827), fray José Ignacio de Larramendi (1828), Juan García (1862), Miguel Masramón y Godó y Salvador de Rementería (1859), entre otros; y la gran obra del padre Eustoquio de Uriarte en 1891.

Ya anteriormente (p. 253) glosa la mala situación en que habían dejado la enseñanza musical en España los maestros de Capilla con sus "pedanterías y complicaciones”, y a partir de la página 256 hasta la 259, narra la manera como fue evolucionando la enseñanza musical en España.

El primer establecimiento del siglo XIX que se ocupó de la enseñanza musical es el Real Seminario de Nobles de Madrid, centro de educación de la clase alta. ${ }^{5}$ A él asistió Víctor Hugo, cuando su padre, José Leopoldo Hugo, conde de Cifuentes y marqués de Sigüenza era gobernador de Madrid en el reinado de José I. Allí no sólo aprendían violín, piano y bailes, también dibujo, esgrima y equitación. Pero la música solamente la enseñaban para el baile de salón, ya que estaba prohibida la ópera y otros espectáculos considerados de malas costumbres.

En 1810 se produce un primer intento de creación de un Conservatorio en Madrid. Se lo propone el violinista italiano Melchor Ronzi a José I, confiando en la cultura del nuevo rey; quizás hubiese llevado a término tal empresa si hubiese tenido tiempo, pues ya en 1809 creó liceos en las capitales que enseñaban humanidades, ciencias, dibujo, música y baile; y posteriormente fundó centros de educación femenina que incluían la enseñanza de la música.

Es en 1830, según Orden de 15 de julio que dicta: El rey nuestro señor se ha servido mandar que se establezca en esta corte un Conservatorio real de música, que llevará el augusto nombre y gozará de la excelsa protección de la Reina Nuestra Seño-

\footnotetext{
${ }^{4}$ Gómez Amat está confundido con el apellido de don Francisco, que debe ser Martí en lugar de Martín. Se trata de don Francisco de Paula Martí, autor del famoso tratado de taquigrafía, tal como comentamos más arriba.

${ }^{5}$ El primer libro que analizaremos en esta tesis, del carmelita Fray Pedro Carrera Lanchares, está escrito para esta institución.
} 
Introducción.

1.3. Antecedentes

$r a{ }^{6}$ cuando se funda el Real Conservatorio de Madrid a iniciativa de la Reina María Cristina, cuarta esposa de Fernando VII y gran filarmónica.

Inspirado en los conservatorios italianos, donde se enseñaba, además de música, otra humanidades, su primer director fue el tenor italiano Francisco Piermarini, elegido por la reina, lo cual fue muy criticado por su escasa significación musical, siendo que había en Madrid y otras capitales españolas músicos de relieve.

Sus primeros profesores fueron Ramón Carnicer en Composición, Baltasar Saldoni de solfeo y canto, Pedro Albéniz en piano... Además de profesores había "adictos de honor", que eran los infantes o Virués; "adictos facultativos" como Soriano Fuertes, y "maestros honorarios" como Rossini o Saverio Mercadante.

Siguieron a este Conservatorio los de otras importantes capitales. Recogemos en un breve resumen algunos acontecimientos destacados de la época, siempre según Gómez Amat:

\begin{tabular}{|c|c|}
\hline AÑO & ACONTECIMIENTO \\
\hline 1838 & Se funda el Liceo de Barcelona \\
\hline 1869 & Escuelas de solfeo patrocinadas por el Ayuntamiento de Valencia \\
\hline 1875 & Se enseñaba música en las escuelas de artesanos de Valencia \\
\hline 1879 & Se crea el Conservatorio de Valencia \\
\hline 1870 & $\begin{array}{l}\text { Málaga crea la Sociedad Filarmónica, que se transformó más tarde en } \\
\text { Conservatorio }\end{array}$ \\
\hline 1878 & $\begin{array}{l}\text { entre } 1878 \text { y } 1882 \text { funcionó en Bilbao una Academia de música del } \\
\text { Ayuntamiento }\end{array}$ \\
\hline 1886 & Se crea la Escuela Municipal de Música de Barcelona \\
\hline 1889 & Se crea el Conservatorio de Sevilla \\
\hline 1890 & $\begin{array}{l}\text { Se crea una Escuela de Música en Zaragoza que se convertiría } 40 \text { años } \\
\text { más tarde en Conservatorio. }\end{array}$ \\
\hline
\end{tabular}

Otras publicaciones como Historia crítica del Conservatorio de Madrid (Sopeña, 1967), recogen estos y otros comentarios similares.

${ }^{6}$ GÓMEZ AMAT, Carlos. (1984). “Teóricos y tratadistas. La enseñanza musical” en Historia de la música española - 5 - siglo XIX, bajo la dirección de Pablo López de Osaba. Madrid: Alianza Editorial, capítulo XXI, p. 257. 


\subsection{OBJETIVOS CONCRETOS}

Como ya exponemos en la introducción, los objetivos han sido analizar los métodos dedicados a la enseñanza de la asignatura que, dentro de los estudios musicales, se denominaba solfeo (ahora lenguaje musical), su contenido, grado de efectividad en el aprendizaje, forma de organización de los objetivos y contenidos, y particularidades de la bibliografía que sirvió para comenzar a andar por el camino de la música a generaciones anteriores; y que quizás pueda servir en la actualidad para, conociendo cómo se desarrolló la enseñanza/aprendizaje de esta materia en épocas anteriores, imitar lo que tuvo de bueno y huir de lo que pudo tener de erróneo.

En nuestro caso, la tesis pretende indagar sobre la forma en que se llevaba a cabo la enseñanza/aprendizaje del solfeo en el s. XIX y primer cuarto de s. XX, a través del análisis de una gran cantidad de métodos de solfeo editados por autores españoles durante esos años, y que tuvieron gran influencia en la formación de las generaciones de músicos desde entonces, y como veremos, en algunos casos, hasta casi nuestros días.

No nos hemos querido limitar a hacer un muestreo sobre los más importantes; no están todos, pero creemos que están casi todos, o la gran mayoría de los que hemos considerado significativos. También consideramos algunos de los pocos que habían destinados a la enseñanza de la música no profesional.

Una vez trazado el camino que queríamos seguir, nos pusimos como objetivos analizar libro por libro en todos sus aspectos musicales, sin descuidar los pedagógicos, y exponerlos de la forma más clara posible, sin embargo no de la más concisa, reflexionando sobre sus enfoques, sus aportaciones, positivas o negativas, al aprendizaje y la utilidad de cada uno de ellos, comparándolos todos entre sí llegando a las conclusiones que al final expondremos.

Todo ello para conocimiento de los profesionales de la materia, y por si puede servir para extraer en la actualidad lo que tuvieran de bueno y desechar lo que poseyeran de malo; incluso, quizás, llegar a conclusiones o respuestas del porqué hay aspectos históricos deficientes en la enseñanza del solfeo. El estudio del estado de la cuestión nos ha permitido analizar lo ya realizado, observar las lagunas de conocimiento, y establecer las hipótesis avaladas por el marco conceptual 
Introducción.

1.4. Objetivos concretos 


\subsection{ANTECEDENTES HISTÓRICOS EN LA ENSEÑANZA DE LA SOLMIZACIÓN Y EL SOLFEO, Y SISTEMAS DE ENSEÑANZA APLICADOS AL LENGUAJE MUSICAL.}

Una de las grandes conquistas de nuestra civilización ha sido el solfeo, es decir, la invención de la escritura musical moderna. Escritura que, de suyo, es universal, sirve para todos los idiomas y razas. El solfeo es como un esperanto sonoro que todos lo podrían entender.

La técnica musical de escribir los sonidos es, sin género de duda, la técnica más difícil y compleja entre todas las técnicas artísticas. Muchas civilizaciones han existido a través de la historia, que han desarrollado técnicas impresionantes -en arquitectura, escultura, pintura- , pero la técnica de escribir la música no pasó de balbuciente o imperfecta. ${ }^{7}$

El solfeo actual proviene de los neumas gregorianos, y éstos de los acentos gramaticales, la etimología de esta palabra deriva de las notas SOL - FA que eran las que se movían en el hexacordo de Güido d'Arezo (ca. 980 - ca. 1050) para situar el semitono Mi - Fa donde los hubiera. De ahí solmización, solfa, solfeo.

Desde un principio, fue preocupación constante de los maestros y compositores, la invención de sistemas que pudieran llevar al iniciado en música a su comprensión lectora, incuso que pudieran llevar al simple aficionado a un aprendizaje sencillo, rápido y poco arduo, que se trasluce en procedimientos como la mano de Guido, y desde los principios de la imprenta moderna las tablaturas, los libros para laúd y vihuela y otros sistemas de representación.

Otros teóricos como Bartolomé Ramos de Pareja (ca. 1440 - 1491?) en su tratado Música Práctica (1482) introducen teorías renovadoras, nuevos métodos de solmización y la manera de calcular diferentes clases de intervalos cromáticos. Se hallan en ese tratado diferentes maneras que habían de dar nombre a las notas y también el que propone él: psal, li, tur, per, vo, ces, is tas (psallitur per voces istas), colocadas desde la letra "C" grave hasta la "C" aguda, esto es, desde el Do grave al agudo. (Pérez Gil, inédito, pp. 3 y 4$)$

Las raíces de la enseñanza musical podemos encontrarlas en el destacado pedagogo y filósofo checo Juan Amós Komensky de Comma, conocido como "Comenius" (1592 - 1670), quien en su obra, publicada en 1657, Didáctica Magna, seu omnes om-

\footnotetext{
${ }^{7}$ PRECIADO, Dionisio. (1978). Don Hilarión Eslava y su "Método completo de solfeo" en Monografía de Hilarión Eslava, AAVV. Pamplona: Diputación Foral de Navarra, p. 229.
} 
Introducción.

1.5. Antecedentes históricos...

nia docendi artificum, expone sus teorías sobre la organización de las escuelas y desarrolla una metodología para la enseñanza de la música. (Oriol, 2005, p.10)

Ya en el s. XVIII encontramos las propuestas didácticas de los Enciclopedistas, como las de Jean-Jacques Rousseau y sus continuadores, basadas en las cifras como indicadores de alturas sonoras, hasta llegar a las primeras corrientes didácticas de principios del siglo XX. En todos ellos está presente la dicotomía ya histórica entre el solfeo relativo y el absoluto, abundando en gran manera la vertiente relativista sobre la del sonido absoluto. Esta preocupación por resolver las dificultades de aprendizaje del código musical está presente en los métodos de solfeo del s. XVIII, proponiendo "inventos" para intentar resolver la lectura musical en diferentes claves, tonalidades, etc. reduciendo los problemas en la iniciación del aprendizaje musical.

Jean Jacques Rousseau (1712 - 1778) en 1742 divulgó como invención propia un método de escritura y lectura musical simplificada, que en realidad pertenecía al monje Jean Jacques Souhaitty quien había publicado en París (ca. 1677) su Essai du chant de l'èglise par un nouvelle méthode des chiffres...y otro posterior con el título de Nouvelle méthode pour aprendre le plain chant et la musique. Consistía en tratar de facilitar la lectura musical con menos signos y más sencillos que los tradicionales.

Para la entonación utilizaba un sistema numérico como expresión de la altura relativa de los sonidos. Tomando el DO como sonido fundamental, al que se le llama 1, sigue el orden numérico a través del resto de sonidos de la escala natural:

$$
\begin{array}{llllllll}
\text { Do } & \text { re } & \text { mi } & \text { fa } & \text { sol la } & \text { si } \\
1 & 2 & 3 & 4 & 5 & 6 & 7
\end{array}
$$

Así sería la octava central, la superior se indicaba colocando un punto en la parte superior de la cifra, y la inferior con el mismo punto pero debajo de la cifra. Esto facilita el cantar en cualquier tonalidad a partir de un sonido dado, pero no sirve para las escalas menores.

Las alteraciones accidentales se representan con una línea diagonal, en forma ascendente, de izquierda a derecha, para el sostenido, y el forma descendente para el bemol, el becuadro no es necesario.

Los cambios de tono o modulaciones se indican con dos cifras en forma de quebrado, la superior indica la nota en el tono de donde sale, la inferior el tono al cual modula. 
La duración de los sonidos también tiene una forma distinta de indicarse en este sistema. Los compases se reducen a 2 ó 3 tiempos, se indican con una cifra grande separada por una doble línea perpendicular. Los compases se separan mediante una línea vertical (al igual que las tradicionales líneas divisorias), dentro de un compás se separan los tiempos por una coma: si entre dos comas sucesivas no hay más que una cifra, ésta llena todo el tiempo, si hay varias, divide el tiempo en tantas partes iguales como cifras hayan. Si dentro de un mismo tiempo no todos los sonidos tienen que ser iguales, se subdivide el tiempo uniendo con una línea superior las cifras que ocupen una mitad. Si una sola nota cubre todo el compás, se coloca sola entre dos líneas divisorias.

De cualquier manera, ni Rousseau ni Souhaitty inventaron totalmente la notación cifrada que ya desde la Edad Media se venían utilizando las cifras del 1 al 15 para sustituir a las 15 letras del abecedario utilizadas para las dos octavas que comprendía la tesitura vocal. En Francia fue introducido por el P. Mersenne $(1588$ - 1648) y posteriormente por Jean Jaques Souhaitty, como arriba se dice. (Pérez Gil, 1989, pp. 37 a 42; Zamacois, 1973, p. 160; Serrallach, 1953, capítulo VI, pp. 175 y 76).

Guillermo Wilhem (1781 - 1842) hizo varias propuestas para la enseñaza musical inicial.

En la iniciación musical, se excluían los signos usuales. Las escalas se cantaban con las cifras, 1, 2, 3, etc., partiendo de cualquier sonido que se tomaba como tónica (hasta aquí es el método de Rousseau). Los estudios preparatorios podían hacerse de varias maneras:

a) Basándose en la escala vocal representada de dos curiosas maneras: como una escalera de ocho peldaños y los que representan los semitonos la mitad de altos que los otros, y con una regla centimetrada vertical en la que las distancias 3-4 y $7-8$ eran la mitad que las otras.

b) O también con signos manuales, pautas mudas como la mano que representa las cinco líneas y cuatro espacios del pentagrama, la derecha para la clave de sol y la izquierda para la de fa, también sin claves o con todas ellas; con escalas cifradas, empleando los números arábigos para los grados complementarios y romanos para los tonales

También usaba las manos asignando lugar a las alteraciones, con lo que se podían hacer modulaciones, analizar intervalos y formas escalas. (Scholes, 1984, tomo II, p. 1353; Zamacois, op. citada, p. 161; Serrallach, op. citada, capítulo VI, pp. 180 a 185). 
Introducción.

1.5. Antecedentes históricos...

Sarah Glover (1785 - 1867) maestra noruega, fue la inventora, en 1835, de un sistema de unificación de todas las tonalidades, se basa en otro anterior llamado Lancashire. Fue publicado en el texto Scheme for Rendering Psalmody Congregational.

Más tarde, alrededor de 1840, fue adoptado y perfeccionado por John Curwen $(1816$ - 1880) y que se conoce con el nombre de Tonic Sol - Fa. Su primera edición se divulgó a partir de 1841, se reeditó muchas veces y en 1980 se ha publicado de nuevo con el título New Curwen Method, lo que demuestra su vigencia actual.

Este sistema tuvo una gran aceptación para el aprendizaje en la escuela y entre la clase trabajadora en Inglaterra, también fue introducido en Alemania, donde se le conoce como Tónica-do, y ha servido como base para posteriores métodos como el de Kodaly. (Jorquera, 2004, pp. 20 y 21 y Valenzuela, s/f, pp. 5 y 6)

En lugar de emplear las cifras para designar los sonidos, emplea las consonantes de las sílabas guidonianas: $\mathrm{d} \mathrm{r} \mathrm{m} \mathrm{f} \mathrm{s} 1 \mathrm{t}$, poniéndoles una coma arriba si pertenecen a la octava superior, y bajo si a la inferior; los sonidos alterados cambian la vocal por "e" (pronunciada en inglés “ $i$ "), si son sostenidos y "a" si son bemoles (por eso le llama al SI, TI, para no confundirlo con el Sol sostenido).

Una característica más de Tonic Sol - Fa, es el uso de sílabas rítmicas para los tiempos de un sonido, y también las señas para indicar la altura del sonido (aspectos estos que luego tomó y desarrolló Kodaly). (Pérez Gil, op. citada, p. 46; Acholes, op. citada, tomo II, pp. 1255 a 1262 y Serrallach, op. citada, capítulo VI, pp. 190 a 192).

Pierre Galin (1786 - 1821), fue un matemático y músico francés que tomó el sistema de Rousseau y lo amplió, consiguiendo con él gran revuelo en la enseñanza a partir de 1817. Este método recibe el nombre de Método del Meloplaste, título que le dio un discípulo de Galin, llamado Lemoine, quien lo publicó.

Envió a París, a la Sociedad de instrucción elemental, el manuscrito de la exposición de su método, proponiendo que lo adoptasen en sus escuelas, para que en toda Francia pudiera estudiarse música de forma tan económica y casi infalible en los resultados. Galin afirmaba que la mayoría de los que han estudiado música, no saben cantarla:

Casi todos han necesitado un instrumento para saber como suena un canto que no conocían; es el instrumento el que cantaba por ellos. Es como si para leer cualquier libro necesitaran un aparato especial, y no utilizando el mejor medio, que es su propia voz. El proceso es el siguiente: la vista de los signos escritos hace mover los dedos, éstos actúan sobre el instrumento, y es éste el que materializa el pensamiento. Pero, ¿por qué 
la vista de los signos no dice nada directamente a la mente del lector? No son capaces de frasear, no saben cuándo pasan de un tono, de un modo a otro, porque el instrumento solo lee notas, y es la mente la que tendría que dirigir, por lo que afirmamos que la verdadera música es la vocal.

En efecto, ¿qué es la música sino el arte de hablar, leer y escribir el canto?; una lengua en la que las ideas están vinculada a signos instituidos para comunicarse con la mente. Estos signos son articulados con las palabras do, re, mi... o escritos, no importa de qué manera. Mientras que estos signos no se conviertan en melodías en el interior del lector, y recíprocamente las melodías no pueden traducirse en signos escritos, el estudiante no sabe hablar el idioma de la música. ${ }^{8}$

La simplificación mayor que se introdujo en esta clase de escrituras fue la que se conoció con el nombre de "principio modal". Todas las tonalidades se reducen a los modos mayor y menor. En el aspecto métrico, este método sigue el principio de Rousseau. (Pérez Gil, op. citada, p. 43; Scholes, op. citada, tomo I, p. 568; Zamacois, op. citada, p. 160 y Serrallach, op. citada, capítulo VI, pp. 176 a 186).

Estos sistemas, siendo oportunos para la enseñanza inicial porque facilitan el canto y la lectura musical de forma sencilla, son limitados, solamente sirven o son útiles cuando se trata de leer o ejecutar música con pocas dificultades, cuando la métrica y la interválica, se complican, las tonalidades son muy alteradas o el ritmo es irregular, esto es, en cuanto se quiere pasar de ellos al Solfeo de forma profesional presentan problemas e inconvenientes. Serrallach señala dos inconvenientes: la falta de formación del gusto musical, y que los cantos buenos que se pueden utilizar son muy pocos ...Deben componerse otros que, por lo limitado de los recursos que se pueden emplear, resultan pobres, monótonos y hasta contraproducentes. ${ }^{9}$

Hasta la fundación del Real Conservatorio Superior de Música de Madrid (1830) se habían ocupado de la enseñanza de la música los maestros de capilla que prestaban sus servicios en las instituciones religiosas más importantes, sobre todo en las catedrales y también en las capillas reales. A partir de ese momento, se van escribiendo y editando métodos dedicados a la enseñanza de la música profesional, y también algunos para el simple conocimiento lúdico de la música, ambos formando el "corpus" principal de esta tesis y que se describen con detalle más adelante. Pero estos métodos convivieron con las diferentes metodologías, que al igual que las ya descritas, siguieron

\footnotetext{
${ }^{8}$ CANDELA ROMÁN, Rebeca. (2005). "Nuevo método para la enseñanza musical". I + E Revista Digital "Investigación y Educación", ISSN 1696 - 7208, número 14, enero, pp. 1 a 4.

${ }^{9}$ SERRALLACH, Lorenzo. (1953). Historia de la Enseñanza Musical. Buenos Aires: Ricordi Americana S. A., Cap. VI, p. 195.
} 
Introducción.

1.5. Antecedentes históricos...

apareciendo para tratar de hacer más asequible, y llegar a más gente, el aprendizaje del lenguaje musical.

André Gedalge (1856 - 1926) compositor francés, autor de un método que él tituló Enseñanza de la Música por la educación metódica del oído. Basado un poco en el método de Wilhem, la entonación se trata por la relación interválica de las notas entre si y con referencia a los grados de la escala; las notas se cantan pronunciando su número de orden en dicha escala en lugar de su nombre; no se usan claves, por lo cual las notas deber ser identificadas por las líneas y espacios del pentagrama en que están colocadas (la $2^{\mathrm{a}}$ línea una $3^{\mathrm{a}}$ más alta que la $1^{\mathrm{a}}$, etc.); una cifra romana puesta debajo de la primera nota de cada ejercicio, indica el grado de la escala que debe atribuirse a dicha nota (parte de esto lo aprovecha más tarde Kodaly). (Zamacois, op. citada, p. 142).

Emile Jaques - Dalcroze (1865 - 1950). Este músico y eminente pedagogo de origen suizo, aunque nació en Viena, pero vivió y ejerció en Ginebra, creó un método de enseñanza musical, en principio destinado a la enseñanza profesional, pero que más tarde él mismo vio que podía ir dirigido a la enseñanza en la escuela, circunstancia por la que luchó personalmente hasta implantarlo, y no solamente como método cuyo fin es aprender música, sino también como vehículo para llegar a entender y dominar otras disciplinas. Es una enseñanza a través de la música pero no sólo para la música, sino para el desarrollo integral de la personalidad del individuo, su voluntad y facultades imaginativas.

Él lo tituló Método de educación por el ritmo y para el ritmo. Desarrolla ante todo el concepto de ritmo que hay en la base del solfeo cantado. El alumno aprende a escuchar y a concentrarse en la escucha; breves motivos al piano le inspiran movimientos de andar, correr, saltar, pararse, acelerar o retardar movimientos. Gradualmente se pasa a música más compleja, que permite desarrollar toda la fantasía de creación de movimientos con todo el cuerpo. Más tarde el niño aprenderá las notas y distinguirá los intervalos, leerá y escribirá música, aprenderá solfeo y distinguirá tonalidad y modalidad. Más tarde todavía, aprenderá cualquier instrumento melódico o rítmico con el que desarrollar su fantasía improvisatoria.

Otro aspecto importante del método, pero no dirigido a la escuela, sino a quien deba enseñarlo, es la improvisación y acompañamiento al piano, que es como una síntesis del mismo. (Llongueras, 1942). 
Otros sistemas para la enseñanza fácil de los inicios musicales (solfeo), aparecieron después, ya fuera de nuestro periodo analizado, son sobradamente conocidos: Ward, Kodaly, Orff y Willems. En ellos se han basado muchos de los métodos modernos, pero muchos aspectos de esta moderna pedagogía es consecuencia o desarrollo de los arriba citados.

En esta tesis veremos, muy detalladamente, cómo se desarrolló, a través de métodos editados, la enseñanza profesional, y casi profesional de la música en España durante el siglo XIX y primer cuarto del XX.

Pero ¿influyeron en nuestros eruditos músicos las enseñanzas de tan grandes y universales maestros? ¿Lo que pensaron y pusieron en práctica eminentes músicos y pedagogos europeos, para tratar de hacer llegar la lectura musical a todos los niveles de la sociedad y de la enseñanza, caló o contribuyó en algo en los métodos que se hicieron en la época estudiada?

Quizás el aislamiento español de Europa, sumida en sus conflictos internos después de la guerra de la Independencia, influyera en la poca información pedagógica de sus músicos, pero al final de este estudio se verá que para las dos preguntas anteriores, la respuesta es: muy poco, y en algunos casos nada. 
Introducción.

1.5. Antecedentes históricos... 
- 2 -

METODOLOGÍA 


\subsection{TIPO DE METODOLOGÍA EMPLEADA Y CAUSA}

\subsubsection{MARCO METODOLÓGICO}

Se empleará el método descriptivo, ya que no se incluye ninguna experimentación con estos materiales. El objetivo de la investigación descriptiva es mostrar, sacar a la luz ciertas características de una situación particular en uno o más puntos del tiempo, para permitir su evaluación. En la triple faceta de la investigación descriptiva, esto es, observación, indagación, y análisis de contenido, es esta última la que emplearemos principalmente, mediante una detallada exposición y crítica de los contenidos de cada uno de los métodos de solfeo, secuenciados temporalmente.

Según Porta y Silva (2003, p. 8), Krippendorff define el análisis de contenido como: la técnica destinada a formular, a partir de ciertos datos, inferencias reproducibles y válidas que puedan aplicase a un contexto. Calvo Pascual y Martín Sánchez (U .C. M., s. f., p. 18), lo definen como: el método consistente en considerar todo mensaje como una secuencia de elementos aislables, susceptibles de ser ordenados por categorías y tratados de manera estadística.

Creemos pues, que este tipo de metodología es la que mejor se adapta a nuestro asunto, porque el análisis de contenido se refiere a aquellas técnicas destinadas a determinar las características de la comunicación didáctica, describiéndolas críticamente y analizando su aportación y adecuación a las enseñanzas regladas de la época, así como a su grado de vigencia actual.

La utilización del análisis de contenido es ideal para la investigación del currículum. En ocasiones, el sistema escolar deja algo indefinido el currículum, de manera que no queda clara la consecución de objetivos del sistema. Para ello se analiza el contenido de los textos de enseñanza, guías del maestro, sistemas de evaluación, exámenes, y otro material impreso, y se registran las lecciones y reuniones de trabajo realizadas en las clases.

Se analizan los métodos de solfeo por orden cronológico, de la misma manera que el historiador interpreta la historia a través de la iconografía, del hallazgo de restos de las civilizaciones antiguas, deduciendo lo que pudo pasar en función de todas esas huellas históricas. Nuestras huellas serán los métodos de solfeo.

También se realizan análisis comparativos desde dos puntos de vista; primero, comparando la bondad de las fuentes en función de su adaptación a los programas ofi- 
ciales del Conservatorio de Madrid en los años respectivos en que aparecen las publicaciones; después, constatando su vigencia actual o su nivel de adaptación a los programas actuales de formación en los Conservatorios, con el objeto de que este trabajo pueda tener una repercusión positiva en la enseñanza de esta materia en la actualidad.

Utilizaremos el análisis comparativo mediante un tratamiento globalizado de la información extraída de todas las aportaciones de los distintos autores, con gráficos y tablas para una mejor comprensión del alcance de todos ellos en conjunto.

\subsubsection{DEFINICIÓN DE LA UNIDAD DE ANÁLISIS.}

La definición de las unidades de análisis se efectúa según el método inductivo, a partir de las similitudes de sentido del material de análisis y también del deductivo, derivándolas de una teoría existente. (Gómez Mendoza, s. f., p. 6)

La unidad de análisis debe ser lo suficientemente extensa para ser significativa. Un simple párrafo no sería suficiente a nuestro propósito, por lo que hemos optado por el análisis de cada uno de los libros de cada método, lo que nos permitirá observar su progresión didáctica en conjunto, la secuencia de los contenidos expuestos y su adecuación formal al curriculum de su tiempo y compararlo con el actual. A pesar de lo arduo de la tarea no hemos utilizado técnicas de muestreo, sino el análisis exhaustivo del contenido.

Nuestro propósito es un análisis evolutivo o del grado de dificultad de los contenidos. (Pascual y Martín, op. citada, p. 18)

\subsubsection{TÉCNICAS Y PROCEDIMIENTOS DE RECOLECCIÓN DE INFORMACIÓN}

La mayor parte de las fuentes de esta tesis son primarias, y han sido obtenidas en distintas bibliotecas, como la Biblioteca Valenciana, Biblioteca del Conservatorio Superior de Música “Joaquín Rodrigo” de Valencia, Biblioteca del Real Conservatorio Superior de Música de Madrid, Biblioteca Nacional, Biblioteca de Cataluña, Biblioteca de la E. U. de Magisterio “Ausias March” y en la Red de Bibliotecas Universitarias Españolas, REBIUN.

Las fuentes secundarias son escasas, pero también han sido consultadas, en especial, el artículo de Dionisio Preciado (op. citada), y el capítulo correspondiente a la 
obra de Gómez Amat (op. citada). También se han utilizado, especialmente en la obtención de las reseñas biográficas de los autores, enciclopedias de prestigio como el Diccionario de la Música española e Hispanoamericana (AAVV, 1999), entre otros.

\section{PROCEDIMIENTO SEGUIDO}

Base de datos "Teseo" para cerciorarse de que no existía en España ninguna tesis doctoral con este contenido.

Biblioteca Valenciana, allí encontramos los siguientes libros:

\begin{tabular}{|l|l|}
\hline \multicolumn{1}{|c|}{ AUTOR } & \multicolumn{1}{|c|}{ NOMBRE } \\
\hline Panseron, Auguste- Mathieu & $\begin{array}{l}\text { 36 ejercicios de solfeo para el cambio de las } 7 \text { claves, manuscritos y } \\
\text { sin acompañamiento, } \text { cuaderno } 3\end{array}$ \\
\hline Espino, Felipe & $\begin{array}{l}\text { Doce estudios melódicos y progresivos de perfeccionamiento de solfeo } \\
\text { para el cambio de todas las claves }\end{array}$ \\
\hline Sociedad Didáctico Musical & El progreso musical $3^{\circ}$ curso \\
\hline Sociedad Didáctico Musical & El progreso musical $4^{o}$ curso \\
\hline Sociedad Didáctico Musical & El progreso musical parte segunda \\
\hline Amorós, Amancio & Elementos del solfeo \\
\hline Maestros nacionales & Escuela de solfeo libro I \\
\hline Maestros nacionales & Escuela de solfeo libro II \\
\hline Amorós, Amancio & Lecciones manuscritas graduadas $2^{\circ}$ curso \\
\hline & Lecciones manuscritas graduadas $3^{\circ}$ curso \\
\hline Busser, Henri & Leçons manuscrites de solfège $2^{\circ}$ livre \\
\hline Moré, Justo & Método completo de solfeo \\
\hline Suñol, Gregorio M ${ }^{\circ}$ & Método completo de solfeo, teoría y práctica del canto gregoriano \\
\hline Pérez Gascón, Pascual & Método de solfeo, principios de canto \\
\hline Barasoain Julve, Manuel & Música científica I $^{\circ}$ curso 1948 \\
\hline Pérez Gascón, Pascual & Principios de solfeo y canto \\
\hline Lemoine, Henry & Solfège des solfèges \\
\hline Arrieta, Emilio & Solfeo autografiados, primer libro \\
\hline Arrieta, Emilio & Solfeo autografiados, tercer año \\
\hline
\end{tabular}

También consultamos en esa biblioteca algunas teorías del solfeo para esclarecer algunos conceptos y signos que encontrábamos extraños en época actual y que vimos quedaban poco consensuados de forma general en la época estudiada.

A través de la misma fuente averiguamos que había métodos de solfeo en la Biblioteca Nacional, en la de Cataluña y en la Universidad de Valencia, aunque muchos de ellos coincidían. No se encontraron en ninguna otra de la red pública.

Biblioteca del Conservatorio Superior de Música "Joaquín Rodrigo" de Valencia.

Allí hallamos, entre muchos, los siguientes métodos que están dentro de nuestro período investigado: 


\begin{tabular}{|l|l|}
\hline \multicolumn{1}{|c|}{ AUTOR } & \multicolumn{1}{c|}{ NOMBRE } \\
\hline Arrieta, Emilio & Solfeos autografiados, vol. 1 \\
\hline Arrieta, Emilio & Solfeos autografiados, vol. 2 \\
\hline Arrieta, Emilio & Solfeos autografiados, vol.3 \\
\hline Arrieta, Emilio & Solfeos autografiados, vol. 4 Concursos, primer libro \\
\hline Brull, Melecio & Lecciones autografiadas para repentizar en el primer año de solfeo \\
\hline Buxó, Tomás & Método de solfeo: Libro 1. Libro 2. libro 3 \\
\hline Eslava, Hilarión & Método completo de solfeo \\
\hline Funoll Alpuente, Francisco & Método completo de solfeo sin acompañamiento. Primera parte \\
\hline Moré y Gil & Método completo de solfeo \\
\hline
\end{tabular}

Nos desplazamos posteriormente a la Biblioteca de Cataluña, en donde localizamos los siguientes métodos:

\begin{tabular}{|l|l|}
\hline \multicolumn{1}{|c|}{ AUTOR } & \multicolumn{1}{c|}{ TÍTULO } \\
\hline AAVV & Escuela del solfeo, Libro segundo \\
\hline Abrantes Bello, Joaquín & Método de solfeo abreviado \\
\hline Abreu, Avelino & $\begin{array}{l}\text { Solfeo } 5^{\circ} \text { curso } \\
\text { Solfeo } 2^{\circ} \text { curso }\end{array}$ \\
\hline Calvó i Puig, Bernat & Método de solfeo, o sea, elementos generales para aprender a leer la música \\
\hline $\begin{array}{l}\text { Claparols y Maruñs, Pedro } \\
\text { Pablo }\end{array}$ & $\begin{array}{l}\text { El maestro y discípulo de música: } \text { método breve y fácil de elementos genera- } \\
\text { les de música.... }\end{array}$ \\
\hline Espino, Felipe & Doce estudios melódicos y progresivos de perfeccionamiento de solfeo \\
\hline Lavignac, Albert & Nociones escolares de música \\
\hline LAZ & Método graduado de solfeo, libro IV \\
\hline Lemoine, Henry & Solfège des solfèges volumen I $^{\circ}$ \\
\hline Llorca, Miguel & Método de solfeo para repentizar en 4 meses, $1^{a}$ parte \\
\hline Llupart, C & Treinta solfeos a tres voces iguales \\
\hline Manent i Puig, Nicolau & Método teórico práctico musical \\
\hline Moré, Justo & Método completo de solfeo \\
\hline Obiols, Marià & Método de solfeo \\
\hline Panseron, Auguste Mathieu & ABC musical o Método de solfeo \\
\hline Pedrell, Felipe & Gramática o Manual expositivo de la teoría del solfeo \\
\hline Penella, Manuel & Principios de solfeo \\
\hline Pérez Gascón, Pascual & Método de solfeo y principios de canto \\
\hline Rodolphe, Jean-Joseph & Solfeo de Rodolphe elemental y progresivo \\
\hline Sabatés Estaper, Mateo & Solfeo, 3 tomos \\
\hline Suñol, Gregorio M ${ }^{a}$ & $\begin{array}{l}\text { Método completo de solfeo, teoría y práctica de canto gregoriano, según la } \\
\text { escuela de Solesmes }\end{array}$ \\
\hline Valero, José y Romero A. & Nuevo método completo de solfeo \\
\hline Vancell Roca, Juan & El libro de música y canto 1a parte \\
\hline Velázquez, Juan & Nuevo curso teórico práctico de solfeo \\
\hline Willems, Edgar & Solfeo curso elemental libro del alumno \\
\hline
\end{tabular}

Y el otro gran bloque lo obtuvimos en la Biblioteca Nacional, allí topa-

mos con los siguientes:

\begin{tabular}{|l|l|}
\hline \multicolumn{1}{|c|}{ AUTOR } & \multicolumn{1}{c|}{ NOMBRE } \\
\hline A. Brull, Int. Campo & Método completo de solfeo \\
\hline Agero Feliciao & Método completo de solfeo, dividido en 3 partes \\
\hline Alcocer Antonio M & Desatinos de un protestante puestos en solfa \\
\hline Aldás Conesa, Tomás & Método de solfeo primer curso \\
\hline Aliaga López Matías & Cartilla de música ó sea La música en el bolsillo \\
\hline Aliaga López Matías & $\begin{array}{l}\text { El más barato de los solfeos ó sea La música puesta al alcance de todas las } \\
\text { inteligencias y fortunas }\end{array}$ \\
\hline
\end{tabular}




\begin{tabular}{|c|c|}
\hline Amorós Amancio & $\begin{array}{l}\text { Elementos de Solfeo } \\
\text { Nociones teóricas de solfeo } 1^{o} \text { curso } \\
\text { “ “ } \quad 2^{o} \text { curso }\end{array}$ \\
\hline Arabaolaza, Gaspar de & Lecciones teóricas de solfeo $1^{o}$ curso-[segundo] \\
\hline Benito, Cosme José de & Método completo de Solfeo en Compendio \\
\hline Bobadilla, Emilio & Solfeo: crítica y sátira \\
\hline Buxó, Tomás & Método de solfeo \\
\hline Carrera y Lanchares, Pedro & $\begin{array}{l}\text { Solfeo práctico: metódicamente formado según el orden de las instrucciones } \\
\text { anteriores para el uso.... } \\
\text { Rudimentos de música: divididos en cinco instrucciones que facilitan la más } \\
\text { pronta inteligencia.... }\end{array}$ \\
\hline Codinach, Carmelo & Nociones de solfeo \\
\hline Egea, Pedro $\mathrm{M}^{\mathrm{a}} \mathrm{de}$ & Método de solfeo o Nuevo arte de la música \\
\hline Eslava, Hilarión & Método completo de solfeo \\
\hline Fetis, François-Joseph & Gran Método de solfeo o Nueva Escuela de Música \\
\hline Font i Romagosa, Joan & Sistema musical numérico: con método dodecasílabo de solfeo \\
\hline Gomis, José Melchor & Méthode de Solfège et de Chant \\
\hline Lemoine, Henry & Solfeo de los solfeos \\
\hline Lladó, Joaquín & $\begin{array}{l}\text { Método analítico par el estudio de solfeo, ob. } 11 \\
\text { Método de solfeo analítico, fácil y conciso, ob. } 25\end{array}$ \\
\hline López Remacha, Miguel & Melopea: instituciones de canto y de armonía.... \\
\hline Panseron, Auguste-Mathieu & $\begin{array}{l}\text { ABC musical o Solfeo: compuesto expresamente para jóvenes de corta edad } \\
\text { El ejercicio de solfeo para el cambio de las } 7 \text { clave. } 2^{a} \text { parte }\end{array}$ \\
\hline Pardás y Font, Primitivo & Método completo de solfeo \\
\hline Prellezo, Mariano de & Método de Solfeo sencillo y claro en estilo familiar y en forma de diálogo \\
\hline $\begin{array}{l}\text { Reguart y Mestre, Salvador } \\
\mathbf{M}^{\mathrm{a}}\end{array}$ & Elementos musicales: método sencillo para aprender.. \\
\hline Roca y Bisbal, J. B. & Gramática musical; dividida en 14 lecciones \\
\hline Roger Junio, A & Método práctico de lectura musical y de solfeo \\
\hline Sobejano, José & Escuela de solfeo, según el estilo moderno \\
\hline Sociedad Didáctico Musical & $\begin{array}{l}\text { El Progreso Musical. Método especial de solfeo con acompañamiento de } \\
\text { piano y bajo numerado [lecciones para repentizar en los exámenes de } 3^{o} \text { año } \\
\text { en el Conservatorio de Madrid] }\end{array}$ \\
\hline Speardero, R. & Breve complemento de Solfeo \\
\hline Vancell y Roca, Juan & El libro de música y canto: tratado de solfeo y cantos escolares \\
\hline $\begin{array}{l}\text { Velasco de Velasco, Manue- } \\
\text { la }\end{array}$ & $\begin{array}{l}\text { Apuntes musicales: } 1^{o}, 2^{o} \text { y } 3^{a} \text { año de solfeo. Nociones sobre la manera de } \\
\text { escribir la música dictada. Conocimientos preliminares de armonía }\end{array}$ \\
\hline
\end{tabular}

Después de examinarlos uno a uno, escogimos los que se ajustaban en época, disciplina y nacionalidad del autor a nuestro objetivo, y basándonos en el instrumento registrador, hemos ido anotando las características de cada uno de ellos y la descripción detallada de su contenido, así como de cualquier signo fuera de lo normal, particularidad, definición, exposición y forma de afrontar el estudio de la materia.

Además hemos consultado la Red de Bibliotecas Universitarias, "Rebiun", en la web, para obtener la relación de existencia y ubicación de métodos de solfeo en las universidades españolas, comprobando que cuantos métodos de solfeo de la época estudiada figuran en la dicha red, estaban en nuestro poder, a excepción de los dos que describimos a continuación: 
Nuevo método de solfeo, de Santiago de Masarnau, sin lugar ni fecha. Santiago de Masarnau y Fernández, nació y murió en Madrid entre 1805 y 1882, fue pianista y compositor, ocupó varios cargos en la Casa Real española y tuvo grandes épocas de estancia, estudio y trabajo en París (donde trabó amistad con Gomis) y Londres. En 1843 se ocupó de la vicedirección de un colegio de segunda enseñanza, agregado a la universidad, que había fundado su hermano y en el que se incluía la enseñanza de la música; es para ese colegio que escribió este método, entre otras obras didácticas, y aunque empezó en él en 1843, la autora del artículo consultado afirma que se publicó en 1832. ${ }^{1}$ Este libro se encuentra en la Biblioteca Central del CSIC, sin referencia de lugar ni año, por toda descripción figuran 30 páginas, 20 centímetros y que carece de portada, pero puestos al habla con dicha biblioteca, nos manifiestan que están en periodo de fusión y no es posible el préstamo ni la consulta.

Gramática musical razonada, dispuesta en cuatro lecciones o sea Nuevo tratado teórico - práctico de solfeo, por Gabriel Melitón Baños, Toledo, Imp. y Lib. de Fando y Hermano, 1868. Este autor, pedagogo y compositor, nació en Toledo en 1850 y murió en 1924. Dice Javier Suárez Pajares ${ }^{2}$ de este libro que: es excepcional dentro del panorama de publicaciones teóricas destinadas a la formación primaria de los estudiantes de música..., pero que no llegó a publicarse completamente, por razones supuestamente de índole económica. Expone que resulta una obra más lógica y avanzada pedagógicamente que la de Eslava, y describe el plan de la obra que es como sigue:

Se compone de cuatro lecciones teórico - prácticas, en las que se halla contenida toda la escuela de solfeo tal y como debe ser en el día. Sigue una reseña histórica, donde el discípulo puede ver prácticamente la razón de ser, que antes tenían - y de la cual carecen hoy - todas las fórmulas, procedimientos y sistemas impugnados en esta obra. A la vez que se proscriben en ella todas las teorías y prácticas inútiles, se presentan otras esenciadísimas que no se encuentran en los métodos actuales o se dan en ellos muy superficialmente.

Este método, o lo que haya de él publicado, se encuentra en la Universidad de Las Palmas de Gran Canarias, lo hemos solicitado por correo electrónico repetidamente y ninguna contestación se ha recibido.

\footnotetext{
${ }^{1}$ AAVV. (1999). Diccionario de la Música española e Hispanoamericana, Director y coordinador general Emilio Casares Rodicio. Madrid: SGAE, tomo 7, pp. 323 a 331, firma Gemma Salas Villar

${ }^{2}$ Suárez Pajares, Javier es el firmante del artículo "Baños, Gabriel Melitón" en Diccionario de la Música española e Hispanoamericana..., pp. 175 a 178
} 
Pudimos encontrar en el Real Conservatorio Superior de Música de Madrid, programas referidos a la asignatura de solfeo de los años 1831, 1832, 1861, 1875, 1876, 1891 y 1898.

Y otra de las fuentes de obtención de información ha sido la biblioteca de la E. U. de Magisterio “Ausias March" de la Universidad de Valencia, donde fuimos buscando las pequeñas reseñas biográficas de los autores estudiados, y con la inestimable colaboración de los directores de este estudio, tuvimos acceso a las revistas, artículos, libros y demás bibliografía pedagógica y complementaria. 
2.1. Tipo de metodología empleada y causa 


\subsection{CATEGORÍAS DE ANÁLISIS Y RAZONES}

Afirma el Dr. Luís Porta que la categorización consiste en la operación de clasificar los elementos de un conjunto a partir de ciertos criterios previamente definidos. ${ }^{1}$

Por tanto, a continuación exponemos los criterios que servirán para valorar las distintas categorías que se van a analizar.

\subsubsection{EL INSTRUMENTO REGISTRADOR}

En el análisis de contenido es necesario definir el instrumento registrador, un formulario que ayude a la clasificación y registro de las unidades. El ordenamiento del formulario se efectúa mediante una ficha resumen del contenido de cada libro, expuesta al principio de cada método o libro particular, en el que se sintetizan los contenidos didácticos y la secuencia de las lecciones de los métodos en los siguientes aspectos:

- $\quad$ Extensión de las lecciones

- $\quad$ Claves empleadas y orden en que se enseñan

- $\quad$ Tesituras que abarcan

- $\quad$ Tonalidades que trata y estudia, y en qué orden

- $\quad$ Compases que emplea y estudia y su orden

- Dificultades Métricas que contiene

- Dificultades Melódicas, o sea, dificultades de entonación y orden en que se en$\underline{\text { señan los intervalos }}$

- $\quad$ Armonía utilizada

- $\quad$ Formas que tienen las lecciones

- $\quad$ Introducciones, codas o intermedios

- $\quad$ Teoría de la música que incluyen

\footnotetext{
${ }^{1}$ PORTA, Luís y SILVA, Miriam. (2003). "La investigación cualitativa: El Análisis de Contenido en la investigación educativa". Universidad Nacional de Mar del Plata (Argentina). Disponible en web: http://www.uccor.edu.ar/paginas/REDUC/porta.pdf, p. 11.
} 


\subsubsection{CRITERIOS PERSONALES, Y DE ALGUNOS AUTORES, SOBRE LA CON- DUCCIÓN DE LA ASIGNATURA, QUE SIRVEN DE BASE PARA LA VALORA- CIÓN POSTERIOR DE CADA MÉTODO.}

Generalidades sobre la enseñanza.

Modernamente se recomienda la división del estudio del solfeo en: solfeo rítmico, de entonaciones, melódico e instrumental. Así lo detalla pormenorizadamente y elogia las ventajas de esta metodología Zamacois (1973, capitulo VI, pp. 117 a 123).

Serrallach opina que se han dividido las dos dificultades, la rítmica y la melódica con el fin de facilitar el estudio del solfeo, que es necesario hacer ejercicios de entonación separados de las lecciones de solfeo, y que, aunque lo ideal sería enseñar el solfeo sin acompañamiento: "es muy raro encontrar alumnos que tengan el sentido tonal lo bastante desarrollado para poder hacerlo...”, éste siempre será conveniente. Y en otro momento de su libro vuelve a insistir en la separación de la lectura rítmica de la melódica, diciendo que el solfeo tiene una doble dificultad, por tanto la lectura rítmica trata de vencer por separado una dificultad de la otra. ${ }^{1}$

También López de Arenosa juzga muy conveniente trabajar la entonación interválica pura fuera de la tonalidad, cree que son dos vías paralelas pero complementarias, y que incluso a mitad de los estudios de solfeo, debe ser el trabajo interválico puro el que predomine, dentro de lo tonal, lo menos tonal y lo atonal. Asimismo asegura que no debe incluirse la melodía en los acompañamientos a las lecciones. (López de Arenosa en AAVV, 1990, p. 48)

Creemos que se deben emplear todas las formas, tomando el solfeo melódico como básico, y las demás formas como auxiliares; que se debe trabajar cada lección procediendo primero a la lectura de las notas (mientras no se domine la clave), después a la lectura medida, luego a la entonación y finalmente todo conjuntado. Por ello un buen método será aquel que contenga ejercicios para todas estas fases.

Se verá en la descripción de los distintos métodos, que había quienes pensaban que se debe conducir al alumno acompañándole instrumentalmente siempre, y quienes consideraban que el alumno debe realizar las lecciones sin ningún acompañamiento. Opinamos, como lo hace Serrallach, (1947, pp. 153 y 54) que se deben acompañar las 
lecciones, y que se puede hacer de tres maneras: en un principio, y una vez trabajadas las dificultades por separado, acompañar al alumno instrumentalmente con melodía y acompañamiento, posteriormente sólo acompañamiento, para que el alumno se obligue a cuadrar perfectamente dentro del ritmo, y a entonar dentro de una armonía más o menos consonante, tonal o no, y finalmente la misma lección sin acompañamiento. De lo contrario no estaríamos facilitando el sentido tonal al alumno.

Zamacois detalla asimismo estas 3 maneras de acompañamiento, y aconseja que éstas se aplique en la mayoría de las clases. (Zamacois, 1973, p. 124)

María Cecilia Jorquera en su artículo Lectoescritura musical expone:

...la aproximación a las alturas basada en el aprendizaje de intervalos aislados, no integrados en un contexto musical propiamente dicho, no cuenta con estudios que la puedan justificar de modo similar a las células rítmicas, ya que las alturas forman parte de sistemas más complejos, como es el caso del sistema tonal. ${ }^{2}$

No obstante, se pueden alternar lecciones acompañadas con otras, de menor dificultad, en las que el alumno busque la entonación sin valerse del instrumento acompañante.

También se observan en los diferentes métodos, dos tendencias respecto al tipo de lecciones que se deben emplear, las de melodía fácil y rápidamente asimilable, o las de características opuestas.

Creemos que, preferentemente, las que no sean muy factibles de retener pronto en la memoria y cantarlas de oído, pero siempre lecciones musicales, agradables, no ejercicios de acrobacias y saltos de obstáculos. Además se pueden ilustrar los conocimientos que se van adquiriendo con alguna canción popular o del repertorio de los grandes compositores, que hagan ver al alumno, la aplicación práctica de esos conocimientos, y a la vez le estimulen.

Convenimos con Díaz y Llorente cuando manifiestan:

Así mismo, no podemos obviar la gran importancia que tiene el modo de concebir o transmitir cualquier concepto. Estamos con Arnaus (M. A. Arnaus, (1993): "Ilusión y calidad”. Actas del Segundo Simposio Nacional, «La Educación Musical elemental», ISME - ESPAÑA, pp. 123, 124, cuando se pregunta el porqué en la enseñanza del lenguaje musical e utilizan textos sin sentido, llenos de dificultades inconexas, cuando dis-

\footnotetext{
${ }^{1}$ SERRALLACH, Lorenzo. (1947) Nueva Pedagogía Musical. Buenos Aires: Ricordi Americana S. A. E. C. A) Metodología general, VIII, pp. 150 a 152 y B) Metodología especial, IX Metodología del solfeo, p. 211.

${ }^{2}$ JORQUERA JARAMILLO, María Cecilia. "Lectoescritura musical: fundamentos para una didáctica". http://musica.rediris.es/leeme. Centre d'Educació Musical de Terrasa.
} 
ponemos de una literatura inagotable, tanto coral como instrumental, donde sólo hace falta ordenar progresivamente las dificultades técnicas que presenta... ${ }^{1}$

Muy pocos son los que incluyen en sus métodos, las lecciones a 2 voces o más.

No es que sea indispensable para una formación solfística, pero sí resulta extraordinariamente provechosa para la práctica de la interpretación en grupo o a dúo, y para adiestrar al educando en la dificultad de entonar y medir con absoluta precisión, sin que otra melodía y otro ritmo consiga desviarlos del suyo.

Estas prácticas también se deben hacer con acompañamiento y sin él.

\section{$\underline{\text { Sobre las Claves. }}$}

Hay discrepancias en cuanto a la práctica o no de todas las claves, unos métodos las incluyen todas, otros, solamente algunas de ellas, o nada más que la de Sol, a lo sumo también la de Fa en $4^{\mathrm{a}}$ línea, y algunos las utilizan mezclándolas todas.

Zamacois, en el libro que estamos referenciando, comenta esta cuestión, defendiendo el estudio de todas ellas, más no los cambios frecuentes y exagerados:...nos parece que la enseñanza del Solfeo tiene demasiados problemas reales a resolver para que se la complique con los irreales a que acabamos de referirnos. Aludiendo a estos cambios irreales y frecuentes que en la práctica instrumental, o cantada, jamás se presentan. $^{2}$

Serrallach, refiriéndose al orden en que deben enseñarse las claves, textualmente dice: el orden de uso de las claves es: Sol en $2^{a}$, Fa en $4^{a}$, Do en $3^{a}$, Do en $4^{a}$ y luego las demás en orden indiferente. ${ }^{3}$

Nuestra opinión es que deben conocerse y practicarse todas las claves por igual, $y$ en el orden que mayoritariamente necesita el alumno conocer (Sol en $2^{\mathrm{a}}$, Fa en $4^{\mathrm{a}}$, Do en $3^{\mathrm{a}}$, Do en $4^{\mathrm{a}}$, Do en $1^{\mathrm{a}}$, Do en $2^{\mathrm{a}}$ y Fa en $3^{\mathrm{a}}$ líneas) que es de mayor a menor uso. Ya que nunca se sabe a qué punto de los estudios puede llegar un alumno, debe conocerlas y practicarlas todas, pero eso sí, de una manera progresiva, y que cada vez que se aborde el estudio de una nueva clave, se haga con lecciones poco complicadas en cuanto al ritmo y a la entonación, y que éstas vuelvan a aumentar en dificultad a medida que se domina la nueva clave. Pero nos mostramos totalmente contrarios a los cambios fre-

\footnotetext{
${ }^{1}$ DÍAZ, Maravillas y LLORENTE, Joxean. (1998). "El lenguaje musical en la escuela de música" en Eufonía. Didáctica de la Música, n 11, año IV. Barcelona: Graó, abril., p. 50.

${ }^{2}$ ZAMACOIS, Joaquín: obra citada, pp. 125 y 26.

${ }^{3}$ SERRALLACH, Lorenzo: obra citada. P. 242.
} 
cuentes de claves, porque en la práctica profesional no ocurre jamás, solamente al leer una partitura de orquesta, y ésta es una lectura vertical y no horizontal.

Jaime Pahissa, compositor catalán (Barcelona 1880 - Buenos Aires 1969) ${ }^{1}$, tenía tan poca simpatía como nosotros a esos endiablados cambios de clave, y lo confirma con este texto incendiario:

No hay cosa de una locura e insensatez más grandes que una lección de último curso de solfeo de un Conservatorio o Academia de Música. Consiste en una pieza musical en la que, a cada dos o tres notas, o cada una, llevan delante una clave distinta. Pero el delirio, la furia para cambiar las claves llega a tal extremo que no se satisfizo, quien escribió aquel pandemonium, con cambiar la clave delante de cada nota, sino que descuartiza las notas enteras de una cierta duración para poder colocar entre sus pedazos - que une con ligaduras- claves diversas y de disparatada relación. Es una cosa de un tal despropósito y de una inutilidad t al, que parece increíble que haya habido mente sana capaz de ocurrírsele. $Y$ no se comprende cómo aun hoy en día se pueda tener la buena voluntad, mejor, la mansa paciencia o la inconsciencia oscura, de persistir en el desvarío de tan absurda práctica. ¿Para qué sirven tan complicados malabarismos? Fuera de marear a los alumnos, para nada. Alguien acaso diga que son ejercicios para el perfecto dominio de las diferentes claves. Si hubiese necesidad de conocer las viejas claves - que no la hay- su estudio se podría hacer sin este cambiar descabellado y loco, pues en la práctica nunca se salta epilépticamente de una clave a otra, sin orden ni concierto, sin necesidad ni provecho ${ }^{l}$

Apoya nuestra creencia Javier Boliart, Catedrático del Conservatorio Superior Municipal de Música de Barcelona (“Los Conceptos Teóricos y su Metodología” en AAVV, 1990, p. 92), cuando declara que para instruir lo más completamente posible a un alumno no se puede excluir el estudio de todas las claves, por que existen diversas facetas en la actividad musical en la que son indispensables, entre ellas la lectura de partituras en claves antiguas, la partitura de orquesta y la transposición.

\section{$\underline{\text { Sobre las Tonalidades }}$}

Serrallach (op. citada, p. 228), comenta que después de la tonalidad de Do mayor, debe enseñarse el modo menor, y luego las demás tonalidades siguiendo el orden de sostenidos y/o bemoles.

Así lo creemos nosotros también, y concretando más, alternando el orden de sostenidos con el de bemoles y las tonalidades del modo mayor con sus relativas, con el objeto de distribuir mejor las dificultades que se presentan al entonar sostenidos y al

\footnotetext{
1 SCHOLES, Percy A.. (1984). Diccionario Oxford de la Música, 2a edición. Barcelona: Edhasa/Hermes/Sudamericana, tomo 2, p. 986.
} 
entonar bemoles; e impregnarse mejor el alumno, en esa secuencia, de las dos tonalidades que habitan en cada armadura.

\section{$\underline{\text { Sobre los Compases }}$}

Serrallach (op. citada, p. 241), establece el orden en que deben aparecer los compases: dice que primero los simples de denominador cuatro, a continuación los compuestos de denominador ocho, luego los otros más usados, 2/2, 3/8, 4/8, 2/8, y de igual manera los compuestos, completándose con los de amalgama, compases antiguos, compases teóricos, irregulares, y sin compasear. ${ }^{2}$

Narcís Bonet ("La crisis del solfeo" en AAVV, 1990, p. 24) preconiza familiarizarse de entrada con el compás de 2 tiempos, con la unidad de tiempo atribuida a la blanca primero, a la negra y a la corchea después. Esto es, primero el 2/2, luego el 2/4 y después el $2 / 8$.

Nosotros suscribimos esa idea, pero únicamente en lo que respecta a comenzar con el compás de 2/4; eso sí, explicando que el valor de una figura no es absoluto, y que en otro momento la "negra" no durará un tiempo; los otros compases binarios mejor dejarlos para cuando se hayan dominado todos los simples de denominador 4 .

$\underline{\text { Sobre las dificultades métricas, u orden de aparición de las figuras y sus combinaciones }}$

Javier Boliart (“Los Conceptos Teóricos y su Metodología” en AAVV, 1990, p. 90) recomienda empezar por el intervalo SOL - MI y las figuras de nota negra y corcheas, según el método Kodaly. Y en el mismo texto, más adelante añade, refiriéndose a los grupos artificiales, que lo mejor es repartirlos, tanto teórica como prácticamente, entre los diversos cursos de la asignatura.

Así lo creemos nosotros, siguiendo el criterio Kodaly, empezar por la negra, su silencio, corcheas, blanca, su silencio, blanca con puntillo, compás de silencio, grupo de semicorcheas, redonda, semicorcheas, puntillo en la negra, fórmulas combinadas, contratiempos y síncopas largas, contratiempos y síncopas cortas, grupos irregulares más importantes (dosillo, tresillos, cuatrillo y seisillo), contratiempos con las semicorcheas, fusas, síncopas muy breves, doble puntillo, resto de grupos de valoración irregular, notas de adorno, combinaciones varias y combinaciones polirrítmicas.

\footnotetext{
${ }^{1}$ PAHISSA, J. (1954). Los grandes problemas de la Música. Buenos Aires: Ricordi Americana.. (En Zamacois, 1973, p. 157).

${ }^{2}$ Wilhem opinaba que se debía comenzar con el de cuatro tiempos, que es lo que hicieron la mayor parte de metodistas. Así lo indica SERRALLACH, Lorenzo. (1953). Historia de la Enseñanza Musical. Buenos Aires: Ricordi Americana S. A., Cap. VI, p. 183.
} 
María Fuensanta Gómez López, ("Nuevos aspectos a considerar en la Enseñanza del Solfeo" en AAVV, 1990, p.121) haciendo referencia a "Ritmo y Lectura 4" de López de Arenosa, defiende que se aborden aspectos tan interesantes como las polimetrías, los valores añadidos y los compases irregulares.

Aspectos estos que nosotros incluimos en el último nivel de la enseñanza.

$\underline{\text { Sobre las dificultades melódicas o de entonación u orden de aparición de los intervalos }}$

Serrallach (op. citada, pp. 222 y 23) afirma que el orden de los intervalos, que debe ser segundas, terceras, quintas y octavas; después cuartas y sextas; dejando para final las séptimas. Y en la p. 226 manifiesta categóricamente que es mucho mejor comenzar por practicar el semitono cromático antes que el diatónico.

Encarnación López de Arenosa expone varios comentarios sobre la forma de organizar la enseñanza de la entonación interválica. Dice literalmente: Una cosa es común a los diversos sistemas de enseñanza: el comienzo de la entonación por dos sonidos...Y explica que sistemas de enseñanza como los de Orff y Kodaly prefieren comenzar por la tercera menor, sin embargo otros lo hacen por la quinta justa.

Nosotros preferimos lo primero, por lo que la misma López de Arenosa en otro momento escribe: ...parten de ese intervalo de tercera menor tan presente en las inflexiones de la voz del niño pequeño ${ }^{l}$.

Por ello nosotros defendemos comenzar por la $3^{\mathrm{a}}$ menor, pues como dicen algunos teóricos, es el intervalo más parecido a la inflexión natural de la voz humana; después la $5^{a}$ justa, que es el intervalo generador y el de más fácil entonación después del de $3^{\mathrm{a}}$ menor, siguiendo con la $3^{\mathrm{a}}$ mayor, $4^{\mathrm{a}}$ justa, $2^{\mathrm{a}}$ mayor y menor y $8^{\mathrm{a}}$ justa. Para una nueva secuencia todos los intervalos naturales excepto los de $7^{\mathrm{a}}$, alteraciones cromáticos del fa sostenido, si bemol y sol sostenido. Semitonos diatónicos y cromáticos, en este orden, para seguir con la $7^{\mathrm{a}}$ mayor primero y menor después. Comenzar los intervalos aumentados por el de $2^{\mathrm{a}}$, por su contenido en la escala menor armónica, siguiendo los otros aumentados y disminuidos. Intervalos doblemente aumentados y disminuidos, enarmonía, finalizando por intervalos compuestos y toda clase de combinaciones melódicas.

\footnotetext{
${ }^{1}$ LÓPEZ DE ARENOSA, Encarnación. (1990)."Entonación y Audición en la Enseñanza del Solfeo” en Primer Congreso Nacional de la Enseñanza del Solfeo. Las Palmas de Gran Canaria del 9 al 11 de octubre de 1989. Madrid: Editorial Música 2000, pp. 39, 40 y 42.
} 
Y respecto a la teoría de la música, aunque no es el tema de nuestra tesis, pero sí comentamos esta parte en los métodos que la incluyen, hemos visto que hay dos tendencias: 1) incluirla en los libros de solfeo e ir introduciéndola conforme al desarrollo de las lecciones, y 2) separar en texto distinto la teoría y solfeo.

Esto último es, a nuestro entender, lo mejor, ya que permite abordar cada tema conforme a la necesidad de la aplicación práctica, y ampliar cuanto se quiera o pueda.

Refiriéndonos a los métodos que incluyen ésta, opinamos que la teoría debe ir abordándose conforme a la necesidad de poner los conocimientos teóricos en práctica, y que mientras no se necesite para la comprensión de una lección, no se debe llenar al alumno con conocimientos teóricos que no vayan a ser desarrollados en la práctica; eso especialmente en los niveles iniciales, más adelante, cuando la parte teórica es más formativa que de tipo práctico, se puede intercalar a voluntad.

Serrallach dice al respecto:

...es, por consiguiente, absolutamente impropio inculcar conocimientos que no tengan inmediata aplicación. Antiguamente l os conocimientos teóricos se explicaban cuando la necesidad de la lección de Solfeo o del instrumento lo exigían. Y sin rechazar este procedimiento, pues todavía puede y debe aplicarse, cuando los conocimientos teóricos se generalizan, se metodizan y se considera la Teoría como materia separada, hay que regular esos conocimientos teóricos a fin de aclarar su aplicación práctica, agrupándolos, relacionándolos y haciendo más fácil su asimilación mental. ${ }^{1}$

Creemos también que inicialmente se deben silenciar a los alumnos las discrepancias técnicas y terminológicas existentes entre los diversos tratadistas, y más tarde, cuando no pueda ocasionarle confusión, dárselas a conocer.

También Zamacois opina sobre esto:

...existen entre los tratadistas, criterios contrapuestos. Pedagógicamente, parece mejor dar a conocer primero, sólo uno - el que se considere más idóneo- a los alumnos, con el fin de evitar confusionismos. Pero cuando este peligro ya no exista, la enseñanza resultará incompleta si el profesor no instruye debidamente a sus discípulos respecto a tales discrepancias. ${ }^{2}$

Andrea Giradles:

En resumen: Enseñar sonidos antes que signos. Provocar situaciones de aprendizaje en las que los estudiantes observen y descubran escuchando e imitando, en

\footnotetext{
${ }^{1}$ SERRALLACH, Lorenzo. (1947). Nueva Pedagogía Musical. Buenos Aires: Ricordi Americana S. A. E. C., A) Metodología general, VIII, pp. 140 y 41.

2 ZAMACOIS, Joaquín. Temas de Pedagogía Musical. Barcelona: Ediciones Quiroga, Capítulo VI, p. 136.
} 
lugar de explicar conceptos. Trabajar con cada uno de los elementos de la música independiente y progresivamente hasta que el alumnado pueda atender a todos ellos de forma simultánea. Procurar el dominio de un contenido antes de progresar hacia el siguiente. Y proporcionar los principios y la teoría después de la práctica. ${ }^{1}$

Y de nuevo citamos a Javier Boliart (op. citada, p. 89) coincidiendo con estas opiniones sobre la manera de enseñar la teoría. Él cree que debe enseñarse en profundidad, pero anexionada completamente a la parte práctica.

Una de las definiciones de solfeo dice que es el arte de entonar y medir correctamente los sonidos musicales ${ }^{2}$. Otra que es la gramática de la música ${ }^{3}$. Nosotros decimos que es la ciencia que nos enseña a traducir en sonidos los signos con que se escribe la música ${ }^{4}$.

De cualquier manera no sólo hay que leer, medir y entonar correctamente los sonidos, hay que tratar de crear belleza, hacer arte en suma.

Por tanto un buen método de solfeo debe reunir teoría y práctica, y debe enseñar no solamente a leer, sino a hacer música. Debe ser progresivo y de gran calidad melódica, puede llevar composiciones de autores consagrados y también melodías populares.

Seguimos haciendo referencia a Serrallach cuando define un buen método de solfeo como aquel que tiene sus lecciones debidamente escalonadas, de manera que un alumno pueda pasar de una dificultad a otra sin esfuerzo. Y más adelante, en el mismo punto, añade que es indispensable que todas las lecciones sean de buen gusto y correctamente construidas. ${ }^{5}$

Por último afirmamos que un método de solfeo debe ser progresivo y amplio, tratar el ritmo, la entonación, la lectura, todos los signos, escalonada y profundamente, con lecciones amenas cuya musicalidad haga del estudiante un músico entusiasta.

Con pequeños apuntes y escasas lecciones en las que se quiere condensar varios de los conocimientos de la lectura musical, no se consigue, no sólo grandes profesionales, ni siquiera informados aficionados.

\footnotetext{
${ }^{1}$ GIRADLES, Andrea. (1998). "Desde el sonido a el símbolo y a la teoría" en Eufonía. Didáctica de la Música, $\mathrm{n}^{\circ}$ 11, año IV. Barcelona: Graó, abril, $p .7$

${ }^{2}$ GOMAR, José Ma'. (1956). Teoría de la música, primer curso. Valencia: (sin editorial), p. 3

${ }^{3}$ CHAilley, J: y CHAllan, H. (1947). Théorie Complète de la Musique, $1^{\circ}$ volumen. París: Alphonse Leduc, capítulo 1, punto 1, p. 5.

${ }^{4}$ LORAS VILLALONGA, Roberto. (1998). Aspectos Teóricos del Lenguaje Musical. Valencia: Rivera Editores, p. 11

${ }^{5}$ SERRALLACH, Lorenzo: Nueva Pedagogía Musical......, A), VIII, p. 184.
} 
Dice $M^{a}$ Cecilia Jorquera que según un estudio de Sloboda (en 1988) los mejores lectores a primera vista son los que tienen grandes conocimientos de música, y así pueden prever lo que van a encontrar en una partitura, lo que no pueden hacer quienes carecen de estos vastos conocimientos. Y por ello afirma que para comprender los mecanismos de la lectoescritura musical es necesario poseer conocimientos y competencias musicales complejos y amplios. ${ }^{1}$

\footnotetext{
${ }^{1}$ JORQUERA JARAMILLO, María Cecilia. "Lectoescritura musical: fundamentos para una didáctica",
} http://musica.rediris.es/leeme,. Centre d'Educació Musical de Terrasa. 


\subsection{CRITERIOS PARA LA VALORACIÓN DE LAS CATEGORÍAS.}

\subsubsection{ELEMENTOS DE COMPARACIÓN Y EVALUACIÓN DE LOS MÉTODOS}

Programas oficiales de solfeo del Real Conservatorio SuPERIor De Música DE MADRID Y DE LA EsCUEla NACIONAL DE MúSICA DE MADRID DE lOS AÑOS 1831, 1832 , $1861,1875,1876,1891$ Y 1898.

$\underline{\text { Sobre los programas de solfeo de los año } 1831 \text { y } 1832}$

En primer lugar vamos a referir las Memorias encontradas en la Biblioteca del Conservatorio Superior de Música de Madrid, que hacen referencia a programas de exámenes y cuestiones relacionadas con la enseñaza del solfeo en los años 1831 y 32, por las que se deducen algunos contenidos.

Programa de los exámenes públicos que a los 11 meses de su erección, El Real Conservatorio de música de María Cristina, celebra para solemnizar el segundo cumpleaños de la Entrada en Madrid de su augusta protectora Doña María Cristina de Borbón, reina amadísima de España, en los días 11, 12, 13, 14 y 15 de diciembre de 1831, dando principio a las once de la mañana.

Clase de Solfeo del Departamento de Alumnos del Profesor D. Baltasar Saldoni. ${ }^{1}$

Se relacionan los nombres de varios alumnos, divididos en 3 secciones, que deben corresponder a los 3 cursos que había.

Luego expone los 5 puntos de que constará el examen:

$1^{\circ}$ Los alumnos de todas las secciones cantarán un solfeo a cuatro voces, compuesto por el Director D. Francisco Piermarini.

$2^{\circ}$ Serán examinados en el valor de las notas, sus silencios, efecto del sostenido, bemol y demás concerniente a la parte teórica de la música.

\footnotetext{
1 MINISTERIO DE FOMENTO. INSTRUCCIÓN PÚBLICA. MEMORIA acerca de la ESCUELA NACIONAL DE MÚSICA Y DECLAMACIÓN DE MADRID. Escrita para ser presentada en la EXPOSICIÓN UNIVERSAL DE LA MÚSICA Y DEL TEATRO. Que ha de verificarse en Viena en el año de 1892, Madrid, Imprenta de José M. Ducazcal, 1892. pp. 103 y 104. Apéndice, página 189. De 1831 a 1868 se llamó REAL CONSERVATORIO DE MÚSICA Y DECLAMACIÓN MARIA CRISTINA

De 1868 a 1900 ESCUELA NACIONAL DE MÚSICA, por problemas de presupuesto Después recobra su nombre de REAL CONSERVATORIO DE MÚSICA Y DECLAMACIÓN, perdiendo, aproximadamente a mitad del XX, el apéndice de Declamación
} 
$3^{\circ}$ Uno de los señores examinadores escribirá en el encerado una lección, en la que pondrá expresamente faltas de valor; será corregida por un alumno y cantada por otro de la segunda sección; y después esta misma lección se cantará transportada por otro de la primera.

$4^{\circ}$ Se escribirá en papel pautado una lección, con varias llaves, la que al tiempo que se cantará por un alumno de la segunda sección, será escrita en el encerado, sin verla, por los de la primera.

$5^{\circ}$ Uno de los señores examinadores se pondrá al piano, y hará que un alumno cante los intervalos que vaya formando con el piano, pero indicándole las distancias que quiere que haga con la voz: v. gr., bajando una tercera, subiendo medio punto, etcétera, haciendo que la voz forme las modulaciones sin el auxilio del acompañamiento.

$6^{\circ}$ Nombra a unos alumnos concretos que cantarán una lección a 3 voces.

Programa de los exámenes públicos que, El Real Conservatorio de música de María Cristina, celebra para solemnizar el tercer cumpleaños de la Entrada en Madrid de su augusta protectora Doña María Cristina de Borbón, reina amadísima de España, en los días 11, 12, 13, 14 y 15 de diciembre de 1832, dando principio a las once de la mañana. ${ }^{1}$

Ese año los alumnos de solfeo del profesor Saldoni, sólo solfearon un coro del $2^{\circ}$ acto de Ana Bolena de Donizetti, sin embargo la clase de alumnas, tenía que hacer los mismos ejercicios que hicieron los alumnos el año anterior.

De la lectura de este programa de examen, se puede deducir parte del programa, si lo había, de la asignatura:

-Figuras de nota, silencios, alteraciones y resto de la teoría de lo signos.

-El transporte ya se estudiaba en el primer curso

-Las claves se estudiaban todas y ya en segundo curso

-El dictado musical ya se efectuaba, aunque oyendo el nombre de las notas, pero desde primer curso.

-La lectura a primera vista era objeto de atención desde el principio.

-La práctica intensa de todos los intervalos ya se consideraba necesaria.

Es de destacar que los alumnos del Conservatorio en esa época, además de música, estudiaban geometría, literatura castellana, doctrina cristiana, lengua italiana y esgrima. Había alumnos internos y externos. Este intento de formación integral del es-

\footnotetext{
${ }^{1}$ MINISTERIO DE FOMENTO. INSTRUCCIÓN PÚBLICA..., pp. 108 y 109. Apéndice, página 190.
} 
tudiante de música del Conservatorio fue recogido, ya en el s. XX, en la reforma musical introducida en la Segunda República española, que no pudo llevarse a efecto por el golpe militar que dio lugar a la Guerra Civil española.

\section{PROGRAMA DE LA ASIGNATURA DE SOLFEO EN 1861.}

El primer documento que hemos podido recuperar del Real Conservatorio de Música y Declamación de Madrid consiste en unas instrucciones, impresas en el año 1861, respecto a las enseñanzas en ese Centro, de las que emana ya un programa de enseñanza para cada asignatura. Se adjuntan en el apéndice, página 191.

Están clasificadas por capítulos y artículos, a modo de reglamento. Trasladamos todo lo que hace mención a la asignatura de Solfeo, que como se verá, tenía dos vertientes: el solfeo en general y el solfeo para estudiantes de canto.

\section{INSTRUCCIONES DEL REAL CONSERVATORIO DE MÚSICA Y DECLAMA- CIÓN DE MADRID. AÑO $1861^{1}$.}

\section{CAPÍTULO PRIMERO. Enseñanza de solfeo general}

ARTí́CULO $1^{\circ}$.- las materias que comprende esta enseñanza, son:

La entonación de los sonidos en todas las claves, intervalos y géneros.

La medida del tiempo en todos los aires, compases y figuras.

Los conocimientos teóricos que corresponden a ambas materias.

ARTículo $2^{\circ}$.- se observará como base del tecnicismo la que establece el Método de Eslava, que es la obra de texto adoptada para esta enseñanza.

El profesor que juzgue conveniente hacer uso además de los Solfeos de Saldoni, de Panseron, del Conservatorio de París, de Garaudé, de Piermarini, de Bordese y de la Gramática de Romero, igualmente aprobados, deberá uniformar sus definiciones con las de la obra citada como texto, prefiriendo para estudios finales de esta enseñanza los que sean a dos voces.

ARTículo $3^{\circ}$.- Los estudios que constituyen la enseñanza del Solfeo, se distribuyen en los tres cursos de Reglamento en la forma siguiente:

\footnotetext{
${ }^{1}$ Instrucciones para el buen desempeño de las enseñanzas y para el régimen y disciplina del Real Conservatorio de Música y Declamación. Las firma el Director, Ventura de la Vega, en Madrid a 30 de enero de 1861 , pp. 305 y 306.
} 
El primer año comprende toda la primera parte del Método de Eslava, y las nueve primeras lecciones de la segunda; practicándose además otras de los métodos aprobados, o escritas expresamente por el Profesor, y que no excedan de los conocimientos que en aquéllas se contienen.

El segundo año comprende desde la lección 10 de la segunda parte, hasta la 23 de la tercera de dicho Método de Eslava, y las análogas de los otros métodos, en los términos que indica el párrafo anterior.

El tercer año comprende desde la lección 24 de la tercera parte, hasta el final del citado Método de Eslava, con las respectivas ampliaciones análogas.

ARTículo 4.- El estudio del primer año se hará en una clase especial, Colectiva de Solfeo, cuyo Profesor establecerá el sistema conveniente para que todos los alumnos den lección diaria, practicando colectivamente las asignadas a este curso.

ARTí́culo 5.- El estudio de los años segundo y tercero será individual, y le harán los alumnos en una clase y las alumnas en otra; debiendo asimismo todos dar lección diaria. Con tal objeto, se asignará a estas dos clases el número de Repetidores y Repetidoras que sea necesario, para que nunca excedan de 12 los alumnos que diariamente deban dar lección, tanto con el Profesor, como con cada uno de los respectivos Repetidores. Estos serán responsables de la instrucción de los alumnos que se les encomienden, aunque siempre estarán bajo inspección del Profesor.

ARTí́culo $6^{\circ}$.- Siendo el estudio del Solfeo la base de todas las carreras musicales, no permitirán los Profesores que ningún alumno, por aventajado que sea, traspase los límites de las materias comprendidas en el curso respectivo; asegurándolos bien en ellas y ejercitándolos con empeño en solfear de repente desde el primer año de esta enseñanza. ARTíCULO $7^{\circ}$.- Los exámenes generales constarán de los ejercicios siguientes: $1^{\text {a }}$, solfear una lección estudiada, de las últimas que el alumno haya aprendido; $2^{\circ}$, ejecutar un breve solfeo de 16 a 20 compases de los escritos ad hoc en los tres grados en que deben hallarse los alumnos, eligiendo de aquellos el que corresponda al año que ha cursado el examinando, debiéndolo primeramente entonar sin medir, midiéndole después sin entonar, y ejecutándolo últimamente con entonación y medida; $3^{\circ}$, contestar a tres preguntas que versen acerca de la teoría del solfeo, las cuales sacará el alumno de la urna en que se hallarán depositadas por papeletas separadas.

ARTí́culo $8^{\circ}$.- $^{-}$El ejercicio de concurso será el siguiente: $1^{\circ}$, solfear una lección estudiada y elegida por el concurrente, $2^{\circ}$, solfear de repente una lección escrita en tres cla- 
ves, cuyas dificultades sean propias de la música vocal, y no excedan de la capacidad de un mero solfista que improvisa; y $3^{\circ}$, transportar una frase de esa misma lección.

\section{CAPÍTULO II Enseñanza de Solfeo para canto}

ArTículo 9.- Esta enseñanza se diferencia de la de Solfeo general, en estar destinada exclusivamente para los alumnos, que por su buena organización vocal y demás circunstancias físicas, se dedican a la carrera de cantante teatral.

No ingresará en esta clase ninguno que no reúna las dos cualidades expresadas; y sólo en muy raros casos podrá dispensarse la segunda, en gracia de disposiciones vocales extraordinarias.

ARTíCUlO 10.- Las materias que comprenden esta enseñanza y su distribución, son las mismas que establece el art. $3^{\circ}$ para el Solfeo general.

ARTículo 11.- El estudio del Solfeo en esta enseñanza será siempre individual, y se practicará con las condiciones siguientes:

$1^{\circ}$ El alumno no hará uso de las notas extremas de su voz; para lo cual se transportarán las lecciones al tono que le sea más cómodo.

$2^{\circ}$ No solfeará a toda voz.

$3^{\text {o }}$ Pronunciará los nombres silábicos de los signos.

$4^{\circ}$ Afinará con exactitud y precisión los intervalos.

ARTículo 12.- La adopción de obras de texto, y el modo de efectuarse los exámenes y concursos, son comunes a ambas enseñanzas de Solfeo general y de Solfeo para canto.

Hay otros aspectos de estas Instrucciones que venimos exponiendo, referentes al ingreso de los alumnos en el Real Conservatorio, reglas que regían en los exámenes, en los concursos, calificaciones, etc., que recapitulamos aquí por creerlas de curioso interés.

CAPÍTULO XIV Del ingreso de los alumnos

ARTículo 106. Habrá una Comisión permanente, denominada de Exámenes de ingreso, compuesta de un Profesor de Composición, que la presidirá, de un Profesor de Harmonía [sic], de otro de Canto y del correspondiente a la enseñanza en que el aspirante pretenda ingresar, si alegare conocimientos adquiridos.

ARTículo 107. Esta Comisión se reunirá el día $1^{\circ}$ de septiembre y con presencia de las solicitudes de matrícula, que le pasará la Dirección, dará principio al examen de los aspirantes.

ARTíCUlO 108. Examinará la Comisión, si el aspirante se halla con las circunstancias y conocimientos previos, que exigen el Reglamento orgánico y las presentes Instruccio- 
nes, para ingresar en la enseñanza que solicite, poniendo por escrito, y bajo la firma del presidente, en cada solicitud, el juicio que haya formado del aspirante, y la enseñanza en que la Comisión opina que debe ingresar, como asimismo el curso escolar a que debe incorporarse, con arreglo al programa de dicha enseñanza, y atendiendo el grado de instrucción en que se halle el aspirante.

ARTí́culo 109. Siempre que la Comisión lo crea oportuno, probará la voz del aspirante, y si le hallase con disposiciones para el Canto, aunque él no lo haya solicitado, tratará de inclinarle a este estudio, proponiéndole ingresar en esta enseñanza o en la de Solfeo especial, si careciese de los conocimientos indispensables.

ARTículo 110. Si en vista de la edad y del desarrollo de las facultades vocales y físicas del aspirante, creyese la Comisión que era conveniente no diferir su instrucción en el Canto, podrá proponer que desde luego ingrese en esta enseñanza y simultáneamente en la de Solfeo.

ARTículo 111. La Comisión celebrará juntas diarias hasta terminar el examen de los aspirantes presentados, y al fin de cada una devolverá a la Dirección las solicitudes de los que en ella hayan sido examinados, con el informe correspondiente.

ARTículo 112. Se reunirá asimismo durante el curso, cuando la Dirección la convoque, para informar acerca de los casos de admisión excepcional que previene el Reglamento.

\section{CAPÍTULO XV De los exámenes generales y concursos.}

ARTícUlo 113. En los exámenes de cada clase regirá el programa formado por el respectivo Profesor, donde debe hallarse incluida la suma de materias que se fija en estas Instrucciones, distribuidas en el número máximo de cursos escolares que el Reglamento orgánico señala a cada enseñanza.

ARTíCUlO 114. Desde la publicación de las presentes Instrucciones, todo Profesor clasificará sus respectivos alumnos, colocando a cada uno según el grado de instrucción que tenga, en el curso que le corresponda, con arreglo al programa de aquella clase.

ARTículo 115. El profesor llenará la hoja, que le será remitida oportunamente, expresando en ella con claridad cuáles son los alumnos que han estudiado todas las materias correspondientes al curso escolar respectivo, cuáles los que no, y finalmente, cuáles los que han aprovechado tanto, que han llegado a estudiar otras correspondientes al curso siguiente. Expresará además los que propone para concurso, ya por serles obligatorio, ya por juzgarlos aptos para ello, dentro de las condiciones del Reglamento. 
ARTículo 116. Con presencia del programa y la hoja de que hablan los artículos precedentes, calificará el Jurado a los alumnos, poniendo a cada uno la nota que merezca, en vista del examen, y con relación a las materias correspondientes al curso en que se examina.

ARTículo 119. Las notas con que el Jurado deberá calificar a los alumnos, son las siguientes:

\section{Sobresaliente.- Notable.- Bueno.- Mediano.- Reprobado.}

ARTículo 120. La nota de Reprobado, puesta por primera vez a un alumno, lleva consigo la baja en aquella enseñanza.

Se exceptúan las de Composición y Harmonía, en las cuales se observará lo que establece el Reglamento orgánico.

ARTículo 121. Terminados los exámenes de cada enseñanza, se pasará a los Profesores una relación de los alumnos de su respectiva clase que hubieren obtenido únicamente las tres primeras notas, a fin de que la lea en presencia de todos, para satisfacción de los calificados y estímulo de los demás.

ARTí́CULO 122. El alumno propuesto en la hoja para concurso, por primera vez, ya por serle obligatorio, ya por elección del profesor, además del correspondiente examen, ejecutará la pieza que haya sido designada para aquel certamen; y el Jurado, en su vista, resolverá si dicho alumno se halla en el caso de concurrir.

ARTículo 123. Los Profesores presentarán a la Dirección, con la anticipación conveniente, las piezas que hayan elegido para el concurso de sus respectivos discípulos, a fin de que por aquella sean examinadas y aprobadas.

ARTículo 124. Los alumnos concurrentes sortearán dentro de cada clase y de cada sexo, el turno en que han de presentarse al ejercicio.

ARTí́culo 125. En los concursos de Declamación, los alumnos concurrentes se auxiliarán entre sí para la ejecución de la obra, o de las escenas sueltas en que cada uno de ellos ha de figurar principalmente para ser juzgado; y sólo en caso de absoluta necesidad, se presentará como auxiliar en estos ejercicios un alumno que no sea concurrente. ${ }^{1}$

\section{PROGRAMA DE SOLFEO DEL AÑO 1875}

\footnotetext{
${ }^{1}$ Instrucciones para el buen desempeño de las enseñanzas y para el régimen y disciplina del Real Conservatorio de Música y Declamación. Las firma el Director, Ventura de la Vega, en Madrid a 30 de enero de 1861 , pp. 313 y 314 .
} 
Incluido dentro del Programa de las enseñanzas de la Escuela Nacional de Música y Declamación, a fecha de 1 de agosto de 1875 en Madrid. Firmado por Emilio Arrieta. ${ }^{1}$

\section{PRIMER AÑO}

-Normas preliminares en que se hacen las definiciones de lo que es solfeo, conocimiento de las notas, figuras, silencios, pentagramas, líneas adicionales, claves, compás intervalos mayores y menores, escala diatónica.

-Ejercicios y lecciones prácticas de intervalos conjuntos y disjuntos.

-Movimientos del compás, llamados también aires, puntillos hasta en la corchea, silencios hasta de semicorchea, síncopa hasta la corcha inclusive, ligadura, calderón 4/4, 2/4, $3 / 4$, sostenidos, bemoles, becuadros y su práctica haciéndolo uno solo de grado a distancia de $1 / 2$ tono.

-En las lecciones prácticas de este primer año, sólo se hace uso del tono de Do en clave de Sol y las combinaciones de medida hasta la semicorchea inclusive y su silencio.

\section{SEGUNDO AÑO}

-Conocimiento de los tonos y modos, compás binario 3/8, 6/8, 9/8 y 12/8.

-Claves de Fa en cuarta línea y Do en primera.

-Apoyaturas, mordentes, doble puntillo, tresillos, seisillos, intervalos aumentados y disminuidos.

-En las lecciones prácticas de este segundo año, no se hace uso más que de los tonos siguientes: La menor y hasta 3 sostenidos y 3 bemoles mayores y menores, combinaciones de medida hasta la semifusa.

\section{TERCER AÑO}

-Práctica de los tonos restantes

-Claves de Do en segunda, tercera y cuarta líneas y Fa en tercera

-Dobles alteraciones

-Combinaciones irregulares de medida

-Géneros

-Transporte

-Compases de 6/4, 7/4, 5/4, 5/8 y 10/8

\footnotetext{
${ }^{1}$ Biblioteca del Real Conservatorio Superior de Música de Madrid. (programa totalmente manuscrito, con prohibición de fotocopiar).
} 
-Conocimiento de las principales abreviaturas, de las figuras y compases antiguos y tablas de los intervalos y sus inversiones.

Hay una nota al final que dice que este programa se ha formado con arreglo al método de solfeo de los señores Gil y Moré, que es la obra de texto para las enseñanzas en esta Escuela, método que se analiza en el cuerpo de la tesis.

\section{PROGRAMA DE SOLFEO DEL AÑO 1876}

PROGRAMA de la enseñanza de Solfeo, con las materias y estudios que comprenden cada año de los tres de que consta. ${ }^{1}$

El primero y segundo año, son exactamente iguales al programa anterior autografiado, el Tercer año difiere del preliminar en que sólo consta hasta Dobles alteraciones, obviando por tanto los restantes puntos y elementos. Hay una nota al final que dice:

Los siguientes programas han sido hechos por los profesores respectivos y revisados por una Comisión facultativa, para cumplimentar la Real orden de 18 de Octubre de 1871, transmitida a esta Escuela por el Ilmo. Señor Rector de la Universidad Central con fecha 28 del mismo, con el objeto de informar y coordinar los estudios y exámenes de los alumnos procedentes de la enseñanza oficial y la libre o privada; sirviendo de sólida garantía respecto a la actitud de los examinados, conforme al espíritu demostrado en dicha Real orden.

\section{PROGRAMA DE SOLFEO DEL AÑO 1891}

ESCUELA NACIONAL DE MÚSICA Y DECLAMACIÓN

PROGRAMA OFICIAL DE LA ENSEÑANZA DE SOLFEO

Madrid, Imprenta de José M. Ducazcal, 1891. Apéndice página 193.

\section{PRIMER AÑO}

-Nociones preliminares. Definición. Conocimiento de las notas, figuras, silencios, pentagrama, líneas adicionales, claves, compás intervalos mayores y menores, escala diatónica.

-Ejercicios y lecciones prácticas de intervalos conjuntos y disjuntos.

\footnotetext{
1 ESPAÑA. INSTRUCCIÓN PÚBLICA. MEMORIA presentada por la ESCUELA DE MÚSICA Y DECLAMACIÓN en la Exposición Internacional de Filadelfia, Madrid, Imprenta y Fundición de J. Antonio García, 1876. Apéndice, página 192.
} 
-Movimientos del compás, llamados aires, puntillos hasta la corchea, silencios hasta los de semicorchea inclusive, ligadura, calderón, compases de compasillo $2 / 4$ y 3/4, sostenido, bemol y becuadro, y su práctica, sólo de grado en distancias de medio tono.

-En las lecciones prácticas de este año, sólo se hace uso del tono en Do en clave de Sol, y en las combinaciones de medida, hasta la semicorchea inclusive y su silencio.

-Lectura a primera vista de lecciones manuscritas.

\section{SEGUNDO AÑO}

-Conocimiento de los tonos y modos, compases binarios 3/8 6/8 9/8 y 12/8. Claves de Fa en cuarta línea y de Do en primera.

-Apoyaturas y mordentes, doble puntillo, seisillos, intervalos aumentados y disminuidos.

-En las lecciones prácticas no se hace uso más que de los tonos siguientes: La menor, y hasta los que tienen tres sostenidos y tres bemoles, mayores y menores, y en las combinaciones de medida hasta la semifusa.

-Lectura a primera vista de lecciones manuscritas.

\section{TERCER AÑO}

-Práctica de los tonos restantes.

-Claves de Do en segunda, tercera, cuarta y Fa en tercera.

Es exacto a los dos anteriores con la excepción de que a éste le faltan las síncopas (sin duda una omisión involuntaria) y también los últimos elementos como al programa de 1876.

\section{$\underline{\text { PROGRAMA DE SOLFEO DEL AÑO } 1898}$}

\section{ESCUELA NACIONAL DE MÚSICA \\ Programas oficiales de Solfeo y Piano ${ }^{1}$}

\section{SOLFEO}

El primer y segundo año son exactamente iguales a los del programa de 1891; el tercero cambia, teniendo la siguiente redacción:

\footnotetext{
${ }_{1}^{1}$ BOLETÍN MUSICAL DE VALENCIA, no 165, de 30 agosto de 1898, página 1.283. Apéndice, p. 194.
} 


\section{TERCER AÑO}

-Práctica de los tonos restantes.

-Claves de Do en segunda, tercera, cuarta y Fa en tercera.

-Dobles alteraciones.

-Combinaciones irregulares de medida.

-Géneros.

-Transportes.

-Compases de 6/4, 7/4, 5/4, 5/8 y 10/8

-Conocimiento de las principales abreviaturas, de las figuras y compases antiguos, y tablas de los intervalos y sus inversiones.

-Lectura a primera vista de lecciones y manuscritos.

Este tercer año es como el programa de 1875 de Arrieta, al que se añade el último punto del conocimiento de las abreviaturas, etc. 


\subsubsection{PARÁMETROS Y GRADACIONES DE LOS DISTINTOS ELEMENTOS MUSICALES QUE CONSIDERAMOS ÓPTIMOS EN EL PROCESO DE ENSE- NANZA/APRENDIZAJE}

Para llegar al estudio en profundidad de todos estos métodos de solfeo, y con el objeto de buscar su adecuación a las necesidades de los estudiantes de música en cada momento, nos parece oportuno exponer una serie de parámetros y gradaciones de los distintos elementos musicales que consideramos óptimos en el proceso de enseñanza/aprendizaje actual del solfeo.

Para elaborar estos parámetros nos hemos basado en las siguientes fuentes y fundamentos:

A) En las opiniones de algunos pedagogos de reconocido prestigio, dentro de lo poco que hay escrito sobre ello, y desde luego sin que haya de por medio un estudio comparativo, que son:

Joaquín Zamacois (op. citada), con sus criterios expuestos en el punto 2.2.2.

Lorenzo Serrallach que se extiende más sobre la forma de afrontar varias de las dificultades de la materia, en su libro varias veces citado (1947), expone, en las páginas 154 y 55, la progresión que deben llevar los contenidos de la asignatura.

B) En algunas de las ponencias del, varias veces, citado Primer Congreso Nacional de la Enseñanza del Solfeo celebrado en las Palmas de Gran Canaria entre el 9 y el 11 de octubre de 1989, y más concretamente en las opiniones de los ponentes Narcís Bonet, Encarnación López de Arenosa , Javier Boliart y María Fuensanta Gómez López.

C) Bebiendo en las fuentes de las modernas metodologías, y teniendo en cuenta los estudios que se han realizado al respecto, no sobre la enseñanza profesional del Lenguaje Musical, que hay muy pocos, ${ }^{1}$ sino en cuanto al aprendizaje en los estudios de la educación obligatoria, unido a la reflexión sobre los postulados de los grandes pedagogos citados en el punto 1.5, más los no citados, como Orff y Kodaly que tan decisivos han sido en la enseñanza musical desarrollada a partir de ellos.

D) En las modernas pedagogías del lenguaje musical (basadas en gran parte en los postulados de Orff, Dalcroze o Kodaly) aportadas por Araval (1993 a 1999); Barceló Amorós (2001) Barrio (1975, 1987, 1988, 1990); López de Arenosa, Oliver y Pildain (1988 - 1994; Mayor Ibáñez, De Pedro Cursá (1994 - 1997); Navarrete Porta (1993,

\footnotetext{
${ }^{1}$ HODGES, Donald A. (1992). de la Universidad de Texas, en San Antonio, EEUU, en su artículo "Adquisición de habilidades de lectura musical" en Hanbook of research on music teaching and learning, New Cork, Richard Colwell - Schirmer books, pp. 466 a 471, dice: Las teorías explícitas lectura musi-
} 
1994); Rueff (1964); Sarget Ros, Bertrán Romero y Moltó Romero (1993 - 1996); Seguí, Carbonell y Montesinos (1985 - 1999).

E) En nuestra propia experiencia y en la de compañeros del Departamento de Solfeo y Teoría de la Música del Conservatorio de Valencia, posteriormente de Lenguaje Musical (el cual dirigí 6 años), en cuyas aulas se han formado multitud de jóvenes músicos, por lo que a través del tiempo y de la experiencia vivida, llegamos a estas conclusiones.

F) En la Programación Didáctica de la asignatura del Departamento de Lenguaje Musical del Conservatorio Profesional de Música de Valencia, en el curso 2002 - 2003 y siguientes, elaborado por los profesores Roberto Loras Villalonga, Josefina Guasp Carrascosa, Alejandro Maicas Carrasquer, Lidia Romero Cayetano, Carlos Gimeno Estellés, José Llusar Bernat, José Miguel Sánchez Ruiz, Ma Elena Rivilla Tejera, José López García y Andrea Solomando Molina. Programación cuyos contenidos extractamos a continuación, contenidos totalmente adecuados al Decreto 151/1993 de 17 de agosto, del Gobierno Valenciano, por el que se establece el currículo de los grados elemental y medio de música: 


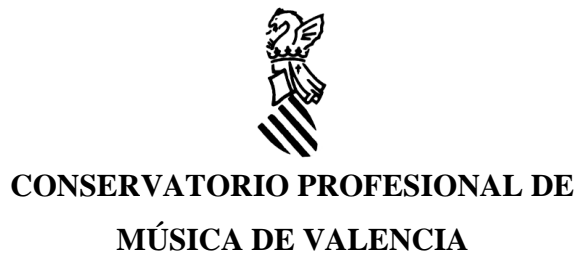

Plaza San Esteban, 346003 Valencia

Centralita : 96 - 3919221 / 3919294

Fax: 3910172 / 3919294

\title{
PROGRAMACIÓN DIDÁCTICA CURSO 2002-2003
}

\section{ASIGNATURA: Lenguaje Musical}

\author{
PROFESORES: \\ Roberto Loras Villalonga \\ Josefina Guasp Carrascosa \\ Alejandro Maicas Carrasquer \\ Lidia Romero Cayetano \\ Carlos Gimeno Estellés \\ José Llusar Bernat \\ José Miguel Sánchez Ruiz \\ $\mathrm{M}^{\mathrm{a}}$ Elena Rivilla Tejera \\ José López García \\ Andrea Solomando Molina
}




\section{LENGUAJE MUSICAL}

Secuenciación progresiva de los contenidos comunes y propios por cursos.

Primer curso

División de los contenidos propios del curso en Materias y Elementos:

SOLFEO ESTUDIADO Y MEMORIZADO. SOLFEO REPENTIZADO.

Elementos rítmico - métricos:

- Figuras de nota blanca, negra, corchea y fórmula rítmica de 4 semicorcheas. Blanca con puntillo

- Silencios de negra, blanca y de compás completo.

- Compases de 2/4,3/4

- Anacrusa

- Fórmulas rítmicas derivadas de dichos elementos métricos, excluyendo las síncopas.

- Ejercicios de movimiento para el desarrollo psicomotriz y la cuadratura musical con los elementos previamente aprendidos

Elementos melódicos:

- Ámbito vocal: escala de DO mayor

- Intervalos mayores, menores y justos, excepto $6^{\mathrm{a}}$ y $7^{\mathrm{a}}$.

Otros elementos de lectura, interpretación y expresión:

- Pentagrama

- Clave de SOL en $2^{\mathrm{a}}$ línea

- Doble barra de repetición

- Coma de respiración o vírgula

- Ligadura de fraseo

Canto canónico, al unísono y a varias voces. Canto popular tradicional

Ejercicios de improvisación rítmicos y/o rítmico - melódicos con propuesta previa, cada vez que se incorpore un elemento nuevo. 
Segundo curso.

División de los contenidos propios del curso en Materias y Elementos:

SOLFEO ESTUDIADO Y MEMORIZADO. SOLFEO REPENTIZADO

Elementos rítmico - métricos:

- Figuras de nota: $o, d$, silencio de corchea, fórmula rítm $\sqrt{\sqrt{J}}$

- Puntillo de prolongación sobre la negra y la corchea

- Compases: los mismo más 4/4 y 6/8. Cambios entre los de 2/4 y 6/8

- Fórmulas rítmicas derivadas de las combinación de los elementos propios del curso, incluyendo las síncopas y notas a contratiempo largas y breves, regulares e irregulares

- Ejercicios de movimiento para el desarrollo psicomotriz y la cuadratura musical, con los elementos previamente aprendidos

Elementos melódicos:

- Ámbito vocal de duodécima ( $\operatorname{Sol}_{2}$ a $\left.\operatorname{Re}_{4}\right)$

- Intervalos: todos los formados entre notas naturales. De segunda, tercera, octava, quinta, cuarta, sexta mayor y menor.

- Alteraciones: Fa sostenido, Si bemol y Sol sostenido. El becuadro

- Tonalidades: DO mayor, SOL mayor, FA mayor y La menor

Otros elementos de lectura, interpretación y expresión:

- Aprendizaje progresivo rítmico y/o melódico de la clave de FA en $4^{\text {a }}$ línea, sin cambios entre éstas y la de SOL.

- Términos de intensidad uniforme y de variación progresiva de la misma. Matices dinámicos: $\mathbf{p}, \mathrm{mp}, \mathrm{mf}, \mathrm{f}$ "crescendo", "diminuendo", reguladores

- Términos del movimiento uniforme: Andante, Adagio, Allegro

Canto canónico a varias voces. Canto popular tradicional.

Lectura a vista cada vez que se incorpore un nuevo elemento.

Ejercicios de improvisación rítmicos y rítmico - melódicos con propuesta previa. 


\section{Tercer curso.}

\section{División de los contenidos propios del curso en Materias y Elementos:}

\section{SOLFEO ESTUDIADO Y MEMORIZADO. SOLFEO REPENTIZADO}

Elementos rítmico - métricos:

- Silencio de semicorchea

- Contratiempos regulares e irregulares con utilización de silencio de semicorchea

- $\quad$ Compases de $9 / 8$ y $12 / 8,2 / 2$ y $3 / 8$

- Grupos de valoración especial: dosillo, tresillo, seisillo y cuatrillo, equivalentes a un tiempo de compás simple o compuesto.

- Síncopas y contratiempos regulares e irregulares en los compases simples y compuestos

- Ejercicios de movimiento para el desarrollo psicomotriz y la cuadratura musical, con los elementos previamente aprendidos.

Elementos melódicos:

- Semitonos diatónicos y cromáticos. Identificación y dominio

- Intervalos: los estudiados más séptimas mayores y menores y segundas aumentadas

- Tonalidades mayores y menores, hasta con dos alteraciones en la armadura. (Escalas menores natural, armónica y melódica)

Otros elementos de lectura y de interpretación o expresión:

- Lectura de notas SIN CLAVE, basándose en la posición relativa de las notas en líneas y espacios del pentagrama (SISTEMA DE "DO" MÓVIL)

- Conocimiento y lectura rítmica de la clave de $\|_{j}$ en $3^{\mathrm{a}}$ línea

- $\quad$ Cambio de clave entre las de $\oint_{\text {y }}$ g: en $4^{\mathrm{a}}$

- Ligadura de articulación o expresiva

- Matices agógicos y dinámicos

Ejercicios de improvisación cada vez que se incorpore un nuevo elemento, con propuesta previa

Canto popular tradicional

Lectura a primera vista 


\section{Cuarto Curso}

\section{División de los contenidos propios del curso en Materias y Elementos}

\section{SOLFEO ESTUDIADO Y MEMORIZADO. SOLFEO REPENTIZADO}

Elementos rítmico - métricos:

- La fusa y su silencio

- Compases de 2/8,3/8 marcados a 1, 4/8 marcado a 2, 3/2, 4/2, 6/4 y 9/4

- Cambios entre compases con igual o distinta unidad de tiempo, con equivalencia tiempo $=$ a tiempo, o figura $=$ a figura $\mathrm{y}$ combinando simples y compuestos.

- Síncopas muy breves, regulares e irregulares. Notas a contratiempo regulares e irregulares

- Grupos de valoración especial: dosillo, tresillo, cuatrillo, quintillo, seisillo y septillo.

- El doble puntillo aplicado a la blanca, negra y corchea.

Elementos melódico - armónicos:

- Claves de $\left\|3_{3} 3^{\mathrm{a}} \mathrm{y}\right\| \mathrm{g}^{\mathrm{a}}$

Ámbito vocal: del $\mathrm{Sol}_{2}$ al $\mathrm{Fa}_{4}$

Intervalos: cuartas, quintas y octavas justas. Segundas, terceras, sextas y séptimas mayores y menores. Intensificación y dominio fuera y dentro de contexto tonal.

Tonalidades mayores y menores hasta con cuatro alteraciones en la armadura. (Escalas menores, natural, armónica y melódica)

Intervalos pertenecientes a estas escalas comprendidos en el ámbito vocal, excluidos los intervalos compuestos.

Intervalos aumentados y disminuidos, obtenidos por alteración de los grados de las escalas, o utilizando las notas propias de las mismas

Repentización:

Conocimiento y lectura rítmica de la clave de $\| 4^{\mathrm{a}}$

- Ejercicios de lectura rítmica. en claves de $\oint_{\text {y }}$ : $4^{\mathrm{a}}$, conteniendo cambios métricos y teniendo como figura unidad de tiempo en los compases simples, $\downarrow$, $\bullet$ o •); y en los compuestos, $\downarrow$.

Solfear lecciones, con o sin acompañamiento de piano; en clave de $\oint_{\text {y: }} 4^{\mathrm{a}}$, conteniendo los elementos rítmico - melódicos y expresivos utilizados en el curso anterior. 


\section{GRADO MEDIO \\ SECUENCIACIÓN DE LOS CONTENIDOS POR CURSOS \\ CONTENIDOS. CURSO $1^{\circ}$ \\ División de los contenidos propios del curso en Materias y Elementos}

\section{SOLFEO ESTUDIADO}

Elementos melódico - armónicos:

- Ámbito vocal: el mismo señalado para el curso anterior

- Tonalidades mayores y menores hasta con seis alteraciones en la armadura. Tonalidades enarmónicas. Cambio de tonalidad

- Introducción a las modalidades no clásicas: escalas exóticas, escala exátona o de tonos enteros

- Intervalos doblemente aumentados y disminuidos.

- Enarmonía

Elementos rítmico - métricos:

- Compases formados por agrupaciones irregulares de negras (5/4 y $7 / 4)$ y de corcheas $(5 / 8,7 / 8$, y 8/8). Cambios entre compases conservando la igualdad de duración de sus figuras

Elementos de lectura e interpretación:

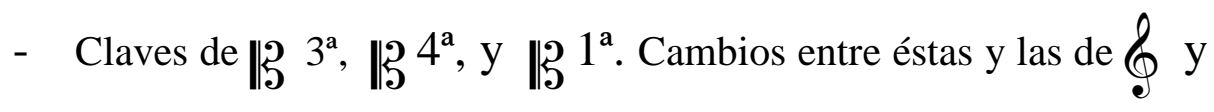
9: $4^{\mathrm{a}}$

- Notas de adorno: todas

- Signos y elementos expresivos: signos y términos de articulación

- Cambios de aire o movimiento

\section{SOLFEO REPENTIZADO}

Solfear lecciones inéditas, con acompañamiento de piano, que no apoye la melodía en su mayor parte, de una extensión mínima de ocho compases, con cambios de clave entre las propias del curso, y cuyos elementos rítmicos y melódicos sean los propios del curso anterior. Práctica de la lectura rápida en claves, de la entonación pura y de la lectura rítmica.

\section{SOLFEO POLIFÓNICO}

Solfear lecciones u obras a 2, 3 y 4 voces, con dificultad rítmica y melódica menor que la del curso. 


\section{CONTENIDOS $2^{\circ}$ CURSO}

\section{División de los contenidos propios del curso en Materias y Elementos SOLFEO ESTUDIADO}

Elementos melódico - armónicos:

- Tonalidades mayores y menores, hasta con 7 alteraciones en la armadura

- Politonalidad, atonalidad, dodecafonismo

- Intervalos melódicos libres, dentro del ámbito vocal.

Elementos métrico - rítmicos:

- Compases formados por agrupaciones irregulares de semicorcheas $(5,7,8,11,13 \ldots / 16)$

- Compases irregulares formados por aumentación o disminución de los tiempos de los compases regulares (compases con numeradores mixtos)

- Cambios entre todos los compases

- Combinaciones polirrítmicas

- Métrica libre (música sin compasear)

Elementos de lectura e interpretación:

- Claves de 諍 en $2^{\mathrm{a}}$ y 9: en $3^{\mathrm{a}}$. Cambios entre las 7 claves

- Nuevas grafías

\section{SOLFEO POLIFÓNICO}

Solfear lecciones u obras a 2, 3 y 4 voces, con dificultad rítmica y melódica menor que la del curso.

\section{SOLFEO REPENTIZADO}

Repentizar lecciones inéditas de solfeo entonado, con acompañamiento de piano que no apoye la melodía, de extensión mínima de ocho compases, y cuyo nivel de dificultad corresponda a la del curso anterior, incluyendo además cambios entre las siete claves. Práctica separada de la lectura rápida en claves, de la entonación pura y de la lectura rítmica.

\section{TRANSPOSICIÓN REPENTIZADA}

Repentizar la transposición de lecciones inéditas, con acompañamiento de piano que no apoye la melodía, de extensión mínima de ocho compases, a los intervalos de $2^{\mathrm{a}}$ y $3^{\mathrm{a}}$ mayores y menores, superiores e inferiores. El nivel de dificultad de este ejercicio, en cuanto a métrica y entonación, será el del curso anterior. Las claves serán las de @ y 9: $4^{\text {a }}$, con cambios. 
Con todo ello, hemos formulado hipótesis sobre lo que es, o no, idóneo para la enseñanza de esta disciplina, que aun siendo tan básica para la formación de un futuro músico, pesa sobre ella, históricamente, una mácula que la hace, casi siempre, objeto de un aprendizaje con deficiencias.

En la introducción del Primer Congreso Nacional de la Enseñanza del Solfeo (AAVV, 1990), el Editor dice textualmente:

...la situación de esta enseñanza en España siempre ha adolecido de una característica común: la falta de unificación de criterios en torno a su función y a sus sistemas pedagógicos. El hecho de que la mayor parte de las publicaciones sobre este tema hayan tenido una finalidad predominantemente práctica, no ha facilitado que exista una filosofía de fondo que unifique los criterios.

Y en la misma publicación, Bonet Armengol dice:

La primera constatación de fracaso del solfeo que podemos consignar es que al cabo de muchos años de estudio, la mayoría de alumnos continúan sin saber leer, o sin comprender lo que leen. ${ }^{1}$

\footnotetext{
${ }^{1}$ BONET ARMENGOL, Narcís, en "La crisis del solfeo”, Primer Congreso Nacional... p. 13
} 
2.3. Criterios para la valoración de las categorías 


\subsection{PATRONES DE COMPARACIÓN Y VALORACIÓN}

De los programas del Conservatorio de Madrid relativos a la asignatura de solfeo, hemos extraído los siguientes patrones de comparación para, una vez analizado su contenido, proceder a comparar cada método con el programa vigente en los años de su edición:

\subsubsection{PATRONES SECUENCIADOS DE LOS PROGRAMAS DEL RCSMM}

\section{PROGRAMAS DE 1831 Y 1832}

Son muy pocas las consecuencias, que en cuanto a contenidos, se pueden obtener de la lectura de los exámenes públicos de 1831 (punto 2.3.1.), pues programas no habían, o al menos no existen en la actualidad. Con la lectura de la Memoria citada en ese punto, confeccionamos los siguientes programas

\section{Primer curso:}

\begin{tabular}{|l|l|}
\hline Claves a emplear & Sol \\
\hline $\begin{array}{l}\text { Dificultades de ento- } \\
\text { nación o melódicas }\end{array}$ & Práctica intensa de todos los intervalos \\
\hline & Transporte \\
\hline & Lectura a primera vista \\
\hline & Dictado musical, pero hablado \\
\hline Teoría de la música & Figuras, silencios, alteraciones y otras..... \\
\hline
\end{tabular}

Segundo curso:

\begin{tabular}{|l|l|}
\hline Claves a emplear & Todas \\
\hline $\begin{array}{l}\text { Dificultades de ento- } \\
\text { nación o melódicas }\end{array}$ & Práctica intensa de todos los intervalos \\
\hline & Transporte \\
\hline & Lectura a primera vista \\
\hline & Dictado musical \\
\hline Teoría de la música & Figuras, silencios, alteraciones y otras..... \\
\hline
\end{tabular}


De todo el articulado de las "Instrucciones del Real Conservatorio" en ese año, se saca la conclusión que el programa por el que se regía la asignatura era el método de Eslava.

He aquí pues el programa extraído de él, atendiendo a las delimitaciones que las "Instrucciones" hacen para cada curso.

\section{Primer curso:}

-Los contenidos de esta parte, más los que se desprenden de las lecciones 1 a la 9 de la $2^{\mathrm{a}}$ parte.

-Noción de música. Agrupación de los caracteres y señales en 2 grupos: sonido: agrupa a las claves, signos (así llama a las notas), sostenidos, bemoles, becuadros, las letras $\boldsymbol{P}$ y $\boldsymbol{f}$ y todos los términos que modifiquen el sonido; tiempo: agrupa el aire, compás, figuras, puntillos, silencios, puntos de reposo y fermatas (llamados calderones), accelerando, ritardando y otros que modifiquen el valor del sonido. Pentagrama, Solfeo. Calificación de los intervalos y sus inversiones.

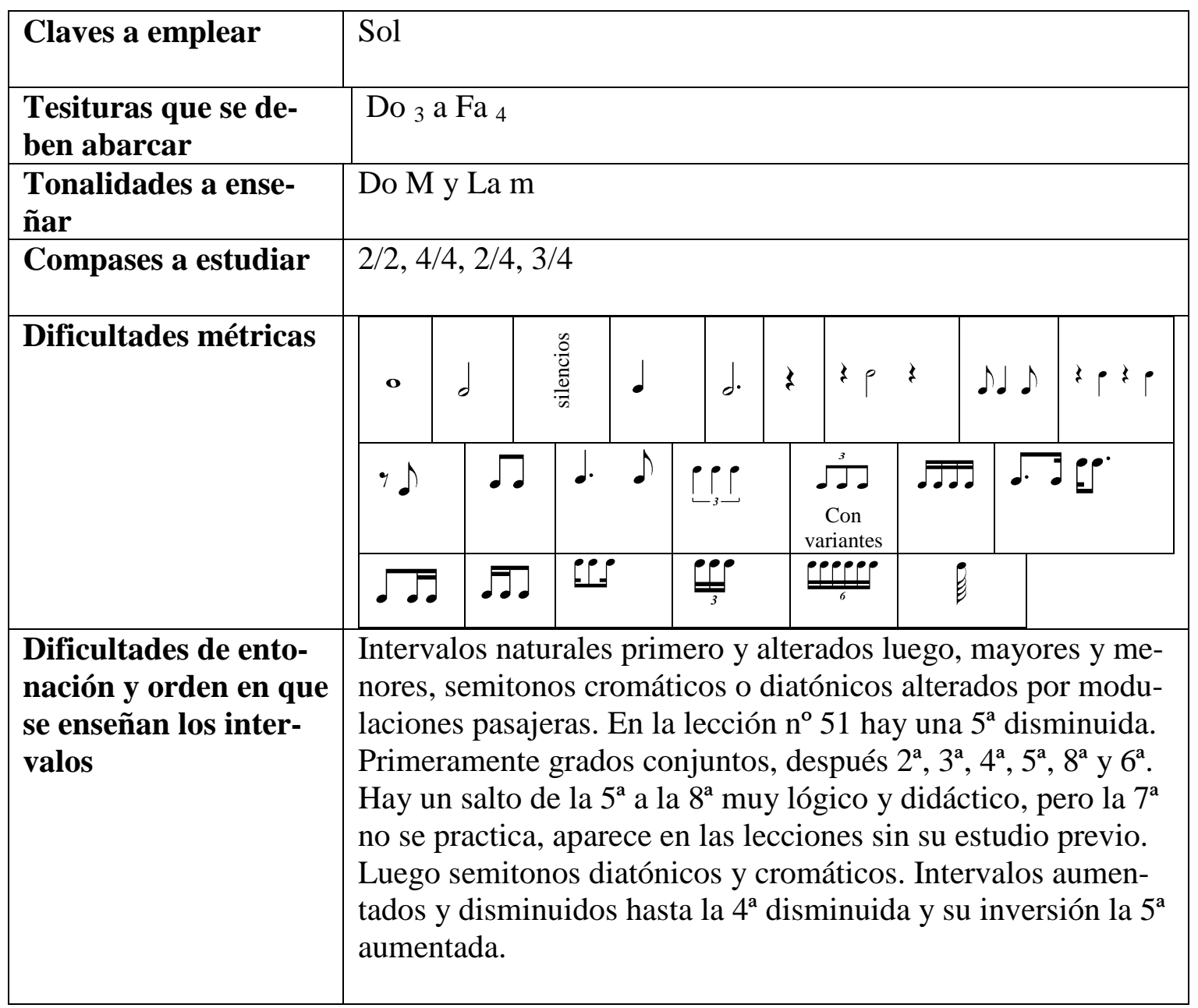

\section{Segundo curso:}


-Los contenidos de esta parte más los que se desprenden de las lecciones 1 a la 23 de la $3^{\mathrm{a}}$ parte.

-Modo de escribir la música dictada: consejos para esta materia. Silencios de figuras largas en desuso.

\begin{tabular}{|c|c|c|c|c|}
\hline Claves a emplear & \multicolumn{4}{|c|}{ Sol, Fa en $4^{\mathrm{a}}$, Do $1^{\mathrm{a}}$, Do $2^{\mathrm{a}}$} \\
\hline $\begin{array}{l}\text { Tesituras que se deben } \\
\text { abarcar }\end{array}$ & \multicolumn{4}{|c|}{$\mathrm{Do}_{3}$ a Fa $_{4}$, predominando hasta $\mathrm{Mi}_{4}$} \\
\hline Tonalidades a enseñar & \multicolumn{4}{|c|}{$\begin{array}{l}\text { Sol M, Mi m, Fa M, Re m, Re M, Si m, Si b M, Sol m, } \\
\text { La M, Fa \# m, Mi b M y Do m }\end{array}$} \\
\hline Compases a estudiar & \multicolumn{4}{|c|}{$\begin{array}{l}\text { Los anteriores más } 3 / 8,6 / 8,9 / 8 \text { y } 12 / 8,4 / 2,4 / 8,3 / 2,2 / 1 \\
2 / 8 \text { y } 12 / 4\end{array}$} \\
\hline \multirow[t]{2}{*}{ Dificultades métricas } & .0.0. & $\overline{100}$ & Doble puntillo & Notas de adorno \\
\hline & 9 & \& & & \\
\hline $\begin{array}{l}\text { Dificultades de entona- } \\
\text { ción y orden en que se } \\
\text { enseñan los intervalos }\end{array}$ & $\begin{array}{l}\text { Intervalos de } 9 \\
2^{\mathrm{a}} \mathrm{M} \text { y su inver } \\
3^{\mathrm{a} M} \\
4^{\mathrm{a} M} \\
5^{\mathrm{a} M} \\
6^{\mathrm{a} M} \\
7^{\mathrm{a} M} \\
9^{\mathrm{a}} \text { y } 10^{\mathrm{a}} \mathrm{M} \text { y } \mathrm{c} \\
2^{\mathrm{a}} \mathrm{A} \text { y su inver } \\
3^{\mathrm{a}} \mathrm{d} \\
4^{\mathrm{a}} \mathrm{c}\end{array}$ & $\begin{array}{r}10^{\mathrm{a}} ; \mathrm{au} \\
\text { ión } 7^{\mathrm{a}} \mathrm{n} \\
6^{\mathrm{a}} \mathrm{n} \\
5^{\mathrm{a}} \mathrm{n} \\
4^{\mathrm{a}} \mathrm{n} \\
3^{\mathrm{a}} \mathrm{n} \\
2^{\mathrm{a}} \mathrm{n} \\
\text { ión } 7^{\mathrm{a}} \mathrm{d} \\
6^{\mathrm{a}} \mathrm{A} \\
5^{\mathrm{a}} \mathrm{A}\end{array}$ & 更 & 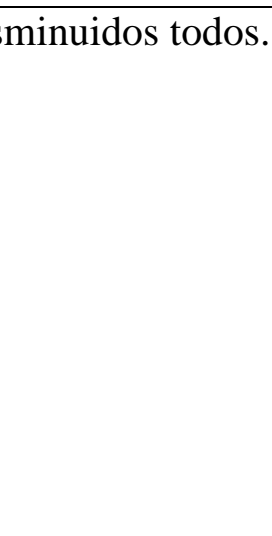 \\
\hline
\end{tabular}

Hay una tabla de compases más usados agrupados de la siguiente forma:

Compases de combinación doble a 4 partes 4/2, 4/4, 4/8

Compases de combinación doble a 3 partes $3 / 2,3 / 4,3 / 8$

Compases de combinación doble a 2 partes $2 / 1,2 / 4,2 / 2,2 / 8$

Compases de combinación triple a 4 partes 12/4, 12/8, 12/16

Compases de combinación triple a 3 partes $9 / 4,9 / 8,9 / 16$

Compases de combinación triple a 2 partes $6 / 2,6 / 4,6 / 8,6 / 16$

\section{Tercer curso:}

Los contenidos que abarcan desde la lección 24 de la parte tercera, hasta el final de la cuarta parte.

\begin{tabular}{|l|l|}
\hline Claves a emplear & $\begin{array}{l}\text { Do } 3^{\mathrm{a}}, \text { Do } 4^{\mathrm{a}} \text { y Fa } 3^{\mathrm{a}}, \text { intercalando las anteriores. (Do } 3^{\mathrm{a}} \text { y } 4^{\mathrm{a}} \\
\text { no están en su altura real) }\end{array}$ \\
\hline $\begin{array}{l}\text { Tesituras que se deben } \\
\text { abarcar }\end{array}$ & Como en las anteriores partes. \\
\hline Tonalidades a enseñar & $\begin{array}{l}\text { Mi M, Do \# m, La b M, Fa m, Si M, Sol \# m Re b M, Si b m, } \\
\text { Fa \# M, Re \# m, Sol b M y Mi b m }\end{array}$ \\
\hline
\end{tabular}




\begin{tabular}{|l|l|}
\hline Compases a estudiar & $\begin{array}{l}\text { Los anteriores más música sin compasear, 12/16, 9/4, 9/16, } \\
6 / 2,6 / 4,6 / 16,7 / 4,5 / 4, y 10 / 8,\end{array}$ \\
\hline Dificultades métricas & $\begin{array}{l}\text { No más que en los anteriores volúmenes, excepto las que se } \\
\text { desprenden de los nuevos compases. Además valores irregu- } \\
\text { lares de quintillo a oncillo. Fermata }\end{array}$ \\
\hline $\begin{array}{l}\text { Dificultades de entona- } \\
\text { ción y orden en que se } \\
\text { enseñan los intervalos }\end{array}$ & $\begin{array}{l}\text { Igual que en los anteriores, (que no son muchas) más dobles } \\
\text { alteraciones y enarmonías }\end{array}$ \\
Lecciones a 2 voces
\end{tabular}

\section{$\underline{\text { PROGRAMA DE } 1875}$}

Extractando las cuatro partes del método de Moré y Gil en 3 cursos, y teniendo en cuenta lo que prescribe Arrieta en el "programa manuscrito de las enseñanzas de la Escuela Nacional de Música, el programa de la asignatura en 1875 queda de la siguiente forma:

\section{Primer curso:}

\begin{tabular}{|l|l|l|l|l|l|l|l|}
\hline Claves a emplear & \multicolumn{3}{|l|}{ Sol } \\
\hline Tesituras que se deben \\
abarcar
\end{tabular}


Segundo curso:

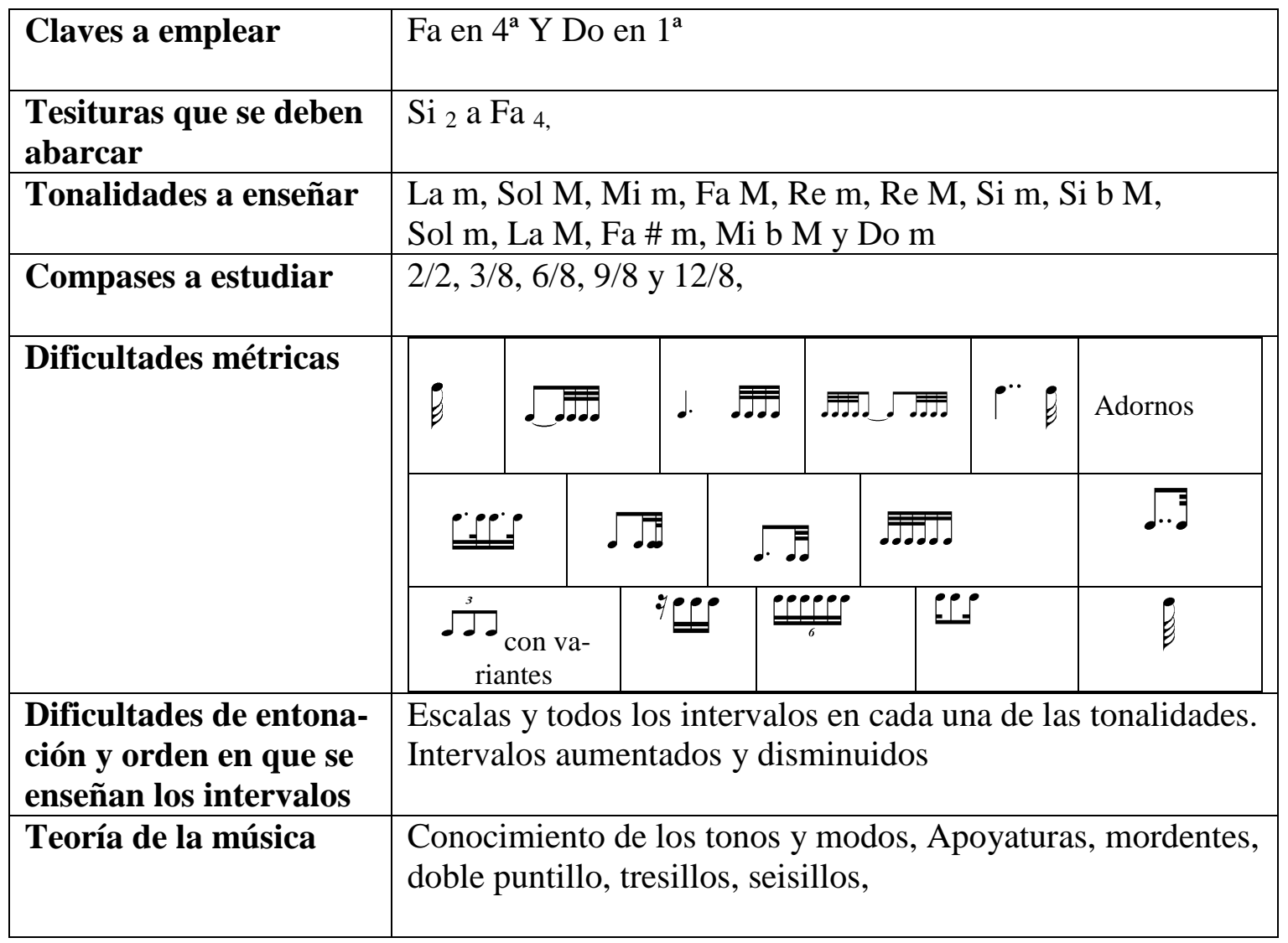

Tercer curso:

\begin{tabular}{|c|c|c|c|c|c|}
\hline Claves a emplear & \multicolumn{5}{|c|}{ Do en $2^{\mathrm{a}}, 3^{\mathrm{a}}$ y $4^{\mathrm{a}}$ líneas, $\mathrm{Fa}$ en $3^{\mathrm{a}}$} \\
\hline $\begin{array}{l}\text { Tesituras que se deben } \\
\text { abarcar }\end{array}$ & \multicolumn{5}{|c|}{$\mathrm{Do}_{3} \mathrm{a} \mathrm{Mi}_{4}$} \\
\hline Tonalidades a enseñar & \multicolumn{5}{|c|}{$\begin{array}{l}\text { Mi M, Do \# m, La b M, Fa m, Si M, Sol \# m, Re b M, Si b } \\
\text { m, Fa \# M, Re \# m, Sol b M, Mi b m }\end{array}$} \\
\hline Compases a estudiar & \multicolumn{5}{|c|}{$6 / 4,7 / 4,5 / 4,5 / 8$ y $10 / 8$} \\
\hline \multirow[t]{2}{*}{ Dificultades métricas } & $\stackrel{3}{=.0}$ & $\begin{array}{l}\text { Comparación de fórmu- } \\
\text { las rítmicas similares }\end{array}$ & .6 & $\begin{array}{l}\text { Repaso de } \\
\text { fórmulas ante- } \\
\text { riores }\end{array}$ & \\
\hline & \multicolumn{4}{|c|}{ Medidas irregulares desde quintillo a diecillo } & \\
\hline
\end{tabular}

\begin{tabular}{|l|l|}
\hline $\begin{array}{l}\text { Dificultades de entona- } \\
\text { ción y orden en que se } \\
\text { enseñan los intervalos }\end{array}$ & Dobles alteraciones. Enarmonías. \\
\hline Teoría & $\begin{array}{l}\text { Géneros. Transporte. Conocimiento de las principales abre- } \\
\text { viaturas, de las figuras y compases antiguos y tablas de los } \\
\text { intervalos y sus inversiones. }\end{array}$ \\
\hline
\end{tabular}


$\underline{\text { PROGRAMAS DE } 1876 \text { Y DE } 1891}$

Primer curso:

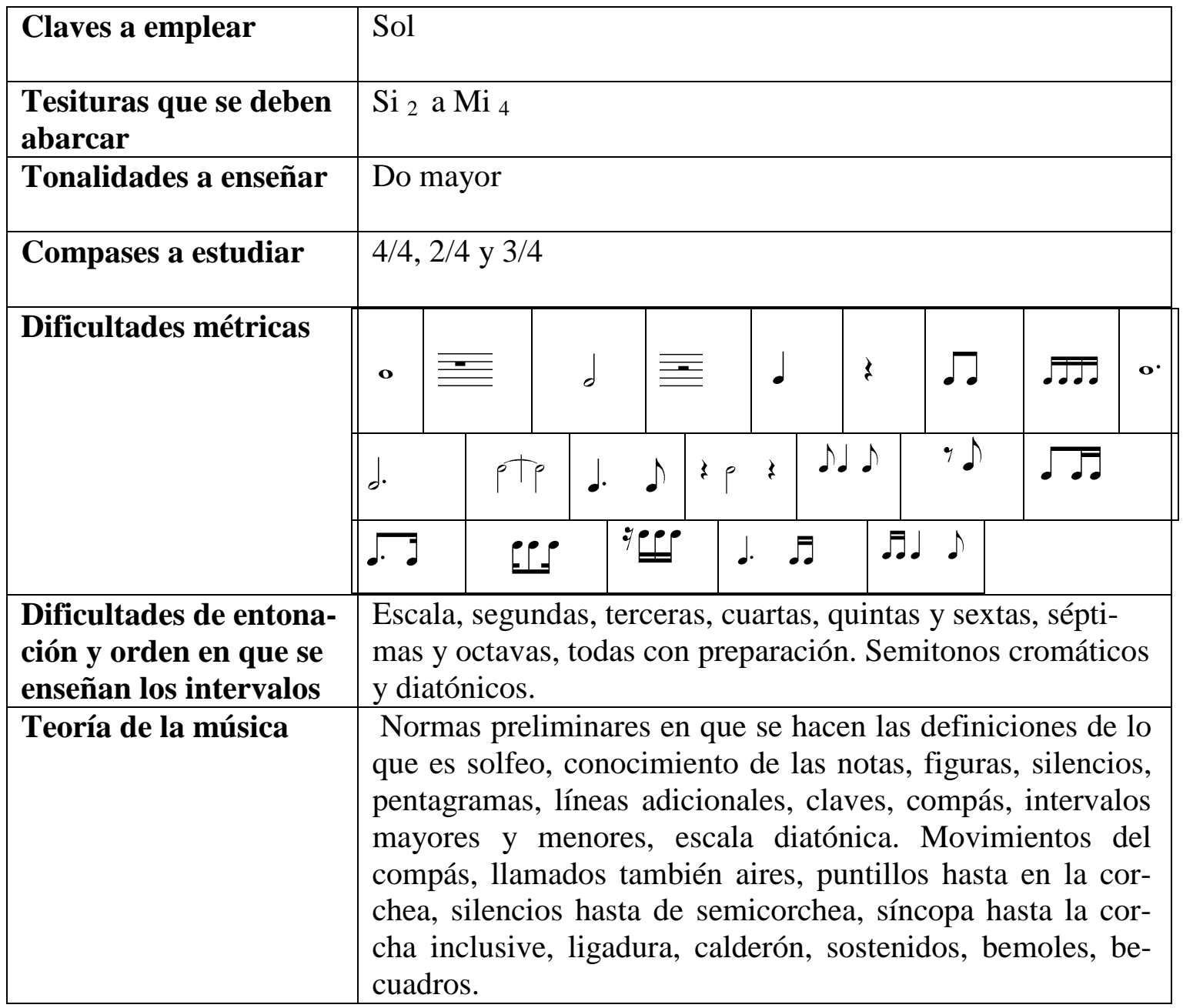

Segundo curso:

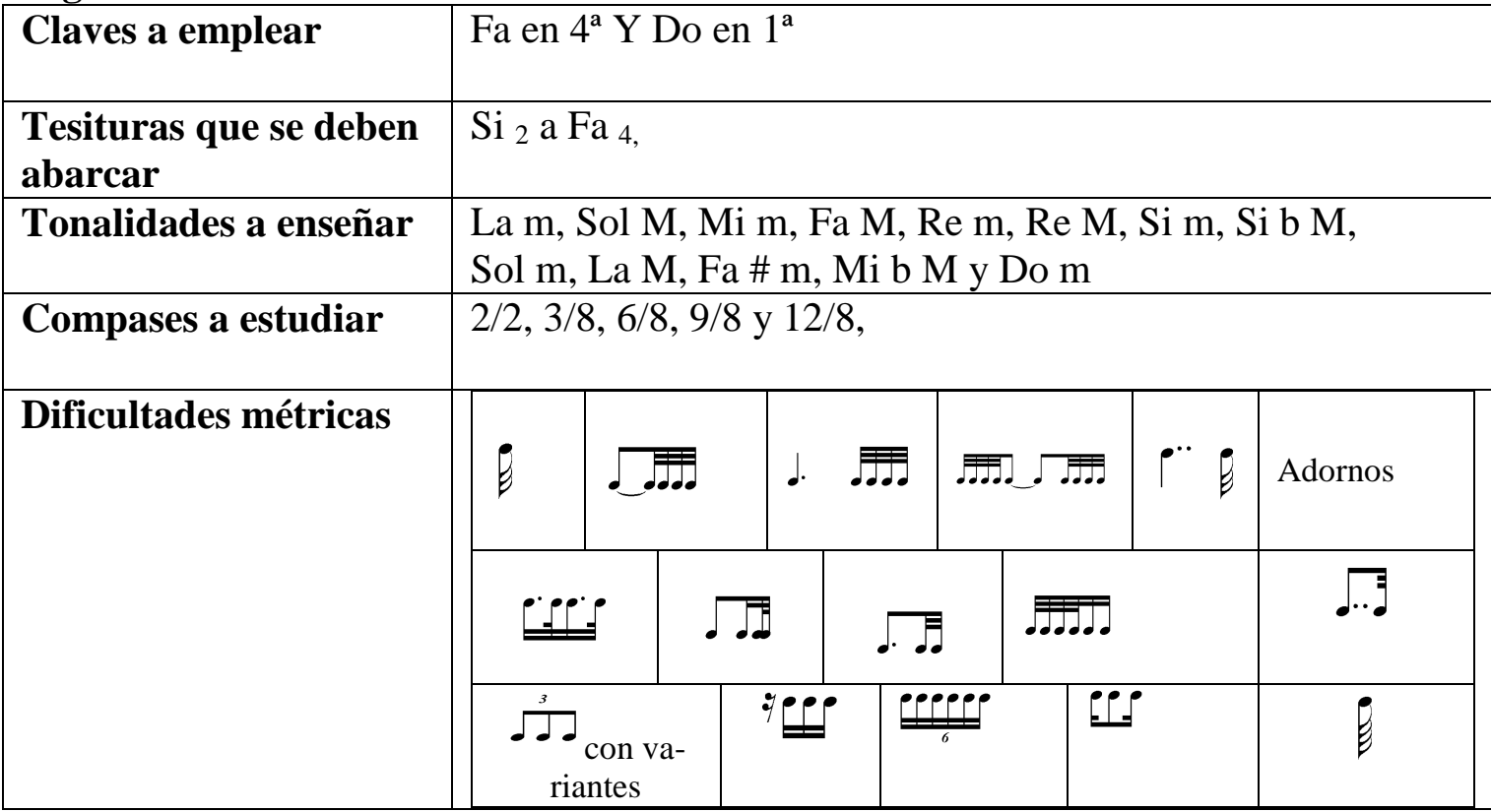




\begin{tabular}{|l|l|}
\hline $\begin{array}{l}\text { Dificultades de entona- } \\
\text { ción y orden en que se } \\
\text { enseñan los intervalos }\end{array}$ & $\begin{array}{l}\text { Escalas y todos los intervalos en cada una de las tonalidades. } \\
\text { Intervalos aumentados y disminuidos }\end{array}$ \\
\hline Teoría de la música & $\begin{array}{l}\text { Conocimiento de los tonos y modos, Apoyaturas, mordentes, } \\
\text { doble puntillo, tresillos, seisillos, }\end{array}$ \\
\hline
\end{tabular}

\section{Tercer curso:}

\begin{tabular}{|c|c|c|c|c|c|}
\hline Claves a emplear & \multicolumn{5}{|c|}{ Do en $2^{\mathrm{a}}, 3^{\mathrm{a}}$ y $4^{\mathrm{a}}$ líneas, Fa en $3^{\mathrm{a}}$} \\
\hline $\begin{array}{l}\text { Tesituras que se deben } \\
\text { abarcar }\end{array}$ & \multicolumn{5}{|c|}{$\mathrm{Do}_{3} \mathrm{a} \mathrm{Mi}_{4}$} \\
\hline Tonalidades a enseñar & \multicolumn{5}{|c|}{$\begin{array}{l}\text { Mi M, Do \# m, La b M, Fa m, Si M, Sol \# m, Re b M, } \\
\text { Si b m, Fa \# M, Re \# m, Sol b M, Mi b m }\end{array}$} \\
\hline Compases a estudiar & \multicolumn{5}{|c|}{ Los mismos } \\
\hline Dificultades métricas & $\stackrel{3}{=.00}$ & $\begin{array}{l}\text { Comparación de fórmu- } \\
\text { las rítmicas similares }\end{array}$ & . & $\begin{array}{l}\text { Repaso de } \\
\text { fórmulas ante- } \\
\text { riores }\end{array}$ & \\
\hline $\begin{array}{l}\text { Dificultades de entonación } \\
\text { y orden en que se enseñan } \\
\text { los intervalos }\end{array}$ & \multicolumn{5}{|c|}{ Dobles alteraciones. Enarmonías. } \\
\hline
\end{tabular}

PROGRAMA DE 1898

Primer curso:

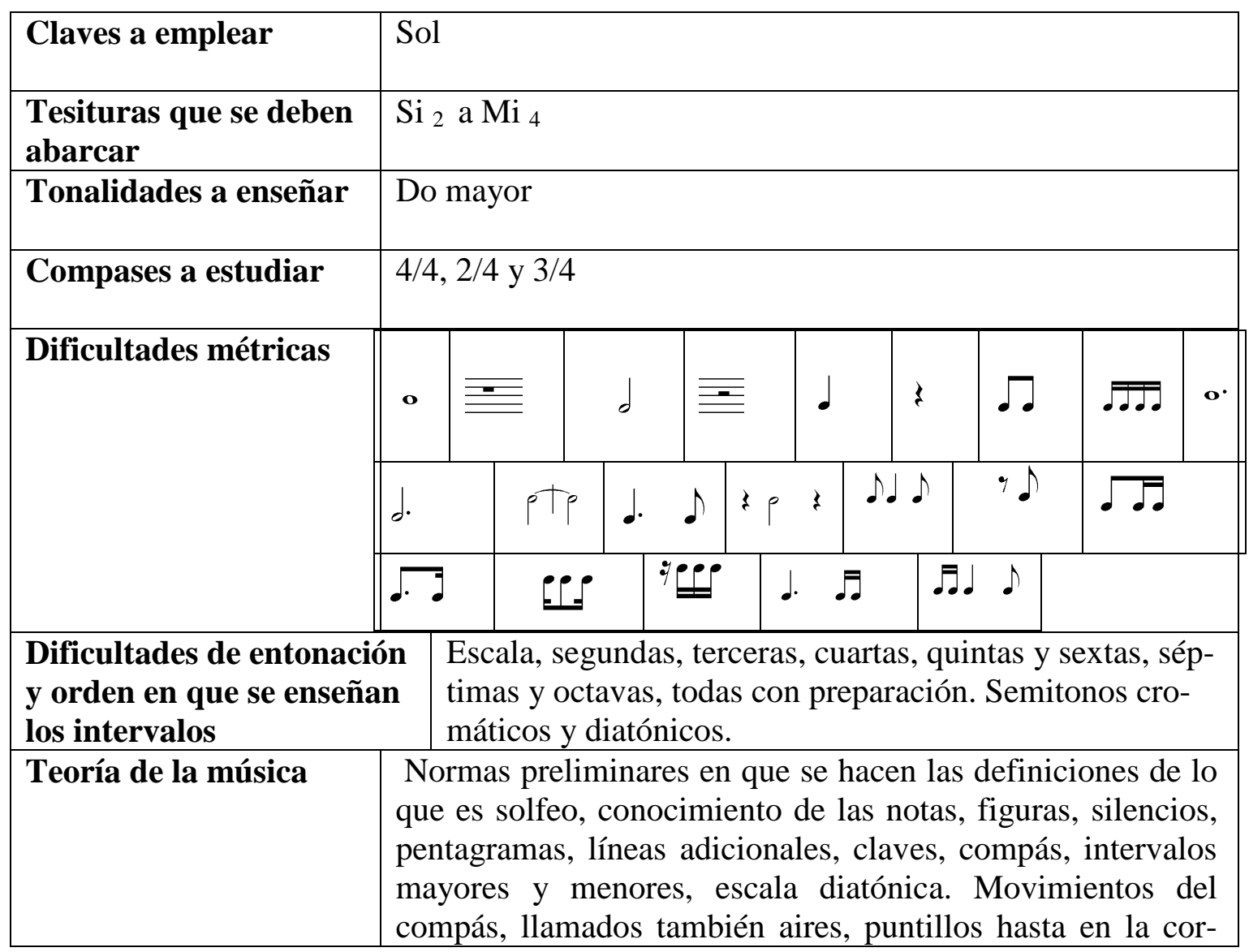




\begin{tabular}{|l|l|}
\hline & $\begin{array}{l}\text { chea, silencios hasta de semicorchea, síncopa hasta la cor- } \\
\text { cha inclusive, ligadura, calderón, sostenidos, bemoles, be- } \\
\text { cuadros. }\end{array}$ \\
\hline
\end{tabular}

Segundo curso:

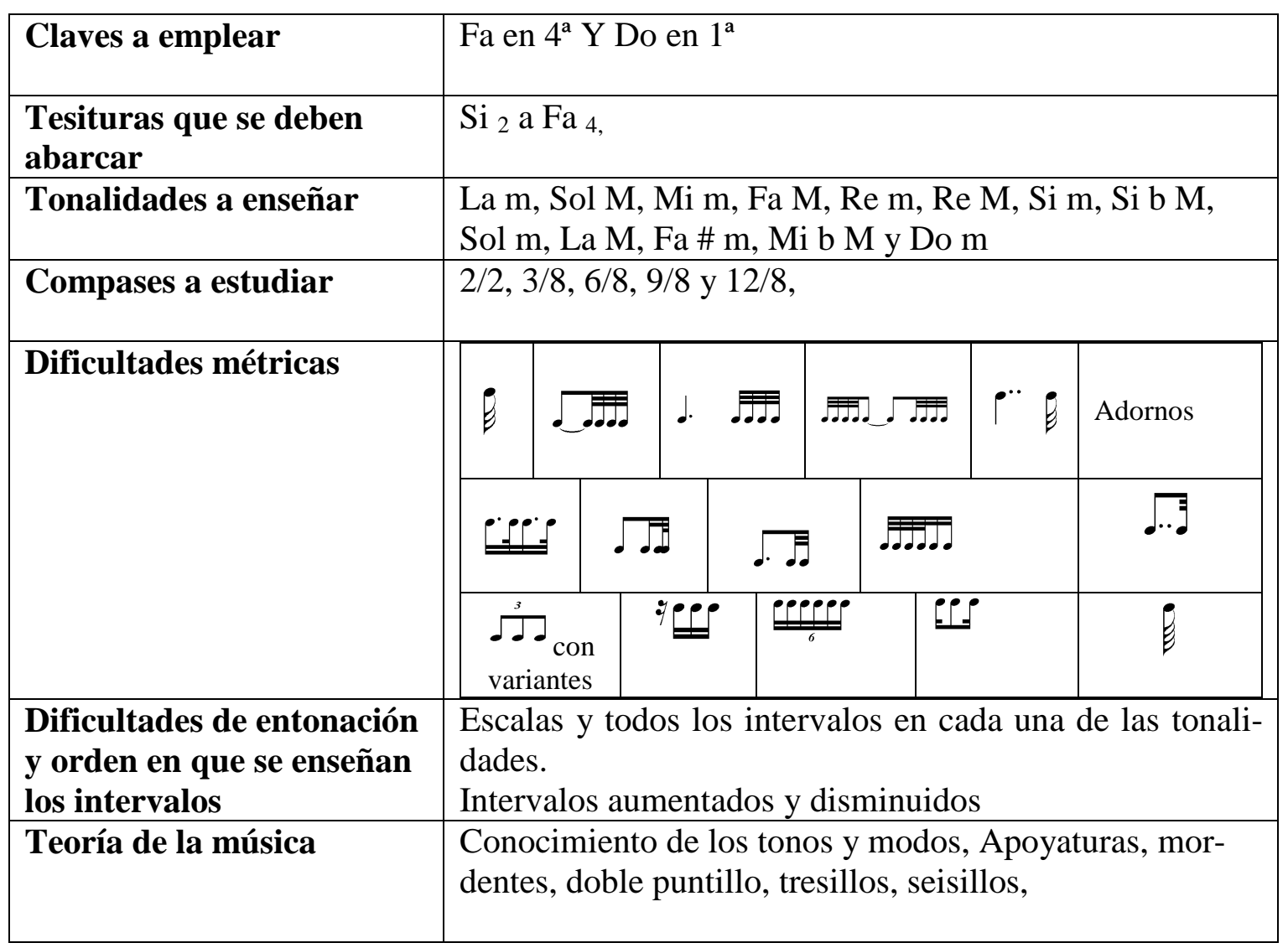

\section{Tercer curso:}

\begin{tabular}{|c|c|c|c|c|c|}
\hline Claves a emplear & \multicolumn{5}{|c|}{ Do en $2^{\mathrm{a}}, 3^{\mathrm{a}}$ y $4^{\mathrm{a}}$ líneas, Fa en $3^{\mathrm{a}}$} \\
\hline $\begin{array}{l}\text { Tesituras que se deben } \\
\text { abarcar }\end{array}$ & \multicolumn{5}{|c|}{$\mathrm{Do}_{3} \mathrm{a} \mathrm{Mi}_{4}$} \\
\hline Tonalidades a enseñar & \multicolumn{5}{|c|}{$\begin{array}{l}\text { Mi M, Do \# m, La b M, Fa m, Si M, Sol \# m, Re b M, Si b } \\
\text { m, Fa \# M, Re \# m, Sol b M, Mi b m }\end{array}$} \\
\hline Compases a estudiar & \multicolumn{5}{|c|}{$6 / 4,7 / 4,5 / 4,5 / 8$ y $10 / 8$} \\
\hline \multirow[t]{2}{*}{ Dificultades métricas } & $\stackrel{3}{=0}$ & $\begin{array}{l}\text { Comparación de fórmu- } \\
\text { las rítmicas similares }\end{array}$ & .0.0.0 & $\begin{array}{l}\text { Repaso de } \\
\text { fórmulas ante- } \\
\text { riores }\end{array}$ & \\
\hline & \multicolumn{5}{|c|}{ Medidas irregulares desde quintillo a diecillo } \\
\hline $\begin{array}{l}\text { Dificultades de entona- } \\
\text { ción y orden en que se } \\
\text { enseñan los intervalos }\end{array}$ & \multicolumn{5}{|c|}{ Dobles alteraciones. Enarmonías. } \\
\hline Teoría de la música & \multicolumn{5}{|c|}{$\begin{array}{l}\text { Géneros. Transporte. Conocimiento de las principales abre- } \\
\text { viaturas, de las figuras y compases antiguos y tablas de los }\end{array}$} \\
\hline
\end{tabular}


intervalos y sus inversiones.

En el análisis de contenido, la fase de numeración o recuento se refiere a la forma de contar las unidades de registro (Porta y Silva, 2003, p. 11), y de entre las distintas formas de hacerlo, nosotros compararemos y valoraremos los distintos métodos analizados, estudiando el grado de adecuación a los programas vigentes en la época de edición del mismo, por la presencia de los elementos que figuran en los programas y por la apa$\underline{\text { rición en el orden en que figuran }}$

\subsubsection{SECUENCIAS DE CONTENIDOS QUE CONSIDERAMOS IDÓNEAS CON LOS PROCEDIMIENTOS ACTUALES DE ENSEÑANZA/APRENDIZAJE DEL SOLFEO}

De los distintos apartados del punto 2.3.2., (parámetros y gradaciones de los distintos elementos musicales que consideramos óptimos en el proceso de enseñanza/aprendizaje), obtenemos las siguientes secuencias (repartidas en 6 que son los cursos en que se divide la asignatura actualmente) que sirven para deducir el grado de vigencia que los contenidos de cada método y su desarrollo metodológico tendrían en la actualidad. 


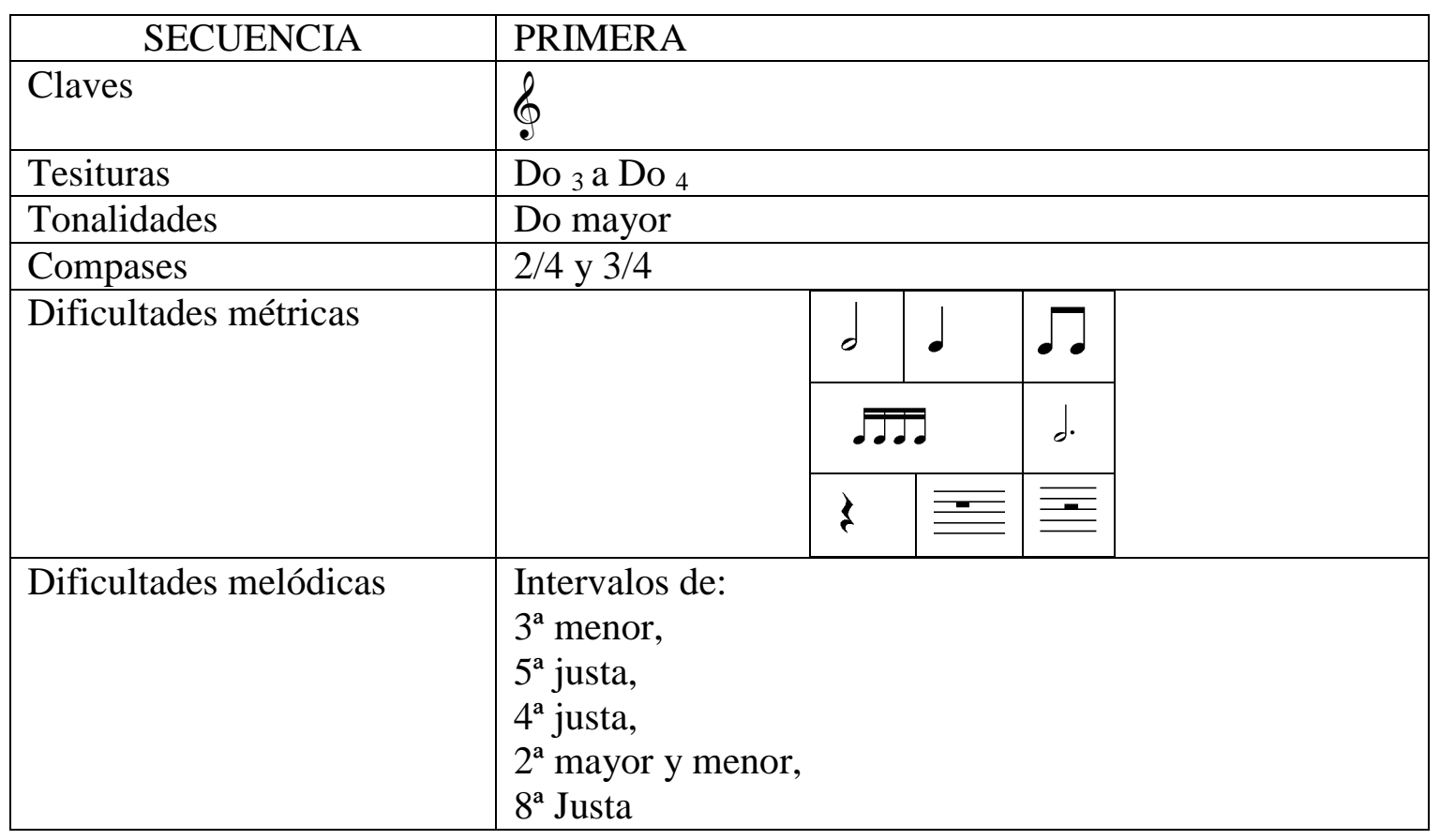

\begin{tabular}{|c|c|c|c|c|c|}
\hline SECUENCIA & \multicolumn{5}{|l|}{ SEGUNDA } \\
\hline Claves & \multicolumn{5}{|c|}{$\oint_{9}$ y: $4^{\mathrm{a}}($ sin cambios entre ellas $)$} \\
\hline Tesituras & \multicolumn{5}{|c|}{$\mathrm{Sol}_{2} \mathrm{a} \mathrm{Re}_{4}$} \\
\hline Tonalidades & \multicolumn{5}{|c|}{ La menor, Sol mayor, Fa mayor. } \\
\hline Compases & \multicolumn{5}{|c|}{$4 / 4$ y $6 / 8$} \\
\hline \multirow[t]{5}{*}{ Dificultades métricas } & & $\mathbf{0}$ & & d. $d$ & \\
\hline & & $\sqrt{.}$ & $\bar{\sigma}$ & zp & \\
\hline & & 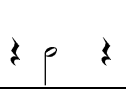 & y & $9 d$ & \\
\hline & & . & $\therefore D$ & 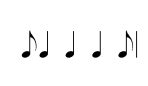 & \\
\hline & & & & & \\
\hline Dificultades melódicas & \multicolumn{5}{|c|}{$\begin{array}{l}\text { - Intervalos entre notas naturales, todos excepto los de } 7^{\mathrm{a}} \text {. } \\
\text { - Alteraciones cromáticas del } \mathrm{Fa} \sharp, \mathrm{Si} \text { b y Sol } \sharp \\
\text { - El becuadro }\end{array}$} \\
\hline
\end{tabular}




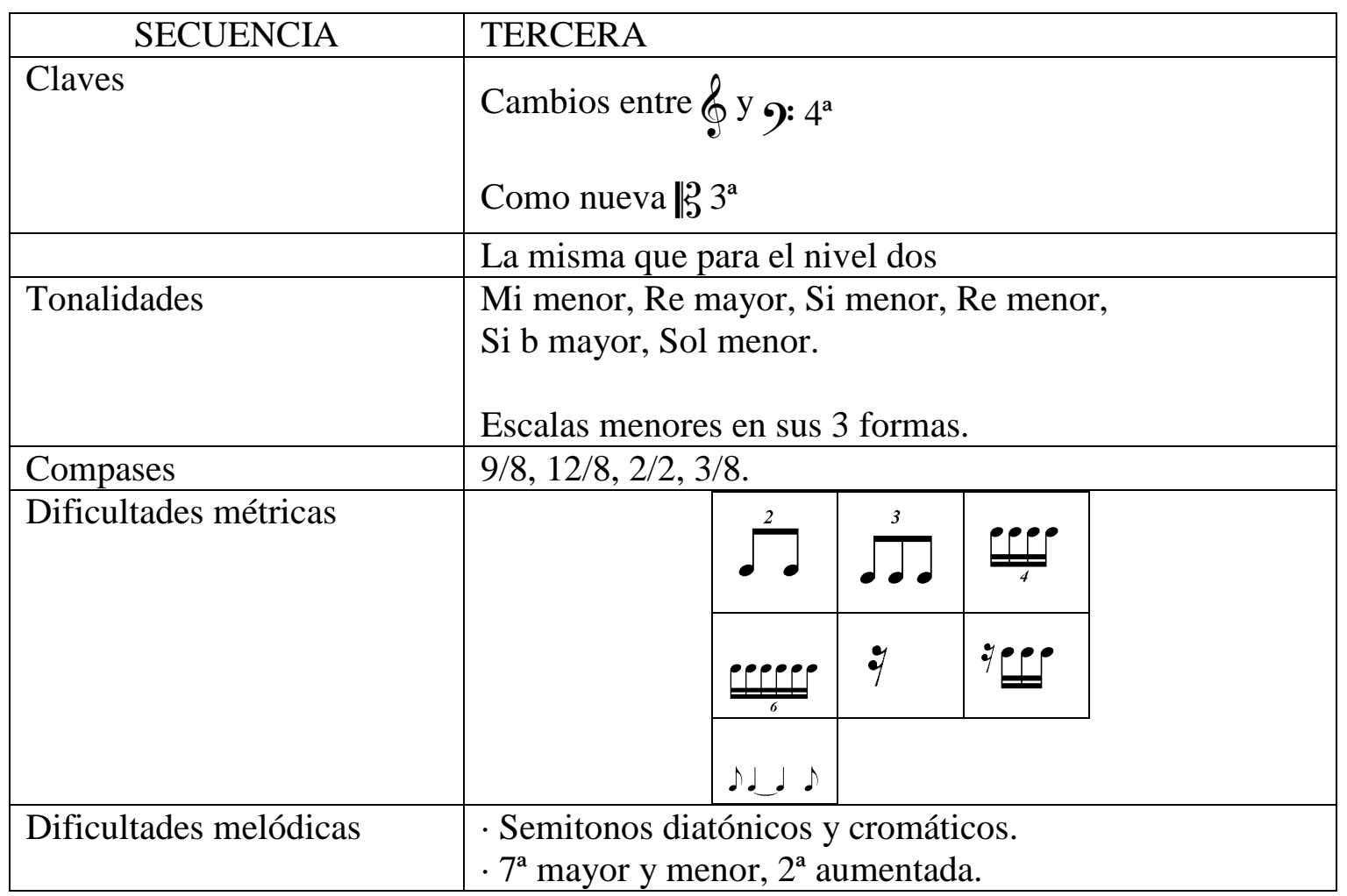

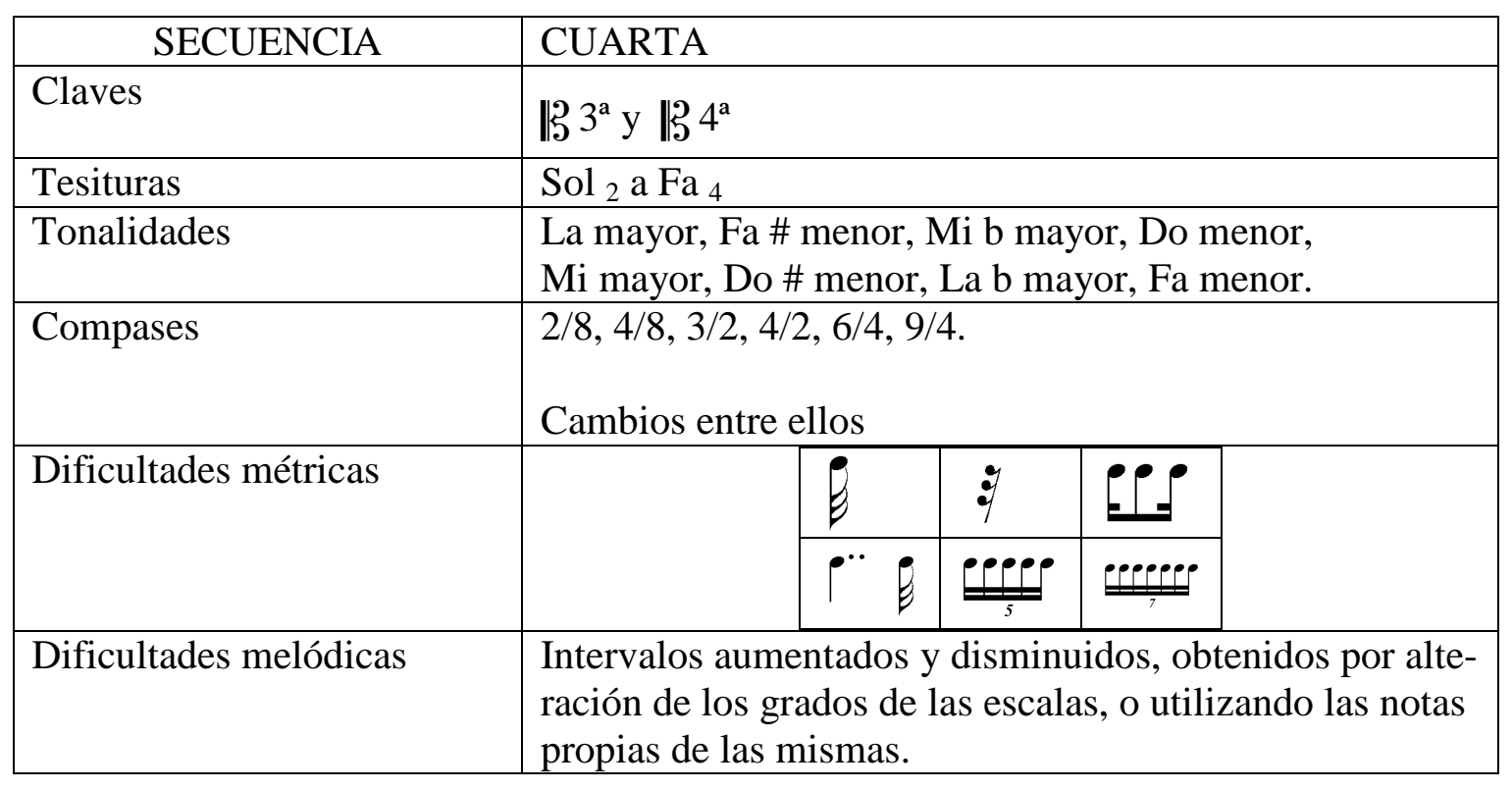




\begin{tabular}{|c|c|}
\hline SECUENCIA & QUINTA \\
\hline Claves & $\begin{array}{l}\| \int_{9} 1^{\mathrm{a}} \\
\text { Con cambios entre las estudiadas }\end{array}$ \\
\hline Tesituras & La misma que en el nivel anterior \\
\hline Tonalidades & $\begin{array}{l}\text { Si mayor, Sol \# menor, Re b mayor, Si b menor, } \\
\text { Fa \# mayor, Re \# menor, Sol b mayor, Mi b menor. } \\
\text { Tonalidades enarmónicas. } \\
\text { Cambios de tonalidades }\end{array}$ \\
\hline Compases & $\begin{array}{l}5 / 4,7 / 4,5 / 8,7 / 8,8 / 8 \\
\text { Cambios entre compases }\end{array}$ \\
\hline Dificultades métricas & $\begin{array}{l}\text { Notas de adorno. } \\
\text { Todas las combinaciones métricas posibles. }\end{array}$ \\
\hline Dificultades melódicas & $\begin{array}{l}\text { Intervalos doblemente aumentados y disminuidos. } \\
\text { Enarmonía. } \\
\text { Modalidades no clásicas; escalas exóticas, escala exáto- } \\
\text { na. }\end{array}$ \\
\hline
\end{tabular}

\begin{tabular}{|l|l|}
\hline \multicolumn{1}{|c|}{ SECUENCIA } & SEXTA \\
\hline Claves & $\begin{array}{l}\boldsymbol{\|} \mathbf{S}^{\mathrm{a}} \mathrm{y} 9: 3^{\mathrm{a}} . \\
\text { Cambios entre las } 7 \text { claves }\end{array}$ \\
\hline Tesituras & La misma que en niveles anteriores \\
\hline Tonalidades & Do \# mayor, La \# menor, Do b mayor, La b menor \\
\hline Compases & $5,7,8,11$ y $13 / 16$. \\
& Compases con valores añadidos y de disminución. \\
& Cambios entre todos los compases. \\
\hline Dificultades métricas & Combinaciones polirrítmicas \\
\hline Dificultades melódicas & Intervalos melódicos libres. \\
\hline
\end{tabular}

Igualmente como hacemos con los programas antiguos, valoramos el grado de ajuste con los procedimientos actuales de enseñanza/aprendizaje del solfeo, por la pre-

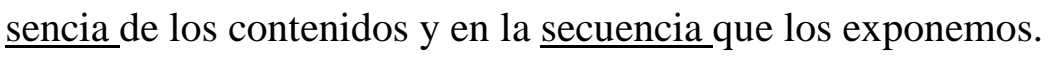




\subsubsection{PATRONES DE VALORACIÓN PARA LA INFERENCIA FINAL DE LOS}

\section{DATOS}

Como cierre del trabajo, se lleva a cabo un Estudio Comparativo de los distintos métodos. Los datos numéricos se procesan para tener la más clara y rápida comprensión de los hechos estudiados, y con ellos se construyen gráficos, cuadros estadísticos, etc. de tal manera que sinteticen sus valores y se pueda, a partir de ellos, extraer enunciados de índole teórica, ya sea agrupando, relacionando y/o generalizando.

Las reglas de recuento serán: la frecuencia valorativa, la frecuencia proporcional o porcentajes de frecuencia y la distribución de frecuencias.

Se hace un recuento de todos y cada uno de los elementos registradores, presencia y secuencia, a excepción del primero "extensión de las lecciones", porque este no es en nada significativo, solamente informativo; algunos se subdividen porque presentan alguna información de interés, y se añaden al final los balances de los apartados de valoración y grados de ajuste con los programas vigentes en el momento y con los procedimientos actuales de enseñanza/aprendizaje.

Cuando de un autor hay varias partes, figuran todos los elementos seguidos, pero en el orden en que aparecen a través de las distintas partes o volúmenes.

Estos son los patrones de comparación y valoración para cada una de las categorías:

\begin{tabular}{|l|l|}
\hline Claves empleadas y orden didáctico & Se cuenta la presencia y la secuencia \\
\hline Tesituras que abarcan las lecciones & $\begin{array}{l}\text { Se cuentan la variedad de tesituras que } \\
\text { comprenden la totalidad de las lecciones. }\end{array}$ \\
\hline Tonalidades y modalidades que emplean & $\begin{array}{l}\text { Se cuentan solamente la cantidad de tona- } \\
\text { lidades que se emplean en las lecciones de } \\
\text { los métodos }\end{array}$ \\
\hline $\begin{array}{l}\text { Compases que enseñan y utilizan para } \\
\text { comenzar la enseñanza }\end{array}$ & $\begin{array}{l}\text { Se cuenta la presencia de todos los com- } \\
\text { pases básicos, tanto simples como com- } \\
\text { puestos (2, 3 y 4/4; 6, 9 y 12/8); la ausen- } \\
\text { cia del total de ellos; la presencia de algu- } \\
\text { nos otros compases y el orden en que apa- } \\
\text { recen }\end{array}$ \\
\hline $\begin{array}{l}\text { Dificultades métricas que se estudian y } \\
\text { secuencia }\end{array}$ & $\begin{array}{l}\text { Senta el máximo de dificultad, en } \\
\text { cuanto a figuras de nota y combinaciones, } \\
\text { introducida en cada método }\end{array}$ \\
\hline
\end{tabular}

En cuanto a la secuencia, la dividimos en 5 categorías:

1) Progresiva - Idónea;

2) Progresiva - Casi idónea;

3) Progresiva - No idónea; 


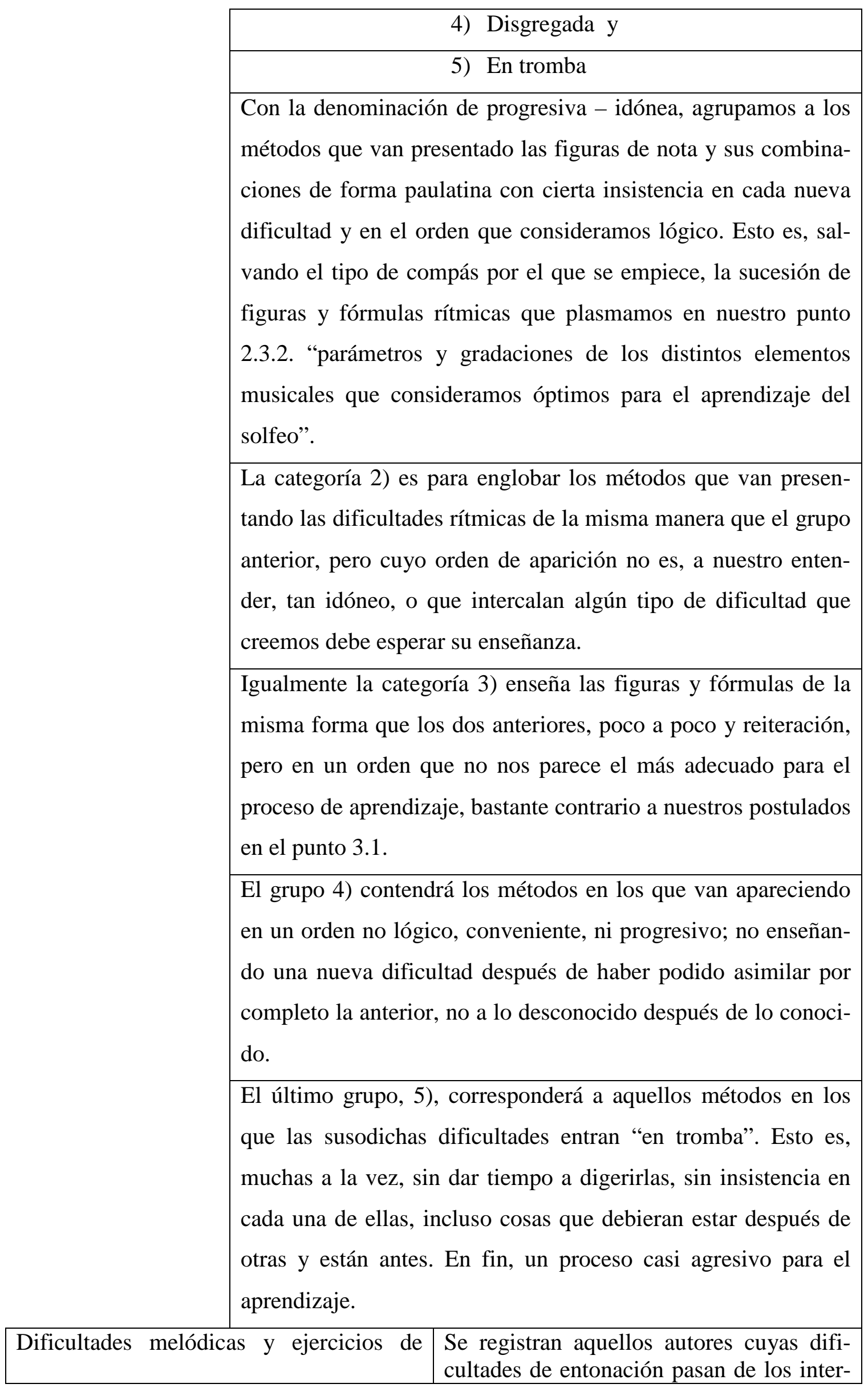




\begin{tabular}{|c|c|c|}
\hline \multicolumn{2}{|l|}{ entonación } & $\begin{array}{l}\text { valos mayores, menores y justos hacia } \\
\text { intervalos aumentados, disminuidos, en- } \\
\text { armonías, cromatismos abundantes e in- } \\
\text { tervalos compuestos. }\end{array}$ \\
\hline & \multicolumn{2}{|c|}{$\begin{array}{l}\text { Después se cuentan los métodos que incluyen ejercicios para la } \\
\text { práctica interválica entonada. } \\
\text { De los que sí incluyen ejercicios para esta práctica, los dividimos } \\
\text { en } 4 \text { grupos: } \\
\text { a) Los que ponen ejercicios de intervalos desde } 2^{\mathrm{a}} \text { a } 8^{\mathrm{a}} \text { y sin prepa- } \\
\text { ración. } \\
\text { b) Los que proceden de la misma manera pero con preparación. } \\
\text { c) Los que personalizan el estudio de cada intervalo, haciéndolo en } \\
\text { un orden más o menos idóneo }{ }^{1} \text {, y preparándolos. } \\
\text { d) Lo mismo pero sin preparación. }\end{array}$} \\
\hline \multicolumn{2}{|c|}{ Tipo de armonía empleada } & $\begin{array}{l}\text { Dividimos en dos grupos los métodos: } \\
\text { - Los que no llevan acompañamiento } \\
\text { - Los que sí lo llevan } \\
\text { Dentro de este segundo grupo, tres sub- } \\
\text { grupos: } \\
\text { - Utilización de armonía clásica } \\
\text { - Utilización de armonía romántica } \\
\text { - Utilización de armonía alterada }\end{array}$ \\
\hline \multicolumn{2}{|c|}{$\begin{array}{l}\text { Formas que adoptan las lecciones en los } \\
\text { diferentes métodos }\end{array}$} & $\begin{array}{l}\text { Dividimos las estructuras formales de las } \\
\text { lecciones en } 6 \text { grupos, } 5 \text { que son las for- } \\
\text { mas que se repiten de mayor a menor asi- } \\
\text { duidad, y } 1 \text { grupo para las formas minori- } \\
\text { tarias: } \\
\text { A-B-A' } \\
\text { A-B } \\
\text { A-B-C } \\
\text { A-A' } \\
\text { A-B-A } \\
\text { Resto, o no tienen forma }\end{array}$ \\
\hline \multicolumn{2}{|c|}{$\begin{array}{l}\text { Lecciones que incluyen introducciones, } \\
\text { codas o intermedios instrumentales }\end{array}$} & $\begin{array}{l}\text { Simplemente un recuento de aquellas que } \\
\text { tienen alguno o algunos de estos fragmen- } \\
\text { tos }\end{array}$ \\
\hline \multicolumn{2}{|c|}{ Métodos que contienen teoría de la música } & Igualmente un recuento de esta inclusión \\
\hline
\end{tabular}

Y además de comentarios sobre aspectos curiosos encontrados en algunos de los métodos, terminamos con 3 patrones de comparación y evaluación:

Consideraciones sobre la utilidad, que a Extraído del punto "valoración de la efecnuestro juicio, pudieron tener los métodos tividad del método y de su aportación a la estudiados enseñanza" que el estudio de cada método

\footnotetext{
${ }^{1}$ Punto 2.4.2. secuencias de contenidos que consideramos idóneas con los procedimientos actuales de enseñanza/aprendizaje del solfeo. El orden puede no ser el considerado óptimo por nosotros, pero desde luego, no es un intervalo tras otro desde $2^{\mathrm{a}}$ a $8^{\mathrm{a}}$, sino buscando, a criterio del autor, un orden más pedagógico.
} 


\begin{tabular}{|c|c|}
\hline & $\begin{array}{l}\text { lleva, discriminamos en dos columnas los } \\
\text { que hemos considerado válidos o no váli- } \\
\text { dos }\end{array}$ \\
\hline $\begin{array}{l}\text { Porcentajes de coincidencia de cada uno } \\
\text { de los métodos con los programas vigen- } \\
\text { tes en el momento }\end{array}$ & $\begin{array}{l}\text { Hay siempre, en este punto y por cada } \\
\text { método, seis elementos de comparación: } \\
\text { Claves, Tesituras, Tonalidades, Compa- } \\
\text { ses, Dificultades rítmicas y Dificultades } \\
\text { melódicas. Valoramos la coincidencia } \\
\text { positiva o negativa, y la convertimos en } \\
\text { un porcentaje: } \\
1 \text { coincidencia = } 17 \% \\
2=33 \% \\
3=50 \% \\
4=67 \% \\
5=83 \% \\
6=100 \% \text {. } \\
\text { Con ello se concluye la cantidad de libros } \\
\text { o partes que coinciden, o en qué porcenta- } \\
\text { je lo hacen. }\end{array}$ \\
\hline $\begin{array}{l}\text { Porcentaje de coincidencia de cada no de } \\
\text { los métodos con los parámetros conside- } \\
\text { ramos, por nosotros, idóneos para los pro- } \\
\text { cesos actuales de enseñanza/aprendizaje }\end{array}$ & $\begin{array}{l}\text { Procedemos exactamente igual que en el } \\
\text { patrón de comparación anterior. }\end{array}$ \\
\hline
\end{tabular}




\subsubsection{MATERIALES A ANALIZAR}

Debido a los años de los programas de solfeo del Real Conservatorio de Música de Madrid, en nuestro poder,, nos parece oportuno dividir el estudio de los métodos en cuatro apartados:

\section{MÉTODOS ANTERIORES A 1831, CREACIÓN DEL RCSMM;}

CARRERA y LANCHARES, Fray Pedro: Rudimentos de música y Solfeo práctico, 1805

LÓPEZ REMACHA, Miguel: Melopea, 1815

GOMIS, José Melchor: Mèthode de Solfège et de Chant, $1^{\mathrm{a}}$ parte, 1826

\section{MÉTODOS POSTERIORES A LA FUNDACIÓN DEL RCSMM Y AN- TERIORES A LA EXISTENCIA DE UN PROGRAMA OFICIAL;}

REGUART MESTRE, Salvador: Elementos musicales, 1839

ESLAVA, Hilarión: Método completo de solfeo, $2^{\text {a }}$ edición, 1845

SOBEJANO AYALA, José: Escuela de solfeo, según el estilo moderno, 1845

ALIAGA LÓPEZ, Matías: Cartilla de música o sea La música en el bolsillo, 1847

PÉREZ GASCÓN, Pascual: Principios de solfeo y canto y Método de solfeo y principios de canto, 1848

PRELLEZO, Mariano de: Método de solfeo sencillo y claro en estilo familiar y en forma de diálogo, 1851

VALERO PERIS, José y ROMERO, Antonio: Nuevo método completo de solfeo, 1856

FUNOLL Y ALPUENTE, Francisco: Método completo de Solfeo sin acompañamiento, 1860 CALVÓ I PUIG, Bernat: Método de solfeo, o sea, elementos generales para aprender a leer la música, 1860

MANENT I PUIG, Nicolás: Método teórico - práctico musical, 1860

\section{POSTERIORES A 1861, CUANDO YA HAY UN PROGRAMA, DENTRO DEL REGLAMENTO, DEL RCSMM;}

LLADÓ BARCELÓ, Joaquín: Método analítico para el estudio del solfeo, 1862

ARRIETA CORERA, Emilio: Solfeos autografiados, primer, segundo y tercer año, 1868, 69 y 70, y Solfeos autografiados, Concursos primer libro, 1871

OBIOLS I TRAMULLAS, Mariano: Método de solfeo, 23ª ed., 1870

MORÉ CUDOLAR, Justo: Método completo de solfeo, 1870 


\section{POSTERIORES A 1875, 1876, 1891 Y 1898 CUANDO YA HAY PRO- GRAMAS OFICIALES DE SOLFEO DE LA ESCUELA NACIONAL DE MÚSICA.}

ABRANTES BELLO, Joaquín: Método de solfeo abreviado $3^{\text {a }}$ edición, 1879

PENELla RAGA, Manuel: Principios de solfeo, $3^{\text {a }}$ edición, 1879

BENITO BARBERO, Cosme José Damián de: Método completo de Solfeo en Compendio, $5^{\text {a }}$ ed., 1880

EGEA, Pedro Ma de: Método de Solfeo o nuevo Arte de la Música, 1881

SABATÉS ESTAPER, Mateo: Solfeo: curso completo, 1881

AGERO AMATEY, Feliciano Primo: Método completo de solfeo: dividido en tres partes, 1882

LLUPART, ALVERNI, Carlos: Escuela de Conjunto. Treinta solfeos a tres voces iguales, 1884

CODINACH, Carmelo: Nociones de solfeo, 1885

ROGER JUNOI, A: Método práctico de lectura musical y de solfeo, (Escuela alemana), 1891

AMORÓS SIRVENT, Amancio: Elementos de solfeo, 1893

VELÁZQUEZ, Juan: Nuevo curso teórico-práctico de solfeo, 1897

BRULL AYERRA, A y otros: Método completo de solfeo, 1898

PARDÁS Y FONT, Primitivo: Método completo de solfeo, 1900

AAVV: Escuela del Solfeo, 1900

VANCELL ROCA, Juan: El Libro de música y canto, 1902

BRULL, Melecio: Lecciones autografiadas, 1910

AMORÓS, Amancio: Lecciones manuscritas graduadas: Segundo y tercer curso, 1910 y 1912

ESPINO, Felipe: Doce estudios melódicos y progresivos de perfeccionamiento de solfeo, 1912 ?

ABREU, Avelino, SERRA, Pedro y ZAMACOIS, Joaquín: Solfeo, segundo curso, $2^{\mathrm{a}}$ edición y quinto curso, 1914

LLORCA, Miguel: Método de solfeo, 1916

BUXÓ, Tomás: Método de solfeo Libro I y $2^{\circ}$ Libro, 1920 
- 3 -

ESTUDIO DE LOS DISTINTOS MÉTODOS DE SOLFEO, ORDENADOS CRONOLÓGICAMENTE 


\section{MÉTODOS ANTERIORES A 1831, AÑO DE CREACIÓN DEL CONSERVATORIO DE MADRID}


Describimos y analizamos, en este primer bloque, tres métodos de otros tantos autores, que son anteriores a cualquier referencia a la existencia de programas evaluativos oficiales de la época.

CARRERA y LANCHARES, Fray Pedro: Rudimentos de música y Solfeo práctico, 1805

LÓPEZ REMACHA, Miguel: MELOPEA, 1815

GOMIS, José Melchor: Mèthode de Solfège et de Chant, $1^{a}$ parte, 1826 


\subsection{RESEÑA BIOGRÁFICA DEL AUTOR}

CARRERA y LANCHARES, Fray Pedro. Vivió entre los siglos XVIII y XIX. Fue organista y compositor, predicador general y primer organista del Real Convento del Carmen Calzado de Madrid. Profesor en el Real Seminario de Nobles de Madrid, que era un centro donde se enseñaba música y danza. (Garbayo, Javier en AAVV 1999, tomo 3, pp. 243 y 44; Saldoni 1868-1881, tomo IV, p. 56 y Preciado 1978, p. 223)

\subsubsection{DESCRIPCIÓN DETALLADA DEL MÉTODO}

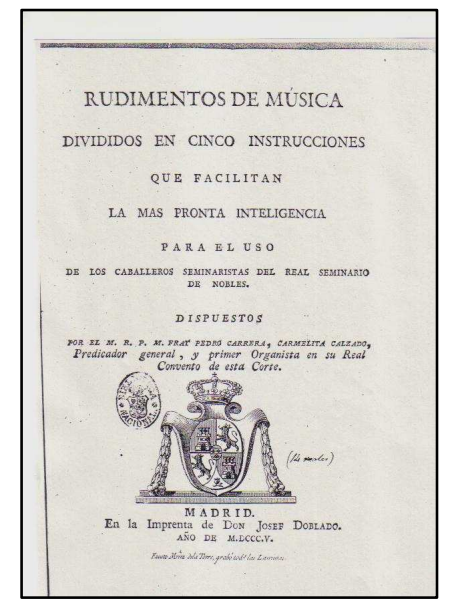

\section{Título del primer libro:}

Rudimentos de música: divididos en cinco instrucciones que facilitan la más pronta inteligencia para el uso de los caballeros seminaristas del real seminario de nobles, Madrid, Imp. de Don Josef [sic] Doblado, 1805. Apéndice, página 195.

Este primer libro, es esencialmente teórico. Lo aborda con el título "Idea general y particular de la música", en el que da diversas definiciones de música: según San Bernardo un arte humano, admirable y meloso, que sonoramente concierta sus variaciones en el cielo y en la tierra. Según San Isidoro una sabiduría de la modulación, que consiste en el Canto, y en el sonido. Según San Agustín ciencia de bien medir, como han dicho algunos, y ciencia de bien modular, como más acertadamente han discurrido otros, fundados en que los latinos no dan al verbo «modulor» otra significación que cantar suavemente, o cierto modo delicado de tocar algún instrumento. Y sigue con disquisiciones laudatorias sobre el arte musical.

Divide el libro, como en su enunciado figura, en «Instrucciones», que vienen a ser como capítulos. En su Primera Instrucción, y en forma de pregunta y respuesta, como todo el resto de la teoría, da su propia definición de música: una reunión de señales o caracteres con diferentes nombre y oficios, que por reglas ciertas e infalibles enseñan a cantar, o dirigen para saber tañer algún instrumento. Esto nos parece más bien una definición, y original, de solfeo. Luego define el concepto de pentagrama, y bajo el 
epígrafe "Este es el teatro de la Música", habla de las notas, líneas adicionales (que dice que pueden ser 4 por arriba y otras tantas por bajo [?]), y de las distancias de tono y semitono. Por cierto que curiosamente el nombre de las notas las representa sin clave, pero en el lugar que tomarían el nombre con la clave de Fa en $3^{a}$ línea.

Segunda Instrucción:

Dice que son 8 las señales esenciales en música: Llaves, Notas, Puntillos, Pausas, Sustenidos, [sic] Bemoles, Bequadros, [sic] y Tiempo o Compás. Explica las Llaves, y las representa con estos extraños dibujos, sobre todo las de Do:

$$
\text { DE LAS LLAVES. }
$$
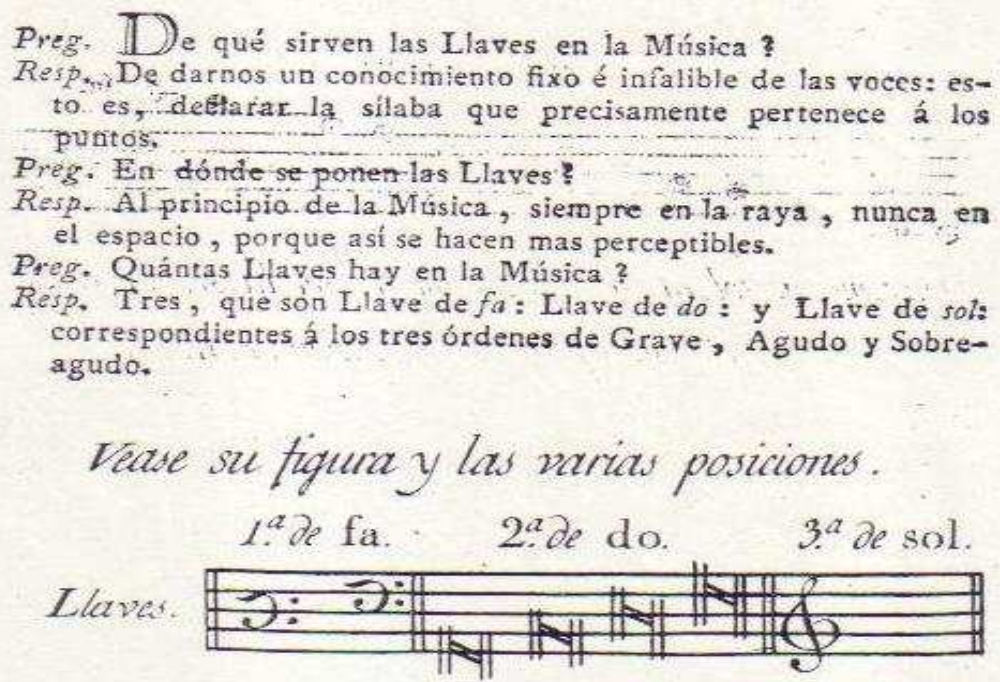

Las figuras de nota, con su denominación antigua: Semibreve, Mínima, Semínima, Corchea, Semicorchea, Fusa y Semifusa, y el valor de ellas, los puntillos de aumentación, las pausas, que también mostramos a continuación por su singularidad,
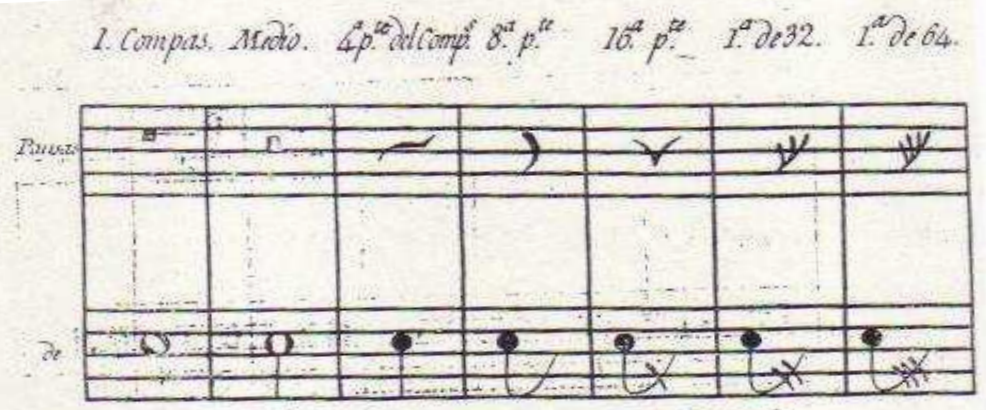

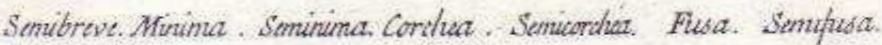

y en ese mismo momento habla de los tresillos, precipitaciones, que como se verá, son frecuentes en los autores de los primeros métodos. Sigue con los sostenidos (sustenidos 
según él), los bemoles y los becuadros. También es singular el signo del sostenido y muy extraño el doble bemol:

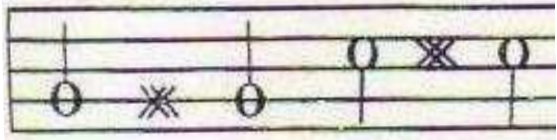

Las divide en "naturales" (así llama a las propias) y accidentales.

\section{Tercera Instrucción:}

La dedica enteramente al compás. Chocantes son las dos definiciones que da: acción de dar y levantar con igualdad la mano, cuya acción es el régimen y gobierno del Canto, y báxo la qual se arreglan y uniforman un sin número de sujetos, como se ve en una Orquesta [sic]. O también la Música que hay entre raya y raya. Dice que se usan 6 compases: compasillo, compás mayor, dos por cuatro, seis por ocho, tres por cuatro y tres por ocho. No sabemos qué ocurre con los otros. Para marcar los compases (él dice "echar el compás") aclara que el de cuatro se hace marcando dos golpes bajo y dos arriba; o uno a cada lado; o uno bajo, otro más alto, otro más subido y otro más alto, exótica esta última manera. Explica el significado de los indicadores del compás, y acaba con los términos de la velocidad uniforme.

Cuarta Instrucción:

Se ocupa de las restantes señales de la música, según reza, e incluye en este capítulo: vírgulas y guiones, apoyaturas, ligados, calderones, trinos, mordentes y repeticiones.

Llama vírgulas a las líneas divisorias, y guiones a las vírgulas. Llama apoyaturas a todas las notas de adorno, dice que "las hay muy largas, de muchas carreras y saltos" y "siendo dilatadas y de muchos compases, regularmente son después de algún calderón, que no van precisadas al compás sino ad libitum, evidentemente se refiere con estas últimas a la fermata. Y añade Ya se ha dicho son gracias, y deben executarse [sic] con limpieza, claridad y distinción.

Sigue con los ligados, e incluye entre éstos a las síncopas [?]. Luego el calderón; el trino, en el que incluye también a la fermata, que dice es un trino más largo sin precisión de tiempo, en el que se detienen haciendo Volatas, Glosas, con otras muchas gracias, y para terminar hacen un descenso y luego el trino de bastante duración, em- 
pezando con lentitud y acelerándole paulatinamente.... Luego vuelve de nuevo a los mordentes y dice que son una señal al modo de una "saetilla", y así llama a los grupetos,

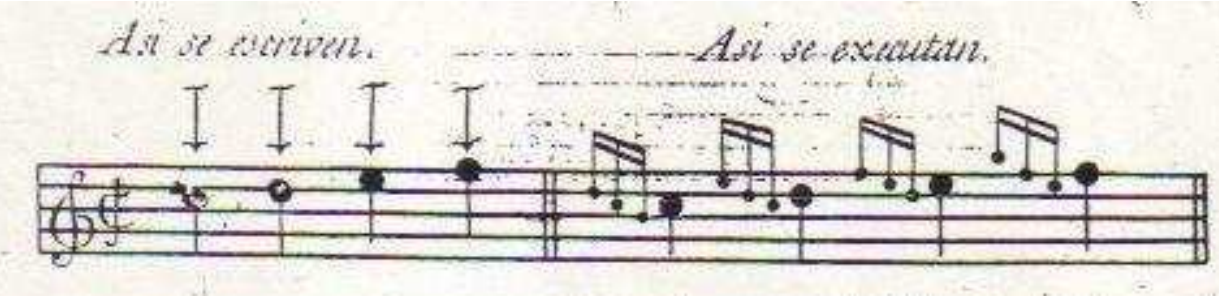

Acaba la instrucción mezclando algún signo de repetición con matices dinámicos. Quinta Instrucción:

Trata de los Movimientos del Canto, de los Tonos o Modos, de la transportación de éstos y del modo de cantarlos, y de la música perteneciente al género cromático.

Los movimientos del canto significan los intervalos. Se limita a clasificarlos como subiendo recto, bajando recto (escalas), subiendo de grado y bajando de grado (segundas), subiendo por saltos conjuntos (se refiere a intervalos desde $3^{\mathrm{a}}$ a $8^{\mathrm{a}}$ en sus extremos, pero preparados por sus sonidos intermedios), bajando por saltos conjuntos (lo mismo pero descendiendo) y subiendo y bajando por saltos disjuntos.

Los tonos son las tonalidades; afirma que se reducen a uno mayor y otro menor, pone el ejemplo de las escalas tipo, y añade, con la menor, que "según la práctica corriente y admitida por los buenos Maestros y sabios Profesores, debe tener y necesita para subir dos sostenidos en el Fa y en el Sol", y pone el ejemplo de la escala melódica. Y a esto se reduce todo, según el autor, sin otra diferencia que el estar más o menos altos los otros tonos, y necesitar el auxilio de sostenidos y bemoles. Y para acabar de embrollar al estudiante añade: teniendo siempre presente que el menor tiene naturalmente la sexta menor correspondiente a su tercera, porque el tener los dos sostenidos para subir, es por gracia del arte y buen cantar: y por esta razón se califica más bien el modo menor baxando la Escala que subiéndola. Luego habla de la distancia de tercera mayor o menor, según los modos, y pone ejemplos. Y de los intervalos perfectos, imperfectos y disonantes, a los que llama géneros o especies; incluye entre los disonantes, a los que llama también falsos, a las cuartas, que dice, no pueden usarse libremente o de golpe, sino por medio de ligadura. También dice que a veces la quinta tiene la cualidad de falsa, y entonces se hace uso de ella en los mismos términos y circunstancias que las especies del género disonante, por medio de ligadura. Acaba esta exposición diciendo que también los autores suelen distinguir las referidas especies, nombrando tónica a la primera, mediante a la tercera, a la quinta dominante, a la sexta acorde de 
la tercera, a la séptima sensible y la octava equisonante. Lo que no vemos claro es como mezcla las "especies", o sea, clasificación de los intervalos armónicos, con el nombre de los grados de la escala. Subrayamos la denominación del VI y VIII.

De la transposición de los tonos habla dos párrafos, pero en síntesis no dice nada, al menos nada comprensible para el neófito; desde luego ninguna instrucción da de cómo transportar.

Le toca el turno a la escala cromática y a la división en semitonos cromáticos y diatónicos, (mayores y menores). Y es ahora cuando da normas, algunas bastante ininteligibles, para el transporte:

Hay dos modos, el uno nombrando las notas como son en sí en el orden del «Diccionario o Silabeo», con el cuidado de formar todos los semitonos procedidos de bemol o sostenido que tenga la obra. El otro es trasportar la música en llave natural. Uno y otro, diré con un famoso escritor, tienen particulares y notables ventajas. Para los instrumentistas es fácil y pronto el método primero; para los que hayan de cantar tengo por más seguro el segundo. Conozco sus dificultades, y por lo mismo no decido ni por uno ni por otro

Y ahora explica la regla para hacer la trasportación [sic] en llave natural:

Cuando la obra música llevase en el principio uno, dos, tres, cuatro, o más sostenidos, se contará en el último la voz o sílaba «si», y subirá mentalmente, o bajará hasta encontrar una llave de las usuales, y situada en raya. Cuando fuesen bemoles, se gobernará por el mismo orden y del mismo modo que en el anterior, diciendo en el último bemol «fa», y descender o subir por grados hasta encontrar una llave de las naturales.

Esto, o similar también lo dicen otros autores de la época. Pero Carrera continúa:

Aunque esto sirve generalmente para el todo o la mayor parte de la obra, no por eso dejará de necesitar de hacer algunos semitonos accidentales, dimanados de sostenido o bemoles, o por el uso del becuadro. Y se advierte que esto de mudar llave en estos casos, es solamente para el acierto y seguridad, en las entonaciones de su progresión, del sugeto [sic] que lo haya de cantar; que para tocarlo en cualquiera instrumento, siempre debe dirigirse por los mismos puntos materiales que está escrita la obra.

Si hay alguien, que no conozca el mecanismo, ser capaz de transportar con estas normas, será un milagro.

Después pone una pequeña melodía en distintas tonalidades como ejemplo.

Acaba con una tabla en la que se representan con notas comprendiendo el arpegio de tónica, todas las tonalidades mayores y menores.

Esto viene a confirmar la fuerza histórica que tenía el sistema relativo de entonación sobre el absoluto, la mutanza, la mano de Guido, etc. Es el solfeo relativo versus el absoluto, que las metodologías del s. XX como Kodaly, y otros, utilizaron profusamente. Presenta dos problemas el uso de este procedimiento, uno es que nada más sirve para melodías sencillas y unitonales; composiciones, por tanto, de no mucho fondo, 
pues es necesario que el intérprete sepa cuando y donde se está modulando, y a qué tonalidad, para hacer las mutaciones pertinentes. El otro problema es que va en detrimento de la formación del oído absoluto.

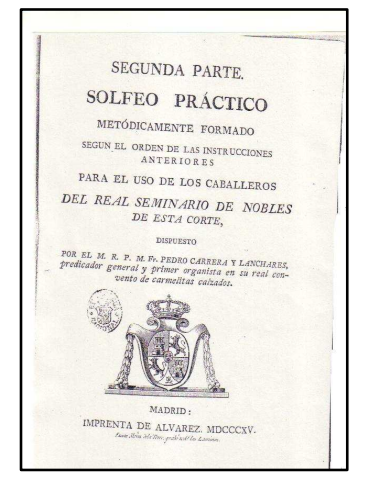

\section{Título del segundo libro:}

Solfeo práctico (segunda parte) metódicamente formado según el orden de las instrucciones anteriores para el uso de los caballeros seminaristas del real seminario de nobles, Madrid, Imp. De Álvarez, 1815.

\section{CUADRO DE INFORMACIÓN GENERAL DEL MÉTODO. ${ }^{1}$}

$N^{0}$ de lecciones 112

Extensión de las lec- Entre 16 y 67 compases ciones

Claves empleadas

Tesituras que abarcan

Tonalidades que trata y estudia

Compases que emplea y estudia

Dificultades métricas que contiene
Do en $1^{\mathrm{a}}$, Fa en $4^{\mathrm{a}}$, Do en $4^{\mathrm{a}}$, Do en $3^{\mathrm{a}}$, Do en $2^{\mathrm{a}}, \mathrm{Fa}$ en $3^{\mathrm{a}} \mathrm{y}$ Sol

$\mathrm{Do}_{3} \mathrm{a} \mathrm{Sol}_{4}$

Do M, La m, Fa M, Re m, Si b M, Sol m, Sol M, Mi m, Mi b M, Do m, Re M, Si m, La M, Fa \# m, Fa m y Mi M

$2 / 2,4 / 4,2 / 4,3 / 4,3 / 8$ y $6 / 8$

Contratiempos, síncopas, apoyaturas, semicorcheas, fórmulas combinadas, contratiempos irregulares, fusas y semifusas, tresillos y sesillos de corcheas y semicorcheas

Ninguna digna de mención, en general discurre por intervalos mayores y menores, sin grandes saltos ni complicaciones.

Todos los intervalos de golpe, primero por grados y luego por salto

Armonía utilizada Totalmente clásica y tonal

\footnotetext{
${ }^{1}$ Siempre, en este cuadro, y en el de todos los métodos, se enumeran los elementos que trata el método y por el orden que lo hace
} 


\section{Formas que tienen A-B; A-B-C \\ las lecciones}

Introducciones, Inter- No tienen

medios o Codas ins-

trumentales

Teoría de la música Carece porque ya la ha expuesto en la anterior parte que incluye

\section{SECUENCIA}

Tal como dice el enunciado es un tratado práctico de las cuestiones teóricas que expone en la primera parte. Así lo dice el autor en el prólogo, son lecciones cortas, con tipografía manuscrita, con acompañamiento de bajo, sin cifrar, para que cada profesor improvise la armonía (según dice el autor)

Lo más peculiar es que ya empieza con la clave de Do en primera línea.

De la lección 1 a la 17, se dedica a presentar, para cantar la escala, los intervalos desde segunda a octava, por grados y por salto, con las figuras de semibreve, y luego ésta y la mínima.

A partir de la 18, ya aparecen las semínimas y son lecciones con mezclas de las 3 figuras y todos los intervalos.

El compás que primero se estudia es $2 / 2$. No parece, en este momento histórico, lo más apropiado pedagógicamente. Sí un binario, pero no el de dos por dos, sino el de dos por cuatro, mas parece que en la época era bastante frecuente comenzar con este compás, y hay muchos otros métodos posteriores a éste que así proceden.

Puntillo sobre la redonda y luego sobre la blanca son los signos que se ven a continuación.

Ya en la lección 27, sostenidos y bemoles. En la 31 pausas y ligados. Es evidente que la precipitación por introducir alteraciones es grande, pero hacerlo antes que las pausas y la ligadura es antilógica.

Luego, las corcheas y el compás de compasillo. Pausas de corchea formando contratiempos.

En la lección 42, ya apoyaturas, y entre la 43 y la 46, semicorcheas, fórmulas combinadas y contratiempos irregulares.

La escala de La menor, solamente aparece en 2 lecciones.

Pasa a las fusas y semifusas, tresillos y seisillos de corcheas y semicorcheas. 
Comienza, después de esto, exposición de diferentes tonalidades y resto de claves, dedicando 3 ó 4 lecciones a cada una de las tonalidades arriba indicadas. Va asimismo cambiando de compases, según también se indican, y de claves, siguiendo el inusitado orden que reseñamos en el esquema.

Pero no acaba ahí lo llamativo, sino que, siguiendo lo que en la época se llamó ficción de claves, con cada una de las que presenta, sigue utilizando la de Do en $1^{\mathrm{a}}$ para su lectura real dentro de la tonalidad en que esté escrita la lección, pero la situación de las notas en la clave que se muestra es siempre, y en cada una de ellas, la de la escala de Do. Por ejemplo, en la lección 58, página 76, ocurre que está en clave de Fa en $4^{\text {a }}$, tonalidad de Fa mayor; antes de empezar la lección figura la clave de Do en $1^{\mathrm{a}}$. Si leemos en esta clave, suena la melodía en Fa mayor, si leemos en la clave de Fa en $4^{\text {a }}$, estamos trasportándola a Do mayor. Pero eso es un grave error, además de mutilar el oído absoluto, no se le ha enseñado al alumno a modificar las alteraciones accidentales, por lo que el transporte pocas veces puede resultar efectivo.

Cuando terminan de aparecer todas las claves, sigue con lecciones a modo de resumen, en las que alguna tonalidad nueva aparece, con los compases que ya se han visto, y con la clave de Do en $1^{\text {a }}$ línea en la mayor parte de ellas. Es en la lección de la tonalidad de Fa menor, cuando habla de las variantes de escala del modo menor, sin darles los nombres de natural, armónica y melódica, ni ningunos otros.

Termina con un epílogo, lección 112, en la que va uniendo distintos periodos para repasar diferentes dificultades: corcheas, semicorcheas, fusas, semifusas, sostenidos, pausas y ligaduras, puntillos, tresillos, seisillos, apoyaturas, tonalidad menor, cambio de tonalidad, relativo de la nueva tonalidad y conclusión.

\subsubsection{VALORACIÓN DE LA EFECTIVIDAD DEL MÉTODO Y DE SU APORTACIÓN A LA ENSEÑANZA.}

El primer libro, como se ha dicho, no es más que un preámbulo teórico de la segunda parte, la clasificación de los signos y elementos musicales es arbitraria y desordenada. Hay definiciones que hoy no se entenderían (no sabemos en su momento). Está escrito en un lenguaje muy vulgar, pero dentro de la dialéctica decimonónica. Prepara al estudiante para afrontar luego la práctica, pero no creemos fuera, ni sea, la forma adecuada, indigestando al educando antes de poner manos a la obra. 
En el segundo, que es el de la práctica, el orden de aparición de las distintas dificultades no es, ni mucho menos, el mejor, pero es que ni siquiera siempre respeta la progresión que hizo en la primera parte. El orden de aprendizaje de las claves es de lo más peculiar, lo mismo que la manera que van apareciendo las distintas tonalidades, 1 bemol, 2 bemoles, 1 sostenidos, 3 bemoles, 2 sostenidos, 3 sostenidos, 4 bemoles (pero sólo el modo menor), 4 sostenidos (sólo el modo mayor), y el resto las ignora por completo.

Con respecto a los compases, no pasa del de 6/8, y dice en la página 105 que estos son los tiempos que en el día regularmente se practican y a los que se han reducido todos los del sistema antiguo. O sea que el 9 y 12 por 8 no se practican. Curiosa es la forma que indica de marcarlos ( $3^{\mathrm{a}}$ instrucción); también curiosa la denominación de los intervalos (movimientos del canto) y su clasificación ( 5 a instrucción)

El sistema de ficción de claves es una práctica nada recomendable. ${ }^{1}$ En general no es un método nada completo, útil, ni acertado.

\footnotetext{
${ }^{1}$ SERRALLACH, Lorenzo. (1947). Nueva Pedagogía Musical. Buenos Aires: Ricordi Americana S. A. E. C., B), Metodología especial, p. 226: Este sistema, tratando de evitar una dificultad, creaba otra mayor, pues era necesario que el sentido tonal interior se transportara, cada vez que se fingía clave, a otro diapasón
} 


\subsection{RESEÑA BIOGRÁFICA DEL AUTOR}

LÓPEZ REMACHA, Miguel. Madrid 6/5/1772 - 14/3/1827. (Afirma Saldoni que en la partida de bautismo que él ha visto, figura por orden del vicario, suprimir el apellido materno de Remacha y sustituirlo por los de Bartolomé Zahonero que eran también de la madre, el caso es que según dice él nunca se firmó el músico este de esa manera. Fue sacerdote y tenor de la Real Capilla, profesor de canto (según figura en su método), hijo del compositor y organista Félix Máximo López, pintado por Goya, compuso algo de música religiosa, alguna ópera.

\subsubsection{DESCRIPCIÓN DETALLADA DEL MÉTODO.}

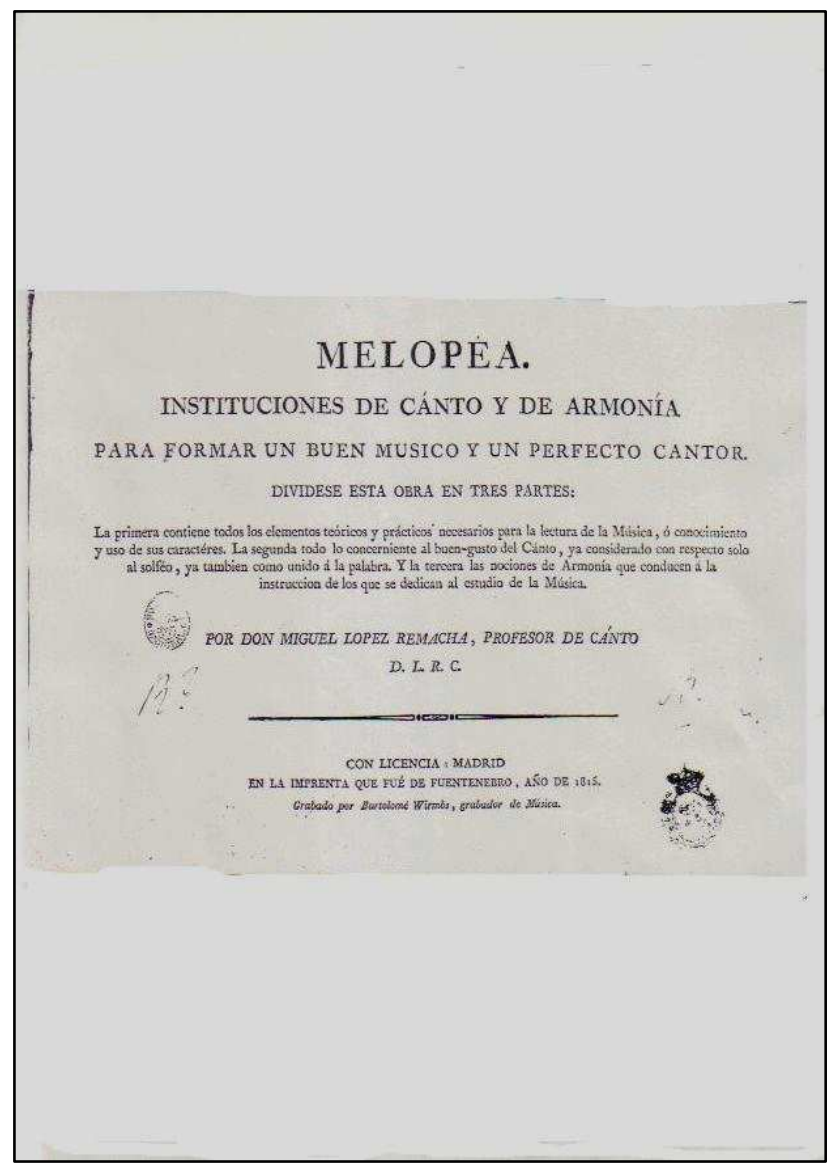

\section{Título del Método:}

MELOPEA ${ }^{1}$ Instituciones de canto y de armonía para formar un buen músico y un perfecto cantor, Madrid, Impr. Que fue de Fuentenebro, 1815. Apéndice página 196.

Su obra Melopea, se divide en tres partes: la primera contiene los principios teóricos y prácticos del solfeo, la segunda la teoría del buen gusto del canto, y la tercera las nociones de armonía que bastan a ilustrar a cualquier profesor o aficionado ${ }^{1}$.

Está dedicado a la

Excelentísima Señora Doña Manuela Isidra Tellez Girón Alfonso y Pimentel, Duquesa

\footnotetext{
${ }^{1}$ Del francés mélopée, canto monótono, canturia. Femenino y plural Melopeya, del latín melopoeia, y éste del griego melopoiía, de melopoiós, de melos, canto y poieîn, hacer. Arte de reproducir melodías. COUTURE - DIABET. (1987). Salvat Universal diccionario enciclopédico. Barcelona: Salvat Editores S. A., p. 145, tomo 14. Y según ROUGNON, Paul. (1945). La música y su historia, resumen histórico. Buenos Aires: Caymi, p. 15, melopea eran el conjunto de reglas que tenían los griegos para la composición del canto aplicado a la poesía.
} 
de Abrantes y Linares, Condesa de Aguilar y de Coquinas, Marquesa de Valdefuentes, entre otros muchos títulos, y Grande de España de primera clase. Según dice el autor, por su afición a la música y por haberla cultivado con aprovechamiento.

Seguidamente, hace un resumen de lo que contienen las tres partes en que divide el método, la segunda es puramente teórica, sin que haya ningún ejemplo, y la tercera casi, aunque sí que le siguen a la teoría pequeños y poco esclarecedores ejemplos.

\section{PRIMERA PARTE}

Como ya se indica al pie del título, comienza el método por los principios teóricos. Definiciones de Música, Sonido, Tiempo, Caracteres, Armonía y Melodía. De la melodía dice que es una sucesión de sonidos progresivos agradable al oído. Y llama caracteres a las señales visibles que representan el sonido, sus diferencias, el tiempo y sus divisiones.

Respecto a los caracteres, presenta la pauta, las claves y los nombres de las notas (que al Do aun le llama Ut).

En el Tiempo y sus particiones, habla de los compases, sus divisiones y subdivisiones. Los divide en Binarios o Perfectos, Ternarios o Imperfectos y Mixtos o compuestos; seguramente se refiere a los compases de denominador 2, pues luego habla del Tiempo Binario primitivo, del que dice que tiene varios derivados, y ese Binario primitivo es el compasillo; por lo que establece la siguiente clasificación y denominaciones: 4/4, tiempo binario primitivo, compasillo o cuaternario; $2 / 2$, el mismo partido, breve o de capilla; $2 / 4$, derivado diminuto; $3 / 4$, ternario derivado; $3 / 8$, otro diminuto y $6 / 8$ o Sexquialtera, mixto o derivado de ambos. Luego una tabla de las notas o figuras para cantar y para callar (o sea los silencios) desde la longa (de la que dice que tiene poco uso) pasando por la breve, semibreve o redonda, mínima o blanca, semínima o negra, corcheas, semicorcheas o dobles corcheas, fusas o triples corcheas y semifusas o cuádruples corcheas. El silencio de negra tiene forma antigua, esto es, como el de corchea al revés, con la curva de izquierda a derecha. También indica las términos del movimiento y revela que hay otras palabras que le dan un poco más de lentitud o rapidez, pero que no escribe porque su comprensión es sencilla. Completa esta explicación con la cantidad de figuras que entran en cada uno de los compases referidos, y con la disqui-

\footnotetext{
${ }^{1}$ SALDONI, Baltasar. (1868-1881). Diccionario biográfico-bibliográfico de Efemérides de músicos españoles. Madrid: Imprenta a cargo de D. Antonio Pérez Dubrull, tomo II pp. 273, 74 y 376 . Y PRECIADO, Dionisio: op. citada, p. 234
} 
sición del significado de numerador y denominador. Todavía hace una nota al pie, diciendo que había unos "tiempos" usados por los antiguos y con muy poco uso en, que son la sexquialtera 9 de la familia de las ternarias (esto es 9/8) y la sexquialtera 12 de partición binaria (12/8).

Le toca ahora el turno a los accidentes musicales o signos de alteración. Le da al sostenido el nombre de "Diesis", los explica brevemente, así como las dobles alteraciones, y dice que tanto el bemol como el diesis se reproducen en un orden establecido (confundiendo así al principiante, pues no dice que esa es la formación en armadura de las alteraciones propias y no de las accidentales).

Con el epígrafe de "otros caracteres", da a conocer de manera muy sucinta, el puntillo, el ligado simple (ligadura), el ligado sincopado (la síncopa larga), el ligado expresivo, acentos (los signos de articulación), párrafos, (la ※ y la doble barra), división

(la línea divisoria), calderones, apoyaturas (éstas y mordentes de 1 nota), mordentes (grupetos de 3 notas sólo anteriores), trino, trémolo y regulador. Le sigue un resumen de todos los elementos vistos hasta este momento.

La escala en general es el tema que aparece a continuación, así la define: es un procedimiento uniforme y sistemático del sonido, que manifiesta recta y progresivamente todos los puntos de gravedad y elevación, de que él es susceptible. La recta serie de sonidos graves y agudos que arroja esta dilatada progresión, se divide en pequeñas y geométricas escalas.... La escala - diapasón la divide en 3 géneros: diatónica, cromática y enarmónica, la primera que consta de 5 tonos y dos semitonos mayores (así llama a los diatónicos; la segunda a la que llama también accidental, que consta de 12 semitonos mayores y menores (estos últimos los cromáticos) y la tercera o alterada, que es un conjunto de intervalos de tercer orden pero tan diminutos que apenas se hacen sensibles a un oído fino (es la cromática, pero enarmonizando cada nota alterada). Divide la escala diatónica en mayor o generadora y menor o relativa, explicándolas mediante la distancia interválica de la tónica a la mediante.

Para referirse a las tonalidades, las epigrafía con el nombre de transportes de la escala, comparando, evidentemente, todas las escalas con la generadora, y auxiliándose de sostenidos o bemoles, explica que se llega a las que tienen bemoles a través de quintas "perfectas" descendentes a partir del sonido Fa para las mayores y Re para las menores, y esas mismas quintas, pero ascendentes, en el caso de sostenidos, empezando por 
Sol para las mayores y Mi para las menores. Luego advierte de la posibilidad o permisión que hay de alterar el $6^{\circ}$ y $7^{\circ}$ grado al subir en las escalas menores, y aprovechando ello, informa que los intervalos pueden ser, además de mayores y menores, "superfluos y diminutos" (aumentados y disminuidos).

Concluye la parte teórica con referencia al transporte o "fingimiento de claves", con una explicación tan corta y extraña que lo hace totalmente ininteligible e imposible de llevar a cabo. Quizás por eso, en nota al pie, advierte que en su solfeo práctico no se contempla ningún ejercicio destinado a tal fin.

\section{SEGUNDA PARTE}

La segunda parte, también de texto, es la dedicada a "Instituciones generales sobre el buen gusto del canto", la divide en 6 apartados:

1.- De la pronunciación o uso de las vocales, en el que dice que una vez el alumno esté seguro en la entonación y la medida de los sonidos, cambie las sílabas de las notas por vocales, y completa este punto con consejos de cómo emitir cada una de las vocales.

2.- Del uso o portamento de la voz, consejos de emisión.

3.- Del gorjeo, aludiendo al canto melismático, esto es, una melodía bajo una sola vocal.

4.- Del Adorno, refiriéndose sobre todo a las fermatas.

5 y 6.- El buen gusto en el canto y la expresión.

Se extiende, aunque no mucho, en cada uno de estos puntos, y sobre todo en los dos últimos, pero no es materia que incumba a nuestro tema, por eso nos limitamos a referenciar la existencia de estas cuestiones en este libro. Además, el autor, remite a los muchos ejemplos que hay en la literatura del canto para la práctica de todos estos consejos.

\section{TERCERA PARTE}

La tercera parte, casi teórica, es la que él llama "tratado de armonía", un tratado que tiene 4 hojas y media, de las dimensiones de este libro. Habla sobre todo de los intervalos y de las disonancias y consonancias; un poco después, de los enlaces de acordes, de los movimientos prohibidos, y algunos consejos que son de difícil comprensión para el neófito. Le siguen a estas notas, 15 ejemplos o prácticas, que nadie, que no sea un consumado armonista, entenderá. Tampoco es este nuestro tema, y por tanto no en- 
tramos más en él, sólo comentar algunas denominaciones curiosas: consonancias o con-

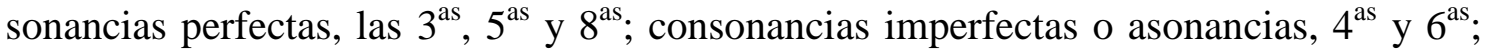
disonancias $2^{\text {as }}$ y $7^{\text {as }}$. Ya hemos dicho que llama superfluo al intervalo aumentado, también máximo. Después va calificando cada uno de ellos y cuando llega a la cuarta, la califica de Mayor o de Tritono (Do a Fa sostenido) y Menor (de Do sostenido a Fa) [de modo que no sabemos como será la cuarta justa, o es que para el autor no existe]; y la quinta en Mayor (de Do a Sol sostenido) y Menor, Falsa o Diminuta (de Do sostenido a Sol) [tampoco parece que existe la justa].

\section{PARTE PRÁCTICA}

Y ya por fin pasa a la parte práctica, o sea a las lecciones de solfeo, no sin antes definir éste y el concepto de canto, además de hacer unas instrucciones preliminares para su estudio, aconseja dividir éste en tres partes: aprender el nombre de las notas, su medida y su entonación (proceso que creemos muy acertado). Lo más llamativo es que para la segunda fase, dice que se marcará el compás con la mano o de otro modo "sensible" [?], que si es de cuatro, se marcarán dos abajo y dos arriba, si es de dos, uno bajo y otro arriba, y si fuera de tres, uno abajo y dos arriba.

Comienza esta práctica por la escala, y los intervalos, preparados mediante puntos intermedios y un resumen de todos los intervalos, ya con acompañamiento, en forma de bajo cifrado, desde el primer ejercicio.

\section{Variaciones Primeras:}

Así comienzan las lecciones, con un tema de 16 compases, simétrico con cuatro subperiodos, con blancas y negras y compás de 4/4 y siete variaciones o "glosas", en las que se van introduciendo: corcheas, tresillos, semicorcheas, aspiraciones (silencios), puntillos, síncopas y apoyaturas (que como ya se ha dicho, también son mordentes), en orden respectivo y una de ellas en cada glosa (naturalmente los silencios, al haber también de corchea, producen contratiempos).

Variaciones Segundas.

Exactamente lo mismo, pero con un nuevo tema y la misma cantidad de variaciones con la misma progresión de dificultades. Únicamente el D. C. es la novedad.

Introducción al sistema cromático y enarmónico: 
Un ejercicio con la escala cromática.

Conocimiento de los compases o cifras del tiempo:

Dos lecciones en cada uno de estos compases: 2/2, 2/4, 3/4, 3/8 y 6/8, aunque todas ellas no están en Do mayor, sin previo aviso, y sin armadura, las de 2/2 están en La menor, las de 2/4 en Re menor y Fa mayor, las otras vuelven a Do mayor, menos las de 6/8 que están en La menor. Aparecen las notas partidas, el mordente (en la lección 1 de 2/4 así le llama, mientras que anteriormente no había mencionado esta palabra, y representaba el mordente dentro de la denominación de apoyatura), el trino, y mezcla todas las dificultades vistas hasta el momento.

Uso frecuente de tresillos y seisillos de semicorcheas:

Cuatro lecciones utilizando abundantemente estos valores.

Uso frecuente de los semitonos para facilitar su entonación:

Dos lecciones con abundancia de cromatismos.

A partir de aquí se empiezan a utilizar todas las claves según el orden que señalaremos.

Clave de $\mathrm{Fa}$ en $4^{\mathrm{a}}$.- Cuatro lecciones, en las que no se restringe las dificultades lectoras y rítmicas, con una particularidad notable: la voz está en la tonalidad de Do mayor para las dos primeras, y La menor para las otras dos, pero el acompañamiento está en Fa mayor y Re menor respectivamente, y en una nota anterior al comienzo de las lecciones, advierte al acompañante que debe figurarse los sonidos de la parte cantante como expresados en Clave de Ut en $1^{a}$ línea, solamente hay armadura en el pentagrama del acompañamiento de la primera lección, en las otras tres, hay un bemol en el primer espacio adicional superior.

Incomprensible, ¿por qué no pone en la misma tonalidad melodía y acompañamiento?, y o bien tiene que transportar el pianista, o el solfista.

Clave de Do en $1^{\mathrm{a}}$.- También cuatro. La segunda lección es una fuga vocal, con valores largos, y la cuarta lleva un acompañamiento brillante que el autor denomina "estilo sinfónico", por lo demás las tres primeras están en La menor y la última en Do mayor, pero tanto melodía como acompañamiento. 
Clave de Do en $2^{\text {a }}$.- Igualmente cuatro lecciones. Las melodías en La menor tres lecciones y Do mayor la cuarta, el acompañamiento Do menor y Mi bemol mayor respectivamente. Hay una nota después de la primera que propone realizar también esta lección, escrita en compás de 3/8, en los de 6 y 12/8. Otra cosa a la que no vemos utilidad.

Clave de Do en $3^{\mathrm{a}}$.- En este grupo sólo hay 3 lecciones, la primera lleva el compás de 12/8. Las melodías están en Do mayor, dos de ellas, y La menor la tercera, y el acompañamiento en Sol mayor y Mi menor.

Clave de Do en $4^{\mathrm{a}}$.- Cuatro también. Tres melodías en La menor y el acompañamiento en Sol menor, y una de ellas, la tercera, ambas cosas en Do mayor. Después de la primera, que está en el compás de 4/2, aunque lleva la indicación $\notin$, hay de nuevo la nota de repetirla escrita en otras cifras binarias.

Clave de Fa en $3^{\mathrm{a}}$.- Tres lecciones, las más largas, cargadas de adornos y signos de articulación. Las melodías en Do mayor y La menor la última, los acompañamientos en Re Mayor y Si menor.

Termina con una fe de erratas en la que rectifica muchas de las faltas de ortografía que aparecen a lo largo del método. De todas formas, aun quedan algunas que no rectifica.

\section{CUADRO DE INFORMACIÓN GENERAL DEL MÉTODO}

$\mathbf{N}^{\circ}$ de lecciones

Extensión de las lecciones Claves empleadas

Tesituras que abarcan

Tonalidades que trata y estudia

Compases que emplea y es-
55

Entre 16 y 148 compases

Sol, Fa en $4^{\mathrm{a}}$, Do en $1^{\mathrm{a}}$, Do en $2^{\mathrm{a}}$, Do en $3^{\mathrm{a}}$, Do en $4^{\mathrm{a}} \mathrm{y}$ Fa en $3^{\mathrm{a}}$

$\mathrm{Do}_{3} \mathrm{a} \mathrm{La}_{4}$

Do M, La m, Re m, Fa M (aunque sin armadura) 4/4, 2/2 al que llama mayor, 2/4, 3/4, 3/8, 6/8 y 12/8 
tudia

Dificultades métricas que contiene

Dificultades de en-

\begin{tabular}{|c|c|c|c|c|c|c|c|c|}
\hline o & $d$ & d & . & $\sqrt{\sigma}$ & $\stackrel{3}{.0}$ & ब. & 9 & $d$. \\
\hline d. $d$ & $\sqrt{.}$ & $d \perp$ & 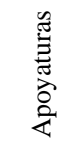 & $\stackrel{00}{\frac{00}{3}}$ & еререр & ep & $\begin{array}{l}Y \text { toda } \\
\text { de com } \\
\text { nacion }\end{array}$ & $\begin{array}{l}\text { clase } \\
\text { bi- } \\
\text { ss }\end{array}$ \\
\hline
\end{tabular}
tonación que se enMuy pocas, siempre intervalos dentro de la escala propia de la tonalidad o vecinas.

cuentran

y orden en que se

Primero la escala y seguidamente todos los intervalos en orden de menor a mayor.

enseñan los interva-

los

Armonía utilizada

Sencilla, clásica con modulaciones a los tonos más vecinos.

Formas que tienen las lecciones

Introducciones, Intermedios o Codas instrumentales

A-B-coda; A-B-C- coda; A-B-A'; A-A'-A',

En general no hay, excepcionalmente algún compás de tránsito que hace el piano.

Teoría de la música que incluye

Toda la primera, segunda y tercera parte, excepto la dedicada a la práctica del solfeo.

\subsubsection{VALORACIÓN DE LA EFECTIVIDAD DEL MÉTODO Y DE SU APORTACIÓN A LA ENSEÑANZA.}

Es un método muy antiguo y por tanto difícil de juzgar con la perspectiva de hoy, aparte de su retórica decimonónica, naturalmente, son de difícil comprensión las exposiciones teóricas. Curiosa la manera de aconsejar que se marquen los compases.

En cuanto a la práctica, no podemos juzgar si fue útil en aquel tiempo, pero la tesitura de sus lecciones es excesiva. Es plausible presentar las primeras lecciones como tema y variaciones, pero en 7 lecciones, y cortas, llegamos ya a las notas de adorno, habiendo pasado por contratiempos y síncopas, lo cual es exagerado y nada pedagógico, no queda en la mente del alumno la experiencia, ni puede, en tan corto espacio, asumir plenamente las dificultades. Otra cuestión que llama la atención es la poca extensión de las lecciones en la clave de Sol, y sin embargo, a medida que se adentra en las otras claves, aumenta la duración y la dificultad rítmica, hasta llegar a la de Fa en $3^{\text {a }}$ línea, que son las más largas y difíciles. 
López Remacha 


\subsection{RESEÑA BIOGRÁFICA DEL AUTOR}

GOMIS, José Melchor. Onteniente 6/1/1791 - París 27/7/1836. Operista exiliado en Francia por la represión antiliberal junto a Goya, Espronceda y Fernando Sor. En 1826 publicó en París un "Método de solfeo y de canto" (Gisbert, Rafael en AAVV, 1999, tomo 5, pp.729 a 733). Según Saldoni (1868-1881, tomo I, pp. 110 a 113), estudió música en Valencia con el maestro de capilla de la Catedral D. José Pons. Fue director de la música del regimiento de artillería en Barcelona. En 1820 director de la música de la Guardia de S. M. en Madrid. 1823 marchó a París, en 1826 a Londres. En el método de solfeo y canto publicado en París, hay dos cartas de Rossini y Bö̈eldieu, y en él dice que es profesor de canto. Tiene un método Gran método de solfeo o Nueva Escuela de Música, en colaboración con François-Joseph Fetis y Alexis de Garande, publicado en Madrid, editor Carrafa, ca. 1839.

\subsubsection{DESCRIPCIÓN DETALLADA DEL MÉTODO.}

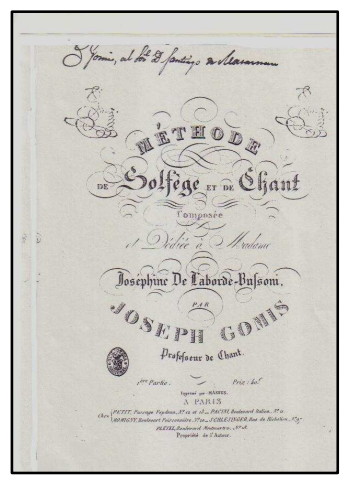

\section{Título del Método:}

Mèthode de Solfège et de Chant, $1^{\mathrm{a}}$ parte, París, Masus, s. f. ${ }^{1}$

Apéndice, página 197.

\section{CUADRO DE INFORMACIÓN GENERAL DEL MÉTODO.}

$\mathbf{N}^{0}$ de lecciones 163

Extensión de las lec- Entre 3 compases y 137 ciones

Claves empleadas Sol, Do en $1^{\mathrm{a}}$, Do en $2^{\mathrm{a}}$, Do en $3^{\mathrm{a}}$, Do en $4^{\mathrm{a}}$, Fa en $3^{\mathrm{a}}$ y Fa en $4^{\mathrm{a}}$

Tesituras que abarcan $\quad \mathrm{Do}_{3} \mathrm{a} \mathrm{Sol}_{4}$

Tonalidades que trata Do M y La m exclusivamente y estudia

\footnotetext{
${ }^{1}$ Aunque en la contestación y comentario de Rossini a Gomis que está al principio del libro, figura la fecha de 24 de enero de 1826, y PRECIADO, Dionisio: op. citada, p. 235 así lo indica.
} 
Compases que emplea y estudia

Dificultades métricas que contiene

Dificultades de entonación que se encuentran $y$ orden en que se enseñan los intervalos

\section{Armonía utilizada}

Formas que tienen las lecciones

Introducciones, Intermedios o Codas instrumentales

Teoría de la música que incluye
$4 / 4,2 / 4,3 / 4,3 / 8,6 / 8,9 / 8,12 / 8,12 / 16,2 / 2$

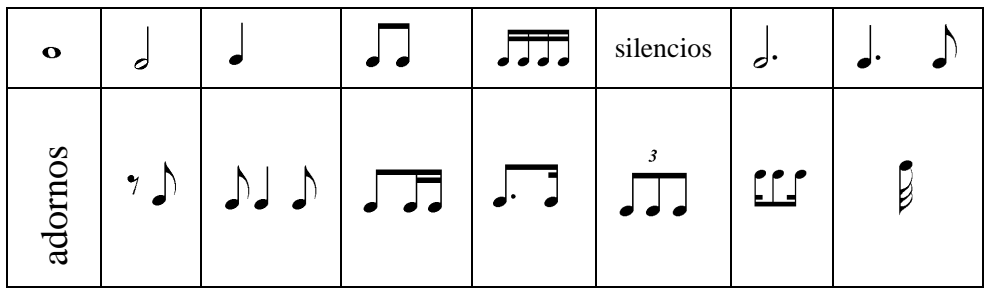

Muy pocas. Todo se desenvuelve entre los intervalos naturales de la tonalidad y alguna alteración propia de las modulaciones pasajeras.

La escala. Luego DO RE, DO MI, DO FA, hasta Do Re'.

$3^{\text {as }}$ abundantemente, $4^{\text {as }}$, Arpegios sobre grados tonales de Do Mayor, $8^{\text {as }}, 6^{\text {as }}$ y $7^{\text {as }}$, todas sin preparar

Clásica, como corresponde al momento, pero hay mucha modulación desde los primeros ejercicios

Algunas no tienen forma, son escalas ritmadas. Otras tienen forma primaria; y algunas A-A';A-B-C; A-B-A'

No tienen

Solamente al principio y para las cuestiones muy básicas, y está escrita en español, francés e italiano

\section{SECUENCIA}

Comienza con dos cartas, una del autor dirigida a Joaquín Rossini, encomendándole lea el libro y le de su opinión, y la otra de Rossini contestándole a Gomis y dándole sus felicitaciones y parabienes por la calidad del libro.

Le sigue un prólogo explicativo de sus intenciones y objetivos al escribir este método. Manifiesta que lleva más de 20 años en la enseñanza de esta materia, y que al principio había sido dirigida a enseñar lecciones de solfeo y no de canto, tal como eran hasta entonces todos lo métodos, pero que observaba que hasta los mejores alumnos tenían que superar después un cúmulo de estudios para llegar al canto y dulcificar el oído. Se dio cuenta de que el estudio del canto no sirve para los que estudian esta especialidad, sino también para los instrumentistas que quieran llegar a tocar con buen gusto.

Detalla las particularidades: explicaciones escuetas y en el momento oportuno, lecciones que contienen un canto agradable y susceptible de expresión para imbuir en el discípulo el hábito del buen gusto, ejercicios para la voz a utilizar solamente quienes se 
dediquen al canto, tratamiento de todas las claves y acompañamientos completos y dobles (o sea transportados), con el fin de que pueda cantar las lecciones cualquier tipo de voz.

Después de todo esto, la parte teórica elemental previa al comienzo: las figuras de nota, (con nombre antiguo, pero a la negra no le llama semínima, sino "semina"), la pauta, escala diatónica, llaves, compases, pero todo ello en lo que afecta solamente a los elementos con los que se va a comenzar a estudiar. Nombres de las notas en 3 octavas (la 3,4 y 5) y ya las lecciones.

Lecciones con la escala:

Con la advertencia previa de que todas las lecciones de este método deberán ser primero solfeadas y enseguida vocalizadas, se encuentran 5 lecciones con la escala natural y distintas figuras de nota, todas con acompañamiento completo de piano. La primera, dedicada a la redonda, lleva en cada una de ellas un "filado" (ambos reguladores), las siguientes para las blancas, negras, corcheas y semicorcheas; en ninguna aparecen aun los silencios, y demasiado pronto las semicorcheas.

Ejercicios para la vocalización:

Ocho ejercicios con la advertencia previa de que sirven para unir la voz de pecho con el Médium o voz mixta y la de cabeza, y que el maestro debe comenzar por el tono más grave e ir subiendo por semitonos hasta llegar al más agudo posible. El primero sólo con dos notas, Do, Re; y cada uno va aumentando una más hasta llegar en el último desde Do a Re agudo. Pero los ritmos son un desatino en momento tan precoz, fíjese que en la página 11 nos encontramos: $1^{\text {a }}$ ejercicio, un compás de blancas, otro de negras, otro de corcheas, otro de semicorcheas, el siguiente y último de fusas. $2^{\circ}$ ejercicio lo mismo. $3^{\circ}$, primer compás con dos tresillos de negra, segundo con tresillos de corcheas, tercero con seisillos de semicorcheas. Y así los siguientes, incluso con fórmulas de seisillos irregulares.

Lecciones para la práctica de intervalos:

Terceras directas.- con redondas, blancas, negras, corcheas y semicorcheas, y las mismas después, pero añadiendo apoyaturas (las notas reales van por grados conjuntos, y son las apoyaturas las que forman el intervalo de $3^{\mathrm{a}}$ ), y también la ligadura de expre- 
Gomis

sión entre dos notas. Otra medida prematura la de presentar tan pronto esta nota de adorno.

Lo mismo sucede a continuación con los intervalos de $4^{\mathrm{a}}$.

Lecciones para el conocimientos de los silencios (llamados por el autor "pausas o aspiraciones":

Siguiendo con los intervalos de tercera, y en la misma progresión de figuras que hasta ahora, incluyendo las apoyaturas, va presentando los silencios.

El puntillo:

Sigue con las terceras como intervalo, incorporando el puntillo, pero sólo se practica, por ahora, con la blanca y la negra.

Hay en este momento un ejercicio de entonación en el que, partiendo siempre de la nota Do, arpegia los acordes de Do mayor, Fa mayor ( $2^{\mathrm{a}}$ inversión) y Do $7^{\mathrm{a}}$, formando terceras, quintas y sextas, y ligando sus notas dos a dos; su objeto el autor lo explica así:

...conducir bien la voz de un sonido a otro que es lo que los italianos llaman portamento di voce. Para conseguirlo se debe pasar mui [sic] poco a poco de un sonido a otro ligado de modo que se hagan sensibles las notas que haya entre las dos que abraza la ligadura.

Cuando todo parecía que iba en forma progresiva, de repente aparecen 3 lecciones, una para el salto de octava, otra para el de sexta y séptima juntas, y la tercera para mezcla de intervalos. Y nos preguntamos ¿cuándo se ha practicado el intervalo de $5^{\mathrm{a}}, \mathrm{y}$ porqué solamente se practican de salto y nunca preparados? Nos parece perfecto haber trabajado las terceras, no tanto sin embargo las cuartas, pero luego debía haber habido, al menos, tantas lecciones o ejercicios con el intervalo de octava, después el de quinta, luego sexta, por último séptima y al final mezclados.

Dos lecciones ahora para el contratiempo corto, la primera es de doble melodía, por lo que es como si fueran 3 lecciones. Con la misma célula melódica (3 notas formando intervalo de tercera en progresión melódica ascendente y luego descendente) produce el contratiempo cada vez en un tiempo distinto. La idea es buena, pero hubiera habido que explicar un poco el concepto, e incluso anteriormente practicar los contratiempos largos. 
Alteraciones:

Explica éstas y pone una lección con el Fa, Do y Sol sostenidos, de forma cromática; otra con el Si, Mi y La bemoles, en igual forma, y otra mezclando y aumentando alteraciones, siempre en forma cromática.

Síncopas:

Primeramente pone 4 ejemplos cortitos de síncopas, a las que les llama: regulares de una sola nota, y ahí incluye la larga (negra - blanca - negra), breve (corchea negra - corchea) y muy breve (semicorchea - corchea - semicorchea); de dos notas iguales, dos blancas ligadas, o sea notas partidas; de dos notas desiguales, blanca ligada a negra o a corchea y negra ligada a corchea; regulares de varias notas, síncopas breves enlazadas. Y a cada una de estas especies dedica una lección, lecciones en las que también entran ya las alteraciones y en las que, como en las anteriores, no deja de utilizar las apoyaturas.

Ahora es cuando realmente empiezan las lecciones. Hasta este momento han sido más bien ejercicios de aplicación de novedades, aunque el autor llama lecciones. Y como un retroceso, hay 4 lecciones, ya con todos los intervalos, pero con blancas y negras, además de las nunca abandonadas apoyaturas.

Lecciones con doble acompañamiento:

A partir de aquí, en cada lección que sobrepasa el Fa agudo, lleva un doble acompañamiento, uno en Do mayor, y otro en Sol mayor, el primero para acompañar a Tiples y Tenores, el segundo para Contraltos y Bajos. Son 9 lecciones, ya también con corcheas, y los elementos anteriores.

Escala en La menor de las modernas:

Así llama a la escala melódica y dedica 5 lecciones a esta tonalidad, pero con blancas, negras y corcheas.

Sigue a esto, de nuevo en Do mayor, ejercicios y lecciones para la práctica de las semicorcheas y sus fórmulas combinadas. Primero un ejercicio con las escalas naturales de Do, Re, Mi, Fa y Sol ascendiendo y luego descendiendo, comenzado con corchea dos semicorcheas en el primer tiempo, y grupos de semicorcheas en los otros tres. Des- 
pués cuatro lecciones, unificadas en un acompañamiento común, porque en realidad es la misma que varía rítmicamente: la primera son semicorcheas, negra y su silencio, la segunda fórmula corchea - dos semicorcheas negra y su silencio, la tercera corchea con puntillo - semicorchea negra y silencio y la cuarta igual que la anterior sustituyendo el puntillo por silencio de semicorchea. Mantienen estos ritmos dos lecciones más, combinando con síncopas breves de corchea - negra - dos semicorcheas.

Otra lección cuádruple con acompañamiento común. Le antecede un ejercicio con tresillos de corchea, y las lecciones son variaciones rítmicas sobre la escala ascendente y descendente dentro del ritmo de tresillos, semicorcheas y las fórmulas que habíamos visto en el grupo anterior.

Compás de 2/4:

Dos lecciones sencillas y otra triple con acompañamiento común en la que ya aparece el puntillo en la semicorchea y la fusa.

Apoyaturas dobles:

Así llama, como otros autores, a los mordentes de dos notas, con las que vuelve al compás de compasillo con cuatro lecciones.

Compás de 3/4:

Dedica catorce lecciones a este compás, comienza con ritmos fáciles y poco a poco va aumentando la dificultad, introduciendo todo lo aprendido hasta el momento, hasta llegar a la fusa.

Llave de Do en $l^{\mathrm{a}}$ raya:

Entabla ahora la enseñanza de cada una de las claves restantes, iniciando con ésta. Catorce lecciones, comenzando por ritmos sencillos y complicándolos poco a poco, sin llegar a más de lo aprendido anteriormente. También va cambiando entre los compases aprendidos, y al llegar a la cuarta lección, introduce el compás de 3/8. Cuando hay doble acompañamiento, son en Do y Mi mayor 
Llave de Do en $2^{\mathrm{a}}$ raya:

Diecisiete lecciones, igualmente empezando por métricas muy fáciles, e introduciendo en medio el compás de 6/8. Los dobles acompañamientos, cuando los hay, son en Do y Fa mayor.

Llave de Do en $3^{\text {a }}$ raya:

Dieciocho lecciones, igual progresión, y aparece un signo que debió haberlo hecho muchísimo antes, el Calderón; también poco después se presenta el compás de 9/8. Igualmente hay dobles acompañamientos en Do y Sol mayor.

Llave de Do en $4^{\mathrm{a}}$ raya:

Trece lecciones entre las que surge el compás de 12/8. Cuando vemos dobles acompañamientos están en las tonalidades de Do y La mayor.

Llave de Fa en $3^{\text {a }}$ raya:

Ocho lecciones, entre las que aborda los compases de 12/16 y 2/2. No comprendemos la utilidad de tratar el compás de 12/16 aisladamente, es decir, sin ver también otros de denominador 16 o los de denominador 2 en los simples y 4 en los compuestos. Los dobles acompañamientos son en Do y Fa mayor, o sus relativos si la lección está el La menor.

Llave de Fa en $4^{\text {a }}$ raya:

Las siete últimas lecciones las deja para esta importante clave, y además en algunas también hay cambios de compás. Los acompañamientos son en Do y Fa mayor.

\subsubsection{VALORACIÓN DE LA EFECTIVIDAD DEL MÉTODO Y DE SU APORTACIÓN A LA ENSEÑANZA.}

Observamos una cierta precipitación en presentar las semicorcheas, fusas, medidas irregulares y apoyaturas en los primeros ejercicios. Magnífica decisión la de ir viendo y practicando distintos signos sin pasar del intervalo de tercera, pues así los alumnos afianzan éste, el más importante y básico; no obstante no ocurre lo mismo con los demás, que carecen de abundancia en el trato y progresión adecuada. Aunque al principio hay mucha aglomeración de información, luego se va dosificando al aplicar los distintos 
Gomis

signos o dificultades, pero no siempre; es demasiado prematuro en la lección 33, sin haber trabajado dificultades rítmicas, presentar ya las alteraciones.

Hay momentos que parece que sigue un proyecto personal y estudiado, o que se fundamenta en una metodología personal, pero vemos que enseguida lo abandona, o que insiste poco en desarrollar una idea pedagógica interesante, o quizás está salpicado de buenas ideas pero sin proyecto organizativo, y es más bien un acierto casual.

Un desatino es enseñar en último lugar la clave de Fa en $4^{\mathrm{a}}$ línea, será por seguir el orden de las claves naturales para las voces humanas, ya que el método se titula "método de solfeo y de canto", y si no es sólo de canto, sino principalmente de solfeo, la clave de Fa en $4^{\mathrm{a}}$ es necesaria para el alumno mucho antes que las demás.

En resumen, no es un mal método, pero tampoco es lo que su fama le precede, hay que considerar que es uno de los primeros, tiene cosas buenas y otras no tan buenas quizás producto de la inexperiencia general en la enseñanza de la materia.

No sabemos si habrá más partes de este método, en ninguna bibliografía ni catálogos de bibliotecas aparecen, pero en este que hemos expuesto dice $1^{a}$ parte. Es extraño porque para ser la primera es muy extensa y completa. 


\section{MÉTODOS POSTERIORES A LA FUNDACIÓN DEL CONSERVATORIO DE MADRID Y ANTE- RIORES A LA EXISTENCIA DE UN PROGRAMA OFICIAL}


Analizamos en este punto, diecisiete métodos o partes pertenecientes a diez autores.

REGUART MESTRE, Salvador $\mathrm{M}^{\text {a': }}$ Elementos musicales, 1839

ESLAVA, Hilarión: Método completo de solfeo, $2^{\text {a }}$ edición, 1845

SOBEJANO Y AYALA, José de: Escuela de solfeo, según el estilo moderno, 1845

ALIAGA LÓPEZ, Matías: Cartilla de música o sea La música en el bolsillo; 1847

PÉREZ GASCÓN, Pascual: Principios de solfeo y canto.

Método de solfeo y principios de canto, 1848

PRELLEZO, Mariano de: Método de solfeo sencillo y claro en estilo familiar y en forma de diálogo, 1851

VALERO, José y ROMERO, Antonio: Nuevo método completo de solfeo, 1856

FUNOLL Y ALPUENTE, Francisco: Método completo de Solfeo sin acompañamiento, 1860

CALVÓ I PUIG, Bernat: Método de solfeo, o sea, elementos generales para aprender a leer la música; 1860

MANENT I PUIG, Nicolau: Método teórico - práctico musical, 1860 


\subsection{RESEÑA BIOGRÁFICA DEL AUTOR}

REGUART (o Regart) MESTRE, Salvador. Barcelona. Estuvo activo entre 1840-1860. Profesor y escritor. Abogado de profesión, dio clases de música en el Colegio de $2^{\mathrm{a}}$ enseñanza de San Isidoro, agregado en la Universidad (Sanhuesa Fonseca, María en AAVV, 1999, tomo 9, p. 87).

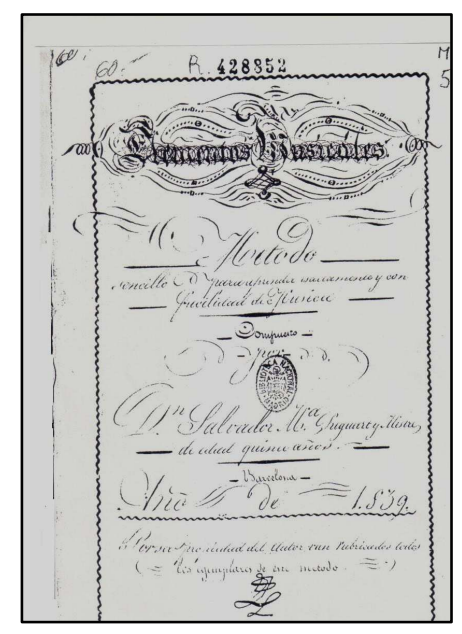

\section{Título del Método}

Elementos musicales. Método sencillo para aprender exactamente y con facilidad de Música, Barcelona, F. Vallés, 1839. Apéndice, página 198.

En la portada dice que lo escribió a la edad de 15 años.

\subsubsection{DESCRIPCIÓN DETALLADA DEL MÉTODO.}

\section{CUADRO DE INFORMACIÓN GENERAL DEL MÉTODO.}

$\mathbf{N}^{\circ}$ de lecciones

Extensión de las lecciones

Claves empleadas

Tesituras que abarcan

Tonalidades que trata y estudia

Compases que emplea y estudia
49 más 5 para la mutación de tonos, pero son cortos ejercicios, solamente la última es una lección.

Entre 5 y 8, excepto la única lección que hay que tiene 30 compases

Do en $1^{\mathrm{a}}$, Do en $2^{\mathrm{a}}$, Do en $3^{\mathrm{a}}$, Do en $4^{\mathrm{a}}$, Sol, Fa en $3^{\mathrm{a}}$ y Fa en $4^{\mathrm{a}}$.

$\mathrm{Do}_{3}$ a Do 5

Do M, La m, Sol M, Re M, La M, Mi M, Si M, Fa\# M, Do \# M, Fa M, Si b M, Mi b M, La b M, Re b M, Sol b M, Do b M $4 / 4,3 / 4,2 / 4,2 / 2,6 / 8$ 


\section{Dificultades métricas que contiene}

Dificultades de entonación que se encuentran $y$ orden en que se enseñan los intervalos

Armonía utilizada

Formas que tienen las lecciones

Introducciones, Intermedios o Codas instrumentales

\section{Teoría de la música} que incluye

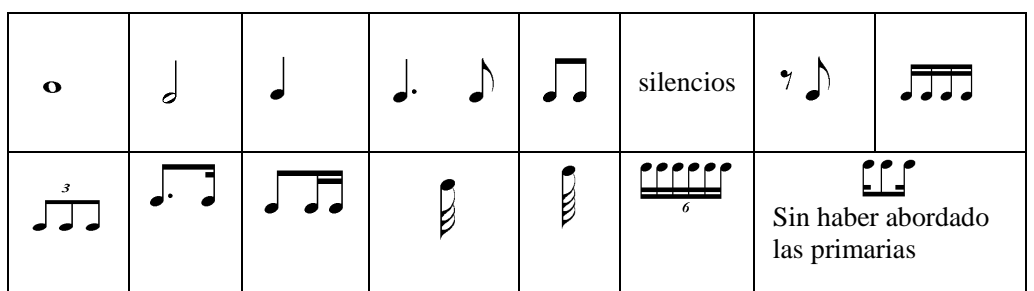

No hay grandes dificultades, pero muy pronto se abordan las alteraciones y también aparecen toda clase de intervalos aumentados y disminuidos.

Solamente se ejercitan los intervalos naturales de la escala desde $2^{\mathrm{a}}$ a $10^{\mathrm{a}}$

No hay

No tienen

No existen

Bastante, toda la primera parte

\section{SECUENCIA}

Primeramente un prólogo para cantar las excelencias de la música, lo mucho que él la ama, y el diseño de la obra. Toda ella está en escritura manuscrita, con letra redondilla, pero a pesar de ello bastante ininteligible y en algunos tramos algo borrada.

El comienzo es, como tantos otros, con abundante teoría, y como era de rigor en la época y mucho más adelante, en forma de diálogo. Definición de música: una ciencia físico-matemática que trata de los sones armónicos. ¿En qué consiste la música? En el conocimiento científico de los intervalos de las voces, que se llaman consonancias y disonancias (llamaré también el concierto de instrumentos y voces). Pues si sólo en eso consiste la música, cosa sencilla es.

Según el autor la música se compone de 20 partes: Pauta, Llaves, Compases, Notas o puntos musicales, Gama, Tono, Líneas perpendiculares, Silencio, Sostenidos, Bemoles, Becuadros, Modo, Movimiento, Llamada o Párrafo, Calderón o Suspensión, Trino, Semi - copados, Picados y Repetición. Muchas partes tiene así la música, y todavía podríamos descomponerlas en más, es asombroso el desorden que hay y la falta total de organización de estos elementos, que para el autor son partes de la música.

A partir de aquí, va describiendo cada una de estas "partes". Solamente comentaremos alguna rareza o descripción singular. La forma de marcar los compases, es una 
de ellas, pero no exclusiva de este autor, en otros de la misma época también se ve: para el ternario, el primero bajo, el segundo a la izquierda y el tercero arriba; y para el cuaternario, bajo, izquierda, derecha y arriba. Dentro de la explanación de Notas o puntos musicales, enumera la cantidad de cada una de ellas que entran en cada clase de compás. O sea, que había que aprender la composición de cada compás y no deducirlas por su representación. El puntillo, y este autor es el primero en mostrar el doble, triple y cuádruple puntillo, como se verá más adelante otros también lo hicieron, pero aquí sólo se ven representados, sin explicar equivalencias, y sin que haya después ninguna práctica de ellos en las lecciones o ejercicios; las agrupaciones irregulares y los términos dinámicos. Dentro del apartado Gama, también habla de los intervalos. Con los sostenidos y los bemoles habla de armaduras, a su manera, pero lo indica. Semi - copados es la forma de llamar a las síncopas.

Y después de esta teoría, viene la práctica. Hay una advertencia al profesor o maestro de que debe hacer por su cuenta algún ejercicio o lección similar a éstas (vaya enseñante que deja su faena a los demás), y que para no ser aburrido, vaya alternando los intervalos en cada clave con lecciones posteriores o con las que haga el maestro.

Lo primero que encontramos son 7 páginas dedicadas cada una a una clave, empezando (y ahí está lo curioso) por la de Do en $1^{a}$ línea, siguiendo el orden numérico de estas claves, luego la de Sol, y acabando con las de Fa, pero primero la de la $3^{\text {a }}$ línea y luego la situada en la $4^{\mathrm{a}}$ (el orden no puede ser menos pedagógico y útil). En todas ellas hallamos la escala natural, que a la vez hace de ejercicio de lectura de notas, y un pentagrama para practicar cada uno de los intervalos desde los de $2^{\mathrm{a}}$ a los de $10^{\mathrm{a}}$, siempre dentro de la misma escala natural de Do

Después una sucesión de pequeños ejercicios, en los que alterna las distintas claves y compases, empezando por redondas y blancas, y siguiendo todo en el orden expuesto arriba. Intercala preguntas y repuestas teóricas referentes a las novedades que va introduciendo.

Siguen 5 ejercicios de "Mutación de tonos", o sea cambios de tonalidad, también con cambios de clave. Y acaba con una canción "Canción española el Recuerdo", para demostrar cómo se aplica la letra 


\subsubsection{VALORACIÓN DE LA EFECTIVIDAD DEL MÉTODO Y DE SU APORTACIÓN A LA ENSEÑANZA.}

La teoría no puede estar más desorganizada e incompleta, amén de utilizar descripciones e indicaciones de lo más singulares. Curiosa, como los anteriores, la forma de marcar los compases.

El primer defecto que encontramos en la parte práctica, es el orden en el que aparecen las claves, ya que empezar con la clave de Do en $1^{\mathrm{a}}$ no tiene justificación pedagógica alguna.

Todo él es muy insuficiente, antipedagógico y lamentable. Ni es sencillo ni se aprende con facilidad la música, como dice su título; lo que sí es corto, pero no por ello sencillo, y menos, útil para aprender. 


\subsection{RESEÑA BIOGRÁFICA DEL AUTOR}

ESLAVA, Hilarión.

Su nombre completo es Miguel Hilarión Eslava Elizondo, nació en Burlada (Navarra) el 21 de octubre de 1807 y falleció en Madrid el 23 de julio de 1878. Figura destacada de la música española del siglo XIX. A los 9 años entró como niño de coro en la Catedral de Pamplona, a pesar de la resistencia de su padre, sin haber estudiado anteriormente música. Estudió posteriormente solfeo con Mateo Jiménez, el maestro de capilla de su catedral, y órgano con Julián Prieto; posteriormente estudió violín y contrabajo. Ya estudiando solfeo, escribía pequeños fragmentos de música para que la interpretaran sus compañeros. A los 19 años comenzó a sustituir ocasionalmente, en la dirección de la capilla musical, a su maestro Prieto. Al año siguiente estudió composición y participó en las oposiciones a maestro de capilla de la Catedral de El Burgo de Osma, plaza que consiguió. Una vez allí decidió acceder al estado clerical, matriculándose en la Universidad de Santa Catalina, donde estudió Filosofía, ordenándose subdiácono y diácono.

A los 4 meses de su estancia en El Burgo de Osma, solicitó participar en la oposición para maestro de capilla de la Catedral de Sevilla, que junto con la de Toledo y la Capilla Real, eran las más prestigiosas; las ganó Francisco Andreví, quedando él en segundo lugar. Este resultado fue criticado por la opinión general, más favorable a Eslava, y debido al clima que se instauró, el ganador Andreví no se presentó en Sevilla. Inmediatamente salieron oposiciones a la Capilla Real, a las cuales se presentaron, entre otros, ambos contendientes; volvieron a darle la plaza a Andreví, siendo también criticada esta decisión; entonces Eslava pidió la plaza de Sevilla aduciendo que había quedado en segundo lugar. En 1832 accedió a maestro de capilla de esta catedral, y en ese mismo año fue ordenado sacerdote. En Sevilla desarrolló una actividad desbordante, componiendo, allí hizo su famoso Miserere, comenzó su método de solfeo y comenzó a investigar en los músicos españoles de los siglos anteriores, convirtiéndose en el padre de la musicología española. Compuso también 3 óperas, no obstante su fuerte fue la música religiosa.

En 1844 opositó a maestro director supernumerario de la Real Capilla, y a los 3 años después, por jubilación del maestro titular, fue nombrado maestro de capilla de la 
Real, tenía 44 años. Allí se dedicó a componer y a investigar por las catedrales de toda España y también en países de Europa

Fue profesor auxiliar de composición del Real Conservatorio en 1854 y al año siguiente catedrático de Armonía, Contrapunto y Fuga; sus libros Método de solfeo y Escuela de composición, fueron textos obligados a partir de 1861; en 1866 fue nombrado director del centro, cesando al poco tiempo. Dimitió de su cátedra en 1868.

Creó la sociedad “el Orfeo Español”, la "Sociedad Artístico-Musical de Socorros Mutuos, de las que fue su presidente, ayudó a muchos estudiantes sin posibilidades económicas, entre ellos al que sería célebre tenor Julián Gayarre.

Perdió sus puestos con la caída de la monarquía de Isabel II, los que recuperará al llegar la Restauración con Alfonso XII, pero su prestigio nunca lo perdió, siendo un referente en la música española mientras vivió, e incluso después de su muerte (Ansorena, José Luís en AAVV, 1999, tomo 4, pp. 748 a 759) .

\subsubsection{DESCRIPCIÓN DETALLADA DEL MÉTODO.}

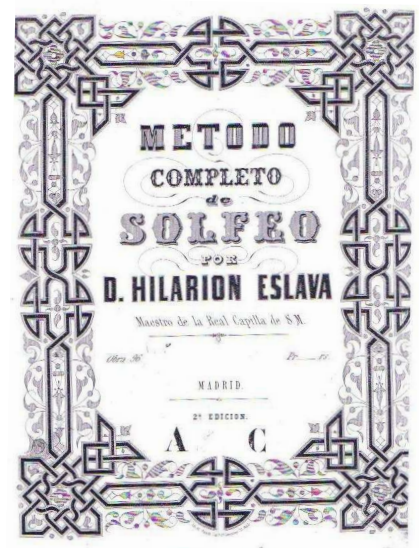

\section{Título del Método}

Método completo de solfeo, $2^{\mathrm{a}}$ edición, Madrid, Lit. de Peant Car ${ }^{\mathrm{a}}$ s. f. ${ }^{1}$ Apéndice, página 199.

\section{A MIS COMPROFESORES}

Hace este exordio al inicio del libro, en el que proclama que lleva 15 años practicando la enseñanza del solfeo. Que ha observado, analizado y practicado lo que se

\footnotetext{
${ }^{1}$ AAVV (1999) p. 750, tomo 4, el firmante del artículo José Luís Ansorena, afirma que el método fue editado el año1845, y que el autor en su introducción manifiesta que fue escrito en Sevilla en 1837 [así es en cuanto al año, pero nada hemos leído referente a la ciudad. ¿Porqué no puedo ser en Burgo de Osma donde Eslava fue Maestro de Capilla y empezó a enseñar solfeo?]. Dionisio Preciado: Don Hilarión Eslava y su "Método completo de solfeo" en Monografía de Hilarión Eslava..., 1978, pp. 246 a 251 afirma que el método comenzó siendo editado por entregas en Madrid en 1845, y que existe un manuscrito sin fecha ni lugar que lleva por título Método de Solfeo de Don Hilarión Eslava, Maestro de Capilla, no de la Capilla Real, por lo que puedo ser este el embrión de su Método cuando estaba en Sevilla o quizás en Burgo de Osma. Además, en las páginas 247 y 248 aparece que con fecha 13 de julio de 1845, ya estaba editada la primera entrega, y para el 9 de octubre del mismo año, había sido editada la cuarta; también señala (p. 249) que hay otros autores, como Gilbert Chasse o F. J. Fétis, que creen que fue editado en el año siguiente 1846, mas anteriormente ha quedado suficientemente demostrado que fue en 1845 .
} 
había publicado en ese momento, y ha encontrado falta de claridad y orden en la teoría, defectos de progresión, cantos que el discípulo aprende de memoria, y otros que dañan el desarrollo de la organización o educación del oído. Que compuso el método en el año 37, pero que luego lo ha ido perfeccionando con la práctica.

Tiene 4 partes y él las explica así:

Primera.- Teoría clara y compendiosa, un número de lecciones progresivas, excluyendo todos los intervalos aumentados y disminuidos e instrucciones acerca de la emisión pura de la voz. Clave de Sol.

Segunda.- Teoría de los intervalos, tonos y modos, notas de adorno, menos trino, alteraciones y lecciones progresivas en los compases más usuales, introduciendo progresivamente las dificultades respecto al sonido y tiempo. Claves de Sol y Fa 4 a

Tercera.- instrucciones para el dictado. Todas las claves, compases menos usados y géneros diatónico, cromático y enarmónico.

Cuarta.- Relación de las claves entre si, modo de conocer el tono de una pieza, transporte, lecciones a 2 voces, modo de cantar con letra, articulaciones, abreviaciones, palabras italianas, explicación de acordes y algunos conocimientos de armonía.

Tesitura que no sobrepasa la onceava.

\section{ADVERTENCIAS GENERALES ACERCA DE LA PRÁCTICA DEL MÉTODO.}

Anterior a este epígrafe, hace un comentario referente a la mala situación en que se encuentra en ese momento la enseñanza del solfeo: muchas veces encomendado a profesores de $2^{o}$ orden...Parece que esta materia siempre fue defectuosa en cuanto a su didáctica, y se la consideró, y se la considera, algo complementario o subsidiario, cuando debe ser objeto de atención prioritaria en la formación de un músico, y ello da paso a este enunciado, cuyo contenido divide en 5 apartados:

$1^{\circ}$.- No extender las explicaciones teóricas más de lo necesario, y siguiendo un orden que es: en primer lugar lo que corresponde al sonido, y en segundo al tiempo.

$2^{\circ}$.- Explicar la teoría de cada lección antes de practicarla, y esta explicación que sea en forma de pregunta y respuesta. (Como venía siendo usual y como sería bastante tiempo después)

$3^{\circ}$.- No permitir al alumno hacer ninguna práctica por si solo hasta que se esté seguro de su justeza en la entonación de los intervalos y del sentido rítmico.

$4^{\circ}$.- Aconsejar el estudio de las lecciones en 3 fases: a) observar y comprender el significado de todos los grafismos que se hallan en una lección; b) entonarla sin medida; c) 
solfearla midiendo y repitiendo los fragmentos en los que se halle especial dificultad, para por fin, entonarla y medirla, sin parar, al tiempo debido.

[No son estas las fases que creemos necesarias para un estudio concienzudo, sino estas; a) lectura pura de las notas (sobre todo al comenzar a estudiar una nueva clave); b) lectura medida; c) entonación pura de los sonidos; d) solfeo rítmico - melódico; e) solfearla con acompañamiento de piano].

$5^{\circ}$.- No ayudar al discípulo con el canto o con el instrumento una vez se hayan aprendido las primeras lecciones, sino dejar que sea él quien venza las dificultades por si mismo. [Suponemos que estaría conforme en que una vez descifrada la lección por el alumno, se le acompañe].

\subsubsection{MÉTODO ESLAVA: PRIMERA PARTE}

\section{CUADRO DE INFORMACIÓN GENERAL DE LA PRIMERA PARTE.}

$\mathbf{N}^{\circ}$ de lecciones

58

Extensión de las lec-

ciones

Claves empleadas

Tesituras que abarcan Máxima de $11^{\mathrm{a}}$

$\mathrm{Do}_{3} \mathrm{a} \mathrm{Fa}_{4}$

Tonalidades que trata Do M

y estudia

Compases que emplea y estudia

Dificultades métricas que contiene

Sol

$2 / 2,4 / 4$ y $2 / 4$
Entre 10 y 70 compases

Pero las lecciones 43, 46, 49, 52, 54 y 56 están en La menor, aunque no lo especifica.

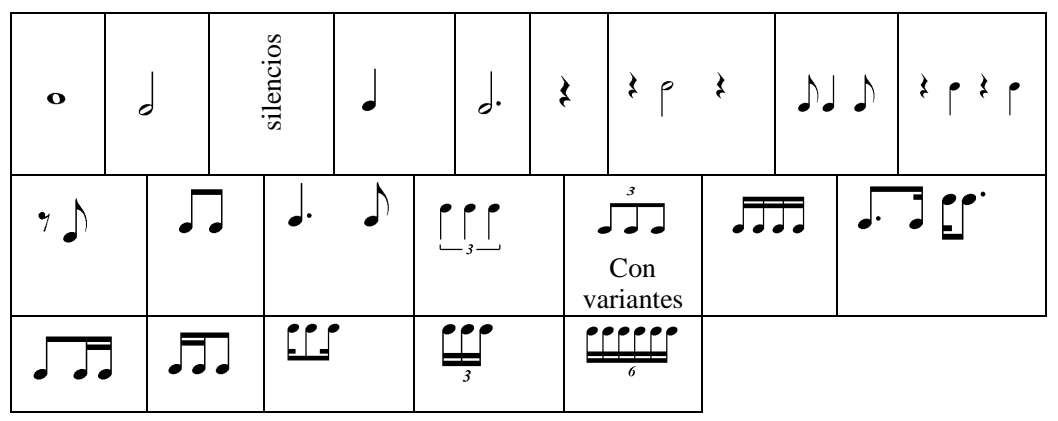


Dificultades de entonación que se encuentran y orden en que se enseñan los intervalos

Armonía utilizada

Formas que tienen las lecciones

Introducciones, Intermedios o Codas instrumentales

Teoría de la música que incluye
Intervalos naturales primero y alterados luego, mayores y menores, semitonos cromáticos o diatónicos alterados por modulaciones pasajeras. En la lección $n^{\circ} 51$ hay una $5^{\text {a dis- }}$ minuida.

Primeramente grados conjuntos, después $2^{\mathrm{a}}, 3^{\mathrm{a}}, 4^{\mathrm{a}}, 5^{\mathrm{a}}, 8^{\mathrm{a}}$ y $6^{\mathrm{a}}$. Hay un salto de la $5^{\mathrm{a}}$ a la $8^{\mathrm{a}}$ muy lógico y didáctico, pero la $7^{\mathrm{a}}$ no se practica, aparece en las lecciones sin su estudio previo. Luego semitonos diatónicos y cromáticos

Armonía clásica, pero ya con modulaciones a la dominante, relativo y II grado desde el principio

Predomina A-B-A'; A-A'; A-B-C

No tienen ninguna lección

Tiene la necesaria y la básica

\section{DESCRIPCIÓN DETALLADA DE ESTA PARTE.}

\section{Conocimientos preliminares.}

Noción de música. Agrupación de los caracteres y señales en 2 grupos: sonido: agrupa a las claves, signos, sostenidos, bemoles, becuadros, las letras $\boldsymbol{P}$ y $\boldsymbol{f}$ y todos los términos que modifiquen el sonido; tiempo: agrupa el aire, compás, figuras, puntillos, silencios, puntos de reposo y fermatas (llamados calderones), accelerando, ritardando y otros que modifiquen el valor del sonido. Pentagrama, Solfeo.

Hay una nota para el Maestro indicando que ya puede empezar con la $1^{a}$ lección, que es la escala, procediendo a explicar los signos (llama así a las notas), la clave y concretamente la de Sol en $2^{\mathrm{a}}$, las líneas adicionales (que es lo que pertenece al sonido). Luego lo que pertenece al tiempo: compás, hablando del compasillo y el binario (con notas al pie sobre el origen de estos nombres y sus signos), y terminando por definir el binario (como hacen muchos teóricos de la época, que comienzan por el de 2 tiempos, pero no el de $2 / 4$ como se hace en la actualidad, sino $2 / 2$ que es más difícil de leer); figuras (definiendo sólo la redonda) y líneas divisorias. 
Eslava, primera parte

A partir de aquí comienzan las lecciones.

Seis lecciones, naturalmente cortas, que son más ejercicios que lecciones, pero él las llama así, en las que va introduciendo las figuras de redonda, blanca y sus silencios. Único compás: binario simple. De la 1 a la 5, melódicamente es la escala diatónica de Do; la primera y segunda sólo comprende la redonda, la tercera la blanca, la cuarta y quinta éstas más sus silencios, más la ligadura entre 2 redondas; y la sexta deja ya de ser una escala, aunque sigue la melodía por grados conjuntos.

El acompañamiento, tanto de estas primeras como de todas las demás en las 4 partes que tiene el método, es en forma de bajo cifrado. La primera de redondas y grados tonales; pero ya en la segunda modula a la subdominante y dominante, incluyendo algún grado minorizado; en la tercera vuelve a utilizar sólo grados tonales. Ya en la cuarta no sólo utiliza redondas, sino también blancas, con modulaciones al relativo, notas de paso cromáticas y dominantes secundarias. Así sigue en las venideras.

\section{Consejos para la emisión de la voz:}

En los que dice que se tengan en cuenta para evitar dañarla y dejar inservible al alumno para el canto, aunque para quienes no se vayan a dedicar a él, o no sirvan, pueden omitirse estos consejos. Forma de evitar la voz gutural y nasal y un ejercicio de vocalización con las notas Sol, Do grave y Do agudo. Acaban los consejos prohibiendo al solfista todo esfuerzo violento, esto es, cantar a media voz.

Lecciones 8, 9 y 10, aparece la negra mezclada con las figuras de antes, seguimos con grados conjuntos.

De las lecciones 11 a la 20, con las mismas figuras y compás, dedica cada 2 a la entonación de un intervalo, una con preparación y otra sin preparación. (Hay dos, las número 16 y 17, que llevan el signo , c sonemos que se tratará de un error de imprenta, pues después de la lección 20 es cuando empieza a hablar de este compás)

Ahora hay unos ejercicios de entonación pura de intervalos mezclados, con la recomendación previa de practicarlos para adquirir seguridad en la entonación, advirtiendo al Maestro que si ve que se hacen fastidiosos, los reparta a lo largo de las próximas lecciones, y también advirtiendo que ya puede el alumno estudiar por sí solo, previa explicación por parte del Maestro de las novedades que encierre la nueva lección a 
estudiar. O sea que era el alumno quien estudiaba y el profesor quien corregía, no como sucede ahora.

A continuación explica el Aire, dando 4 términos como principales: Allegro, Andante, Adagio y Largo, y los demás como modificaciones; también explica el compasillo muy sucintamente.

\section{Combinaciones progresivas de entonación y figuras:}

Cuatro lecciones con las figuras hasta ahora incorporadas, compás de compasi1lo, con distintas interválicas; segundas y terceras, terceras y cuartas, cuartas, quintas y octavas. La segunda lección incluye el calderón, al que el autor llama punto de reposo, vulgarmente calderón, y en nota al pie dice que también se le llama Fermata (detención), pero que este término también se aplica a ejecutar la voz o instrumento algún paso ad libitum.

\section{Del puntillo:}

Siguiendo con las mismas figuras y aumentando la interválica al de sexta, incorpora el puntillo, solamente a la blanca, y el silencio de negra (forma antigua, como López Remacha), esto en dos lecciones.

De la Síncopa:

Ya en la lección 27 acomete este difícil ritmo (lo cual nos parece muy prematuro), y las define como notas que se dan a contratiempo. Añade que el resultado es acentuar la parte débil del compás, y que dado que esto es invertir el orden natural, por eso se dice que son a contratiempo. Pero nada dice de la diferencia entre contratiempo y síncopa, pues no habla de la prolongación del sonido que ha entrado a contratiempo, o sea que para Eslava era lo mismo una cosa que otra, y lo demuestra con lo que dice a continuación: Hay síncopas largas, muy largas, breves y muy breves. Se escriben de 3 modos. $1^{o}$ por medio de ligaduras; $2^{o}$ por medio de notas partidas; $y 3^{\circ}$ cortadas por medio de pausas. (Aquí es donde está el contratiempo y no la síncopa). Y acompaña esta teoría con ejemplos de las tres maneras por él expuestas, siendo el tercer ejemplo claramente notas a contratiempo,

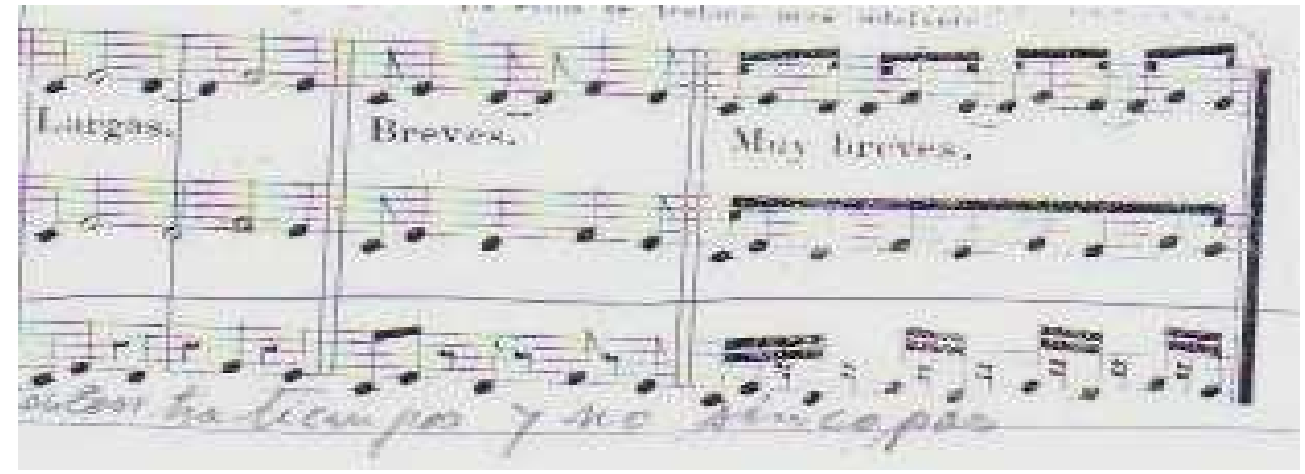


Eslava, primera parte

De la corchea:

Dos lecciones, las $n^{\circ} 30$ y 31 , que son reducciones de la 21 y 22 respectivamente. Él llama reducciones a lo que en realidad es contracción rítmica. Las lecciones 21 y 22 contienen las figuras de redonda, blanca y negra; y las 30 y 31 blanca, negra y corchea, o sea, están reducidas las figuras a la mitad de su valor. Este procedimiento también lo empleará en su método Funoll Alpuente, aunque nada más en dos ocasiones, quizás fuera Eslava quien lo ideara, y aquél quien lo imitase.

De los intervalos y de las alteraciones:

Define intervalo, los clasifica en conjuntos y disjuntos para hablar del tono y semitono en la escala diatónica, y de ese modo enlaza con las alteraciones, que las presenta como una manera de dividir el tono en dos semitonos.

$\underline{\text { Sostenido accidental en FA precedido de SOL: }}$

Una lección con este semitono diatónico, vuelve al compás de 2/2.

Sostenido en DO precedido de RE:

De nuevo en $4 / 4$, este semitono más el anterior. Prefiere el autor comenzar por los diatónicos y no por los cromáticos que son más sencillos.

\section{Negra con puntillo:}

Reducción de la lección 25 que dedicaba a la blanca con puntillo.

Bemol en SI y sostenido en SOL precedidos de LA:

Una lección en $2 / 2$ con estos semitonos más los anteriores.

\section{Del becuadro:}

Una lección para utilizarlo como accidental, para destruir sostenidos y bemoles accidentales en las notas que se han alterado hasta ahora.

Hace al pie un comentario muy curioso sobre el origen de las palabras bemol y becuadro: respecto al bemol, dice ciertamente que viene de la palabra "be moll" (blando), pero en cuanto al significado de "be-cuadro" (que no be cuadratum) (duro), dice: suponiendo que este ultimo[sic] (cosa verdaderamente estraña)[sic] hacía en el oído un 
efecto parecido al de un cuerpo cuadrado o con esquinas sobre un plano como el de la mano.

Síncopas breves:

Una lección, que es reducción de la 27, dedicada a síncopas largas y otra inédita.

Bemoles en MI y en LA precedidos el primero de RE y el segundo de SOL:

Una lección con los anteriores semitonos más éstos, pero al menos, antes de que aparezcan en la lección, hay una semifrase igual, una $3^{\mathrm{a}}$ menor inferior, para que en los mismos lugares que aparezcan después los semitonos entre Re-Mib y Sol-Lab, se entonen antes entre Si-Do y Mi-Fa.

De los tresillos:

Siguiendo con su principio de comenzar por el compás binario simple, una lección en este compás, con tresillos de negra en abundancia.

Del compás de 2/4:

Breve explicación de este compás comparándolo con el de compasillo.

Bemol en SI y sostenido en FA seguidos de sus respectivos signos naturales:

Una lección dedicada a la utilización del becuadro, y al nuevo compás de $2 / 4$, a la vez el tresillo que era de negras por aparecer en el compás binario simple, ahora ya es de corcheas.

Sostenido en SOL y DO seguidos de sus respectivos signos naturales:

Dos lecciones para este intervalo cromático, pero además, siguiendo con los tresillos de corchea, ya aparecen con alguna de sus notas sustituida por un silencio; esto en la primera, pues en la segunda además hay algunos tresillos formados por negra y corchea, y aunque él no lo advierte, esta lección no está en Do mayor sino en La menor. 
Eslava, primera parte

De las dobles corcheas:

Así llama, a la semicorchea, ${ }^{1}$ como también lo hace Funoll Alpuente. Vuelve al compás de 4/4 para presentarlas, y lo hace con una reducción de la lección 30 que era con corcheas. A partir de esta lección, $n^{\circ} 44$, ya las utiliza mezcladas con las anteriores. En cuanto a los compases, va alternando el de compasillo con el de 2/4.

Bemoles y sostenidos precedidos de sus respectivos signos naturales:

Tres lecciones para práctica de las figuras y los ritmos hasta ahora estudiados, y del semitono cromático. La segunda, también sin advertirlo, está en La menor, y la tercera es una reducción de la n 31 que constaba de corcheas.

$\underline{\text { Sostenidos y bemoles precedidos los primeros de sonidos de un tono más bajo, y los }}$ segundos de otro más alto:

Dos lecciones, una en Do mayor y la otra en La menor, para práctica del semitono cromático. Y una más, que no tiene que ver con este intervalo, porque además no tiene ninguna alteración, sino que es una reducción de la lección 34, compuesta a base de negras con puntillo y corcheas, para dar a conocer la fórmula rítmica corchea con puntillo - semicorchea. Pero de entrada, y en una sola lección, entran esta fórmula y su forma inversa, lo cual nos parece un exceso.

$\underline{\text { Sostenidos y bemoles precedidos y seguidos de grados disjuntos o notas de salto: }}$

Dos lecciones, una en Do mayor y otra en La menor, en las que hay intervalos alterados que siguen siendo mayores o menores, porque se debe su alteración a modulaciones. Sí aparece en la primera, $\mathrm{n}^{\circ} 51$ un intervalo de quinta disminuida dentro de la escala de Do mayor. En la segunda se añade como novedad rítmica la fórmula corchea dos semicorcheas e inversa.

\section{Síncopas muy brebes [sic]:}

Primeramente una reducción de la lección 37 que estaba destinada a la síncopa breve. Luego una lección en La menor con la doble barra de repetición. Y una tercera, de nuevo en Do mayor con todo lo anterior.

\footnotetext{
${ }^{1}$ A esta denominación se refiere en nota al pie como "antiguo nombre"
} 
Hace Eslava en la primera lección de este grupo una observación al pie, a nuestro criterio muy sabia, recomendar que para facilitar los primeros encuentros con la síncopa muy breve, se refuerce un poco la segunda mitad de ella, advirtiendo también que ello no es más que un recurso y que esa ejecución es contraria al efecto deseado.

De los tresillos y seisillos de dobles corcheas:

Dos lecciones, en las modalidades de La menor y Do mayor, una con tresillos de semicorcheas y dobles tresillos, y la otra con seisillos.

$\underline{\text { Recopilación de toda la primera parte: }}$

Cierra con una larga lección dividida en 5 partes, distintas unas de otras, aunque la última tiene alguna relación melódica con la primera, es una especie de A’. Primera parte Do mayor, 4/4, Largo, tresillos, seisillos, intervalos alterados. Segunda parte La menor, 4/4, Andante, negras, dobles tresillos, fórmulas combinadas, síncopas breves, menos intervalos alterados. Tercera parte Do mayor, 2/2, Allegro moderato, redondas, blancas, negras, puntillos y ligaduras, muy pocas alteraciones. Cuarta parte Do mayor 4/4, Adagio, síncopas muy breves y semicorcheas con sus silencios. Quinta parte mismo compás y tonalidad, es como una continuación, aunque empieza en la dominante para ir al final a la tónica, corcheas, negras y negras con puntillo, escasísimas alteraciones.

\section{VALORACIÓN DE ESTA PRIMERA PARTE.}

Es el primero, que no utiliza la denominación de breve y semibreve sino la de redonda y blanca (porque como dice él llamar breve y semibreve a las notas de mayor duración...), tampoco el de compás mayor y menor, ni los de aspiración, suspiro o pausa para los silencios. Nos parece que a partir de la lección 27 hay poca cantidad de lecciones para cada dificultad. Se agolpan unas tras otras sin dar tiempo a digerirlas. Es de gran ingenio repetir algunas lecciones o transcribirlas con otro compás u otro ritmo, porque es una demostración de la interrelación de los compases, las figuras y el aire. El alumno tiene así una referencia y puede comparar. Además Eslava comenta que se pueden solfear las lecciones originales en compás binario y así demostrar al educando la similitud entre un 2/2 y un 4/4 con figuras a la mitad de valor. Las melodías suelen ser agradables, musicales y asequibles. 


\subsubsection{MÉTODO DE ESLAVA: SEGUNDA PARTE}

\section{CUADRO DE INFORMACIÓN GENERAL DE LA SEGUNDA PARTE.}

$\mathbf{N}^{\circ}$ de lecciones

Extensión de las lec- Entre 14 y 62 compases

ciones

Claves empleadas

Tesituras que abarcan

Tonalidades que trata y estudia

Compases que emplea y estudia

Dificultades métricas
que contiene

Dificultades de entonación que se encuentran $y$ orden en que se enseñan los intervalos

Armonía utilizada

Formas que tienen las lecciones

Introducciones, Intermedios o Codas instrumentales

Teoría de la música que incluye

52

Sol y Fa en $4^{\mathrm{a}}$ Si m, Si b M y Sol m. $2^{\mathrm{a}} \mathrm{M}$ y su inversión $7^{\mathrm{a}} \mathrm{m}$

$3^{\mathrm{a}} \mathrm{M} \quad$ “ $\quad 6^{\mathrm{a}} \mathrm{m}$

$4^{\mathrm{a}} \mathrm{M} \quad$ “ $\quad 5^{\mathrm{a}} \mathrm{m}$

$5^{\mathrm{a}} \mathrm{M} \quad$ “ $\quad 4^{\mathrm{a}} \mathrm{m}$

$6^{\mathrm{a}} \mathrm{M} \quad$ “ $\quad 3^{\mathrm{a}} \mathrm{m}$

$7^{\mathrm{a}} \mathrm{M} \quad$ “ $\quad 2^{\mathrm{a}} \mathrm{m}$

$9^{\mathrm{a}}$ y $10^{\mathrm{a}} \mathrm{M}$ y $\mathrm{m}$

$2^{\mathrm{a}} \mathrm{A}$ y su inversión $7^{\mathrm{a}} \mathrm{d}$

$3^{\mathrm{a}} \mathrm{d} \quad$ " $\quad 6^{\mathrm{a}} \mathrm{A}$

$4^{\mathrm{a}} \mathrm{d} \quad$ “ $\quad 5^{\mathrm{a}} \mathrm{A}$ rio $\mathrm{A}-\mathrm{B}-\mathrm{A}^{\prime}$

No tienen ninguna

Tiene bastante
$\mathrm{Do}_{3} \mathrm{a} \mathrm{Fa}_{4}$, predominando hasta $\mathrm{Mi}_{4}$

La m, Sol M, Mi m, Fa M, Re m, Re M,

Los anteriores más 3/4, 3/8, 6/8, 9/8 y 12/8

\begin{tabular}{|c|c|c|c|c|}
\hline 8 & 6 & $\overline{0.0 .0}$ & Doble puntillo & Notas de adorno \\
\hline & 8 & & & \\
\hline
\end{tabular}

Intervalos de $9^{\mathrm{a}}, 10^{\mathrm{a}}$; aumentados y disminuidos todos.

Ya en la segunda lección aparece un acorde de $6^{\mathrm{a}}$ aumentada, los cuales abundan. En la tercera lección hay un acorde de apoyatura, pero es algo aislado. Normalmente sigue con una armonía más bien clásica. Cuando se tratan los intervalos aumentados y disminuidos hay acordes alterados cromáticamente, de vez en cuando algún grado alterado, acordes minorizados o mayorizados. (lecciones 11 y 12)

Las mismas de la primera parte, predominando el lied terna- 


\section{DESCRIPCIÓN DETALLADA DE ESTA SEGUNDA PARTE.}

Intervalos:

Comienza esta parte con teoría sobre los intervalos, clasificación en conjuntos y disjuntos, nombre de ellos, calificación en mayores y menores e inversión con su calificación. Hay una aclaración en la calificación respecto a las cuartas y quintas, que dice son también mayores y menores, y añade: que algunos a imitación de los extranjeros, han dado hasta ahora el nombre de justa y perfecta, y en nota al pie agrega: Los nombres dados a los intervalos de $4^{a}$ y $5^{a}$ son conforme a la doctrina de los antiguos maestros españoles, que procedieron en esto con más acierto que los modernos. También hay otros, como Pérez Gascón o Justo Moré, que así lo sostienen, teoría con la que estamos totalmente de acuerdo.

Ya por último en esta primera información, hay una nota para el maestro, indicándole que en muchas de las lecciones venideras, hay señaladas, de tanto en tanto, con unos puntos intermitentes algunas notas, y son para que el alumno diga qué clase de intervalo es.

Segunda mayor y su inversión séptima menor:

Bajo este epígrafe comienzan las lecciones, y es la $n^{\circ} 1$ que está dedicada a estos intervalos principalmente, teniendo el autor en cuenta de que suene antes el intervalo de segunda, sirviendo de preparación al de séptima que se presenta poco después como inversión del anterior. Tonalidad de Do mayor y compás de 4/4.

\section{Del compás de 3/4:}

Breve descripción de este compás.

\section{$\underline{\text { Tercera mayor y su inversión } 6^{\mathrm{a}} \text { menor: }}$}

Una lección, ya con el nuevo compás, Do mayor y empleo de estos intervalos.

\section{Cuarta mayor y su inversión $5^{\mathrm{a}}$ menor:}

Una lección con estos intervalos, mismo compás y tonalidad. 
Eslava, segunda parte

De los tonos y modos:

Explicación sencilla de la doble acepción de la palabra tono y del significado de modo, comenzando por describir la situación de tonos y semitonos en la escala de Do mayor, así como las notas que forman los intervalos determinantes del modo.

\section{Tono de Do modo mayor:}

Simplemente la escala de Do mayor.

$\underline{5^{\mathrm{a}} \text { y } 6^{\mathrm{a}} \text { mayores y sus inversiones } 4^{\mathrm{a}} \text { y } 3^{\mathrm{a}} \text { menores con todos los demás intervalos pasa- }}$ dos anteriormente:

Una lección, como si inaugurara ahora la tonalidad de Do mayor, compás de $2 / 2$, figuración sencillísima y mezcla de intervalos.

De las triples corcheas fusas: Séptima mayor y su inversión $2^{\mathrm{a}}$ menor:

Con estas nuevas figuras y estos intervalos una lección con compás de 3/4

Novena y décima mayores y menores, duplicación de la $2^{\mathrm{a}} \mathrm{Y} 3^{\mathrm{a}}$ :

Una lección para estos intervalos compuestos, compás de 3/4 y sigue con las fusas. Un poco pronto nos parece la irrupción de intervalos compuestos, sería mejor después de trabajados todos los simples.

Al finalizar la lección hay una anotación de los intervalos disminuidos (a los que Eslava llama "diminutos") y aumentados, incluyendo como disminuidos los de $3^{\mathrm{a}}, 4^{\mathrm{a}}$ y $7^{\mathrm{a}}$, y como aumentados los de $2^{\mathrm{a}}, 5^{\mathrm{a}}$ y $6^{\mathrm{a}}$.

Tono de La modo menor, relativo del de Do mayor:

Explica cómo la situación de los tonos y semitonos, así como el intervalo de $3^{\mathrm{a}} \mathrm{y}$ $6^{\mathrm{a}}$ menor, hacen que una escala se denomine menor. En cuanto a su relatividad con la de Do mayor, lo explica como que ambas son pertenecientes a la misma armadura. Hay una advertencia al maestro para que acompañe las escalas una cuarta baja con el fin de que el alumno cante cómodamente.

Viene a continuación lo que él llama "Escala propia", que es la armónica, con una nota de que si fuese difícil para el alumno entonar la segunda aumentada, realice primero un ejercicio que escribe a continuación en el que prepara el salto $\mathrm{Fa}-\mathrm{Sol \# ,}$ intercalando la nota Mi. Después la escala melódica a la que llama "escala menor". 
Segunda aumentada y su inversión séptima diminuta:

Una lección en esta nueva tonalidad, compás de 2/2, figuración elemental, e inclusión de un intervalo de $2^{\mathrm{a}}$ aumentada y el mismo, poco después invertido.

\section{Tercera diminuta y su inversión sexta aumentada:}

Compás de 3/4. Se encuentra primeramente un intervalo de $3^{a}$ disminuida, bastante después su inversión a modo de semicadencia, y de nuevo el mismo de antes para finalizar dentro de un acorde de la familia de la dominante con $5^{\mathrm{a}}$ en menos. Aunque a partir de aquí, ya no señala la situación de estos intervalos.

\section{Cuarta diminuta y su inversión quinta aumentada:}

Compás de 3/4, y al igual que las otras primero encontramos los intervalos de $4^{\mathrm{a}}$ disminuida y luego los mismo invertidos en $5^{\mathrm{a}}$ aumentada. Aunque el autor no los señala.

\section{Tono de Sol mayor:}

Explica bien claro cómo a partir de la escala de Do mayor y de La menor se pueden constituir otras sobre cualquier sonido, la necesidad de sus alteraciones con las que se forman las armaduras, y la división de aquellas en accidentales y propias.

Una lección en compás de $2 / 2$ y figuración fácil para practicar esta tonalidad. Nota al maestro para que el discípulo repita mucho esta lección a fin de acostumbrarse al Fa sostenido como nota propia de la escala.

Del compás de 2 por cuatro marcado a 4 partes:

Se refiere este epígrafe a la subdivisión de un compás cuando el aire es lento y su figuración complicada (al menos conteniendo fusas, semicorchea con puntillo y fusa o de menor duración), y para facilitar al alumno la ejecución de la siguiente lección subdividida, muestra los primeros ocho compases de esa lección a 4/4 y luego a 2/4, para demostrar que casi sonaría igual de una forma que de otra. Al terminar la lección, anota que una vez bien aprendida se debe ejecutar a 2 despacio.

Lecciones 11 y 12 destinadas a practicar la subdivisión, en la segunda abundan los tresillos de semicorcheas y los seisillos de fusas 


\section{Clave de Fa en $4^{a}$ línea:}

Antes de su explicación, remite a una nota al pie en la que dice que aborda en esta segunda parte esta clave, porque es partidario de que el alumno, una vez haya superado estas dos partes, vaya practicando el instrumento (lo que era preceptivo en ese tiempo, y muchos años después, hasta la entrada en vigor de la LOGSE). También se declara partidario de que se comience con el instrumento cuando se sea un buen solfista, y no, como hacen otros maestros, que se contentan con dar nociones muy ligeras del solfeo y emprenden desde luego el estudio del instrumento...

Luego expone el significado y uso de la clave, el nombre de sus notas formando escala descendente y ascendente, aclarando desde este momento que los cinco últimos sonidos agudos (a partir del Do 3 ), son unísonos de los sonidos graves en la clave de Sol; y advirtiendo también que si el discípulo es niño o "tiple" cantará las lecciones de clave de Fa una $8^{\mathrm{a}}$ más alta de lo que representa, y si es tenor o bajo, habrá cantado las de clave de Sol una $8^{\mathrm{a}}$ más baja.

Tres lecciones seguidas con esta clave y la tonalidad que está tratando. La primera discurre casi toda por grados conjuntos, y el autor así lo expone diciendo que es para facilitar su estudio, lo que ya no ocurre con las otras dos. Pero no sólo hay que tener en cuenta que sea de fácil lectura y entonación, siendo las primeras lecciones en una nueva clave, también deben de ser sencillas de ritmo, lo cual también facilita la lectura; pues no, el autor, como la mayoría en la época, comienza lecciones con una nueva clave con semicorcheas, semicorcheas con puntillo, fusas y contratiempos de semicorcheas; sigue con síncopas muy breves, y ya termina la serie de 3 lecciones con fusas sincopadas.

\section{$\underline{\text { Tono de Mi menor relativo del de Sol mayor: }}$}

Explica la relación de la escala de La menor con la iniciada por la nota Mi, y la necesidad de ponerle un sostenido para conservar los tonos y semitonos en la misma posición, el porqué de llamarle relativa, y expone las dos escalas: armónica y melódica (no la natural), a las que llama, respectivamente, "propia” y "con alteración”

Una lección en compás de $2 / 2$, muy sencilla en cuanto a sus figuras, pero cargada de intervalos aumentados y disminuidos. La clave vuelve a ser la de Sol, y a partir de aquí alterna, no de una forma sistemática, ambas claves. 
Del doble puntillo:

Una explicación de su utilidad, y unos cortos ejemplos.

Dos lecciones para practicar esta medida, compases de 4/4 y 3/4, clave de Fa en las dos.

De las notas de adorno. De la apoyatura:

Definición de este signo como pequeña nota en la cual se apoya la voz antes de pasar a la nota ordinaria que le sigue, y dándole como valor la figura que ella representa, que dice, suele ser la mitad de la nota ordinaria; también dice que muchos maestros crean confusión con la representación de la apoyatura y el valor que en realidad quieren darle, y que afortunadamente, "ahora" ya se suelen escribir las apoyaturas con notas reales. Acompaña a esta explicación un pequeño ejemplo de traducción a notas reales de un pasaje con apoyaturas varias.

Dos lecciones con esta nota de adorno, claves de Sol y Fa, 4/4 y 3/4. En la segunda ya mete tresillos con negras y corcheas, y seisillos con silencios.

Del compás de 3/8:

Una breve explicación, comparándolo con el compasillo, y una lección, clave de $\mathrm{Fa}$, incluyendo la apoyatura.

\section{Tono de Fa mayor:}

Un comentario, ya más breve que los anteriores, del porqué del bemol en esta escala y su consideración de alteración propia, un ejemplo de la escala y 3 lecciones. La primera muy sencilla, blancas, negras y alguna corchea en compás de 2/2 (Es muy curioso que la primera lección de cada tonalidad sea sencilla, y las primeras de una nueva clave o compás no). Las otras dos, bastante más complicadas, en compás de $3 / 8$ con fusas y su silencio; introduce las casillas de $1^{\mathrm{a}}$ y $2^{\mathrm{a}}$ vez.

De las cuádruples corcheas (Semifusas):

Dos lecciones, en $3 / 8$ con abundancia de estas figuras.

$\underline{\text { Tono de Re menor relativo del de Fa mayor: }}$

Misma explicación de las anteriores, y la correspondiente lección en 2/2 sencilla. 


\section{Del mordente:}

En su explicación de este signo, agrupa todas las notas de adorno conocidas en dos grupos: las que nos apoyamos sobre ellas al ejecutarlas, y las que se ejecutan hiriendo o mordiéndolas pasajeramente. Según Eslava, al primer grupo pertenecen la apoyatura y la doble apoyatura, y al segundo el mordente, grupo, medio grupo, círculo y semicírculo (no aclara cual es la descripción de cada una de ellas); y en nota al pie dice que no incluye al trino por no ser materia de estudio solfístico sino con el instrumento. Continúa con la duración de ellas, y para las del segundo grupo afirma que son siempre rápidas de ejecución y tomando el valor de la nota anterior (a no ser que ésta sea muy corta). No tiene en cuenta por tanto la interpretación del periodo barroco.

\section{Mordente de una sola nota:}

Representa la figura con que se escriben para distinguirlos de la apoyatura, pero curiosamente, además de la forma acostumbrada, también los escribe con dos y tres barras cruzadas.
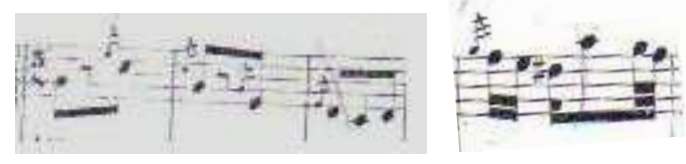

Dos lecciones con estas notas, una bastante sencilla en compás de 3/4, y la otra bastante complicada en compás de $3 / 8$.

\section{Del compás de 6 por 8:}

Una explicación de este compás y su comparación con el de 2/4. Una lección sencilla con negras y corcheas.

Del mordente de dos notas:

Simplemente expresa gráficamente su forma y añade todo lo explicado para el anterior a éste. Pero es curioso que solamente utiliza el recto ascendente y descendente, las otras clases de mordente de dos notas, ni las nombra ni aparecen.

Una lección con el compás y la tonalidad que estamos tratando con estos mordentes.

\section{Tono de Re mayor:}

Misma explicación de siempre y la consabida lección fácil. Añade a esto una disquisición sobre la conveniencia de subdividir el compás de 6/8 cuando su aire es lento a moderado, y propone dos maneras: haciendo dos compases de 3/8, o partiendo en 3 
cada uno de los dos tiempos. Nada dice de la otra opción, marcar la $4^{\mathrm{a}}, 5^{\mathrm{a}}$ y $6^{\mathrm{a}}$ subdivisión en el segundo, tercer y cuarto tiempo, y no nos parece adecuada, porque cambia la acentuación, la primera elección de dividir el compás en dos de 3/8.

Cuatro lecciones con este compás y los mordentes de una y dos notas, pero complicando el ritmo con semicorcheas con puntillo - fusa, precedida de mordentes, corchea sincopada a fusa y otras de parecida índole. En la última aparece el D. C.

\section{Tono de Si menor relativo del de Re mayor:}

Misma explicación que en los anteriores.

$\underline{\text { De los mordentes de } 3 \text { notas (Grupos y en italiano Grupetti): }}$

Divide estos en rectos y circulares, y los contrasta en su ejecución, los primeros siempre rápidos, los segundos según el aire de la pieza. Sigue una lección con estos signos. Después habla de las abreviaturas de estos grupetos, sin separar anteriores de posteriores, y otras dos lecciones con grupetos sin y con abreviación, además de complicaciones rítmicas.

Del compás de 9 por 8 :

Explicación de este compás y lección sencilla para introducirlo.

\section{$\underline{\text { Tono de Si bemol mayor: }}$}

Misma explicación que en los anteriores. Luego 3 lecciones con este compás, complicando más el ritmo, e introduciendo el signo de repetición\$.

\section{Mordente de 4 notas:}

Remite a la explicación de los de 3 notas, sin discriminar, en los posteriores, la manera de constituirse con 3 ó 4 notas. 1 lección para esta práctica.

\section{$\underline{\text { Tono de Sol menor relativo del de Si bemol mayor: }}$}

Misma explicación que en los anteriores y una lección más.

Del compás de 12 por 8:

Su explicación, una lección sencilla y otras dos con mayores complicaciones. También habla de la subdivisión, como en los anteriores. 
$\underline{\text { Recopilación de toda la } 2^{\mathrm{a}} \text { parte: }}$

Igual que al final de la primera, una lección que abarca varios componentes: empieza con compás de 4/4, Do mayor, fusas y síncopas muy breves también con fusas. Cambia a 12/8 y La menor, también con fusas. Pasa a Fa mayor y 3/4. Sigue en Fa mayor pero 9/8, hasta ahora clave de Sol. A partir de ahora clave de Fa en $4^{\mathrm{a}}$, Re mayor, compás de 2/4, notas de adorno. Siguen Si menor y 3/8. Sol mayor y 2/2, redondas y blancas. Mi menor y 2/4, figuración sencilla. Y acaba con Sol menor y 6/8 tampoco con grandes dificultades.

\section{VALORACIÓN DE ESTA SEGUNDA PARTE.}

Aunque ya en la primera parte se dieron todos los intervalos mayores y menores, está muy bien que en esta segunda parte dedique lecciones específicas a cada uno de estos intervalos. Es muy pertinente al exponer la clave de Fa en cuarta línea que hable de sus peculiaridades de altura o tesitura y de la relación entre ella y la de Sol. Nos parece, sin embargo, muy poco adecuado el comenzar las lecciones en la clave de Fa en $4^{\mathrm{a}}$, con figuraciones y dificultades métricas avanzadas. Al igual que en la primera parte las melodías son muy musicales.

\subsubsection{MÉTODO ESLAVA: TERCERA PARTE}

\section{CUADRO DE INFORMACIÓN GENERAL DE LA TERCERA PARTE.}

$\mathbf{N}^{\circ}$ de lecciones

Extensión de las lec- Entre 10 y 58 compases

ciones

Claves empleadas

Tesituras que abarcan

Tonalidades que trata y estudia

Compases que emplea y estudia

Dificultades métricas

49 Sol b M y Mi b m $10 / 8$,
Do $1^{\mathrm{a}}$, Do $2^{\mathrm{a}}$, Do $3^{\mathrm{a}}$, Do $4^{\mathrm{a}}$ Y Fa $3^{\mathrm{a}}$, intercalando las anteriores. (Do $3^{\mathrm{a}}$ y $4^{\mathrm{a}}$ no están en su altura real)

Como en las anteriores partes

La M, Fa \# m, Do M, Mi b M, Do m, Mi M, Do \# m, La b M, Fa m, Si M, Sol \# m Re b M, Si b m, Fa \# M, Re \# m,

Los anteriores más 4/2,4/8, 3/2, 3/8, 2/1, música sin compasear, 2/8, 12/4, 12/16, 9/4, 9/16, 6/2, 6/4, 6/16, 7/4, 5/4, y

No más que en los anteriores volúmenes, excepto las que se 
que contiene

Dificultades de entonación que se encuentran y orden en que se enseñan los intervalos

Armonía utilizada

Formas que tienen las lecciones

Introducciones, Intermedios o Codas instrumentales

Teoría de la música que incluye desprenden de los nuevos compases. Además valores irregulares de quintillo a oncillo

Igual que en los anteriores, (que no son muchas) más dobles alteraciones y enarmonías

Grados minorizados o mayorizados, acordes de $9^{\text {a }}$ diatónicos como retardos, modulaciones a tonos lejanos, algún grado alterado

A-B; A-B-C; A-B-A'

No tienen ninguna

Tiene bastante

\section{DESCRIPCIÓN DETALLADA DE ESTA TERCERA PARTE.}

\section{Del modo de escribir la música dictada:}

Comienza esta tercera parte con disquisiciones y consejos acerca de lo que hoy llamamos dictado musical, y D. Hilarión lo define así: arte de saber «notar» una pieza de música que se está oyendo, o que después de oírla se ha retenido en la memoria, o que se compone de propias ideas.

Y después de esta definición continúa diciendo que hay diversos procedimientos de utilización en el extranjero, que las escuelas llamadas de "enseñanza mutua" [?] acostumbran a ejercitarlo, que hay maestros particulares que emplean demasiado tiempo en ello, quitándoselo a otros estudios más convenientes, y por fin se declara poco partidario de esta práctica porque asegura que aquel que llegue a ser buen solfista, no tendrá ninguna dificultad en asimilar el dictado, por lo que esta materia la considera sólo adecuada a aquellos que tienen una mediana disposición respecto a la entonación y la medida.

No obstante, da unos consejos: el discípulo debe, al mismo tiempo que estudia esta tercera parte, repasar las primeras lecciones del método, y sobre la lección que esté repasando, el maestro le dictará 8 o más compases de similares características melódicas 
Eslava, tercera parte

y rítmicas, empezando y terminando siempre por la tónica. Se debe decir al alumno al principio el tono y el compás, y desglosar las dificultades rítmicas y melódicas; empezando por las rítmicas, propone que el maestro tararee, siempre con el mismo sonido, las figuras batiendo el compás, después cantando las notas; y así hasta que el discípulo se manifieste hábil para esto, sucesivamente deberá adivinar compás, tonalidad y aire. Dice que la extensión no debe ser mayor de una oncena (tesitura en la que se desenvuelven sus lecciones). No estamos de acuerdo con sus postulados respecto a la poca utilidad de esta materia, más bien la consideramos de todo punto importante para la educación del oído; si bien es cierto que, quien tiene disposición natural para la música tanto da que lo practique como que no, pero eso no sirve para la inmensa mayoría. Sin embargo suscribimos en su casi totalidad los consejos que da para realizarlos.

\section{De la clave de Do en primera línea:}

Nombre de las notas en escala ascendente y descendente y comparando su altura con las notas en la clave de Sol.

Una lección en Do mayor, 12/8 en la que la dificultad melódica es pequeña, pues discurre por grados conjuntos o terceras, pero la figuración es de semicorcheas, semicorcheas con puntillo - fusas, y notas de adorno. Ya en la parte anterior sucede lo mismo, al presentar una nueva clave la dificultad melódica la rebaja, no así la rítmica, contra lo cual ya nos hemos manifestado.

\section{Tono de La mayor:}

Procede como en la segunda parte, la escala y una lección en compás de 2/2 muy sencilla.

Hay una nota posterior a la lección en la que dice que para que se practiquen las tonalidades estudiadas en la $2^{\mathrm{a}}$ parte, habrá lecciones que tendrán transiciones a ellas. Y vuelve a insistir en que el alumno debe entonar las lecciones sin compás antes de medirlas, deteniéndose en cada nota todo lo que sea necesario para la seguridad de la afinación.

Dos lecciones más en 2/4 y 3/4, la primera todavía sencilla, la segunda con mayor complicación. 
De los compases o tiempos en general:

Largo discurso sobre los compases que se utilizan y los que están más en desuso. Expone que sería suficiente con la utilización de los compases de 2, 3 y 4 por cuatro para las divisiones binarias, y 6, 9 y 12 por 8 para las ternarias, pero que mientras llega el tiempo que eso ocurra [ya ha llegado], él debe de dar a conocer todos los compases, se usen poco o mucho. Comenta luego la existencia anterior de las figuras mayores que la redonda, cuadrada, longa y máxima, así como que desaparece su uso después de la invención del compás y las líneas divisorias. Divide luego los compases en simples (de combinación doble) y compuestos (de combinación tiple [sic]) y pone una gran tabla de compases agrupados de la siguiente manera:

Compases de combinación doble a 4 partes: 4/2, 4/4 compasillo, 4/8. Compases de combinación doble a 3 partes: 3/2, 3/4 y 3/8. Compases de combinación doble a 2 partes: compás mayor o de 2/1, compás binario 2/2, 2/4, 2/8 llamado rápido. Compases de combinación triple a 4 partes: 12/4, 12/8, 12/16. Compases de combinación triple a 3 partes: 9/4, 9/8, 9/16. Compases de combinación triple a 2 partes: 6/2, 6/4, 6/8, 6/16 llamado rápido.

Continúa con aclaraciones de nomenclatura respecto a la denominación de compasillo, y compás mayor o de proporción mayor (2/1 y 4/2), compás ternario al 3/2, y apostilla que los compases de denominador 1 y 2, y los llamados rápidos, dejaron de tener efecto cuando aparecieron las palabras Largo, Adagio, Allego, Vivo, etc.

Una lección, todavía en La mayor y compás de 4/4.

\section{Compás de 4/2:}

Dos lecciones con las figuras propias de este compás y armonía muy tradicional, propia de los motetes renacentistas.

Tono de Fa sostenido menor, relativo del de La mayor:

Misma explicación que en los anteriores

\section{Compás de 4 por 8 :}

Una lección y otra en compás de 3/4. 
Eslava, tercera parte

Compás de 3 por 2, llamado ternario:

Dos lecciones con las figuraciones propias del compás, la segunda en clave de Sol, según dice el autor para practicar las anteriores, y además con notas de adorno.

Clave de Do en $2^{\text {a línea: }}$

Como con las anteriores, nombres de las notas y su equivalencia con la de Sol.

Una lección en Do mayor y 3/4.

Tono de Mi bemol mayor:

Misma explicación que en los anteriores.

Compás de 3 por 8:

Una lección.

Compás de 2 por 1 :

Una lección.

De los grandes silencios:

Explica aquí el silencio de cuadrada y la manera antigua de indicar varios compases de silencio en los compases mayores y en los menores, y la forma actual,

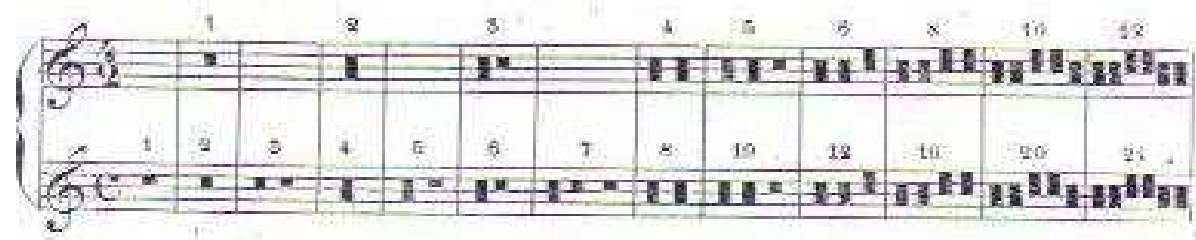

Sigue hablando de la música sin compasear y la ilustra con dos lecciones, compases de 2/1 y 2/2 sin líneas divisorias, la primera en contrapunto doble y la segunda en estilo fugado. Completa esta disertación aconsejando al alumno que si quiere ampliar el estudio de la música sin compasear, le quite mentalmente las líneas divisorias a cualquier lección de denominador 2 ó 1.

Compás de 2 por 8 :

Una lección en clave de Sol. 
$\underline{\text { Tono de Do menor relativo de Mi bemol mayor: }}$

Misma explicación que en los anteriores, más una lección en compás de 12/8.

Compás de 12 por 4 :

Dos lecciones.

Clave de Do en $3^{\text {a línea: }}$

Explicación de costumbre y una lección en Do mayor y compás de 12/8.

\section{Tono de Mi mayor:}

Misma explicación que en los anteriores, más una lección. A partir de esta lección, cada vez que hay una nueva tonalidad, aparece la voz en dos pentagramas: el primero en clave de Sol y medio tono alto o bajo con respecto a la tonalidad que ahora se está estudiando, esto es, comparando la nueva tonalidad con otra ya practicada que se haya a distancia de semitono de la nueva, y así, según dice el autor, comparar uno con otro y ver que ninguna dificultad presenta la entonación con muchas alteraciones, y también la diferencia de alteraciones accidentales.

Compás de 12 por 16 :

Una lección.

Tono de Do sostenido menor relativo del de Mi mayor:

Misma explicación que en los anteriores, más una lección comparando esta tonalidad con la de Do menor.

Compás de 9 por 4 :

Una lección.

$\underline{\text { Tono de La bemol mayor: }}$

Una lección comparándola con la tonalidad de La mayor.

Compás de 9 por 16:

Una lección. 
Eslava, tercera parte

Tono de Fa menor relativo del de La bemol mayor:

Una lección comparándola con la tonalidad de Fa sostenido menor.

Compás de 6 por 2 :

Una lección.

Clave de Do en $4^{\text {a }}$ línea:

Explicación de siempre y 1 lección en Do mayor y compás de 9/16.

Tono de Si mayor:

De las dobles alteraciones:

Comentario del efecto de ellas, que dice suele aparecer en las tonalidades de $4 \mathrm{o}$ más alteraciones en la armadura, y ejemplos de su efecto.

Una lección en esta tonalidad comparándola con la de Si bemol mayor.

Compás de 6 por 4 :

Una lección.

Tono de Sol sostenido menor relativo del de Si mayor:

Como siempre, más una lección comparándola con el tono de Sol menor.

Compás de 6 por 16 :

Una lección.

Tono de Re bemol mayor:

Una lección comparándola con Re mayor.

Compás de 7 por 4 :

Explica este compás del grupo de los amalgamados, su forma de marcar, haciendo uno de 4 y otro de 3, y lo utiliza en una lección que, al menos en esta ocasión, contiene figuras sencillas y es asequible su ejecución.

$\underline{\text { Tono de Si bemol menor relativo del de Re bemol mayor: }}$

Una lección comparándola al tono de Si menor. 


\section{Compás de 5 por 4:}

Igual que en el anterior amalgamado, pero esta vez la lección es un poco más difícil.

De los géneros:

Habla en este momento de los tres géneros, el diatónico, el cromático y el enarmónico. De los semitonos diatónicos y cromáticos y de la enarmonía.

\section{Clave de Fa en $3^{\text {a línea: }}$}

Como siempre que ha presentado una nueva clave, pero en esta ocasión aumenta la información con la escala diatónica de Do mayor con esta clave y la escala cromática.

\section{Práctica del género enharmónico [sic]:}

Una lección, previamente advierte que señala las enarmonías con este signo Tono de Fa sostenido mayor:

Una lección comparándola al tono de Fa mayor.

\section{Compás de 10 por 8 , llamado de zorzico [sic]:}

Antecede a las lecciones de este ritmo, una larga explicación de este compás característico, con una presentación de él como algo inaudito. Es un compás distinto de todos los demás, dice Eslava, "que consiste en la combinación de 10 corcheas de igual valor repartidas en 2 solas partes, entrando 5 de ellas en cada una". Asevera que el nombre viene de zorzi, que en vascuence significa 8 ; y este 8 no se refiere, no hace referencia a la unidad de tiempo, sino a los versos que son 8 los que componen este género de canciones. ${ }^{1}$ Prosigue apuntando que ha visto escrito este compás en $5 / 8$ y 6/8, y que en este último es un grave error (así lo consideramos nosotros también), porque su división es por tercios y el zortzico se divide en quintos y "décimos". Descarta el de 5/8 diciendo que aunque es exacto, es dificilísimo para marcarlo, porque hay que dividirlo en 2 partes, dando a la $1^{a} 3$ quintos y a la $2^{a} 2$ y da como compás verdadero el de 10/8

\footnotetext{
${ }^{1}$ PRECIADO, Dionisio. (1978). Don Hilarión Eslava y su "Método completo de solfeo" en Monografía de Hilarión Eslava..., p. 258, asegura que "zorzico" es igual a ocho, y que en vasco significa "estrofa de ocho versos"; y añade que: la métrica del euskera conoce diversas estrofas de ocho versos - la larga, la mediana y la corta - ...
} 
Eslava, tercera parte

dividido en 2 partes iguales, entrando en cada una de ellas 5 corcheas. No estamos en absoluto de acuerdo, pues los acentos se producen alternativamente en tiempo fuerte y débil, convierten a la segunda parte del compás en tiempo fuerte. Quizás lo hiciera como recurso pedagógico, pero debió aclararlo.

A continuación viene una lección preparatoria del verdadero zortzico, que justifica el autor como acomodo del oído del alumno a la combinación quíntuple, es en 10/8 con 10 corcheas por compás.

Sigue otra con los mismos sonidos, o sea igual, pero ya con el ritmo propio del zortzico.

Tono de Re sostenido menor:

Una lección comparándola con el tono de Re menor.

\section{Tono de Sol bemol mayor:}

Valores irregulares:

Se llaman valores irregulares, cuando en lugar de entrar 4 figuras en una parte entras 5, o en lugar de 8 entran 7, 9 o más notas etc. Así define Eslava estos grupos, y pone ejemplos de quintillo, septillo, nonillo, diecillo y oncillo. Para nada los relaciona con el tresillo y seisillo, y nada dice del dosillo, cuatrillo y octosillo. Sólo añade que cuando la irregularidad es por aumentación hay que apresurar la ejecución de las notas, y cuando es por disminución retrasarlas. [Evidente]

Dos lecciones con estas medidas y en la tonalidad epigrafiada, la primera comparándola con el tono de Sol mayor.

$\underline{\text { Tono de Mi bemol menor relativo del de Sol mayor: }}$

Una lección comparándola con el tono de Mi menor.

Después de esta lección, que es la última, explica que no es necesario acometer el estudio de lecciones con más de 6 alteraciones en la armadura, ya que éstas son enarmónicas de otras, y pasa a exponer una tabla de tonalidades enarmónicas, en la que figuran las 3 con armaduras practicadas, y todas las otras con dobles sostenidos y dobles bemoles. Y con esto termina la tercera parte 


\section{VALORACIÓN DE ESTA TERCERA PARTE.}

Nos parece muy positivo el estudio de lecciones en, prácticamente, todos los compases existentes, incluso algunos de los irregulares más utilizados. No nos parece adecuado el orden de estudio de las claves, pero es el que se solía llevar en la época y hasta no hace muchos años (prácticamente hasta los años 90 del siglo XX). Sigue con la misma tónica de rebajar las dificultades melódicas al presentar una nueva clave pero no las rítmicas que también entorpecen mucho, o quizás más, la lectura de una clave con la que no se tiene familiaridad. También nos parece útil comparar tonalidades desconocidas con armaduras abundantes, con otras ya conocidas de menor cuantía en sus armaduras. Puesto que pasa por todas las tonalidades practicadas, no vemos porque no ha de haber alguna lección en Do sostenido mayor y su relativo, pues aunque como él dice, son enarmónicas de Re bemol mayor, también lo son Fa sostenido mayor y Sol bemol mayor, con sus relativas, y las dos están contempladas. Pero no tiene esto demasiada trascendencia.

\subsubsection{MÉTODO DE ESLAVA: CUARTA PARTE}

\section{CUADRO DE INFORMACIÓN GENERAL DE LA PARTE CUARTA.}

$\mathbf{N}^{\circ}$ de lecciones

Extensión de las lec- De 20 a 132 compases

ciones

Claves empleadas

Tesituras que abarcan

Tonalidades que trata y estudia

Compases que emplea y estudia

Dificultades métricas que contiene

Dificultades de entonación que se encuentran $y$ orden en que se enseñan los intervalos

Todas, excepto Fa $3^{\mathrm{a}}$ rece la fermata
8 estudios a 2 voces y una canción

Las mismas que en las anteriores partes

Do M, Re m, Sol M, La m, Mi M, Sol \# m, Re b M, Sol b M. Con cambios al relativo o enarmónico

4/4, 12/8, 3/4, 9/8, 2/4, 6/8, 2/2.

Las mismas que en las anteriores partes. En los simples son muy sencillas, en los compuestos llegan hasta la fusa. Apa-

No más que en los anteriores, tal vez menos, ya que son lecciones melódicas a modo de práctica coral. 
Eslava, cuarta parte

Armonía utilizada La misma que anteriormente, incluso más sencilla.

Formas que tienen las A-B-A'; A-B; A-A'- A

lecciones

Introducciones, Inter- No hay

medios o Codas ins-

trumentales

Teoría de la música Tiene mucha, aproximadamente $50 \%$ de teoría que incluye

\section{DESCRIPCIÓN DETALLADA DE ESTA CUARTA PARTE.}

De las claves:

Da a conocer la relación que tienen entre si las 7 claves, lo ilustra gráficamente con un ejemplo comparando todas al Do 3 de la clave de Sol, y con un esquema de la utilización antigua de las claves para voces y sus extensión.

Instrucciones para conocer el tono y modo en que está escrita una pieza:

Aquí es donde detalla el orden de las alteraciones en las armaduras, la distancia entre los tonos relativos, las normas para hallar cada tonalidad sabiendo su armadura y la manera de cerciorarse de en cual de las dos tonalidades posibles nos hallamos.

Entresacamos algunas de las reglas dadas que creemos útiles o más originales: El relativo menor está un tono más abajo del último sostenido. Si en una melodía aparece la $5^{\text {a }}$ del modo mayor alterada, es porque estamos en su relativo menor. No obstante hay ocasiones en las que solamente el bajo del acompañamiento puede dar la seguridad del tono en que nos encontramos.

Y añade unos cuantos ejemplos de todo ello.

Del transporte:

Definición y explicación de su utilidad. Pero carece de explicación concreta y precisa de las normas para llevarlo a cabo; se extiende mucho, pero a base de ejemplos, con lo que un tema tan complejo en su inteligibilidad requiere, de muchos ejemplos, sí, pero primeramente de mucha teoría y normas claras y ordenadas. 


\section{De la ficción de claves:}

Hace mención este epígrafe al Do móvil o solfeo relativo que preconizó Sarah Glover y adoptó Zoltan Kodaly, esto es, transportar todo a Do mayor o La menor para evitar el cantar con alteraciones propias.

Da muchas normas, de las que extraemos las que nos parecen más curiosas: En los tonos que llevan bemoles en la clave, el último de ellos se cuenta Fa, y según la colocación de este signo en el pentagrama, se busca la clave fingida o supuesta que le pertenece. En los tonos que llevan sostenidos el último de ellos se cuenta Si, y según su colocación en el pentagrama, se busca igualmente su correspondiente clave. Los becuadros accidentales se ejecutan como sostenidos cuando destruyen bemoles, y se entonan como bemoles cuando destruyen sostenidos.

Hay 3 ejemplos que ilustran esta cuestión.

Después da su opinión, que es la de que en muchos casos puede ser útil adiestrar a los alumnos en este sistema, pero que en otros, lejos de facilitar el solfeo, lo complica.

Serrallach explica este concepto de ficción de claves:

Así como el sistema de la mutación exigía que todos los semitonos se llamaran "mi-fa" y todos los exacordios "Ut, re, mi, fa, sol,, la", en la ficción de claves se buscaba de cantar siempre en la tonalidad de DO MAYOR o de LA MENOR....se trataba de evitar las alteraciones accidentales, sosteniendo que su entonación era de extrema dificultad.

Resulta inexplicable que no echaran de ver que era más difícil trasladar el sentido tonal interno que entonar directamente la alteración. ${ }^{1}$

\section{ESTUDIOS DE SOLFEO A 2 VOCES:}

Prologa ligeramente esta sección fijando sus objetivos: Acostumbrar al discípulo al canto simultáneo. Hacerle practicar la relación de las claves entre si. Ejercitarlo en los dos modos correspondientes a un mismo tono. Completar la instrucción del solfista tanto en las dificultades de medida como en las de entonación.

Todas llevan como acompañamiento un bajo sin cifrar, por lo que hay que adivinar el acorde mediante el análisis del bajo con las voces.

Estudio 1: Do mayor, 4/4, claves de Sol y Do $1^{\mathrm{a}}$. Tres secciones, en la segunda cambia a Do menor, e invierte las voces, en la tercera vuelve a Do mayor y al orden primero. 
Eslava, cuarta parte

Estudio 2: Re menor, 12/8, Do $1^{\mathrm{a}}$ y Do $3^{\mathrm{a}}$ en su altura real. Dos secciones, la segunda en Re mayor e inversión de partes.

Estudio 3: Sol mayor, 3/4, Do $3^{\mathrm{a}}$ y Do $4^{\mathrm{a}}$. Tres secciones, la segunda en Sol menor, y la tercera es un Da capo.

Estudio 4: La menor, 9/8, Do $4^{\mathrm{a}}$ y Fa $4^{\mathrm{a}}$, dos secciones, la primera entre la voz superior, y la inferior con una imitación al unísono a distancia de 4 compases, que mantiene otros 4 , después pequeños fragmentos homofónicos, alternan con otras imitaciones a distancia de tiempo e incluso de parte; la segunda sección está en La mayor, es más corta y no presenta esas características, es un contrapunto libre.

Estudio 5: Mi mayor, 2/4, Sol y Do 1 ${ }^{\mathrm{a}}$. Tres secciones, la segunda, en Mi menor, es una especie de variación de A, pero en el sentido de que las dos partes proceden como en un movimiento contrario libre con respecto a la primera, acaba esta sección con una pequeñísima fermata; la tercera sección es un Da capo de la primera.

Estudio 6: Sol sostenido menor, 6/8, Do $3^{\mathrm{a}}$ y Do $4^{\mathrm{a}}$. Dos secciones, en la primera hay una imitación a la $4^{\text {a }}$ descendente, a distancia de 4 compases, que se terminan cuando la segunda voz ejecuta esos mismos compases; pero esa semifrase o periodo se repite varias veces a lo largo de esta sección; la segunda está en La bemol mayor, el enarmónico mayor de la tonalidad principal, y no tiene que ver con la anterior.

Estudio 7: Re bemol mayor, 2/2, Do $4^{\mathrm{a}}$ y Fa $4^{\mathrm{a}}$. Tres secciones, la primera con bastantes imitaciones; la segunda en Do sostenido menor, distinta a la anterior, aunque dentro del mismo ritmo; la tercera de nuevo en la tonalidad principal, y llevando la $2^{\text {a }}$ voz, la melodía, variada, que llevaba la $1^{\text {a }}$ en la sección inicial.

Estudio 8: Sol bemol mayor, 4/4, Sol y Fa 4a. Dos secciones, distintas una de otra, aunque similares en cuanto al ritmo, muy contrapuntísticas ambas; la segunda en Fa sostenido menor.

\footnotetext{
${ }^{1}$ SERRALLACH, Lorenzo. (1953). Historia de la Enseñanza Musical..., Cap. VI, p. 187,
} 


\section{Líneas adicionales:}

Como las lecciones no rebasan la extensión de undécima, ve el autor la necesidad de que el alumno conozca al menos la existencia de notas que sobrepasan el pentagrama para la lectura de partituras instrumentales, y pone unos ejemplos para leer tanto en clave de Sol, como en la de Fa.

\section{$\underline{\text { Trino y semitrino: }}$}

Breve explicación de estos adornos, con algún ejemplo, ya que tampoco han aparecido en las lecciones, debido a no ser propios del solfeo, según dice el autor.

\section{Vocalización:}

Simplemente aconseja al solfista ejercitarse en vocalizar (principalmente con la a) algunas de las lecciones anteriores, antes de dar paso a cantar con palabras.

\section{Canto con palabras:}

Una lección, que es una fugueta a 4 voces, en Si bemol mayor, compás de 4/4, ritmo sencillo, y letra religiosa.

Pero previamente, advierte que al cantar con palabras hay que tener presente que se debe pronunciar exageradamente tanto vocales como consonantes, o sea, que se entienda perfectamente el texto. En contra, afirma, del vicio de muchos cantantes que no se distingue si pronuncian en español, italiano o en árabe (literal). Y no le falta razón.

\section{Articulaciones:}

Las resume en dos: ligado y picado; y este último lo subdivide en picado, muy picado (stacato) y picado ligado. No habla de los acentos.

\section{Abreviaciones:}

Se refiere a las barras que desdoblan figuras, al trémolo, y a los signos $\%$ y $\%$

\section{Matices:}

Una gran tabla, dividiendo éstos por grupos: primero los dinámicos y agógico dinámicos (sin establecer esta división); luego los Aires o Movimientos con todas sus posibilidades, incluyendo ahí algunos de los agógicos; por último los Términos que pertenecen al carácter y la expresión. 
Eslava, cuarta parte

Conocimientos generales de harmonía [sic]:

Termina el libro con referencias a los intervalos armónicos y a los acordes, su formación, incluso su cifrado, incluyendo los acordes cuatríadas (a los que llama acordes disonantes, contra consonantes que llama a las tríadas).

\section{VALORACIÓN DE ESTA CUARTA PARTE.}

Es complementaria de las otras tres, formativa, y a la vez informativa de las materias, que sin ser imprescindibles, rematan la formación del que se educa en la música. Aborda las cuestiones teóricas de mayor nivel, sin profundizar demasiado en ellas, pero sin dejar fuera ninguna de las importantes. También vienen a completar la formación del nuevo músico la serie de lecciones a 2 voces en las que se practican todas las claves importantes, los compases más usados, y se repasa todas las dificultades rítmicas tratadas a lo largo de los métodos; a lo que hay que añadir su gran musicalidad, su magnífica estructura y textura polifónica.

\subsubsection{VALORACIÓN DE LA EFECTIVIDAD DEL MÉTODO Y DE SU APORTACIÓN A LA ENSEÑANZA}

En general es un buen método, con sus defectos como todos, pero, salvando las costumbres de su época, afronta todas las cuestiones solfísticas, no deja nada en el aire, no va de pasada por ninguna dificultad, sin ser tampoco exhaustivo, está bien calculada la progresión de las dificultades, abunda en consejos para el enseñante que juzgamos muy oportunos, y sobre todo tiene musicalidad. Sus melodías son bonitas, asequibles y agradables de cantar. Si añadimos a la aridez del solfeo la fealdad de las lecciones con que vamos a inculcar la música, pocas probabilidades de éxito tendremos.

Su aportación a la enseñanza fue de capital importancia, y ha sido durante muchos años el referente para la programación de muchos métodos posteriores.

De la importancia de este método hablan por si solos los datos que siguen, referentes a la cantidad de ediciones que tuvo, que prácticamente llegan a nuestros días:

\begin{tabular}{|c|c|}
\hline$\frac{\text { Año de }}{\text { edición }}$ & Editorial. (Todas en Madrid) \\
\hline 1878 & Gran Casa Editorial \\
\hline 1878 & Litografía de Santos González \\
\hline 1893 & Sin editorial \\
\hline 1896 & Librería de Hernando y Cía. \\
\hline
\end{tabular}


1899 Sin editorial

1901 Librería de Perlado, Páez y Cía.

1910 Librería de Perlado, Páez y Cía.

1981 Librería y Casa Editorial Hernando S. A.

1983 Unión Musical Española

1985 Editorial Música Moderna S. A.

1986 Editorial Música Moderna S. A.

1987 Música Moderna D. L.

1987 Editorial Música Moderna S. A.

1994 Editorial Música Moderna S.A.

1998 Ediciones Musicales Mega S. L.

1999 Ediciones Musicales Mega S. L ${ }^{1}$

\footnotetext{
${ }^{1}$ Datos extraídos de las páginas webs de "rebiun” e ISBN.
} 
Eslava, cuarta parte 


\subsection{RESEÑA BIOGRÁFICA DEL AUTOR}

SOBEJANO AYALA, José de. Cintruénigo (Navarra) 16/12/1791 - Madrid 14/9/1857. Profesor, organista, pianista y compositor. Organista en la Catedral de Pamplona. Músico mayor de la división Espoz y Mina durante la guerra de la Independencia, organista de la capilla musical de Bilbao y de León. Organista de la Real Capilla de San Isidoro de Madrid. Profesor del Real Seminario de Nobles de Madrid (Casares, Emilio en AAVV, 1999, tomo 9, pp.1042 y 43 y Saldoni, op. citada, tomo III, p. 195).

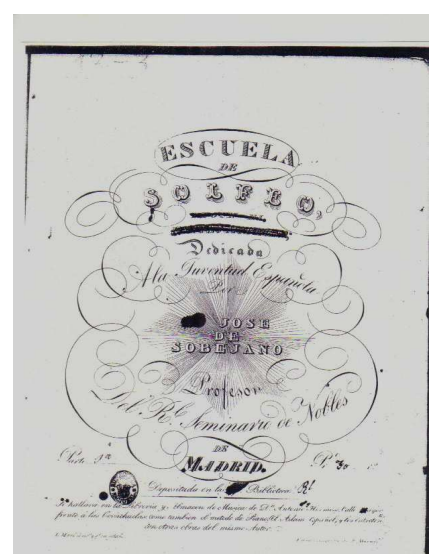

\section{Título del Método}

Escuela de solfeo, según el estilo moderno, dedicada a la juventud española, Madrid, B. Wirmbs, s. f. ${ }^{1}$ Apéndice, página 200.

\subsubsection{DESCRIPCIÓN DETALLADA DEL MÉTODO.}

Comienza con un "Advertencia a la juventud", que a modo de prefacio cuenta cómo nació su intención de hacer este libro (para enseñar a sus hijos), los progresos que con él han hecho sus alumnos, y los contenidos de las 3 partes en que se divide, que analizaremos separadamente de forma detallada.

\subsubsection{PARTE PRIMERA: ELEMENTOS DE LA MÚSICA}

\section{CUADRO DE INFORMACIÓN GENERAL DE LA PARTE PRIMERA.}

$\mathbf{N}^{\circ}$ de lecciones

Extensión de las lec- Entre 24 y 224 compases

ciones

Claves empleadas

\section{9}

Sol

\footnotetext{
${ }^{1}$ En el catálogo de la Biblioteca Nacional pone con interrogante 1820, ello no sería posible si su vida transcurrió entre 1819 y 1885 como figura en el dicho catálogo; sí lo sería si vivió entre 1791 y 1857 y es el José Soberano Ayala que aparece en Diccionario de la Música española e Hispanoamericana, tomo 10, p. 11, firmado por Emilio Casares, y en Diccionario Saldoni, tomo III p. 151. PRECIADO, Dionisio. (1978). Don Hilarión Eslava y su "Método completo de solfeo" en Monografía de Hilarión Eslava,..., p. 239 indica: ca, 1845.
} 
Tesituras que abarcan $\mathrm{Do}_{3} \mathrm{a} \mathrm{Fa}_{4}$

Tonalidades que trata Do M y La m, y estudia

Compases que emplea $4 / 4,3 / 4,2 / 4,3 / 8,6 / 8,9 / 8,12 / 8,2 / 2$ y $6 / 4$ y estudia

\section{Dificultades métricas que contiene}

Dificultades de entonación que se encuentran y orden en que se enseñan los intervalos

Armonía utilizada

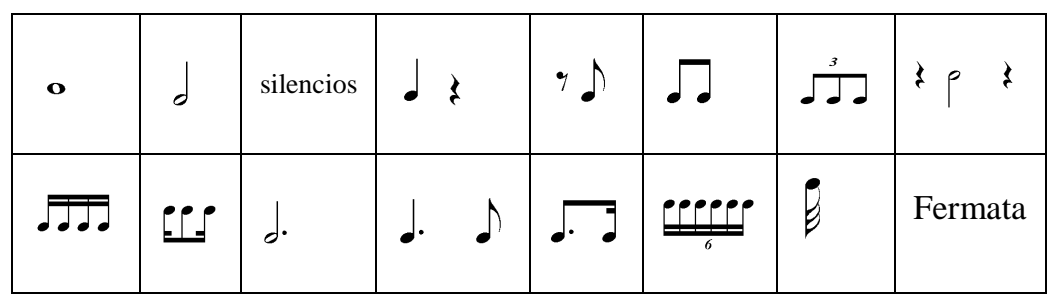

Muy pocas, a veces hay algún intervalo aumentado y disminuido.

De segundas a octavas, preparadas y de salto
Muy clásica y sencilla, hasta la 17 todas tienen la misma estructura armónica, la parte A está en Do La parte B, modula a La m, a Sol para volver a A Las demás no es que cambien mucho, pero no llevan exactamente esa estructura. También aparece en alguna ocasión algún acorde de $7^{\mathrm{a}}$ disminuida

A-B-A; A-B-A'; A-B; A-A'-B

No tienen

\section{Introducciones, In- termedios o Codas instrumentales}

Teoría de la música que incluye
Al principio para conocer los elementos indispensables

\section{SECUENCIA}

Y ya entrando en materia, la teoría básica dividida en artículos, 10 en total, y en forma de diálogo.

Conceptos de música, música vocal, música instrumental, partes principales de la música (que según el autor son armonía y melodía, olvidando absolutamente el ritmo) y solfeo. Pentagrama, líneas adicionales. Los signos o voces de la música y la escala diatónica. Figuras, compás de compasillo (las figuras con denominación antigua) y aspiraciones o pausas. Intervalos, tono y semitono, voces de la escala ("tónica, segunda, 
mediante, subdominante, dominante, relativa, sensible y equisonante u octava"), escala cromática y escala enarmónica. Las llaves o claves. Los accidentes, incluido el orden de las armaduras. Los compases, que los divide en binarios y ternarios (por lo que los cuaternarios también los agrupa con los binarios), puntillo de aumento y síncopa o semicopado. Abreviaturas o signos de repetición y signos de expresión entre los que figuran las notas de adorno, el calderón, la ligadura y el movimiento. Los adornos simplemente los divide en apoyaturas (que son éstas y los mordentes de 1 y 2 notas, y los mordentes, que son los grupetos de 3 notas anteriores y su abreviatura.

Terminada la teoría, da instrucciones de cómo se debe seguir una vez el alumno haya fijado en su mente todas estas cuestiones (o sea que primero toda la teoría y luego la práctica. Todo lo contrario a los postulados pedagógicos actuales): memorizar perfectamente el nombre de las notas en la clave de Sol, líneas adicionales incluidas y solamente leer notas con las primeras lecciones. Pasar luego a leer y entonar sin medir todas las lecciones. Luego leer, medir y entonar. Una vez haya solfeado las 19 lecciones de esta primera parte, puede ir comenzando a vocalizar los intervalos, y luego puede aplicar letra a la música una vez haya vocalizado este número de lecciones.

Por ello refleja el nombre de las notas en líneas y espacios, en líneas y espacios adicionales hasta el $\mathrm{Mi}_{2}$ y hasta el $\mathrm{Fa}_{5}$, entonaciones de intervalos desde segundas hasta octavas, preparadas y de salto y un resumen de todos.

Empezando ya las lecciones propiamente dichas, lo hace con redondas, blancas y sus silencios una lección, y añade, desde ésta el párrafo\&; todas ellas llevan acompañamiento en forma de bajo cifrado. Otra lección con negras y su silencio, cuatro con corcheas y calderón, a la quinta ya aparece el silencio de corchea formando contratiempo corto, a la siguiente tresillos de corchea y síncopas largas a la que sigue (que es la 9).

Una lección para cada una de estas novedades: semicorcheas, síncopas muy breves, contratiempo irregular, puntillo a la blanca, negra y corchea, ligadura, apoyaturas, abreviaturas, mordentes, seisillos de semicorcheas y fusas.

Como si de una segunda sección se tratase, aparece la escala cromática y la de La menor. A partir de este momento se suceden lecciones con alteraciones accidentales, formando toda clase de intervalos, y con los distintos compases que figuran arriba, a razón de una lección, o máximo dos por compás. En algunas se incluye una pequeña fermata. 


\section{CUADRO DE INFORMACIÓN GENERAL DE LA PARTE SEGUNDA.}

$\mathbf{N}^{\circ}$ de lecciones

Extensión de las lec- Entre 17 y 57 compases

ciones

Claves empleadas

Tesituras que abarcan

Tonalidades que trata y estudia

Compases que emplea y estudia

Dificultades métricas que contiene

Dificultades de entonación que se encuentran $y$ orden en que se enseñan los intervalos

Armonía utilizada

Formas que tienen las lecciones

Introducciones, Intermedios o Codas instrumentales

Teoría de la música No tiene que incluye

\section{2}

Sol y Fa $4^{\mathrm{a}}$

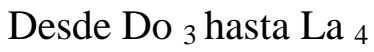
tad sirve de intermedio
Sol M, Mi m, Re M, Si m, La M, Fa \# m, Fa M, Re m, Si b M, Sol m, Mi b M, Do m, Mi M, Do \# m, La b M, Fa m, Si M, Sol \# m, Re b M, Si b m.

Los mismos que en la otra parte

Las anteriores más semifusa

Las mismas, pero muchos saltos en la melodía

Igualmente muy clásica, alguna serie de séptimas diatónicas. Muchas segundas inversiones en tiempo fuerte, esto es característica más romántica

A-A'; A-B-A; A-B; A-B-C; A-B-A'

Una lección solamente tiene introducción rítmica, que a mi-

\section{DESCRIPCIÓN DETALLADA DE ESTA SEGUNDA PARTE.}

Está toda ella dedicada a practicar las distintas tonalidades mayores y menores hasta 5 alteraciones en la armadura. También la clave de $\mathrm{Fa}$ en $4^{\mathrm{a}}$ línea. No incluye ninguna otra novedad, los mismos compases y dificultades que en la primera parte.

Cada vez que aparece una nueva tonalidad, hay unos ejercicios de entonación con la escala, intervalos distintos a partir de la tónica, el arpegio sobre el acorde de tóni- 
ca (que aunque así figura, en realidad es el arpegio de tónica, subdominante, dominante y tónica, empezando siempre por el primer grado) y la escala cromática.

Cuando la tonalidad es del modo menor, no hay distintos intervalos, y la escala que presenta es en la forma natural y melódica.

El término medio de cantidad de lecciones por tonalidad viene a ser de dos. Tres de ellas tienen 3 lecciones (Mi bemol mayor, Mi mayor y La bemol mayor). Una tiene 4 (Si menor) y dos tienen 1(Mi menor y Re menor), sin que se descubra a qué se debe este mayor o menor número de lecciones en algunas tonalidades.

En las lecciones con fusas y semifusas, indica "en 4 tiempos" para que se subdividan.

Una de ellas, la $\mathrm{n}^{\circ} 62$, es un canon entre la voz y el bajo cifrado. Comienza la voz, y a distancia de dos compases le imita el bajo a la octava, a la segunda sección, comienza el antecedente el bajo, y a la misma distancia le imita la voz.

\subsubsection{PARTE TERCERA: LECCIONES POR LAS LLAVES RESTANTES}

\section{CUADRO DE INFORMACIÓN GENERAL DE LA PARTE TERCERA.}

$\mathbf{N}^{\circ}$ de lecciones

Extensión de las lec- Entre 28 y 90 compases

ciones

Claves empleadas

Tesituras que abarcan

Tonalidades que trata y estudia

Compases que emplea y estudia

Dificultades métricas que contiene

Dificultades de entonación que se encuentran $y$ orden en que se enseñan los intervalos Armonía utilizada

Formas que tienen las lecciones
17
$\mathrm{De}_{3}$ a Do $_{5}$

Do M, Re M, Si b M, Do m, La M, La m, La b M Fa M, Mi M, Sol m, Re b M, y Si M

Los mismos que en las otras partes

Las mismas, aunque en menor abundancia

Las mismas

La misma

A-B-A'; A-B-C; A-A'; A-B-A 
Introducciones, Inter- 1 intermedio de 2 compases medios o Codas instrumentales

Teoría de la música No tiene que incluye

\section{DESCRIPCIÓN DETALLADA DE ESTA TERCERA PARTE.}

En el orden de aparición de las claves que figura arriba, dedica tres lecciones a cada una de ellas, a excepción de la primera de Do, que comprende cinco lecciones. En la segunda de esta clave, hay un recitativo dialogado entre el bajo del piano y la voz a modo de introducción. En la quinta hay una introducción a voluntad. No son muy difíciles las lecciones dedicadas a esta clave.

En las de Do en $4^{\mathrm{a}}$, ya empieza a haber más dificultades métricas, en una de ellas vuelve a haber un recitativo intermedio, y las melodías vuelven a ser, como en la mayoría de la parte segunda, verdaderas cabriolas y arabescos.

Las de Do en $3^{\text {a }}$ vuelven a ser más sencillas; la tercera de ellas es un canon a la octava en la misma manera que había hecho con la lección 62 de la parte segunda.

Tampoco tienen excesivas dificultades las de Do en $2^{\mathrm{a}}$. Pero al llegar a Fa en $3^{\mathrm{a}}$, cuando debían ser menos dificultosas, al menos la primera, está llena de fusas y florituras de 12 notas; ya las otras dos son de menor dificultad, siendo la del medio otro canon a la octava, pero con la separación de 4 compases.

\subsubsection{VALORACIÓN DE LA EFECTIVIDAD DEL MÉTODO Y DE SU APORTACIÓN A LA ENSEÑANZA}

En la primera parte, está muy comprimida la enseñanza, sobre todo la práctica, de cada nueva dificultad; una lección, o pocas más, para cada nuevo elemento, no es, ni mucho menos, suficiente para que un alumno interiorice los conocimientos. La progresión de ellos es adecuada

La segunda no es más que una serie de lecciones para conocimiento de algunas tonalidades. Las melodías, muchas de ellas, más parecen ejercicios de intervalos por sus muchos saltos. 
La tercera parte tiene una progresión de aparición de claves casi lógica, no tiene demasiadas dificultades en las lecciones, aun así todavía debían ser de menor complejidad, habida cuenta de que son claves no dominadas. De todas maneras hay algunas que sobrepasan la dificultad debida.

En general es un método casi completo, falta practicar las tonalidades con 6 y 7 alteraciones, y el transporte. Las melodías no son muy musicales, incluso en las dos partes últimas, algunas son verdaderos ejercicios gimnásticos. No obstante para su antigüedad es aceptable. 
Sobejano Ayala 


\subsection{RESEÑA BIOGRÁFICA DEL AUTOR}

ALIAGA LÓPEZ, Matías. España, siglo XIX, organista y teórico. Fecha probable de nacimiento 1825 en Madrid (Virgili Blanquet, M ${ }^{a}$ Antonia en AAVV, 1999, tomo 1, p. 281).

\subsubsection{DESCRIPCIÓN DETALLADA DEL MÉTODO.}

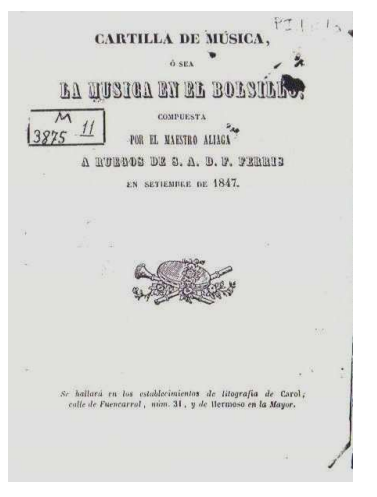

\section{Título del Método}

Cartilla de música o sea La música en el bolsillo, Madrid, Imp. de Alejandro Gómez Fuentenebro, $1847^{1}$. Apéndice, página 201.

\section{CUADRO DE INFORMACIÓN GENERAL DEL MÉTODO.}

\section{$\mathbf{N}^{\mathbf{0}}$ de lecciones $\quad 30$ lecciones, más bien ejemplos prácticos}

Extensión de las lec- Entre 2 y 170 compases

ciones

Claves empleadas $\quad$ Sol, y una sola en Fa en $4^{\mathrm{a}}$

Tesituras que abarcan $\quad \mathrm{La}_{2} \mathrm{a} \mathrm{La}_{4}$

Tonalidades que trata Do M, La m, Sol, Re, La, Mi Fa, Si, Mi b y La b mayores y estudia

Compases que emplea $\quad 4 / 4,3 / 4,3 / 8,2 / 4,6 / 8,9 / 8$ y $12 / 8$ y estudia

\footnotetext{
${ }^{1}$ Según el catálogo de la Biblioteca Nacional, y PRECIADO, Dionisio: op. citada, p. 239, en 1851 se publicó una $3^{a}$ edición de este método, pero con el nombre de El más barato de los solfeos ó sea La música puesta al alcance de todas las inteligencias y fortunas, también en Madrid, pero por el editor Casimiero Martín, seguía teniendo las mismas 85 páginas, pero medía un poco más, $18 \mathrm{~cm}$.
} 


\section{Dificultades métricas que contiene}

Dificultades de entonación que se encuentran $y$ orden en que se enseñan los intervalos

Armonía utilizada

Formas que tienen las lecciones

Introducciones, Intermedios o Codas instrumentales

Teoría de la música que incluye

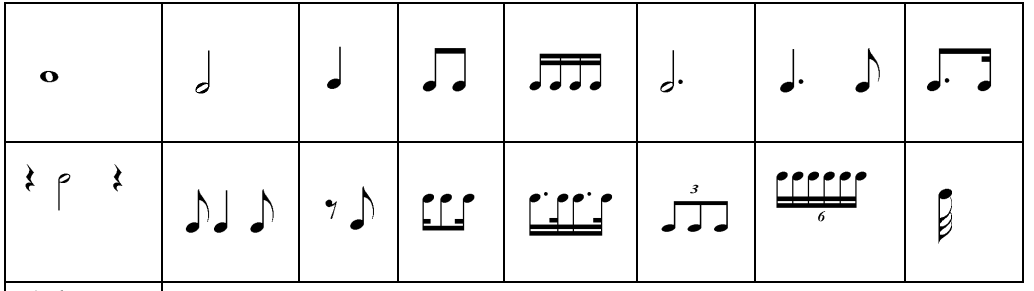

Adornos

Alteraciones. Intervalos aumentados y disminuidos.

Escala, y desde segundas a octavas con indicación de las notas que están entre medio.

Escala cromática.

No existe

No tienen

No tienen

Al 50\% con la práctica

\section{SECUENCIA}

Empieza con una nota al lector en la que explica que el libro es un resumen de elementos teóricos y prácticos, dirigido, más bien, a quien quiera instruirse en la música por diversión que a quien lo hiciera con la idea de ser profesional. Le sigue un poema de dos estrofas, titulado "A la juventud". 


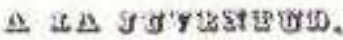

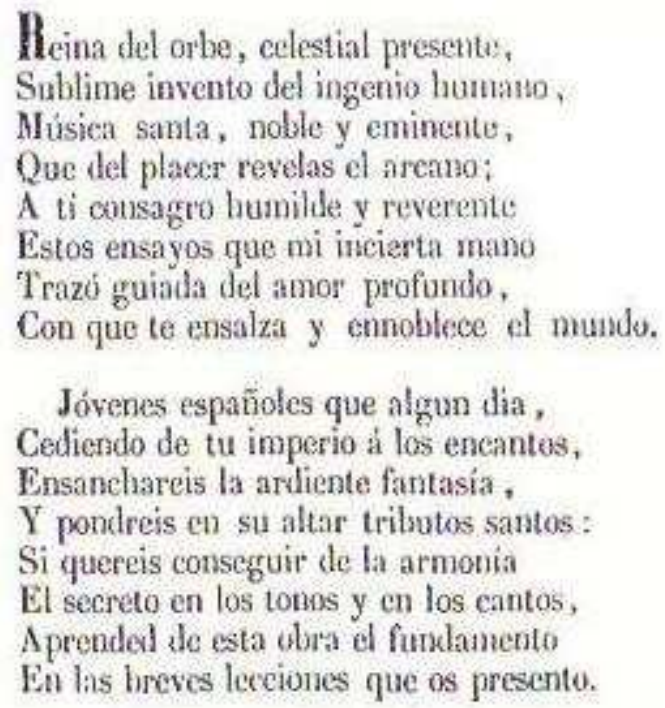

Luego hay una Introducción en la que habla de que todo ser humano tiene propensión a la música, de que muchos la practican, tocan un instrumento o cantan utilizando la intuición y el oído, pero que son muchos los que tienen dificultad para entender y practicar los sonidos escritos. Y explica las notas de la escala diatónica y de la cromática a través de los trastes de la guitarra.

Siguen un "Catálogo de los signos y términos técnicos de la música, y una idea del uso de ellos". A través de varios apartados, va presentando los distintos elementos con los que se va a encontrar el estudiante, y que son prácticamente todos los necesarios para la lectura de una partitura y la práctica de la música. Catálogo que no sirve de nada al iniciático, pues sólo consigue marear con tanto signo; solamente dedicándole un tiempo a su estudio, el profesional puede comprender qué indica o quiere indicar con este catálogo. Lo curioso es que el repetido catálogo está en la página 11 y siguientes, y las ilustraciones en la 33 y siguientes; como también pasa a continuación con las explicaciones de la utilidad de cada lección y la propia lección. O sea, todo lo referente a texto aparece unido al principio, y todo lo que se refiere a práctica, unido de mitad a final.

En el catálogo, llama pauta al pentagrama, "pauta compuesta de rayas y claros", a las líneas adicionales "rayas añadidas por bajo y alto"; para las figuras de nota utiliza la nomenclatura antigua; al puntillo le llama "puntos que aumentan el valor o duración“", 


\section{Aliaga López}

al picado "puntos que disminuyen el valor o duración", a las ligaduras "rayas curvas para atar y prolongar los sonidos" y "rayas o ligados" a la ligadura de expresión.

Una definición de música, amplia y comentada, de la que se resume que la califica de ciencia matemática y de verdadero idioma.

Y la relación de lecciones, con la explicación de la utilidad de cada una. Llama lección al contenido teórico, que él ilustra con ejemplos prácticos, pero sólo hay una o dos lecciones.

Lección 1.- La clave de Sol, las notas en el pentagrama y fuera de él, ascendente y descendentemente, agrupadas de forma que se vea la menor distancia existente entre los dos semitonos. Un ejercicio para indicar los intervalos de grado y salto en una octava: la escala abarcando la octava, unísonos, segundas varias, terceras y sucesivos intervalos, indicando las notas de en medio, y un ejercicio resumen.

Lección 2.- El compás de compasillo, las figuras de nota y de silencio

Lección 3.- Perfecto ajuste del valor y duración de las notas por medio de oscilaciones sobre la letra vocal de la sílaba do, pasando de unas clase a otras, descendiendo y ascendiendo.

División de la nota redonda por ocho movimientos u oscilaciones, $n .14$

División de dos blancas, por cuatro oscilaciones, $n .15$

División de cuatro negras, por dos oscilaciones cada una, $n .16$

Equivalencia de los tres casos en corcheas, $n .17$

Continuación de la anterior lección para dividir mentalmente las notas redondas, blancas, negras y corcheas por el movimiento de las semicorcheas, siguiendo el sistema de oscilaciones que tengo adoptado y que tan buenos resultados me ha dado en mis discípulos, el cual consiste en producir movimientos con la respiración de un modo perceptible al que oye, sin necesidad de pronunciar las sílabas de cada nota.

La semibreve o redonda se dividirá por diez y seis oscilaciones, $n .18$

Las minimas o blancas por ocho, $n .19$

Las semínimas o negras por cuatro, $n .20$

La corchea por dos, $n .21$ 
Hemos copiado literalmente el enunciado de esta tercera lección, e insertamos su ejemplificación práctica, tanto de ésta como de la siguiente, por creer curiosa esta manera de hacer comprender la división y subdivisión del compás.

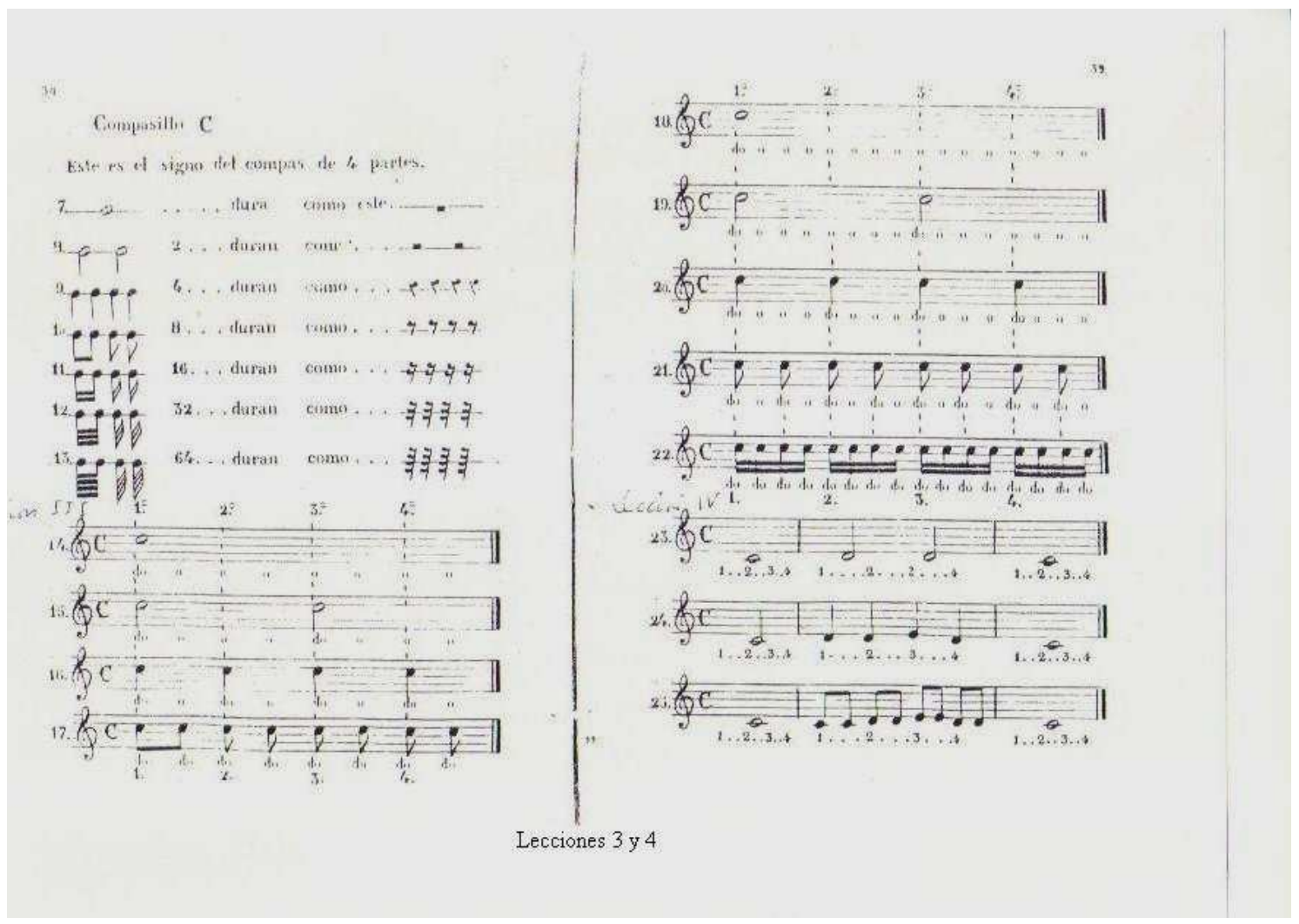

Lección 4.- Concordancia de dos en dos clases de notas: concordancia de redondas y blancas, de redondas y negras, de redondas y corcheas, de redondas y semicorcheas.

Lección 5.- Serie de concordancias en un ejercicio alternando las clases de figura.

Lección 6.- Serie de sonidos interrumpidos..., y en un momento añade: "sin permitir alteración de la mano que suele acontecer cuando entre los principiantes se mira esto con indiferencia". Lección dedicada a los silencios; al llegar a los de corchea, hay una nota al pie, que dice conviene aplicarles interiormente una letra, y los representa gráficamente de este modo:

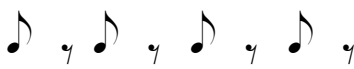

Mi a $\mathrm{Re}$ a $\mathrm{Mi}$ a Fa a 
Lección 7.- El puntillo: aplicado a la blanca, negra, y corchea. Lo explica gráficamente descomponiendo una figura con puntillo en sus equivalentes ligadas. Lo malo es que aun no ha explicado la ligadura.

Lección 8.- La ligadura: con blancas, blancas y negras, negras, corcheas.

Lección 9.- Notas sincopadas: desde la larga a la breve, con y sin ligaduras.

Lección 10.- Un resumen de todo lo visto hasta el momento; primero descomponiendo los puntillos y síncopas en corcheas ligadas, después, una melodía pentáfona ( $\mathrm{Mi}, \mathrm{Fa}$, Sol, La, Do) aparece con la duración de redondas, blancas, negras, mezcla, redondas y su pausa, con puntillo, ligadas, partidas, blancas con su pausa, con puntillo, sincopadas, negras con su pausa, con puntillo, sincopadas, corcheas, corcheas con su silencio, con puntillo, formando síncopa muy breve, semicorcheas, con puntillo seguidas de fusa y sincopadas. Total, en 2 páginas, con ejemplos de 2 compases, resumido todo lo que sería en la actualidad hasta un $3^{\circ}$ curso de solfeo, o para lo que todos los métodos han empleado ríos de tinta.

Lección 11.- Con el ámbito de la escala natural, un ejercicio de recopilación de figuras hasta la semicorchea exclusive.

Lección 12.- Presentación de compases nuevos, según dice el autor, derivados del compasillo. 2 y 3 por $4 ; 3$ por $8 ; 6,9$ y 12 por 8 . Dice que el 3/4, 2/4, 3/8 y 6/8 son compases diminutivos del compasillo, y el 12/8 y 9/8 aumentativos [?]. Cabe destacar que el compás de 6/8 especifica que se puede marcar a 2, a 3 [?] y a 4 . Esto último es sorprendente para la época del libro, ya que hasta muy entrado el siglo XX no se había oído hablar de esta manera irregular, pero acertada en cuanto a acentuaciones, de marcar este compás. Hay una continuación a esta lección, para dar a conocer los tresillos de corchea y seisillos de semicorchea.

Lección 13.- La escala cromática. La presenta comparándola a la diatónica, esto es contrastándola al esquema que hace en la lección 1, demostrando así las diferencias entre distancias de tono y de semitono; y además lo hace utilizando sólo sostenidos o sólo bemoles. 
Lección 14.- Las alteraciones, primero con un ejercicio con semitonos cromáticos, y luego con otro empleándolas libremente.

Lección 15.- Pequeñas frases sobre aires determinados. Da a conocer tres términos de la velocidad: Largo, Moderato y Presto, y uniendo pequeñas frases, hace unos resúmenes de lo visto hasta el momento.

Lección 16.- Ejemplo para el aire moderato en compás de tres por cuatro.

Lección 17.- Ejemplo para el aire presto en compás de dos por cuatro.

Lección 18.- Resumen de los tres aires y tres compases anteriores.

Lección 19.- Signos de modificación para la expresión y colorido del canto. Hace aquí, ejemplos de 4 compases con: acentos; trino y calderón; picado (a los que llama puntos de disminución); ligado; crescendo y diminuendo; apoyaturas de retardo y anticipación, así llama a la apoyatura y mordente de una y dos notas, sin explicación alguna respecto al modo de ejecutarse, solamente las traduce a sonidos reales. Sigue esta lección con un modelo de cinco sonidos (el mismo de la lección 10), a modo de tema y variaciones; y las variaciones son métricas y melódicas empleando alteraciones.

Lección 20.- Continuación usando los adjetivos para el movimiento y las modificaciones. Se refiere a las indicaciones dinámicas. Y luego continúa diciendo el enunciado de esta lección: Procúrese porque se satisfaga el aficionado de las apoyaturas de anticipación y de retardación (curioso el lenguaje), y hay un buen número de notas de adorno, incluidas florituras, sin explicación ni trascripción.

Lección 21.- Escala diatónica en la extensión de dos octavas. Vuelve al esquema de las lecciones 1 y 13, pero con doble octava, y comparando la escala de Do con la de La menor (únicamente el modelo armónico).

Lección 22.- Cuatro preludios diatónicos y cromáticos. Llama así a unos ejercicios de entonación pura, con toda clase de intervalos; y explica que se deben cantar con las síla- 


\section{Aliaga López}

bas solfísticas y luego con la palabra Amor, para darse una idea de la vocalización. La palabra Amor la hace completamente melismática, A es la primera nota, y "mor" la última.

Lección 23.- Melodía sencilla sobre el género diatónico y cromático con adornos.

Lección 24.- Melodía en dos frases, una en Do mayor y otra en La menor, cambiando entre los compases de 3/8, 6/8 y 4/4.

Lección 25.- La misma melodía pero modificando el ritmo para hacer uso de fusas y semifusas.

Lección 26.- Una melodía sencilla para el reconocimientos de algunos tonos mayores. Es chocante cómo explica el significado y concepto de "tono", y por ellos lo transcribimos literalmente:

La palabra tono se usa bajo tres significaciones: una, tono intervalo de segunda; otra como tono mayor o menor; otra el tono de afinar los Pianos; y otra dar tono, cuando se suena la cuerda o un instrumento de madera o latón o el órgano para afinar los demás. El uso diferente de las escalas o tonos mayores y menores, es sin duda el que decide del carácter más o menos brillante de los cantos y de las armonías. El círculo de las 40 escalas o tonos mayores y menores, tan positivo como admirable, nos deja convencidos de las grandes combinaciones que ofrece la armonía, en el campo vasto de la música, a los genios llamados para la composición.

La misma melodía que en las dos lecciones anteriores, en los tonos de Sol, Re, La, Mi, Fa, Si b, Mi b y La b mayores.

Lección 27.- Epílogo práctico. Dos ejercicios de recopilación.

Lección 28.- Un conjunto de frases, con cambios de compases y de tonalidades, también a modo de resumen.

Lección 29.- Llave de fa en "cuarta raya". Nombres de las notas en esta clave y una lección a dos voces en forma de tema con 4 variaciones, la $2^{\mathrm{a}}$ voz es la que se lee en clave de Fa. 
Lección 30.- Presentación de las claves restantes solamente como conocimiento del nombre de las notas.

Acaba con un círculo de las tonalidades mayores y menores, que por su curiosidad adjuntamos en el apéndice en la página 202.

\subsubsection{VALORACIÓN DE LA EFECTIVIDAD DEL MÉTODO Y DE SU APORTACIÓN A LA ENSEÑANZA.}

Explica el puntillo antes de haber explicado la ligadura, cuando al contrario se comprende mejor.

Comprime mucho las dificultades, como decimos anteriormente, en dos páginas, y con cortos ejemplos, introduce un sinnúmero de elementos distintos.

Es muy asombroso, como ya se ha comentado, una de las formas que dice se puede marcar el compás de seis por ocho.

No es un libro elemental, contiene todo lo que un músico necesita saber solfísticamente, pero está tan comprimido que dudamos fuera de utilidad para el neófito (quizás para un adulto acostumbrado al estudio), es necesario ser experto para entender lo que quiere enseñar el método, en todo caso sería preciso la concurrencia de un profesor, y para eso, habían más métodos. 
Aliaga López 


\subsection{RESEÑA BIOGRÁFICA DEL AUTOR}

PÉREZ GASCÓN, Pascual. Nació en Valencia, el 18 de mayo de 1802 y murió en Valencia el 27 de junio de 1864. Organista y compositor. Empezó a estudiar música con su tío Sebastián Pérez, tenor de la Capilla Real, que pasó a la Catedral de Valencia con motivo de la invasión francesa, y teniendo Pascual 10 años, ingresó en dicha Catedral, donde estudió armonía con el maestro de capilla José Pons y composición y órgano con el organista Francisco Cabo. A los 18 años fue nombrado organista de la parroquia de Santo Tomás, a los 25 maestro de capilla de Villena (Alicante), cargo al que renunció para volver a Valencia como organista primero de la Catedral, en donde estuvo desde el 15 de diciembre de 1830, hasta su muerte. Fue tan importante su labor como organista en esta Catedral, que el Cabildo tuvo que pedir dispensa papal para que pudiera desempeñar esta función sin ser clérigo (condición que exigía el Concordato de 1851). En marzo de 1845 vino Franz Liszt a Valencia a dar tres conciertos, fue a visitar la Catedral y le escuchó, después le felicitó públicamente por su facilidad para la improvisación.

Su mayor contribución a la música valenciana fue su faceta pedagógica desarrollada en el ámbito de la Sociedad Económica de Amigos del País de Valencia. Existía en esa entidad, desde 1819, la inquietud por la enseñanza gratuita de la música entre la infancia, y en 1850 crean la Escuela Popular de Música bajo la dirección de Pérez Gascón, y en los años siguientes se extiende esta enseñanza gratuita a otras escuelas; éste ya había experimentado con el método Wilhem en el Colegio Real de San Pablo de Valencia, y su sistema se extendió a la Escuela Normal de Valencia en 1859, y a la de Zaragoza después, utilizándose en ambas el segundo de los métodos que a continuación analizamos, método que se deriva del primero que escribió para los alumnos de San Pablo, y que fue reconocido, en 1858, oficialmente por el Conservatorio de Madrid. Este tratado, basado en el método Bocquillon - Wilhem, primero basado en la enseñanza colectiva, y germen de la creación de orfeones, fue utilizado en escuelas como la Casa de Misericordia, Niños de San Vicente o Beneficencia. Su última publicación, póstuma, fue el Método de armonía.

Quizás el hecho más importante de este músico sea que su método, junto con la enseñanza de la música en las escuelas públicas, dio origen a que surgieran coros de niños no relacionados con comunidades religiosas, y que el éxito de la enseñanza a través de tal método, provocó que posteriormente la Sociedad Económica de Amigos del País, creara el Conservatorio. 
Entre sus alumnos tuvo al organista José $\mathrm{M}^{\mathrm{a}}$ Úbeda, primer director del Conservatorio de Valencia, y al "Patriarca de la música valenciana" Salvador Giner.

Como compositor, su producción más abundante es la religiosa, pero también es abundante su producción coral, y más pequeña la de órgano. Su fama llegó a París, donde Panseron le remitió su Tratado de Armonía para que lo revisase. Dominaba varios idiomas y fue un entusiasta estudioso de la filosofía y la estética (Galbis López, Vicente en AAVV, 1999, pp.647 y 648).

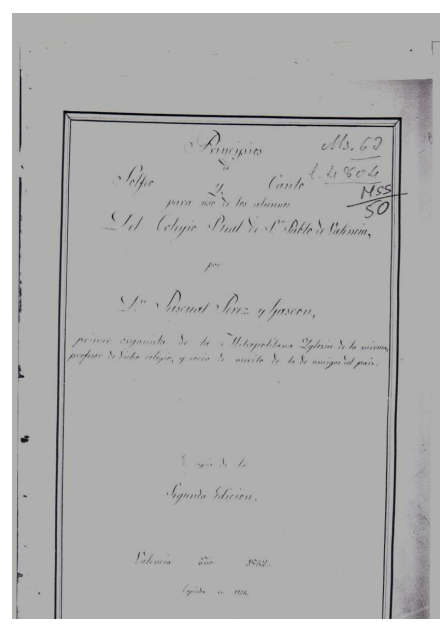

\section{Título del Método}

Principios de solfeo y canto para uso de los alumnos del Colegio Real de S. Pablo de Valencia, Valencia, copia de la $2^{a}$ edición, manuscrita, 1852 ; copiado en $1854 .^{1}$ Apéndice, página 203

\subsubsection{DESCRIPCIÓN DETALLADA DEL MÉTODO.}

\section{CUADRO DE INFORMACIÓN GENERAL DEL MÉTODO.}

$\mathbf{N}^{\mathbf{0}}$ de lecciones 120 (Hay un error de numeración, repite el número 118, y de ellos pasa al 120)

Extensión de las Entre 8 (Los primeros ejercicios, que él numera como lecciones) lecciones y 48 compases.

Claves empleadas Sol, Fa y Do $1^{\mathrm{a}}$. Al final mezcla entre ellas

Tesituras que abar- $\quad \mathrm{Do}_{3} \mathrm{a} \mathrm{Fa}_{4}$

can

Tonalidades que Do M, La m, Sol M, Mi m, Fa M, Re m, Re M, Si m, Si b M Sol trata y estudia $\mathrm{m}$

Compases que em- $\quad 2 / 2,4 / 4,3 / 4,2 / 4,3 / 8,6 / 8,9 / 8,12 / 8$

plea y estudia

\footnotetext{
${ }^{1}$ PRECIADO, Dionisio: op. citada, p. 240 figura, 1848 como año de edición.
} 
Dificultades métricas que contiene

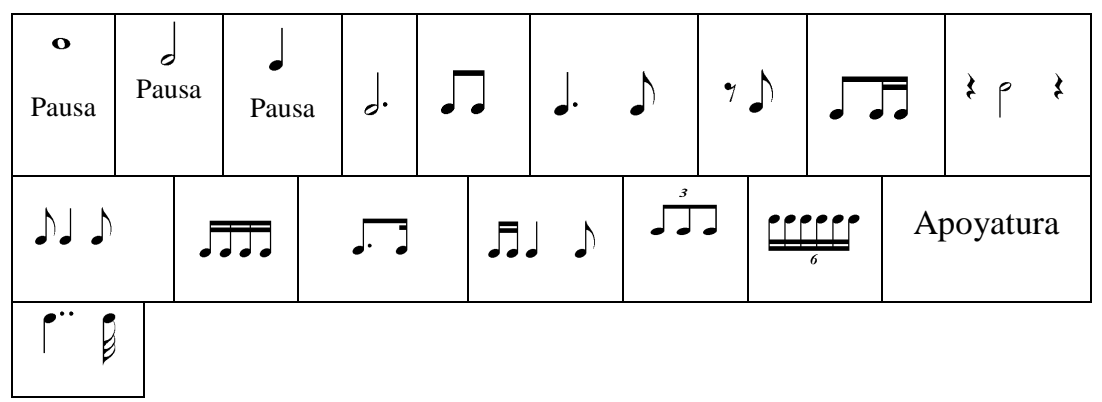

Dificultades de entona- Las normales en un primer o segundo curso. Cromatismos, ción que se encuentran $2^{\text {a }}$ Aumentada. y orden en que se ense- Escala, ñan los intervalos $\quad 2^{\mathrm{a}}$

Unísono

$2^{\mathrm{a}}$ y $3^{\mathrm{a}}$

$2^{\mathrm{a}}, 3^{\mathrm{a}}$ y $4^{\mathrm{a}}$

$2^{\mathrm{a}}, 3^{\mathrm{a}}, 4^{\mathrm{a}}$ y $5^{\mathrm{a}}$

$6^{\mathrm{a}}, 7^{\mathrm{a}}$ y $8^{\mathrm{a}}$

Alteraciones: semitonos diatónicos y cromáticos

Armonía utilizada

En la única lección que lleva acompañamiento, emplea una armonía clásica con tintes románticos, algún grado alterado, modulación a la subdominante, a la dominante. En las otras no se aprecia en absoluto ni modulaciones ni nada, debido a su corta extensión.

Formas que tienen las La mayor parte de ellas son tipo primario, una sola frase o lecciones semifrase. La única que tiene forma es la $\mathrm{n}^{\circ} 103$ A-B-A'

Introducciones, Inter- No hay en ninguna medios o Codas instrumentales

Teoría de la música La básica que incluye

El autor dice, en la tercera edición, 1855, que este método reúne cuatro requisitos que no tienen los escritos en Francia o Alemania:

- Lo suficiente para formar coros en el colegio o iniciarse en el estudio de un instrumento,

- Lecciones para voces de poca extensión

- Diversa dificultad en las melodías, con letras religiosas.

- Gradación lenta en las dificultades. Pensado para clases colectivas en las que no todos los alumnos tienen las mismas cualidades (Fontestad, 2005, p. 116). 


\section{SECUENCIA}

Comienza con una dedicatoria larga a sus discípulos y con unos comentarios a los profesores, ambas cosas bastante ilegibles, como todo lo que sigue, pues a la escritura manuscrita se une el haber obtenido este material de un microfilm en bastante mal estado. Aconseja a los profesores que basen la enseñanza del solfeo en su método, que no prescindan de ningún ejercicio; que empiecen cada clase con la entonación de la escala correspondiente a la tonalidad de la lección, luego la lectura del texto, continuando por el análisis y la lectura rítmica de ella antes de solfearla rítmica y melódicamente. Destaca la importancia de la vocalización y prescinde por completo del acompañamiento del piano. No estamos totalmente de acuerdo, ni se debe acompañar constantemente al alumno, ni tampoco privarle de la formación armónica del oído que proporciona un acompañamiento.

Vienen a continuación instrucciones teóricas cortas: pentagrama, nombre de las notas, signo de clave, dando como claves tres signos, y presentando la de Sol en $2^{\mathrm{a}}$ línea. Nombre de las notas en las líneas, espacios, líneas y espacios adicionales superiores e inferiores.

Definición de escala diatónica, y de la diatónica del modo mayor, sin explicar qué es tono o semitono. (Muy pronto es para tal conocimiento)

Seis ejercicios de entonación, escala ascendente, descendente, intervalos de segunda y unísonos, mezcla de segunda y alguno de tercera, mezcla de segunda y tercera, mezcla de segunda tercera y alguno de cuarta.

Nombres y representación de las figuras de nota, y su relación entre ellas.

Les da a dichas figuras los nombres de Semibreve, Mínima, Semínima, Corchea, Semicorchea, Fusa y Semifusa, como los anteriores (excepto Eslava). Representación de las pausas de cada una de las figuras. El signo curioso es el silencio de negra, claro, es manuscrito, pero ni es imitación al impreso actual, ni tampoco al antiguo en forma de silencio de corchea al revés. Lo representa como una "ese" horizontal.

El signo que viene a continuación es el del compás, que lo define como una porción de tiempo dividido en otras porciones de dos, de tres y de cuatro tiempos. $\mathrm{O}$ tam- 
bién como todo lo que hay escrito entre dos barras. Y comienza por el compás binario $2 / 2$.

Siete ejercicios, suponemos que de lectura y entonación, pues nada dice el autor, con este compás: redondas, luego redondas y su pausa, blancas, blancas y su pausa, blancas, redondas y sus pausas. Intervalos de segunda, tercera y cuarta.

Tres ejercicios de entonación pura, pues sólo hay cabezas de nota. Intervalos de segunda, tercera, cuarta y alguna quinta.

Tres ejercicios más con negras, mezcla de blancas y negras y pausa de blanca. Intervalos hasta quinta.

Dos ejercicios de entonación pura con intervalos hasta la quinta.

Una canción, totalmente con blancas, excepto la nota final que es redonda. La letra está totalmente ilegible.

Dos lecciones con blancas y negras y 3 ejercicios de entonación, con sextas, séptimas y octavas.

Descripción del compás de compasillo y manera de marcarlo

Cinco lecciones, muy cortas, blancas y negras, y en la última aparece el silencio de negra.

Dos ejercicios de entonación, el segundo con notas por debajo del pentagrama, hasta el $\mathrm{Si}_{2}$.

Sucinta explicación del puntillo.

Una lección aplicando el puntillo sólo a la blanca, y otra con letra, que sí es legible y dice: Cuanta calma y dicha goza el sencillo labrador en la puerta de su choza bendiciendo al Hacedor.

Explicación del concepto de intervalo y nombres de ellos.

Cinco ejercicios de entonación con intervalos bastante más disjuntos que en los anteriores ejercicios. Previamente hay una advertencia de que estos ejercicios sólo sirven para alumnos que tengan la suficiente extensión de voz, pues ya llegan hasta el Fa 4.

Cinco lecciones en las que ya hay corcheas, puntillo acoplado a la negra y silencio de corchea formando contratiempo. 
Pérez Gascón (Principios de solfeo y canto)

\section{Explicación de la ligadura}

Una lección con la ligadura entre blanca y negra, blanca y corchea, redonda y negra.

Explicación de la ligadura de fraseo.

Una lección con este signo.

Explicación del signo contrario, el picado.

Dos lecciones, una con negras picadas, y otra con corcheas seguidas de su silencio.

Una lección a 3 voces, para acostumbrar el oído a la armonía. Es el acorde tríada de Do mayor, con la fundamental en el bajo tenida, tercera en la voz del medio tenida hasta que entra la quinta en la superior, y luego con el acorde en primera inversión.

Signos de repetición.

Escuetísima explicación de las barras de repetición y muestra, sin explicación del signo $\%$.

Dos lecciones empleando barra de repetición, una a tres voces, que es un arpegio en redondas del acorde de Do mayor, y la segunda a dos voces, que es la escala en blancas, ambas en forma de canon.

Explicación de canon, y 2 canciones, para formar canon a dos voces y a tres.

Pequeña lista de matices dinámicos.

Tres lecciones con reguladores, y 2 a dos voces por terceras en movimiento paralelo.

$\underline{\text { Palabras italianas que se utilizan para indicar el aire o movimiento, y también términos }}$ que expresan el carácter. 
Una pequeña lista de estos términos del movimiento y de los que marcan el carácter de la interpretación

\section{Síncopas:}

Presenta curiosas definiciones: una nota que ocupa la mitad de un compás y la mitad de otro (notas partidas), o la nota que en el compás de cuatro tiempos ocupa el segunda y tercero, o el cuarto y primero del compás siguiente.

Una lección con síncopas largas. Tras una preparación 3 con síncopas breves, 1 con contratiempos y 1 con semicorcheas.

Explicación amplia de los compases representados por quebrados (por lo que el binario y el compasillo no se representan así para él), siempre referidos a una porción del compasillo. Empieza por el de 3/4.

Tres lecciones y una canción en forma de canon en este compás.

\section{Signos Accidentales:}

Escueta y efectiva explicación de las alteraciones.

Tres lecciones con sostenidos y bemoles, formando semitonos diatónicos. Cambia el compás a $2 / 4$, sin previa explicación, se supone que vale la que ha hecho anteriormente.

Semitonos diatónicos y cromáticos expuestos sencilla y claramente.

Tres lecciones formando las alteraciones semitonos cromáticos.

\section{$\underline{\text { Modo Menor: }}$}

Aclaración de la escala menor, situación de sus semitonos y distancia entre tónica y mediante. Luego anota que se alteran el $6^{\circ}$ y $7^{\text {a }}$ grados cuando suben, sin hablar de escala melódica.

Dos lecciones con esta variante de escala menor.

Ahora escribe que, a pesar de lo dicho, conviene practicar la escala menor con la sexta nota sin alteración, también sin decir que es la escala armónica.

Dos lecciones siguiendo con 2/4 y la escala armónica.

Instrucciones en este momento de que los sostenidos y bemoles afectan a todas las notas del mismo nombre que se hallen en el mismo compás. 
Dos lecciones empleando fórmulas rítmicas de corchea y dos semicorcheas.

\section{Tono de Sol mayor:}

Explica la tonalidad de Sol mayor diciendo que es la escala que tiene la nota Sol por tónica y que lleva el Fa sostenido como esencial. Luego aclara que los sostenidos y bemoles que son esenciales para la formación de las escalas se escriben junto a la llave.

Cuatro lecciones, en las que alterna los compases conocidos, e introduce la fórmula rítmica corchea con puntillo - semicorchea. Y acaba con una canción.

Tono de Mi menor. Relativo de Sol mayor.

Muestra su escala, anotando que lleva las mismas alteraciones esenciales que Sol mayor, y tres lecciones.

\section{Tono de Fa mayor:}

Muestra su escala y tres lecciones, la tercera con síncopas breves formadas por 2 semicorcheas - negra - corchea. Acaba la tonalidad con dos canciones, El Pastor y otra sin título. Ambas a 2 voces homofónicas.

Llave de Fa en cuarta:

Muestra la posición de las notas en líneas, espacios y adicionales.

Una lección con blancas, negras y corcheas.

\section{Tono de Re menor. Relativo de Fa mayor:}

Presenta la escala y tres lecciones, clave de $\mathrm{Fa}$, las dos primeras son fáciles de medida, la tercera complicada para estar con una clave nueva, pues tiene numerosas síncopas enlazadas.

$\underline{\text { Tresillos: }}$

Los describe como 3 notas que ocupan el tiempo de dos. Perfecta y sencilla explicación.

Dos lecciones con tresillos de corchea.

$\underline{\text { Seisillos: }}$

Los explica de la misma manera. Dos lecciones con este valor irregular. 
$\underline{\text { Tono de Re mayor: }}$

Presenta la escala y una lección muy sencilla.

Compás de 3/8:

Sigue ahora con la tonalidad expuesta, pero con este compás 4 lecciones, y termina con una canción en canon.

$\underline{\text { Tono de Si menor. Relativo de Re mayor: }}$

Presenta la escala y tres lecciones en las que alterna los compases, una canción a 3 voces más polifónica que las otras.

Tono de Si bemol mayor:

Presenta la escala y dos lecciones.

Compás de 6/8:

Sin previa explicación seis lecciones con las combinaciones rítmicas básicas posibles en este compás, 1 canción en forma de canon.

$\underline{\text { Tono de Sol menor. Relativo de Si bemol mayor. }}$

Presenta la escala y tres lecciones, en las que alterna los compases de 4/4, 3/4 y $6 / 8$.

\section{Calderón:}

Explicación del calderón, con una canción, la única del método acompañada de piano, en compás de 6/8 y en la tonalidad que se está estudiando, en la que hay un calderón no conclusivo, y con forma de lied ternario

Llave de Do en Primera: singular dibujo de esta clave:

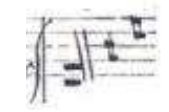

Posición de las notas en las líneas, espacios y adicionales, como siempre.

Tres lecciones, compases de 4/4, 3/8 y 4/4, en las que la figuración, seguramente debido al estudio de una nueva clave, es sencilla. 
Pérez Gascón (Principios de solfeo y canto)

\section{Compás de 9/8:}

Lo desarrolla en cuatro lecciones, con las que se practica las combinaciones rítmicas básicas en este compás.

Compás de 12/8:

Utiliza dos lecciones, de mayor extensión que las anteriores, por lo que es igual a las 4 que tenía el compás de 9/8.

Apoyatura:

Expone una breve explicación de lo que es apoyatura, sin relacionarla para nada con su grupo de notas de adorno.

Dos lecciones incluyendo este adorno, y siguiendo con la clave de Do en $1^{\mathrm{a}}$.

Doble puntillo:

Realiza un comentario de la utilidad del doble puntillo.

Una lección con esta medida, y una canción con solista y coro a dos voces.

Escala cromática:

Notifica su existencia y representación gráfica.

Una canción a tres voces, en la que hay pasajes de melodía acompañada por las otras dos voces, pasajes polifónicos y otros homófonos.

Una lección, la segunda que lleva el $n^{\circ} 118$, con cambios de clave entre las tres que se han aprendido.

Una representación gráfica del destino de cada una de las claves a sus voces naturales.

Representación de las armaduras con sostenidos y con bemoles, hasta las 7 alteraciones, y explicación del efecto del doble sostenido y doble bemol.

Clasificación de los intervalos:

Una tabla con los intervalos aumentados, mayores, menores y disminuidos, a partir de distintas notas; y una explicación posterior de cómo analizar esta calificación, atendiendo al número de semitonos que componen cada intervalo, para ello los divide 
en dos grupos, los de segunda, tercera y cuarta con una característica, y los de quinta, sexta y séptima con otra común. Y además, aconsejando se analicen siempre en estado natural, añadiendo posteriormente la o las alteraciones para ver si el intervalo encoge o dilata. Es la misma que figura en nuestro libro "Aspectos teóricos del lenguaje musical", página 62 (Loras, 1998), teoría que siempre hemos defendido como idónea para el aprendizaje, y que curiosamente leemos ahora. O sea que la hicimos nuestra muchísimos años antes de tener contacto con el libro de este autor.

La Lección 120, la última, es una Salve a 3 voces a "capella" con 5 letras.

Acaba el libro con una serie de notas sobre cómo explicar cada una de las cuestiones teóricas que se abordan, y la importancia que debe dar el enseñante a la entonación y a la emisión de la voz desde el comienzo. Muchos párrafos están ilegibles. Concluye definitivamente con una lista de preguntas, en concreto 72, sobre cuestiones teóricas, e indicación de en qué página pueden encontrar las respuestas.

\subsubsection{VALORACIÓN DE LA EFECTIVIDAD DEL MÉTODO Y DE SU APORTACIÓN A LA ENSEÑANZA.}

Empezar por definir la escala diatónica sin conocer qué es un tono y un semitono, no nos parece lo más adecuado.

Observamos en general que se comprime el aprendizaje de notas e intervalos en unos pocos ejercicios y lecciones, y además sin especificar o aclarar qué es lo que se está estudiando. Aunque debía ser bastante corriente en su tiempo, se precipitan las cuestiones y las dificultades con muy poca reiteración en cada uno de ellas.

Muy acertada explicación, a nuestro entender, de la calificación de los intervalos y de la manera de analizarlos.

Es un nivel de lo que antes de la LOGSE sería primer y segundo curso, pero con menos complicaciones rítmicas que en otros métodos posteriores. Pudo, no obstante, ser útil en aquellos primeros pasos en la enseñanza del Solfeo. 


\subsubsection{DESCRIPCIÓN DETALLADA DEL SEGUNDO MÉTODO.}

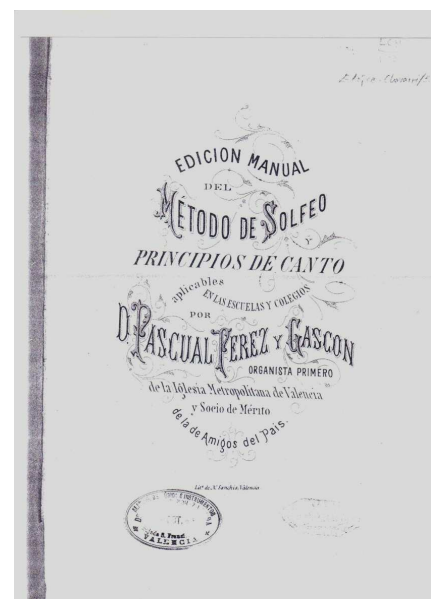

\section{Título del Método}

Método de solfeo y principios de canto: aplicables en las escuelas y colegios, Valencia, Lit. de N. Sanchis $1857^{1}$ Apéndice, página 203.

.....Los métodos dedicados al solfeo eran los que más abundaban en las escuelas municipales, habitualmente los escritos por Pascual Pérez Gascón e Hilarión Eslava.

Este párrafo se refiere a las escuelas municipales de música de Valencia antes de la fundación del Conservatorio ${ }^{2}$

Comenta Ana Fontestad, que los conocimientos de música solían, antes de la creación de los Conservatorios, impartirse de forma particular, y eran los maestros quienes proporcionaban lecciones de solfeo manuscritas que no pertenecían a ninguna colección editada. Los métodos extranjeros eran caros y no estaban traducidos. ${ }^{3}$

\section{CUADRO DE INFORMACIÓN GENERAL DEL MÉTODO.}

$\mathbf{N}^{\circ}$ de lecciones

Extensión de las lec- Desde 10 hasta 40 compases

ciones

Claves empleadas Sol, Fa $4^{\mathrm{a}}$ y Do $1^{\mathrm{a}}$, igual que en el anterior

Tesituras que abar- $\quad \mathrm{Si}_{2}$ a $\mathrm{Mi}_{4}$. En la clave de $\mathrm{Fa}$, las mismas pero $8^{\mathrm{a}}$ baja. En la can

\footnotetext{
${ }^{1}$ Esa es la fecha que figura en la catalogación de la Biblioteca Valenciana, pero quizás sea una deducción, debido a la fecha que lleva el dictamen del Real Conservatorio de Música y Declamación, firmado por Ventura de la Vega, Vice-Protector, que es en Madrid, 27 de octubre de 1857, pero para que se pudiera emitir este dictamen, el método ya estaba impreso, por lo que debió editarse antes. También en PRECIADO, Dionisio, obra citada, p. 240, figura este año como fecha de edición de este método.

${ }^{2}$ FONTESTAD PILES, Ana. (2005). El Conservatorio de Música de Valencia. Antecedentes, Fundación y Primera Etapa (1879 - 1910). Tesis doctoral. Director Vicente Galbis López. Universidad de. Valencia, Departamento de Historia del Arte, p. 87

${ }^{3}$ IBÍDEM, p. 115.
} 
Tonalidades que trata y estudia

Compases que emplea y estudia

Dificultades métricas que contiene

Dificultades de entonación que se encuentran $y$ orden en que se enseñan los intervalos

Armonía utilizada

Formas que tienen las lecciones

Introducciones, Intermedios o Codas instrumentales

Teoría de la música que incluye
Do M, La m, Sol M, Mi m, Re M, Si m, Fa M, Re m, Si b M, Sol m, La M, Fa \# m, Mi b M, Do m.

$2 / 2,4 / 4,3 / 4,2 / 4,3 / 8,6 / 8,9 / 8,12 / 8$. Igual que en el anterior

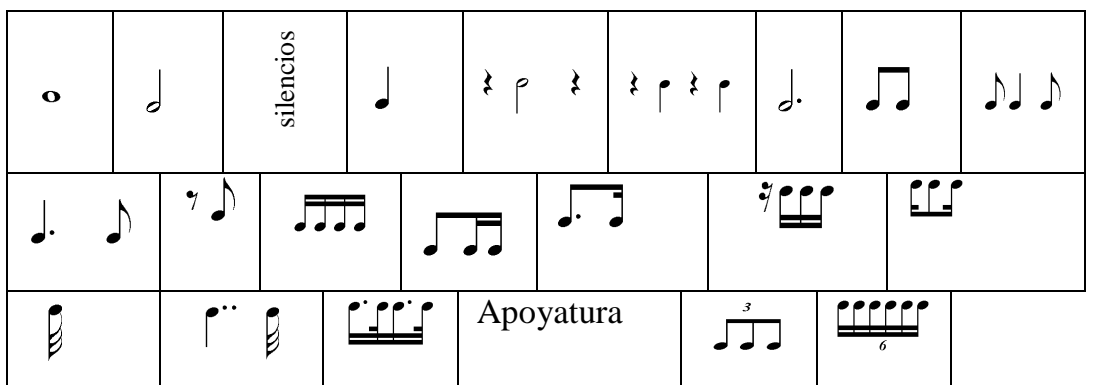

Las iniciales, intervalos de la escala natural. Alteraciones accidentales, $4^{\mathrm{a}}$ Aumentada, $5^{\mathrm{a}}$ disminuida, $3^{\mathrm{a}}$ disminuida, $6^{\mathrm{a}}$ Aumentada, $2^{\text {a }}$ Aumentada, $7^{\text {a }}$ disminuida, $5^{\text {a }}$ Aumentada y $4^{\text {a }}$ disminuida.

Do - Sol / Do - Mi - Sol / Mi - Fa / y sus combinaciones

$\mathrm{Do}$ - Mi - Fa; Do - Re - Mi; Do - Re - Mi - Fa;

Do - MI - Sol - La; Sol - La - Si; Sol - La - Si - Do.

Intervalos de $5^{\mathrm{a}}, 3^{\mathrm{a}}$ y semitonos diatónicos.

Luego desde $2^{\mathrm{a}}$ a $8^{\mathrm{a}}$ Mayores y Menores, semitonos diatónicos y cromáticos.

Después empleando alteraciones para convertir intervalos diatónicos naturales en alterados, y cambiar a tono donde suele haber semitono.

Por último $4^{\mathrm{a}}$ aumentada, $5^{\mathrm{a}}$ menor, arpegios en todas las tonalidades, $3^{\mathrm{a}}$ disminuida, $6^{\mathrm{a}}$ aumentada, $2^{\mathrm{a}}$ aumentada, $7^{\mathrm{a}}$ disminuida, $5^{\text {a }}$ aumentada y $4^{\text {a }}$ disminuida.

No hay acompañamiento, solamente en los cantos a voces se puede observar una armonía tradicional.

A-A'; A-B; A-B-C; A-B-C-D

No existen

La básica al inicio

\section{SECUENCIA}

Este nuevo método nace con la creación de la nueva Escuela de música de la Real Sociedad Económica de Amigos del País de Valencia, (a quien está dedicado), apén- 
dice página $\mathrm{n}^{\mathrm{o}} 204$, y como consecuencia del bajo poder económico de sus alumnos. Su método anterior, y los pocos que a la sazón existían, estaban hechos para alumnos que estudiaban en academias o escuelas costosas, como la del Colegio Real de San Pablo, para quienes había compuesto su anterior método; pero no era tal la situación del alumnado en la nueva escuela, y Pérez Gascón quiere hacer un método que permita con un solo ejemplar impartir clase a todo el alumnado.

En 1852 ya lo debía tener redactado y comenzó a experimentarlo con sus alumnos, tratando de perfeccionarlo, no sólo pedagógicamente, también para que fuera asequible económicamente.

Es en 1857 cuando, después de haberlo experimentado, el mismo autor se hace cargo de la edición, pero con el fin de que tuviera mayor difusión y aceptación le propone a la Sociedad Económica de Amigos del País cederle los derechos a cambio de que se hagan cargo de los gastos de edición, (que fueron 4.755 reales de vellón).

La diferencia esencial entre este método y el anterior, es el estrato social al que va dirigido, el primero a los alumnos del Colegio Real de San Pablo, que lo vendía en su casa, el segundo para la nueva Escuela de Música que se vendía en comercios. Y ¿por qué entra el método en los principios del canto? Pues porque este pedagogo pensaba que la práctica de la música vocal por parte de niños y adultos sería muy beneficiosa; a los primeros porque la letra de las canciones recordaba el cumplimiento de sus responsabilidades hacia Dios, sus padres y el maestro, además de servir de estímulo para asistir a clase (lo que no era muy popular entre clases humildes); y a los segundos para relacionarse socialmente contribuyendo a la igualdad entre todos, y de alguna manera siguiendo el movimiento que había iniciado en Barcelona José Anselmo Clavé con las sociedades corales para obreros (Fontestad, 2005, pp. 117 a 142).

Lleva un dictamen del Real Conservatorio de Música y Declamación de Madrid, firmado por Ventura de la Vega, Vice-Protector ${ }^{1}$, que es en Madrid, del 27 de octubre de 1857, apéndice, página 204, con informes muy favorables de Eslava, Francisco Asís Gil, Mariano Martín y Juan Gil, (seguramente estos informes se anteponían al contenido, en este y otros métodos, porque debían avalar la calidad de los mismos) y manifiestan que es el primer método publicado en España para la enseñanza colectiva de esta materia.

\footnotetext{
${ }^{1}$ Era el representante de la Reina en el Conservatorio, nombrado por ella, una especie de director con autoridad absoluta sobre profesores, empleados y alumnos; distribuía las horas de clase y señalaba los métodos que debían impartirse (Delgado García, 2003, pp. 202 y 203).
} 
Fue libro de texto en el Conservatorio de Valencia desde su fundación para el primer curso de solfeo, para los restantes se impuso el de Hilarión Eslava a partir de la segunda parte de este método. En 1897 dejó de utilizarse aquél y se empleó este último en todos los cursos (Fontestad, 2005, pp. 419 y 20) ${ }^{1}$.

Está repartida la materia entre 25 "carteles" (que eran reproducciones de esas páginas en tamaño grande para colgarlos en las aulas), que según dice el autor, comprenden la parte elemental. Un elemental muy avanzado o extenso, pensamos; quizás sería hoy un $3^{\circ}$ ó $4^{\circ}$ curso, pero más comprimidos, o sea, con menos reiteración en cada dificultad o novedad. El resto, hasta 38 "carteles", son canciones a 2 y 3 voces. Además indica el autor que este libro va acompañado de una Guía para la enseñanza, la cual no existe ya, o no ha sido encontrada.

Esta idea de editar un libro en carteles para su reproducción a gran tamaño, contribuyó a divulgar la música en la Enseñanza Primaria, ya que permitía a un solo profesor enseñar a un gran número de alumnos (de hecho él lo hizo para que pudieran aprender simultáneamente 50 ó 60 alumnos), basándose en el método de la enseñanza mutua, que consistía en primero hacerla simultánea y cuando los primeros alumnos estuviesen en condiciones de enseñar, que lo hicieran a otro grupo iniciático (Fontestad, 2005, pp. 127 a 129).

No vemos la división en carteles qué agrupa, pues tan pronto aparecen con una nueva cuestión, como dos o más novedades van dentro de un cartel.

\section{Cartel no 1:}

Comienza con la teoría más elemental en forma de pregunta y respuesta, algo que en la época no era insólito, más bien abundaba, como hemos visto, aunque con una visión actual de la enseñanza sea erróneo, pues induce a aprender textos de memoria sin asimilar conceptos. Y así sigue a lo largo del método, exponiendo, de esta guisa, la teoría de las novedades que va presentando antes de los ejercicios y lecciones que comprenden tales cuestiones. Además en algunos "carteles", incluye ejercicios para el alumno pero en forma oral, esto es, indica al "Instructor" que pregunte determinadas cuestiones relacionadas con el tema que se va a tratar.

\footnotetext{
${ }^{1}$ También comenta Ana Fontestad que hay terminología en este texto que no se corresponde con el de Eslava, y que quizás no se diera el método completo en primer curso de solfeo, pues es improbable que en un curso académico se puedan asimilar tantos contenidos.
} 
Nombre de las notas y pauta musical, (a las líneas adicionales les llama "auxiliares")

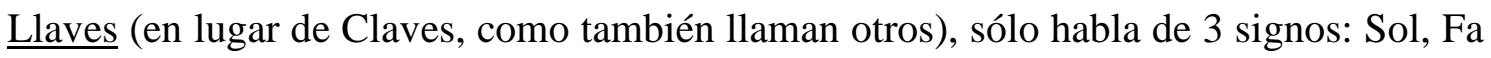
y Do, pero sin mencionar que con ellos se practican 7 .

\section{Primeros ejercicios de entonación}

En 12 ejercicios, de un fragmento cada uno, muestra las notas desde el Do $_{3}$ al $\mathrm{Do}_{4}$, advirtiendo que sirven primero para leer y luego para entonar. Comienza sólo con el Do, luego sólo con el Sol, sigue mezclando esos dos sonidos en unísono y en intervalo de $5^{\mathrm{a}}$; Do, Mi, Sol después, y mezcla de los 3 sonidos; MI - Fa y sus combinaciones; Do, Mi, Fa; Do, Re, Mi; Do, Re, Mi, Fa; Do, MI, Sol, La; Sol, La, Si; Sol, La, Si, Do.

\section{Figuras y Pausas}

Explicación, como siempre, en forma de diálogo, de ellas, a las que llama Semibreve, Mínima, Semínima, Corchea, Semicorchea, Fusa y Semifusa, como en el libro anterior. El silencio de negra no es como en dicho libro, quizás porque el anterior era manuscrito y éste no, sino en la forma antigua, como López Remacha y Eslava

\section{Escala diatónica:}

Explicación de ella y de tono y semitono, preguntas acerca de las distancias entre diversas notas.

\section{Cartel no 2:}

Indicación al Instructor de que haga aprender y repetir a los niños el nombre de las notas en las líneas y espacios, en orden correlativo y salteado, así como después desde fuera del pentagrama. Aún en los años 60 del pasado siglo, se enseñaba así el nombre de las notas, al menos en España.

\section{El Compás:}

Descripción de él como una duración dividida en partes iguales, y afirma que el compás regulador es el compasillo, que se divide en 2 ó 4 tiempos, comienza con el compasillo de 2 tiempos (compás binario o 2/2), como algunos de los libros anteriores. Es muy curioso que en esa época y posteriores años, se diera a conocer y a practicar antes el compás de 2/2 que el de 4/4. En las décadas de 1950 a 1970, se estudiaba pri- 
mero el de compasillo 4/4. Se volvió posteriormente a iniciarse en la práctica del solfeo con el compás binario, a partir de la implantación de la metodología Kodaly, aunque ésta aconseja en primer lugar no el 2/2, sino el 2/4 más sencillo de interpretar.

Principios de los ejercicios rítmicos, de las lecciones de solfeo:

Lección 1, clave de Sol y compás de 2/2, es la escala en redondas, ascendente y descendente. Hay una nota al Instructor de hacer cantar a media voz, y obligar a que empleen los niños el falsete en los casos que se indica en la página 30 de su guía, además de vocalizarla después de solfearla.

Lección 2, la misma escala hasta el Re agudo y el Si grave.

Lecciones 3 a la 6 , sigue con la escala pero con blancas, redondas y sus silencios.

Habla de la ligadura, y pasa a las lecciones 7 y 8, en las que la emplea uniendo blancas, aún en escala. A nuestro entender todo demasiado aprisa, sin dar tiempo a digerir cada paso, quizás en la época la gente era más estudiosa, más entregada, o le dedicaba más horas a la disciplina.

Escala con aplicación de letra, con blancas y silencios y el siguiente texto: "Mi voz implora tu piedad, Señor no niegues tu bondad"

\section{Cartel no 3:}

Intérvalos (acentuado en forma esdrújula) y su división general. Definición de intervalo y unísono, nombre y calificación de ellos (sin clasificación)

\section{Ejercicios rítmicos:}

Seis ejercicios con la escala, empleando redondas, blancas y negras, silencios de blanca y ligaduras.

Ejercicios de entonación de segundas:

Dos ejercicios con segundas mayores y menores, el segundo ejercicio también para vocalizar y como ejercicios teórico de análisis de las segundas.

Continúan las lecciones de solfeo:

Lección 9 con intervalos de segunda, redondas, blancas y negras, la número 10 igual añadiendo ligaduras. 
Canto para aplicar una sílaba a cada nota: indica que hay que hacerlo Solfeando y vocalizando antes de aplicar la letra. Ésta dice: "cumple bien con tu deber si dichoso quieres ser", y está musicada en forma de pregunta y respuesta.

\section{Cartel no 4:}

Explicación del compasillo de 4 tiempos

\section{Ejercicios rítmicos:}

Once ejercicios con este compás, redondas, blancas, negras, sus silencios y ligadura, formando síncopas, tanto ésta como la blanca, y formando contratiempos los silencios de negra. Todo ello sin explicarlo.

\section{Puntillo de Aumentación:}

Explicación sucinta del puntillo y del doble puntillo (al que llama "dos puntillos").

Ejercicio $\mathrm{n}^{\mathrm{o}} 12$, de 5 compases para practicar tal novedad sobre la blanca.

Ejercicios de entonación terceras:

Cincuenta compases para este intervalo, los cuales empiezan por Do 3 y prepara el intervalo por grados conjuntos, sigue hasta $\mathrm{Do}_{4} \mathrm{y}$ luego desciende.

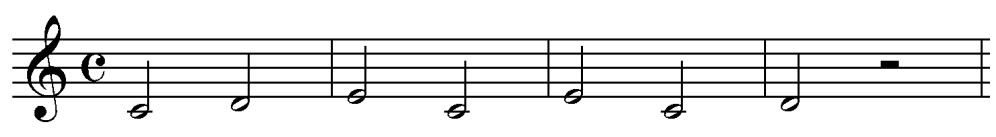

Otro ejercicio, con nota al Instructor, para que realice terceras directas, primero solfeando y luego vocalizadas. Y otro más indicando que sirva como ejercicio práctico y teórico.

Continúan las lecciones de solfeo:

Tres lecciones, números 11, 12 y 13, en el compás que estamos estudiando, y con las figuras aparecidas hasta ahora, intervalos de tercera.

\section{Cartel no 5:}

Diálogo sobre las corcheas.

Ejercicios rítmicos.

Once ejercicios para la práctica de esta figura. 
Ejercicios de entonación por cuartas.

Cuarenta compases para entonar este intervalo, llevados a cabo de la misma manera que con el anterior intervalo.

Otro ejercicio para vocalizar y otro sin preparar (exactamente igual que con las terceras).

Continúan las lecciones de solfeo:

Números 14 a 17 de poca extensión con los elementos estudiados hasta ahora.

Canto para aplicar una sílaba a dos notas: "El prudente y el callado respetado siempre fue", teniendo las sílabas El pru ca res pe do pre, dos sonidos.

\section{Cartel no 6:}

Síncopas:

Con la siguiente definición: Una nota cuya duración se halla entre dos compases o entre dos medios compases, entre dos tiempos o entre dos medios tiempos, bastante difícil de comprender, a nuestro entender, y con la recomendación al Instructor de que haga analizarlas.

\section{Ejercicios rítmicos.}

Puntillo del valor de medio tiempo.

Doce ejercicios con síncopas largas y breves y puntillos en la blanca y negra. Ejercicios de entonación por quintas.

La misma plasmación que con los anteriores. Por cierto que define las cuartas, anteriormente, como mayores con 0 semitonos, menores con 1 semitono; y las quintas mayores con 1 semitono, menores con 2; para nada les da el nombre de justas. Denominación o calificación con la que nos identificamos plenamente.

Continúan las lecciones de solfeo:

Números 18 al 20 con los elementos incorporados hasta ahora.

Canto para aplicar una sílaba a dos notas de salto: Similar al anterior, pero cuando una sílaba tiene 2 sonidos, son éstos disjuntos.

\section{Cartel no 7:}

Ejercicios rítmicos. Pausas de medio tiempo: 
Siete ejercicios para practicar el silencio de corchea formando contratiempo.

Ejercicios de entonación con intervalos de sexta.

De la forma acostumbrada.

Lecciones de solfeo:

Números 21 a 25 con las dificultades ya presentes, y las que ya van teniendo una forma, por ejemplo A - A', Progresiones unitonales, A - B.

Canto para aplicar una sílaba a tres notas: "Tiene el hombre virtuoso generoso corazón", en el que algunas sílabas tienen 3 sonidos.

\section{Cartel no 8:}

Ejercicios rítmicos.

Ocho ejercicios, sin previa explicación, para la semicorchea y su silencio.

Ejercicios de entonación para las séptimas.

De la forma acostumbrada.

Lecciones de solfeo.

De la número 26 a la 31, intercala una en $2 / 2$ y utiliza lo estudiado hasta ahora. Canto para aplicar una sílaba a más de 3 notas: "Niños hermosos todos venid y a Dios bondoso [sic] gracias pedid"

\section{Cartel n⿳0:}

Ejercicios de entonación para las octavas

Procediendo como siempre.

Después da una norma resumen para conocer o determinar cuáles intervalos son mayores o menores. (Es prácticamente la misma que figura al final de su anterior libro Principios de solfeo y canto)

Teoría de los compases indicados por medio de números.

Explicación en forma de Pregunta y Respuesta de lo que expresan los números de los compases, (porque hasta ahora sólo ha empleado la $\mathbf{C}$ y la $\mathbf{C}$ partida) y explicación del compás de 3/4.

Lecciones de Solfeo:

De la 32 a la 35, empleando todos los elementos disponibles en el momento, pero siendo más fácil la 32, y aumentando en dificultad progresivamente.

Canto para la aplicación de una sílaba a varias notas: "Bella pradera, grato pensil, la paz since gózase en ti”. 


\section{Cartel no 10:}

$\underline{\text { Signos accidentales: }}$

Así denomina a las alteraciones, las cuales explica de la forma acostumbrada.

\section{$\underline{\text { Semitono cromático y Semitono diatónico: }}$}

Explicación de ellos, y nota al Instructor para realizar ejercicios orales con estas cuestiones.

Ejercicios de entonación:

- Semitonos diatónicos: Emplea sostenidos y bemoles primero descendiendo y luego ascendiendo.

- Semitonos cromáticos: Igualmente pero ascendiendo primero y descendiendo luego.

- Semitonos diatónicos y cromáticos: Unos ejercicios en la escala cromáticas ascendente y descendente.

Explicación, sin titular, del compás de 2/4

Lecciones de solfeo:

De la 36 a la 39 en este nuevo compás, y todo lo aprendido hasta ahora, yendo de menor a mayor dificultad.

\section{Cartel no 11:}

Ejercicios rítmicos para llegar a sentir la división binaria de los tiempos:

Se trata de ejercicios para practicar y comprender la subdivisión de los tiempos, con corcheas, semicorcheas, combinaciones de ambas, silencios y síncopas.

Intervalos mayores y menores entre notas accidentales: [curiosa denominación]

Hay un cuestionario dialogado para comprender cómo se transforma un mayor en menor o viceversa, y ejemplos para su comprensión y estudio. 
Ejercicios de entonación.

Empleando alteraciones para convertir intervalos diatónicos naturales en alterados, y cambiar a tono donde suele haber semitono, incluso llegan a cuarta aumentada.

Lecciones de solfeo:

Números 40, 41 y 42 en las que predomina la fórmula corchea y dos semicorcheas, y los intervalos alterados trabajados en los ejercicios de entonación anteriores, compases de 2 y 3 por 4 .

\section{Cartel no 12.}

Ejercicios rítmicos:

Fórmulas rítmicas corchea con puntillo - semicorchea; corchea - silencio de semicorchea - semicorchea; silencio de semicorchea - tres semicorcheas y síncopas entre ellas.

Continuación de los intervalos mayores y menores entre notas accidentales:

Ocho ejemplos de intervalos alterados para estudio teórico del alumno.

Ejercicios de entonación:

Empleando alteraciones para llegar a la $5^{\mathrm{a}}$ menor, $6^{\mathrm{a}}$ menor y $7^{\mathrm{a}}$ menor.

Lecciones de solfeo:

Números 43, 44, 45 y 46. Compases de 2 y 3 por 4, en las que introduce la fusa ( $\sin$ haberla explicado) en grupos de 4 , y emplea de nuevo, que no lo hacía desde el cartel $n^{\circ} 4$, el doble puntillo

\section{Cartel no 13:}

Del Movimiento:

Diálogo sobre los términos del movimiento.

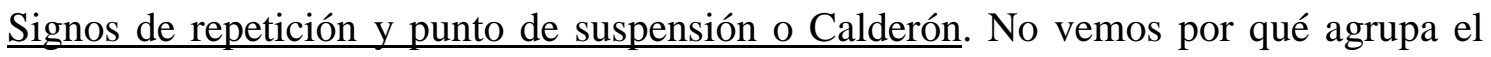
calderón con los signos de repetición y no con los de prolongación. Explicación de la doble barra de repetición, Da Capo y el párrafo $\$$; luego el calderón. 
Lecciones de solfeo:

De la 47 a 49, 3, 2 y 4 por 4 con todos los elementos conocidos hasta ahora.

\section{Cartel n⿳ 14:}

Modos:

Explicación dialogada de los dos modos de la tonalidad y del concepto de modo, las diferencias entre la escala mayor y menor y las variantes de la menor.

Acorde perfecto de la tónica:

Explicación dialogada de cómo se forma un acorde perfecto mayor y menor, y ejercicios de entonación de la escala de La menor y su arpegio.

\section{Lecciones de solfeo:}

Tres lecciones en La menor, 4, 3 y 2 por 4, comenzando con pocas dificultades rítmicas y acrecentándolas en la segunda y tercera hasta llegar a la fórmula semicorchea con puntillo - fusa.

\section{Cartel no 15:}

Intervalos alterados:

Con este título de epígrafe, explica los aumentados y disminuidos, pone preguntas para los alumnos y ejemplos para su análisis.

Palabras y signos más usuales que indican los varios acentos de la expresión:

Aquí explica los matices dinámicos uniformes y los reguladores.

\section{Ejercicios de vocalización para desarrollar la voz:}

Cinco ejercicios: el primero es una escala de Do mayor hasta el Fa agudo y descenso, diciendo que se pasara de la voz de pecho a la de falsete a partir de la última nota de pecho, (suponemos que quiere decir con ello la última nota que abarque nuestra extensión o tesitura). El segundo son notas largas tenidas para cantarlas con voz de pecho, de cabeza y de pecho. El tercero para cantarlo 3 veces, cada una de ellas en un matiz: fuerte, medio fuerte y piano. El cuarto para hacerlo 2 veces: creciendo las notas largas y 
decreciendo la segunda vez. El quinto para hacer un fiato con notas largas, esto es, piano fuerte piano.

\section{Cartel n⿳ 16:}

Tonos naturales, transportados y relativos:

Explicación dialogada, muy primitiva e insuficiente, elemental y rudimentaria de las tonalidades transportadas, sus armaduras, tonos relativos, etc.

Articulación del canto. Ligado y picado:

Una explicación dialogada de estas dos articulaciones, distinguiendo 3 clases de picado: simple, muy picado (stacatto) y picado ligado.

\section{Ejercicios:}

Para ejercitar y comprender estas articulaciones, ligadas dos a dos o más notas, picado, stacatto y picado - ligado. Y todo trascrito a su efecto real.

\section{Cartel no 17:}

Indicación de los compases más y menos usuales:

Indicación al Instructor de enseñar y preguntar unidades de tiempo y compás de todos los simples y compuestos con denominadores del 1 al 16, y pequeño comentario de la existencia de la "breve" (cuadrada).

Escala de Sol mayor y su acorde perfecto:

Un ejercicio con la escala y el arpegio.

Dos lecciones en $4 / 4$ y como compás nuevo $3 / 8$, en esta tonalidad, sin muchas dificultades rítmico - melódicas.

Ejercicios para la práctica de la $3^{\mathrm{a}}$ disminuida y $6^{\mathrm{a}}$ aumentada, $2^{\mathrm{a}}$ aumentada y $7^{\mathrm{a}}$ dismi$\underline{\text { nuida. }}$

Escala de Mi menor y su acorde perfecto:

Escala y arpegio.

Dos lecciones en $3 / 8$ en las que la melodía incluye generosamente los intervalos practicados anteriormente. 


\section{Cartel no 18:}

Escala del tono de Re mayor y su acorde perfecto:

Escala y arpegio.

Dos lecciones en compás de 3/8, aumentado las dificultades rítmicas, fusas, síncopas, contratiempos en este compás.

Escala de Si menor y su acorde perfecto:

Escala y arpegio.

Dos lecciones en $3 / 8$ en las que abundan las fusas.

Tabla de los tonos mayores y menores:

Dos pentagramas con las tonalidades en armaduras de sostenidos.

$\underline{\text { Silencios de uno o más compases: }}$

Indica que la pausa de semibreve (redonda) sirve para indicar el silencio de un compás en cualquier de ellos, menos en el de 4/2 o compás mayor. E indica la forma de poner 2 ó más compases de silencio de manera muy chocante

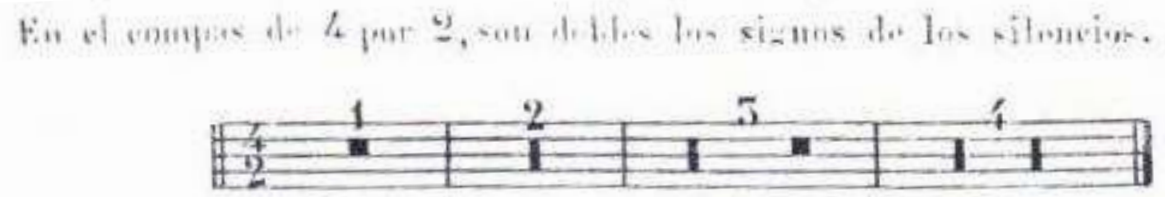

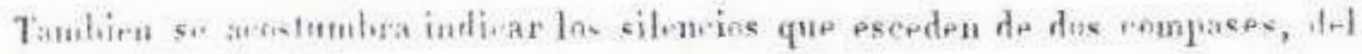
unde sizutirsity.
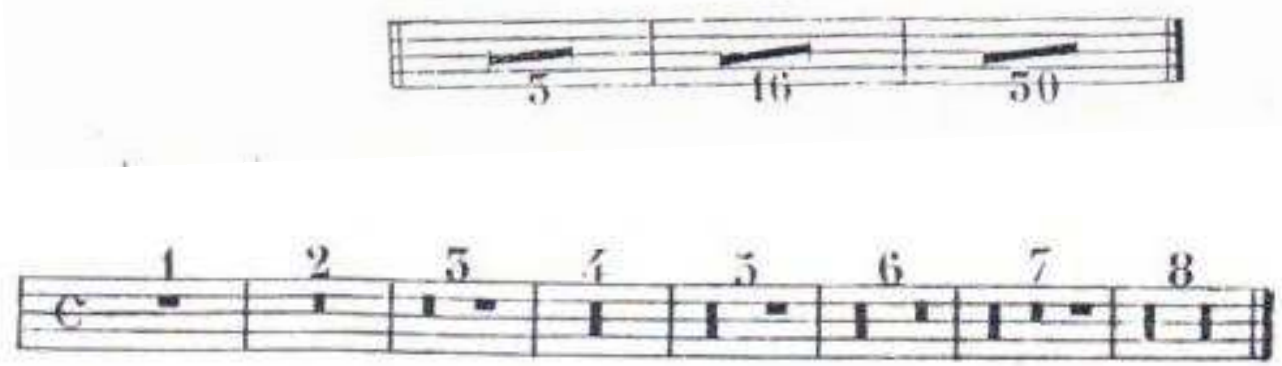

\section{Cartel no 19:}

Tonos con bemoles:

Explicación de que se encuentran las tonalidades bemoladas subiendo por cuartas menores a partir de Do. 
Pérez Gascón (Método de solfeo y principios de canto)

Ejercicios rítmicos:

Compás de 6/8 con variadísimas combinaciones rítmicas.

Ejercicios preparatorios a la entonación de la $5^{\mathrm{a}}$ aumentada y $4^{\mathrm{a}}$ disminuida:

Unos cuantos ejercicios destinados a esta práctica.

Escala de Fa mayor y su acorde perfecto:

Escala y arpegio.

Tres lecciones en 6/8 con modulaciones a sus vecinos y alteraciones para incluir los intervalos antes practicados.

\section{Cartel no 20:}

Ejercicios rítmicos:

Ejercicios en 6/8 para realizarlos subdividiendo y sin subdividir.

Escala de Re menor y su acorde perfecto:

Escala y arpegio.

Cuatro lecciones en 6/8 con combinaciones rítmicas propicias para la subdivisión.

$\underline{\text { Tabla de los tonos relativos con bemoles: }}$

Dos pentagramas con las tonalidades desde 1 a 7 bemoles.

\section{Cartel no 21:}

Ejercicios rítmicos:

Para estudiar más complejidad en el 6/8 subdividido.

Escala de Si bemol mayor y su acorde perfecto:

Escala y arpegio.

Tres lecciones en $6 / 8$.

Escala de Sol menor y su acorde perfecto:

Escala y arpegio.

Dos lecciones en 6/8. 


\section{Cartel no 22:}

\section{Llave de Fa en la cuarta línea:}

Indicación del nombre e las notas en las líneas, espacios y líneas y espacios adicionales.

Tres lecciones en las tonalidades de Do mayor, Sol mayor y Fa mayor, compás de 2/4 la primera y 3/8 las otras dos. Muy difícil para empezar con una nueva clave.

Escala de La mayor y su acorde perfecto:

Escala y arpegio.

Cuatro lecciones, las dos primeras en 3/8 y las dos siguientes en 9/8, compás nuevo, con una breve indicación de su significado.

\section{Cartel no 23:}

Escala de Fa sostenido menor y su acorde perfecto:

Escala y arpegio.

Cuatro lecciones, 3/8, 6/8 y 9/8 las dos últimas. Con bastante complejidad rítmica y de entonación.

\section{$\underline{\text { Llave de Do en la primera línea: }}$}

Indicación del nombre de las notas en líneas, espacios y líneas y espacios adicionales.

Cuatro lecciones en Do mayor, Mi menor, Re mayor y Si bemol mayor, compases de 4/4, 3/8, 6/8 y 9/8. Una enormidad para estar empleando una nueva clave.

\section{Cartel n⿳2 24:}

Escala de Mi bemol mayor y su acorde perfecto:

Escala y arpegio.

Tres lecciones, 2/4 y 12/8 como nuevo compás, sin ninguna explicación al respecto, empleando además, ya desde bastante antes, los signos de articulación y dinámica estudiados.

Escala de Do menor y su acorde perfecto:

Escala y arpegio.

Una lecciones en $12 / 8$. 
Apoyaturas:

Explicación dialogada de esta nota de adorno, a la que no la llama así, sino nota pequeña que toma su duración de la nota siguiente, y también dice que su valor será la mitad de la nota principal, o los dos tercios si lleva la principal puntillo.

Una lección con la clave de do en $1^{\text {a }}$, Do mayor y 4/4 para utilizar la apoyatura. (Si entra en la enseñanza de las notas de adorno, no comprendemos porqué se queda en la apoyatura y no habla del resto de ellas).

\section{Cartel no 25:}

Tresillos y seisillos:

Una breve, pero clara explicación de estos grupos de valoración irregular.

Cuatro lecciones, clave de do en $1^{\mathrm{a}}$, Do mayor y Sol mayor la última, compases de $2 / 2,2 / 4,4 / 4$ y $3 / 4$ con estas medidas.

\section{Cambio de llaves:}

Dos lecciones, Do mayor y compás de 4/4, Sol mayor y 6/8, con cambios entre las 3 claves estudiadas.

Termina explicando lo que es enarmonía y con la lección 100, en clave de Sol, compás de 4/4 y tonalidad de Sol menor, para practicar alguna enarmonía.

Le siguen 22 páginas con cantos corales a una dos y tres voces, y cánones, pero eso no forma parte de nuestro estudio.

\subsubsection{VALORACIÓN DE LA EFECTIVIDAD DEL MÉTODO Y DE SU APORTACIÓN A LA ENSEÑANZA.}

Es un buen libro, bastante completo, tiene parte de teoría y también ejercicios para la comprensión de la parte teórica. También ejercicios de vocalización y de introducción al canto.

Hay que estar conforme con el Dictamen referido que dice, entre otras cosas: "orden, sencillez y claridad en las explicaciones de los diversos signos que constituyen el lenguaje musical, gradación metódica...”. Sin embargo algunas cuestiones se abordan de forma demasiado escueta y precipitada. Un poco apretadas las distintas dificultades y 
con poco desarrollo de cada una de ellas, pero la enseñanza debía ser a la sazón distinta, y los estudiantes más sacrificados.

Las melodías suelen ser atractivas, pero hay bastante dificultad rítmica, al menos en el inicio, o para ser un inicio.

Al empezar a aprender una nueva clave, las lecciones son demasiado difíciles, es decir, que teniendo en cuenta el nulo dominio de la nueva clave, las lecciones deberían ser métricamente muy sencillas para ir progresivamente complicándolas.

Abarca lo que era en esos años un nivel de $3^{\circ}$ curso, que era el último. Por lo que se quedaría un poco corto. En la actualidad sería una cota de $4^{\circ}$, final de grado elemental. $^{1}$

\footnotetext{
${ }^{1}$ Según FONTESTAD PILES, Ana, op. citada, pp. 144 y 145, ese era el objetivo de Pérez Gascón, que la música llegara, aunque fuese en su nivel elemental, a la mayor cantidad de gente posible, que no fuera privilegio de clases altas; también opina que por ello las lecciones no llevaban acompañamiento de piano, porque al eliminar el costo de este instrumento, tenía la enseñanza cabida en muchos más centros, y que sin embargo Pérez Gascón recomendaba reemplazarlo por el diapasón. [No es ni mucho menos reemplazable una cosa por otra, este último sólo sirve para mantener la altura absoluta, y el piano para introducir en los alumnos el sentido armónico, pero es cierto que cuando la necesidad arrecia, hay que prescindir de algo]
} 
Pérez Gascón (Método de solfeo y principios de canto) 


\subsection{RESEÑA BIOGRÁFICA DEL AUTOR}

PRELLEZO, (o Prellero) Mariano de: nace, presumiblemente en Potes (Santander), sin que se sepa a ciencia cierta la fecha, muriendo en Quibel (Turquía) el 15 de noviembre de 1862. Era de familia noble. La música era para él una distracción en el tiempo libre. Se dedicó a la jurisprudencia, siendo magistrado de las Audiencias de Oviedo, Sevilla, Granada y Valencia y fiscal de la de Zaragoza, aunque él mismo dice en su libro que fue fiscal de "S. M. en las de Zaragoza, Sevilla, Granada y Valencia". Ministro del Tribunal Supremo Contencioso-Administrativo en 1858, suprimido después por reestablecimiento del Consejo Real, y gobernador en comisión de la provincia de Almería en 1858. El libro que aquí comentamos estuvo muchos años de texto en el Conservatorio de Madrid, fue elogiado por la prensa madrileña, a excepción de Eslava, con el que tuvo diferencias. Prellezo era partidario de una sola clave, la de Do, considerando las de Sol y Fa de sustitución, y no reconocía los géneros cromáticos y enarmónicos. Consecuencia de su método fue la apertura de una Academia por el profesor José $M^{a}$ Argüelles, en la que según él, los alumnos aprendían en el breve periodo de 4 meses. Fue nombrado en 1861 cónsul español en Jerusalén, pasó a Jaffa por motivos de salud, y al regresar a Jerusalén, murió en la aldea turca de Quibel (Sanhuesa Fonseca, María en AAVV, 1999, pp. 836 y 37).

\subsubsection{DESCRIPCIÓN DETALLADA DEL MÉTODO.}

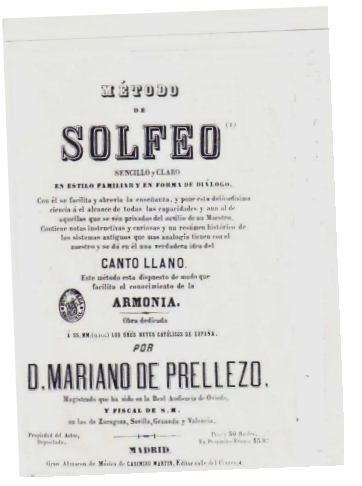

\section{Título del Método}

Método de solfeo sencillo y claro en estilo familiar y en forma de diálogo, Madrid, Casimiro Martín, s. f. ${ }^{1}$ Apéndice, página 205. $1^{\text {a }}$ parte del Método completo de música teórico-práctica. ${ }^{1}$

\footnotetext{
${ }^{1}$ En este ejemplar no consta fecha alguna, pero en el catálogo de la Biblioteca Nacional, la obra total, o sea, el Curso completo de música teórico-práctica: por un método sencillo y claro, en estilo familiar y en forma de diálogo, figura el año 1851 y otra editorial, también de Madrid, Martínez y Minuesa. También lo confirma PRECIADO, Dionisio: obra citada, p. 240 y AAVV, 1999, p. 936
} 


\subsubsection{PARTE TEÓRICA}

Después del título sigue diciendo: "Con él se facilita y abrevia la enseñanza, y pone esta delicadísima ciencia al alcance de todas las capacidades y aun al de aquellas que se ven privadas del auxilio de un Maestro. Contiene notas instructivas y curiosas y un resumen histórico de los sistemas antiguos que más analogía tienen con el nuestro y se da con él una verdadera idea del CANTO LLANO. Este método está dispuesto de modo que facilita el conocimiento de la ARMONÍA"

Primeramente aparece una dedicatoria a SS.MM. la Sra. Doña Isabel II y su Augusto Esposo el Sr. D. Francisco de Asís María de Borbón y Borbón, Reyes Católicos de España

Luego un Prólogo en el que hace un canto poético a la música y una detallada narración de la importancia de ella en la antigua Grecia y después en Roma, con nombres y detalles interesantes, la desaparición de estas artes al principio de la Edad Media, su lenta y posterior recuperación y el grado de perfeccionamiento en el que estaba en su época. Una queja sobre el desprecio que algunos escritores hacen de la música, y en fin los motivos que le han inducido a escribir este método, que son en su opinión la ausencia de un libro sólido en el que se recojan todos los principios y preceptos de este lenguaje, criticando de soslayo algunas de las publicadas "gramáticas musicales", que no llegan a conseguir, puesto que sólo contienen los primeros rudimentos, el laudable objeto que llevó a escribirlas.

Y sin dilación acomete la parte teórica de esta primera parte. La divide en 12 capítulos y un apéndice, y cada uno de ellos los fragmenta en apartados que él llama "artículos". Hay capítulos con dos artículos, con cinco, con seis, con ocho, o con artículo único. Se nota que su autor es jurista. Y como dice el título del libro, está escrita en forma dialogada tan común en la época, aunque, a veces, las respuestas son tan eruditas y extensas, que raramente un alumno, a no ser persona muy avezada en las letras, pudiera retener en mente.

Es casi un tratado teórico, anterior al práctico, que es mucho menor, y por creerlo de interés, comentamos brevemente los aspectos curiosos o infrecuentes que hemos encontrado en sus diversos capítulos y artículos:

\footnotetext{
${ }^{1}$ Según el autor, p. 11 de esta parte, la segunda parte comprende la melodía, la armonía, el contrapunto y la composición.
} 
Capítulo I, con 4 artículos. Habla del origen, etimología, definición y división de la música. Filosofa extensamente sobre su origen ascentral y de aparición del hombre en la Tierra. Atribuye a las Musas y otras mitologías su nombre. Hace la siguiente división: teórica o especulativa, práctica y de ejecución; siendo la primera lo que conocemos hoy por teoría de la música, la segunda el solfeo, contrapunto y composición y la tercera la traslación a los instrumentos o al canto.

Capítulo II, con 2 artículos. Es un pequeño tratado de acústica musical, habla del sonido, su propagación y división según su altura, pero en las notas al pie da una verdadera disertación de las propiedades de los cuerpos sonoros: extensión, porosidad, compresibilidad, elasticidad, dilatabilidad, equilibrio de los cuerpos sólidos y oscilación; también de las propiedades de las cuerdas, de la voz y el oído humanos; hace también un razonamiento de la inexactitud de los intervalos medidos con el sonómetro o monocordio, y defiende la educación por el oído.

Capítulo III, 5 artículos. Las notas, aunque él hace una rara división en Eptacordo [sic], escala, gama y diapasón, para acabar en el nombre de las notas o sonidos, además mezcla éstos con la antigua denominación alfabética, mezcla la teoría con historia de la evolución de las grafías y en definitiva convierte lo fácil en cuestiones dificultosas de comprensión. Un concepto extraño es el de "escala tendida" que se refiere a la sucesión o unión de escalas hacia arriba o hacia abajo en el espectro sonoro.

Capítulo IV, 2 artículos. De los signos de entonación y duración de las cuerdas o sonidos musicales. Los signos de entonación, según el autor, son el pentagrama y las Claves [?], durante dos páginas explica, de forma muy complicada, el origen y utilidad de las claves; explica que cada una de las siete voces tiene entre los sonios una cuerda media que es la más natural y fácil de entonar, y que estas siete cuerdas medias van subiendo por el mismo orden que las siete voces, de tercera en tercera; la cuerda media de cada voz se hace corresponder con la raya o línea del medio del pentagrama, así aparece la clave universal, que es la de Do, que se sitúa en la tercera línea para el contralto, y se va subiendo o bajando a tenor de la cuerda media de cada voz, pero luego algunas se sustituyen por las de Sol o Fa en $4^{\mathrm{a}}$ para evitar el excesivo empleo de las líneas adicionales. Total que para entender esto, hace falta, ya, saber bastante música. Y respecto a los signos de duración, o sea las figuras, enumera todas, desde la máxima a la garrapatea, haciendo observar que las tres primeras, más la última, no están en uso, y habla de la relación entre ellas. Por cierto que dice que la máxima, longa y breve sólo se usan en el canto eclesiástico, llamado Coral o Llano porque se escribe sin divisiones [¿por eso 
se llama llano?]. Además de no usarse en este canto la grafía mensural. No comentamos.

Capítulo V, 4 artículos. Empieza muy bien diciendo que para expresar el valor que tienen las figuras, es necesario fijar la duración absoluta de una, y por ésta, determinar proporcionalmente la de las otras; pero a continuación define compás como el continuo movimiento que el director de un coro o de una orquesta hace con la mano de abajo a arriba... O sea que compás no es una métrica del ritmo, o una parte alícuota del todo. [?]. El caso es que no explica cómo se expresa el valor absoluto de una de las figuras, sino que habla de que dentro de un compás se pueden escribir tantas figuras como valores sumen una semibreve. Después hace un enredo con el término tiempo, porque dice que tanto conviene al compás como al valor de las figuras, y que el tiempo se divide en tres o dos partes iguales. Con lo cual no queda claro qué es compás y tiempo. Defiende la denominación de tiempo perfecto para el ternario e imperfecto para el binario, discurriendo en nota al pie, sobre la excelencia desde los tiempos de Pitágoras del número 3, también del culto a este número por parte de San Agustín, que decía que era el primero que tenía principio medio y fin, y tratando de demostrar que como el círculo es capaz de formar dentro de si un triángulo equilátero, ese es el número perfecto, y el dos el imperfecto, y contraviniendo a sus coetáneos que ya habían dado esas denominaciones al contrario. En cuanto a la forma de marcarlos, también es curiosa: para el compás ternario dos movimientos hacia abajo y uno hacia arriba, para el binario uno bajo y otro arriba, para el cuaternario, dos abajo y dos arriba. Luego comenta las especies de tiempos musicales, esto es, las clases de compases, según él son nueve: tres de tiempos perfectos, que son $3 / 2,3 / 4$ y $3 / 8$; dos de tiempos imperfectos, $2 / 2$, o $2 / 4$ y $4 / 4$; tres compuestos de perfectos e imperfectos, $6 / 4,6 / 8$ y 12/8 y uno de tiempo perfecto doble que es el 9/8. Modificaciones de los tiempos es el artículo que completa este capítulo. Se refiere a los términos de la velocidad, a los matices agógicos y dinámicos, a los acentos y al metrónomo. Mas hay un párrafo que, por lo gracioso, copiamos literal.

A pesar de todo este vocabulario, muy pocas veces se ejecuta una obra de música según el pensamiento del autor: dependiendo una gran parte de la inteligencia y pericia del maestro director, y del entusiasmo unánime de los músicos ejecutores. ¿De qué sirve poner en la escena el más sublime drama lírico, si los más célebres cantantes, dado caso que no alteren su parte con adornos que el compositor rechazó con ignominia y asco, tienen que concertarse con una orquesta compuesta muchas veces de maestros y discípulos, de muchachos, de mozos y de viejos, el uno medio sordo, el otro cuasi ciego, este fogoso, aquel flemático, y esotro holgazán o descuidado? ¿Qué goza el público en semejantes casos? Su continuo charlar, es el indicio infalible del fastidio; y sin embargo, en 
comenzando a cantar una aria, todo el mundo queda en silencio para oír al músico girar y regirar a su gusto y fuera de tiempo por todas las escalas, prorrumpiendo en un estrepitoso palmoteo. Con cuánta razón podrían los músicos alegar por excusa de sus defectos aquellos versos de Lope de Vega: "y pues que paga el vulgo necio, es justo neciamente cantar por darle gusto»

Capítulo VI, 6 artículos. Hace una personal división de la escala: tonos y semitonos, tetracordos, cuerdas naturales y accidentales, intervalos, y modos.

Al relatar las cuerdas accidentales, es cuando muestra las alteraciones, explicándolas de forma bastante compleja. Cabe destacar que llama al bemol B-mol y al becuadro B-cuadro. También explica las dobles alteraciones.

En lo referente a intervalos los divide en simples y compuestos y los subdivide en mayores y menores, incluyendo en esta subdivisión a las cuartas y las quintas, tal como hacen Eslava, Moré, Pérez Gascón, Amorós y Agero. Ya hemos manifestado en esas descripciones nuestra simpatía por esta calificación. Mas lo sorprendente es que incluye entre los compuestos el de octava, y más sorprendente, el de quinta menor [i?]. Emplea, como algunos otros, el término de diminuto para los disminuidos, y no cambia el de aumentados. Por último, los divide en euphonicos, disonantes y cacophonicos; los primeros son los consonantes, los segundos las disonancias absolutas y los terceros las disonancias condicionales.

Acaba este capítulo con el concepto de modo, y con las diferencias entre los modos mayor y menor, aunque en este último sólo plasma la escala armónica, sin hablar de las otras.

Capítulo VII, artículo único. Alteraciones de la escala natural. Así afronta la explicación de las tonalidades, sin que esta palabra aparezca, el autor habla de escalas artificiales (como si de escalas exóticas se tratara), y afirma que hay 21, esto es, la de Do, que es la natural, y otras 20, y ahí incluye las tonalidades enarmónicas no practicadas, como Sol, Re, La, Mi y Si sostenidos y Fa bemol. Todas las explica con el sistema de enlace de tetracordos, sin nombrar las armaduras, ni la relación entre los modos menores y mayores, tan sólo indica que a partir de una escala mayor, modificando hacía el grave el $3^{\circ}$ y $6^{\circ}$ grados, se consigue la menor.

Capítulo VIII, artículo único. Los signos que aumentan el valor común de las figuras, o sea el puntillo y el doble puntillo.

Capítulo IX, 8 artículos. De los signos de expresión y adorno en la música. Pero bajo esta denominación engloba signos tan dispares como la ligadura, claro que habla de las dos, la síncopa también es para Prellezo un signo de expresión o adorno, que la ex- 
plica como "una figura colocada entre otras dos de inferior valor, como por ejemplo una mínima entre dos semínimas". Pobre y no del todo cierta explicación. Se adentra, ahora sí, en las notas de adorno; llama mordentes a unas notas en formas de semicorchea, sin barrar; apoyatura a la apoyatura armónica, y la define de manera bien difícil: una nota que forma parte del compás, y cuyo tiempo de duración está con la inmediata siguiente en la proposición de 2 a 1 o de 4 a 5 ..., y que debe ocupar la parte "sensible" del compás, o sea la fuerte; grupeto a dos, tres o cuatro pequeñas notas en forma de fusas barradas, afirma que para los de 3 y 4 notas se utiliza el signo $\sim$ sin que nombre siquiera el descendente, y los utiliza anteriores, posteriores y cuando los sitúa arriba de la nota principal, es para que sean de 4 notas. Y sigue con los adornos, ahora con el calderón [?], y la volata, forma de este autor de llamar a la fermata, o a pequeñas fermatas o florituras. Y como este capítulo parece un cajón de sastre, también mete ahí a los tresillos, seisillos y nuevillos. No comprendemos porqué ese salto de 6 a 9 notas en los grupos de valoración irregular, omitiendo totalmente los otros.

Capítulo X, artículo único. Este capítulo lo reserva para silencios, a los que llama pausas, medias pausas y aspiraciones; siendo las primeras las de las figuras largas, medias pausas, el de negra, y aspiraciones a partir de corchea. No advertimos porqué aplaza tanto la explicación de los silencios, y no lo hace conjuntamente con las figuras de nota. También Lladó hace esto.

Capítulo XI, artículo único. Caracteres inherentes de la música. Dice que son 3 esos caracteres: carácter gámico, carácter módico y rítmico, refiriéndose a que cualquier música debe pertenecer a una escala, a un modo y que precisa del elemento rítmico. Y en nota al pie da una verdadera clase magistral de los pies métricos griegos.

Capítulo XII, artículo único. Explica las abreviaturas y los signos de repetición.

Sigue todo este compendio teórico con un apéndice, advirtiendo que sirve para quien quiera penetrar en mayores conocimientos y que no es necesario para el aprendiz, con sistemas antiguos, modos, escritura o notación, solfeo y melodía griegos, el sistema de Guido d'Arezzo y el Canto Llano. En ellos diserta abundantemente sobre estas materias, haciendo alarde de gran erudición, y donde informa de conocimientos interesantes, pero también hay otras aserciones para poner en duda, incluso llegando a la sonrisa. Nos limitaremos a transcribir un diálogo imaginario que establece entre Zarlino y un principiante a cuento de la división de la octava "armónica o aritméticamente" en el Canto Llano: 
PRINCIPIANTE. ¿Cómo distinguir el primer Modo del segundo, si en ambos va a terminar el canto con las mismas cuerdas en D-la-sol-re?

ZARLINO. Es cosa fácil: en el primer Modo, la cuerda que hay desde A-la-mi-re, a D-la-sol-re, está en la parte aguda del grupo, y en el segundo en la parte grave, y basta esto para constituir dos distintos Modos.

PRIN. Pero señor, si que tomemos el A-la-mi-re en la parte aguda o en la grave, la cadencia final en D-la-sol-.re es exactamente la misma, ¿en qué razón se funda que una diferencia tan accidental como insignificante a la armonía, haya de constituir dos Modos esencialmente distintos?

ZRL. En que los que tienen la cuarta en lo agudo, están divididos armónicamente: los que la tienen en lo grave, aritméticamente: y como éstas divisiones son esencialmente diferentes, por la misma razón constituyen Modos esencialmente diversos.

PRIN. Pero si la misma cadencia perfecta se hace en D-la-sol-re, con la división armónica del Modo primero que con la aritmética del segundo, ¿qué tienen que ver semejantes divisiones con la música?

ZARL. Mucho. Los Modos armónicamente divididos se llaman principales, porque el honor y la preeminencia se da siempre a aquellas cosas que son más nobles, como lo es la división armónica. Se llaman también auténticos, porque tienen más autoridad que los serviles, divididos aritméticamente, los cuales se llaman plagales, esto es, laterales, oblicuos o torcidos, porque como serviles van detrás de los auténticos y se forman oblicuamente, poniendo en lo grave la cuarta que en los auténticos está en lo agudo. También se llaman aquellos placables, porque aplacan las pasiones excitadas por los auténticos sus principales señores: y así es como producen contrarios efectos; de manera que si D-la-sol-re auténtico te hace reír, D-la-sol-re plaga te hará llorar.

Y termina esta parte teórica con 13 láminas con ejemplos gráficos de casi todo lo que se ha explicado.

\subsubsection{PARTE PRÁCTICA DEL MÉTODO DE SOLFEO}

\section{CUADRO DE INFORMACIÓN GENERAL DEL MÉTODO.}

$\mathbf{N}^{\mathbf{0}}$ de lecciones No las hay, solamente ejercicios

Extensión de las lec- Entre 14 y 30 compases

ciones

Claves empleadas

Tesituras que abarcan $\quad \mathrm{La}_{2} \mathrm{a} \mathrm{Fa}_{5}$

Tonalidades que trata Do M, La m, Sol M, Mi m, Re M, Si m, La M, Fa \# m, Mi y estudia

Compases que emplea y estudia
Sol, y todas las demás, pero usadas como ficción de claves.

M, Do \# m, Si M, Sol \# m, Fa M, Re m, Si b M, Sol m, Mi b

M, Do m, La b M, Fa m, Re b M, Si b m, Sol b M y Mi b m

$2 / 2,4 / 4,2 / 4,3 / 2,3 / 4,3 / 8,6 / 4,6 / 8,12 / 8$ y $9 / 8$ 
Dificultades métricas que contiene

Dificultades de entonación que se encuentran $y$ orden en que se enseñan los intervalos

Armonía utilizada

Formas que tienen las lecciones

Introducciones, Intermedios o Codas instrumentales

Teoría de la música que incluye

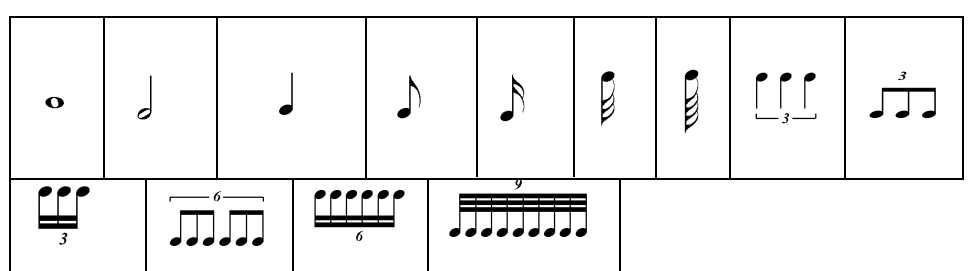

Ninguna, son casi siempre arpegios.

Escalas, $2^{\mathrm{a}}$ mayor y menor, $3^{\mathrm{a}}, 3^{\mathrm{a}}, 5^{\mathrm{a}}, 6^{\mathrm{a}}, 7^{\mathrm{a}}$ y $8^{\mathrm{a}}$, preparados $\mathrm{y}$ de salto

No existe

No tienen

No tienen

Mucha, toda en una primera sección de esta $1^{\mathrm{a}}$ parte, concretamente 98 páginas contra 64 de solfeo

\section{SECUENCIA}

Comienza con el compás de 2/2, haciendo ejercicios de intervalos, primero la escala ascendente y descendente con redondas, luego segundas mayores y menores con blancas; terceras preparadas con blancas en compás de 4/4, y lo mismo con negras en compás de 2/4, luego las hace de salto. Las cuartas van preparadas en compases de 3/2, 3/4 y 3/8, y luego de salto. Las quintas también preparadas y de salto con los compases, ya tan de súbito, vistos. A partir de las sextas, siguiendo con la preparación y de salto, ya se ven las corcheas (aunque ya aparecen con el 3/8, pero con valor unitario), y así se sigue hasta las octavas.

Después de una advertencia al alumno, de que no siga, sin cantar estos ejercicios con entonación y medida perfectas, vienen 3 ejercicios con negras y corcheas mezclando intervalos.

Prosigue con un solo ejercicio para conocer los compases de 6/4, 6/8, 12/8 y 9/8, para las semicorcheas, fusas y para las semifusas.

Y también uno cada uno con tresillos de negra, de corchea y de semicorchea; seisillos de corchea y semicorchea y nonillos (llamados por Prellezo nuevillos)

Siguen las 21 escalas de los modos mayor y menor. Tal como preconiza en su parte teórica, ahora explica las tonalidades relativas y de alguna oscura manera las arma- 
duras, siguiendo ejemplos de todas las escalas mayores y menores, primero con sostenidos y luego con bemoles, incluyendo las teóricas con dobles alteraciones, y cierra con las comparaciones de las enarmónicas. También en cada una de ellas, escribe la clave que sería necesaria para cantar siempre en la escala natural, esto es, el Do móvil.

Después de esto, un ejercicio en cada una de las tonalidades mayor y menor hasta 5 sostenidos y hasta 6 bemoles, poniendo además la clave que se debe usar si se quiere cantarlos todos en las tonalidades modelo.

Un ejercicio para mezcla de claves y compases y el último para ver signos de expresión, notas de adorno y signos de repetición.

\subsubsection{VALORACIÓN DE LA EFECTIVIDAD DEL MÉTODO Y DE SU APORTACIÓN A LA ENSEÑANZA.}

Desde luego ni es sencillo, ni claro, ni en estilo familiar, al menos la teoría, ¿qué quiere decir estilo familiar? ¿Que es con lenguaje coloquial? Pues todo lo contrario, no puede ser más erudito y enrevesado; quizás es el lenguaje de la época, pero aun así, es sumamente confuso.

Eso en cuanto a la teoría, pero no digamos la práctica, no puede ser más escueta y amontonada, no se ven contratiempos, síncopas, fórmulas combinadas, del seisillo pasa al nonillo, que no hace ninguna falta ver si no se han enseñado otras cosas más precisas, como las anteriormente dichas que no las trata.

Las claves van en el orden arbitrario que se necesita para el transporte de todas las tonalidades.

Alteraciones accidentales no aparecen, excepto para las escalas armónicas. En fin, que no puede ser más desastroso el método, la parte teórica peca por exceso y la práctica por mucho defecto. 
Prellezo 


\subsection{RESEÑA BIOGRÁFICA DE LOS AUTORES}

\section{VALERO PERIS, José y ROMERO ANDÍA, Antonio.}

José Valero Peris nació presumiblemente en Valencia y desde luego murió en Valencia en 1868. En 1812 ya figura como músico en el Teatro de Valencia. Hizo óperas, canciones, música religiosa y música coral, fue pianista, director de El Liceo Valenciano. Compuso un himno para la Real Sociedad Económica de Amigos del País, fue tan importante como Pérez Gascón (Galbis, Vicente en AAVV, 1999, pp. 675 y 76). Según reza en el método, era profesor de canto y primer socio de mérito del liceo valenciano.

Antonio Romero Andía, nació en Madrid el 1 de abril de 1815 y murió el 7 de octubre de 1885. Clarinetista, editor y comerciante de música. Pronto se inició con el clarinete con el que actuaba en las compañías teatrales en las cercanías de Madrid, también estudiaba el violín. A los 14 años ya era clarinetista de una compañía teatral en Valladolid y en un regimiento de artillería de esa ciudad. Más tarde obtuvo por oposición el puesto de clarinete primero del Regimiento de Artillería de la Guardia Real, y después el de requinto del Cuarto de Infantería de la Guardia Real. Con motivo de su participación en la guerra carlista, conoció a José Guelbenzu quien lo inició en la armonía y composición. Perdió su puesto al ser disuelto su regimiento y se convirtió en director musical del Circo Ecuestre de Paul. Yendo en gira por Andalucía conoció a Eslava, con quien amplió conocimientos de teoría musical. Volvió a ser contratado como músico mayor del Tercer Regimiento de la Guardia Real; quedando de nuevo disuelto ese regimiento pasó a tocar en una compañía de ópera, época en la que también empezó a estudiar el oboe. En 1844 ganó una plaza de clarinetista supernumerario en la Real Capilla, donde estuvo 23 años, simultaneando con el puesto de primer oboe en el Teatro del Circo. Editó un famoso Método completo para clarinete de trece llaves, que fue el primero de los publicados en España, y que todavía se sigue editando y utilizando. En 1849 ganó la oposición de profesor de clarinete en el Conservatorio de Madrid y 8 años después la de profesor de oboe.

A partir de 1850 se dedicó también a la invención y perfeccionamiento del clarinete denominado "Sistema Romero" y a su editorial y almacén de música Romero, donde se editó gran cantidad de música de autores españoles y extranjeros(Gosálvez Lara y Villa Rojo en AAVV, 1999, pp. 384 a 387). 


\subsubsection{DESCRIPCIÓN DETALLADA DEL MÉTODO.}

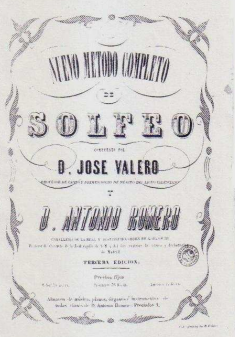

\subsubsection{PRIMERA PARTE}

CUADRO DE INFORMACIÓN GENERAL DE LA PRIMERA PARTE. $\mathrm{N}^{\circ}$ de lecciones 50

Extensión de las lec- Desde 8 a 36 compases, siendo la mayor parte de 16 compases ciones

Claves empleadas Sol

Tesituras que abar- $\quad \mathrm{Do}_{3} \mathrm{a} \mathrm{Fa}_{4}$

can

Tonalidades que Do M y La m

trata y estudia

Compases que em- $\quad 4 / 4,2 / 2,2 / 4,3 / 4,3 / 8,6 / 8,9 / 8$ y $12 / 8$

plea y estudia

Dificultades métricas Son diferentes, y también el orden de aparición, si éstas son que contiene para los ejercicios o para las lecciones.

Para los ejercicios:

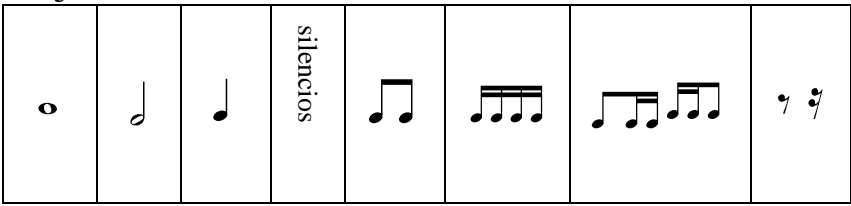

Para lecciones:

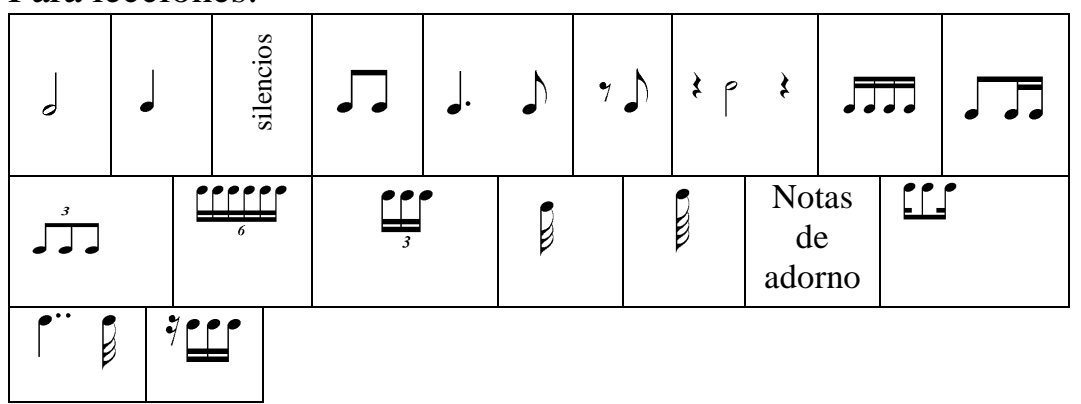

\footnotetext{
${ }^{1}$ Según AAVV. (1999), Tomo 10, pp. 675 y 676, firmado por Vicente Galbis, se llama Nuevo método general de solfeo, y cree que pudo estar publicado hacia 1857 [Desde luego en el libro pone Nuevo método completo de solfeo y no general]; y PRECIADO, Dionisio: obra citada, asienta que fue en el año 1856.
} 
Dificultades de ento- Ninguna, se desenvuelve entre intervalos mayores o menores. nación que se en- $\quad$ Las melodías son de fácil asimilación, sin grandes saltos.

cuentran

$y$ orden en que se enseñan los interva$\operatorname{los}$

Armonía utilizada

Formas que tienen las lecciones

\section{Introducciones, In- No hay termedios o Codas instrumentales}

Teoría de la música La estrictamente necesaria al comienzo que incluye

\section{SECUENCIA}

Hay un prólogo de Antonio Romero, en el que dice que esta es la segunda edición corregida y aumentada, que ha fallecido el otro co-autor, José Valero, y que ha procurado que el método fuese progresivo, variado y de buen gusto, para que sea agradable su estudio, y que cualquiera que tenga algún conocimiento de música, podrá auxiliarse de este método para enseñarla.

Después de este preámbulo, comienza con definiciones y explicaciones teóricas: Música, Solfeo, Entonación, Notas, Pentagrama, Líneas adicionales y Claves. Comentamos las definiciones más curiosas: Música es el arte de espresar [sic] y conmover por medio de los sonidos, combinando su entonación, su duración, su intensidad y su acentuación. Poco corriente es esta enunciación.

Sonido es el producto de la voz cuando canta, o de los cuerpos sonoros puestos en vibración. Según esto la voz no es un cuerpo sonoro.

Entonación es el grado de gravedad o elevación que se da a los sonidos, el cual se determina por medio de varios signos que se llaman notas, claves, sostenidos, bemoles y becuadros. Como si las alteraciones no fuesen notas, además de citar signos de distinto grupo o clasificación.

Explica la utilidad de la Clave, habla de escala y aparece el nombre de las notas en clave de Sol, incluyendo las líneas adicionales desde $\mathrm{Mi}_{2}$ a Fa $_{5}$, luego un ejercicio 
para practicar el nombre de las notas, y la recomendación para aprendérselas, de leer las lecciones del libro sin entonar ni medir.

Los sonidos se forman con la voz al solfear, declara, y también que debe darse igual entonación a la que el profesor haga con la voz o con un instrumento. Dogmatiza que para dedicarse a la música con probabilidades de éxito hay que tener un fino oído tal que con las primeras lecciones ya hay que ser capaz de entonar a la perfección. Discriminatorio es este señor, ¡cuanta educación musical se perdería si a las primeras de cambio dijéramos que el educando no vale!

Expone que para empezar la educación del oído, el alumno debe cantar la escala natural en las dos direcciones, teniendo ya en cuenta las diferencias de distancia. $\mathrm{O}$ sea que la educación a través de la audición y la interiorización no hacen ninguna falta. Son una cantidad de principios totalmente antipedagógicos.

Escala natural, con la discriminación de tonos y semitonos. La duración de los sonidos, en la que dice que intervienen el compás, las figuras cantables, los puntillos y los aires o movimientos. Es curiosa esa amalgama de signos y términos. Enumera los compases, señalando como más importantes el compasillo, el compás binario o mayor $2 / 2$ [?], el 2 y 3 por 4,3 por 8 y los compuestos 6,9 y 12 por 8 . Las figuras cantables son las figuras de nota, y a los silencios les llama figuras de silencio, pausas o esperas; hay una tabla de figuras, con la doble denominación de redonda o semibreve, blanca o mínima, negra o semínima, corchea, semicorchea o doble corchea, fusa y semifusa, sus equivalencias entre sí; las líneas divisorias y la doble barra.

Después de esto hay una serie de ejercicios, hasta 17, con redondas, blancas, negras, redondas y blancas, blancas y negras, redondas blancas y negras, los silencios, corcheas, semicorcheas, negras y corcheas, corcheas y semicorcheas, fórmulas rítmicas combinadas, corcheas con silencio posterior, semicorcheas con silencio posterior, y con silencio al medio. Todos estos ejercicios utilizando la escala natural de Do.

Primero explicación de intervalo, y sin aclarar la calificación entre mayores y menores, muestra una serie de ejercicios de entonación con intervalos de $2^{\mathrm{a}}$ mayores y menores, de $3^{\mathrm{a}}$ preparada y por salto, y sucesivamente hasta $8^{\mathrm{a}}$. Todos entre la escala natural. Pero a partir de las cuartas, introduce ya el puntillo y los contratiempos cortos. La prisa de estos autores es enorme.

Disertación de la importancia de la emisión de la voz, y consejos referentes a la respiración. Luego los términos del movimiento con sus adverbios. Ya por último, antes de empezar las lecciones, consejos al profesor relativos a que si es necesario transporte 
las lecciones, que exija al discípulo un análisis previo de cada lección, y una aclaración del acompañamiento por medio del bajo cifrado.

Dos lecciones con blancas, negras y sus silencios, dentro del arpegio de Do mayor.

Tres lecciones para el sostenido, utilizándolo para el semitono diatónico, incluso saltos de tercera, para las modulaciones y al final para el semitono cromático. Más pronto no puede ser la aparición de las alteraciones. Aberración pedagógica.

Una lección para el becuadro, usado para formar semitonos cromáticos.

Cuatro lecciones para el bemol, mezclado ya con sostenidos y becuadros.

Tono de La modo menor, relativo del tono de Do modo mayor:

Explica que se llama tono de La porque esta nota es la base de la escala, menor porque los intervalos de $3^{\mathrm{a}}$ y $6^{\mathrm{a}}$ son menores, y relativo porque se utilizan las mimas notas, o sea todas naturales, y añade con excepción de la alteración del $7^{\circ}$ grado. A ésta le llama escala propia del modo menor, y justifica la melódica, a la que le llama Escala del modo menor con la $6^{a}$ alterada al subir y la $7^{a}$ menor al bajar, por la dificultad de entonar el intervalo de tono y medio.

Tres lecciones en este tono, en las que todavía nos desenvolvemos entre negras y corcheas, negras con puntillo y contratiempos cortos. Después de éstas, alterna sin orden las tonalidades de Do mayor y esta misma.

Una lección para la ligadura, que desde el principio la utiliza para formar síncopas largas. Dos lecciones para este ritmo, y una más para ligar una blanca con una corchea.

El compás binario tiene ahora su turno, con cuatro lecciones, pero en la segunda añade el calderón.

Es ahora el de 2/4 el que reclama nuestra atención, dos lecciones, en las que debuta la semicorchea, y en la segunda de ellas la fórmula corchea - dos semicorcheas. Naturalmente incluyendo todo lo aprendido hasta el momento.

$\underline{\text { El tresillo, }}$, pero es que es una lección para él, otra para el seisillo y otra para el doble tresillo

La subdivisión ocupa dos lecciones. 
Valero y Romero

Notas de adorno:

Las enumera y empieza por definir la apoyatura, correctamente según nuestro criterio, y curiosamente para la época con criterios de interpretación modernos. Pone un ejemplo y a continuación una lección.

Los mordentes los divide en de una, dos o tres notitas, tomando su valor de la nota siguiente los de una nota, y de la siguiente los de dos y tres si la nota anterior no es de mayor duración, en cuyo caso lo toman de ella. Dos lecciones para ellos.

Los grupetos son siempre de cuatro notas y su duración siempre la toman de la nota que los antecede. Dos lecciones.

El trino lo explica, pero sin dedicarle ninguna lección, porque dicen que no es adorno para el Solfeo.

Entra ahora el compás de 3 por 4 con cuatro lecciones, en las que también añade la síncopa muy breve.

El doble puntillo con una lección y de nuevo el tresillo más los contratiempos de semicorchea cubren las tres lecciones siguientes

Compás de 3 por 8 , cuatro lecciones con este compás, además en la segunda introduce la doble barra de repetición.

Compás de 6 por 8 , explicado a dos y subdividido también a 2 . Tres lecciones

Compás de 9 por 8 , hace la explicación sin subdividir y subdividido a tres. Tres lecciones, en la segunda también figuran las casillas de $1^{\mathrm{a}}$ y $2^{\mathrm{a}}$ vez.

Compás de 12 por 8 , sin subdividir y subdividido a cuatro. Tres lecciones. En todos esta serie de compases compuestos, suelen ser las primeras lecciones de una métrica más sencilla, y se complican más las otras dos, aunque algunas se complican demasiado para haberse enfrentado por primera vez a un tipo de compás.

Acaba esta primera parte con unas consideraciones sobre los compases simples y compuestos, en las que dicen que los primeros se pueden dividir sus tiempos en mitades, y en los segundos en tercios; y la relación o correspondencia que hay entre los simples y compuestos. 


\subsubsection{SEGUNDA PARTE}

\section{CUADRO DE INFORMACIÓN GENERAL DE LA SEGUNDA PARTE.}

$\mathbf{N}^{\circ}$ de lecciones

Extensión de las lec- Entre 12 y 63 compases

ciones

Claves empleadas

Tesituras que abarcan

Tonalidades que trata y estudia

Compases que emplea y estudia

Dificultades métricas que contiene

Dificultades de entonación que se encuentran $y$ orden en que se enseñan los intervalos

\section{Armonía utilizada}

Formas que tienen las lecciones

Introducciones, Intermedios o Codas instrumentales

Teoría de la música que incluye
63 b M, Fa m y Re b M

Los mismos

Dobles alteraciones

$5^{\mathrm{a}}$ disminuida. Enarmonías

A-B; A-B-A'

No tienen ninguna

Al principio y al final.

Las mismas, como alguna excepción, $\mathrm{Sol}_{4}$

Además de las anteriores, Sol M, Mi m, Re M, Si m, La M, Fa \# m Mi M, Fa M, Re m, Si b M, Sol m Mi b M, Do m, La

Las mismas y los valores irregulares teóricamente

Igual que en la parte primera, clásica y sencilla

\section{SECUENCIA}

Comienza esta parte comentando que si en la primera se explicaron las cuestiones relativas a la entonación y duración de los sonidos, en ésta se explicará lo relativo a la intensidad y a todo lo que se necesite saber para dedicarse al estudio de un instrumento, canto, e incluso armonía o composición. Muy ambicioso es el proyecto, y no creemos que llegue, ni mucho menos, a tal objetivo. 
Valero y Romero

Y en efecto, sigue a esta declaración de intenciones una lista de matices y signos dinámicos.

Después la teoría de las alteraciones, accidentales y propias, con el orden en que aparecen éstas junto a la clave, sin nombrar la palabra armadura. Siguen los intervalos alterados, con indicación de los que pueden ser aumentados y disminuidos. Según el criterio de este autor y de otros muchos, solamente pueden ser disminuidos los de $3^{\mathrm{a}}, 4^{\mathrm{a}}$ y $7^{\mathrm{a}}$; y aumentados los de $2^{\mathrm{a}}, 5^{\mathrm{a}}$ y $6^{\mathrm{a}}$. La escala cromática y la discriminación entre semitonos diatónicos y cromáticos.

Trata de hacer una explicación de las tonalidades, pero más bien crea un cúmulo de confusiones. El caso es que habla de ellas y pone una tabla de tonalidades con armaduras de sostenidos y de bemoles, explicando, también de forma confusa, la manera de distinguir el alumno si una lección está en modo mayor o en su relativo menor.

Y comienzan las lecciones:

Tonalidad de Sol mayor, 4 lecciones, todavía con la clave de Sol y empleando los compases ya vistos en la primera parte, y 2 lecciones para su relativa menor.

Clave de Fa en $4^{\mathrm{a}}$ línea: comienza ahora con esta nueva clave, volviendo a la tonalidad de Do mayor y con pocas dificultades. Seguirá con ella internándose en otras tonalidades

Tonalidad de Re mayor, con 4 lecciones, en las que también aparecen pequeñas fermatas. Siguen, con 2 lecciones cada una, las tonalidades de Si menor, La mayor y Fa sostenido menor.

\section{Clave de Do en $1^{a}$ línea:}

Lectura de notas en esta nueva clave. Una lección en la tonalidad de Do mayor, seguramente para ir conociendo la clave. Una nueva tonalidad, Mi mayor, con 3 lecciones.

Luego vuelve a la clave de Sol con 3 lecciones cada una en distinta tonalidad, Re mayor, La mayor y Mi mayor, sin que se vea otra utilidad que no sea la del repaso, y quizás mayor incidencia en los matices dinámicos y agógicos. 
Tonalidad de Fa mayor, con 3 lecciones, y sigue con otra en Do menor, y clave de Sol. Tampoco se ve cuál es la causa.

Tonalidad de La bemol mayor: 2 lecciones pero con la clave de Sol.

Tonalidad de Re menor: 2 lecciones con las que vuelve a la clave de Do en $1^{\mathrm{a}}$. En la primera de ellas, hay una nota del autor muy curiosa: tiene la lección el compás de 6/8, y le precede la dicha nota indicando que se marque el compás a cuatro partes desiguales, en las que entrará en el primer y tercer tiempo una negra, y en los otros dos una corchea. Es ésta la manera moderna de marcar el compás de 6/8, lo que en aquellos años no se hacía, pero lo más extraño es convertir este compás en uno irregular.

Tonalidad de Si bemol mayor: 2 lecciones, y en una de ellas introduce los signos de repetición o llamadas.

Continúan las lecciones con 2 para la tonalidad de Sol menor, 2 más para la de Mi be-

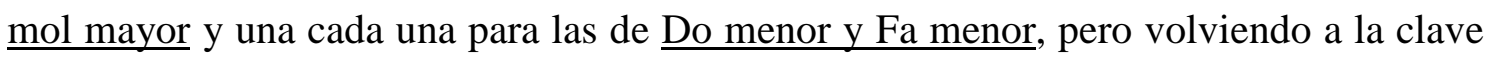
de Sol.

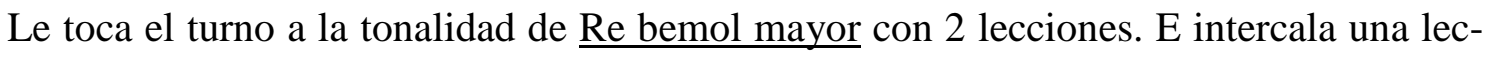
ción en Sol menor con la clave de Fa en $4^{\mathrm{a}}$; sigue con esta clave, pero de nuevo en $\underline{\mathrm{La}}$ bemol mayor, y todavía continúa con esta tonalidad 3 lecciones más, pero volviendo a la clave de Do en $1^{\mathrm{a}}$ línea.

Clave de Do en $4^{\text {a línea: }}$

Siete son las lecciones que dedica a esta clave. Todas en tonalidades ya vistas anteriormente, y por supuesto con compases también practicados, como en las anteriores. Solamente la última tiene cambios de tonalidad, compás y aire; empieza en Fa menor y $12 / 8$, cambia a 3/4 y Re bemol mayor y vuelve a cambiar, para así terminar, a 6/8.

\section{Clave de Do en $3^{\text {a línea: }}$}

Cinco lecciones, sin presentar ya ninguna novedad. Comenzando por una con figuras de blancas y negras, y aumentando la dificultad, sin llevarla a ningún extremo. 
Valero y Romero

Clave de Do en $2^{\text {a línea: }}$

Solamente 2 lecciones. Explica el autor en la primera, que esta clave ya sólo se utiliza para transportar, pero que en la época de los polifonistas, se ponía en la voz de contralto, y por ello incluye aquí dos lecciones, para que la practique quien luego tenga que leer partituras de Tomás Luís de Victoria, Comes o sus coetáneos. Curiosamente llevan el acompañamiento, o sea el bajo cifrado, en clave de Do en $4^{\mathrm{a}}$.

\section{Clave de Fa en $3^{\text {a línea: }}$}

Señala que se utilizaba para la voz de barítono, pero que usándose ahora para ellos la clave de $\mathrm{Fa}$ en $4^{\mathrm{a}}$ línea, aquella ya solo se maneja en el transporte. Por ello, seguramente, solamente incluye una lección, fácil de medida y entonación.

Después de estas lecciones, concluye con las siguientes explicaciones teóricas:

Compases utilizados de los que no hay ejemplos prácticos en el método: 4/2, 4/8, 4/16, 3/2, 2/1, 2/8, 12/4, 12/16, 9/4, 9/16, 6/2, 6/4, 6/16. Amalgamados 5/4 y 7/4

Compases de silencio: indica la forma de señalar éstos, añadiendo que en música antigua se expresaban de la siguiente manera:

Dos compases
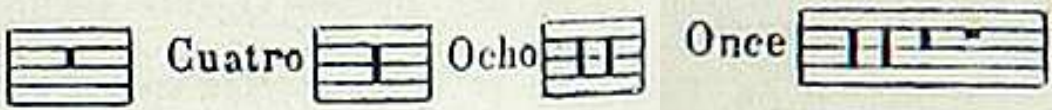

No dice ninguna falsedad, pero lo cierto es que no abunda esta manera de expresar varios compases de silencio por afinidad con los silencios de cuadrada longa y duplex longa, si acaso en algunas partituras antiguas manuscritas.

Valores irregulares por aumentación: solamente comenta que existen grupos de valoración irregular de cinco, siete, nueve, diez y once, que equivalen a cuatro, seis, ocho y doce de su misma especie. Lo cual no siempre es cierto, y no añade ningún ejemplo.

Abreviaturas: mediante un ejemplo, utilizando abreviaturas y transcribiéndolo bajo a notas reales, hace ver algunas de ellas, los signos $\%, \mathscr{\%}$ y las barritas para partir figuras.

De los transportes y ficción de claves: sin explicar qué es el transporte, habla de cómo se pueden leer en clave de Sol las lecciones que están con otras claves, exponiendo gráficamente los casos. Partiendo de la clave de $\mathrm{Fa}$ en $4^{\mathrm{a}}, 3^{\mathrm{a}}$ baja (no dice que ha de 
ser menor); de Do en $1^{\mathrm{a}}, 3^{\mathrm{a}}$ alta (sin decir que ha de ser mayor); de Do en $4^{\mathrm{a}}, 2^{\mathrm{a}}$ alta; de Do en $3^{\mathrm{a}}, 2^{\mathrm{a}}$ baja; de Do en $2^{\mathrm{a}}, 4^{\mathrm{a}}$ baja y de Fa en $3^{\mathrm{a}}, 4^{\mathrm{a}}$ alta (sin decir, como en las otras, si son menores o mayores).

Para leer en clave de Fa en $4^{\mathrm{a}}$, partiendo de la de Sol, una $3^{\mathrm{a}}$, alta; de la de Do en $1^{\mathrm{a}}$, una $4^{\mathrm{a}}$ baja; Do en $4^{\mathrm{a}}, 5^{\mathrm{a}}$ baja; Do en $3^{\mathrm{a}}, 2^{\mathrm{a}}$ alta; Do en $2^{\mathrm{a}}, 2^{\mathrm{a}}$ baja; y Fa en $3^{\mathrm{a}}, 3^{\mathrm{a}}$ baja. Sigue haciendo lo mismo con las claves de Do en $1^{\mathrm{a}}$, en $3^{\mathrm{a}}$ y en $4^{\mathrm{a}}$, no llegando a las de Do en $2^{\mathrm{a}}$ y Fa en $3^{\mathrm{a}}$ porque dice que estaban casi en desuso.

Completa esta insuficiente disertación sobre el transporte, con normas para el cambio de las alteraciones accidentales, las cuales son incompletas, porque indica:

Sirviendo el sostenido para subir medio tono la entonación de la nota que le sigue, cuando se encuentre uno accidental en nota que lleve bemol en el tono que suponemos al transportar, el sostenido accidental hará oficio de becuadro.

Cuando una nota lleve sostenido en el tono supuesto, el accidental hará oficio de doble sostenido.

Sirviendo el bemol para bajar medio tono la entonación de la nota que le sigue, cuando se encuentre uno accidental en nota que lleve sostenido en el tono supuesto, el bemol accidental hará oficio de becuadro.

Y cosas como éstas, que son casi ininteligibles, y que no aclara cuántas son las alteraciones que sufren modificación en las distintas posibilidades de transposición.

Acaba con una tabla de relación de las 7 claves entre sí y la extensión que tiene cada una de las voces humanas que utilizaban estas claves.

Añade un apéndice con los textos recomendados para distintas disciplinas musicales, que acompañamos, por creerlo curioso, en el Apéndice, página 206.

\subsubsection{VALORACIÓN DE LA EFECTIVIDAD DEL MÉTODO Y DE SU APORTACIÓN A LA ENSEÑANZA.}

\section{De la primera parte:}

Mucha prisa por mostrar y afrontar las distintas dificultades. No están mal las melodías, tienen giros agradables y no presentan dificultades

\section{De la segunda parte:}

Casi nada añade esta parte, a excepción del estudio de las tonalidades. 
Valero y Romero

El método no es de gran utilidad, pues con esos amontonamientos y poca insistencia en casi todas las nuevas cuestiones, el alumno más se embrolla que asimila.

No consigue llegar al objetivo, que anuncia al principio de esta parte, de cubrir todo lo que necesita un estudioso para dedicarse al estudio del canto, de un instrumento, de la armonía o de la composición, más bien se queda muy corto.

Hay que hacer observar, como en el párrafo de la "Tonalidad de Re menor" decimos, la manera tan extraña que tiene de decir que se marque el compás de seis por ocho.

Totalmente confusa la explicación de la transposición.

No aporta nada. 


\subsection{RESEÑA BIOGRÁFICA DEL AUTOR}

FUNOLL Y ALPUENTE, Francisco. El texto consultado, no dice sitio de nacimiento ni año, solamente España, siglo XIX. Músico mayor del regimiento de infantería Toledo 35, Caballero de la real orden americana de Isabel la Católica, publicó (no dice el año) Método completo de solfeo sin acompañamiento en 3 partes, y en 1862 un método de bombardino bajo, barítono y trombón tenor (Sobrino, Ramón, en AAVV, 1999, tomo 5, p. 289).

\subsubsection{DESCRIPCIÓN DETALLADA DEL MÉTODO.}

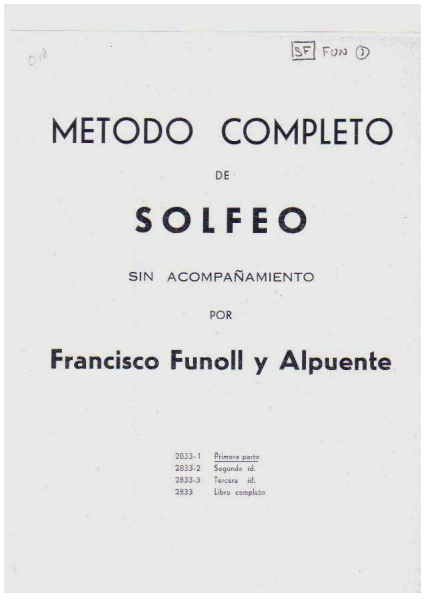

Título del Método

Método completo de Solfeo sin acompañamiento, Primera parte, Madrid, U. M. E. s. f. ${ }^{1}$ Apéndice, página 207.

\section{CUADRO DE INFORMACIÓN GENERAL DEL MÉTODO.}

$\mathbf{N}^{\circ}$ de lecciones

Extensión de las lecciones

Claves empleadas

Tesituras que abarcan

Tonalidades que trata y estudia

Compases que emplea y estudia
58

De 24 a 40 compases, excepto los ejercicios preliminares que son cortos

Sol

$\mathrm{Do}_{3} \mathrm{a} \mathrm{Mi}_{4}$

Do mayor

$4 / 4,2 / 2,2 / 4$

\footnotetext{
${ }^{1}$ Lo situamos detrás del Nuevo método completo de solfeo de Valero, por ser este anterior al método de bombardino, etc., por eso lo suponemos alrededor de 1860, pero podría ser anterior.
} 
Dificultades métricas que contiene

Dificultades de entonación que se encuentran $y$ orden en que se enseñan los intervalos

\section{Armonía utilizada}

Formas que tienen las lecciones

Introducciones, Intermedios o Codas instrumentales

Teoría de la música que incluye

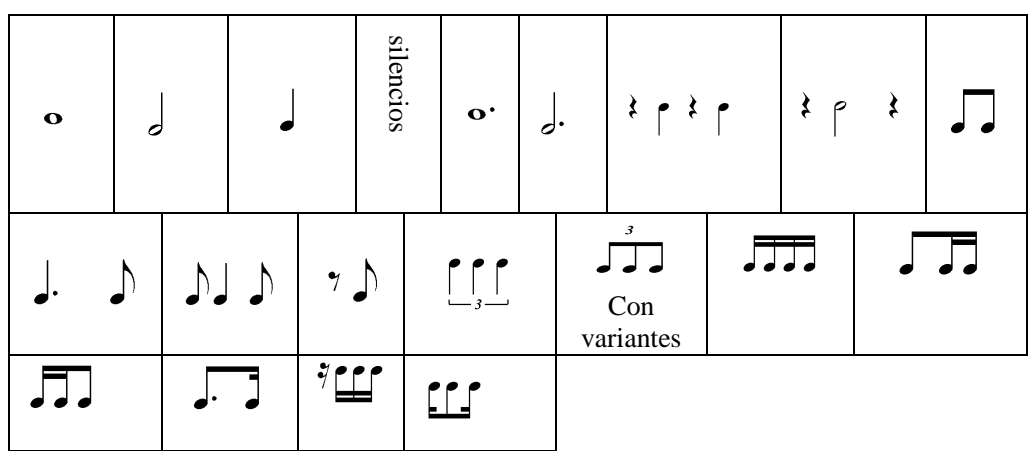

Muy pocas. Las propias de la escala Diatónica y de las alteraciones accidentales. En general, igual que Con las rítmicas, un nivel normal - alto para lo que era un primer curso, antes de la promulgación de la LOGSE

Escala, $3^{\mathrm{a}}, 4^{\mathrm{a}}$, preparadas y no preparadas, así hasta $8^{\mathrm{a}}$. Semitonos cromáticos y diatónicos

Sin acompañamiento. Modulaciones implícitas a tonos vecinos en $1^{\circ}$ y $2^{\circ}$ grado al utilizar alteraciones

A-B-C; A-B-A; A-A'-B; A-A'-A',

No tienen

Bastante, la básica y algo más

\section{SECUENCIA}

Comienza con "Teorías o Principios de Música"

Definición de Música, del que dice que es el arte de combinar los sonidos (pero no dice que con el tiempo). Explicación ${ }^{1}$ de lo que es Sonido, nombres de las notas, a las que compara con el alfabeto de un idioma, esbozo de lo que más tarde explicará como figuras de nota diciendo que las notas se escriben con puntos redondos de estas formas...

Explicación del Pentagrama, de las líneas adicionales (a las que él llama "Líneas y espacios suplentes", de las Claves y nombre de las notas en las cinco líneas y los cuatro espacios (procedimiento muy al uso de la época).

\footnotetext{
${ }^{1}$ Parece que para Funoll no existían las equis ya que escribe esplicación, sestas; o estrangero [sic], tampoco la j, egecutan, ni los acentos.
} 
A continuación hay un ejercicio sobre las líneas y espacios, se supone que para la práctica de su lectura, en el que las notas van tanto por grados como por saltos diversos. Luego la representación de los sonidos fuera del pentagrama, desde $\mathrm{Mi}_{2}$ a $\mathrm{La}_{5}$. Le sigue un ejercicio, creemos que para leer, con estas notas próximas y poco a poco más extremadas.

Habla seguidamente de las Figuras, que las divide en "cantables o de silencio" y les da un doble nombre a cada una (según dice: nomenclatura francesa, que es la moderna, y otra española) Redonda o Semibreve, Blanca o Mínima, Negra o Semínima, Corchea o también Semínima, Doble corchea o Semicorchea, Triple corchea o Fusa y Cuádruple corchea o Semifusa. Señalando después que a la Redonda se le toma como unidad aritmética y que las demás figuras tienen un valor en progresión de mitades. Debajo de ellas figuran los silencios, en el de negra emplea la forma antigua similar al de corchea al revés.

De los compases es de lo que se ocupa consecutivamente diciendo que es la $d u$ ración de tiempo que se da a las figuras contenidas entre dos rayas perpendiculares... a las que llama rayas divisorias de compas [sic] y dice que el principal de ellos es el Compasillo del que proceden todos los demás. Ilustra cómo se marca este compás y hace un esquema de cómo la redonda se desdobla en dos blancas y estas a su vez en cuatro negras etc. etc.

Ya solamente define la escala natural o diatónica como una sucesión de ocho sonidos que toman por base (ó tónica) el signo de la música (DO), y comienza a numerar las lecciones.

De la lección $n^{\circ} 1$ a la n ${ }^{\circ} 10$, va utilizando la escala diatónica de Do, incorporando sucesivamente, dentro del compás de compasillo, la redonda, redonda con su silencio, redonda y blanca, éstas con sus silencios, y redonda, blanca y negra con silencios de blanca.

Lecciones de la 11 a la 16. Empleando la misma combinación de figuras, va introduciendo al estudiante en la práctica de la entonación interválica: terceras con preparación, sin preparación y cuartas con y sin preparación. 
Funoll Alpuente

\section{De la Ligadura:}

Una definición de lo que es y la utilidad de este signo para, con las figuras anteriores más ella, acometer de la lección 17 a la 24 la entonación de quintas, sextas, séptimas y octavas con y sin preparación.

\section{$\underline{\text { Recopilación de las lecciones anteriores: }}$}

Lección $n^{\circ} 25$, en ella hace una recopilación de todos los intervalos simples, alternativamente ascendentes y descendentes, indicando muy cuidadosamente de qué número de intervalo se trata, empezando por orden numérico y de mitad de la lección al final en un orden más arbitrario

\section{Movimiento o aires de la música:}

Describe lo que indica este grupo de palabras o términos y hace una lista de ellos con inclusión de los aumentativos y diminutivos.

\section{Del puntillo:}

Exposición del efecto de este signo de prolongación, haciendo notar que en muchas ocasiones es sustituto de la ligadura; y realiza dos lecciones, las números 26 y 27 aplicando el puntillo a la redonda y la blanca; además utiliza, sin indicarlo ni explicarlo el contratiempo largo.

\section{De la Síncopa:}

Con una definición muy inapropiada: figuras que se hallen entre otras de la mitad de su valor, explica la síncopa larga entre las que incluye la nota partida (de dudosa clasificación como síncopa en un compás de 4/4) y expone las lecciones 28 y 29 con síncopas de blancas con redondas, y de negras con blancas partidas y ligadas.

A continuación expone las lecciones 30 y 31 como modificación de la 28 y 29. Tal modificación consiste en cortar el sonido de la blanca sincopada, en el segundo tiempo, por silencio de negra, con lo cual efectúa un contratiempo. Magnífica idea para demostrar que la síncopa es un contratiempo prolongado, pero ninguna mención hace de ello, por lo que para el alumno pasa desapercibido. 


\section{Del Calderón:}

Simplemente explica la función de él sobre una nota o sobre un silencio

\section{De la Corchea:}

Una breve explicación de esta figura, añadiendo que se puede representar por medio de una barrita, sueltas con corchete o con abreviatura, refiriéndose con esta última clasificación a la antigua costumbre de atravesar la blanca o la negra con una barra para indicar que se dividen en cuatro o dos corcheas respectivamente.

Lecciones de la 32 a la 35 con todo lo estudiado hasta ahora, más las corcheas y el calderón.

\section{De los Intervalos:}

Definición de intervalo, unísono y clasificación de aquellos en conjuntos, disjuntos, y dentro de los conjuntos en tono y semitono, con ejemplo gráficos.

\section{De los signos de alteración:}

Muy buena descripción de lo que son estos signos musicales, porque dice que parten los intervalos con distancia de tono en dos mitades o semitonos. Después hace la descripción de cada una de las tres, la clasificación en accidentales y propias, para ocuparse solamente ahora de las primeras, y hay un ejemplo de la escala diatónica seguida de la cromática (a la que también llama semitónica) para la práctica del sostenido en forma cromática

Lecciones 36 y 37 para practicar el sostenido como semitono diatónico, por lo que hace modular la melodía a Sol mayor, a Re mayor y a La menor; a lo que añade el puntillo sobre la negra.

\section{Lecciones para practicar el becuadro:}

Una única lección, la número 38, en la que lo emplea cromáticamente.

$\underline{\text { Síncopas de corcheas y negras: }}$

Simplemente un ejemplo de la síncopa breve con corcheas ligadas y en su otra forma con negra en medio de dos corcheas. 


\section{Lecciones para practicar el bemol:}

Dos lecciones, números 39 y 40 en las que emplea la síncopa breve y el enlace de síncopas, el bemol, en semitono cromático y también diatónico, además de las otras dos alteraciones.

\section{Del silencio de corchea:}

Aquí explica que se puede usar tanto delante como detrás de la figura. Y da muy buenos consejos; para cuando vaya delante recomienda hacer una aspiración, sin nombrar siquiera que esto es un contratiempo corto, y para cuando el silencio vaya detrás indica hacer corto el sonido de la corchea. Lo plasma con las lecciones 41 y 42 en las que hay contratiempo y síncopas enlazadas. Añade la lección 43 como ejemplo de las corcheas abreviadas, y lo hace de forma muy práctica y visual, a dos pentagramas, poniendo en el de encima las corcheas abreviadas y en el de bajo desarrolladas.

\section{Del compasillo binario o mayor:}

No sabemos porqué le llama a este compás mayor, pues en la denominación antigua el compás mayor era el de 4/2, pero el caso es que así lo llama, y explica sus tiempos, el signo con el que se indica y las figuras que entran en él. Siguen dos lecciones, las números 45 y 46 para practicar este compás con valores únicamente de redonda, blanca y negra.

\section{De los tresillos o valores mistos [sic]:}

Hay una sola lección, pero con tresillos de negra, claro que en compás de 2/2, pero creemos es mejor comenzar por ver el tresillo de corchea de un tiempo de duración, ya que es el más usado.

\section{Del compás de 2 por 4 :}

Hay una descripción de las características de este compás y de su relación con el de compasillo.

Después vienen dos lecciones, las números 47 y 48, que son una trascripción en este compás de las anteriores, números 44 y 45, que estaban en el de 2/2, aunque el autor indica "Reducción de la lección 44 y 45" de lo que se trata es de una copia literal pero transcribiendo a las figuras propias del $2 / 4$ en vez de las del 2/2. Este procedimien- 
to también lo emplea Eslava, no sabemos si ambos coinciden en la idea, o uno se la ha copiado al otro. Es más probable que sea este autor a Eslava, por la difusión del método de éste contra el de aquél, pero no es más que una hipótesis.

\section{$\underline{\text { Tresillos de corcheas: }}$}

Es en este momento cuando afronta el tresillo de corchea, y primero lo hace mediante una nueva trascripción de la lección 46, en la que exponía los tresillos de negra en compás de $2 / 2$, y luego una nueva lección, la $\mathrm{n}^{\circ} 50$, en la que además introduce el silencio de corchea en el tresillo; también, en esta lección vuelve al compás de 4/4, el que no abandona hasta el final de libro. A continuación la lección 51 sigue con tresillos pero con las variaciones de negra y corchea ${ }^{1}$, o silencio de corchea en el lugar de la segunda del tresillo.

\section{De la doble corchea o semicorchea:}

Dos lecciones, números 52 y 53 con grupos de semicorcheas, en la segunda además alguna alteración. Luego la lección 54 con fórmula rítmica de corchea y dos semicorcheas y al revés. Lección 55 con el puntillo a la corchea seguido de semicorchea. La siguiente, $\mathrm{n}^{\mathrm{o}} 56$, esta fórmula y el silencio de semicorchea formando contratiempo. Le sigue la número 57 en la que aparece el silencio de la semicorchea en el tercer lugar del grupo de 4 y también la síncopa muy breve. Y acaba la serie de lecciones con lo que él llama "reducción", o sea trascripción de la lección n 42 en la que trataba de la serie de síncopas breves, en ésta pues contrae rítmicamente las figuras.

\section{Apéndice:}

Añade el autor este apéndice en el que explica que muchos profesores necesiten desde el comienzo para sus alumnos que éstos conozcan la clave de Fa en $4^{\mathrm{a}}$ línea. Hace pues una relación entre ésta y la de Sol, pone el nombre de las notas en la clave de Fa desde el $\mathrm{Do}_{1} \mathrm{al} \mathrm{La}_{3}$; 55 ejercicios para la lectura de las notas en esta clave, y la escala diatónica de Do en la misma

\footnotetext{
${ }^{1}$ Aunque hace una aclaración al pie de que esta clase de tresillos figuran en esta lección como cosa pedagógica, pero que son más propios de los compases compuestos.
} 


\subsubsection{VALORACIÓN DE LA EFECTIVIDAD DEL MÉTODO Y DE} SU APORTACIÓN A LA ENSEÑANZA.

Demuestra muy buena voluntad en hacer sencillo y ameno el aprendizaje, con más práctica que teoría.

La exposición es bastante lógica y progresiva, aunque en algunas cuestiones no estamos conformes, como la inexacta explicación de la síncopa y la inexistente del contratiempo.

Buena idea, si es de él, la de las lecciones reducidas, o mejor dicho contraídas rítmicamente. ${ }^{1}$

Las lecciones tienen una melodía agradable, y muchas de ellas tienen un trabajo interesante de desarrollo o transformación de una única célula o varias de ellas.

No es un método desdeñable.

Sabemos, por que figura en la cubierta, que hay una segunda y quizás hasta tercera parte, pero en ninguna biblioteca hemos dado con ellas.

\footnotetext{
${ }^{1}$ En el análisis del método de Hilarión Eslava, comentamos la bondad de este procedimiento, al ser también por él empleado.
} 


\subsection{RESEÑA BIOGRÁFICA DEL AUTOR}

CALVÓ I PUIG, Bernat. Su nombre completo es Bernardo Calvó Puig Capdevila, pero empleaba el segundo nombre como apellido. España, siglo XIX, compositor y organista. No pone, en el texto consultado, fechas ni lugar de procedencia, aunque por los apellidos debe ser catalán, barcelonés, según dice Preciado (1978, p. 242). Aparece una foto de él en el tomo 8, p. 999, del Diccionario de la Música española e hispanoamericana, del año 1886 en la que ya se ve mayor, luego tuvo que nacer bastante antes de este año (Casares, en AAVV, 1999, tomo 2, p. 946 y tomo 8, p. 999). En su Método de solfeo figura la inscripción: "Maestro y Director de Música de la Sociedad Filarmónica de Barcelona, y Socio Artista de la misma".

\subsubsection{DESCRIPCIÓN DETALLADA DEL MÉTODO.}

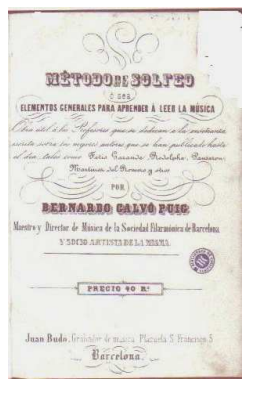

\section{Título del Método}

Método de solfeo, o sea, elementos generales para aprender a leer la música, Barcelona, Juan Budó, grabador de música, s. f. ${ }^{1}$ Apéndice, página 208.

\section{CUADRO DE INFORMACIÓN GENERAL DEL MÉTODO.}

$\mathbf{N}^{0}$ de lecciones

Extensión de las lecciones

Claves empleadas

Tesituras que abarcan

Tonalidades que trata y estudia
155, que no llama lecciones, sino ejercicios

Desde 4 hasta 30 compases en la primera parte y 43 en la segunda, siendo la que más emplea la de 16 y 32 compases

En la primera y $2^{\mathrm{a}}$ parte Sol y Fa. En la tercera el resto, con el orden de Do en $1^{\mathrm{a}}, 2^{\mathrm{a}}, 3^{\mathrm{a}}$ y $4^{\mathrm{a}}$ y Fa en $3^{\mathrm{a}}$

Intervalo de $10^{\mathrm{a}}$, con excepción de las lecciones que lo sobrepasan para el estudio de la música instrumental

En la primera parte casi exclusivamente Do M, La m en 3 ejercicios. En la $2^{\mathrm{a}}$ parte el resto, alternando las de sostenidos con las de bemoles, desde 1 a 7.

\footnotetext{
${ }^{1}$ En el catálogo de la Biblioteca de Cataluña figura como año de publicación 18--?, en el albarán de entrega del documento 1900. PRECIADO, Dionisio: op. citada, p. 242, pone 1860, pero quizás no hablemos del mismo libro, pues Preciado le llama "Curso completo de solfeo o elementos teórico-prácticos para aprender a leer la música". Lo cierto es que en el libro no figura año ninguno.
} 
Compases que em$4 / 4,2 / 2,2 / 4,3 / 4,3 / 8,6 / 8,9 / 8$ plea y estudia

Dificultades métricas que contiene

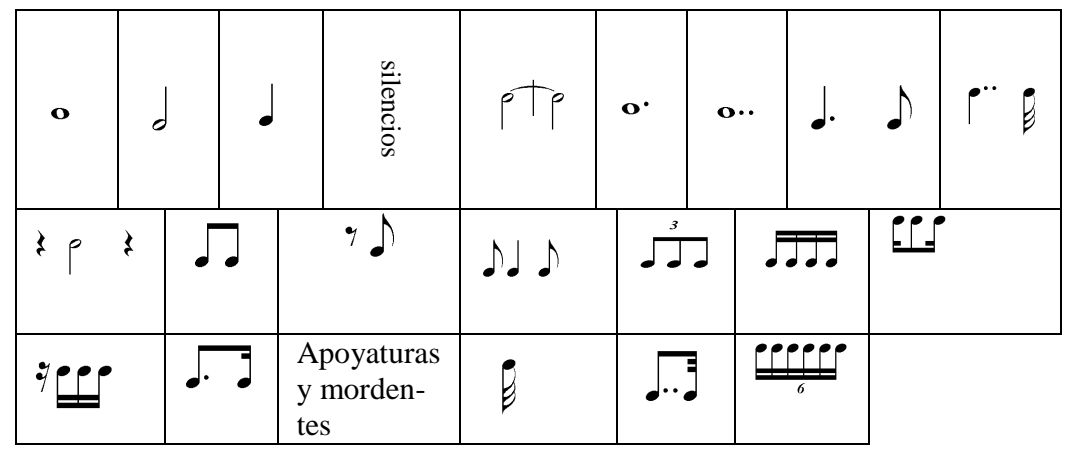

Dificultades de ento-

Pocas. No hay grandes saltos melódicos. En el último tercio se nación que se encuentran y orden en que se enseñan los intervalos

Escala, intervalos desde $2^{\mathrm{a}}$ a $8^{\mathrm{a}}$ preparados y sin preparar. Semitonos cromáticos y diatónicos

Armonía utilizada

En los primeros ejercicios es armonía sencilla, modulando a la dominante, aunque ya emplea algún grado alterado

Formas que tienen las Una sola frase A-B lecciones

Introducciones, Intermedios o Codas instrumentales

Teoría de la música Mucha, toda al comienzo que incluye

No contiene ninguna

\section{OBJETO Y PLAN DE LA OBRA}

Así reza el prólogo en el que el autor comenta que no cree haber escrito un método perfecto, sino un conjunto de ejercicios que sirvan a quienes estudian para cantantes y también para instrumentistas, para quienes tienen facilidad para la entonación y tesitura de voz y para quienes no la tienen. Profiere que la extensión vocal raramente sobrepasa la $10^{\text {a }}$, pero que hay algunos ejercicios imposibles de ejecutar por voz humana, y que están para el conocimiento de quien estudia para la práctica instrumental, aclarando que si el maestro lo cree conveniente puede suprimir aquellos ejercicios que no le convengan al alumno o transportarlos a una tonalidad adecuada, pero que cree conveniente hacerle trabajar todos los ejercicios, pues el discípulo cuando empieza no se sabe hasta donde llegará y por tanto debe ir cargado de un bagaje suficiente. Indica que se 
deben estudiar las lecciones diciendo primero el nombre de las notas, luego su valor, parte del compás a que corresponden, su octava, etc. y termina volviendo a repetir que el maestro puede suprimir lo que crea superfluo así como aumentar la cantidad de ejercicios en aquellas dificultades en las que le parezca que hay pocos.

\section{ELEMENTOS DE LA MÚSICA \\ INTRODUCCIÓN}

Comienza con definiciones y cuestiones teóricas preliminares y fundamentales. Lo primero que hace es definir la música, que por creerla bonita copiamos literalmente: es el arte de comunicar al alma las impresiones que ésta es capaz de sentir, ya de alegría o tristeza, rabia, desesperación, entusiasmo, devoción etc., según sean las combinaciones que con los sonidos se formen.

A través de varios puntos va explicando luego el pentagrama, las notas, líneas adicionales, claves (llaves según el decir de muchos de la época) con indicación del registro que marcan cada una, escala, distancia de tono y semitono, alteraciones, figuras (con la denominación de semibreve, mínima y semínima para las más largas, como también era costumbre en la época), silencios o pausas, tiempo, compás, líneas divisorias.

En el punto 25 dice una cosa muy curiosa respecto a la forma de marcar los compases: no siendo igual entre los maestros el modo de dar los tiempos con la mano, lo dejamos a su voluntad, prefiriendo empero el que en compás de tres o cuatro tiempos se batan los dos primeros. ¿y que pasaba el tercer o cuarto tiempos? También hace la división de los compases en simples y compuestos, pero incluye entre los compuestos a los de tres tiempos, así 3/1,3/2 ,3/4, 3/8 y 3/16, según el autor, forman parte de los compuestos igual que el de 9/4, 9/8 y 9/16. Prosigue con el compás de compasillo, forma de representar los otros compases (significado del numerador y denominador), forma de representar el binario simple, al que llama, erróneamente, compás mayor, puntillo y doble puntillo. Una forma muy curiosa de definir o explicar los valores irregulares:

Hay otro caso a más del compás mayor en que el valor de las notas disminuye y es cuando se pone el número tres sobre tres notas de igual clase, en cuyo caso se da a estas tres notas el mismo valor que corresponde a dos; a esto llamamos tresillos; esto es aplicable a todas las figuras; pero cuando se encuentran dos o más seguidos, lo que sucede a menudo en semicorcheas y fusas, se acostumbra a poner el número seis para cada dos tresillos, el número nueve para cada tres, etc., 
Calvó i Puig

Sigue con la definición de síncopa como sonido que la primera mitad corresponde a un tiempo y la segunda mitad a otro, ligadura, signos de expresión (en los que incluye las notas de adorno), corona o calderón, signos de repetición, alteraciones propias, armaduras, alteraciones accidentales, dobles alteraciones, tonos relativos y transporte.

Total un fárrago de mucho cuidado, si había que empezar el estudio del solfeo con toda esta teoría previa, y con la forma tan enrevesada de explicarla, de no ser personas muy adultas, no es fácil que siguiera ninguno.

\section{EJEMPLOS DEMOSTRATIVOS}

Aquí figuran gráficamente las cuestiones, los signos y grafismos tratados teóricamente en los anteriores puntos.

El silencio de negra ya figura con nuestra grafía actual.

Les da el nombre de apoyaturas dobles a los mordentes de dos notas, sin embargo llama grupetos a lo que otros autores de la época llaman mordentes de 3 y 4 notas.

\section{MÉTODO DE SOLFEO PRIMERA PARTE}

\section{Ejercicios preparatorios:}

Para aprender los nombres de las notas que están más en uso en la llave de Sol:

Escala general de la llave de Sol, desde $\mathrm{Mi}_{2}$ a Do 6, y ejercicios de lectura sobre la primera octava, la segunda y tercera, sobre las notas más graves.

\section{Ejercicios prácticos:}

Para aprender a entender las notas y dar a cada una su respectivo valor:

Ejercicios sobre la escala diatónica con redondas, blancas; redondas y blancas; negras; redondas, blancas y negras, y sus silencios. Después con las mismas figuras, ejercicios para el intervalo de segunda, de tercera, hasta el de octava, preparados y sin preparar; ejercicios con mezcla de todos los intervalos. En total 32 ejercicios 


\section{RECOPILACIÓN}

De los saltos y movimientos contenidos en los ejercicios anteriores con acompañamiento de Forte Piano:

Con un acompañamiento muy sencillo de piano, 10 ejercicios con mezcla de intervalos y figuras de redondas y blancas; síncopas muy largas (notas partidas); blancas y negras; redondas con puntillo y doble puntillo y negras y su silencio.

\section{COMBINACIONES MÁS USADAS}

Entre las Semibreves, Mínimas, Semínimas y corcheas y sus respectivas pausas, puntillo, doble puntillo, síncopas, etc.:

Desde el ejercicio 43 hasta el 65, tal como dice su enunciado toda clase de combinaciones con la redonda, blanca, negra y corchea. Primero por grados conjuntos, en seguida con saltos. En el segundo ejercicio ya aparece el contratiempo de media parte, hasta llegar a los puntillos sobre la negra y el enlace de síncopas breves. Todos, naturalmente, en tono de Do mayor, y compás de compasillo.

Dentro del mismo enunciado, empiezan en el ejercicio 65 las alteraciones, hay uno para el sostenido, formando con él semitono cromático, también se usa el signo de repetición $\$$, otro para el bemol y becuadro, formando ahora semitono diatónico. Los números 67, 68 y 69, están dedicados al tresillo de corchea, sin y con pausas en distintas subdivisiones. 70 y 71 a la ligadura. Del 72 al 77 la semicorchea, sus combinaciones, incluyendo notas muy graves y muy agudas, y también la indicación de $8^{\mathrm{a}}$ alta. Ejercicios 78, 79 y 80 que son para el estudio de la síncopa muy breve (de forma exhaustiva), el silencio de semicorchea puesto en distintas subdivisiones, y el puntillo sobre la corchea, respectivamente.

El 81 está dedicado a la apoyatura, y al mordente de una y dos notas, (a los que él llama también apoyaturas como ya se dijo más arriba) y desde luego se trabaja intensamente, pues solamente hay un compás en el que no hay ninguna, y hay varios en los que llega a haber tres.

Empieza ahora, sin anunciarlo, una serie de lecciones con nuevos compases. Una para lo que él llama compás mayor (dos por dos). Dos para el de $2 / 4$, en las que ya se 
Calvó i Puig

nota mayor dificultad rítmica, incluso en la segunda trata fuertemente de la fusa. Dos lecciones para el compás de 3/4, en las que se ve la corchea con doble puntillo, y con ella llegamos al ejercicio 86.

El ejercicio que sigue, 87, en el que hay diversos valores irregulares, es el primero que no está en la tonalidad de Do mayor, sino en su relativo. Sigue en el compás de $3 / 4$.

Escala general de las notas que están más en uso en la clave de $\mathrm{Fa}$ (se refiere a la que está en la $4^{\mathrm{a}}$ línea):

Exactamente igual que hizo con la clave de Sol, expone la lectura en esta clave.

Una lección, en la que vuelve a Do mayor, 3/4 y la dedica al cromatismo.

Ejercicios sobre los compases compuestos que están más en uso:

Y empieza por el de 3/8, sigue Do mayor, e introduce el picado. Dos más en el mismo compás, en la tercera de ellas, complica la medida hasta la fusa y el seisillo, pero los seisillos que figuran son de semicorchea, con lo cual la relación de $6=4$ no existe, lógicamente tendrían que ser de fusas; además aparecen la doble barra de repetición y signos de abreviación.

Tres lecciones para el compás de 6/8; también en la tercera aparece la fusa, otro tanto ocurre con el de 9/8 y el de 12/8, sólo que en la segunda de ellas volvemos a la tonalidad de La menor.

Con estos ejercicios termina la primera parte.

\section{SEGUNDA PARTE}

Contiene 28 ejercicios escritos en todos los Tonos, Mayores y Menores.

Hay un ejercicio por cada una de las tonalidades, siguiendo un orden alternado de 1 sostenido, tonalidad mayor y relativa menor, 1 bemol, y así sucesivamente. ${ }^{1}$ Emplea todavía las claves de Sol y Fa en $4^{\text {a }}$, aunque no lo hace en forma alternativa, a veces sí y otras hay dos seguidas en una misma clave. En concreto aparecen 13 en clave de 
Sol y 15 en la de Fa $4^{\text {a }}$. Utiliza todos los compases aprendidos, en mayor cantidad el de 4/4 que aparece en 6 ejercicios, 4 llevan el de 2/4, 3/4, 3/8 y 6/8; y 2 los de 9/8, 12/8 y 2/2. Las dificultades rítmicas y melódicas como en la primera parte, no mayores.

\section{TERCERA PARTE}

Ejercicios sobre las llaves de Do en primera, segunda, tercera y cuarta línea y Fa en tercera:

Tres lecciones para el estudio de cada una de estas claves, en el orden que figura en el título de la parte, previamente a la primera lección de cada clave, hay un pentagrama con una escala de 3 octavas con el nombre de las notas. Utiliza todos los compases estudiados, excepto 12/8. En 2 de ellos el de 4/4, 3 veces el de 3/4, 2 el de 2/4, 3 el de 6/8, 2 el de 9/8, 2 el de 2/2 y 1 el de 3/8. Las tonalidades que emplea no pasan de 3 alteraciones en la armadura, siendo la de Do mayor la que más emplea, 6 ejercicios, 3 en la de Fa mayor, dos en La mayor y una vez cada una las de Si bemol mayor y Mi bemol mayor. Las dificultades no mayores que las anteriores, pero tampoco menores, lo que no deja de ser una dureza, pues con la lectura en claves que no se tiene práctica, conviene rebajar las otras dificultades.

Una penúltima sección nos lleva al estudio de compases de poco frecuente uso. Son una para cada uno de los siguientes: 4/2, 3/2,6/4, 6/16, 3/16, 9/4, 9/16, $12 / 4$ y 12/16. Emplea la clave de Sol 2 veces, Do en $4^{\mathrm{a}}$ dos veces, Fa en $4^{\mathrm{a}}$ también dos, y Do en $1^{\mathrm{a}}$, Do en $3^{\mathrm{a}}$ y Fa en $3^{\mathrm{a}}$ una sola vez. La tonalidad de Do mayor se ve en cuatro de ellas, Fa mayor, Re mayor, Sol mayor y Sol menor una vez. Todas son cortas y fáciles en cuanto a medida y entonación.

Ya para cerrar el método, una lección dedicada al cambio de claves. Está en Do mayor y lleva el compás de 4/4, efectúa cambios muy frecuentes. Y otra, la última, para el cambio de tonalidades. Emplea el compás de 3/4 y la clave de Sol, empieza con la tonalidad de La menor, y pasa por La bemol Mayor, Fa menor, Mi mayor y de nuevo a la tonalidad principal con la que termina.

\footnotetext{
${ }^{1}$ Hay un grave error en dos ejercicios: al tono relativo menor con 7 sostenidos le llama el autor La sostenido mayor, y al relativo menor de Do bemol mayor, le llama Do bemol menor
} 


\subsubsection{VALORACIÓN DE LA EFECTIVIDAD DEL MÉTODO Y DE SU APORTACIÓN A LA ENSEÑANZA.}

Es rudimentario, e insuficiente. Una lección única para cada tonalidad es muy poco.

Quizás sirva para tener una pequeña información de lo que es el lenguaje musical a nivel amateur.

Están condensados los cursos primero al tercero, pero demasiado condensados. Es, sin embargo, estimable la sección que dedica a conocer los compases de menos uso. Ahí sí que no son necesarias muchas lecciones, y con un ejercicio para cada uno de estos compases, el alumno al menos pasa por todos ellos, también es de elogiar el que sean métricamente sencillas, ya que algunas llevan claves poco practicadas.

La clasificación de compuestos para los compases ternarios de subdivisión binaria es inaudita. 


\subsection{RESEÑA BIOGRÁFICA DEL AUTOR}

MANENT I PUIG, Nicolás. Mahón 22/6/1827 - Barcelona 5/1887. Estudió en su ciudad natal, tocaba la flauta y el contrabajo, organista de la iglesia de San Francisco en Mahón. A los 18 años se trasladó a Barcelona donde fue contrabajista del Liceo, en 1851 fue nombrado maestro de capilla en la iglesia de San Jaime de Barcelona, donde compuso mucha música religiosa, también óperas y zarzuelas en catalán y en castellano, 9 sinfonías, así como música para baile (Cortés Mir, Francesc, en AAVV, 1999, tomo 7 , pp. 94 y 95 y Saldoni, 1868-1881, tomo II, pp. 571, 72 y 73).

\subsubsection{DESCRIPCIÓN DETALLADA DEL MÉTODO.}

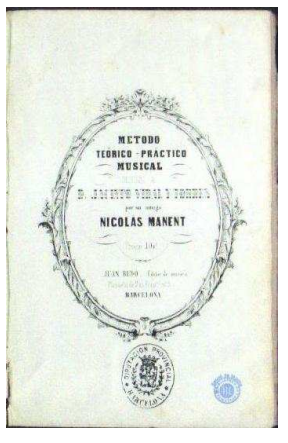

\section{Título del Método}

Método teórico - práctico musical, Barcelona, Juan Budó, s. f. ${ }^{1}$. Dedicado a su amigo D. Jacinto Vidal y Torres. Apéndice, página 209.

\section{CUADRO DE INFORMACIÓN GENERAL DEL MÉTODO.}

$\mathbf{N}^{\circ}$ de lecciones

100, a las que llama ejercicios

Extensión de las lec- Entre 8 y 148 compases

ciones

Claves empleadas $\quad$ Sol, Do $1^{\mathrm{a}}$, Do $4^{\mathrm{a}}$, Do $3^{\mathrm{a}}, \mathrm{Fa} 4^{\mathrm{a}}$

Tesituras que abar- $\quad$ Entre $\mathrm{Do}_{3} \mathrm{y} \mathrm{Sol}_{4}$

can

Tonalidades que tra- Todas, primero las de sostenidos y luego las de bemoles

ta y estudia

Compases que em- $\quad 2 / 4,4 / 4,3 / 4,3 / 8,9 / 8,12 / 8,6 / 8,2 / 2,12 / 4,12 / 16,6 / 4,6 / 16$, plea y estudia $9 / 4,9 / 16$ y $7 / 4$

\footnotetext{
${ }^{1}$ En el libro no indica fecha de edición, sin embargo la hoja de información bibliográfica de la Biblioteca de Cataluña, indica [ca. 1860] [?]
} 


\section{Dificultades métricas que contiene}

Dificultades de entonación que se encuentran y orden en que se enseñan los intervalos

\section{Armonía utilizada}

Formas que tienen las lecciones

Introducciones, Intermedios o Codas instrumentales

Teoría de la música que incluye

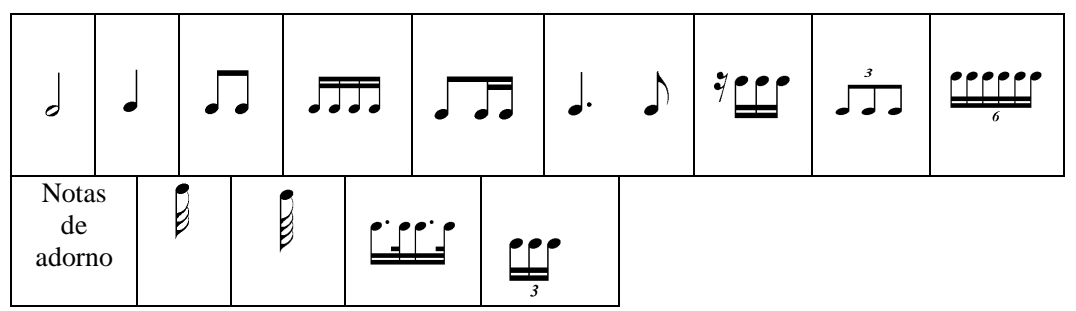

Dobles alteraciones. intervalos aumentados y disminuidos

Desde $2^{\mathrm{a}}$ hasta $8^{\mathrm{a}}$ sin preparación. Escala cromática, semitonos diatónicos. $4^{\mathrm{a}}, 5^{\mathrm{a}}, 8^{\mathrm{a}}$ y $9^{\mathrm{a}}$ aumentadas. Décimas.

Muy clásica y vulgar

A-B; A-B-A'; A-B-C

12 tienen introducción, que va desde un compás de acordes hasta 4 compases de ritmo. 15 tienen final, que suele ser un o unos acordes $\mathrm{Y}$ una tiene intermedio, que es un compás de ritmo La imprescindible.

\section{SECUENCIA}

Comienza con la teoría necesaria para poder iniciar las lecciones: Definición de música: combinación simultánea de los sonidos producidos por un cuerpo sonoro, y que el oído puede apreciar por puntos determinados, pentagrama, líneas adicionales, claves, escala diatónica, intervalos, tono y semitono (a los que el autor llama punto y medio punto). Es de destacar que en este punto tan inicial de la información, hace mención el autor a cuestiones de acústica musical, pues indica que cada punto tiene 9 divisiones llamadas comas, que se reparten éstas en 5 para el punto mayor, que es el que conserva el nombre de la nota (o sea el cromático), y 4 para el punto menor, que es cuando muda el nombre (es decir el diatónico).

Siguen a estas cuestiones, ejercicios de intervalos, desde segundas hasta octavas, ascendentes y descendentes, sin preparación.

Las alteraciones. Pero para darlas a conocer, explica someramente y bastante ininteligible, la teoría de las tonalidades, lo que es a todas luces prematuro, y no se contenta con introducir ya el sostenido y el bemol, sino que también las dobles alteraciones. Después la escala cromática, y ejercicios con alteraciones formando semitonos diatóni- 
cos, pero también cuartas y quintas aumentadas, octavas aumentadas novenas aumentadas, décimas mayores, etc., en fin, un desatino en tan prematuro momento.

El ritmo y el compás. Define ritmo como la medida del compás y la regularidad de los tiempos. O sea, que subyuga ritmo a compás, evidentemente no tiene idea del concepto de ritmo, ni del de compás. Los compases, que los divide en binarios y ternarios, los primeros los que tienen mitad justa, incluye el compasillo y el 12/8, y los segundos los que el número de partes es impar. Las figuras de notas, con una tabla de relación de todas con la redonda. Y algo que no hacen ni los más atrevidos, a continuación y sin haber hecho un solo ejercicio o lección medida, habla del puntillo, y también, como ya leímos en Reguart, asevera que se utiliza el doble y triple puntillo, pero ninguna lección aparece después con ellos; junto con los puntillos, las figuras de silencio.

A partir de aquí, se inician lo que podríamos llamar propiamente las lecciones. Solamente que el autor les llama "ejercicios para la división de los compases”, y continúa con la numeración desde que comenzó los ejercicios de intervalos.

En 10 ejercicios, aborda las negras, blancas y corcheas, por supuesto, ya que ha hablado de ellas, con alteraciones. En la mayor parte utiliza intervalos de segunda, en otras de tercera, y en una de ellas, casi todos los demás. Eso sí, es el primero hasta ahora que comienza con el compás de $2 / 4$.

Cuatro ejercicios con semicorcheas, fórmulas combinadas corchea- semicorcheas, ya todos los intervalos; la ligadura, pero solamente se ve entre dos negras y entre una negra y una blanca, y para liar un poco la cosa, también pone ligaduras de fraseo entre dos notas, sin explicar la diferencia; también el puntillo en la negra y los silencios de semicorchea formando contratiempo corto e irregular, mucho antes de haber visto el largo y regular.

Este autor empieza la casa por la techumbre. A continuación habla del signo\%, de la barra de repetición y de las abreviaturas.

Cuatro lecciones con el compás de compasillo con todo lo que, tan de golpe, se ha visto.

Tres, en el compás de 3/4, también con todos los elementos trabajados. Y tres más, una en cada uno de los compases vistos, ya con tresillos y seisillos.

Los signos dinámicos y los de articulación. Le siguen dos lecciones con compás de 3/8, el concepto de síncopa, sin ninguna lección que demuestre su efecto, los compases de 9,12 y 6 por 8 (curioso el orden de aparición), 2 lecciones para los dos primeros compases, y 4 para el de 6/8, 2 para el movimiento rápido y 2 para el lento, ya que dice 
que se marca a 4 partes en estos casos. También Aliaga comenta esta manera de subdividir el seis por ocho, y volvemos a decir que es sorprendente, quizás en esa época se conocía o practicaba esa subdivisión, después desapareció su práctica y recientemente se ha vuelto a hablar de ella.

Capítulo 2: De los tonos. En este capítulo quiere, no lo consigue, explicar el concepto de tonalidad, y así dar paso a una serie de lecciones, una por cada una, en las distintas tonalidades mayores y menores.

Declara que se emplea la palabra tono para: nombrar al intervalo de segunda mayor, para llamar al timbre de cualquier instrumento, [?] para citar el acorde perfecto mayor y menor [?] . Según él esta palabra es un saco de sastre. Sigue manifestando que como cada nota puede ser la primera de una escala, y teniendo en cuenta que cada sonido puede ser natural, sostenido y bemol, pues resultan 21 tonalidades con el mismo nombre; que se puede mudar de tonalidad, sin cambiar de entonación, bajando la tercera y sexta; que los accidentes que indican el tono se colocan al lado de la clave en orden de cuartas o quintas- No creemos que haya nadie, que sin conocer estas cuestiones, entienda estos razonamientos. Y para colmo, dice que al ir estudiando las lecciones siguientes en las distintas tonalidades, se retengan en la memoria los accidentes de cada una. Como si no fuera posible dar pautas para poderlas deducir.

Empiezan aquí, una serie de lecciones en las distintas tonalidades, en los ejercicios anteriores no había acompañamiento, a partir de éstas, sí hay un acompañamiento de piano realizado.

Después de la lección en Si menor, una pequeña explicación para las notas de adorno. Llama apoyatura a ésta y al mordente de una nota, pero dice que éste es rápido, también apoyatura, pero doble, a los mordentes de dos notas, y grupetos a los de 3 y 4 ; pero nada más explica.

Con la lección en Sol sostenido menor, explica y aplica el calderón (o corona). Con la de Re sostenido menor, alguno de los términos agógicos (naturalmente sin llamarle agógica).

A partir de la primera tonalidad de bemoles, aparecen nuevas claves, en un orden bastante raro, y con dos lecciones por clave: Do en $1^{\mathrm{a}}$ en las tonalidades de Fa mayor y Re menor, Do en $4^{\mathrm{a}}$ para Si bemol mayor y su relativo, Do en $3^{\mathrm{a}}$ para Mi bemol mayor y Do menor (con la que también aparece el compás de $2 / 2$ ) y Fa en $4^{\mathrm{a}}$ para las de 4 bemoles. Después vuelve a repetir todas las claves vistas. 
Siguen dos estudios para los cambios de clave, aire y armadura. Dos más para ver las modulaciones transitorias, en las que se modula a tonalidades vecinas y muy lejanas.

Dos estudios para ejercitarse en las notas muy agudas, y en las muy graves. Estas son de mayor facilidad rítmica y de entonación.

Una lección para cada uno de los compases siguientes: 12/4, 12/16, 6/4, 6/16, 6/4 a 3 partes, 9/4, 9/16 y 7/4.

Dos lecciones de música sin compasear. Con bajo cifrado.

Y termina con un "Estudio Final", que es como la unión de 4 lecciones distintas. Las dos primeras son un compendio de todas las dificultades rítmicas, con cambios de clave y de armadura; y a partir de la tercera, van haciéndose más fácil, no cambia de clave y se hace cada vez más fácil hasta el final.

\subsubsection{VALORACIÓN DE LA EFECTIVIDAD DEL MÉTODO Y DE SU APORTACIÓN A LA ENSEÑANZA.}

La aparición tan temprana de alteraciones es un error, así como de intervalos aumentados y disminuidos y del puntillo.

Sin embargo está muy bien, y es el único hasta ahora, que comienza con el compás de 2/4. Junto con Aliaga, indica que la forma de marcar el de 6/8 sea a 4 partes.

El desorden en la progresión de los elementos es fenomenal, ideal para la total dispersión del alumno. Desastrosa la explicación de la tonalidad.

No son nada fáciles las lecciones, sobre todo a partir de las que se dedican a conocer las tonalidades, van muy sobrecargadas de fusas, semifusas, puntillo sobre la semicorchea, adornos, tresillos de semicorchea... en general mucho arabesco.

Es un método malo, y en las cuestiones teóricas nefasto. 
Manent i Puig 


\section{MÉTODOS POSTERIORES A 1861, CUANDO YA HAY UN PROGRAMA, DENTRO DEL RE- GLAMENTO, DEL REAL CONSERVATORIO DE MÚSICA Y DECLAMACIÓN DE MADRID.}


Con esta referencia, analizaremos once métodos o partes correspondientes a cuatro autores.

LLADÓ BARCELÓ, Joaquín: Método analítico para el estudio del solfeo, 1862

Método de solfeo analítico, fácil y conciso, 1868

ARRIETA, Emilio

Solfeos autografiados, primer año, 1868

Solfeos autografiados, segundo año, 1869

Solfeos autografiados, tercer año, 1870

Solfeos autografiados, Concursos, primer libro, 1871

OBIOLS Y TRAMULLAS, Marià: Método de solfeo, $23^{\mathrm{a}}$ ed. Corregida y aumentada 1870

MORÉ y GIL: Método completo de solfeo,1870 


\subsection{RESEÑA BIOGRÁFICA DEL AUTOR}

\section{LLADÓ BARCELÓ, Joaquín. Muerto en Sarriá (Barcelona) 10/1878. Teórico y} compositor. Presidente de la junta directiva del Montepío Artístico de Barcelona (Molinero Cuesta, Estrella, en AAVV, tomo 6, p. 938 y Saldoni, 1868-1881, tomo III, p. 157 y IV, p. 173).

\subsubsection{DESCRIPCIÓN DETALLADA DEL MÉTODO.}

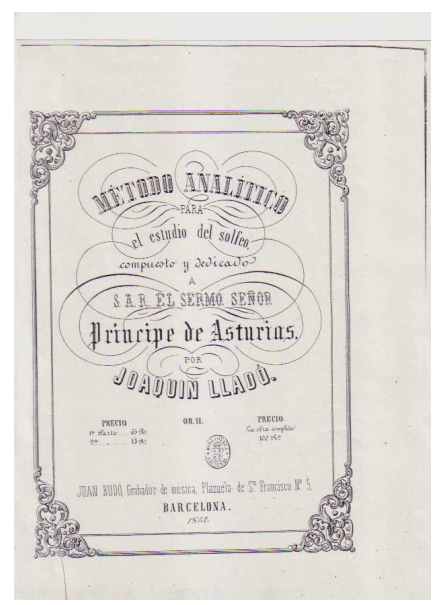

\section{Título del Método}

Método analítico para el estudio del solfeo, compuesto y dedicado a S.A.R. el Serenísimo Príncipe de Asturias, Barcelona, Juan Budó, 1860 ó 62. ${ }^{1}$ Apéndice, página 210.

El método está dividido en dos partes. En la primera de ellas el autor expone un extenso "Plan de la obra" en el que explica los objetivos y contenidos: está dividida en 2 partes, la primera contiene 80 lecciones conteniendo las mayores dificultades que pueden ocurrir en cualquier composición musical; la segunda de 30 lecciones, destinadas a la práctica de lo que se ha aprendido. Inicialmente, y en la primera parte, hay 9 lecciones para la entonación; y luego 6 grupos de lecciones, según el siguiente plan: $1^{\text {o }}$.- Veinticinco lecciones, desde la semibreve a la semifusa, con todas las combinaciones posibles, pero con el sonido de las notas siempre igual, sin alteración alguna. $2^{\circ}$.- Seis lecciones con ejemplos de todas las pausas y sus combinaciones. $3^{\circ}$.- Nueve lecciones con tresillos y seisillos, con sus pausas, y combinaciones desde corchea a fusa. $4^{\circ}$.- Diecisiete lecciones dedicadas al puntillo, desde la mínima a la fusa. $5^{\circ}$.- Diez lecciones para los compases irregulares. Y $6^{\circ}$.- Cuatro lecciones con síncopas desde mínima a semicorchea y sus combinaciones.

\footnotetext{
${ }^{1}$ PRECIADO, Dionisio: obra citada, p. 242, figura 1860, y esa es la fecha que lleva el informe, insertado al principio del libro, que emiten destacados músicos; pero en la cubierta figura (y parece ser manuscrita) la fecha de 1862.
} 
Las razones de esta división y agrupación que da el autor, es que así el que pretende aprender sólo tiene que vencer una dificultad, por que, por ejemplo, cuando está con los tresillos ninguna otra cosa le distrae y puede fijar su atención en esta dificultad y sus variantes; y la otra razón es que si después de haber terminado sus estudios quiere hacer una consulta, sabe a qué apartado tiene que dirigirse según sea el motivo de su duda. Pero aun dice que hay otra razón más poderosa, escribe que todas las combinaciones que puedan hacerse en la música, están perfectamente relacionadas, por lo que resulta que una vez tomada una combinación, el mismo encadenamiento obliga a no apartarse de ella, y pone un ejemplo en la fig. 1 y 2. (Adjuntamos en el apéndice, página 210, sus ejemplos, desde la figura 1 a la 15, por creer que ilustran su metodología). Por ello esta relación que él dice existir, le sirve para apurar hasta el último grado todas las dificultades y para la preparación y simplificación de ellas. Las combinaciones de esta cadena (fig. 2) afirma que se hayan no sólo en las combinaciones escritas hasta ahora, sino en las que puedan escribirse. En eso estriba su sistema, en la división y subdivisión del tiempo a partir de la semínima, porque es a partir de ella cuando en un tiempo entran varios sonidos e incluso de una duración distinta cada uno, por ello las figuras que nos sirven para el análisis de una combinación cualquiera son las semínimas, corcheas, semicorcheas y las fusas. Cuando el discípulo sabe pronunciar un sonido en un tiempo, fácil le resultará la comprensión de las corcheas (fig. 3). Una vez el estudiante se haya hecho cargo de la reducción que tiende a simplificar, él mismo podrá escoger la que más se preste a sus ojos; una corchea con dos semicorcheas puede reducirse a dos corcheas, (véanse figuras 4, 5, 6, 7, 8 y 9). En total, que una vez se acostumbre el discípulo a esa constante división y justeza en la medida, estará en condiciones de leer cualquier trozo de música que se le presente.

Sigue el plan de la obra especificando los contenidos de cada uno de los grupos de lecciones en que está dividida la obra, explicación que dejamos para encabezar la descripción o pormenorización de cada uno de estos apartados.

Sin embargo, sí que explicamos aquí, lo que el autor quiere mostrar en las figuras 10 a 15 que se adjuntan en el apéndice.

Figura 10, para leyendo negras y aumentando la velocidad, llegar a leer semifusas. Él dice que en 5 días [?].

Figura 11 para las fórmulas combinadas. 
Figura 12 para, sustituyendo los silencios por notas, medir con exactitud aquellos.

Figura 13 para la medida de tresillos. No creemos efectiva esta idea.

Figura 14 para los puntillos, sustituyéndolos por ligaduras.

Figura 15 para las síncopas, igualmente sustituidas por ligaduras.

Acabado este plan de la obra, hay un "Plan de enseñanza" en el que explica al posible maestro, que debe afrontar la teoría a medida que haga falta, y que mientras se practica un bloque temático o de dificultades, se puede ir hablando teóricamente del que vendrá después. Y recomienda, con mayúsculas: ...incúlquenles en su espíritu la medición del valor de las notas por medio de la reducción simplificadora, y el análisis de todas las dificultades.

No hay lecciones dedicadas a las claves porque dice que cada cual puede, después de sabido este método, practicar la que le sea necesaria para su instrumento; y puede hacerlo con los ejercicios que hay al final de esta parte, y también con las lecciones de la segunda.

\section{CUADRO DE INFORMACIÓN GENERAL DE LA PARTE PRIMERA.}

$\mathbf{N}^{\circ}$ de lecciones

80

Extensión de las Entre 16 y 63 compases

lecciones

Claves empleadas Sol

Tesituras que abar- $\mathrm{Do}_{3}$ a Fa $_{4}$

can

Tonalidades que Do M, Sol M, Re M, La M, Mi M, Si M, Fa \# M, Do \# M, trata y estudia Si b M, Mi b M, La b M, Re b M, Sol b M, Do b M, La m, Mi m, Si m, Fa \# m, Do \# m, Sol \# m, Re \# m, La \# m, Re m, Sol m, Do m, Fa m, Si b m, Mi b m, La b m

Compases que em- $\quad 4 / 4,2 / 4,3 / 4,3 / 8,6 / 8,12 / 8$

plea y estudia

Dificultades métricas que contiene

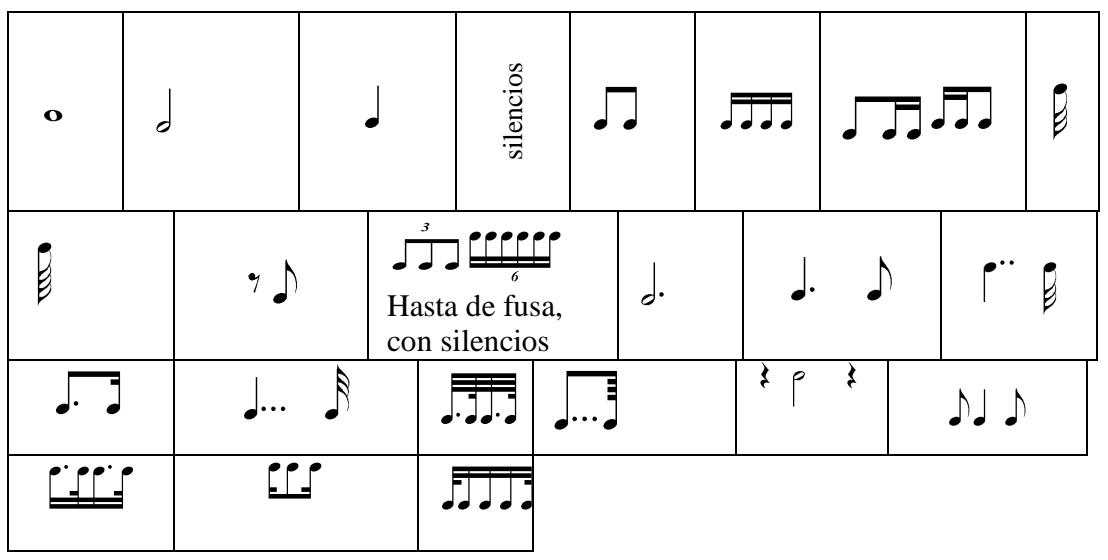


Dificultades de en- Intervalos aumentados y disminuidos. Dobles alteraciones tonación que se encuentran Desde $2^{\mathrm{a}}$ a $8^{\mathrm{a}}$. Semitonos cromáticos y todos los Aumentados y $y$ orden en que se Disminuidos enseñan los intervalos

Armonía utilizada Muy clásica y sencilla

Formas que tienen A-A'-B/A-B/A-B-C/ las lecciones

Introducciones, 1 tiene introducción, Intermedios o Co- 4 intermedio y das instrumentales 12 final, que suelen ser unos pocos acordes

Teoría de la música Nada más la necesaria al comienzo, y para explicar alguna noque incluye vedad

\section{SECUENCIA}

\subsubsection{PRIMERA PARTE}

Empieza con una carta fechada en Barcelona el 14 de octubre de 1860, que la firman Eusebio Font, Mateo Ferrer, José M. Sirvent y Gabriel Balart, dándole los parabienes a Lladó por su ingenio y bien hacer en la confección de este método.

Viene a continuación un prólogo del autor en el que manifiesta su certeza de que hasta ese momento, la mayor parte de las obras didácticas dedicadas a la enseñanza del solfeo, adolecen de un plan bien combinado que facilite la enseñanza. De que aunque tengan gran número de lecciones, no bastan para afrontar todas las dificultades, y muchas de ellas son reiterativas e inútiles, más bien una pérdida de tiempo. Afirma que el discípulo aprende la música de una manera superficial, no entiende lo que ha visto en el método, y por ello al encontrar una nueva dificultad no sabe vencerla, y es por que no se le ha enseñado a analizar las diversas combinaciones posibles. Por lo que él presenta aquí, en pocas lecciones, todas las dificultades imaginables, pero de un modo fácil, y asevera que, ochenta lecciones llevan al discípulo a la perfección en el solfeo, y le ponen en estado de leer todo lo más difícil que pueda escribirse.

Después expone su "plan de obra" y su "plan de enseñanza", que hemos expuesto más arriba.

Y ya comienza con teoría elemental y fundamental: definición de música lenguaje más sublime del alma; la expresión más profunda de todos sus sentimientos por medio de los sonidos. Notas, pentagrama, líneas adicionales, signos de $8^{\mathrm{a}}$ alta y baja, 
claves con explicación de las 7 practicadas y especificación de los nombres de las notas en clave de Sol, a lo que sigue una serie de ejercicios de lectura de notas en esta clave Ejercicios para la entonación:

Nueve ejercicios, desde la $2^{\mathrm{a}}$ hasta la $8^{\mathrm{a}}$, uno para todos juntos en orden creciente, ascendente y descendente; y el último igual pero en orden descendente y ascendente.

No sigue con ejercicios ni lecciones, sino que intercala explicaciones teóricas sobre las figuras de nota y compases. Habla de las formas de las notas para saber su duración, con los nombres antiguos de semibreve, mínima, semínima, corchea, semicorchea, fusa y semifusa, y de la relación entre ellas. El concepto de tiempo, relacionado con la duración de una semínima en el compás de compasillo, y de ahí al concepto de compás. Explica, esquemáticamente, el de 4, 3 y 2 por 4, a los que llama regulares, después los llamados por él irregulares: $2 / 2$, al que le da el nombre de mayor, 12, 9, 6 y 3 por 8. Explica el significado de todos ellos como una fracción del compasillo. Y termina estas instrucciones con compases poco usados como 6/4, 12/16 y 12/4.

\section{Grupo $1^{\mathrm{o}}$ :}

Veinticinco lecciones, sin acompañamiento, que van desde la redonda a la semifusa, utilizando pausas solamente de redonda, blanca y negra, en Do mayor, con todos los intervalos diatónicos, pero utilizando más los grados conjuntos cuando las figuras son rápidas. El autor explica, en el "Plan de la obra", esta extraña forma de presentar las dificultades, con las siguientes frases:

Acaso parecerá demasiado rápido el paso en 25 lecciones, de la semibreve a la semifusa, con sus combinaciones respectivas. Fácil me será probar lo contrario. Es un error el creer que las fusas o semifusas ofrecen grandes dificultades, siendo así que no presentan más que una: la velocidad en la pronunciación.

Además como el valor de las notas no es exacto sino relativo pude decirse que las semínimas son semifusas. Esto que parece una paradoja, es, sin embargo, una verdad fácil de probar. Dese a un principiante la escala de do escrita en semínimas, hágase que cada día doble su velocidad y se tendrá que el segunda día leerá corcheas, el tercero semicorcheas, el cuarto fusas y el quinto semifusas.

El mismo principio debe aplicarse a las combinaciones (fig. 11).

Aparte de estos argumentos incontestables, tenemos que todas las dificultades que presentan las 25 lecciones están intimamente enlazadas, y por lo tanto la una sirve de preparación a la otra; y que por medio de este sistema analítico se simplifican y se reducen a las más sencillas. 
Una lección para redondas, para blancas, para negras y para sus mezclas. Tres para corcheas, negras y blancas; en la primera lección de estas tres, le da a la primera de cada dos corcheas, el valor de corchea y a la vez de negra, con lo que, suponemos quiere conseguir, ejecutar la lección de dos maneras, con negras y desdoblando cada una de ellas en dos sonidos distintos.

Dos lecciones para semicorcheas, haciendo en la primera el desdoble de negra en la primera de cada 4 semicorcheas.

Dos lecciones para la fórmula corchea - dos semicorcheas y al revés, la que aborda desdoblando la segunda corchea en dos semicorcheas.

Cinco para las fusas y sus combinaciones con corcheas y semicorcheas, procediendo del mismo modo con desdobles en corcheas y semicorcheas, y

Siete para las semifusas con desdobles en corcheas, semicorcheas y fusas.

\section{De los tonos:}

Antes de pasar a otro bloque, presenta las tonalidades, hablando de la tónica, de la posibilidad de que otras notas sean las tónicas, y así justifica la necesidad de las alteraciones (enseña también las dobles), para que no se inviertan el orden de las distancias en la escala de do, esto es, que sólo les da la utilidad de armar las tonalidades, sin embargo en las lecciones venideras las usa como accidentales. Dice que los tonos pueden ser mayores y menores, siendo mayores aquellos cuya tercera consta de dos tonos, y menores aquellos cuya tercera consta sólo de uno y medio, difícil de entender para un neófito, puesto que también está difícilmente explicado; advierte que de la $7^{\mathrm{a}}$ a la $8^{\mathrm{a}}$, no debe haber más que medio tono también en los menores (y en ningún momento ha explicado lo que es tono y semitono), y que en melodía produce más efecto alterar también la $6^{\mathrm{a}}$ subiendo la escala y descendiendo volver ambas a su natural estado. Y termina exponiendo una tabla de tonalidades mayores y sus relativos menores.

Ejercicios para practicar los sostenidos y bemoles:

Una hoja con ejercicios, que empiezan por la escala cromática, y enseguida llegan a todos los aumentados y disminuidos. 


\section{Grupo $2^{\circ}$ :}

Seis lecciones, en las tonalidades de Sol, Re, La, Mi, Si y Fa sostenidos mayores, en los mismos compases que el anterior bloque, ya con acompañamiento de piano, con objeto de practicar las pausas y las tonalidades. No salen siquiera a una lección por clase de pausa, en seguida produce contratiempos con los silencios de corchea, e igualmente con los siguientes, formando complicadas combinaciones de contratiempos irregulares y fórmulas rítmicas. El autor, en el "plan de la obra" dice que donde haya silencios se deberán suponer notas para su fácil ejecución, pero él no da ninguna pauta para ello.

De los tresillos y seisillos:

Una muy breve explicación de estas medidas irregulares para acometer el grupo tercero.

\section{Grupo $3^{\circ}$ :}

Nueve lecciones para los tresillos y seisillos, en Do sostenido mayor la primera, y de nuevo el mismo ciclo de tonalidades que el anterior bloque, se añade aquí el compás de tres por cuatro. Estos grupos llegan hasta las fusas, y todas las combinaciones posibles, con y sin silencios. Efectúa los mismos desdoblamientos que en el primer grupo.

\section{Del punto y ligado:}

Explica, muy mal por cierto, el puntillo, el doble puntillo y hasta el triple; y engloba con la misma denominación de "punto" al picado y al staccato. Igual hace con el ligado, que le da el doble significado de ligadura de expresión y de prolongación.

\section{Grupo $4^{\mathrm{o}}$ :}

Diecisiete lecciones, en las tonalidades de Si bemol Mayor, Mi bemol Mayor, La bemol Mayor, Re bemol Mayor, Sol bemol Mayor, Do bemol Mayor, La menor, Mi m menor, Si m menor, Fa sostenido menor y Do sostenido menor, además de algunas anteriores repetidas. Los compases los mismos. Llega a combinaciones dificilísimas, en algunas prepara el puntillo o el doble puntillo con su equivalencia en notas ligadas; el puntillo en la corchea seguida de semicorchea, lo prepara 
con el desdoble de 4 semicorcheas; el bloque semicorchea con puntillo - fusa, con el desdoble de 8 fusas y con semicorchea ligada a fusa; el de negra con triple puntillo seguido de fusa, con negra ligada a corchea con doble puntillo, y así sucesivamente, hasta llegar a fusas con puntillo y semifusas y al contrario, fórmulas combinadas de semicorcheas con fusas con puntillo y semifusa y al contrario; semicorchea con puntillo y fusas; corchea con triple puntillo y semifusa. Eso sí, los intervalos en estos casos, por grados conjuntos casi siempre.

Grupo $5^{\circ}$ :

Diez lecciones para la práctica de los compases que el autor llama "irregulares", el de 3/8, los compuestos de denominador 8 y el de $2 / 2$. Repite algunas tonalidades, y aparecen como nuevas Sol sostenido menor, Re sostenido menor, La sostenido menor, Re menor, Sol menor y Do menor. Curioso orden de aparición.

\section{Grupo $6^{\circ}:$}

Cuatro lecciones dedicadas a la síncopa (que el autor llama "síncope), en las tonalidades de Fa menor, Si bemol menor, Mi bemol menor y La bemol menor. Utiliza las ligaduras para comprender la síncopa; en el enlace de síncopas muy breves, descompone la síncopa en 4 semicorcheas, las del medio ligadas; llega hasta la síncopa brevísima de fusa.

\subsubsection{SEGUNDA PARTE}

\section{CUADRO DE INFORMACIÓN GENERAL DE LA PARTE SEGUNDA.}

$\mathbf{N}^{\circ}$ de lecciones

Extensión de las lec- Entre 21 y 86 compases

ciones

Claves empleadas

Tesituras que abarcan

Tonalidades que trata
y estudia

\section{0}

Sol $\mathrm{Do}_{3} \mathrm{a} \mathrm{Fa}_{4}$
De $\mathrm{Si}_{1}$ a Sol 6 , con el fin de practicar los sonidos sobreagudos y muy graves, aunque la mayoría sigue abarcando desde Do M, Mi m, Sol M, Si m, Fa \# m, Si b M, Re b M, Do \# m, Sol \# m, Do b M, Re \# m, La \# m, Re m, Sol m, Do m, Fa m, Si b M, Re M, Mi b m, Mi b M, La m, La b M, Si M y Sol b $\mathrm{M}$, todas las practicadas pero en un orden aleatorio

Compases que emplea $\quad 3 / 4,4 / 4,2 / 4,2 / 2,3 / 8,9 / 8,6 / 8,12 / 8,6 / 4,12 / 16,6 / 16$ y $3 / 16$ y estudia 
Dificultades métricas que contiene

Dificultades de entonación que se encuentran $y$ orden en que se enseñan los intervalos

Armonía utilizada

Formas que tienen las lecciones

Introducciones, Intermedios o Codas instrumentales

Teoría de la música que incluye
Notas de adorno. Fermatas. Y todas las imaginables: valores irregulares desde quintillo a septillo, mucha síncopa entre fusa y semifusa, mucha fórmula combinada de semicorcheas, fusas, semifusas y puntillos.

Muy pocas, intervalos mayores y menores, y también aumentados y disminuidos, pero dentro de la lógica de las tonalidades principales o transitorias

Igual que en la parte anterior, muy clásica y sencilla, alguna modulación más, pero el acompañamiento más elaborado

A-A'; A-B-C; A-B-A'; A-A'-coda; A-B-coda; A-B-A'-CB-C-coda

3 tienen introducción, y otras 3 intermedio, 24 tienen coda. Suelen ser cortos, pero alguno hay largo.

Al principio, Notas de adorno, Abreviaturas y Términos, con profusión de ejemplos

\section{SECUENCIA.}

En el plan de la obra, al principio de la primera parte, dice que en esta segunda hay 30 lecciones, en las que se hayan reunidas diversas y complicadas combinaciones para poner en práctica lo aprendido en la primera. Que hay lecciones con las notas muy agudas y muy graves, para cantarlas en la octava normal, pero para familiarizarse con ellas. Y que hay diversos movimientos, signos de expresión, de repetición, notas de adorno, etc. con el fin de que cuando el discípulo concluya sus estudios con este método, comprenderá fácilmente cualquier pieza de música que se le presente por difícil que sea.

Empieza con la explicación de las Notas de adorno, a las que clasifica únicamente en dos grupos: apoyaturas y grupetos. Con las primeras engloba al mordente de una y dos notas, representando al de una nota con una barra y con dos; y con los grupetos a los de 3 o más notas, sin distinguir anteriores, posteriores, ascendentes y descendentes. Sólo habla de la abreviatura de grupeto de 3 notas, y no recomienda su uso; nada dice de las abreviaturas de mordentes. En cuanto a su interpretación, manifiesta que son más o menos rápidas y que toman el valor de la nota que adornan o de su antecesora, según el 
gusto del intérprete, por lo cual no recomienda el uso de tales adornos. De todas formas pone varios ejemplos de ejecución, pero sin norma alguna.

Sigue con un apartado al que titula Signos y Abreviaturas. En él incluye al trino y al calderón. No sabemos qué tendrá que ver uno con el otro, ni que trino sea signo o el calderón sea abreviatura, pero parece que Lladó así lo veía. Después las barras para convertir negras en corcheas o semicorcheas, etc.

Continúa con signos de repetición, la doble barra, los signos\%, খ y el párrafo.

Detrás las pausas de compases y varios compases de silencio. Seguidos de los términos del movimiento uniforme, y de una lista alfabética de los términos agógicos, dinámicos y de expresión.

Por último, "Licencias musicales", así llama a los valores irregulares, desde el quintillo al septillo.

A continuación vienen las 30 lecciones, como dice él, a modo de recopilación de lo aprendido en la primera parte. Emplea todas las tonalidades practicadas, excepto las enarmónicas, pero en el orden arriba detallado. En una de ellas, la número cinco, empieza en Fa sostenido menor y sobre la mitad, cambia a su homónimo mayor. Utiliza todos los compases simples y compuestos más usados, y aporta una lección para cada uno de éstos menos usados: 6/4, 12/16, 6/16 y 3/16, lo que hace en las cuatro últimas lecciones. En alguna lección aparece brevemente algún signo de articulación, y en muchas repite fragmentos con notas de adorno y transformadas éstas en notas reales. La dificultad rítmica suele ser extrema.

Termina esta parte, y el método, con información sobre el nombre de las notas en las claves de Fa y en las de Do, y con breves ejercicios de lectura de notas para cualquiera de las claves.

\subsubsection{VALORACIÓN DE LA EFECTIVIDAD DEL MÉTODO Y DE SU APORTACIÓN A LA ENSEÑANZA.}

\section{RESPECTO A LA PRIMERA PARTE DEL MÉTODO}

No es desdeñable esta idea de la comprensión del ritmo por medio del análisis, es decir de la división de las partes y subpartes del compás, y es muy posible que en su tiempo fuera un gran descubrimiento. Hoy eso está superado, y se llega al mismo resultado a través de la progresión lógica de los elementos, siempre y cuando se le explique y 
haga ver al alumno el encadenamiento de ellos, y se le haga analizar la distribución de las distintas notas dentro del compás y del tiempo.

No es cierto que en el primer grupo de lecciones, a través de esos desdobles de figuras, el alumno vaya a dominar la lectura con semifusas, porque a fin de cuentas, tiene que leer negras y luego desdoblarlas, corcheas y los mismo, etc. etc. Eso es lo que hacemos modernamente, y en casi todos los métodos, pero con una progresión más dilatada y mayor insistencia en cada nueva dificultad.

Encontramos lagunas en las explicaciones teóricas, y hasta errores, ya que llamar irregulares a los compases de 2/2, 12, 9, 6, y 3/8, no tiene explicación.

Creemos que es una monstruosidad entrar con las alteraciones y con intervalos aumentados y disminuidos.

En el segundo grupo se forman contratiempos y combinaciones tan dificultosas, que se necesitan varios años de estudio para interpretarlas.

\section{RESPECTO A LA SEGUNDA PARTE DEL MÉTODO}

Es útil, las lecciones son musicales, la melodía fluye con naturalidad. Es un complemento a otro método más completo, sobre todo un complemento para obtener un objetivo de gran perfeccionamiento.

No vemos por qué junta trino y calderón y los clasifica como signos y abreviaturas.

Puede ser más válida esta segunda parte que la primera, que tiene más de voluntad que de resultado efectivo, aunque hay, a veces, demasiada dificultad métrica.

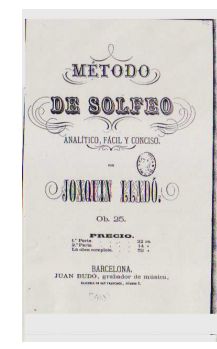

\section{Título del Método}

Método de solfeo analítico, fácil y conciso, Barcelona, Juan Budó, 1868.

En el prólogo dice el autor que la anterior obra ofrecía algunos inconvenientes para ser adoptada en los colegios, donde aprenden solfeo la mayor parte de los que se dedican al piano. Cada lección necesita un detenido estudio al cual no pueden dedicarse los alumnos por falta de tiempo, y su volumen lo hacía por otra parte sobrado costoso.

Estas consideraciones me han inducido a escribir este «nuevo método». Basado sobre el mismo sistema, y hechas en él todas las modificaciones que la práctica me ha enseñado, creo que se acerca más al ideal que he acariciado tanto. 
Es por ello una nueva versión del anterior método, con las mismas directrices pero más fácil y con menos lecciones. En éste hay 95, contra 110 del anterior. Los compases que trata son los mismos que en la primera parte del anterior, y con las tonalidades se queda en las de 5 alteraciones en la armadura.

También lo divide en dos partes, siendo la segunda de similares características que en el primer método expuesto.

En ninguna de las dos hay acompañamiento, por lo que lo convierte a éste en un método con menos utilidad que el anterior, eso sí, más fácil, pero demasiado conciso.

A continuación insertamos un cuadro sinóptico que aparece en el método después del prólogo y de la "Explicación del sistema que sirve de base a este método", en el que se ve en síntesis la concepción de LLadó en cuanto a la manera de aprender el solfeo: 


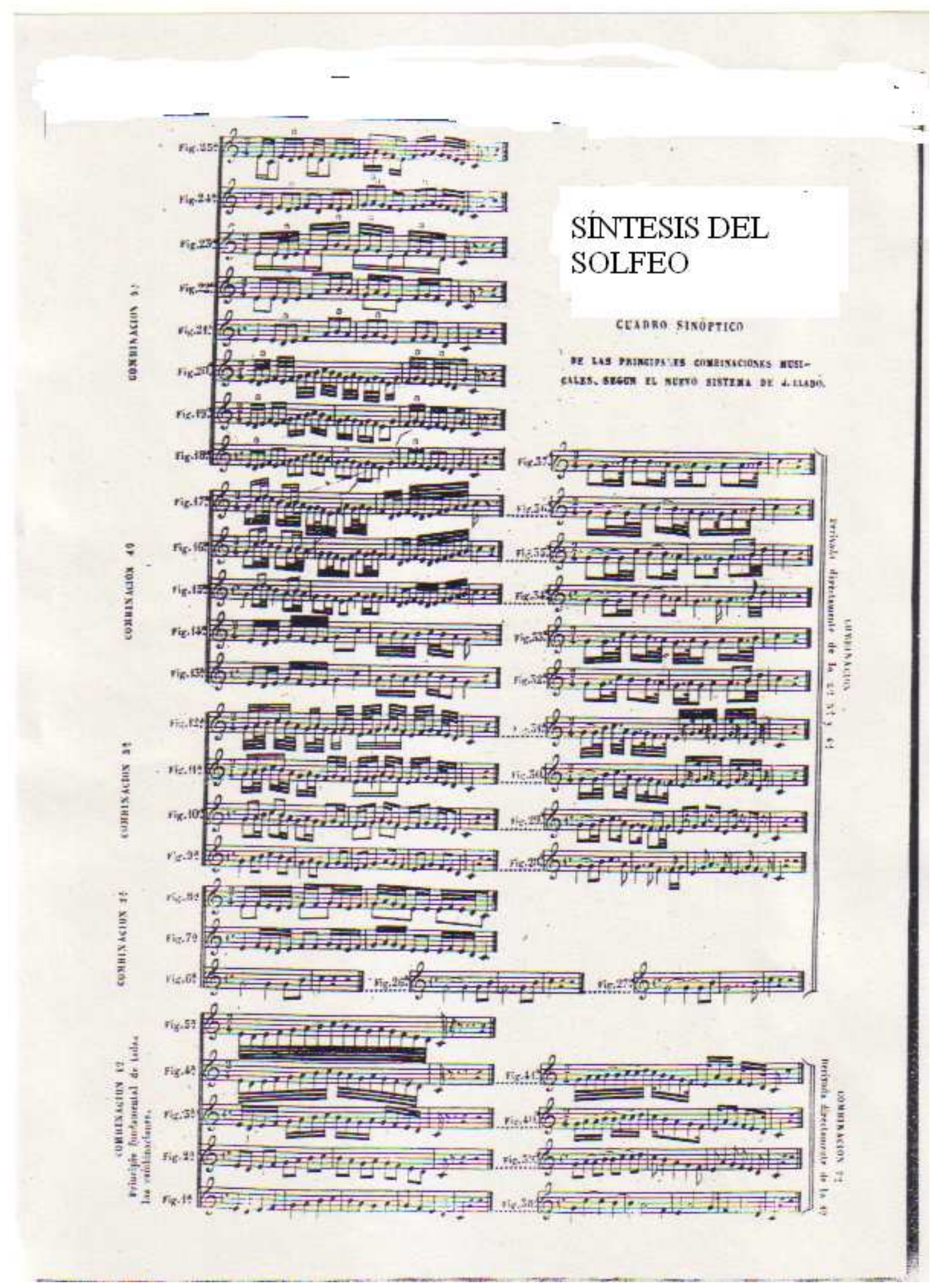

Apéndice página 211. 
Lladó Barceló Método de solfeo analítico, fácil y conciso 


\subsection{RESEÑA BIOGRÁFICA DEL AUTOR}

ARRIETA CORERA, Emilio. Nació en Puente de la Reina (Navarra), el 20 de octubre de 1821, y murió en Madrid el 11 de noviembre de 1894. Uno de los compositores más destacados de zarzuelas y óperas del s. XIX. Director del Conservatorio de Madrid, donde ejerció una destacada labor pedagógica, entre sus alumnos se cuenta Chapí o Bretón. Su verdadero nombre era Juan Antonio Pascual. Siendo un niño se trasladó a Madrid a estudiar música, en 1838 fue a Milán por poco tiempo, regresando a Madrid. Al año siguiente vuelve a Milán donde prolongó su estancia hasta 1846, allí usaba el nombre de Juan, y allí estudió composición entablando relaciones con la ópera italiana, llegando incluso a estrenar una ópera Ildegonda, con la que obtuvo el premio de composición.

Terminada su carrera de composición, volvió a Madrid, a partir de aquí adoptó el nombre de Emilio. No encontró el mismo ambiente musical que había tenido en Italia, y se decidió a ir de nuevo a Milán, pero el 17 de abril de 1848 fue nombrado maestro de canto de la reina Isabel II, lo que le produjo estabilidad económica y prestigio. Compuso para la reina varias canciones de cámara, y consiguió representar y dirigir su ópera Ildegonda con éxito

En 1850 compuso otra ópera, La conquista de Granada, letra del mismo libretista que la anterior, Temistocle Solera, ópera que volvería a estrenar en 1855 con otro título, Isabel la Católica.

1851, parte de nuevo a Italia, y más concretamente a Milán, donde representa sus óperas y compone alguna canción. Vuelve a Madrid al año siguiente, tras haber estado algún tiempo también en París, mientras tanto la reina había suprimido la cámara de música y canto y el teatro de Palacio, por lo que Arrieta perdió sus ingresos seguros, que a pesar de sus muchas solicitudes de seguir cobrando u obtener una jubilación, nunca los obtuvo.

Al volver a Madrid, encontró el ambiente musical más propicio para el teatro lírico, concretamente la zarzuela, sobre todo la zarzuela grande, en 3 actos, comenzaba a hacer furor. Compuso El dominó azul, El grumete, La estrella de Madrid, La cacería real, Los progresos del amor (zarzuela bufa), y otras más, llegando en 1871 a su mayor éxito con la ópera Marina.

En 1868, fue nombrado Director de la entonces "Escuela de Música y Declamación", denominación del anterior Real Conservatorio, donde era profesor de composi- 
Arrieta, primer año

ción desde 1857. Compuso entonces Abajo los Borbones, y mantuvo su puesto todo el tiempo revolucionario y también el de la Restauración monárquica. Consiguió grandes logros, a pesar de los problemas políticos del momento, solucionando los problemas que, años antes siendo colaborador del diario "La Nación", había denunciado repetidamente (Cortijo, Ma Eugenia, en AAVV 1999, tomo 1, pp. 744 a 756).

\subsubsection{DESCRIPCIÓN DETALLADA DEL MÉTODO.}

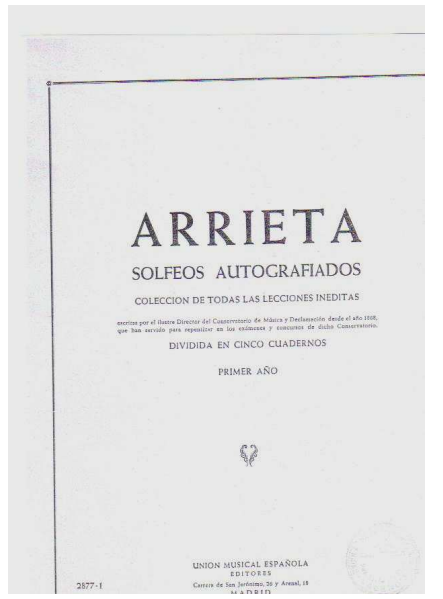

\section{Título del Método}

Solfeos autografiados COLECCIÓN DE TODAS LAS LECCIONES INÉDITAS escritas por el ilustre Director del Conservatorio de Música y Declamación desde el año 1868, que han servido para repentizar en los exámenes y concursos de dicho Conservatorio, Madrid, Unión Musical Española, s.f.. ${ }^{1}$ Apéndice, página 212.

Son, como su nombre indica, lecciones de solfeo con escritura manual, utilizadas para la repentización en los exámenes de Solfeo de primer curso, en este volumen, empezando por las correspondientes al año 1868, y terminando con las del año 1891. Estos libros fueron muy utilizados como texto en los Conservatorios, a pesar de no constituir propiamente un método, y lo han sido hasta bien mediado el siglo XX.

\section{PRIMER AÑO}

\section{CUADRO DE INFORMACIÓN GENERAL DEL PRIMER AÑO.}

$\mathbf{N}^{\circ}$ de lecciones

Extensión de las lec- Entre 11 y 41 compases

ciones

Claves empleadas

Tesituras que abarcan $\quad{\mathrm{De} \mathrm{DO}_{3}}_{3} \mathrm{MI}_{4}$, y más frecuentemente hasta $\mathrm{RE}_{4}$
Tonalidades que trata Do mayor y estudia

\footnotetext{
${ }^{1}$ AAVV (1999) en la p. 756, Tomo 1, dice que estuvo el total de esta obra editada entre 1868 y 1891.
} 
Compases que emplea y estudia

Dificultades métricas que contiene

Dificultades de entonación que se encuentran $y$ orden en que se enseñan los intervalos

\section{Armonía utilizada}

Formas que tienen las lecciones

Introducciones, Intermedios o Codas instrumentales

Teoría de la música que incluye
2,3 y 4 × 4

No es un método didáctico, pero la aparición de éstas es así:

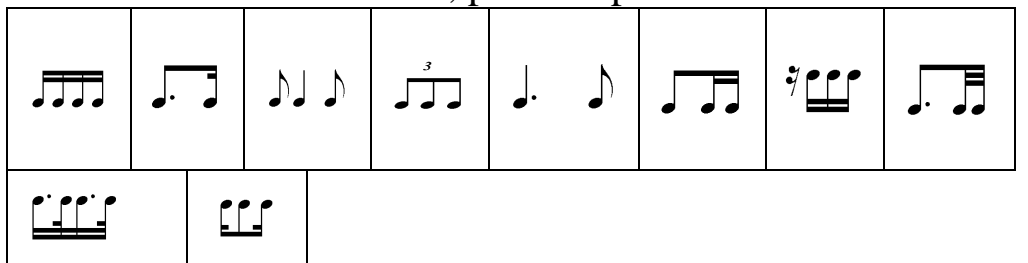

Intervalos propios de la escala tonal empleada. Algún cromatismo, y alteraciones accidentales propias de la modulación a otras tonalidades. Quinta disminuida y $4^{\mathrm{a}}$ aumentada

No hay ningún orden de enseñanza debido al tipo de método que es.

Clásica, con modulaciones a tonos vecinos

Tienen una única sección, con 3 ó 4 semifrases. Escasa reexposición de frases o motivos. Mucha variedad en las semifrases, quizás para darles mayor dificultad. Suelen haber algunas progresiones por la mitad de la lección

Introducción hay en 18 lecciones, aunque son más bien acordes durante uno o dos compases. Además hay algunas que llevan algunos acordes cuando la melodía no es tética. Ninguna coda, a excepción de algún acorde posterior a la última nota de la melodía. Ningún intermedio

No contiene

1868:

Hay tres lecciones, todas en $2 / 4$. Como son todas para evaluar conocimientos terminales de un curso, no presentan progresividad en la aparición de elementos rítmicos y/o melódicos. Sin embargo es de valorar que a pesar de no ser un método, comienza por el compás de $2 / 4$

Componen estas lecciones las figuras de semicorcheas, corcheas con puntillo, síncopas breves, tresillos de corcheas, negras con puntillo y fórmulas métricas combinadas.

Utiliza, además de los intervalos propios de la escala empleada, algún cromatismo, y alteraciones accidentales propias de la modulación a otras tonalidades. 
Arrieta, primer año

1874:

Se produce este salto de años, sin que haya nada en el libro que lo explique o se pueda hacer deducción. Hay en este año dos lecciones, ambas en 4/4. Abundan más las semicorcheas, y las síncopas, así como las semicorcheas a contratiempo; también aparece en la primera de ellas dos fusas precedidas de corchea con puntillo.

Aparece el intervalo de quinta disminuida.

1875:

También dos lecciones, 4/4. Ningún elemento nuevo con respecto a las anteriores, si acaso incrementa en éstas los cromatismos.

1876:

Cuatro lecciones este año, una a 3/4 y las otras tres a 4/4.

1877:

Tres lecciones, las dos primeras de cortas dimensiones. Compás de 4/4 las tres 1878:

Dos lecciones, 4/4 ambas.

1879:

En esta ocasión hizo tres, 3/4, 4/4 y 3/4 respectivamente. Se observa que va aumentando la dificultad rítmica con el paso de los años, sobre todo la dificultad en los contratiempos y las combinaciones sincopadas, como si fuera un método progresivo, quizás observara que los alumnos podían afrontar esas complicaciones.

1880 y 81 :

En ambos años, sendas lecciones, compás de 3/4 y una de ellas 2/4, en el que hacía tiempo que no escribía.

1882:

Tres lecturas, 4/4, 3/4 y 4/4

1883 y 84 :

Dos lecturas para cada año, una en 4/4 las otras tres en 3/4. En la primera del año 84, nos encontramos con un grupo de semicorcheas con puntillo y fusa.

1885,86 y $87:$

Tres lecciones en cada uno de estos años, la mayor parte de ellas en 2/4. En la segunda del 85, aparece la síncopa muy breve, y también el intervalo de $4^{\mathrm{a}}$ aumentada 1888:

Dos lecturas, $3 / 4$ y $4 / 4$ 
1889:

Tres lecciones, 2/4 la primera y otras dos en 3/4

1890 y 91 :

Dos lecciones cada uno de estos años 4/4, 3/4, 4/4, 2/4

Encontramos, en general, bastantes dificultades métricas y melódicas, pero sobre todo métricas, para un primer curso. Eso da a entender que los estudiantes de ese tiempo alcanzaban un nivel mucho más alto que los de ahora. 


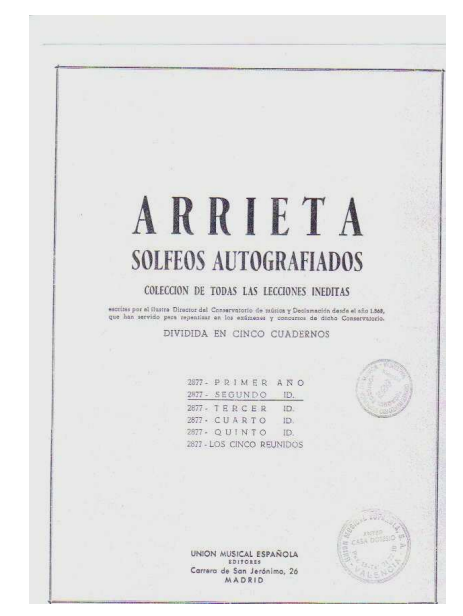

\section{SEGUNDO AÑO}

\section{CUADRO DE INFORMACIÓN GENERAL DEL SEGUNDO AÑO.}

$\mathbf{N}^{\circ}$ de lecciones

Extensión de las lec- Entre 17 y 42 compases

ciones

Claves empleadas

Tesituras que abarcan

Tonalidades que trata y estudia

Compases que emplea y estudia

Dificultades métricas que contiene

Dificultades de entonación que se encuentran y orden en que se enseñan los intervalos

Armonía utilizada

43 $\mathrm{Mi}_{3}$

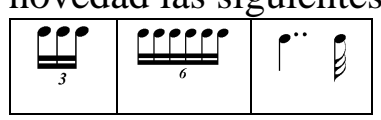

Do $1^{\mathrm{a}}$ y Fa $4^{\mathrm{a}}$ (curiosos los trazos de ambas)

En clave de Do $1^{\mathrm{a}}$, la mayor parte van de $\mathrm{Re}_{3}$ a $\mathrm{Mi}$, y las menos llegan desde $\mathrm{SI}_{2}$ a FA ${ }_{4}$. En clave de Fa $4^{\mathrm{a}}$, las extensiones van comúnmente de $\mathrm{Do}_{2}$ a $\operatorname{Re}_{3}$, y algunas de $\mathrm{Si}_{1}$ a

Re M, SI b M, Fa M, Mi b M y Sol M. Es curioso que no haya ninguna en modo menor.

$2 / 4,6 / 8,3 / 4$ y una en $4 / 4$

Son las mismas que en el anterior volumen, lo que confirma nuestra aseveración de que eran un poco trabajosas. Como novedad las siguientes agrupaciones

$7^{\mathrm{a}}$ disminuida, $4^{\mathrm{a}}$ disminuida y $2^{\mathrm{a}}$ aumentada. En una lección hay una $9^{a}$ menor. Las melodías son bastante deslucidas

Un poco más romántica. Algún acorde de $11^{\mathrm{a}}, 6^{\mathrm{a}}$ aumentada y varios de $7^{\mathrm{a}}$ disminuida. Grados alterados. Normalmente modula a tonos vecinos, también a tonos lejanos y a tonos homónimos en algunas pocas. Algún acorde de $7^{\mathrm{a}}$ disminuida con $3^{\text {a }}$ disminuida 
Formas que tienen las lecciones

No suelen tener una forma específica, pasa como en el anterior volumen. Alguna encontramos con la forma A - A', y también con la ternaria A- B- A'. En varias ocasiones encontramos repetición del motivo principal y alguna repetición de miembro de periodo

Introducciones, Intermedios o Codas instrumentales

Al igual que en el primer año, no hay ninguna con coda ni intermedio. Si hay 26 que tienen uno o dos compases de introducción, que no es más que unos acordes

Teoría de la música No contiene que incluye

\subsubsection{DESCRIPCIÓN DETALLADA DE ESTE SEGUNDO AÑO.}

$\mathrm{Al}$ igual que el volumen anterior son lecciones de solfeo con escritura manual, utilizadas para la repentización en los exámenes de Solfeo, en este caso, de segundo curso, empezando por las correspondientes al año 1868

1868:

Hay dos lecciones, clave de DO $1^{\mathrm{a}}$, Re y Si b mayor, ambas en 2/4. Aparece por primera vez el intervalo de séptima disminuida en la primera lección, y cuarta disminuida en la segunda.

1873. ${ }^{1}$

Al igual que en el año anterior, y hasta el 1877 inclusive, siempre hay dos lecciones por año. En éste son en compases de 3/4 y 6/8, tonalidades de Fa y Mi b mayor, y claves de Do $1^{\mathrm{a}}$ y Fa $4^{\mathrm{a}}$

1874:

Claves de Do y $\mathrm{Fa}^{2}$, tonalidades de Mi b y Re mayor, compases de 2/4 y 6/8 1875:

Ambas en 2/4, Mi b y Si b mayor, claves de Do y Fa 1876:

Claves de Do y Fa, 3/4 y 2/4, Mi b y Re mayor

\footnotetext{
${ }^{1}$ También hay un salto desde el año 68 al 73, pero en el anterior volumen el vacío era hasta el año 74 , un año más, no sabemos porqué el compositor hizo 2 lecciones para el año 73 para $2^{\circ}$ curso y no para $1^{\circ}$.

${ }^{2}$ A partir de ahora nos referiremos a las claves de Do $1^{\mathrm{a}}$ y Fa $4^{\mathrm{a}}$ como Do y Fa
} 
Arrieta, segundo año

1877:

Ambas en 3/4 y clave de Fa, Si b y Re mayor como tonalidades. Encontramos en la primera de ellas, como elemento métrico nuevo, el doble puntillo. 1878:

Éste y los dos años siguientes, tienen 3 lecciones cada uno. En el presente dos en 3/4 y una en 6/8, la primera en Sol mayor y las otras dos en Si b mayor, claves Do, Fa y Fa. 1879:

Claves de Do y Fa en la tercera, Si b, Fa y Re mayor, 2/4 las dos primeras y 3/4 la tercera

1880:

Dos en Sol mayor y 3/4, una en Re mayor y 2/4; claves de Do las dos primeras y Fa la tercera.

1881 al 84:

Todos estos años tienen dos lecciones, dentro de las tonalidades, compases y claves en los que se desenvuelve todo el volumen.

1885,1886 y 1887 :

Ocupan estos tres años tres lecciones cada uno de ellos, con los compases, tonalidades y claves habituales.

1888:

De nuevo dos lecciones, en Fa y Sol mayor, ambas en 3/4 y alternando las claves, primero Do y luego Fa. En la primera, caso insólito, hay un intervalo de $9^{a}$ menor ascendente, compás 21.

1889:

Hay en este año una sola lección. Es un poco extraño, pues no se da este caso en el anterior volumen ni en el resto de años de éste. Está en la tonalidad de Si b mayor, clave de Do y compás de 3/4. Hay en el compás 15 un intervalo de $8^{\text {a }}$ aumentada. Estamos seguros se trata de un error, o mejor dicho de la omisión del bemol en el Re agudo negra. 1890:

Tres lecciones en este año, Sol mayor para las dos primeras y Si b para la tercera, 6/8 para la primera y 2/4 para las otras dos y clave de Do para la primera, Fa para la segunda y tercera.

En la primera, compás 9, debe haber un error; se produce una enarmonía que no tiene ningún sentido melódico mi armónico, por lo que debe de tratarse de un yerro el bemol 
en la nota Do. Más adelante, compás 21, o se trata también de un error, o hay un intervalo de $2^{\text {a }}$ aumentada que hasta ahora no había aparecido.

1891:

Dos lecturas para terminar este volumen, Sol mayor y Si b mayor, 3/4 y 2/4 y alternancia en las claves, Do y Fa.

En la última de nuevo aparecen dos intervalos de segunda aumentada. 


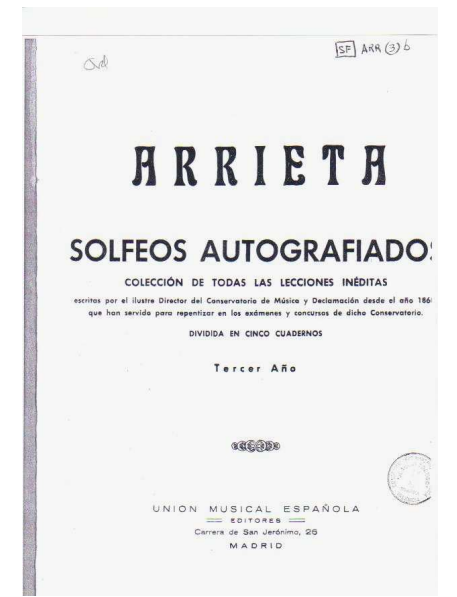

\section{TERCER AÑO}

\section{CUADRO DE INFORMACIÓN GENERAL DEL TERCER AÑO.}

$\mathrm{N}^{\circ}$ de lecciones

Extensión de las lec- Entre 10 y 59 compases

ciones

Claves empleadas

Tesituras que abarcan

Tonalidades que trata y estudia

Compases que emplea y estudia

\section{Dificultades métricas que contiene}

Dificultades de entonación que se encuentran $y$ orden en que se enseñan los intervalos

\section{Armonía utilizada}

Formas que tienen las lecciones entre ellas ${ }^{1}$

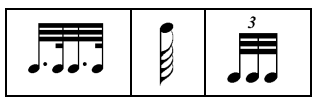

Las anteriores más Do $4^{\mathrm{a}}$ y en las últimas $\mathrm{Fa} 3^{\mathrm{a}}$ y mezclas

Iguales al anterior volumen

La b M, Mi b M, Mi M, Fa m, Sol m, Do m Re m, Re b M

Los anteriores más $9 / 8,3 / 8,5 / 8$

$5^{\text {a }}$ disminuida, dobles alteraciones, $3^{\text {a }}$ disminuida, $9^{\mathrm{a}}$ mayor. $10^{\mathrm{a}}$ menor $i 8^{\mathrm{a}}$ disminuida? (si no es un error. En el año 1884 explicamos este interrogante)

Similar al anterior, pero aumentando la armonía alterada y cromática. $5^{\mathrm{a}}$ aumentada sobre la tónica y II grado. Modulaciones súbitas, sin preparación ni dominante, a tonos lejanos. Modulaciones a tonos vecinos en $2^{\circ}$ grado. Alguna cadencia plagal con el IV minorizado. Resoluciones excepcionales y dominantes por semitono superior. Dominantes con la $5^{\text {a }}$ rebajada. Mucha frecuencia de sextas aumentadas

La mayor parte son de una sola sección Algunas tienen forma A - A'; A- B- B'; A - B- B' - B',; y en menor medida $\mathrm{A}-\mathrm{B}-\mathrm{A}^{\prime}$

\footnotetext{
${ }^{1}$ Es curioso que prescinde de las Claves de Do en $3^{\mathrm{a}}$ y $2^{\mathrm{a}}$ líneas. Se podría comprender que no tratase esta última por su poco uso en la práctica, pero la de Do en $3^{\mathrm{a}}$, no es comprensible que no la aborde.
} 
Introducciones, Intermedios o Codas instrumentales

Teoría de la música que incluye
Hay 6 que tienen una verdadera introducción que van de uno a 4 compases. 21 tienen una introducción rítmica corta, y hay 1 que tiene un intermedio rítmico de 1 compás

No contiene

\subsubsection{DESCRIPCIÓN DETALLADA DE ESTE TERCER AÑO.}

De la misma manera que los anteriores, contiene lecciones de solfeo manuscritas, utilizadas para la repentización en los exámenes de Solfeo, ahora, en el tercer curso, y comprendiendo los mismos años que los anteriores volúmenes.

Año 1868:

Lo componen 3 lecciones en tonalidades de La bemol mayor, Mi bemol, Mayor y Mi mayor, compases de 6/8, 9/8 y 3/4, claves de Do $1^{\mathrm{a}}$ y Do $4^{\mathrm{a}}$ líneas.

$1872:^{1}$

Una sola lección en Mi bemol mayor, compás de 9/8. Cambios de claves entre Sol, $\mathrm{Fa}^{2}$ y Do $4^{\mathrm{a}}$

1873:

Dos lecciones, Re mayor y Sol mayor. Compases $2 / 4$ y 3/4. La segunda con una escritura parcialmente sin barrar, propia de la escritura vocal.

1874:

También 2 lecciones, La mayor y Re mayor. 3/4 con cambios de claves entre Do $1^{\mathrm{a}} \mathrm{y}$ Sol; y 6/8 con clave de Fa solamente.

1875:

Igualmente 2, Mi mayor y La mayor, compás de 2/4 para las dos. Cambios de clave entre las utilizadas en este método

\footnotetext{
${ }^{1}$ También aquí hay un vacío desde el año 68 al 72. En los anteriores volúmenes, el hueco era hasta el año 74 en el primero, y 73 en el segundo. En este año reanudó las lecciones para repentizar solamente en $3^{\mathrm{a}}$ curso, en el siguiente también para $2^{\circ}$ y en el subsiguiente incluyó las de primer curso. Algún motivo justificaría estas lagunas, y su aparición paulatina, quizás en esos años se decidiría no llevar a cabo la prueba de lectura a primera vista.

${ }^{2}$ Siempre que nos referimos a la clave de Fa, lo hacemos con significación a la de $\mathrm{Fa}$ en $4^{\mathrm{a}}$ línea, cuando sea usada la de $\mathrm{Fa}$ en $3^{\mathrm{a}}$ línea, la señalaremos como $\mathrm{Fa} 3^{\mathrm{a}}$.
} 
Arrieta, tercer año

1876:

Cuatro lecciones aparecen en este año. La primera Fa menor (primera en modo menor que vemos en los tres volúmenes), compás de 6/8 y clave de Sol, para efectuar un cambio de modo definitivo a Fa mayor y compás de 2/4, cambiando más tarde a la clave de Do $1^{\text {a }}$. Segunda lección Do $4^{\text {a }}$ para empezar y a 3/4, para cambiar casi enseguida a 5/8 y Fa; empieza en Sol menor y al cambio modula a su variante modal Sol mayor. La tercera empieza en Fa menor, pero solamente 3 compases (toda ella en 3/4), que se mantiene en la dominante de la tonalidad para resolver en el cuarto compás en Fa mayor y continuar así hasta el fin. Comienza con la clave de Sol y al cambiar de modo cambia a la de $\mathrm{Fa}$, así como el compás que en la introducción es 3/4 y luego 2/4. Y la cuarta también la inicia en Fa menor y luego cambia a su homónimo mayor (como ha hecho en las anteriores de ese año), sólo que aquí el cambio se hace esperar más; igualmente cambia el compás que es de 3/4 al inicio y 2/4 al cambio, y las claves que son Fa y Do $4^{\mathrm{a}}$ respectivamente; la escritura es propia de la música vocal.

1877:

Dos lecciones. La primera Fa menor (parece que le toma gusto a esta tonalidad), clave de Sol y compás de 3/8, Después cambio definitivo de modo a su homónimo mayor, donde cambia también la clave, Do $1^{\mathrm{a}}$, volviéndolo a hacer más tarde a Sol y después de nuevo a Do $1^{\mathrm{a}}$. La que sigue toda ella en Si bemol mayor y 2/4, clave de Fa con cambios frecuentes a 1 final entre ésta y Do $4^{\mathrm{a}}$.

1878:

Dos lecciones. Una en tono de Do menor, compás de 6/8 y clave de Sol, para cambiar pronto a 3/8 y Do $1^{\mathrm{a}}$. Otra en Re menor, $3 / 8$ y Fa, para cambiar pronto a Re mayor, 3/4 y Do $4^{\mathrm{a}}$

1879:

Hay tres lecciones este año. La primera Sol mayor, 2/4 y clave de Sol, para cambiar solamente de clave a Do $1^{\mathrm{a}}$. La segunda toda en Fa mayor, y 3/4, Do $1^{\mathrm{a}}$ con cambia en la segunda sección a Sol. Y la tercera Mi bemol mayor, 2/4, clave de Fa al principio, Do $4^{\text {a }}$ segunda sección y Fa para el final 
1880:

Dos lecciones, igual como en los años siguientes hasta el 85. En este año la primera está en Re mayor, compás de 2/4 toda ella y claves de Do $1^{\mathrm{a}}$ y Fa alternando; y la segunda en Mi bemol mayor, mismo compás y alternancia de claves.

1881:

Las lecciones de este curso están en Re mayor y La bemol mayor, ${ }^{1}$ 6/8 y 3/4 respectivamente. Una alterna con las claves de Do $1^{\mathrm{a}}$ y Fa, y la otra con ésta y Do $4^{\mathrm{a}}$ 1882:

La primera de ellas está en Re menor, clave única Do $1^{\text {a }}$ y compás 3/4. La segunda Mi menor la primera sección, clave de Fa y compás de 3/8 para cambiar a Mi mayor, clave de Do $4^{\mathrm{a}}$ y Fa, y compás de 2/4

1883:

Ambas están en la tonalidad de Sol mayor, la primera en compás de 2/4 y clave de Sol la mayor parte de ella, menos un pasaje que cambia a Do $1^{\mathrm{a}}$. La segunda también tiene la primera sección en $2 / 4$ pero cambia en la segunda a 3/8, mientras que las claves son Fa y Sol en la última sección

1884:

La bemol y Mi bemol mayores son las tonalidades escogidas para las lecciones de este año. Además de esto, la primera lleva el compás de $2 / 4$ y alterna la clave de Do $1^{\mathrm{a}}$ con la de Fa; mientras que la segunda lleva el compás de 6/8, y alterna las claves de Do $1^{\mathrm{a}}$ y

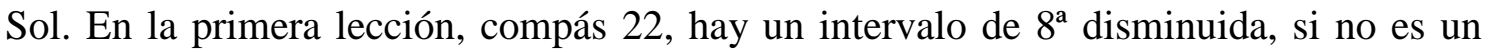
error, se trataría de una dificultad casi insuperable en un alumno para entonar, pues estando sostenida esa melodía por el acorde de $7^{\text {a }}$ de dominante de la tonalidad, y tratándose de un giro melódico propio de dominante a tónica, es bastante inviable el encontrar en el contexto tal afinación

1885:

Mi menor y 6/8 son la tonalidad y compás de la primera; las claves alternas Do $1^{\mathrm{a}}$, Fa y un párrafo en Sol. Si bemol mayor y $3 / 4$ los de la segunda, cambiando entre las de Do $1^{\mathrm{a}}$ y Fa 
Arrieta, tercer año

1886:

Una cosa curiosa se da en este año, y es que no figura escrito tal fecha en la primera lección, sino la de 1883, a la cual le siguen 3 más que sí figura 1886. Suponemos se tratará de un error, o quizás de una lección de ese año insertada fuera de su lugar. El caso es que esta primera señalada con 1883, está en la tonalidad de Mi bemol mayor y un solo compás, 2/4, mientras que las claves son Do 1, Fa y de nuevo Do $1^{\text {a }}$. La siguiente, ya con la fecha 1886, La bemol mayor es su tonalidad, el compás 6/8 cambiando en su segunda sección a su correspondiente 2/4; las claves alternan Sol con Do $1^{\mathrm{a}}$ en frecuentes cambios. La tercera está en Sol menor y en el compás de 2/4, cambiando entre las claves de Do $1^{\mathrm{a}}$ y Sol. Y la última Fa mayor es su tonalidad, es la lección más extensa de la colección, comienza en 3/8 y cambia en la segunda sección a 3/4 y hay frecuentes cambios de clave entre las de Fa, Sol y Do $4^{\mathrm{a}}$

1887:

Dos fueron las lecciones que hizo ese curso, las dos en La bemol mayor y compás de $2 / 4$ sin cambios. Sigue manteniendo los cambios de claves, en la primera entre Do $1^{\mathrm{a}}$, Fa y Sol; en la segunda entre Do $1^{\text {a }}$, Fa y Do $4^{\text {a }}$.

1888:

3 lecciones. Una en Re mayor, 3/4 y cambios entre Do 1a, Sol y Fa. Otra en Fa menor, 2/4, y por primera vez aparece la clave de Fa en $3^{\mathrm{a}}$ línea en cortos periodos, como lo hará después en las restantes. Los cambios son entre Do $4^{\mathrm{a}}, \mathrm{Fa} 4^{\mathrm{a}}$ y $3^{\mathrm{a}}$ y Do $1^{\mathrm{a}}$. Y la tercera en el relativo mayor de la anterior, La bemol mayor, compás de 3/8 y claves de Do $1^{\mathrm{a}}, \mathrm{Do} 4^{\mathrm{a}}$ y Fa $4^{\mathrm{a}}$ 1889:

Dos lecciones. La primera en Mi bemol mayor, entera en compás de 2/4, alternando frecuentemente con las claves de Do $1^{\mathrm{a}}$, Do $4^{\mathrm{a}}, \mathrm{Fa}$, Sol y Fa $3^{\mathrm{a}}$. Una segunda lección, en la tonalidad de La bemol mayor, compás de 3/8 y cambios entre Fa, Fa $3^{\mathrm{a}}$, Do $4^{\mathrm{a}}$ y Do $1^{\mathrm{a}}$.

\footnotetext{
${ }^{1}$ Además de todos estos cambios, desde las lecciones correspondientes al año 1886 también, en su mayoría, cambia el Aire o Movimiento.
} 
1890:

Una sola lección, igualmente en la tonalidad de La bemol mayor, compás de $2 / 4$ y frecuentes cambios entre Do $1^{\mathrm{a}}$, Do $4^{\mathrm{a}}$, Sol y un pequeño pasaje en Fa $3^{\mathrm{a}}$. 1891:

Dos lecciones, que son las últimas del libro porque hay un error, ya que antes de ellas está la lección del año 1892 insertada fuera de lugar. La primera de ellas está en La bemol mayor (vemos que por estas fechas era su tonalidad favorita), figura el compás de 3/8 en toda la lección, y una única clave, Do $1^{\mathrm{a}}$. La siguiente aparece con una tonalidad que no llevaba ninguna, Re bemol mayor, y cambia entre los compases de 6/8, su correspondiente 2/4 y vuelta al primero, uno en cada sección, sin embargo tiene una sola clave, la de Do $4^{\mathrm{a}}$.

1892:

Última y única lección de ese curso, que como hemos dicho arriba no figura en último lugar. Tiene la tonalidad de Mi bemol mayor y el compás de 9/8. Sí cambia sus claves entre todas las usadas en esta colección. 


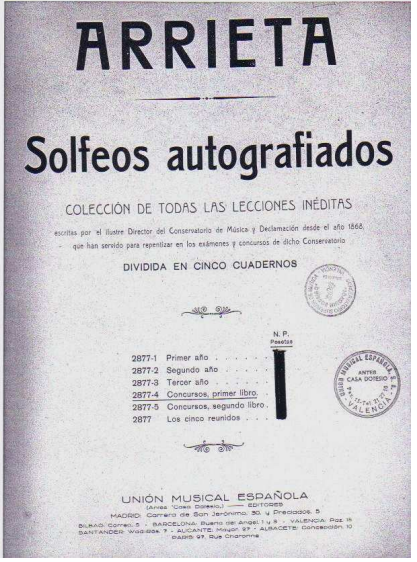

\section{CONCURSOS, PRIMER LIBRO}

CUADRO DE INFORMACIÓN GENERAL DEL PRIMER LIBRO DE CONCURSOS.

$\mathbf{N}^{0}$ de lecciones

Extensión de las lec- Entre 49 y 82 compases ciones

Claves empleadas

\section{Tesituras que abarcan}

Tonalidades que trata y estudia

Compases que emplea y estudia

Dificultades métricas que contiene

Dificultades de entonación que se encuentran $y$ orden en que se enseñan los intervalos

31 homónimos el de $3 / 8$ con $2 / 4$
Sol, $\mathrm{Fa} 4^{\mathrm{a}}$ y Do $4^{\mathrm{a}}$ y muy poco $\mathrm{Fa} 3^{\mathrm{a}}$ incluso con cambios no muy frecuentes (es curioso que bastante menos frecuentes que las lecciones no de concurso)

Igual que en los volúmenes anteriores

Re m, Re M, Fa M, Mi b M. Sol M, Sol m, Si b M, La b M, Fa m, Mi m, Mi M, Re b, Si b m, La m y La M, habiendo más cantidad de las primeras que de las últimas. Se da con mucha frecuencia que una misma lección cambie de tonos

$3 / 8,2 / 4,3 / 4,4 / 4,9 / 8$ y 6/8. Cambiando una o dos veces en la mayoría de lecciones. El cambio que más se encuentra es

Fusas, fusas con puntillo y semifusas. Notas de adorno Escritura unida y separada. Contratiempos regulares e irregulares. Fórmulas con semicorcheas y fusas. Síncopas. Grupos de valoración irregular de diversas duraciones

$5^{\mathrm{a}}$ menor, $7^{\mathrm{a}}$ disminuida, $2^{\mathrm{a}}$ aumentada, $3^{\mathrm{a}}$ aumentada, $8^{\mathrm{a}}$ disminuida, $4^{\mathrm{a}}$ disminuida, $4^{\mathrm{a}}$ aumentada, $5^{\mathrm{a}}$ aumentada.

Células melódicas cuyos extremos forman $3^{a} \mathrm{~d}$ 
Armonía utilizada

Formas que tienen las lecciones

Introducciones, Intermedios o Codas instrumentales

Teoría de la música que incluye
La misma que en el anterior volumen. Una armonía romántica y algo alterada

A-B, teniendo casi todas una división dentro de B en b-b'

24 tienen una introducción de 1 ó 2 compases y que en realidad son unos acordes, 3 que tienen una introducción más larga y con entidad, 14 tienen un pequeño intermedio, normalmente de acordes, coincidiendo con el cambio de tono o modo, de compás, de tiempo o de todo a la vez. Ninguna tiene coda

No contiene

\subsubsection{DESCRIPCIÓN DETALLADA DE ESTE LIBRO.}

Este libro contiene lecciones de solfeo manuscritas, algunas de ellas casi ininteligibles, utilizadas para exámenes de Solfeo de concurso (suponemos que para las oposiciones a premio), comprendiendo menos años que los anteriores volúmenes; éste abarca los años que van de 1870 a 1884 ambos inclusive.

1870:

2 lecciones, Re menor y 3/8, modulando a Re M y 2/4 en su segunda parte, alternando con las claves de Do $1^{\mathrm{a}}$ y Sol. La segunda Fa mayor y 3/8, estando la segunda parte igualmente en Fa mayor pero cambiando el compás a 2/4 como en la anterior. Claves Sol Do $4^{\mathrm{a}}$ y Fa $4^{\mathrm{a}}$.

En el año 1871 no se incluye ninguna lección

1872:

Una lección en Mi bemol mayor toda ella, y en compás de 2/4 también entera, lo único que cambia en la segunda sección es el tempo. Claves Do $1^{\mathrm{a}}$ y Sol. La segunda lección está en Mi menor y 3/4 cambiando luego a su relativo mayor y 2/4. Claves Do $4^{\mathrm{a}}$ y Fa $4^{\mathrm{a}}$.

1873:

Una sola lección en Sol menor y compasillo cambiando a Sol mayor y 2/4. Claves Sol, Do $1^{\mathrm{a}}$ y Fa $4^{\mathrm{a}}$. Le sigue otra en $\mathrm{Si}$ bemol mayor y compás de 3/4, cambiando en la segunda sección a 2/4 pero manteniendo la tonalidad. Claves Do 4a , Sol y Fa $4^{\mathrm{a}}$. 
Arrieta, primer libro de concursos

1874:

También una lección en La bemol mayor y 3/8 cambiando el tempo y al compás de 2/4 pero sin cambiar la tonalidad. Claves Fa $4^{\mathrm{a}}$ y Do $4^{\mathrm{a}}$

1875:

Dos lecciones. Re menor y compás de $2 / 4$, modulando a su variante modal sin cambiar el compás. Claves de Sol y Do $1^{\mathrm{a}}$. La otra Fa menor y 9/8 modulando a su homónimo mayor y 3/8. Claves de Fa $4^{\mathrm{a}}$ y Do $4^{\mathrm{a}}$

1876:

La única lección que hay está en la tonalidad de Mi menor y en el compás de 3/4, cambiando a Mi mayor y $2 / 4$. Claves de Fa $4^{\mathrm{a}}$ y Do $4^{\mathrm{a}}$

1877:

Hasta el año 1880 siempre hay dos lecciones. En este año la primera que aparece está en Sol menor, compás de 2/4 y cambia a su homónimo mayor y al compás de 3/8. Claves Do $1^{\mathrm{a}}$ y Sol. Hay una segunda que lleva la tonalidad de La bemol mayor y el compás de compasillo, cambiando al de 2/4 y a la tonalidad de Re bemol mayor en la segunda parte. Claves de Do $4^{\mathrm{a}}$ en la primera parte y $\mathrm{Fa} 4^{\mathrm{a}}$ en la segunda.

1878:

Una en Re menor 3/8 y luego Re mayor 6/8. Claves Do $1^{\mathrm{a}}$ y Sol. La otra también 3/8 y tonalidad de Fa menor, para cambiar a su homónimo mayor y al compás de 2/4. Claves de $\mathrm{Fa} 4^{\mathrm{a}}$ y $\mathrm{Do} 4^{\mathrm{a}}$.

1879:

Re menor 3/8, Re mayor 6/8. Do $1^{\mathrm{a}}$, Sol y Fa $4^{\mathrm{a}}$. Mi menor y 3/8, Mi mayor y $2 / 4$. Fa $4^{\mathrm{a}}$, Do $4^{\mathrm{a}}$ y 3 compases de $\mathrm{Fa} 3^{\mathrm{a}}$.

1880:

Sol mayor, 3/8, sin cambios de tonalidad, compás y aire. Sin embargo cambia más y con mayor frecuencia de claves entre las de $\mathrm{Do} 1^{\mathrm{a}}, \mathrm{Fa} 4^{\mathrm{a}}$, Sol y Do $4^{\mathrm{a}}$. La siguiente Mi mayor y $2 / 4$ cambiando a Mi menor y $3 / 8$. Claves Fa $4^{\mathrm{a}}$, Do $4^{\mathrm{a}}$, Fa $3^{\mathrm{a}}$ y Sol. 
1881:

De las 3 lecciones que tiene este año, la primera está en la tonalidad de Re menor cambiando a su homónimo, en cuanto a los compases cambia del 3/8 del comienzo al 3/4 de la segunda parte, habiendo en ésta un tercer cambio de tempo que también es de compás, concretamente al 6/8. Las claves Sol, Do $1^{\mathrm{a}}$ y Fa $4^{\mathrm{a}}$. La segunda está en Sol menor y 3/8, modula a Sol mayor y 3/4 y vuelve a cambiar el compás a 6/8 en un nuevo cambio de aire. Utiliza las claves de Sol, Do $1^{\mathrm{a}}$ y Fa $4^{\mathrm{a}}$. Y la tercera está en la tonalidad de Si bemol menor y en el compás de 3/8, cambiando a Si bemol mayor y $2 / 4$. Claves de Fa $4^{\mathrm{a}}$, Do $4^{\mathrm{a}}$ y Sol.

1882:

También 3 lecciones este año. Una 2/4 y La menor que cambia a La mayor conservando el mismo compás. Claves de Sol, Do $1^{\mathrm{a}}$ y Fa $4^{\mathrm{a}}$. Otra Re menor y Re mayor e igualmente compás de 2/4 toda la lección, Claves Sol, Do $1^{\mathrm{a}}, \mathrm{Fa} 4^{\mathrm{a}}$. Y la tercera Fa mayor y 2/4 toda la lección. Las claves Fa en $4^{\mathrm{a}}$ la mayor parte, Do $4^{\mathrm{a}}$ y Sol algunos pasajes. 1883:

Este curso tuvo algo de especial, quizás muchos opositores al premio de Solfeo, pues hay nada menos que 5 lecciones. La primera está en Si bemol mayor, compás de 3/4, el cual cambia a 2/4 en la segunda mitad sin cambiar de tonalidad. Las claves que emplea son Sol, Do $1^{\mathrm{a}}$ y Fa $4^{\mathrm{a}}$. La siguiente Sol mayor, compases de 3/4 y 2/4 como en la anterior al igual que las claves. La tercera está en La mayor y utiliza los mismos compases, las claves solamente las de Sol y Do $1^{\text {a }}$. La cuarta lección de este curso está en La bemol mayor y compás de 2/4 toda la lección. Utiliza las claves de Fa 4 , Sol y Do $4^{\mathrm{a}}$. Y la última lección se desarrolla en Sol mayor y compás de 2/4 durante toda su extensión. Las claves son $\mathrm{Fa} 4^{\mathrm{a}}$ y Sol.

1884:

Llegamos al último curso en el que hay lecciones que se dedicaron a concursos. En éste hay 2 lecciones. Una que está en la tonalidad de Si bemol mayor toda ella, al igual que el compás único que es 2/4. Claves de Sol, Fa $4^{\mathrm{a}}$ y Do $1^{\mathrm{a}}$. La segunda lección de este año, y última de la colección está toda ella en Fa mayor, compás de 3/4, cambiando a 9/8 y volviendo al inicial. Claves de Fa $4^{\mathrm{a}}$, Do $4^{\mathrm{a}}$ y Sol. Y a no ser que falte alguna indicación de repetición o Da Capo (y no se descubre que así pueda ser), está inconclusa, y no parece que al libro se le hayan soltado hojas. 
Arrieta, primer libro de concursos

Como se observará por la descripción de estas lecciones, no había una uniformidad de dificultades en todos los cursos y/o lecciones, sino que algunas tienen mayor dificultad que otras, además de extensión.

\subsubsection{VALORACIÓN DE LA EFECTIVIDAD DEL MÉTODO Y DE SU APORTACIÓN A LA ENSEÑANZA.}

No es un método pedagógico, ni está hecho con ese fin, simplemente reúne lecciones que a lo largo de varios años fueron pruebas de madurez para los alumnos. Pero debieron ser buenos alumnos los que pasaban esta prueba, si es que la pasaban, pues las lecciones son harto difíciles, poco musicales y enrevesadas; haciendo falta un verdadero esfuerzo para estudiarlas. No aporta nada y más bien creemos que puede hacer desistir a quien se inicie en esta disciplina sin excesiva predisposición.

Narcís Bonet, en su ponencia "La crisis del Solfeo", que defendió en el Primer Congreso Nacional de la Enseñanza del Solfeo (AAVV, 1990, p. 15), piensa que los niños que en el pasado iban a aprender solfeo, ya poseían una predisposición adquirida, bien genéticamente o por ambiente familiar. Quizás eso justifica la dificultad de estos métodos, que no tendría vigor ahora.

El total de esta obra son 5 libros, los expuestos y uno más que es el segundo libro de Concursos, más un libro de los cinco reunidos, pero estos dos últimos no los hemos encontrado en ningún archivo. 


\subsection{RESEÑA BIOGRÁFICA DEL AUTOR}

OBIOLS I TRAMULLAS, Mariano. Barcelona 1809 - 1888. Estudió en Italia con Mercadante. Compositor, violinista y profesor. En 1837 estrenó su ópera Odio ed amore en Milán. Profesor del Liceo de canto, solfeo, piano, armonía y composición. Como director del Liceo Filarmónico Dramático, fue el primer director musical del Gran Teatro del Liceu, inaugurado con su cantata Il Regio Imene (El Himeneo Real), cargo que mantuvo hasta su muerte. También lo fue del Conservatorio de Barcelona (Sobrino, en AAVV, 1999, tomo 8, p. 7).

\subsubsection{DESCRIPCIÓN DETALLADA DEL MÉTODO.}

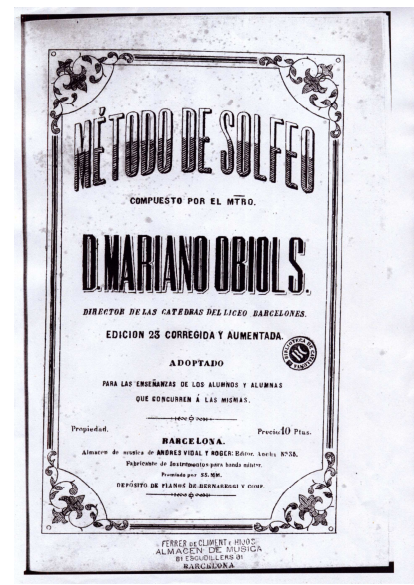

\section{Título del Método}

Método de solfeo, $23^{\mathrm{a}}$ ed. Corregida y aumentada, adoptado para las enseñanzas de los alumnos y alumnas que concurren a las mismas, Barcelona, Andrés Vidal y Roger, s. f. ${ }^{1}$ Apéndice, página 213.

\section{CUADRO DE INFORMACIÓN GENERAL DEL MÉTODO}

$N^{0}$ de lecciones

Extensión de las lecciones

Claves empleadas

Tesituras que abarcan

Tonalidades que trata y estudia
81

Entre 10 y 52 compases

Sol hasta la 64. Luego todas las demás en este orden. Do $1^{\mathrm{a}}, 2^{\mathrm{a}}, 3^{\mathrm{a}}, 4^{\mathrm{a}}, \mathrm{Fa} 3^{\mathrm{a}}, \mathrm{y} 4^{\mathrm{a}}$

$\mathrm{De} \mathrm{Do}_{3} \mathrm{a} \mathrm{Mi}_{4}$. excepcionalmente $\mathrm{a} \mathrm{Fa}_{4}$

Do M, La m, Do m, Sol M Re M La M Mi M SI M, Fa M. Si b M, Mi b M, La b M, Re b M, Sol b M, Mi m, Fa \# M, Si m, Fa \# m, Do \# m, Sol \# m, Re \# m, Re m, Sol m, Fa m, Mi b m (un orden extraño)

\footnotetext{
${ }^{1}$ Lo hemos situado en los años de la publicación de los libros de Arrieta por pura deducción, basándose tan sólo en el número de edición del método y el año de muerte de su autor. También teniendo en cuenta que hay un Complemento a este método de solfeo editado en 1866.
} 
Obiols i Tramullas

Compases que emplea y estudia

Dificultades métricas que contiene

Dificultades de entonación que se encuentran y orden en que se enseñan los intervalos

Armonía utilizada

Formas que tienen las lecciones

Introducciones, Intermedios o Codas instrumentales

Teoría de la música que incluye
$4 / 4,2 / 4,3 / 4,6 / 8,9 / 8,12 / 8,2 / 2,3 / 2$ y $6 / 4$

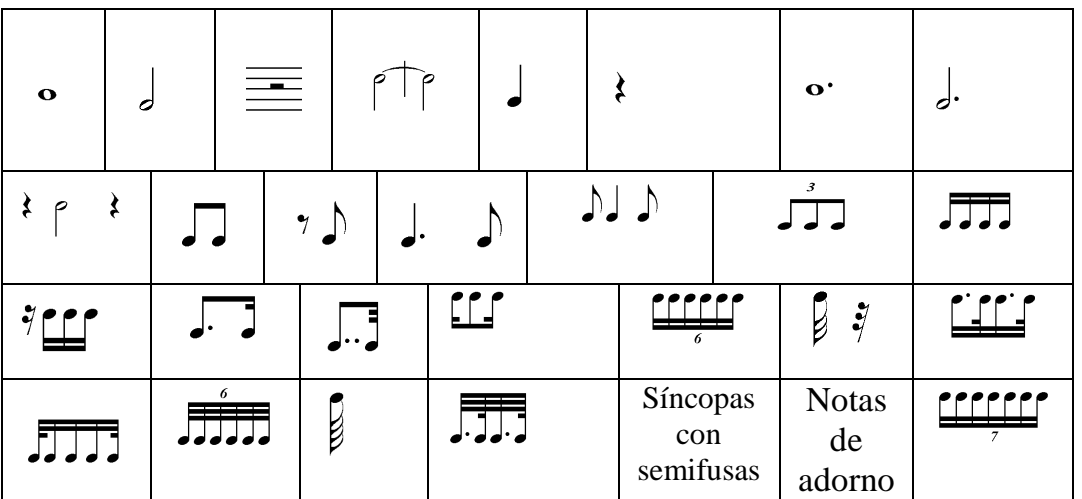

Dobles alteraciones, enarmonías.

Escala, intervalos desde $2^{\mathrm{a}}$ a $8^{\mathrm{a}}$ con y sin preparación. Semitonos diatónicos y cromáticos.

Desde la segunda lección hay modulaciones a relativos y vecinos. Acordes de $7^{\text {a }}$ diatónica y disminuida. Pronto empieza a modular a tonos lejanos. Una armonía con tintes románticos.

La mayor parte son de una sola frase. También las hay A-B; AB-C; A-A'

Excepto la $n^{\circ} 78$ que tiene un compás de introducción, ninguna más

Poca, principalmente en el comienzo para los primeros conocimientos, posteriormente la necesaria para explicar las novedades que se presentan

\section{SECUENCIA}

El método comienza con los más elementales conocimientos de los signos musicales: pentagrama, llaves o claves, notas, figuras de nota (con los nombres de semibreve, mínima, semínima, corchea, semicorchea, fusa y semifusa), pausas o silencios (el de negra con la forma antigua), compás (del cual dice que "sirve para medir el valor de las figuras" pobre concepto de la utilidad del compás), y la diversidad de ellos, pero avisando que por ahora se va a utilizar el ordinario o compasillo; expresa gráficamente la forma de marcarlo, pero curiosamente habla de dos maneras: la acostumbrada y otra, que consiste en marcar $1^{\circ}$ y $2^{\circ}$ tiempo bajo (uno a continuación del otro, como una sub- 
división del mismo tiempo), $3^{\circ}$ hacía arriba inclinado a la derecha y el $4^{\circ}$ más arriba en la misma dirección.

Líneas adicionales, líneas divisorias (llamándole "líneas finales" a la doble barra final), escala de semibreves, ligadura y escala de mínimas.

Siguen ejercicios de entonación con segundas, terceras preparadas, terceras sin preparar, cuartas preparadas, sin preparar, lo mismo con las quintas, sextas, séptimas y octavas, y uno al final como recopilación de todos.

Empiezan las lecciones. Una con blancas, otra incorpora el silencio de blanca y una tercera ya con ligaduras que sincopan el ritmo. (Aunque no dice nada de la síncopa)

Cuatro lecciones para tratar de la negra, con mezcla de blancas, redondas y pausas, no de negra.

\section{De las alteraciones:}

Con breve comentario, explica estos signos, e inicia su práctica con el sostenido al Fa.

Se suceden una serie de lecciones en las que se va incorporando una alteración a una nueva nota, y a la vez una novedad en cuanto al ritmo, con la secuencia siguiente: Silencio o pausa de Semínima; Sostenido al Do. Puntillo a la Semibreve. Puntillo a la Mínima; Sostenido al Sol. Ligadura de Semínima; Sostenido al Re. Semicopado (llama así al ritmo sincopado), explica esto diciendo que "prolonga sobre una parte del compás el sonido que empezó antes de ella”, y se trata de la síncopa larga. Corcheas; Bemol al Si. Silencio o pausa de corchea (puesto tanto detrás como delante, con lo que produce contratiempo, sin preparar ni hacer mención alguna). Bemol al Mi. Puntillo a la semínima; Bemol al La. Ligadura de corchea, Bemol al Re. Semicopado de corchea (se refiere a la síncopa breve). Bemol al Sol.

Tresillos:

Tras la explicación de este grupo irregular, dos lecciones para practicarlos.

Intérvalos [sic, como era de uso en la época]:

Definición de intervalo, a la que añade que consta de un tono o medio tono que 
es lo mismo que semitono. El descomedimiento es grande, pues según eso un intervalo es un tono o un semitono, y no existirían los disjuntos. Después habla de escala compuesta de 5 tonos y 2 semitonos, precisando el lugar de ellos, (a la que no llama de ninguna manera) y luego aclara que los intervalos de tono se dividen en dos semitonos por medio de alteraciones, con lo que forma escalas cromáticas con sostenidos, con bemoles y con ambos.

De los tonos: se dividen en mayores, relativos y menores:

Tan extravagante epígrafe es para referirse a las tonalidades, y pone un ejemplo del que se deduce, (quien ya lo sepa) que relativos son la escala menor armónica o la melódica. Lo que son tonos menores no lo explica.

\section{$\underline{\text { Tonos mayores por sostenidos y sus relativos: }}$}

Explica cómo aparecen los sostenidos, pero sin especificar que se colocan en la clave, que eso se llama armadura, ni nada parecido, y da una tabla de todas las tonalidades mayores y menores con sostenidos.

De las dobles alteraciones:

Explicación de estos signos.

Tonos mayores por bemoles y sus relativos:

Igual que hace anteriormente, pone una tabla de todas las tonalidades mayores y menores con bemoles.

Tonos mayores y menores por sostenidos:

A este incoherente enunciado, corresponde una tabla de tonalidades mayores con sostenidos y sus tonos homónimos menores.

$\underline{\text { Tonos mayores y menores por bemoles: }}$

Los mismo que arriba pero con armaduras de bemoles.

Ahora sentencia desfachatadamente que los tonos con siete alteraciones no se usan, y en su lugar se emplean los enarmónicos, sin darles esta denominación. Pero no dice que se usan poco, sencillamente que no se usan. 


\section{Tono de Do mayor}

\section{Tono de La menor relativo de Do mayor}

Tono de Do menor:

Previamente a estos 3 epígrafes, hace el comentario de que para demostrar las diferencias entre la tonalidad mayor, la relativa y la menor, continúa con una lección cuya melodía la sitúa en las 3 tonalidades. Y aparece en Do mayor, la misma a continuación en La menor, escala armónica, transportada una tercera menor descendente, y de nuevo la primera pero en Do menor. Ahora es cuando se comprende a qué llama Obiols tonos relativos y menores, esto último llama a los homónimos.

De los movimientos:

Aclara aquí el concepto de aire o movimiento, los términos de él y sus adverbios.

\section{De los tiempos o compases:}

Dice que hay de tres especies, de cuatro movimientos, de tres y de dos. El de cuatro ya se ha explicado y practicado, y reseña gráficamente el de 3 y el de 2 . Tenemos que hacer expresa mención a cómo indica que se marque el de 3 tiempos: bajo, izquierda y arriba. (Sin comentarios).

Siguen una serie de lecciones, una por cada tonalidad, en tonalidades mayores de las armaduras de sostenidos, y a la vez en cada una de ellas fija una nueva dificultad rítmica, a la vez que va variando entre los tres compases simples de denominador 4.

Semicorcheas. Tono de Sol mayor. Silencio o pausa de semicorchea. Tono de Re mayor. Puntillo y doble puntillo a la corchea. Tono de La mayor. Ligadura a la corchea. Tono de Mi mayor. Semicopado de corchea. Tono de Si mayor.

De los tresillos y los seisillos. Tono de Fa mayor:

Una lección con doble pentagrama para la voz, con el objeto de demostrar la diferencia entre tresillo y seisillo (Así lo explica él; lo cierto es que establece la diferencia entre seisillo y doble tresillo). La melodía es la misma para ambas pautas, pero en los compases que hay un doble tresillo en el pentagrama superior, está el mismo en el inferior pero como seisillo. 
Obiols i Tramullas

Compás de 6 por 8 a dos tiempos:

Hay 3 lecciones en este compás, en las tonalidades de Si bemol, Mi bemol y La bemol mayores.

Compás de 9 por 8 a tres tiempos:

Para este compás son sólo 2 lecciones, en las tonalidades de Re bemol y Sol bemol mayores.

Compás de 12 por 8 a cuatro tiempos:

También 2 lecciones, en Mi menor y Fa sostenido mayor.

Compás de 3 por 8 a tres tiempos:

Dos lecciones, la primera repite la tonalidad de Re mayor, y la segunda aporta la de Si menor.

\section{Compasillo a 2 tiempos:}

Aparece aquí una lección en Do mayor, con redondas, blancas, negras y corcheas, en 4/4. No explica si sirve de preparación al compás de $2 / 2$, o cual es la utilidad que en este momento tiene esta lección, y no es que le llame compasillo a 2 al 2/2, habida cuenta que bastante más adelante aparecen lecciones con este compás.

Fusas:

Una serie de lecciones con estas figuras. Vuelve a tonalidades ya practicadas y de cuando en cuando aparece alguna nueva. Los compases también va alternando los ya aprendidos. Se suceden las dificultades rítmicas de esta manera: Pausa de fusa. Tono de Fa sostenido menor. Puntillo a la semicorchea. Ligadura de fusa. Tono de Do sostenido menor. Síncopa de fusa (ahora sí que llama síncopa y no semicopado). Tresillos y seisillos (naturalmente de fusa). Tono de Sol sostenido menor. Semifusas. Pausa de semifusa. Tono de Re sostenido menor. Puntillo a la fusa. Ligadura a la semifusa. Tono de Re menor. Semicopado de semifusa. Tresillos y seisillos (de semifusa). Tono de Sol menor.

Notas de adorno:

Comienza por definir la Apoyatura, y lo hace de forma muy curiosa y poco inteligible: es una pequeña nota que se apoya la voz antes de pasar a la que le sigue, su valor es de la mitad de la misma. 
La nota que forma la apoyatura no se pronuncia verificándolo con la nota que le sigue. Como decimos, extraños conceptos y extrañas normas. Y pone apoyaturas de dos notas (lo que actualmente llamamos mordente recto ascendente). Sigue con ejemplos de mordentes, (sin explicarlos) e incluye las abreviaturas, no sólo de mordentes, también de grupetos (aunque las alista entre los mordentes, y también sin explicar ninguno). Después ejemplos de Grupos, (suponemos que quiere decir grupetos) y están los de 3 y 4 notas, pero solamente los rectos ascendentes y descendentes.

Dos lecciones con estos adornos, una en Do mayor y la otra en Sol mayor.

\section{Tono de Do menor:}

Con este nuevo tono, afronta dos lecciones, métricamente sencillas, y sigue incluyendo más notas de adorno.

Compás a dos tiempos:

Es ahora cuando presenta el compás binario o $2 / 2$ y no en la lección que decía “compasillo a 2", con una lección en Sol mayor.

\section{Enarmónico:}

Con la breve definición de este concepto, presenta una lección que teniendo como tonalidad principal Re bemol mayor, cambia enarmonizando dos notas y subiendo cromáticamente a Mi mayor, y con el mismo proceso a la inversa vuelve al tono principal.

\section{Valores irregulares:}

Con este epígrafe aparece una sola lección, en la nueva tonalidad de Fa menor, pero en la que sólo hay septillos (se ve que solamente este grupo es valor irregular).

\section{Lección a tres tiempos:}

Así titula a una lección en compás de 3/2.

\section{A dos tiempos. Tono de Si bemol menor:}

Y así a una en compás de 6/4.

$\underline{\text { Lecciones de las rayas y espacios adicionales por arriba y por abajo: }}$ 
Obiols i Tramullas

Dos lecciones, en Do mayor, sencillas, con el fin de leer notas muy agudas, la primera, y muy graves la segunda.

\section{Abreviaciones:}

Una lección para ver y solfear con las abreviaciones de barras y los signos \% y $\%$

\section{Compás a 2 tiempos. Tono de Mi bemol menor:}

De nuevo una lección en $2 / 2$, que no sabemos porque no está detrás de la que en su momento aparece.

\section{Llaves o Claves:}

Empieza una sección del libro para el estudio del resto de claves. Hasta ahora solamente se ha estado utilizando la de Sol. Siguiendo el orden de: Do $1^{\mathrm{a}}$, Do $2^{\mathrm{a}}$, Do $3^{\mathrm{a}}$, Do $4^{\mathrm{a}}, \mathrm{Fa} 3^{\mathrm{a}}$ y Fa $4^{\mathrm{a}}$, inserta dos lecciones para la primera clave, y una para cada una de las otras, hasta llegar a Fa en $4^{\text {a }}$; eso sí, son lecciones de poca dificultad métrica y melódica.

Una vez llegados a esta última clave, hay 10 lecciones, utilizando los compases más empleados, y las tonalidades más sencillas; también empezando por redondas y blancas, siguiendo con negras y corcheas, y elevando poco a poco, sin llegar a mucho, las dificultades.

\section{Escala a dos voces:}

Termina el libro con una lección a dos voces, en la que comienza la voz grave haciendo la escala de Do mayor en redondas, a modo de "cantus firmus", y la otra voz a manera de un contrapunto florido, luego cambian a la inversa, haciendo la voz aguda la escala de La menor melódica y la voz inferior el contrapunto, y después se incorporan figuras de semicorcheas haciendo como imitaciones o contestaciones, como si fuera un contrapunto florido a 3 voces, faltándoles la del "cantus firmus".

\subsubsection{VALORACIÓN DE LA EFECTIVIDAD DEL MÉTODO Y DE SU APORTACIÓN A LA ENSEÑANZA.}

Hay una o dos lecciones para practicar cada dificultad.

Las melodías no son difíciles, pero insustanciales. 
La teoría escueta, eso podría ser adecuado, pero además con lagunas enormes, conceptos y explicaciones que dan lugar a equívocos, como la definición de intervalo, comentado arriba, o la afirmación de que las tonalidades con siete alteraciones no se usan.

El epígrafe de notas de adorno bastante oscuro y poco comprensible. Como valores irregulares sólo reconoce el septillo, pues ningún otro aparece.

Es un método al que le faltan pocas cosas, pero pesado e inservible, y de todo punto contrario a la pedagogía. A pesar de ello, a tenor de sus 23 ediciones, debió ser profusamente utilizado

También tiene este autor un complemento a este método titulado así Complemento al método de solfeo, Barcelona, Andrés Vidal y Roger, ca. 1866 
Obiols i Tramullas 


\subsection{RESEÑA BIOGRÁFICA DE LOS AUTORES}

\section{JUSTO MORÉ CUDOLAR Y JUAN GIL}

MORÉ CUDOLAR, Justo. ¿ - 1887. Profesor supernumerario de Solfeo y Secretario del Conservatorio de Madrid. Publicó en 1870 Método completo de solfeo junto a Juan Gil. Este método fue libro de texto en este Centro. Actuaba como acompañante de cantantes aficionados en salones, tertulias filarmónicas y academias en Madrid (Sanhuesa Fonseca, María, en AAVV, 1999, tomo 7, p. 788).

GIL, Juan. No dice nacimiento ni muerte, ni lugar, sólo siglo XIX. Profesor de Solfeo en el Conservatorio de Madrid. Hacia 1870 publicó con Justo Moré el Método de solfeo, premiado en la Gran Exposición Internacional de París en 1878 (Sanhuesa, op. citada, tomo 5, p. 603).

\subsubsection{DESCRIPCIÓN DETALLADA DEL MÉTODO.}

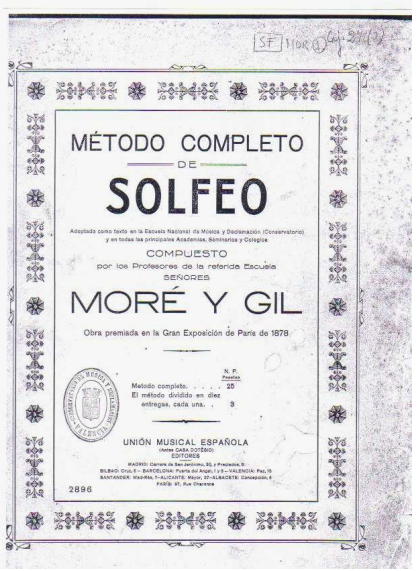

\section{Título del Método}

Método completo de solfeo adoptado como texto en la Escuela Nacional de Música y Declamación (Conservatorio) y en todas las principales Academias, Seminarios y Colegios. Obra premiada en la Gran Exposición de París de 1878, Madrid, U. M. E., s. f. ${ }^{1}$ Apéndice, página 214.

\section{PRIMERA PARTE}

\section{CUADRO DE INFORMACIÓN GENERAL DE LA PRIMERA PARTE.}

$\mathbf{N}^{\circ}$ de lecciones 55

Extensión de las Desde 6 a 48 compases

lecciones

Claves empleadas
Sol

\footnotetext{
1 Aunque PRECIADO, Dionisio. (1978). Don Hilarión Eslava y su "Método completo de solfeo" en Monografía de Hilarión Eslava. Pamplona: Diputación Foral de Navarra, p. 243 asevera que es 1870, y lo mismo el Diccionario arriba citado.
} 
Tesituras que abar- $\quad \mathrm{Si}_{2} \mathrm{a} \mathrm{Mi}_{4}$

can

Tonalidades que Do mayor

trata y estudia

Compases que em- $\quad 4 / 4,2 / 4$ y $3 / 4$

plea y estudia

Dificultades métricas que contiene

Dificultades de en-

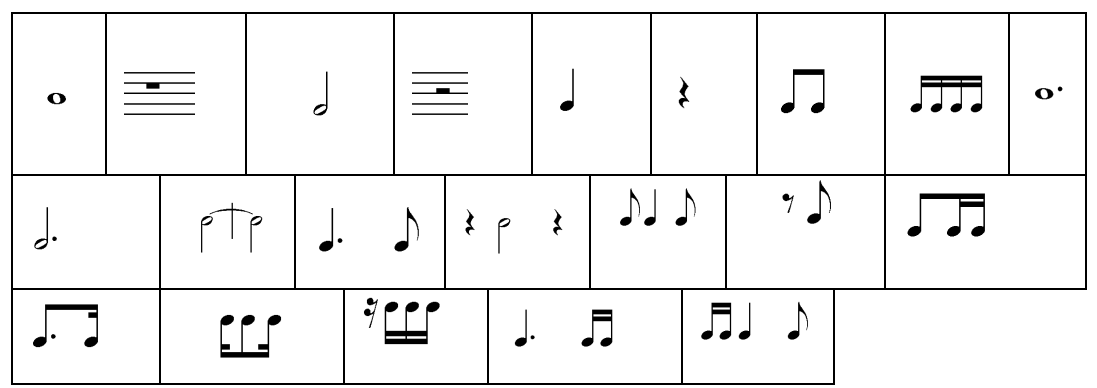

tonación que se en-

Ninguna especial. Todo se desenvuelve dentro de una melodía cuentran

$y$ orden en que se enseñan los intervalos

accesible, lógica y sin grandes saltos.

Escala, segundas, terceras, cuartas, quintas y sextas, séptimas y octavas, todas con preparación. Semitonos cromáticos y diatónicos

Armonía utilizada

En las primeras muy clásica, no obstante con alguna modulación al relativo y tono de la dominante. A partir de las lecciones de bemoles, ya utiliza algún grado alterado y rebajado, así como modulaciones a otros tonos vecinos, incluso algún acorde de $5^{\text {a }}$ aumentada con $7^{\mathrm{a}}$ y de $6^{\mathrm{a}}$ aumentada. Acordes apoyatura. Modulaciones a tonos lejanos a partir de la lección 41 . Tiene costumbre de modular al II bien como cadencia o utilizando dominante secundaria.

Formas que tienen A-B-A; A-B-C- coda: A-B-A'

las lecciones

Introducciones, Intermedios o Codas

A excepción de la $\mathrm{n}^{\mathrm{o}} 2$, que lleva un compás de entrada y otro instrumentales de intermedio con negras, ninguna más. La $\mathrm{n}^{\circ} 14$ tiene un compás de intermedio como enlace de B a A', solamente el acorde de dominante

Teoría de la música Bastante que incluye

\section{DESCRIPCIÓN DETALLADA DE ESTA PRIMERA PARTE}

\section{Nociones Preliminares:}

Definen Solfeo como lectura musical dando a los sonidos nombre y duración. Y explican los sonidos, sus nombres, la duración (sin llamarles figuras de nota), los silen- 
cios (empleando para el de negra la forma antigua), ${ }^{1}$ la relación entre las figuras y sus silencios y un esquema piramidal del desdoble de la redonda en dos blancas y éstas en cuatro negras y sucesivamente hasta alcanzar las 64 semifusas. Después explicación del pentagrama y de las líneas y espacios adicionales. ${ }^{2}$

\section{De las Claves:}

Sencilla y efectiva explicación de este signo, citando las 7 existentes.

\section{Del Compás:}

Definición de éste como división en partes iguales de cierta cantidad de tiempo, y la existencia de compases de 2, 3 y 4 partes, comenzando por el de 4 por 4 , al que como todos en ese tiempo llaman solamente Compasillo, su división en tiempos fuertes y débiles, y la función de las líneas divisorias.

\section{$\underline{\text { De los Intervalos }}$}

Definición de intérvalo [sic] como era el uso en la época, y división simplemente en disjuntos y conjuntos, a la vez que de tono o semitono.

\section{De la Escala:}

Descripción de este elemento y de su forma diatónica. A continuación ejercicios para la lectura de las notas en las líneas, en los espacios, en las líneas y espacios alternativamente y en las líneas y espacios adicionales superiores e inferiores; aunque con la advertencia de que este último debe estudiarse antes de la lección 51 (porque anteriormente no emplea estos sonidos). Termina con la indicación de la utilidad de la doble barra final, aunque le llaman dos líneas, y exponen el grafismo.

Después de todas estas cuestiones preliminares, aborda las lecciones, haciendo antes advertencia de que se proceda de tres maneras: nombrando las notas y entonando sin marcar el compás, marcando el compás y dando la duración a las figuras sin entonar y haciendo todo a la vez. ${ }^{3}$.

\footnotetext{
${ }^{1}$ Es curioso el signo que emplea para significar etcétera.

if

${ }^{2}$ También, al igual que Funoll, utiliza las palabras estrangero, espresa, egecutar, obgeto, debía ser la ortografía de la época

${ }^{3}$ A nuestro entender, falta una fase: leer sin entonar y midiendo, o sea solfeo rítmico
} 
Moré y Gil, primera parte

Todas las lecciones llevan dos pentagramas, el superior para la voz, y el inferior para el acompañamiento, solamente reflejado por un bajo cifrado.

Ocho lecciones desarrollando la escala, primero con redondas, redondas y su silencio, blancas y redondas, blancas y su silencio, blancas y redondas aumentando la tesitura, que en un principio solo era hasta el Do 4 , negras, negras y su silencio y por fin blancas, negras y su silencio. El bajo del acompañamiento comienza con redondas y se va haciendo más rítmico.

Ejercicio para la entonación de intervalos conjuntos subiendo y bajando indistintamente:

Un ejercicio para esta práctica, con una fórmula melódica que asciende con las notas de la escala, con notas al pie que advierten encarecidamente de la importancia de estos ejercicios y de la necesidad de no abordar lecciones mientras no se dominen éstos.

Dos lecciones con estos intervalos y usando redondas, blancas y negras, así como sus silencios.

Ejercicio para practicar las corcheas:

Un corto ejercicio para explicación práctica de esta figura.

Tres lecciones en las que se incluye esta duración, pero se sigue con intervalos conjuntos.

Ejercicio para practicar las semicorcheas:

Corto ejercicio para estas figuras, barradas de 2 en 2, de 4 en 4 y con corchete, al igual que hizo con las corcheas.

Dos lecciones con estas figuras e intervalos conjuntos y las figuras anteriores.

De los intervalos disjuntos o de salto:

Explican lo que son, sus nombres y el unísono, llegando hasta los compuestos (sin explicar que se llaman así). Aborda igualmente su clasificación en mayores, menores, aumentados y disminuidos, dejando sin explicar estos dos últimos ${ }^{1}$, y ponen ejemplos de segundas hasta séptimas mayores y menores incluidas alteraciones (si bien expresa que estos intervalos alterados servirán para más adelante, ya que aun no se ha

\footnotetext{
${ }^{1}$ También utiliza la denominación de cuartas menores o justas, aumentadas o mayores, quintas menores o disminuidas, mayores o justas, como otros muchos autores estudiados.
} 
abordado el estudio de las alteraciones). Nos parece un exceso tan rápida información de la calificación de los intervalos.

\section{Ejercicio de terceras:}

Un ejercicio en la que primero se refleja el intervalo con un puntito en el centro que representa el sonido intermedio, y luego el intervalo directo. Hay una advertencia previa de quedarse bastante tiempo sonando las notas del intervalo y pasar rápidamente por el sonido del medio.

Dos lecciones, una sólo con negras, silencio y blancas, la otra con semicorcheas inclusive.

\section{Ejercicios de cuartas:}

Un ejercicio y dos lecciones exactamente en la misma forma que los anteriores, pero con estos intervalos.

Exactamente igual sigue con los intervalos de quinta y sexta.

Con los de séptima y octava también procede igual, sólo que la primera lección que en la práctica de los otros intervalos era con negras, en estos es también con corcheas.

De los movimientos del compás:

Explicación de los términos del movimiento o aire y cuadro sinóptico de ellos. A partir de aquí usará éstos al principio de las lecciones.

Camuflado después de esta explicación, surge una breve del puntillo, al que dedica una sola lección, menos mal que solamente es aplicado a la blanca y a la redonda.

\section{De la síncopa:}

Una explicación de este ritmo, en la que incluye la ligadura (no como signo de prolongación independiente, sino como si estuviese ligado al efecto síncopa). Después un ejemplo de síncopas muy largas, largas, breves y muy breves; y también escritas como notas partidas

Una lección con síncopas largas y notas partidas. A continuación una breve explicación del calderón y una lección con alguna síncopa y este signo.

\section{Del 2/4:}


Moré y Gil, primera parte

Explicación de este compás relacionándolo con el de compasillo, su forma de marcar e intensidad de sus tiempos, y una lección con negras, corcheas y semicorcheas, sin emplear para nada los anteriores conocimientos, lo cual está bien al encontrarnos con un nuevo compás, pero debería ser de menor dificultad rítmica, o incluir algunas de las materias aprendidas con toda prisa.

De las alteraciones de los sonidos:

Amplia descripción de estos signos musicales y su efecto dentro del pentagrama. Un ejemplo de escala cromática. A continuación ejercicios para practicar solamente el sostenido, primeramente cromáticamente y luego diatónicamente, después un ejercicio con la escala cromática enteramente con sostenidos.

Dos lecciones con escasa dificultad rítmica, simplemente negras, corcheas y alguna blanca, y abundante empleo de sostenidos en forma cromática, diatónica y como apoyaturas inferiores.

Ejercicio para practicar el puntillo en la negra:

Un ejercicio con doble escritura; una primera utilizando la negra ligada a la corchea, y bajo la negra sustituyendo la ligadura por puntillo, incluso desplazado al compás siguiente.

Una lección, en la que vuelve al compás de compasillo, para la práctica del puntillo aplicado a la negra y del sostenido.

Ejercicio para la práctica del bemol:

Dos ejercicios empleando bemoles, primeramente en descenso cromático y seguidamente como semitono diatónico.

Dos lecciones, 2/4 y 4/4 respectivamente, utilizando ya sostenido, bemoles, puntillo y síncopas.

Ejercicio para practicar la negra sincopada:

Un ejercicio también con doble notación, sincopando corcheas, y bajo transcribiéndolas por negras.

Dos lecciones en 4/4 para la práctica de las síncopas breves y las alteraciones. 
Ejercicio para practicar el silencio de corchea en la $1^{\mathrm{a}}$ mitad de una parte:

Un ejercicio con doble escritura, la de arriba corcheas completando las dos mitades de cada tiempo, bajo sustituyendo la primera corchea de cada grupo por su silencio (contratiempo).

Ejercicio para practicar el silencio de corchea en la $2^{\mathrm{a}}$ mitad de una parte:

Igualmente un ejercicio doble, pero en esta ocasión sustituyendo la corchea segunda de cada tiempo por su silencio.

Ejercicio para practicar el silencio de corchea en la $1^{\mathrm{a}}$ y $2^{\mathrm{a}}$ parte alternativamente:

Tal como indica el enunciado se trata de un ejercicio doble en el que se sustituyen por silencios ora la corchea primera, ora la segunda.

Dos lecciones una 4/4 y la otra en 2/4 para la práctica de casi todos los elementos estudiados hasta el momento.

Del 3/4:

Descripción de este compás, de su forma de marcar y de la intensidad de sus tiempos.

Ejercicio para practicar la medida de una corchea y dos semicorcheas:

$\mathrm{Al}$ igual que otras veces, un ejercicio doble conteniendo grupos de 4 semicorcheas, dos de ellas ligadas, y sustituyendo éstas por corchea. Una lección para practicar esta fórmula rítmica y seguir con todo lo anterior.

Ejercicio para practicar el puntillo en la corchea:

Lo mismo que con los otros, primero corchea y dos semicorcheas con ligadura desde la corchea hasta la primera semicorchea, y debajo la sustitución de la ligadura por puntillo. Dos lecciones, compases de $4 / 4$ y $3 / 4$, en las que refunde todo lo estudiado hasta ahora.

Ejercicio para practicar la corchea sincopada:

Como siempre, en el ejercicio de arriba ligando las dos semicorcheas del medio, dentro del grupo de cuatro, y en el segundo formando la síncopa muy breve y también haciendo una sucesión de ellas. 
Moré y Gil, primera parte

Dos lecciones en $2 / 4$ y 4/4, incorporando de manera decisiva la dificultad rítmica estudiada.

Ejercicio para practicar el silencio de semicorchea:

Con grupos de cuatro semicorcheas, va sustituyendo en diversos subtiempos éstas por su silencio.

Dos lecciones en compases de 4/4 y 2/4 en las que sigue sumando todos los conocimientos adquiridos.

Ejercicio de medida:

Así llama a un ejercicio rítmico para practicar, y demostrar su origen, el puntillo puesto a la negra y seguido de semicorcheas, y la síncopa breve con semicorcheas.

Dos últimas lecciones, compases de $3 / 4$ y $2 / 4$, en las que se refunde toda dificultad rítmica y melódica expuesta a lo largo de esta primera parte.

Hay después 5 lecciones, de la número 51 a la 55, que según explican están dedicadas a la lectura de las notas muy agudas y muy graves, para lo que indica que se realicen a compás y sin entonar (solfeo rítmico), por lo que también carecen de armonía cifrada. La dificultad rítmica está también rebajada.

\section{SEGUNDA PARTE}

CUADRO DE INFORMACIÓN GENERAL DE LA SEGUNDA PARTE.

$\mathbf{N}^{\circ}$ de lecciones 43

Extensión de las lec- Desde 6 a 50 compases

ciones

Claves empleadas $\quad$ Sol y Fa en $4^{\mathrm{a}}$

Tesituras que abarcan $\mathrm{Si}_{2}$ a $\mathrm{Fa}_{4}$, con una excepción, la lección $1^{\mathrm{a}}$ que llega hasta el $\mathrm{La}_{2}$. En la clave de Fa la misma extensión pero octava grave

Tonalidades que trata y estudia

La m, Sol M, Mi m, Fa M, Re m, Re M, Si m, Do M, Si b M, Sol m, La M, Fa\# m 
Compases que emplea y estudia

\section{Dificultades métricas que contiene}

Dificultades de entonación que se encuentran $y$ orden en que se enseñan los intervalos

\section{Armonía utilizada}

Formas que tienen las lecciones

Introducciones, Intermedios o Codas instrumentales

Teoría de la música que incluye
Los anteriores más $2 / 2,3 / 8,6 / 8,9 / 8$ y 12/8,

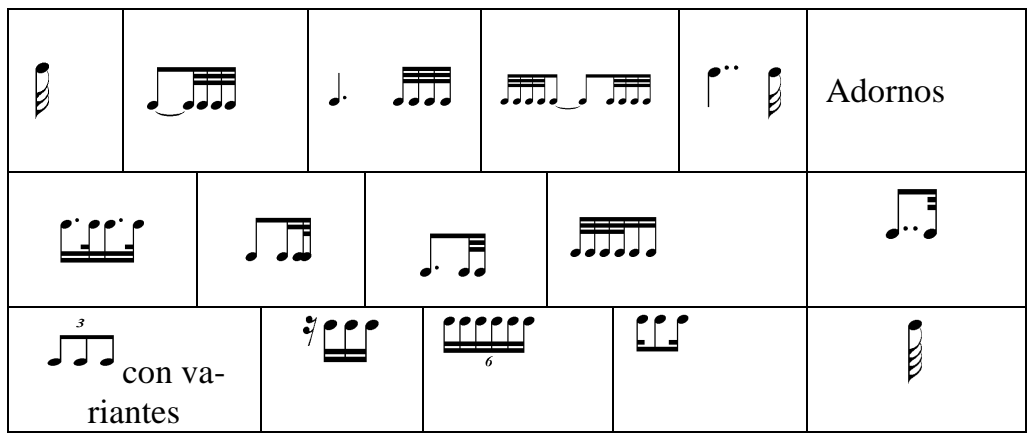

Igual que en la primera parte, la melodía transcurre sencillamente. En las tonalidades menores, al menos la melodía suele desenvolverse dentro de la escala natural, aunque la armonía sea de dominante. Hay un intervalo de $3^{\mathrm{a}}$ disminuida en la lección 15 , sin haber hablado de ellos.

Escalas y todos los intervalos en cada una de las tonalidades.

Algún acorde de $7^{\text {a }}$ disminuida, pero en estado fundamental. Empieza, a partir de la lección 18 a modular a tonos lejanos. En esta parte ya abundan más los acordes de $6^{\mathrm{a}} \mathrm{A}$

A-B; A-B-coda; A-B-A ${ }^{\mathrm{m}}$; A-B-A'

No tienen ninguna

Bastante

\subsubsection{DESCRIPCIÓN DETALLADA DE ESTA SEGUNDA PARTE.}

De los Tonos y Modos:

Explicación de lo que supone la tonalidad, partiendo de la transposición de la escala mayor de Do, armadura, alteraciones propias y accidentales, concepto de tónica y división de la escala diatónica en dos modos, marcando la diferencia en el III y VI grados. A continuación un ejemplo de la escala de La menor variante armónica, aunque sin llamarle de este modo, sino "escala de La natural modo menor", haciendo una nota al pie en la que dicen que: la distancia de tono y medio entre el $6^{\circ}$ y $7^{\circ}$ grado forma uno de los intervalos aumentados, de los que trataremos en la $3^{a}$ parte de este método con el detenimiento debido..., También dicen: se usa frecuentemente la escala menor haciendo 
Moré y Gil, segunda parte

la $6^{a}$ mayor al subir, y la $6^{a}$ y $7^{a}$ menores al bajar..., y ponen un ejemplo de escala melódica menor (omiten que también el $7^{\circ}$ grado es mayor en esta escala cuando asciende). Seguidamente explican el concepto de tonos relativos y la distancia que los separa; y exponen una tabla con todas las tonalidades mayores y menores desde 0 a 7 alteraciones, primero con sostenidos y luego con bemoles, utilizando siempre para las menores la escala armónica. Por último, dentro de esta explicación de las tonalidades, especifica el orden en que se producen las alteraciones en las armaduras.

\section{Del compás binario:}

Lo explican diciendo que el compás de compasillo se divide algunas veces en dos partes, indica la señal de la $\mathrm{C}$ partida y no le da el nombre de dos por dos, pero erróneamente, y en nota al pie, ponen que antiguamente se denominaba compás mayor (cuando esta denominación pertenecía al cuatro por dos). También aclaran que las duraciones de las figuras son las mismas que en el compasillo pero con la mitad de duración.

Una sola lección en este compás, y en la tonalidad de La menor, escala natural, bastante sencilla de medida. Creemos muy insuficiente una única lección para practicar un compás que en ciertos tipos de estilos es muy frecuente, aunque los autores aclaran al pie que no hay más lecciones en este compás por ser igual al compasillo, y que el profesor puede, cuando lo crea conveniente, cualquiera de las lecciones en 4/4 realizarlas en este compás. No es lo mismo ni la acentuación, ni la concepción rítmica, no es lo mismo pensar una lección a 4 que a 2 .

Todas las lecciones las siguen acompañando con el bajo cifrado, como en la primera parte. Usan un cifrado bastante anticuado, como por ejemplo, en los acordes de séptima de dominante usar alteraciones en vez de + indicando la sensible, y otras veces sí indican la sensible pero con aspa en vez de cruz.

\section{Ejercicio de medida:}

Un ejercicio para sustituir, dentro de la fórmula corchea dos semicorcheas, alguna semicorchea por su silencio, creando fórmulas rítmicas similares a corchea con puntillo - semicorchea, pero cortando el sonido.

Una lección, en Do mayor, 2/4 para practicar esto, y continuar con las síncopas breves con semicorcheas que había sido la última dificultad de la parte anterior; también contiene mucho cromatismo. 
Ejercicio para practicar las fusas:

Un corto ejercicio para conocimientos de estas figuras, agrupadas de ocho en ocho, de cuatro en cuatro, dos a dos y con corchetes.

Ejercicio para practicar las fusas combinadas con otras figuras:

Ejercicio combinado con negras, silencio de negra, corcheas, semicorcheas y estas figuras.

A continuación hablan de la doble barra de separación, sin darle este nombre, solamente diciendo que cuando se quieren separar varias partes, cambiar de compás o de tono se usa esta señal, y está dibujada la doble barra, pero con el segundo trazo más grueso, con lo que en nada se diferencia de la doble barra final. Después se refieren a las dobles barras de repetición, sin tampoco darles nombre, solamente explican cuál es su efecto, y también explican las casillas de primera y segunda vez..

Una lección en La menor, 3/4 utilizando estos signos de repetición y las figuras de nota fusas.

Ejercicio de medida:

Un ejercicio con grupos de corchea y cuatro fusas, lo mismo pero ligada la corchea a una fusa, negra con puntillo y cuatro fusas, cuatro fusas con corchea y al revés ligando las dos corcheas contiguas en forma sincopada. Previamente hay una advertencia para el alumno de que si encuentra mucha dificultad podrá subdividir el compás. Después hay otro ejercicio con el silencio de fusa

Una lección en La menor, 3/4 con todas estas dificultades métricas

De la clave de Fa en $4^{\mathrm{a}}$ :

Una breve explicación del significado y utilidad de este signo, con nota al pie para el profesor invitándole a que si le parece conveniente indique al alumno que esta clave es usada para voces intermedias y graves, en contra de la de Sol que lo es para medias - agudas. Ejercicios para la lectura de las notas en esta clave en las líneas, en los espacios, en las líneas y espacios y en las líneas y espacios adicionales.

\section{Tono de Sol natural mayor:}

Una aclaración de porqué esta escala debe llevar como propia la nota Fa sostenida. Y un ejercicio de entonación en Do mayor, en doble pentagrama, bastante largo y 
Moré y Gil, segunda parte

variado en interválica, poniendo en el de bajo los mismos intervalos transportados a Sol mayor, y advirtiendo que lo mismo deberá hacerse con los demás ejercicios que con el mismo objeto aparezcan en las siguientes tonalidades. ${ }^{1}$

Una lección en esta tonalidad, clave de Fa y 4/4, pero no fácil para ser la primera en esta clave.

\section{Ejercicio para practicar el doble puntillo en la negra:}

Previamente aclaran el efecto del doble puntillo con ejemplos sobre la blanca, la negra, y la corchea. Luego un ejercicio preparando el doble puntillo con la ligadura de la negra a la corchea con puntillo. Y un segundo ejercicio alternando un solo puntillo con el doble.

\section{De las notas de adorno:}

Un largo comentario de lo que son estos adornos, pero dividiéndolos únicamente en apoyaturas y mordentes. Dan varias reglas para la duración de la apoyatura, pero al final aclaran que algunos autores escriben con cualquier figura de nota dejando al intérprete la duración de ella. Siguen unos ejemplos con apoyaturas y transcritos a notas reales, y unos ejercicios para la práctica de este adorno.

Una lección en clave de $\mathrm{Fa}$, como todas las que siguen hasta la número 16, en que ya empieza a alternar con las dos claves; sigue con la tonalidad de Sol mayor y el compás de 4/4, en la que introduce apoyaturas y también dobles puntillos, sin olvidar las anteriores dificultades.

Ejercidos de medida:

Son dos, para aprender el puntillo colocado a la semicorchea y ésta seguida de fusa, en grupos de 3 notas (corchea, semicorchea con puntillo y fusa) o en grupo de cuatro.

Una lección con estas métricas, misma tonalidad y 2/4. Pero es la primera que empieza anacrúsicamente, previa advertencia de lo que es este ataque.

Tono de Mi natural menor:

La escala armónica y melódica y un ejercicio de medida con los puntillos en la semicorchea, y otras veces sustituyendo estos puntillos por silencios de fusa.

\footnotetext{
${ }^{1}$ Lo curioso es que este ejercicio aparece en todas las tonalidades mayores, pero nunca en las del modo menor
} 
Una lección en esta tonalidad, 3/4, escala natural, e incorporación de las dificultades tratadas en el ejercicio anterior, más las predecesoras.

Ejercicios de medida:

Fórmulas combinadas de corchea, semicorchea y dos fusas, corchea con puntillo y dos fusas, cuatro fusas y dos semicorcheas, sustitución de alguna fusa por su silencio.

Una lección en la misma tonalidad anterior, 2/4 con estas dificultades.

\section{Ejercicios de medida:}

Preparación para el doble puntillo sobre la corchea, y también silencio de corchea con puntillo.

Una lección más en Mi menor, 3/4 y los ritmos estudiados.

\section{Del compás de 3 por 8 :}

Explicación de este compás comparado al compasillo y un ejemplo doble, en 3/4 y las mismas notas en $3 / 8$.

Tono de Fa natural mayor:

La escala y ejercicios de entonación en Do mayor y transportados a Fa mayor.

Dos lecciones con esta tonalidad y compás, además de apoyaturas, y en la segunda abordan también la indicación Da Capo.

Ejercicio de medida:

Corchea con puntillo y dos fusas, y sustitución del puntillo por el silencio de fusa.

Una lección con esta dificultad, misma tonalidad pero compás de 4/4.

\section{Tono de Re natural menor:}

Escalas armónica y melódica

Tres lecciones, claves de Fa y Sol la tercera, las tres en compás de 3/8, incluyendo las dificultades métricas estudiadas y las apoyaturas. 
Moré y Gil, segunda parte

De los mordentes:

Dividen estos adornos en mordentes de una, dos, tres y cuatro notas, anotando que su duración debe ser rápida. Hay un ejemplo con mordentes de una nota, y su trascripción a notas reales. Toman los mordentes su valor de la nota anterior, y en algunos casos, como excepción (según indican) de la nota que adornan. ${ }^{1}$ Sigue un ejercicio rítmico con mordentes de una nota.

\section{Tono de Re natural mayor:}

Escala y ejercicio de entonación doble, como se ha explicado en la tonalidad de Sol mayor.

Dos lecciones, clave de Sol ambas y compases de 3/4 y 3/8, incluyendo mordentes y también apoyaturas.

\section{De la subdivisión de las partes del compás:}

Una larga explicación de esta forma de medir el ritmo, dividiendo los compases en "de combinación doble o de mitades" y "de combinación triple o de tercios" (curiosa denominación que dan a los compases simples o compuestos). Agrupan los estudiados hasta ahora entre los de "combinación doble", y dan a conocer como de "combinación triple" los que van a venir a continuación: 6,9 y 12 por 8 . Aconsejan subdividir las obras que lleven un movimiento lento, incluso hasta Andantino, y exhortan a no subdividir siempre los compases compuestos, sino a acostumbrarse también a marcarlos sin subdividir, para ello anuncian que pondrán ejercicios con el fin de estudiar cada compás primero subdividido y luego sin subdividir, así como facilitar métricamente las primeras lecciones con este mismo fin.

\section{Del seis por ocho:}

Breve explicación de este compás con detalle de los grupos de figuras que entran en él.

Dos ejercicios de medida, solamente con corcheas, negras y negras con puntillo.

Una lección en la tonalidad que se está aprendiendo y naturalmente con este compás, clave de Fa.

\footnotetext{
${ }^{1}$ Nada dicen de la posibilidad de que el mordente tome su valor de la nota anterior o posterior según la época de la obra, y dan como criterio principal el ataque a contratiempo, y como excepción la interpreta-
} 
El mordente de dos notas:

Como única explicación dan que se ejecutan según los mismos preceptos que el de una nota. Ponen un ejemplo con interpretación a tiempo y a contratiempo. ${ }^{1}$ Después un ejercicio para practicar estos mordentes, y otro ejercicio de medida para la práctica de la semicorchea y su silencio en el compás de seis por ocho.

\section{Tono de Si natural menor:}

Escalas armónica y melódica. 3 lecciones para esta tonalidad. La primera con la clave de Sol y las otras dos con la de Fa. Las tres con el compás de 6/8 pero aumentando la dificultad métrica en cada una. En la primera ya hay semicorcheas; en la segunda combinaciones de semicorcheas con corcheas, semicorcheas con puntillo y fusas; y en la tercera corchea con puntillo - semicorchea; corchea, corchea con puntillo - tres semicorcheas, sustitución del puntillo por el silencio de semicorchea. Todo ello tras previos ejercicios de medida de cada una de estas dificultades. Además en todas ellas aparecen las notas de adorno hasta ahora estudiadas.

\section{De los Tresillos:}

Una escueta explicación de esta medida irregular, aislada, sin incluirla en su grupo de valoraciones irregulares, definiéndola como tres notas de igual duración que deben ejecutarse en el mismo tiempo que se invierte para dos de la misma figura. También de la posibilidad de sustituir notas por silencios o de ligar dos de ellas doblando el valor de una de las tres. Unos ejemplos con corcheas y con negras y un ejercicio de medida para practicar.

Una lección con la inclusión de algunos tresillos de corchea, compás de 2/4 y clave de Sol. Sin embargo, aunque está dentro del epígrafe de la tonalidad de Si menor, está en la de Do mayor.

\section{Del mordente de tres notas:}

Están representados, como los de dos notas, en forma de fusas, pero también solamente usan esta forma para los ejemplos y ejercicios, y en las lecciones los repre-

ción a tiempo. Debe ser el momento histórico que no contemplaba otra interpretación que la propia de la época en que se desarrolla el libro.

${ }^{1}$ La representación de estos mordentes es en forma de dos pequeñas fusas, en lugar de en forma de semicorchea como es de uso; lo curioso es que esto ocurre en el ejemplo y ejercicio práctico, pero posteriormente en las lecciones están representados en forma de semicorcheas. También ESPINO, Felipe en sus Doce estudios melódicos y progresivos de perfeccionamiento de solfeo (obra analizada aquí, más adelante), usa esta forma, pero no solamente para los de dos notas, sino también para los de una. 
Moré y Gil, segunda parte

sentan mayormente en la forma actual de semicorcheas, y decimos mayormente, porque a veces usan indistintamente la representación de estos adornos con dos o con tres barras. Al igual que, después, Amorós, usan estos mordentes como rectos ascendentes y descendentes, o como nuestro actual grupeto.

También explican las abreviaturas de estos mordentes ${ }^{1} \sim$, pero que tanto sirven para los rectos que para el mordente circular o grupeto, sin que haya ninguna pauta que diferencia un uso de otro. Sí que especifican que no debe haber entre los extremos de las notas del mordente mayor distancia de tercera menor.

Hay varios ejemplos y un ejercicio para practicarlos, con notas y con abreviaturas.

\section{Tono de Si bemol mayor:}

Escala y ejercicio de entonación, pero no como los anteriores, sino directamente en esta tonalidad, o sea sin compararlos intervalos con los que se producen en Do mayor.

Cuatro lecciones en esta tonalidad. Claves Fa, Fa, Sol, Fa. Compases 2/4, 4/4, 4/4, 6/8. La primera tresillos y mordentes no abreviados; la segunda los mordentes de 3 notas abreviados y además de 1 y 2 notas; tras un ejercicio de medida con tresillos de semicorchea, viene la tercera lección con estas medidas y también adornos variados; y la última de este grupo también emplea los tresillos de semicorchea pero en compás compuesto, también algo los adornos.

\section{$\underline{\text { De los Seisillos: }}$}

Los explican como seis notas que ocupan el lugar de cuatro de su misma especie, sin relacionarlos con el doble tresillo, que anteriormente habían utilizado, ni con corcheas desdobladas.

Una lección, todavía en Si bemol mayor, con la clave de Sol y el compás de 3/4, incluyendo tresillos de corchea, seisillos de semicorchea y alguna nota de adorno.

\section{Del compás de nueve por ocho:}

Descripción de él comparándolo al de compasillo, como en todos los otros. 


\section{Tono de Sol natural menor:}

Escalas armónica y melódica. Ejercicio de medida para este nuevo compás, empleando ya medidas complejas; esto es, trasladando al 9/8 lo que ya se había practicado en el $6 / 8$.

Tres lecciones, las tres en la clave de Fa, y naturalmente con este compás. Cada una de ellas con más complejidad rítmica que la anterior, previo ejercicios de medida. La primera vuelve a utilizar las casillas de $1^{\mathrm{a}}$ y $2^{\mathrm{a}}$ vez, que no se veían desde la lección

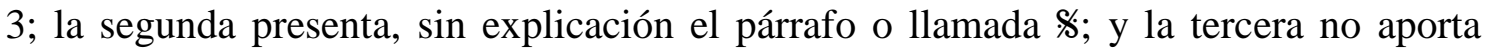
novedad, salvo la complejidad rítmica.

\section{Tono de La natural mayor:}

La escala y el ejercicio interválico de entonación. Después un ejercicio de medida con síncopas muy breves, tresillos de semicorcheas y silencios de fusas.

Dos lecciones en esta tonalidad y compás utilizado anteriormente. Claves de Sol y Fa. La segunda presenta la aparición de la semifusa después de un corto ejercicio de medida, lleva el compás de 2/4 y también notas de adorno.

\section{Del mordente de cuatro notas:}

También los explican como los de tres notas, sin diferenciación de cuando son una floritura recta, o cuando son un grupeto de 4 notas. La abreviatura de estos mordentes, solamente la usan como grupetos posteriores, nunca anteriores, y en ese caso se comportan dentro de las normas de estos adornos, mientras que los mordentes no abreviados los emplean indistintamente anteriores o posteriores.

Hay 3 ejercicios con los adornos y su trascripción a notas reales. Y dos lecciones, todavía en la tonalidad de La mayor, claves de Fa y Sol respectivamente, y empleo abundante de estos adornos y de los anteriores.

Del compás de doce por ocho:

Escueta descripción, como siempre comparándolo al compasillo.

\footnotetext{
${ }^{1}$ Sin embargo nada dicen de las abreviaturas de los mordentes de dos notas.
} 
Moré y Gil, segunda parte

Tono de Fa sostenido menor:

Escalas armónica y melódica

Tres lecciones con este compás y tonalidad. Claves de Fa, Sol, Fa. Yendo, en esta ocasión, (no como al conocer el 9/8), de una forma progresiva; la primera lección con negras, blancas y corcheas; la segunda ya con semicorcheas, y la tercera incluso fusas y fórmulas combinadas. En todas se practican también notas de adorno.

Lecciones de lectura en líneas adicionales:

De la misma manera que en la parte primera, figuran aquí 5 lecciones, sin bajo cifrado, para la práctica de notas muy graves y muy agudas en la clave de $\mathrm{Fa}$ en $4^{\mathrm{a}}$. Usando los compases simples de 2, 3 y 4 por 4 .

\section{TERCERA PARTE}

\section{CUADRO DE INFORMACIÓN GENERAL DE LA TERCERA PARTE.}

$\mathbf{N}^{\circ}$ de lecciones

Extensión de las lec- De 16 a 53 compases

ciones

Claves empleadas

Tesituras que abarcan

Tonalidades que trata y estudia

Compases que emplea y estudia

\section{Dificultades métricas que contiene}

Dificultades de entonación que se encuentran $y$ orden en que se enseñan los intervalos

52 octava baja

Ninguno nuevo

Enarmonías.
Do en $1^{\mathrm{a}}, 2^{\mathrm{a}}, 3^{\mathrm{a}}$ y $4^{\mathrm{a}}$ líneas, Fa en $3^{\mathrm{a}}$ y al final mezcla de ellas. De vez en cuando algún recuerdo de las anteriores

Normalmente de $\mathrm{Do}_{3} \mathrm{a} \mathrm{Mi}_{4}$, y en excepcionalmente desde $\mathrm{La}_{2} \mathrm{a} \mathrm{Fa}_{4}$. Las claves de Do en $3^{\mathrm{a}}$ y $4^{\mathrm{a}}$ no están escritas en su altura real. La de $\mathrm{Fa}$ en $3^{\mathrm{a}}$, al igual que la de $\mathrm{Fa}$ en $4^{\mathrm{a}}$ está

Mi b M, Do m, Mi M, Do \# m, La b M, Fa m, Si M, Sol \# m, Re b M, Si b m, Fa \# M, Re \# m, Sol b M, Mi b m, de vez en cuando alguna de las anteriores

\begin{tabular}{|c|c|c|c|}
\hline$\stackrel{3}{\equiv=}$ & $\begin{array}{l}\text { Comparación de fórmu- } \\
\text { las rítmicas similares }\end{array}$ & .0.0.0 & $\begin{array}{l}\text { Repaso de } \\
\text { fórmulas ante- } \\
\text { riores }\end{array}$ \\
\hline
\end{tabular}

Intervalos aumentado y disminuidos. Dobles alteraciones.

Ejercicios de entonación en todas las tonalidades. 
Armonía utilizada

Formas que tienen las

lecciones

Introducciones, Intermedios o Codas instrumentales

Teoría de la música que incluye
Acordes apoyatura. Acordes alterados cromáticamente Familia de la dominante con la $5^{a}$ en menos y en más. Cada vez modulan a tonalidades más lejanas

A-A'-coda; A-B-C; A-A'; A-B-A'

No tienen ninguna

Bastante

\subsubsection{DESCRIPCIÓN DETALLADA DE ESTA TERCERA PARTE.}

De los intervalos aumentados y disminuidos:

Unos cortos ejemplos de los intervalos que ellos consideran que pueden ser aumentados y disminuidos, clasificando así solamente, como aumentados $2^{\mathrm{a}}, 5^{\mathrm{a}}$ y $6^{\mathrm{a}}$, y como disminuidos $3^{\mathrm{a}}, 4^{\mathrm{a}}$ y $7^{\mathrm{a}}$. Son los más habituales y lógicos, pero también pueden ser todos aumentados y disminuidos aunque se conviertan en enarmónicos de otros; la $4^{\mathrm{a}}$ no la juzgan aumentada sino mayor.

Siguen una lista de adverbios modificadores de los términos del movimiento y las palabras que describen el género o carácter. Después un ejercicio de entonación de intervalos aumentados y disminuidos.

\section{De la clave de Do en $1^{\mathrm{a}}$ :}

Exposición del significado y utilidad de esta clave. Ejemplos de lectura en las líneas, en los espacios y en las líneas y espacios; por último, como siempre, en las líneas y espacios adicionales.

Una lección en esta clave, en la tonalidad de La menor, compás de 4/4, en la que, para ser la primera que se lee en una nueva clave hay demasiadas dificultades rítmicas: notas de adorno, tresillos de corchea y semicorchea, semicorcheas con puntillo y fusas y síncopas muy breves. Se añade a esto los intervalos aumentados y disminuidos; es decir que es un compendio de lo estudiado hasta ahora más las novedades. Demasiadas dificultades, a nuestro juicio, cuando iniciamos una nueva clave. 
Moré y Gil, tercera parte

\section{Tono de Mi bemol mayor:}

Escala y ejercicio de entonación directamente en la tonalidad.

Tres lecciones, compases de 6/8,2/4 y 9/8. Cada una de ellas con mayor dificultad métrica y melódica, y previo a cada cual un ejercicio de entonación, el primero dentro de la escala diatónica de la tonalidad, y los otros con intervalos aumentados y disminuidos.

Aún dentro de este epígrafe, hay un ejercicio de entonación en la tonalidad de La menor, y una lección en dicha tonalidad, compás de 3/4, tresillos de fusa e intervalos alterados. Es una cosa que hacen con frecuencia a lo largo de esta parte, dentro del epígrafe de una tonalidad, intercala alguna lección en otra tonalidad ya vista con anterioridad, suponemos que como recuerdo o refresco.

\section{$\underline{\text { Tono de Do natural menor: }}$}

Escalas armónica y melódica y ejercicio de entonación.

Tres lecciones en esta tonalidad, en los compases de 12/8, 3/8 y 2/2.

Tras un ejercicio de entonación en Do mayor, una lección en esta tonalidad, compás de $6 / 8$ y clave de Sol.

\section{Tono de Mi natural mayor:}

Escala y ejercicio de entonación, con intervalos naturales; un ejercicio de medida para comparar dos notas en cada tiempo, una larga y la otra corta; alternando la fórmula corchea con puntillo - semicorchea con la de tresillo de negra - corchea, otro ejercicio de entonación con intervalos alterados y 1 lección en esta tonalidad, clave de Fa en $4^{\mathrm{a}}$ y compás de $4 / 4$.

\section{De las dobles alteraciones:}

Exposición clara y concisa de estas alteraciones expresando que para volver un doble sostenido o bemol a sostenido o bemol sencillo, se usa el becuadro y el sostenido o bemol al lado; aclarando también que algunos compositores vuelven de la doble alteración a la sencilla prescindiendo del becuadro conjunto. Si bien no especifican de qué manera se anularía por completo la doble alteración y se pasaría a una nota natural. 
De la clave de Do en $2^{\mathrm{a}}$ línea:

Ejemplos de lectura, como en todas las demás claves, en las líneas, espacios, líneas y espacios y en las adicionales.

Ejercicios de entonación y 3 lecciones con esta clave y la tonalidad que anteriormente a la clave habíamos conocido. Los compases, como anterior y posteriormente, los cambian en cada lección, siempre dentro de los ya conocidos.

\section{Tono de Do sostenido menor:}

Escalas, ejercicios de entonación y 3 lecciones.

Tono de La bemol mayor:

Escala y ejercicio de entonación diatónico.

Una lección con la clave de Sol y compás de 4/4, utilizando medidas ya muy complicadas, fórmulas combinadas con semicorcheas y fusas, y seisillos de fusas.

Otro ejercicio de entonación y 1 lección con la clave de Fa en $4^{\text {a }}$, compás de 9/8, en esta ocasión rebajan un poco las dificultades.

Un ejercicio de medida con fusas y sus silencios y 1 lección con la clave de Do en $1^{\text {a }}$, compás de $2 / 4$, fusas y sus silencios y semifusas. Una lección francamente complicada.

\section{De la clave de Do en $3^{\text {a: }}$ :}

Ejemplos exactamente igual a las otras ocasiones.

Una lección con esta clave, pero tonalidad de Do mayor y compás 4/4

Un ejercicio de medida que no aporta ninguna novedad

Una lección en el compás de 3/4 tonalidad de Sol mayor

Un ejercicio de entonación, quizás como repaso de intervalos alterados

Una lección en 12/8 y Si menor.

\section{Tono de Fa natural menor:}

Tras las escalas, un ejercicio de medida y otro de entonación, también como repaso de dificultades bastante anteriores.

Tres lecciones en esta tonalidad y con la clave que se había anteriormente iniciado. Como siempre varían los compases. 
Moré y Gil, tercera parte

$\underline{\text { Tono de Si natural mayor: }}$

Escala y ejercicio de medida sencillo.

Tres lecciones, pero la tercera lleva clave de Sol. Se intercalan ejercicios de medida y entonación como repaso.

\section{$\underline{\text { Tono de Sol sostenido menor: }}$}

Las escañas correspondientes y un ejercicio de entonación

Dos lecciones, pero las claves son Do en $1^{\mathrm{a}}$ y Fa en $4^{\mathrm{a}}$. Se intercalan un ejercicio de medida y otro de entonación.

De la Clave de Do en $4^{\mathrm{a}}$ :

Lecturas de notas en la forma acostumbrada con las anteriores claves.

Dos lecciones, la primera en la tonalidad de Re mayor y la segunda en la de Sol sostenido menor. Las dificultades métricas son excesivas para leer por primera vez esta clave.

Tono de Re bemol mayor:

Escala y una lección con la clave estudiada.

De las combinaciones de medida irregulares:

Referencia a los grupos de valoración irregular de 5, 7, 9 y 10 notas, con un ejercicio de medida como ejemplo y práctica.

Tras un ejercicio de entonación, 2 lecciones en esta tonalidad y la clave antes estudiada. En esta ocasión las dificultades métricas alcanzan las fusas, los grupos de valoración irregular arriba explicados y la tonalidad en que nos encontramos.

\section{Tono de Si bemol menor:}

Escalas, ejercicio de entonación y de medida, este último con septillos y nonillos.

Tres lecciones en esta tonalidad y parecidas dificultades, aunque quizás ahora un poco rebajadas. 
De los Géneros:

Declaran en este punto que los géneros son tres: diatónico, cromático y enarmónico, ${ }^{1}$ y lo hacen para explicar qué es la enarmonía (todavía escrito por ellos con $\mathrm{h}$ intercalada).

Hay un ejercicio de entonación con diferentes enarmonías

\section{Tono de Fa sostenido mayor:}

Escala y una lección en la que aprovechan para modular de forma transitoria a Sol bemol mayor.

De la Clave de Fa en $3^{\mathrm{a}}$ línea:

Ejercicios de lectura en la forma acostumbrada

Dos lecciones en la tonalidad abordada anteriormente, compases de 4/4 y 9/8. En la primera, todavía es abordable la dificultad, pero la segunda con fusas, y medidas irregulares, notas de adorno y fórmulas combinadas, contando con que es la segunda lección con esta clave es una enormidad.

\section{$\underline{\text { Tono de Re sostenido menor: }}$}

Sus escalas correspondientes y 2 lecciones. La primera un poco menos dificultosa, y con la segunda, es la primera vez que cambian de tono, a Mi bemol mayor, para volver a la principal de Re sostenido menor.

\section{De la relación que tienen las claves entre si:}

Aclaración del papel que tienen las claves para las voces e instrumentos según sus registros. Distribución de ellas en voces graves, medias y agudas. Ejemplo de la relación de todas ellas teniendo como referencia el Do 3 .

Tono de Sol bemol mayor:

Escala y dos lecciones. Pero a partir de éstas, hay cambios de claves. En la primera empieza con la de Sol y cambia a Do $4^{\mathrm{a}}$, Fa $4^{\mathrm{a}}$ y $\mathrm{Do} 1^{\mathrm{a}}$; menos mal que la dificultad métrica en sencilla. En la segunda ya arremeten con complicaciones rítmicas y cambian 5 veces de clave.

\footnotetext{
${ }^{1}$ No comprendemos porqué le llaman a esto género y no distinta clasificación de los semitonos.
} 
Moré y Gil, tercera parte

\section{Tono de Mi bemol menor:}

Las dos escalas, y dos lecciones. En éstas hay cambios de clave, de tonalidad y de movimiento.

Siguen a estas últimas lecciones en tesitura normal, unos comentarios sobre el poco uso de la tonalidad de Do sostenido mayor y Do bemol mayor, con sus relativos, por ser éstas enarmónicas de Re bemol y Si mayor respectivamente, y según dicen los autores, se prefieren usar antes bien éstas que aquéllas; por este motivo aducen que no figuran en este método lecciones en las tonalidades de Do sostenido y Do bemol mayores ni sus respectivas tonalidades relativas.

Añaden a estas explicaciones las de que no se escriben nunca en la armadura más de 7 alteraciones, pero que sí existen tonalidades con mayor cantidad de sostenidos y bemoles, o sea con dobles alteraciones, pero que éstas se pueden ver en el análisis armónico como modulaciones transitorias.

$\underline{\text { Lecciones de lectura en líneas adicionales. }}$

De la misma manera que aparecen en las dos primeras partes, hay al final de ésta 5 lecciones dedicadas a la lectura medida de notas excesivamente graves y agudas, pero en la primera parte estaban escritas en clave de Sol, en la segunda en la de Fa en $4^{\mathrm{a}}$, y en esta tercera, mezclando ambas.

\section{CUARTA PARTE}

\section{CUADRO DE INFORMACIÓN GENERAL DE LA CUARTA PARTE.}

$\mathbf{N}^{\circ}$ de lecciones

Extensión de las lec- De 12 a 54 compases

ciones

Claves empleadas Sol, Do $1^{\mathrm{a}}$, Do $4^{\mathrm{a}}$ y Fa $4^{\mathrm{a}}$

Tesituras que abarcan Igual que en las partes anteriores

Tonalidades que trata Do m, Do M, Re M, Mi b M, Sol m, Mi m, Sol M, Fa M y y estudia La m

Compases que emplea Los anteriores, más los irregulares 7/4, 5/4, 5/8 y 10/8 y estudia 
Dificultades métricas que contiene

Dificultades de entonación que se encuentran $y$ orden en que se enseñan los intervalos

Armonía utilizada

Formas que tienen las lecciones

Introducciones, Intermedios o Codas instrumentales

\section{Teoría de la música Mucha} que incluye
No hay muchas más, si acaso menos debido al estudio de nuevos compases.

Como novedad sólo está la Fermata

Melodía muy alterada, cromática y rebuscada en algunas lecciones

Como en la anterior parte.

A-B-A'; A-B-C-coda; A-B-C

No tienen

\subsubsection{DESCRIPCIÓN DETALLADA DE ESTA CUARTA PARTE.}

Del Transporte: ${ }^{1}$

Se afronta aquí una algo extensa explicación de lo que consiste el hecho de transportar una obra o fragmento y la mecánica de su proceder. Consejos claros y prácticos de qué tener en cuenta para los cambios de armadura y de clave (en ese orden lo explica, aunque parecería más lógico hablar primero del cambio de clave y luego de la armadura), acompañados de algunos, aunque pocos, ejemplos.

Después normas y ejemplos para acometer el cambio, si se produce, en las alteraciones accidentales.

Y son curiosas, poco leídas en distintos tratados teóricos, y a la vez sencillas. No hablan de armaduras elevadas y rebajadas, de diferencias positivas o negativas, sino que de forma sencilla, y repetimos, nada frecuente ponen al alumno en condiciones de proceder a estos cambios de forma muy práctica, eso sí, nada científica.

Por creerlo de interés, trasladamos literalmente las tales normas:

... cuando los signos de alteración accidentales tienen por objeto hacer subir un semitono la nota en el tono que se vá á trasportar, hay que considerarlos en el nuevo á que se trasporta del modo siguiente: Si la nota que tiene un sostenido accidental, resulta

\footnotetext{
${ }^{1}$ Los autores utilizan la palabra "trasporte" y el verbo "trasportar", suponemos que sería lo usado en la época.
} 
Moré y Gil, cuarta parte

ser natural en el tono á que se trasporta, conserva el sostenido el mismo efecto que en el tono primitivo.

Si en el nuevo tono tubiese ya sostenido propio en la clave, hay que considerar el sostenido como doble.

Si resultase en el nuevo tono con bemol accidental en la clave, se considerará el sostenido como becuadro.

Si en el tono primitivo tubiese la nota doble sostenido, y resultase esta misma nota ser natural en el nuevo tono, se considerará el doble sostenido como sencillo.

$Y$ si la nota tubiese becuadro en el tono primitivo, con el objeto de destruir el efecto de un bemol, y esta misma nota resulta ser natural en el tono á que se trasporta, se considerará el becuadro como sostenido. [sic]

Luego vienen las mismas normas, pero al contrario para los bemoles.

Observaciones sobre los modos mayores y menores:

Razonan aquí sobre la manera, vista la armadura, de saber si una pieza está en la tonalidad mayor que corresponde a tal armadura, o en su relativa menor. Ya advierten que es una cuestión no siempre matemática y que se necesitan más grandes conocimientos que los solfísticos para determinar sin lugar a error tal cuestión. Pero dando ejemplos gráficos de melodías que pueden parecer que están en una tonalidad y están en otra según su armonía, o melodías que engañan porque no llevan el séptimo grado alterado y son del modo menor, dan dos normas para que los alumnos puedan, con cierta garantía de éxito discernir en cuál de las dos tonalidades está una determinada obra.

La segunda norma es la más clara: mirar la última nota de la melodía, o aún mejor la nota del bajo del acompañamiento, que debe ser la tónica.

Pero es la primera norma, para cuando no termina el bajo con la tónica, o no hay acompañamiento, la que es poco ortodoxa, mas también efectiva:

observar si en los primeros compases de la melodía ó parte cantante que se trate de analizar, la $5^{a}$ del tono mayor que corresponde, está alterada de un semitono mas alto, en cuyo caso estará escrita en modo menor.[sic]. ... si la $5^{a}$ del tono mayor que corresponde no está alterada, será modo mayor. Claro la $5^{\text {a }}$ del modo mayor es la $7^{\mathrm{a}}$ del menor, pero no entendemos porqué dicen que en los primeros compases, ya que podría encontrarse la sensible a lo largo de la melodía.

De las palabras y signos de espresión. [sic]:

Está dedicado este epígrafe a los matices agógicos, dinámicos y a algunos signos de articulación (aunque no los dividen de esta manera, sino que están todos englobados como signos de expresión). 
Primero hay unos cuantos agógicos. Como término poco usual destacamos el que figura en el grupo de los que retrasan gradualmente la velocidad: Lusingando (lisonjeándose, recreándose). Después los matices dinámicos; observamos que incluye entre los que disminuyen progresivamente la intensidad Stinguendo, Calando y Smorzando, cuando en realidad éstos son matices agógico - dinámicos a un tiempo; pero entre éstos incluyen un término también poco usado como Mancando, y otro, cuyo significado es: casi imperceptible, Stinto. Continúan con los reguladores, el Ligado y el Picado, igualmente dentro de un grupo común. Engloban dentro de los reguladores a los acentos, que los consideran como reguladores pequeñitos; el Picado lo dividen en 3 , pero dándole a todo el nombre de picado (las tres divisiones son: el picado, el picado ligado y el staccato), aunque las normas en cuanto a la duración o sonidos reales que resultan de su aplicación son las exactas.

Incluyen en todo este cajón de sastre la Fermata. Y por último hacen una advertencia, que no están de acuerdo en que se exija a los solfistas la aplicación de estos matices, como hacen otros maestros en sus libros de solfeo, y que ellos las ponen en algunos de las lecciones venideras para que los discípulos se acostumbres a verlas, pero aconsejan a los profesores no exijan a sus alumnos que los pongan en práctica. Craso error, creemos.

Lección $n^{\circ} 1$; clave Do $1^{\text {a }}$, tonalidad de Do menor, compás de 4/4, en la sección B cambia al de 12/8 y al relativo, Mi bemol mayor, en la sección A', vuelve a 4/4 y a Do, pero comienza en mayor, cambiando luego a menor y terminando en él. Incluye notas de adorno, matices, y al final una pequeña fermata.

Lección $n^{\circ}$ 2: clave de Do $4^{\mathrm{a}}$, Do mayor, 3/4. No tiene cambios más que de movimiento, métricamente es sencilla

\section{Del Seis por cuatro:}

Explicación del compás, siempre comparándolo con el compasillo, como en todos los anteriores, un ejemplo y 1 lección, con la clave de Sol y la tonalidad de Re mayor sin grandes dificultades. En ésta, y a partir de aquí, ya no aparecen más matices ni signos de articulación. 
Moré y Gil, cuarta parte

\section{Del Siete por cuatro:}

Explicación del compás, diciendo que tiene 7 partes y que las figuras duran lo mismo que en el compasillo, apuntan que algunos autores le llaman de amalgama, y así lo representan ellos en la lección que está destinada a estudiar este compás, con línea intermitente separando un parte de cuatro tiempos y la otra de tres. La lección está en clave de $\mathrm{Fa}$ en $4^{\mathrm{a}}$ y $\mathrm{Mi}$ bemol mayor. No presenta muchas dificultades, la melodía es sencilla y el ritmo también, solamente una parte central que modula transitoriamente a La bemol menor y a Sol bemol mayor, presenta mayor dificultad por la cantidad de notas alteradas.

\section{Del Cinco por cuatro:}

Lo exponen como un compás de amalgama dividido en una parte de 3 y otra de 2, y así lo recomiendan que se realice, pero también manifiestan que otros autores prefieren marcarlo con dos tiempos en la primera parte y los otros tres distribuidos en los restantes tiempos, según la forma de marcar un cuaternario. La lección está en clave de Sol, y tonalidad de Sol menor, no tiene grandes dificultades métricas, aunque melódicamente más que las anteriores, la melodía es más rebuscada, quizás debido a las modulaciones frecuentes a tonos lejanos.

\section{Del Cinco por ocho:}

Afirman que este compás, hasta ese momento, solamente se ha usado para los zortzicos, y aconsejan que se marque a 1, o sea con un solo movimiento por compás. Consejo que creemos errado pues el característico ritmo de zortzico se pierde con esta forma de marcar el compás, y aumenta la dificultad de medirlo.

Luego hay dos ejercicios en este compás, uno con corcheas, y otro con el ritmo del zortzico. Les sigue una lección con la clave de Sol y en Do mayor, sin ninguna dificultad melódica.

Continúa el libro con una corta lección con el compás de 10/8, clave de $\mathrm{Fa} 4^{\mathrm{a}}$ y tonalidad de Do menor. Este compás, ya anteriormente explicando el de 5/8, manifiestan que algunos autores escriben el zortzico en el compás de 10/8 con el fin de agrupar 5 corcheas en cada parte, es decir que se debe marcar a dos, o sea un 5/8 doble. Claro estos compases irregulares se pueden marcar a 2, a 3 o a 4 según estén distribuidas sus figuras, pero la lección que dedican a este compás está claramente dividida en 2 tiempos, y cada tiempo en 3 y 2 corcheas, así lo demuestra el bajo cifrado que es constante- 
mente negra con puntillo - negra por cada tiempo. Quizás se trata de una alusión a la tesis de Eslava respecto a la forma de marcar este ritmo característico, y con el fin de no desautorizarle.

Vienen a continuación, y hasta el final, una serie de lecciones a dos voces, asimismo acompañadas con bajo cifrado

Las primeras, números 8 y 9, muy cortas, llevan una voz en redondas y otra en una figuración similar a la especie del contrapunto florido. La 8 lleva clave de Sol para la $1^{\mathrm{a}}$ voz, que es la que se mueve, y de $\mathrm{Fa}$ en $4^{\mathrm{a}}$ para la segunda que es como un "cantus firmus", compás de compasillo. La número 9, compás binario, tonalidad de Mi menor, clave de Do en $1^{\mathrm{a}}$ para la $1^{\mathrm{a}}$ voz, con redondas, y Sol para la $2^{\mathrm{a}}$ con melodía más movida.

La lección 10, un poco más larga, Do mayor, 4/4, clave de Sol para la $1^{\text {a }}$ voz y Do en $4^{\mathrm{a}}$ para la $2^{\mathrm{a}}$, lleva una figuración de negras y blancas en ambas voces, comienza con imitaciones o contestaciones entre las voces, un periodo luego homofónico, aunque no paralelo, otro de nuevo en forma de contestaciones, y de nuevo ritmo homófono con el que termina.

De la 11 a la última, la 19, ya se forman verdaderas dos voces, unas veces homofónicamente, otras contrapuntísticamente, unas en forma de imitaciones, otras como contestaciones. Todas ellas, llevan una clave para la $1^{\mathrm{a}}$ voz y otra distinta para la $2^{\mathrm{a}}$, de entre las claves que figuran como empleadas en esta parte. Los compases son los simples o, de entre los compuestos, el de 6/8. La rítmica empleada es sencilla, y la melodía, en algunas de ellas es muy rebuscada, en otras más fluida y sencilla. En todas vuelven a aparecer los términos y signos de los matices.

\section{De las Abreviaturas:}

Describen el signo $\%$ y $\%$ y las barras partiendo una blanca o negra en corcheas,

semicorcheas, fusas o tresillos. El ejemplo muestra las figuras abreviadas y en un pentagrama inferior transcritas a notas reales. También muestran la representación de varios compases de silencio. 
Moré y Gil, cuarta parte

De las figuras y compases antiguos:

Comentan aquí que existieron compases con figuras de más larga duración que la redonda. Representan gráficamente la cuadrada, longa y máxima con sus silencios. Afirman que no es necesario en la actualidad (en su actualidad), usar otros compases que los estudiados en este libro, y por ello no incluyen lecciones en compases más antiguos, pero con el fin de que los alumnos vean prácticamente todas las posibilidades y no les extrañe una partitura que pudieran ver escrita en otro tipo de compás, a continuación establecen unas tablas en las que relacionan compases conocidos, o estudiados, con desconocidos, poniendo la misma melodía, y transcribiendo las figuras en cada uno de ellos.

Son 6 tablas:

1.- compases a 4 partes de combinación doble: 4/4, 4/2, 4/8 y 4/1

2.- compases a 3 partes de combinación doble: $3 / 4,3 / 2$, $3 / 8$ y 3/1

3.- compases a 2 partes de combinación doble: 2/4, 2/2, 2/8 y 2/1

4.- compases a 4 partes de combinación triple: 12/8, 12/16, 12/4 y 12/2

5.- compases a 3 partes de combinación triple: 9/8, 9/16, 9/4 y 9/2

6.- compases a 2 partes de combinación triple: $6 / 8,6 / 16,6 / 4$ y $6 / 2$

Del Trino:

Descripción del trino, corta y clara, con y sin terminación, incluye la explicación del semitrino como mordente de 2 notas.

De la inversión de los intervalos:

Termina así el libro, explicando qué es la inversión de intervalos, en qué se convierte cada uno y una tabla de ejemplos de inversiones.

\subsubsection{VALORACIÓN DE LA EFECTIVIDAD DEL MÉTODO Y DE SU APORTACIÓN A LA ENSEÑANZA.}

En la primera parte, creemos que va demasiado deprisa en la incorporación de dificultades métricas, aunque es diferente a otros en cuanto que incorpora hasta la semicorchea sin abordar los intervalos por salto, y luego de aplicarlos sigue con las mismas figuras de nota. 
Como otros autores, introducen la síncopa antes del contratiempo, incluso enlace de síncopas y negra con puntillo seguida de corchea antes del contratiempo, y cuando lo hacen, es directamente con el contratiempo breve, cuando lo normal hubiese sido empezar con el largo, o sea el de tiempo débil y no el de parte débil; además aporta pocas lecciones o ejercicios para practicar tan gran dificultad rítmica.

Valoramos positivamente el trato que da a los ejercicios de entonación y las recomendaciones que hace de dominar la interválica.

Respecto a la segunda parte, la dificultad métrica es quizás fuerte demasiado pronto. Ya en la primera lección de clave de Fa hay demasiadas complicaciones rítmicas, síncopas, fórmulas rítmicas, semicorcheas, y alteraciones accidentales, además de la propia de la tonalidad. Pero en general, es difícil rítmicamente.

Igual que en la primera, a veces una sola lección para cada novedad es muy poco.

Lo que nunca tiene exceso de dificultad es la melodía, postura ésta elogiable, ya que al alumno se le quita al menos una dificultad, y no pequeña, y se le hace menos árida la materia.

En la tercera, el orden de exposición de las claves no nos parece el correcto. Siguen un proceso ordinal y no de mayor a menor uso.

Otra cosa, que por otra parte era habitual en los métodos de la época, y de años más tarde, es que cada vez que aparece una nueva clave, las lecciones debieran ser de menor dificultad rítmica y melódica, e ir progresando éstas; pero no siempre lo hacen así, por el contrario sólo lo hacen poquísimas veces.

La cuarta parte es de perfeccionamiento, ampliación, y casi virtuosismo solfístico.

Las lecciones, algunas son difíciles, va acompañada de teoría, y con ella se completa un ciclo que, aunque nunca es total, faculta al estudiante para afrontar las distintas disciplinas que tendría a lo largo de sus estudios.

Muy plausible la manera de explicar la transposición.

En cambio no estamos muy de acuerdo con la afirmación que hacen de no exigir al alumno la aplicación de los matices que figuren en la partitura. Nuestra experiencia 
Moré y Gil, cuarta parte

nos dice que si desde el principio no se les acostumbra a hacerlos, después es una lucha constante para que maticen.

En general es un buen método, como todos, tiene sus defectos y carencias, pero es bastante completo. 
Creemos oportuno en este punto insertar los Ejercicios de entonación y medida de José Pinilla, que aunque no se trata de ningún método, sí de un libro complementario, aplicable a cualquier método, que pudo ser de uso frecuente en esa época, debido al puesto social de su autor y a juzgar por los contenidos métricos y de lectura tan similares al resto de métodos de estos años.

Este libro está dividido en dos partes: ejercicios de entonación, y ejercicios de medida. Tan sólo podemos reflejar el análisis de la segunda parte, porque habiendo solicitado a la Biblioteca Nacional el envío de fotocopias de este ejemplar, recibimos solamente las de la segunda parte, y reclamada la primera por teléfono, correo electrónico, a través de préstamo interbibliotecario de la U. V., varias veces, al cabo de 4 meses, volvieron a enviar la segunda parte, sin explicación alguna, lo que nos hace deducir que solamente existe ya esta segunda que pasamos a analizar.

\subsection{RESEÑA BIOGRÁFICA DEL AUTOR}

PINILLA Y PASCUAL, José, Logroño 1837, Madrid 1902, discípulo de Eslava y catedrático numerario de solfeo en el Conservatorio de Madrid, fue desde 1864 profesor de armonía, y en 1865 fundó una escuela de armonía, contrapunto, fuga y composición por correspondencia. Caballero de la orden de Carlos III en 1882 (Sancusa Fonseca, en AAVV, 1999, tomo 8, p. 812). ${ }^{1}$

\subsubsection{DESCRIPCIÓN DETALLADA DEL MÉTODO.}

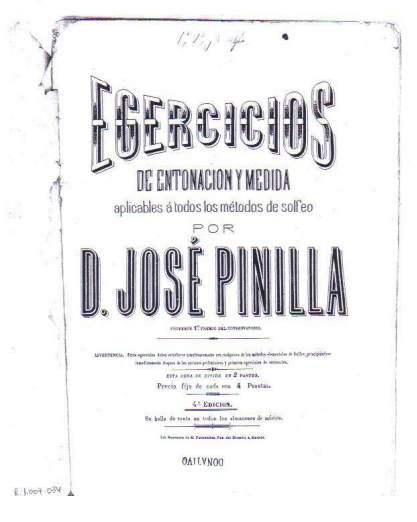

\section{Título del Método}

Egercicios de entonación y medida aplicables a todos los métodos de solfeo [sic], Madrid, Bonifacio Eslava, s. f. Apéndice, página 215.

\footnotetext{
${ }^{1}$ Colocamos este libro aquí, aproximadamente en 1970, por deducción, teniendo en cuenta el año que empezó a ser profesor y las características de contenidos tan parecidas a Moré.
} 
José Pinilla

\section{PRIMER CURSO ${ }^{1}$}

Claves empleadas Sol

Compases que em- $\quad 2 / 2$ y $4 / 4$

plea y estudia

Dificultades métricas que contiene

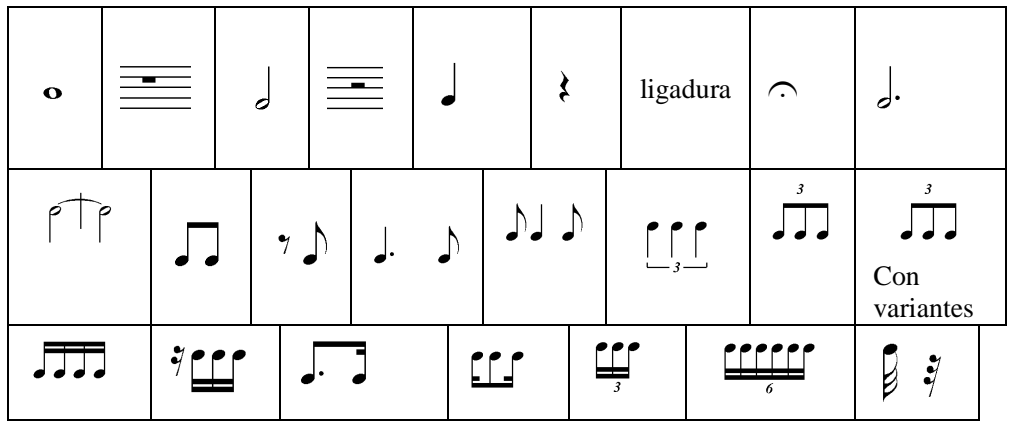

\section{SEGUNDO CURSO}

Claves empleadas $\quad \mathrm{Sol}$ y $\mathrm{Fa}^{\mathrm{a}}$

Compases que em- $\quad 2 / 4,3 / 4,3 / 8,6 / 8,9 / 8$ y $12 / 8$

plea y estudia

Dificultades métricas que contiene

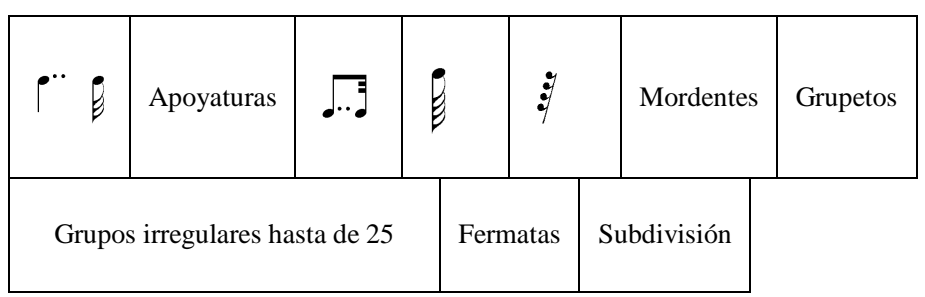

\section{TERCER CURSO}

\section{Claves empleadas Do $1^{\mathrm{a}}$, Do $2^{\mathrm{a}}$, Do $3^{\mathrm{a}}$, Do $4^{\mathrm{a}}$ y Fa $3^{\mathrm{a}}$}

Compases que em- $\quad 4 / 2,4 / 8,3 / 2,2 / 1,2 / 8,12 / 4,12 / 16,9 / 4,9 / 16,6 / 2,6 / 4,6 / 16$ plea y estudia $\quad 5 / 4,7 / 4$ y $10 / 8$

Dificultades métri- Las mismas que en los anteriores pero con estos compases cas que contiene

\footnotetext{
1 Según el mismo autor indica. Al final de la primera página, en una nota al pie, recomienda la extensión que debe abarcar cada curso.
} 
A pesar de ser una parte dedicada a ejercicios de ritmo, y por tanto no estar incluida la entonación, a partir de los ejercicios en clave de Fa en $4^{\text {a }}$ línea, también se presentan armaduras, y hay ejercicios en las siguientes tonalidades: Do M, la mayor parte, pero después La m, Sol M, Mi m, Fa M, Re m, Re M, Si m, Sol m, La M, Mi b M, Do m, Mi M, Do \# m, La b M, Fa m, Si M, Sol \# m, Re b M, Si b m, y Fa \# M.

Lo cual no es comprensible pues si es solamente lectura rítmica y no se debe entonar, porque muchas veces la tesitura es excesiva, ¿para qué las distintas tonalidades?

Fácilmente se observa que siguen un orden de dificultades métricas al uso de la época. Lo mismo ocurre con el orden de aparición de las claves.

En general, sirven de bastante poco estos ejercicios 
José Pinilla 
MÉTODOS POSTERIORES A 1875, 1876, 1891 Y 1898, CUANDO YA HAY PROGRAMAS OFICIALES DE SOLFEO DE LA ESCUELA NACIONAL DE MÚSICA. 
En este último y más extenso bloque, pormenorizamos 37 métodos o partes correspondientes a 21 autores.

ABRANTES BELLO, Joaquín: Método de solfeo abreviado $3^{\text {a }}$ edición, 1879

PENELLA, Manuel: Principios de solfeo, $3^{\mathrm{a}}$ edición, 1879

BENITO, Cosme José de: Método completo de Solfeo en Compendio, Edición 5a 1880

CABALLERO, Manuel: Gramática Filarmónica o Tratado de los Elementos Generales de Música, 1880

EGEA, Pedro María de: Método de Solfeo o nuevo Arte de la Música, 1881

SABATÉS ESTAPER, Mateo: Solfeo: curso completo, 1881

AGERO, Feliciano: Método completo de solfeo: dividido en tres partes, 1882

LLUPART ALVERNI, Carlos: Escuela de Conjunto. Treinta solfeos a tres voces iguales, 1884

CODINACH, Carmelo, R. P.: Nociones de solfeo, 1885

ROGER JUNOI, A: Método práctico de lectura musical y de solfeo, (Escuela alemana), 1891

AMORÓS, Amancio: Elementos de solfeo, 1893

VELÁZQUEZ, Juan: Nuevo curso teórico-práctico de solfeo; 1897

BRULL AYERRA, A y otros: Método completo de solfeo, 1898

PARDÁS Y FONT, Primitivo: Método completo de solfeo, o sea, Curso Teórico Práctico puesto al alcance de todas las inteligencias, 1864 ? 1900

AAVV: Escuela del Solfeo. Libro I, 1900

VANCELL ROCA, Juan: El Libro de música y canto, 1902

BRULL, M.: Lecciones autografiadas, 1910

AMORÓS, Amancio: Lecciones manuscritas graduadas: segundo curso de solfeo, 1910

Lecciones manuscritas graduadas, tercer curso de solfeo, 1912

ESPINO, Felipe: Doce estudios melódicos y progresivos de perfeccionamiento de solfeo, 1912 ?

ABREU, Avelino, SERRA, Pedro y ZAMACOIS, Joaquín: Solfeo, segundo curso, 2ª edición, 1914

Solfeo, quinto curso, 1914

LLORCA, Miguel: Método de solfeo, 1916

BUXÓ, Tomás: Método de solfeo Libro I, 1920

Método de solfeo $2^{\circ}$ Libro, 1920 


\subsection{RESEÑA BIOGRÁFICA DEL AUTOR}

ABRANTES BELLO, Joaquín. España siglo XIX, teórico. Dice el texto consultado que el método está publicado en 1879 (A. V. T., en AAVV, 1999, tomo 1, p. 11).

\subsubsection{DESCRIPCIÓN DETALLADA DEL MÉTODO.}

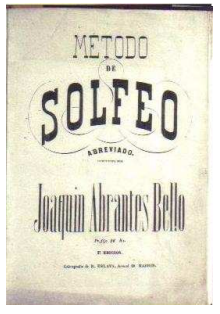

\section{Título del Método}

Método de solfeo abreviado, Madrid, Calcografía de B. Eslava, s.f. ${ }^{1}$ Apéndice, página 216.

El método consta de tres partes, que analizaremos separadamente.

\section{PRIMERA PARTE}

\section{CUADRO DE INFORMACIÓN GENERAL DE LA PRIMERA PARTE.}

$\mathbf{N}^{0}$ de lecciones

51

Extensión de las lec- Entre 7 y 48 compases

ciones

Claves empleadas

Sol, y Sol y Fa en $4^{\mathrm{a}}$ simultáneas

Tesituras que abarcan $\mathrm{Do}_{3} \mathrm{a} \mathrm{Fa}_{4}$

Tonalidades que trata Do M

y estudia

Compases que emplea $\quad 4 / 4$

y estudia

Dificultades métricas que contiene

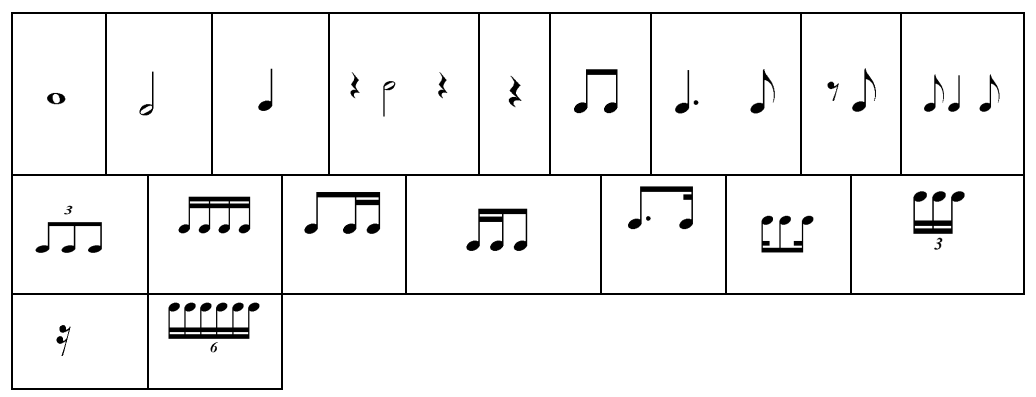

Dificultades de entona- Ninguna. Todas van por grados conjuntos. ción que se encuentran y orden en que se ense- No hay práctica de intervalos ñan los intervalos

\footnotetext{
${ }^{1}$ Aunque como decimos arriba, el texto referenciado indica el año 1879.
} 


\title{
Armonía utilizada Ninguna \\ Formas que tienen las No tienen lecciones
}

\section{Introducciones, Inter- No hay medios o Codas ins- trumentales}

\section{Teoría de la música Muy poca, solamente al comienzo que incluye}

\section{DESCRIPCIÓN DETALLADA DE ESTA PRIMERA PARTE}

El autor hace un prólogo justificando lo abreviado del método, y es porque está hecho, no para formar a futuros músicos profesionales, sino para aquel que quiera instruirse rápidamente en los rudimentos del solfeo y poderlos aplicar a la práctica de un instrumento como simple aficionado. Él mismo recomienda, para quien quiera cultivarse en el arte de la música con fines profesionales los métodos de Hilarión Eslava o José Pinilla. Explica literalmente:

\begin{abstract}
La larga esperiencia que he tenido en enseñar y dirijir orquestas en varios pueblos, me ha echo comprender esta necesidad. La mayor parte de los aficionados que se reunen para formar una orquesta, ya por sus ocupaciones, ya por su poca paciencia, se conforman con saber tocar regularmente el instrumento que eligen. Pues bien; si para ello el profesor les obliga á estudiar por uno de los metodos completos, el aficionado concluirá por dejarlo y no comprender nada, y por el contrario, si le presenta principios mas amenos y faciles, los entenderá bien, y desempeñará perfectamente una de las partes que compone en su orquesta. [sic]
\end{abstract}

Sigue opinando que es mejor aprender algo que no nada, y que quien quiera posteriormente ampliar conocimientos siempre puede hacerlo con los métodos completos. Dice que con este método ha formado orquestas regulares, y que tiene suficiente con él quien no aspire a apurar las máximas dificultades. Lo recomienda a los músicos mayores, a los músicos de plaza y a quien quiera poder comenzar con el piano después de haber dedicado un mes a la enseñanza del solfeo. Afirma que en dos o tres meses se puede aprender este método, (se entiende que para poder comenzar con algún instrumento) y luego poder profundizar con la segunda parte. Por último advierte que el método no sirve para alumnos de canto, porque carece de una profundización en la entonación. 
De la lección 1, en la que comienza con los nombres de las notas en la escala diatónica de Do, figuras redondas y compás de 4/4. A la lección 8 , introduce la blanca, negra e incluso la síncopa larga, siempre siguiendo con la escala ascendente y descendentemente.

Ya antes de la lección 9 explica, muy sucintamente pero eficaz, la ligadura y el puntillo, a lo que dedica una cortísima lección para cada cosa y continúa con el silencio de negra, las corcheas y combinaciones con negras y blancas. También aparece la doble barra de repetición. Todo sin explicación, a excepción de la ligadura y puntillo, como ya habíamos señalado. Así llega hasta la lección 17

\section{Preparación para el puntillo en la negra:}

Tres lecciones, una primera ligando una corchea a la negra para preparar el efecto del puntillo, y las otras dos ya con el puntillo al lado de la negra. Hace previamente la advertencia de que se medirá sin la ligadura, y después con ella; reforzando con la voz las notas que llevan una señal (un acento), que son las corcheas de la primera mitad del tiempo ligadas a la negra, luego se medirán sin ese acento. Es un ardid muy útil para que el alumno se percate de que ya ha hecho la corchea que corresponde a la prolongación del puntillo.

\section{Preparación a la síncopa breve en 2 partes:}

Una lección para prepararlas mediante ligadura, y 2 más para practicarlas.

\section{Preparación a la síncopa breve en 3 partes y en 4 partes:}

Una lección para la preparación mediante ligaduras de síncopas de 3 tiempos de duración, y otra para lo mismo pero con 4 tiempos de duración. Después 2 lecciones, pero de inmediato, y sin previa advertencia o explicación, sustituye el puntillo de la negra por silencio de corchea, creando el contratiempo. 
Llevamos 32 lecciones de una extensión media de 10 compases y ya se enfrenta con el tresillo de corchea, con una breve explicación, y 1 sola lección para esta medida.

Le sigue enseguida una lección para el conocimiento de la semicorchea, mediante un artificio muy útil, que consiste en que de las 4 semicorcheas de un tiempo cada 2 sean la misma nota, y lleven hacia abajo plica de corchea, con lo cual se convierten en un desdoble de las corcheas.

Enseguida mezcla de semicorcheas, corcheas, negras y blancas, y a la tercera lección fórmula rítmica corchea - dos semicorcheas y a la inversa.

Preparación a los puntillos de corchea:

Una lección de preparación ligando la primera semicorchea de las dos que forman la fórmula rítmica combinada. Enseguida mezcla de todo lo conocido hasta ahora, y puntillo puesto en la semicorchea seguida de fusa.

Preparación a las síncopas muy breves en una y dos partes:

Como en las demás preparaciones, ejemplos ligando, de cuatro semicorcheas, las dos del medio.

Estamos en la lección 46, y sin previo aviso ni explicación aparecen los tresillos de semicorchea, el silencio de semicorchea, el seisillo y el enlace de síncopas muy breves, acabando así en la lección 51 la primera parte.

Melódicamente todas las lecciones de esta primera parte proceden por grados conjuntos, ascendente y descendentemente. 


\section{$2^{\text {a }}$ PARTE}

\section{CUADRO DE INFORMACIÓN GENERAL DE LA SEGUNDA PARTE.}

$\mathrm{N}^{\mathbf{o}}$ de lecciones

Extensión de las lec- Entre 10 y 51 compases

ciones

Claves empleadas

Tesituras que abarcan

Tonalidades que trata

y estudia

Compases que emplea y estudia

\section{Dificultades métricas} que contiene

Dificultades de entonación que se encuentran $y$ orden en que se enseñan los intervalos

Armonía utilizada

\section{3}

Sol y Fa en $4^{\mathrm{a}}$

Las mismas

Do M

$2 / 4,3 / 4,3 / 8,6 / 8,9 / 8,12 / 8$

Grupos irregulares y sin preparación.

Pocas, predomina la marcha por grados conjuntos.

Intervalos desde $3^{\mathrm{a}}$ a $8^{\mathrm{a}}$, sin incluir los de $7^{\mathrm{a}}$; con preparación

Básica, modulaciones al relativo, a la dominante y a la subdominante. Algún acorde alterado

A-B; A-B-A

lecciones

Introducciones, Inter- No tiene ninguna

medios o Codas ins-

trumentales

Teoría de la música $\quad$ Escueta, pero algo más que en la primera que incluye

\subsubsection{DESCRIPCIÓN DETALLADA DE ESTA SEGUNDA PARTE.}

Comienza con la definición de intervalo y una diferenciación entre conjuntos y disjuntos solamente, un ejemplo de unísono y de intervalos hasta la $11^{\mathrm{a}}$, sin hablar de simples o compuestos, ni de lo que significan los números ordinales que hay en cada uno de ellos. 
Le sigue la aparición del compás de 2/4 con la explicación de la cantidad de figuras de nota que pueden entrar en él, y comienzan las lecciones.

De la 1 a la 10 las dedica a la práctica de intervalos simples, dos lecciones para cada intervalo, una con preparación y otra sin preparación. Las lecciones hechas para trabajar los intervalos con preparación, llevan cada una de ellas una célula rítmica repetida, pero distinta en cada lección, por lo que reproducimos a continuación cada una de ellas; las lecciones para el intervalo sin preparación son todas figuras de negra con silencio de negra para separar cada nuevo salto. La clave sigue siendo Sol, y emplea el nuevo compás aprendido de $2 / 4$.

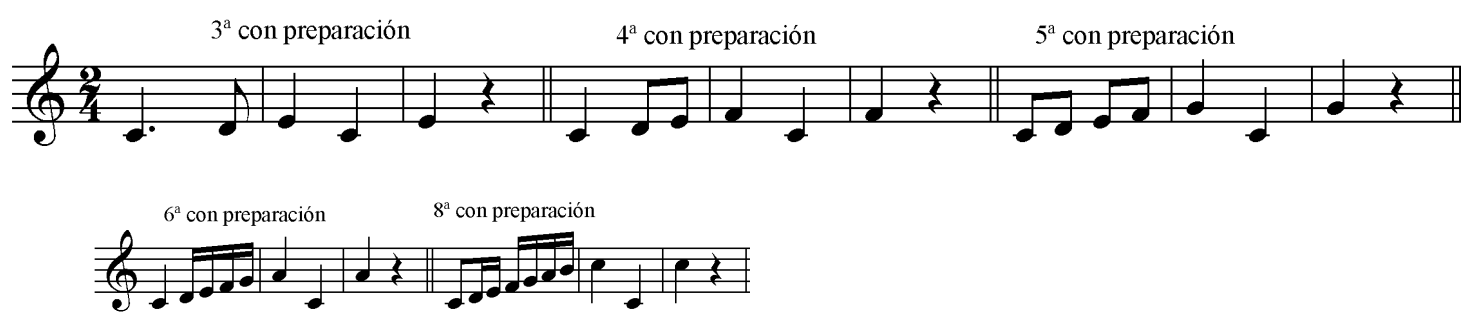

No hay lecciones para practicar el intervalo de $7^{\text {a }}$, es algo curioso.

Continúa con la explicación de Aire y dando a conocer tan sólo 4 términos: Largo, Adagio, Andante y Allegro, ya que dice que los demás son modificaciones de éstos.

Todo seguido la explicación de los compases de 3/4 y 3/8, simplemente, como hizo en el de $2 / 4$, la forma de marcarlos y la cantidad de figuras de notas que pueden entrar en ellos.

También de forma continuada presenta la clave de Fa en $4^{\mathrm{a}}$ línea, con una cuádruple escala de notas en líneas, espacios y líneas adicionales; y recomienda hacer los ejercicios de lectura que le siguen sin medir ni entonar. ${ }^{1}$ Advierte que esta clave sólo sirve para instrumentos bajos y para la mano izquierda del Piano, y que si alguien no quiere o no necesita aprender la clave de Sol por dedicarse a un instrumento que no la use, debe copiársele lo que antecede en clave de Fa; no obstante declara que todos deben aprender la clave de Sol debido a su gran uso.

Tras estas notas, 5 ejercicios ${ }^{2}$ para la práctica de la lectura en la nueva clave.

Comienzan ahora una serie de lecciones, desde la número 11 a la 23 , que es la última, a 4 pentagramas. El primero expone la pieza en clave de $\mathrm{Fa}$ en $4^{\mathrm{a}}$, compás de 3/4. El segundo la misma melodía pero en la clave de Sol. El tercero lo mismo trascrito al compás de $3 / 8$. Y el último es un bajo cifrado como acompañamiento.

\footnotetext{
${ }^{1}$ Por cierto que pone "Egercicios"

${ }^{2}$ En los que sí escribe la palabra con "J"
} 
De la 11 a la 15 va incrementando la dificultad métrica, hasta llegar a grupos de valoración irregular como seisillo, quintillo, septillo, nonillo y oncillo. La dificultad melódica es escasa.

A partir de la lección 16 aborda los compases compuestos, sin que los agrupe bajo esta denominación.

Comienza como es lógico con el de 6/8, indicando cuántas figuras de cada una entran en él, y comparándolo al de 2/4, con la simple salvedad de que éste se agrupa en mitades y aquél en tercios. También habla de la posibilidad de subdividir estos compases, bien como dos compases de 3/8, o marcando 3 subdivisiones en cada tiempo; lo mismo indica para con los compases simples ya vistos, pero evidentemente subdividiéndolos en mitades.

De la 16 a la 19 inclusive, se ocupa del compás de 6/8, y en esta última

añade la doble barra de repetición, el D. C. y el párrafo※. Va aumentando el grado de

dificultad rítmica, hasta las fusas y los puntillos en la semicorchea

Las números 20 y 21 son para el compás de 9/8, la primera de métrica sencilla y la segunda bastante más complicada.

Las dos últimas, 22 y 23, son para el compás de 12/8, la primera con una métrica normal en estos compases, y la segunda con semicorcheas, puntillos en la semicorchea, doble puntillo en la corchea, y la abreviatura de repetición de compás o parte de él $\%$. 


\section{$3^{\text {a PARTE }}$}

\subsubsection{DESCRIPCIÓN DETALLADA DE ESTA TERCERA PARTE.}

Está dedicada totalmente a llenar, en forma teórica algunas lagunas sobre conceptos totalmente necesarios.

Primero expone gráficamente las notas en líneas adicionales superiores e inferiores en la clave de Sol, haciendo una escala que abarca desde el $\mathrm{Mi}_{2}$ al $\mathrm{Do}_{6}$.

Después habla de las alteraciones, sencillas y dobles, de su efecto, de las accidentales y las propias, orden de las alteraciones en las armaduras. Una relación de las tonalidades mayores y menores con sus alteraciones en las armaduras de sostenidos y en las de bemoles (todo ello sin ninguna explicación acerca de lo que es una tonalidad ni lo que significan tonalidades relativas). Eso sí, hay una nota para el profesor recomendando que si sus alumnos van a afrontar el estudio de un instrumento al acabar la primera parte, debe hablarles de esta tercera, para que no les extrañe la aparición de una alteración en alguna partitura.

Le toca el turno ahora a las notas de adorno, que las divide en apoyaturas y mordentes. Los mordentes en de una, dos, tres y cuatro notas, y estos últimos en rectos y circulares. El valor de ellos dice que se toma casi siempre de la nota o silencio anterior, y excepcionalmente de la nota adornada (se ve que no contemplaba la interpretación barroca o clásica), y curiosamente, dice que los de tres notas rectos son siempre rápidos, y los circulares según el movimiento y carácter de la música. Incluye la abreviatura de grupetos de 3 y cuatro notas, no habla para nada de la abreviatura de mordentes de 2 notas.

Termina esta parte, y el método, con una lista de términos del movimiento, adverbios que modifican estos términos y de matices solamente dinámicos.

\subsubsection{VALORACIÓN DE LA EFECTIVIDAD DEL MÉTODO Y DE SU APORTACIÓN A LA ENSEÑANZA}

Nos parece exagerada la aseveración del autor que estudiando la primera parte es suficiente para un músico amateur. Sí que es cierto que las dificultades básicas están todas contempladas, pero tan poco reiteradas. Y por otra parte $i$ es que los instrumentos que van a tocar esos músicos amateurs son todos diatónicos?, porque ni se habla de las 
alteraciones. ¿Y no van a ver otras partituras que no sean las escritas en compás de compasillo?

Por supuesto ni el matiz, ni el aire tendrá cabida en la interpretación de estos músicos

En definitiva es demasiado escueta.

La segunda parte, y la teoría de la tercera, completan un poco la cortedad de la primera, pero sigue siendo un método muy primario e insuficiente a todas luces.

Las tonalidades no existen, y muchas cuestiones se ven de paso sin ahondar en ellas.

Llama la atención que no existan lecciones para practicar el intervalo de $7^{\mathrm{a}}$.

En definitiva no es un método útil para los aficionados ni para los profesionales. 
Abrantes Bello, $3^{\underline{a}}$ parte 


\subsection{RESEÑA BIOGRÁFICA DEL AUTOR}

PENELLA RAGA, Manuel. Masanasa (Valencia) 1847 - Valencia 1909. Profesor y Director. Flautín en la Banda Municipal de Alicante. Infantillo en El Patriarca y alumno de Pérez Gascón en la Escuela de Música de la Real Sociedad Económica de Amigos del País. Director de coros. Fundó el Orfeón valenciano. Profesor de José Serrano y Vicente Lleó. En 1864 se hace cargo de la clase de Pérez Gascón por muerte de éste. 1869 funda la primera Escuela Municipal de Música para Niños. 1899 fue nombrado Profesor Especial de Música y Canto en la Escuela Normal Superior de Maestros. Fue profesor honorario del Conservatorio. Según el firmante del artículo el método de solfeo es de 1879 (Galbis y Pidal Fernández, en AAVV, 1999, tomo 8, pp. 574 y 75).

\subsubsection{DESCRIPCIÓN DETALLADA DEL MÉTODO.}

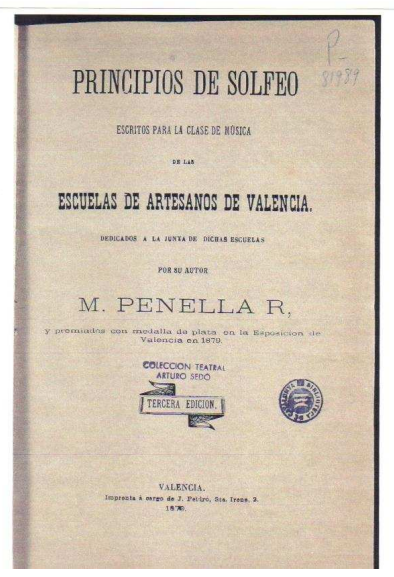

\section{Título del Método}

Principios de solfeo: escritos para la clase de música de las Escuelas de Artesanos de Valencia, $3^{\text {a }}$ edición, Valencia, Imp. de J. Peidró, 1879. Apéndice, página 217.

\section{CUADRO DE INFORMACIÓN GENERAL DEL MÉTODO.}

$\mathrm{N}^{0}$ de lecciones

Extensión de las Entre 8 y 38 compases

lecciones

Claves empleadas

Tesituras que abar-

can

Tonalidades que trata y estudia

Compases que emplea y estudia

64

$\mathrm{Do}_{3} \mathrm{a} \mathrm{Fa}_{4}$

4/4. $3 / 4.2 / 4,3 / 8$ y $6 / 8$
Sol y $\mathrm{Fa} 4^{\mathrm{a}}$ en 8 lecciones

Do mayor y La menor. Excepcionalmente y al final 2 lecciones en Sol mayor y 1 en Fa mayor 


\section{Dificultades métri- cas que contiene}

\section{Dificultades de en- tonación que se en- cuentran y orden en que se enseñan los interva- los}

\section{Armonía utilizada}

Formas que tienen las lecciones

Introducciones, Intermedios o Codas instrumentales

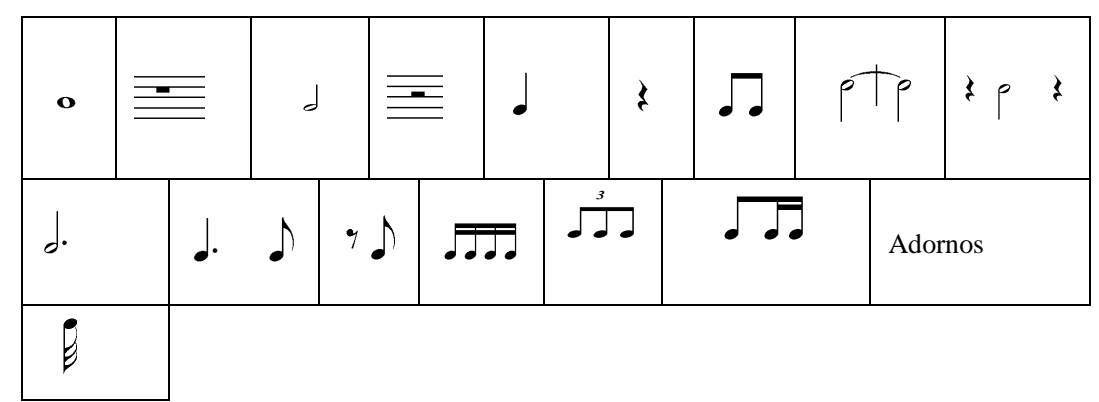

Ninguna.

Grados conjuntos, saltos sin preparación, semitonos diatónicos y cromáticos

No hay acompañamiento

Son de cortas proporciones, y suelen tener una sola frase, pero la mayoría tienen 3 semifrases a-b-c; también las hay a-b, incluso a-a'

No tienen

Teoría de la música Tiene el mismo número de lecciones como de solfeo que incluye

\section{SECUENCIA}

Presentación del pentagrama, nombre de las notas en las líneas y en los espacios, escala de Do con redondas, y sin explicaciones (que están detrás en la parte teórica) comienzan las lecciones.

De la lección 4 a la 18 desarrolla, en compás de compasillo, primero con la escala, y siempre por grados conjuntos, las redondas, silencio de redonda, blancas, redondas y blancas, ambas con sus silencios, blancas sus silencios y negras, éstas con redondas, todas con silencios de negra (con su grafía antigua).

Lecciones 19 y 20 afrontan ya las corcheas, siguiendo la melodía por grados conjuntos. A partir de la 21 empiezan a haber intervalos disjuntos que ya se suceden con bastante prisa. Se intercala también la ligadura entre blancas formando síncopas muy largas, e inmediatamente las largas.

Lecciones 26 a la 29, introducen el puntillo, primero sobre la blanca y sobre la negra después. 
Lecciones 30 y 31 abordan el silencio de corchea, pero en lugar de comenzar situándolo detrás de la corchea, es delante, formando contratiempos cortos, sin haber visto los largos. Es una falta pedagógica, así como dedicarle solamente 2 lecciones. Después los sitúa detrás.

En las números 32, 33 y 34 empiezan los sostenidos; primero en el Fa, después en el Do, formando semitonos diatónicos, luego en el Sol formando semitono cromático. Sigue con 3 lecciones más en las que aparece el becuadro formando cromatismos descendentes o ascendentes.

El bemol en el La y en el Si es la alteración que viene en las siguientes lecciones, mezclado con los sostenidos que ya se habían practicado. A la vez se utiliza el Calderón.

Lecciones 41 y 42, la figura de nota semicorchea hace su aparición, desde luego en grupos de 4. El autor las llama dobles corcheas.

Le toca ya el turno a nuevos compases, y es el de 3/4 el que ahora se contempla, en una lección muy sencilla, seguida de otra ya con semicorcheas, y las siguientes en las que se van incorporando las dificultades anteriormente estudiadas. Y así llegamos a la lección 52 en la que se ven las dobles barras de repetición y las casillas de primera y segunda. En la lección anterior se había visto el signo \%

Presenta la clave de Fa en $4^{a}$ línea: Nombre de las notas en espacios y líneas. Una lección con blancas, negras y corcheas en 4/4. Después de ella el compás de 2/4, dos lecciones un poco más difíciles, sin que sean demasiado.

Continúa con dos lecciones en Compás de $3 / 8$.

Luego tres lecciones en el de 6/8; pero la segunda y tercera de nuevo en la clave de Sol.

Sin advertencia ni explicación aparecen dos lecciones, 4/4 y 3/8 en la tonalidad de Sol mayor; también clave de Sol; una en clave de Fa en la tonalidad de Fa mayor, 3/4 y con la repetición de D. C. hasta el Fin.

Por último una lección en clave de Fa, Do mayor, 4/4, en la que se incluyen notas de adorno, apoyaturas y mordentes de una y dos notas.

A partir de aquí empieza la parte de teoría, en forma dialogada. Pentagrama, notas, clave de Sol, tono y semitono, compás y figura redonda, silencios, la blanca, intervalo de $2^{\mathrm{a}}$ mayor y menor, la negra, intervalo de $3^{\mathrm{a}}$ menor y mayor, intervalo de $4^{\mathrm{a}}$ me- 
nor y mayor, la corchea, la ligadura, intervalo de $5^{\mathrm{a}}$ mayor, el puntillo, $6^{\mathrm{a}}$ y $7^{\mathrm{a}}$ menor y mayor, accidentales (o sea alteraciones), calderón, el movimiento, la doble corchea, signos de "espresión" (un poco de dinámica), el compás de 3 tiempos, el picado y el ligado, tresillos y seisillos, signos de repetición, las claves de Fa y de Do, compás de dos tiempos, la fusa, compás de seis por ocho, otras escalas mayores y menores y notas de adorno.

\subsubsection{VALORACIÓN DE LA EFECTIVIDAD DEL MÉTODO Y DE SU APORTACIÓN A LA ENSEÑANZA.}

Es un libro muy escueto, posiblemente por el alumnado al que estaba destinado, no encaminado en absoluto al terreno profesional.

Sirve como aproximación al solfeo al conocimiento teórico de sus signos y a la lectura musical muy elemental.

No obstante está carente de cualquier línea pedagógica, como ejemplo, la introducción del silencio de corchea formando contratiempos breves y no situándolo detrás de la corchea. 


\subsection{RESEÑA BIOGRÁFICA DEL AUTOR}

BENITO BARBERO, Cosme José Damián de. Madrid 27/9/1829 15/1/1888. Maestro de capilla, organista y musicólogo. Músico importante en la música religiosa. 222 obras en total (Casares Rodicio, en AAVV, 1999, tomo 2, pp. 368 a 71).

En la cubierta del libro dice que era Maestro de Capilla del monasterio del Escorial y Profesor honorario de la Escuela Nacional de Música. Caballero de la real y distinguida Orden de Carlos III.

\subsubsection{DESCRIPCIÓN DETALLADA DEL MÉTODO.}

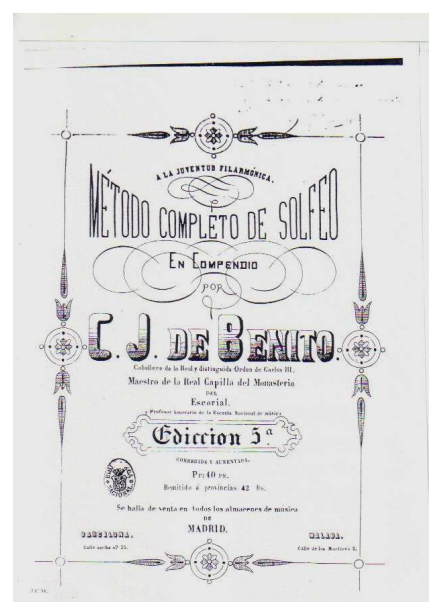

\section{Título del Método}

Método completo de Solfeo en Compendio, Edición 5a , s. 1., s. f. ${ }^{1}$ Apéndice, página 218.

\section{PARTE PRIMERA}

\section{CUADRO DE INFORMACIÓN GENERAL DE LA PRIMERA PARTE.}

$\mathbf{N}^{\circ}$ de lecciones

39

Extensión de las lec- Entre 16 y 40 compases

ciones

Claves empleadas $\quad$ Sol y Fa en $4^{\mathrm{a}}$

Tesituras que abar- $\quad{\operatorname{De~} \mathrm{Do}_{3}}_{3} \mathrm{Fa}_{4}$

can

Tonalidades que tra- Do M y La m

ta y estudia

Compases que em- $\quad 2 / 2,4 / 4,2 / 4,3 / 4$ y $3 / 8$

plea y estudia

\footnotetext{
${ }^{1}$ En la cubierta de las fotocopias enviadas por el servicio de reprografía de la Biblioteca Nacional, donde figura la signatura del libro, añaden a las referencias [S. 1. ]: [s. n. ], [ca. 1880].
} 
De Benito, parte primera

\section{Dificultades métricas que contiene}

Dificultades de entonación que se encuentran y orden en que se enseñan los interva$\operatorname{los}$

\section{Armonía utilizada Formas que tienen las lecciones}

Introducciones, Intermedios o Codas instrumentales

Teoría de la música que incluye

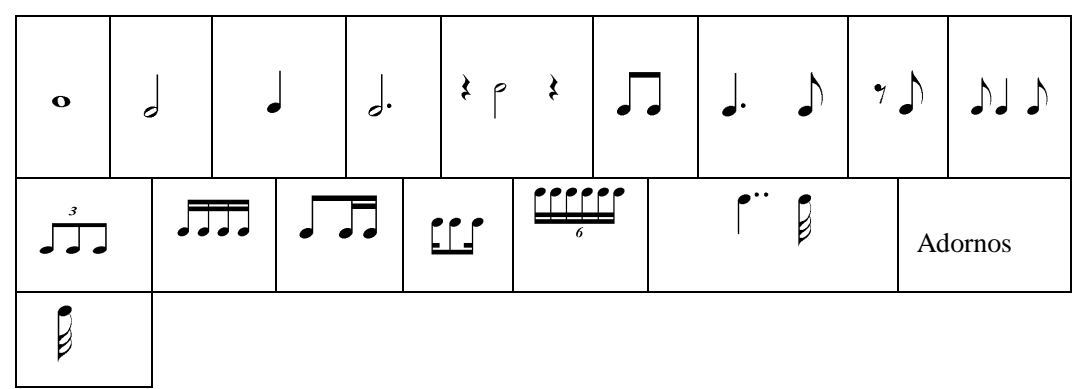

Intervalos naturales y alterados mayores y menores. Una $5^{\mathrm{a}}$ disminuida aparece en una lección.

Intervalos desde $2^{\mathrm{a}}$ a $8^{\mathrm{a}}$ preparados. Semitonos diatónicos

No tienen acompañamiento

Monofrases y A-B

No hay

Tiene la indispensable

\section{SECUENCIA}

Comienza con un prólogo en el que el autor indica que el método contiene una breve teoría y lecciones prácticas de corta extensión, lo indispensable para quien quiera dedicarse al estudio de algún instrumento o canto. Pero también dice que quien quiera llegar a un grado de perfección, puede acudir a otros muchos métodos, más voluminosos (y cita el de Eslava), no obstante él considera éste un pequeño tratado para que los jóvenes y niños no desmayen ante la vista de un voluminoso método de solfeo.

Tras él, las nociones preliminares: definición de música, que transcribimos literalmente: una de las bellas artes que tiene por obgeto escitar [sic] los sentimientos del alma, por medio de la combinación de sonidos apreciable al oído, pentagrama, notas, claves, compases, figuras de nota y de silencio, concepto de intervalo, de tono y semitono y escala diatónica; aquí comienzan los ejercicios con el compás de $2 / 2$ y redondas, un ejercicio, otro con blancas, otro con negras otro con corcheas.

Luego ejercicios, bastante largos, de intervalos, desde segunda hasta octava, preparados por grados conjuntos. Al final de éstos, un ejercicio de resumen. 
Y tras la explicación de Aire, empiezan las lecciones. Con éstas ya emplea el compás de compasillo.

Una para redondas y blancas, una para redondas, blancas y negras, una para negras y silencios de negra, (los de redonda y blanca se han visto en los ejercicios de intervalos). Sigue una para el puntillo colocado a la blanca, y otra para la ligadura entre blanca y negra. Síncopas largas y notas partidas, las corcheas y a la vez el calderón.

Y a tan breve altura de los conocimientos (lección 8), ya se tratan las alteraciones. Una lección para el sostenido, semitonos diatónicos; otra para el sostenido y el bemol.

Barra de repetición, y puntillo aplicado a la negra.

Siempre siguiendo con una lección para cada dificultad, vemos los contratiempos cortos, la síncopa breve, y los tresillos, de corchea en una lección y de negra, pero con compás binario, en otra.

La escala de La menor, concepto de modo y diferencias entre el mayor y el menor. Dos lecciones con los elementos rítmicos vistos hasta ahora.

Las semicorcheas y sus fórmulas combinadas, cinco lecciones, en las que también se incluye la síncopa muy breve.

El seisillo de semicorchea y recopilación en compás de tres por cuatro.

Las notas en la clave de $\mathrm{Fa}$ en $4^{\mathrm{a}}$ línea; una lección relativamente fácil, máximo corcheas, aunque debería ser todavía más fácil al iniciar una clave.

Una lección, de nuevo en clave de Sol, para el doble puntillo.

Y de nuevo en clave de Fa, pero por si fuera poco la lectura en nueva clave, añade las notas de adorno: apoyaturas, mordentes de una y dos notas, mordentes de 3 , y llama grupeto solamente a los de 4 notas.

Añadiendo leña al fuego, fusas con la clave de $\mathrm{Fa}$, fusas y fórmulas combinadas.

Tres lecciones para el compás de tres por ocho, en las que incluye las casillas de $1^{\mathrm{a}}$ y $2^{\mathrm{a}}$ vez, así como el signo\%.

Para acabar el signo D. C., § y las abreviaturas. 
De Benito, parte segunda

\section{PARTE SEGUNDA}

\section{CUADRO DE INFORMACIÓN GENERAL DE LA SEGUNDA PARTE.}

$\mathbf{N}^{\circ}$ de lecciones

Extensión de las lec- Entre 12 y 38 compases

ciones

Claves empleadas

Tesituras que abarcan Las mismas que en la anterior parte

Tonalidades que trata y estudia

Compases que emplea y estudia

Dificultades métricas que contiene

Dificultades de entonación que se encuentran $y$ orden en que se enseñan los intervalos

Armonía utilizada

Formas que tienen las lecciones

Introducciones, Intermedios o Codas instrumentales

Teoría de la música que incluye
Sol M, Mi m, Fa M, Re m, Re M, Si m, Si b M, La M, Fa \# m, Sol m, Mi b M, Do m, Mi M, Do \# m, La b M, Fa m, Si M, So l \#m, Re b M, Si b m, Fa \# M, Re \# m, Sol b M y Mi b m

Los anteriores más 6,9 y $12 / 8$

Semifusas. Valores irregulares

Intervalos aumentados y disminuidos. Dobles alteraciones. Enarmonía

Ejercicios de entonación en todas las tonalidades

Totalmente clásica

La mayor parte A-B, alguna A- B- A'

No tienen

Como en la parte anterior

\subsubsection{DESCRIPCIÓN DETALLADA DE ESTA SEGUNDA PARTE.}

Teoría de los semitonos, intervalos, su inversión y todo lo referente a tonalidades. Dedica esta parte al conocimiento de las claves y de las tonalidades, a razón de 2 ó 3 lecciones por tonalidad. Acaban las lecciones con una relación de las claves entre si.

Hay después un apéndice que consta de: teoría sobre el transporte; figuras y silencios antiguos; compases de amalgama; forma de saber en la tonalidad que se encuentra una pieza, términos dinámicos, agógicos y signos de articulación. 
Cuatro ejercicios de lectura, aplicables a todas las claves, con notas sobre agudas y muy graves; ejercicios de entonación en todas las tonalidades mayores y menores en el orden que han aparecido en esta parte; y un ejercicio de entonación cromático.

Cierra por completo una canción a 3 voces iguales, homofónica con fragmentos de voz solista y acompañamiento de piano. Indica sobre texto de D. P. Mingote.

\subsubsection{VALORACIÓN DE LA EFECTIVIDAD DEL MÉTODO Y DE SU APORTACIÓN A LA ENSEÑANZA.}

Está todo muy comprimido. Como ya hemos comentado con otros métodos, no se puede aprender ni comprender las distintas dificultades que surgen con una lección para cada una de ellas, y menos con ese agolpamiento.

En el prólogo de la primera parte dice que está pensado para niños y jóvenes; son precisamente ellos quienes necesitan una progresión adecuada del aprendizaje y abundar en cada una de los nuevos problemas que se van presentando.

Además las lecciones son francamente feas y aburridas.

Respecto a la segunda parte, en ningún momento se tiene en cuenta que aparece una nueva clave o un nuevo compás, siguen las dificultades como si de elementos ya conocidos se tratara. Vale todo lo dicho en la primera parte. 
De Benito, parte segunda 


\subsection{RESEÑA BIOGRÁFICA DEL AUTOR}

EGEA, Pedro $\mathrm{M}^{\mathrm{a}}$ de. En el mismo libro que vamos a describir, hay una nota autografiada de, José Asenjo Barbieri, en la que dice que Pedro $\mathrm{M}^{\mathrm{a}}$ de Egea nació en Cehegin el año 1823, que escribió este libro autografiado entre 1880 y 1881, que murió en Lorca en diciembre de este año. Y añade que compró este libro inédito al hijo de Egea en Mayo de 1883 por 25 pesetas.

\subsubsection{DESCRIPCIÓN DETALLADA DEL MÉTODO.}

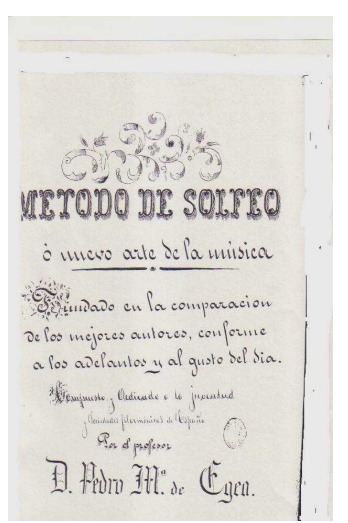

\section{Título del Método}

Método de Solfeo o nuevo Arte de la Música, S. L., 1880-81.

Apéndice, página 219.

Debajo del título el autor sigue poniendo: "Fundado en la comparación de los mejores autores, conforme a los adelantos y al gusto del día. Compuesto y dedicado a la juventud y sociedades filarmónicas de España, por el profesor D. Pedro Ma de Egea”.

Hay una "advertencia" al comienzo del libro, con firma autógrafa, en la que el autor dice que se ha dedicado un tiempo a la enseñanza de la música, y que viajando por países como Francia, Bélgica e Italia, ha visto y analizado los mejores métodos de solfeo que en ellos se han publicado, siendo unos muy sencillos y otros demasiado extensos, por lo que con motivo de abrirse una academia filarmónica en Lorca bajo su dirección, se ha animado a elaborar este método. Apéndice, página 219

\section{CUADRO DE INFORMACIÓN GENERAL DEL MÉTODO.}

$\mathbf{N}^{\mathbf{0}}$ de lecciones $\quad 82$

Extensión de las Desde 3 hasta 58 compases

lecciones

Claves empleadas $\mathrm{Sol}, \mathrm{Fa} 4^{\mathrm{a}}$

En la $3^{\mathrm{a}}$ parte Do $1^{\mathrm{a}}$, Do $2^{\mathrm{a}}$, Do $3^{\mathrm{a}}$, Do $4^{\mathrm{a}}$ y Fa $3^{\mathrm{a}}$

Tesituras que $\quad \mathrm{Do}_{3} \mathrm{a} \mathrm{La}_{4}$

abarcan

Tonalidades que

Do mayor y La menor

trata y estudia

En la $3^{\text {a }}$ parte Mi b M, Mi M, Sol M, Sol b M, Si M, Si b M,

Re M, Re b M, Fa M, Fa \# M, La M y La b M 
De Egea

Compases que emplea y estudia

Dificultades métricas que contiene

\section{Dificultades de entonación que se encuentran y orden en que se enseñan los inter- valos}

Armonía utilizada

Formas que tienen las lecciones

Introducciones, Intermedios o Codas instrumentales

Teoría de la música que incluye
$4 / 4,3 / 4$ y $2 / 4$

En la $2^{\mathrm{a}}$ parte $3 / 8,6 / 8,9 / 8,12 / 8$ y $2 / 2$

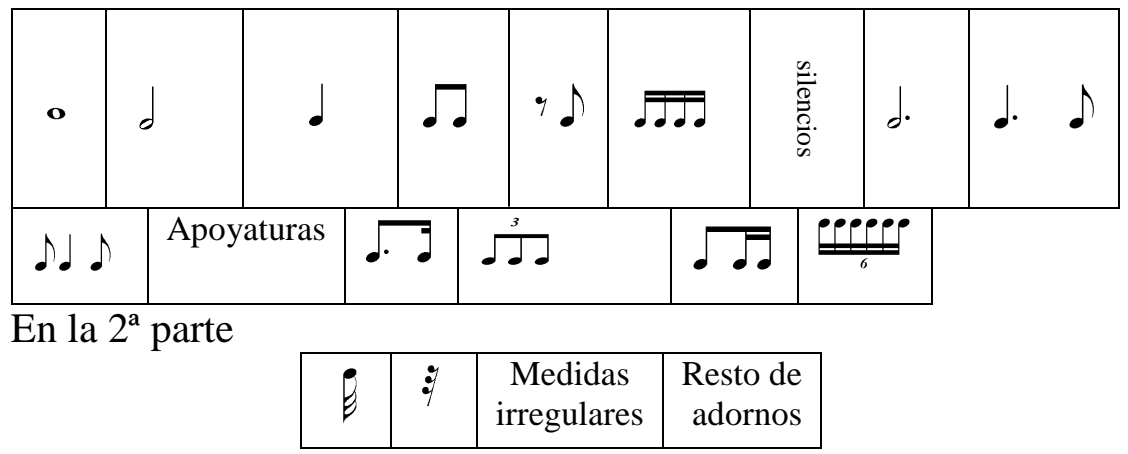

Ninguna

Escala, desde $2^{\mathrm{a}}$ a $8^{\mathrm{a}}$ preparadas y sin preparar, semitonos cromáticos y diatónicos

Romántica, no muy avanzada, con grados alterados

Algunas son forma primaria, muchas A-B, algunas A-A' o también A-B-A'

No tienen

Abundante, sobre todo al comienzo, pero también cuando hay algo nuevo

\section{PRIMER PARTE}

Teoría y definiciones de la música:

Por medio del diálogo de preguntas y respuestas, expone, muy brevemente, pero muy clara y ampliamente las cuestiones teóricas básicas: conceptos de música, sonido, de dónde procede éste, nombres de las notas también con su denominación alfabética anterior, pentagrama, figuras con los nombres antiguos y actuales, compases con su clasificación, compasillo, silencios, claves, alteraciones (que él llama accidentes), signos de aumentación (en los que incluye el puntillo y doble puntillo, ligados simples y sincopados, tresillos y seisillos) [extraño y heterogéneo grupo], signos de agregación o caracteres de adorno (apoyatura simple, doble, grupeto o mordente, trino inferior y su- 
perior y cadencia o fermata). Es, a nuestro entender, un error de muchos tratadistas, incluir entre las notas de adorno la fermata; no es ésta una nota de adorno, ni siquiera un grupo de 3 o 4 notas, es un pasaje virtuosístico que quizás adorne, aunque en numerosas ocasiones no está hecho para ornato sino para demostrar las dotes de un intérprete. Sigue con el calderón (al que, como se ve, no incluye entre los signos de prolongación), caracteres o signos que representan la expresión, y que según él son los picados, ligados, los esforzadores [reguladores] y trémulos, añade a esto que también hay otros caracteres o señales como las cifras, repeticiones y párrafos, por economía y brevedad de la escritura.

Relaciona los compases usados en el momento (nombra uno como compasillo breve o de Capilla, que suponemos será el binario simple o dos por dos), y también dice que hay otros pero en desuso. Escala, géneros de la música, composición de la diatónica, cromática y enarmónica, tono y semitono. Modos mayor y menor, orden de las armaduras, número de tonalidades que salen con armaduras de sostenidos y de bemoles. Definición de melodía y armonía. Y para terminar definición de composición musical. La ciencia de escribir y dar forma al pensamiento música, realzando las ideas con la más perfecta colocación y variedad de las voces e instrumentos.

Después de todas estas informaciones, siguiendo el mismo orden, pone ejemplos gráficos de ellas.

Práctica del solfeo:

De la lección 1 a la 9, las dedica a la entonación de la escala natural, con distintas figuras, desde redonda hasta semicorcheas, sus silencios, y combinación de todas ellas, acompañadas con un bajo de piano, como el resto de lecciones. Lo malo es que ya en la lección 5 aparecen las semicorcheas, pero antes han aparecido los contratiempos cortos, y con las semicorcheas, los contratiempos cortos irregulares. Sólo se puede calificar de barbaridad.

Una serie de lecciones - ejercicios de intervalos, desde segundas a octavas, por grados y por salto.

Nueva serie de 12 lecciones en forma de Tema y variaciones en cada una de las siguientes (a las que él llama "glosas"), y en las que abarca, puntillo a la blanca y negra, ligaduras, síncopas cortas, contratiempos, apoyaturas simples, puntillos en las corcheas, 
tresillos de corcheas, fórmulas corchea - semicorcheas, semicorcheas y seisillos de semicorchea.

Cuatro lecciones para las alteraciones, primero los sostenidos formando semitonos cromáticos, luego los bemoles de igual forma, y después mezclados formando semitono cromáticos y diatónicos.

Al presentar el compás de 3/4, aparecen 4 lecciones, también en forma de tema y una variación por cada lección, todas ellas en La menor (sin que haya previamente explicado nada), y en las que interviene todos los elementos vistos hasta el momento.

Tres lecciones para el compás de 2/4, distintas cada una, vuelve a Do mayor, la segunda está en La menor, y la tercera como la primera. Sigue usando todos los elementos vistos.

Dos para los signos de articulación y la dinámica. Va variando las dos tonalidades naturales, abundando más en la mayor.

\section{SEGUNDA PARTE}

Es una sección dedicada a conocer el resto de los compases más usados y los términos del movimiento uniforme; dedica 2 lecciones a cada uno de los 3/8, 6/8, 9/8, 12/8 y 2/2. El 6/8 dice que se puede marcar como dos de 3/8, y el 9/8 como tres de ellos. Como novedad rítmica aparece la fusa y su silencio. Acaba con un fugado a 2 voces entre la melodía y el bajo cifrado.

La siguiente serie es para: práctica del trino, medidas irregulares hasta docillo, agógica, notas excesivamente agudas, signos de repetición, grupetos y abreviaturas.

\section{TERCERA PARTE}

Dedicada al conocimiento del resto de claves, y algunas tonalidades. Si hay algo mal explicado en este libro es lo referente a tonalidades. En principio no explica el concepto ni la relación de cada armadura con su tonalidad, la relación del modo menor con el mayor tampoco. A medida que presenta cada nueva clave, a las que dedica 2 lecciones, las relaciona con dos tonalidades, a saber: Do en $1^{\mathrm{a}}$ con Mi bemol y Mi, Do en $2^{\mathrm{a}}$ con Sol y Sol bemol, Do en $3^{\mathrm{a}}$ con Si y Si bemol, Do en $4^{\mathrm{a}}$ con Re y Re bemol, Fa en $3^{\mathrm{a}}$ con Fa sostenido y Fa, y Fa en $4^{\mathrm{a}}$ con La y La bemol. Todo ello al trasladar el nombre de las notas de cada una de ellas a la clave de Sol, y añadirle la armadura correspondiente. Pero eso no sirve para el modo menor y nada dice de ello. 
Añade 3 lecciones para ver y practicar la modulación en el solfeo.

Cierra con una tabla de escalas en todos los tonos mayores y menores.

\subsubsection{VALORACIÓN DE LA EFECTIVIDAD DEL MÉTODO Y DE SU APORTACIÓN A LA ENSEÑANZA}

Como en muchos otros métodos de la época, se plantea una progresión demasiado rápida para poner en práctica ritmos y figuras que deben esperar un tiempo de maduración.

Sólo se puede calificar de despropósito el que antes de abordar las semicorcheas se practique los contratiempos cortos, y que justo con aquellas aparezcan los contratiempos irregulares.

Es bastante completo para su corta extensión.

Absurda y totalmente inoperante la manera de aplicar prácticamente las tonalidades.

No es útil. 
De Egea 


\subsection{RESEÑA BIOGRÁFICA DEL AUTOR}

SABATÉS ESTAPER, Mateo. Teyá (Barcelona) 1838- ? 1920. Compositor, profesor y teórico. Estuvo en 1857 en Puerto Rico dedicado a la docencia y en 1871 en Selva del Campo (Tarragona). Fue profesor de solfeo y piano del instituto provincial de Tarragona. En Barcelona fundó una academia. Obtuvo medalla de oro en la Exposición Universal de 1888 por su Método de Solfeo en 3 volúmenes (Sobrino, en AAVV, 1999, tomo 9 , p. 516). ${ }^{1}$

\subsubsection{DESCRIPCIÓN DETALLADA DEL MÉTODO.}

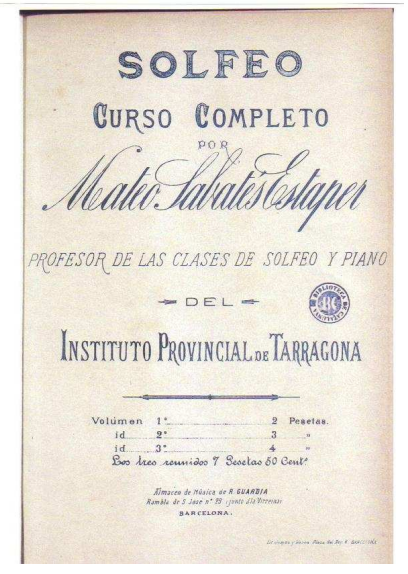

Título del Método

Solfeo: curso completo, Barcelona, Rafael Guardia, 1888. Apéndice, página 220.

\section{VOLUMEN I}

\section{CUADRO DE INFORMACIÓN GENERAL DEL VOLUMEN I.}

$\mathbf{N}^{\circ}$ de lecciones

173

Extensión de las lec- Entre 4 y 48 compases

ciones

Claves empleadas

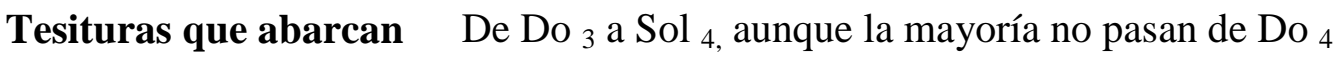

Tonalidades que trata y estudia

Compases que emplea Solamente $4 / 4$ y estudia

Do mayor, con dos excepciones: La lección $n^{\circ} 85$ en La m. escala modal, y la ${ }^{\circ} 112$ escala armónica

\footnotetext{
${ }^{1}$ Ramón Sobrino es quien dice que pudo estar publicado el método de solfeo en el año 1888.
} 


\section{Dificultades métricas que contiene}

Dificultades de entonación que se encuentran $y$ orden en que se enseñan los intervalos

\section{Armonía utilizada}

\section{Formas que tienen las} lecciones

Introducciones, Intermedios o Codas instrumentales

Teoría de la música que incluye

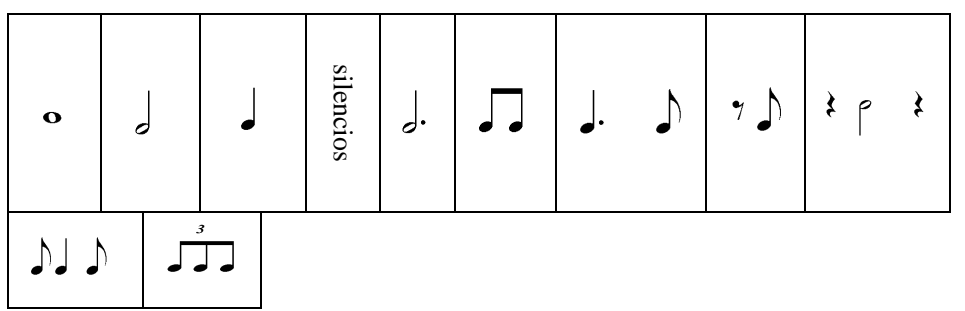

Muy pocas, normalmente intervalos naturales Semitonos diatónicos alterados y cromáticos. Como consecuencia de las alteraciones Alguna $5^{\mathrm{a}}$ menor y $4^{\mathrm{a}}$ disminuida

Escala, $3^{\mathrm{a}} \mathrm{M}$ y $\mathrm{m}, 4^{\mathrm{a}} \mathrm{m}, 5^{\mathrm{a}} \mathrm{M}, 6^{\mathrm{a}} \mathrm{M}, 7^{\mathrm{a}}$ y $8^{\mathrm{a}}$, semitonos cromáticos y diatónicos.

No existe

A-A'A'”; A-B-A'

No los hay

No tiene.

\section{DESCRIPCIÓN DETALLADA DE ESTE PRIMER VOLUMEN}

Comienza el libro con un "NÓTESE", en el que el autor hace algunos comentarios referentes a las características pedagógicas del libro, como éstos: las combinaciones de signos se presentan gradualmente y con toda sencillez; que no se agotan todas las posibilidades de combinación de un signo hasta más adelante; que hay varias lecciones sobre la misma dificultad para que el alumno tenga materia suficiente, dejando en libertad al profesor de practicarlas todas o pasar a las siguientes; en una misma lección no se afrontan distintas dificultades con el fin de facilitar al alumno su entendimiento; las definiciones son cortas; la extensión de las lecciones también; en la primera parte se usa exclusivamente el compás de compasillo, por creer el autor que una vez dominado éste los demás se asumen con facilidad; (craso error) y que los intervalos van apareciendo de forma gradual.

Continúa con Dictámenes de unos 10 músicos del momento en los que todos alaban la obra, la mayoría sin decir por que, y los menos destacan la progresividad del método.

Empieza ya la parte didáctica después de estos prolegómenos con el dibujo del pentagrama, llave de Sol, el signo del compás de compasillo, nombre de algunas notas 
en las líneas y espacios, escala ascendente y descendente y la figura de redonda, a la que dedica 3 lecciones, aun sin numerar, dos de ellas en escala y la tercera repitiendo alguna nota y siguiendo por grados conjuntos.

Cinco lecciones, cortas, para la figura de nota blanca, también por grados conjuntos, y dos para mezcla de redondas y blancas.

Cinco con negras, ya empieza a numerar las lecciones; siete negras y redondas, ocho negras, blancas y redondas.

Lección 21, sigue mayoritariamente por grados conjuntos, pero en algún compás ya se ve el intervalo de tercera mayor $(\mathrm{do}-\mathrm{mi})$.

En la 23 empieza el silencio de redonda, en la 25 el de blanca, y se alarga hasta nueve lecciones con estas combinaciones; sigue preferentemente con grados conjuntos y algún salto de la tercera mencionada.

La pausa de negra y las anteriores combinaciones ocupan 13 lecciones; los intervalos van agrandándose: tercera menor, cuarta menor y quinta mayor, pero en bastante menos cantidad que los conjuntos.

El calderón hace su aparición con cinco lecciones, en la última ya se ve el intervalo de sexta mayor.

Veinticinco lecciones para la corchea combinada con las anteriores figuras y silencios, llegamos ya al intervalo de séptima y octava.

El puntillo en la blanca, siete lecciones. Aunque no los usa, habla del doble y triple puntillo (como también hicieron Reguart y Manent). También Amancio Amorós comenta este triple puntillo, e incluso él llega hasta el cuádruple, con la diferencia de que sí que aparecen en algunas de sus lecciones, como también se ven ejemplos en Lladó. Ningún otro autor analizado nos expone este signo de prolongación

Sigue con el puntillo en la blanca, pero además extiende la tesitura hasta el $\mathrm{Sol}_{4}$, a esto le dedica 6 lecciones.

Corcheas sueltas es el epígrafe que encabezan las cuatro lecciones que siguen. Se trata de que aparecen en algunos compases corcheas no barradas.

Estamos en la lección 92, y el encabezamiento es: la negra con puntillo vale una parte y media. Encima del primer pentagrama figuran estas letras: "do O"; suponemos que quiere indicar al profesor, para que él traslade al alumno, que un ardid para darle a la negra con puntillo la duración que tiene, es alargar la última letra de la sílaba sonora de manera que sea ésta la que cubra el tiempo de la corchea que ocupa el puntillo. Es un 
buen sistema como medio para empezar a dominar esta medida, siempre evitando que el alumno llegue a desvirtuar la música. Ocho lecciones dedicadas a esto.

Lección 100, empiezan aquí las alteraciones. Hay una brevísima descripción de las tres y comienzan las lecciones para el sostenido, en total 14. Comienza con 4 para el semitono cromático alterando el Fa y el Sol, con figuras de nota blanca y negra. Sigue con las mismas notas alteradas pero con semitono diatónico, ya se incorporan de nuevo las corcheas. Mezcla de semitonos diatónicos con cromáticos. Y las siguientes tienen alteradas el resto de notas, cromática y diatónicamente.

Ahora el bemol, una lección con blancas y negras y bemolizado el Si cromáticamente. Luego de nuevo con corcheas el Mi bemol también cromáticamente. El La después, las otras notas y semitonos diatónicos.

El becuadro para anular el efecto de las otras dos alteraciones. Utilizado en seis lecciones para deshacer el cromatismo.

Dos lecciones más para realizar la extensión de una alteración a todas las notas de su mismo nombre que estén en un compás.

Aparece ahora el silencio de corchea puesto detrás de ella, cuatro lecciones para ello.

Le llama "aspiración" al silencio puesto delante de la corchea y que produce un contratiempo, (de lo que no habla). No está mal este concepto para que el neófito acceda a la comprensión del contratiempo corto, aunque hay otras maneras mejores. Nueve lecciones en las que también hay negras con puntillo y alteraciones.

La ligadura es ahora el signo que se aborda. Primeramente entre dos redondas, blanca y negra después, negra y corchea, blanca y corchea.

La definición de síncopa que hace el autor es: una nota cuya duración se halla entre dos compases, entre dos medios compases, entre dos partes o entre dos medias partes. Se acentúa la primera mitad de la nota sincopada. Es una definición aceptable, aunque las hay más claras y precisas. Una lección para la redonda partida, tres para la síncopa de blanca y diez para la de negra, o sea la síncopa breve.

Las siete últimas lecciones son para el tresillo de corchea, al que define como un grupo de tres notas que se ejecutan en igual tiempo que dos de las mismas figuras, y en las que aparece profusamente el tresillo. 


\section{SEGUNDA PARTE}

\section{CUADRO DE INFORMACIÓN GENERAL DE LA SEGUNDA PARTE.}

$\mathbf{N}^{\circ}$ de lecciones

Extensión de las lec- Entre 18 y 32 compases

ciones

Claves empleadas

Tesituras que abarcan

Tonalidades que trata y estudia

Compases que emplea y estudia

Dificultades métricas que contiene

Dificultades de entonación que se encuentran y orden en que se enseñan los intervalos

Armonía utilizada

Formas que tienen las lecciones

Introducciones, Intermedios o Codas instrumentales

Teoría de la música que incluye

95

Do M y La m

Igual que en la anterior.

Ninguna

A-A'-A'; A-B-A'

No tienen

No tiene
Sol hasta la $70 \mathrm{Fa} 4^{\mathrm{a}}$ el resto

Como en la anterior parte

$4 / 4,2 / 4,3 / 4,3 / 8,9 / 8,12 / 8,6 / 8,2 / 2$

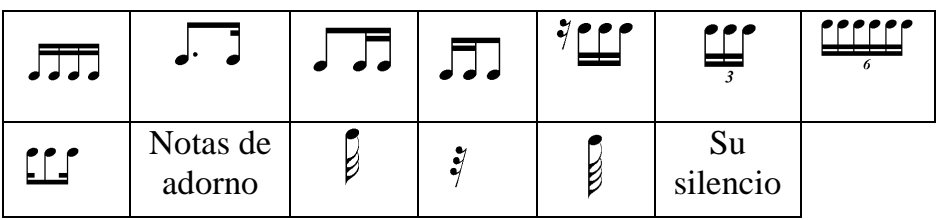

\subsubsection{DESCRIPCIÓN DETALLADA DE ESTA SEGUNDA PARTE.}

Comienza esta parte con el grupo de 4 semicorcheas. Nueve lecciones dedica a esta medida, empleando todavía el compás de compasillo. Además maneja todos los recursos vistos en la parte primera.

Le toca el turno a la corchea con puntillo seguida de semicorchea. Cinco lecciones. 
Las corcheas seguidas de dos semicorcheas, y al contrario ocupan 10 lecciones, también la sustitución de la corchea por su silencio, (debería ser la secuencia al contrario, primero esta fórmula rítmica y luego la anterior).

Contratiempo con el silencio de semicorchea, cuatro lecciones.

Cuatro más para el tresillo de semicorchea, incluso sincopado.

Otras tantas para el seisillo. Además se van utilizando todos los elementos que han sido aprendidos.

La Síncopa muy breve ocupa también 4 lecciones, y la última enlaza varias síncopas.

Ya por fin hay un nuevo compás, el de 2/4. La tonalidad sigue siendo la misma. Al iniciar este compás volvemos a ritmos sencillos, blancas, negras y corcheas; poco a poco va incorporando mayores dificultades rítmicas, pero las aprendidas en el compás de 4/4, ninguna nueva. Semicorcheas, tresillos, corchea con puntillo y semicorchea, síncopa breve, síncopa irregular, corchea y dos semicorcheas, en total 8 lecciones.

Compás de 3/4, también 8 lecciones, en las que procede de forma parecida en cuanto a dificultades rítmicas.

Compás de 3/8, 3 lecciones, también de más fácil a más difícil.

Dos lecciones para el de 9/8 y otras dos para el 12/8.

Compás de 6/8, (no parece lo más lógico este orden). Son 3 lecciones, y una última que indica: a cuatro partes. Suponemos que querrá decir subdividir marcando dos subtiempos en el primero, uno en el segundo, dos en el tercero y uno en el cuarto; esto es marcando el compás con los movimientos de un cuaternario como se hace modernamente.

Acaban las lecciones en la clave de Sol con el compás de 2/2, 3 lecciones.

Llave de Fa en $4^{\text {a }}$ línea. El nombre de las notas en líneas y espacios y 7 lecciones, en las que va cambiando de compases, entre los aprendidos, y también va progresivamente de menor a mayor dificultad rítmica.

Notas de Adorno:

Se suceden ahora una serie de lecciones, 2 por cada clase de adorno, con las notas de adorno según la denominación que les da Sabatés:

Apoyatura lenta a la auténtica apoyatura. Apoyatura rápida al mordente de una nota. Apoyaturas dobles a los mordentes de 2 notas, tanto rectos como mixtos. Morden- 
tes a los mordentes a la segunda superior o inferior y a su abreviatura. Grupetos rectos y circulares, de 3 y 4 notas con sus abreviaturas.

Termina esta parte tratando la fusa, su silencio, la semifusa y el suyo, con dos lecciones para cada cosa.

\section{TERCERA PARTE}

\section{CUADRO DE INFORMACIÓN GENERAL DE LA TERCERA PARTE.}

$\mathbf{N}^{\circ}$ de lecciones 70

Extensión de las lec- 22 a 45 compases

ciones

Claves empleadas

Sol y Fa $4^{\mathrm{a}}$ y al final Do $1^{\mathrm{a}}$, Do $2^{\mathrm{a}}$, Do $3^{\mathrm{a}}$, Do $4^{\mathrm{a}}$ y Fa $3^{\mathrm{a}}$.

Con una lección para cada una

Tesituras que abarcan $\quad \mathrm{Do}_{3} \mathrm{a} \mathrm{Fa}_{4}$

Tonalidades que trata Todas

y estudia

Compases que emplea Los mismos que en la anterior

y estudia

Dificultades métricas que contiene

Dificultades de entonación que se encuentran $y$ orden en que se enseñan los intervalos

Armonía utilizada

Formas que tienen las lecciones

Introducciones, Intermedios o Codas instrumentales

Teoría de la música No tiene que incluye

No tienen
Doble puntillo. Triple puntillo. Valores irregulares hasta docillo

Dobles alteraciones. Enarmonía

Como en las anteriores 


\subsubsection{DESCRIPCIÓN DETALLADA DE ESTA TERCERA PARTE.}

Hasta la lección 31, se suceden una por cada tonalidad, sin explicación de este concepto, cambiando entre los compases estudiados en la otra parte, y también entre las claves de Sol y Fa en $4^{a}$ línea. No se añade ninguna dificultad nueva.

Después, repitiendo compases y tonalidades ya vistas, se suceden lecciones con signos de repetición y de abreviación hasta la lección 44.

A partir de la 45, cada lección (a veces dos lecciones), está dedicada a una cuestión:

Cuarenta y cinco: cambio de tono, como principal Do sostenido mayor, cambia a La mayor y vuelve al principal.

Cuarenta y seis: $\operatorname{signos} \%$ y $\%$

Cuarenta y siete y cuarenta y ocho: dinámica

Cuarenta y nueve: enarmonía, tonalidad de Si bemol menor, cambia a La sostenido menor y vuelta al primero.

Cincuenta: de Sol menor a Sol mayor

Cincuenta y uno: términos del carácter

Cincuenta y dos: compás de 2/4 subdividido

Cincuenta y tres: de nuevo términos del carácter

Cincuenta y cuatro: dinámica y agógica

Cincuenta y cinco: en la que aparece una pequeña fermata

Cincuenta y seis: de Si bemol menor a Si bemol mayor

Cincuenta y siete: de la tonalidad de Sol bemol mayor, por enarmonía con el Fa sostenido pasar a la de Re mayor, y vuelta a Sol bemol.

Cincuenta y ocho: notas de adorno, aunque ya habían aparecido en la segunda parte.

Cincuenta y nueve: trino

Sesenta: valores irregulares hasta docillos

Sesenta y uno y sesenta y dos: líneas adicionales para notas muy graves y muy agudas, desde $\mathrm{Mi}_{2}$ hasta $\mathrm{Do}_{6}$

Sesenta y tres y sesenta y cuatro: líneas adicionales pero en clave de $\mathrm{Fa}$ en $4^{\mathrm{a}}$

Sesenta y cinco: correspondencias entre las dos claves utilizadas hasta ahora

Sesenta y seis a setenta: una lección dedicada a cada una del resto de claves, y no demasiado sencillas, en el siguiente orden: Do $1^{\mathrm{a}}$, Do $2^{\mathrm{a}}$, Do $3^{\mathrm{a}}$, Do $4^{\mathrm{a}}$ y Fa $3^{\mathrm{a}}$. 
Acaba el método diciendo que el alumno puede practicar estas últimas claves leyendo las anteriores lecciones en la clave que quiera practicar, a lo que sigue una lista de términos de la velocidad, adverbios y términos del carácter.

\subsubsection{VALORACIÓN DE LA EFECTIVIDAD DEL MÉTODO Y DE SU APORTACIÓN A LA ENSEÑANZA}

Lo que tiene de positivo el primer volumen es que hay muchas lecciones para ejercitar una misma dificultad.

Valorable la manera de enseñar la negra con puntillo seguida de corchea y el contratiempo corto.

Por lo demás es carente de todo interés musical, sus melodías son insípidas, no tiene acompañamiento, por tanto referente armónico, tienen una construcción formal que, la mayor parte, son la misma frase con cambios de dirección.

Sólo se practica un compás.

Entre las dos partes hacen una, según los elementos que se programaban en la época, a excepción de las notas de adorno y las fusas que deberían estar en otro nivel más alto.

No tiene la segunda parte mayor interés que la anterior. También insiste mucho en cada dificultad, pero sólo hasta que aparecen nuevos compases, entonces dedica pocas lecciones a cada uno de ellos.

No nos agrada el orden de consignar los compases compuestos.

La tercera parte tiene un poco más de nivel, pero sigue siendo insuficiente una lección para cada dificultad, y menos una para cada clave, no siendo solución lo que el autor dice a este respecto, excepto que se emplee como lectura rítmica.

En general un método insustancial y de escasa utilidad. 
Sabatés Estaper, tercera parte 


\subsection{RESEÑA BIOGRÁFICA DEL AUTOR}

AGERO AMATEY, Feliciano Primo. San Idelfonso (Segovia) 9/6/1825 - Madrid? Teórico, pianista. En 1860 profesor de solfeo en el Conservatorio de Madrid (Virgili Blanquet, $\mathrm{M}^{\mathrm{a}}$ Antonia, en AAVV, 1999, tomo 1, p. 85).

\subsubsection{DESCRIPCIÓN DETALLADA DEL MÉTODO.}

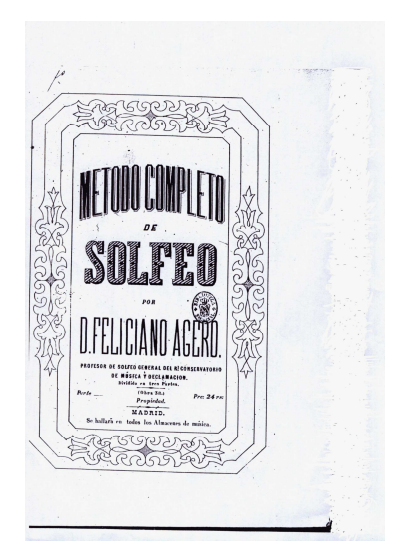

\section{Título del Método}

Método completo de solfeo: dividido en tres partes, Madrid, sin editorial, 1900 probable $^{1}$. Apéndice, página 221.

En la cubierta pone que este autor era profesor de solfeo general del Real Conservatorio de Música y Declamación.

\section{$1^{\text {a }}$ Parte}

\section{CUADRO DE INFORMACIÓN GENERAL DE LA PRIMERA PARTE.}

$\mathbf{N}^{\circ}$ de lecciones

74, a las que llama ejercicios. Previamente hay 35 ejercicios de entonación y de entonación y medida

Extensión de las lec- Entre 16 y 86 compases

ciones

Claves empleadas Sol

Tesituras que abarcan $\mathrm{De} \mathrm{Do}_{3} \mathrm{a} \mathrm{Fa}_{4} \mathrm{y}$ a veces $\mathrm{Sol}_{4}$

Tonalidades que trata Do M y La m

y estudia

Compases que emplea $\quad 2 / 2,4 / 4,2 / 4$ y $3 / 4$

y estudia

\section{Dificultades métricas que contiene}

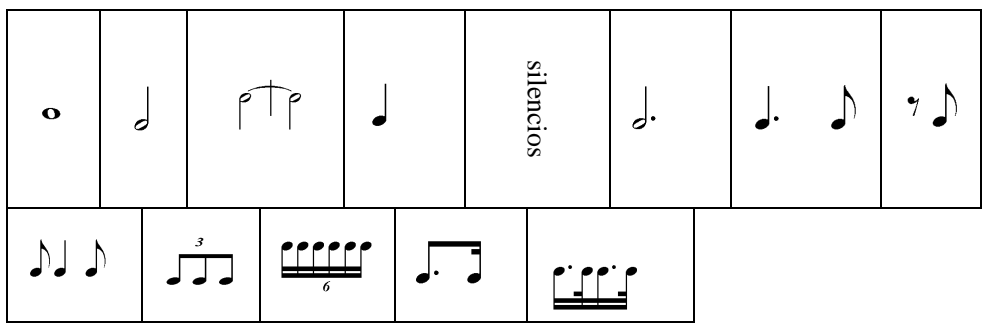

\footnotetext{
${ }^{1}$ En el catálogo de la Biblioteca Nacional y en el libro no figura la fecha. Pero en la obra citada arriba, artículo firmado por $\mathrm{M}^{\mathrm{a}}$ Antonia Virgili Blanquet, dice que el método es de 1882.
} 
Dificultades de entonación que se encuentran $y$ orden en que se enseñan los intervalos

Armonía utilizada

Formas que tienen las lecciones

Introducciones, Intermedios o Codas instrumentales

\section{Teoría de la música \\ Tiene mucha} que incluye B-C
Intervalos naturales primero, semitonos diatónicos y cromáticos después. $5^{\mathrm{a}}, 4^{\mathrm{a}}$ y $3^{\mathrm{a}}$, disminuida.

$2^{\mathrm{a}}, 3^{\mathrm{a}}$ y $4^{\mathrm{a}}$, preparadas y de salto

De $4^{\mathrm{a}}$ a $8^{\mathrm{a}}$ preparadas y de salto

Compuestos hasta la $11^{\mathrm{a}}$

En las lecciones, primero hasta la $6^{\text {a }}$, luego semitonos diatónicos y cromáticos, después el resto de intervalos.

Sin acompañamiento

No se aprecia ninguna forma concreta; son sucesiones de frases inconexas. Si acaso algunas parecen tener la forma $\mathrm{A}-$

No tienen ninguna

\section{DESCRIPCIÓN DETALLADA DE ESTA PRIMERA PARTE.}

Comienza con unas breves consideraciones y advertencias generales acerca de la práctica del método en las que aconseja el estudio por separado de la entonación y medida, y la reiteración lenta de los fragmentos que se resistan, además de recomendar interés en esta materia, ardua, pero totalmente imprescindible, hasta el punto de afirmar que el que no llegue a ser un buen solfista, que no pretenda seguir los estudios posteriores, ya que no llegará a ser más que una medianía.

Después la, en muchos acostumbrada teoría, de los conceptos básicos. Al llegar a explicar el compás, da como primer compás (o sea el principal), el compasillo binario y cuaternario. A las figuras las nombra, a partir de semicorchea, como doble, triple y cuádruple corcheas.

Un ejercicio de lectura de notas en clave de Sol, primero en líneas, luego en espacios, y posteriormente en líneas y espacios adicionales.

Se inician una serie de ejercicios de entonación pura, segundas, terceras y cuartas, preparadas por medio de puntos en las notas intermedias, aconsejando que se canten primero por grados y luego por salto; mezcla de todas ellas. Después desde cuartas a octavas, igualmente preparadas por grados intermedios y también de salto. 
De nuevo teoría, para hablar de la ligadura, los silencios y las síncopas (obsérvese que mezcolanza de conceptos, y que inoportunos dos de ellos). A partir de aquí, la teoría es en forma dialogada.

Un nuevo ejercicio de entonación pura, mezcla de intervalos, pero también los compuestos hasta la $11^{\mathrm{a}}$ (también fuera de lugar totalmente).

Y una nueva serie de ejercicios de entonación y medida, en compás de 2/2 y con redondas, luego blancas, (con el dislate de hacer síncopas con las blancas y notas partidas) blancas y negras en definitiva, más sus silencios (el de negra es de la forma acostumbrada antiguamente), vuelve a componer ejercicios con intervalos variados y de nuevo desde segunda a octava con preparación y sin ella.

Ahora el Aire y el compás de compasillo con la duración de las figuras de nota en él; y como si tuviese algo que ver con todo esto, el calderón.

Tres lecciones con negras, blancas y sus silencios, ligadura y calderón. Intervalos hasta la $6^{\mathrm{a}}$.

El puntillo, concepto de intervalo, tono, semitono y alteraciones. Dos lecciones con el puntillo aplicado a la blanca. A continuación sostenido en el Fa, tras tres lecciones, para el Fa y el Do. Además aquí ya empieza con las corcheas, pero no en grupos de dos o cuatro, sino después de la negra con puntillo y también a contratiempo, y por si eso aun fuera poco, en la misma lección las síncopas breves y enlazadas. No acaba ahí el desbarro del autor, sino que además recomienda en una nota al pie, que debido a la dificultad de las síncopas, que se subdivida el compás. De modo que a la vez, alteraciones, contratiempos, síncopas y subdivisión del compás; todo en la lección 13.

Alteraciones para el Fa, Do y Sol, y otra precipitación: los tresillos de negra en $2 / 2$ y corchea en $4 / 4$, y los seisillos de corchea y semicorchea (antes de haber conocido éstas).

Alteraciones del bemol para el Si, después para el Mi y luego para el Si, Mi y La, sin abandonar los sostenidos, y ello lleva a algún intervalo de $3^{\text {a }}$ disminuido. A pesar de no haber aparecido la semicorchea en grupo, sí que se incluyen, entre estas lecciones, la fórmula rítmica corchea con puntillo - semicorchea.

El compás de 2 y 3 por 4 . Los signos de repetición. Unas cuantas lecciones con las dificultades aprendidas hasta ahora.

Tono y modo, intervalos, su calificación e inversión; y una tabla de intervalos, que no son los que forman la escala natural, esto al menos está bien; y otra cosa que está bien es que llama a las cuartas mayores y menores, como casi todos los de su tiempo. 
Varias lecciones en La menor, todavía en 2/4 y luego en 3/4, ya en este compás aparece la semicorchea con puntillo - fusa.

Siguen, hasta el final, las lecciones entremezclando las cuestiones aprendidas. Termina con un cuestionario de los elementos teórico - prácticos que deben entrar en el primer curso, que son los que se han desarrollado en esta parte.

\section{$2^{\mathrm{a}}$ Parte}

\section{CUADRO DE INFORMACIÓN GENERAL DE LA SEGUNDA PARTE.}

$\mathbf{N}^{0}$ de lecciones

38 y 24 ejercicios

Extensión de las lec- Entre 16 y 48

ciones

\section{Claves empleadas $\quad \mathrm{Fa} 4^{\circ}$ y Do $1^{\mathrm{a}}$}

Tesituras que abarcan $\mathrm{De} \mathrm{Do}_{3} \mathrm{a} \mathrm{Mi}_{4}$, aunque en algunas llega hasta el $\mathrm{Fa}_{4}$

Tonalidades que trata Sol M, Mi m, Re M, Si m, La M, Fa \# m, Mi M, Do \# m, y estudia

Fa M, Re m, Si b M, Sol m, Mi b M, Do m, La b M, Fa m

Compases que emplea Los de antes más 3/8, 6/8, 9/8 y 12/8

y estudia

Dificultades métricas Las de antes más notas de adorno que contiene

Dificultades de entona-

$5^{a}$ aumentada, intervalos compuestos, dobles alteraciones ción que se encuentran $y$ orden en que se enseñan los intervalos

Armonía utilizada

Formas que tienen las lecciones

Introducciones, Intermedios o Codas instrumentales

Teoría de la música que incluye
Sin acompañamiento

$\mathrm{Al}$ igual que en la parte anterior, la mayoría son A-B-C, pero en otras no se aprecia la forma, y algunas son pequeños motivos desarrollados

No tienen

Muy poca, la indispensable para explicar las novedades. 


\subsubsection{DESCRIPCIÓN DETALLADA DE ESTA SEGUNDA PARTE.}

Comienza con la clave de Fa en $4^{\mathrm{a}}$, el compás de tres por ocho y la tonalidad de Sol mayor. En esta parte introduce, cada vez que aborda una nueva tonalidad, ejercicios de entonación y medida.

Tras varias lecciones en las que se va entrando en las diferentes tonalidades, a la altura de la número 14, y cuando está en la tonalidad de Do sostenido menor, trata de las Notas de Adorno. Hay ejercicios para practicar cada una de ellas, lo curioso es que después no las incluye en las lecciones hasta pasadas varias de ellas, y en muy pocas ocasiones. Lo único a observar en la explicación de las notas de adorno es que representa a la apoyatura, además de con los distintos formatos de figuras de nota, con la forma propia del mordente, corchea barrada. A los grupetos les llama mordentes de 3 y 4 notas, como muchos otros autores, y los divide en rectos y circulares.

A la altura de la lección 18, aborda la clave de Do en $1^{\mathrm{a}}$ línea. Primero ejercicios de lectura de notas, líneas, espacios y adicionales. Empieza con cuatro lecciones en Do mayor, lo que es facilitar un poco el aprendizaje de la clave, aunque las dificultades rítmicas no son pequeñas.

Acaba con la lección 38, recopilación, según indica, en la que hay cambios de compases, de armadura y de aires; a la que le sigue un ejercicio de lectura de notas, en las 3 claves hasta ahora conocidas, sobre agudas y sobre graves.

Añade, como en la primera parte, un programa de las cuestiones tratadas en ella.

\section{$3^{\text {a }}$ Parte}

\section{CUADRO DE INFORMACIÓN GENERAL DE LA TERCERA PARTE.}

$\mathbf{N}^{\circ}$ de lecciones

50 , de las cuales 41 son a una voz, el resto a 2, y la última a 3

Extensión de las lec- Entre 11 y 114 compases ciones

Claves empleadas

Además de las anteriores, Do $2^{\mathrm{a}}$, Do $3^{\mathrm{a}}$, Do $4^{\mathrm{a}}$, y Fa $3^{\mathrm{a}}$, también mezcla de ellas.

Tesituras que abarcan Como en las anteriores partes

Tonalidades que trata Si M, Sol \# m, Fa \# M, Re \# m, Re b M, Si b m, Sol b M, y estudia

\section{Mi b m}


Agero Amatey, 2aㅡ parte

Compases que emplea y estudia

Dificultades métricas que contiene

Dificultades de entonación que se encuentran $y$ orden en que se enseñan los intervalos

Armonía utilizada

Formas que tienen las lecciones

Introducciones, Intermedios o Codas instrumentales

Teoría de la música que incluye
Los anteriores más 4/2, 4/8, 3/2, 2/1, 2/8, 12/4, 12/16, 9/4, $9 / 16,6 / 2,6 / 4,6 / 16,7 / 4,5 / 4$ y $10 / 8$

Valores irregulares hasta diecillo

Enarmonías

A partir de las lecciones a 2 voces, que son las que tienen acompañamiento, es una armonía clásica con algún grado alterado

Las de 1 voz como en las anteriores partes. Las de 2 voces, la mayoría A- B- A', también A- B y A- B- C

No tienen

Bastante

\subsubsection{DESCRIPCIÓN DETALLADA DE ESTA TERCERA PARTE.}

Comienza con la clave de Do en $2^{\mathrm{a}}$ línea y la tonalidad de Si mayor. Procede como en la anterior parte, con ejercicios de lectura de notas cuando aparece una nueva clave, y de entonación con la introducción de una nueva tonalidad.

Incluye, poco después de empezar, teoría sobre los signos de articulación y dinámicos, transporte, aunque muy de pasada, y fermata.

A partir de las tonalidades con 6 alteraciones, repite la melodía en ese tono y en el del semitono cromático; y con las de 7 alteraciones, compara las enarmónicas entre si.

Después de la lección 19, nos encontramos con una serie de lecciones cortas con los compases menos usados; previamente ha hablado de las figuras antiguas. Opina, igual que Eslava, que el compás de 10 por 8 es el que corresponde al ritmo de zortzico.

Hay una tabla de las tonalidades con dobles alteraciones y sus enarmónicas con alteraciones sencillas, a la que sigue unos cortísimos, (de dos compases de longitud) y sin explicación ninguna, ejemplos de transporte medio punto alto, medio punto bajo, un punto, punto y medio y dos puntos, bajos y altos. Completa estas exiguas ilustraciones con los siguientes consejos: 
¿Qué debemos hacer para transportar una lección escrita en tono de sostenidos y que quede en tono natural?

Nombrar el último sostenido en SI y solfear en la clave que resulte. ¿Y teniendo bemoles?

Nombrar el último bemol en Fa y solfearla en la clave que resulte

Es una curiosa teoría, pero resulta efectiva, solamente, eso sí, para transportar a Do mayor o La menor. Por eso luego incluye cuatro lecciones en Mi mayor, Sol mayor, Re menor y Mi bemol mayor, para transportarlas a natural.

Sigue con 3 lecciones con cambios de claves.

Después viene una sección con lecciones a 2 y 3 voces. Son 6 lecciones a 2 voces, con acompañamiento de piano en forma de bajo cifrado. Luego hay una a 3 voces, también con acompañamiento y una a 3 voces sola. Las tonalidades en que se desenvuelven son Do mayor, Fa mayor, Si menor, Si bemol mayor, Fa menor y Re bemol mayor; emplea las claves de Sol, Fa en $4^{\mathrm{a}}$, Do en $3^{\mathrm{a}}, 1^{\mathrm{a}}$ y $4^{\mathrm{a}}$. Su textura es, la mayor parte, homofónica, aunque también hay algunas contrapuntísticas, incluso con algún pasaje canónico.

Acaba con unos ejemplos de abreviaturas, y con el programa de este curso.

Añade como final un vocabulario musical de términos más usados, que comprende 11 páginas.

\subsubsection{VALORACIÓN DE LA EFECTIVIDAD DEL MÉTODO Y DE SU APORTACIÓN A LA ENSEÑANZA}

No es el único que lo hace, pero no es la mejor manera de empezar con el compás de dos por dos. La ligadura, y la síncopa antes de empezar las lecciones es una precipitación sin fundamento.

No puede estar más desorganizada la teoría, ni más precipitada tampoco, amén de que mezcla conceptos muy dispares, no los lleva a la práctica de inmediato.

Las alteraciones antes de conocer ritmos de corcheas, semicorcheas y fórmulas combinadas, es otro disparate, al que se le suma el agolpamiento de dificultades, y muchas de ellas muy al principio.

Sin embargo es muy útil la forma de realizar los ejercicios de entonación. 
Agero Amatey, 3aㅗ parte

La segunda parte está mejor pensada que la primera, no hay tanta precipitación en el abordaje de las distintas dificultades y la progresión de los diferentes elementos es, dentro de los parámetros de la época, más lógica.

La tercera parte, al igual que la otra es más razonable y no presenta sobresaltos.

Pero en general, un método poco afortunado e inservible para aficionar a un educando. 


\subsection{RESEÑA BIOGRÁFICA DEL AUTOR}

LLUPART, ALVERNI, Carlos: No hemos podido encontrar ninguna reseña biográfica de este autor ${ }^{1}$.

\subsubsection{DESCRIPCIÓN DETALLADA DEL MÉTODO}

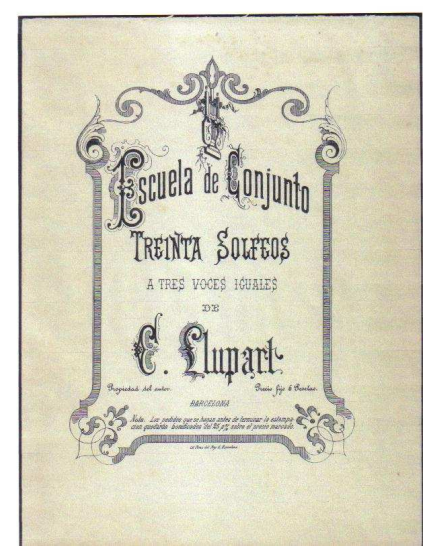

\section{Título del Método}

Escuela de Conjunto. Treinta solfeos a tres voces iguales, Barcelona, Amorós, 1884 o posterior ${ }^{2}$ Apéndice, pág. 222.

\section{CUADRO DE INFORMACIÓN GENERAL DEL MÉTODO.}

$\mathbf{N}^{\circ}$ de lecciones

Extensión de las lec- 33 a 201 compases

ciones

Claves empleadas

Tesituras que abarcan

Tonalidades que trata y estudia

Compases que emplea y estudia

30 todas a capella

Sol en las 3 voces La b m
$\mathrm{Sol}_{2} \mathrm{a} \mathrm{Fa}_{4}$ aunque pocas veces agota esta extensión

Do M, La m, Sol M, Mi m, Re M Si m, La M Fa \# m,

Mi M, Do \# m, Si M Sol \# m, Fa \# M, Re \# m, Do \# M, La \# m, Fa M. Re m, Si b M, Sol m, Mi b M, Do m,

La b M, Fa m, Re b M, Si b m, Sol b M, Mi b m, Do b M y

$4 / 4,2 / 4,3 / 4,3 / 8,2 / 2,6 / 8,2 / 1,9 / 8$ y $4 / 2$

\footnotetext{
${ }^{1}$ En AAVV. (1999). Diccionario de la Música española e Hispanoamericana, Director y coordinador general Emilio Casares Rodicio. Madrid: SGAE. En el tomo 6, p. 960, firmado por Josep Ma Vilar i Torrens, hay un Llopart Carles, del siglo XIX que tiene algunas obras manuscritas en el archivo de Manresa. Podría ser Llopart con fonética catalana, pero no podemos asegurarlo

${ }^{2}$ En el catálogo de la Biblioteca de Cataluña aparece esta fecha. En el libro no figura en absoluto la editorial Amorós, sino Lit. Plaza del Rey 6, Barcelona, ni tampoco el año. Éste quizás sea una deducción por los que figuran en las primeras páginas dentro del juicio crítico que esta obra ha merecido..., que son 1883 y 1884.
} 


\section{Dificultades métricas que contiene}

Dificultades de entonación que se encuentran $y$ orden en que se enseñan los intervalos

Armonía utilizada

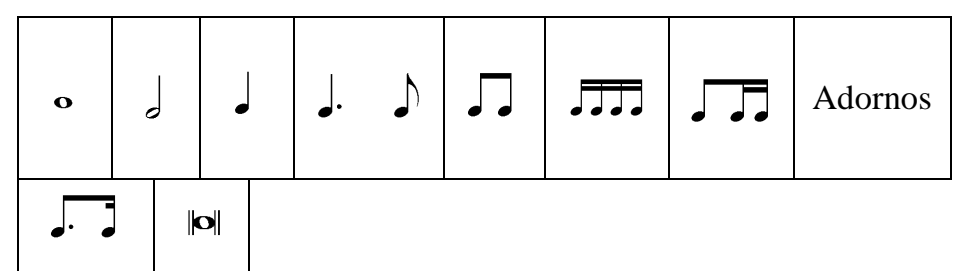

Muy pocas, todo discurre sobre intervalos propios de la tonalidad.

No hay orden de aparición de los intervalos por que no es un método convencional

En principio bastante sencilla, modulaciones a relativos, y vecinos. Algún grado alterado. Algún pasaje de indefinición tonal. A partir de la 19 alguna modulación a lejanos, también algún cambio de tonalidad sin utilizar su dominante, y por enarmonía

A-B-C; A-B-A-coda; A-B-A; A-A'-A'’; A-B-B'; A-B-A'-C; A-A'-B; A-B-A'-C-A'’; A- B- C- A'; A-B-A'-A',; A-A'

Introducciones, Intermedios o Codas instrumentales

Teoría de la música que incluye
No hay acompañamiento, ninguna tiene, a excepción de la $n^{\circ}$ 20 en la que hay unos compases de bajo al principio y dos intermedios en los que el bajo da entrada a una nueva sección

No contiene

\section{SECUENCIA}

Antes del prólogo hay unos comentarios de varios compositores de la época referentes a este método. Entresacamos las frases que nos han parecido más relevantes con respecto a las características del libro:

Francisco de P. Sánchez Gavanyach. Ritmos bien medidos a la par que originales, armonización clara y correcta sin ser vulgar ni rutinaria, melodías de aire elegantísimo... Pedro Tintorer: Los conceptos están de todos modos muy bien desarrollados, las voces bien conducidas, bien armonizadas..., los divertimentos de contrapunto, en cánones, y de estilo fugado vienen a enriquecer el conjunto de su obra...

C. Martínez Imbert: Siempre he considerado de suma utilidad los solfeos a dos, tres o más voces, especialmente cuando al discípulo tiene ya formada exacta idea de la entonación y valores musicales...Así se explicará $V$. , mi buen amigo, la importancia que concedo a los estudios de combinación a varias voces, por lo que ellos obligan a cada una de sus partes a la completa seguridad de relativa entonación, justo valor, preciso ritmo, etc. etc.... 
José Marraco: ...la variedad de géneros, belleza de melodías, riqueza de armonía y modulación, y lo que más de admirar es, el rigor de tesitura a que se ha obligado, y la no menos severidad juguetona con que trata $V$. los pies forzados unas veces, los ritmos otras, temas caprichos, etc., etc.

Adjuntamos íntegros estos comentarios en el apéndice, página 223.

Y en el prólogo, entre otros comentarios hace el autor el siguiente: Heme preguntado en mil ocasiones. ¿Por qué razón el solfeo, base fundamental de cualquiera de los ramos del arte musical a que nos dediquemos, no ha tenido que perder esa aridez propia de todos los principios? ¿Será por ventura porque no tiene atractivos?...

\section{Lección 1:}

Do mayor, 4/4, redondas, blancas y negras. Armonía sencilla, modulaciones a la subdominante, algunas imitaciones contrapuntísticas a 2 y a 3 voces. A-B-C-

\section{Lección 2:}

La menor, 2/4, negras, negras con puntillo, corcheas, semicorcheas, fórmulas combinadas, incluso dos veces un mordente de 2 notas recto descendente. A- BA- coda. La primera frase es una imitación en las 3 voces al unísono a distancia de dos compases; la segunda en el relativo mayor, es casi homofónica; la tercera es copia literal de la primera; y una pequeña coda de dos compases.

\section{Lección 3:}

Sol mayor - do mayor - sol mayor, 3/4. Negras, corcheas y alguna fórmula corchea - dos semicorcheas. A-B-A-, la primera sección casi homofónica, a distancia de terceras, pero también con alguna contestación y movimientos contrarios. Comienza con el acorde de tónica en segunda inversión; la segunda sección toda en el tono de la subdominante, las dos voces superiores comienzan con un acompañamiento rítmico mientras la $3^{\mathrm{a}}$ hace la melodía, aunque después pasa ésta a la $1^{\mathrm{a}}$ y discurren las tres en forma homofónica. La armonía bastante sencilla.

\section{Lección 4:}

Mi menor - mi mayor - mi menor, 3/4, blancas y negras. A-B-A-, las 3 secciones son similares, todas ellas a modo de motete medieval. Modulaciones a la dominante, y alguna dominante secundaria. 


\section{Lección 5:}

Re mayor, 2/4, corcheas y semicorcheas, mordentes de 2 notas y trinos. A-B-C. Armonía muy sencilla, modulación al relativo menor. Funciona como una melodía acompañada por las otras dos voces; en la última sección es la segunda voz la que inicia las semifrases.

\section{Lección 6:}

Si menor, 3/8, negras, corcheas y semicorcheas. A-B-A. Armonía sencilla, modulación a la dominante, mezcla de melodía acompañada y contrapuntos.

\section{Lección 7:}

La mayor, 4/4, blancas y negras en la voz superior, semicorcheas en la del medio y fórmula rítmica corchea con puntillo - semicorchea en la inferior. A-A'A''(recortada en su primera mitad y utilizada como coda)

\section{Lección 8 Divertimento a Fuga:}

Fa sostenido menor, 2/2, blancas negras y corcheas. Figuración típica del contrapunto florido, no vemos la fuga por ninguna parte, es un contrapunto florido, con una sección de imitaciones al unísono. Tiene 3 secciones: una que entran las tres voces al unísono, se separan, modula al relativo mayor y luego a la subdominante del relativo, para entrar en un periodo de imitaciones que acaba con una semicadencia; la segunda sección empieza en la tonalidad principal, modula a su dominante, vuelve a la principal y termina con una semicadencia, no tiene ningún periodo imitativo; la última, más corta que las anteriores, comienza con la dominante de la tonalidad relativa mayor, para modular después a la tonalidad inicial con la que acaba, tampoco tiene ningún periodo imitativo, es simplemente contrapunto florido.

\section{Lección 9:}

Mi mayor, 6/8, figuración propia de este compás, predominando la fórmula rítmica corchea con puntillo - semicorchea - corchea propia de este compás. A $\mathrm{B}-\mathrm{B}^{\prime}$.

La primera sección establece una línea melódica que salta en las distintas voces en forma dialogada, mientras las otras hacen principalmente notas tenidas, comienza la primera voz, le contesta la tercera, primeramente a distancia de dos compases 
y después de un compás, mientras la segunda es homofónica de la primera, termina en el tercer grado mayorizado; la segunda sección corre casi totalmente la melodía a cargo de la tercera voz, mientras las otras dos mantienen armonías, casi al final hay un dúo con la primera y segunda voz siendo la tercera la que mantiene notas, termina en la dominante; y la tercera sección tiene más alternancia en cuanto a la melodía en las distintas voces, al final las tres en forma homofónica determinan la tonalidad.

\section{Lección 10:}

Do sostenido menor, 2/1 (compás infrecuentemente visto), redondas y cuadradas. A-B-C. Es un corto motete medieval.

\section{Lección 11:}

Si mayor, 6/8, negras y corcheas. A-B-A'-C. Primera sección, melodía a cargo de la primera voz, pasando luego a la segunda, las demás mantienen armonías, termina en el tono principal; siguiente sección, en el tono de la dominante, lleva totalmente la melodía la voz tercera; siguiente sección, empieza en la tonalidad principal, se alternan las voces con la melodía, modula luego a Mi mayor con el que termina, pero con $7^{\mathrm{a}}$ añadida, lo que hace el efecto de una semicadencia de La mayor que no resuelve, la cuarta sección empieza con la dominante de Re mayor, pero en ningún momento se determina esta tonalidad, por lo que es una sección de indefinición tonal, la melodía empieza en la primera voz, pasa a dúo entre la primera y la segunda, pasa también a la tercera, y hay una coda con la primera célula melódica de A en las distintas voces alternadas a modo de eco o contestación.

\section{Lección 12:}

Sol sostenido menor, 3/4, blancas, negras y semicorcheas. A-A'-B. En la primera y segunda sección llevan la melodía la primera voz, y al final de la segunda la toma la tercera, ambas terminan en la dominante; en la tercera comienza la melodía en la voz grave, pasando de nuevo a la primera, alguna dominante secundaria y modulación a la dominante del relativo mayor, para terminar en la principal.

\section{Lección 13:}

Fa sostenido mayor, 9/8, blancas, negras y corcheas. A-A'. Escrita en forma muy contrapuntística. 


\section{Lección 14, RITMO A 3 [sic]:}

Re sostenido menor, 3/4, prácticamente toda negras y blancas, alguna corchea al final, y casi toda ella homofónica.

\section{Lección 15. RITMO A 5 Canon:}

Do sostenido mayor, 6/8, negras, corcheas y corcheas con puntillo - semicorcheas. Se trata de un canon al unísono, cuyas imitaciones proceden por semifrases de 5 compases. Comienza la primera voz con una semifrase de 5 compases, enlaza con una nueva semifrase, y al tercer compás entra con la primera semifrase la segunda voz. Cuando ésta lleva 7 compases entra con la primera la tercera voz, entonces la primera comienza una nueva semifrase, y con esas tres, mantiene el canon siempre a distancia de 7 compases. Al final hay una coda de 6 compases.

\section{Lección 16. Religioso:}

La sostenido menor, 4/2, y como su título indica es muy semejante a la lección 10, un motete medieval.

\section{Lección 17:}

Tonalidad principal Fa mayor. Compás de 3/4, pone "tempo di vals". Es una melodía muy bonita en la voz superior, acompañada por las otras dos, con algún pequeño dúo. A-B-A'-C-A'”. A es el tema acompañado por las otras dos voces; B es una sección con notas largas tenidas, casi homofónica, a modo de susurro, porque el autor indica: "a fior de labro". De nuevo A con alguna modificación y al entrar la sección $\mathrm{C}$, cambia a la tonalidad de Si bemol mayor, es también una melodía acompañada, y tras una soldadura vuelve a A, convirtiéndola en frase conclusiva.

\section{Lección 18, Pie forzado en terceras:}

Tonalidad principal Re menor, compás 4/4, blancas, negras y corcheas. Tiene una introducción, de voces a unísono, luego A- B- C- A'. A es una melodía en la voz superior acompañada por las otras dos armonizadas con terceras. B la misma estructura. C cambia la modalidad a Re mayor, tiene dos partes, ambas con la primera y segunda voz por terceras y la tercera voz libre, la primera parte más sobria y una segunda de progresiones modulantes, progresiones que se repiten terminando la sección con la primera parte. A’ viene a terminar la lección, después de repetir la introducción del inicio. 


\section{Lección 19. REDOVA [sic]:}

Tonalidad principal Si bemol mayor, compás de 3/4, tiene como fórmula rítmica característica la corchea con puntillo - semicorchea. A- B- A'. La primera sección muestra un tema con carácter popular en la primera voz acompañado por las otras dos, se repite el tema y tras un pequeño enlace, aparece en la segunda voz la cabeza de él, siguiendo de nuevo la primera voz. La siguiente sección que está en Mi bemol mayor, formada con elementos de A que saltan por las 3 voces, modula también a Sol mayor, cromáticamente a Mi bemol mayor, a La bemol mayor y con un acorde de la dominante con la $5^{\mathrm{a}}$ rebajada vuelve a Mi bemol. La sección que cierra nos devuelve a la tonalidad inicial, pero sin que haya mediado ninguna dominante (actúa la cabeza del tema como dominante), y termina con una coda.

Lección 20. Imitación libre evitando el cruce de las voces:

Sol menor, 4/4, blancas, negras, corcheas y semicorcheas, predominando la fórmula rítmica corchea con puntillo - semicorchea. A- B- A', en las que el bajo da entrada a cada sección, que se forman imitaciones de la voz que comienza la sección, pero como el título indica libres.

\section{Lección 21. Melodía a la voz $3^{\text {a }}$ :}

Mi bemol mayor, 12/8, figuración de notas largas en las voces, y en el bajo, máximo corcheas. A- B- A'. La melodía la lleva el bajo y las voces mantienen armonías.

\section{Lección 22. Melodía a la voz $1^{\mathrm{a}}$ :}

Tonalidad principal Do menor, 9/8, figuración muy sencilla. A - B - A'. Es la primera voz la que lleva la melodía, y las otras realizan armonías tenidas; en la sección $\mathrm{B}$, que cambia la tonalidad a La bemol mayor, y de forma abrupta sin mediar una dominante, sigue llevando la melodía la voz superior, pero completándose con una segunda voz a distancia de terceras en la voz del medio; de nuevo en A' volvemos a la tonalidad inicial.

Lección 23. Pensamiento a pie forzado:

Tonalidad principal La bemol mayor, compás inicial 6/8, combinaciones con negras, corcheas y semicorcheas. A- B- A'. A con la melodía a dos voces por terce- 
ras en las dos superiores, pero los fragmentos de periodo, los termina la segunda voz con fórmulas rítmicas más ligeras (es lo que el autor denominado el "pie forzado"); B está en la tonalidad de Mi mayor, que cambia por enarmonía de una de sus notas, tiene esta sección 4 partes, la segunda cambia al compás de 3/8, y no está en Mi mayor, sino en el modo natural de Mi, siguen las voces superiores a dúo, como en la parte primera, y en esta segunda sobre un bajo que forma nota pedal, la tercera parte de esta sección, vuelve al compás de 6/8 y está en Sol mayor, la cuarta vuelve a reexponer la primera; A' es una reexposición recortada, y tras un compás de silencio, una coda de dos compases en $3 / 8$.

\section{Lección 24. Síncope:}

Fa menor, 3/4, negras y corcheas. A- B- A'. En A, las dos voces inferiores discurren paralelamente a distancia de tercera, y la superior independiente melódicamente a ellas, pero rítmicamente totalmente sincopada, al finalizar la sección la segunda voz marcha paralela a la primera; en B es la segunda voz quien toma la melodía sincopada que antes llevaba la primera voz, y las otras discurren de forma independiente; en A' volvemos a comenzar para buscar el final.

\section{Lección 25. Pasodoble:}

Tonalidad principal Re bemol mayor, 2/4, predomina la fórmula rítmica, propia del pasodoble, corchea - dos semicorcheas y la de corchea con puntillo - semicorchea. A - B - C - coda. Empieza la sección A con una introducción repetida a dúo primera con segunda y luego las tres voces, tras ella el tema $\boldsymbol{a}$ dúo entre las voces extremas, mientras la del medio rellena, sigue un segundo tema $\boldsymbol{b}$ de la misma manera y tras repetir la introducción un tema $c$ en el que el dúo está entre las dos agudas; cambiamos a la tonalidad de Re mayor, por simple descenso cromático, al principio reparto de los motivos entre las voces y después dúo entre las extremas; sección $\mathrm{C}$, de vuelta a la tonalidad principal, igualmente por descenso cromático, es las voz inferior la que efectúa una melodía muy rítmica, que luego pasa a dúo entre las voces superiores, acaba con una coda también a dúo entre las superiores, con algún compás a solo.

\section{Lección 26. Diálogo dentro del tono:}

Si bemol menor, 3/4, negras, corcheas y semicorcheas. A- B- A'. Es como su nombre indica un diálogo constante entre las 3 voces. En la A, son la segunda y 
tercera las que dialogan, mientras la primera calla. En B empieza la voz superior, le contesta la del medio, sigue la superior mientras las otras dialogan o se imitan con pequeñas células rítmicas; A’ vuelve a los motivos del principio pero en un movimiento contrario libre; acaba con una pequeña coda.

\section{Lección 27. Capricho:}

Tonalidad principal Sol bemol mayor, $6 / 8$ y $2 / 4$, negras y corcheas en el 6/8, corcheas y semicorcheas en el 2/4. A - B - A' - A'. La primera sección lleva la melodía la voz superior acompañada por las otras, aunque al final son homofónicas; la segunda en tono de Re mayor, al que pasamos por enarmonía de algunas de sus notas, cambia al compás de 2/4 con la misma configuración armónico - melódica; la tercera sección nos devuelve a la tonalidad y compás original, siendo una pequeña variación de A, acabando en semicadencia; pasa por tanto a A" con la que concluye.

\section{Lección 28. Marcha fúnebre:}

Tonalidad principal Mi bemol menor, compás 2/4, negras y corcheras excepto la melodía que usa frecuentemente la corchea con puntillo - semicorchea. A B - A'. La sección A expone el tema en la voz superior, ora sola, ora a dúo, tiene dos partes; la B en Mi bemol mayor y compás de 4/4, lleva una melodía menos rítmica; A' es una reexposición recortada, solamente la segunda parte de A.

\section{Lección 29. Género descriptivo:}

Do bemol mayor, $3 / 4$, corcheas y blancas. $\mathrm{A}-\mathrm{A}^{\prime}$. Ambas son similares, la melodía es un motivo de dos corcheas y una blanca, que comienza en la voz inferior y pasa, tras varios periodos, a las otras.

\section{Lección 30. Zorzico [sic]:}

Tonalidad principal La bemol menor, 5/8 y figuración propia de este ritmo característico. A - B - A'. Comienza la melodía en la tercera voz, para acabar en la primera, vuelve a reiniciar la frase de la misma manera; pasa a la sección B, en La bemol mayor, muy corta y homofónicas, dos voces en paralelo y otra divergente; y acaba con A'. 


\subsubsection{VALORACIÓN DE LA EFECTIVIDAD DEL MÉTODO Y DE SU APORTACIÓN A LA ENSEÑANZA.}

Es un buen método, aunque es complementario. Pero buen complemento para conseguir musicalidad en los alumnos. Sus melodías son bonitas, discurren entre intervalos sencillos, no tienen grandes saltos, sus ritmos no son difíciles, por lo que es agradable su estudio y ejecución. Muy cuidado el contrapunto. Es lástima que no lleve acompañamiento, ya que a capella es más dificultosa la entonación. 


\subsection{RESEÑA BIOGRÁFICA DEL AUTOR}

CODINACH, Carmelo. Ismael Martínez Carretero firma un artículo titulado La exclaustración y restauración del Carmen en España, y dice que sobre 1880 se restaura el convento de Jerez y poco después profesa Carmelo Codinach, que era compositor. ${ }^{1}$ Según su libro, que ahora describimos, era Director de la Schola Cantorum Carmelitana de Jerez de la Frontera.

\subsubsection{DESCRIPCIÓN DETALLADA DEL MÉTODO.}

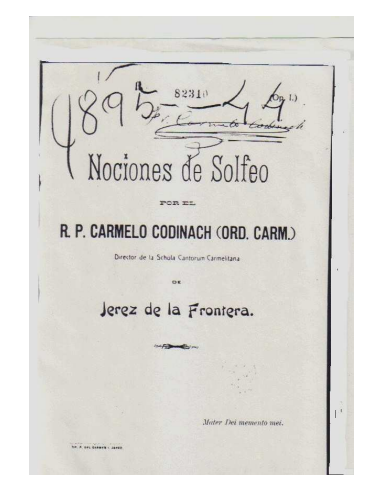

\section{Título del Método}

Nociones de solfeo, Jerez, Tip. P. del Carmen, s. f. ${ }^{2}$ Apéndice, página 224.

\section{CUADRO DE INFORMACIÓN GENERAL DEL MÉTODO.}

$\mathbf{N}^{\circ}$ de lecciones

Extensión de las lec- Desde 6 hasta 28 compases, a excepción de la recopilación ciones

Claves empleadas

Tesituras que abarcan

Tonalidades que trata y estudia

Compases que emplea y estudia

\section{Dificultades métricas que contiene} última que tiene 110

25

Únicamente Sol

$\mathrm{Do}_{3} \mathrm{a} \mathrm{Mi}_{4}$

Do M, La m, Sol M, Mi m, Re m, Fa M, Re M, Si b M, Sol m Si m, Do m, Mi b M. Curioso orden de aparición

$4 / 4,2 / 4,3 / 4,2 / 2,3 / 8,6 / 8,9 / 8$

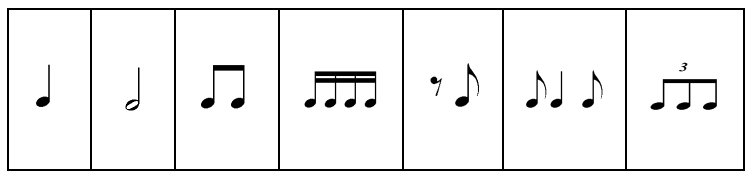

\footnotetext{
${ }^{1}$ Extraído de Internet a través de google

${ }^{2}$ Por la forma de redactar las explicaciones, empezar por el compás de compasillo, y el nombre actual que da a las figuras de nota, no debe ser de los más antiguos, quizás sea de principios del XX.
} 
Dificultades de entona- Ninguna

ción que se encuentran

$y$ orden en que se ense-

Grados conjuntos, intervalos de $2^{\mathrm{a}}$ a $6^{\mathrm{a}}$, semitonos diatónicos

ñan los intervalos

Armonía utilizada

Formas que tienen las lecciones

Introducciones, Intermedios o Codas instrumentales

Teoría de la música que incluye
No hay acompañamiento

La mayor parte son células que sufren transformación, otras llevan la forma A-B

No tienen

Tanta como práctica

\section{SECUENCIA}

Comienza con un comentario sobre la pretensión y alcance del método, que encabeza "A los señores directores de escolas [sic] y de masas corales."

En él dice que no pretende ofrecer un trabajo completo del estudio del solfeo, sino que lo que ha hecho es reunir en un breve compendio los conocimientos y ejercicios preliminares, para que, quienes quieran pertenecer a "escolas" o cualquier persona pueda solfear piezas fáciles, que no tengan más que una o dos alteraciones propias, y que sin estos conocimientos, tendrían que aprender de memoria.

Alterna la teoría básica con su aplicación práctica, e inicia con aquella en forma de pregunta y respuesta, conceptos de solfeo, pentagrama, signo (así llama a las notas), claves y clave de Sol, nombres de las notas en las líneas y espacios, escala natural mayor (con la indicación de distancias), concepto de compás, el compasillo, líneas divisorias (en las que incluye las barras finales y de repetición), figuras (a las que les da el nombre actual), valor de ellas en el compás de compasillo, silencios (el de negra todavía es el signo antiguo) y termina esta sección dando el nombre de nota o punto a la unión de signo y figura.

A partir de aquí empiezan las lecciones, 7, en clave de Sol, como todas las del método, y compás de 4/4, empezando con negras y blancas, e introduciendo en las últimas las corcheas, siendo las primeras la entonación por grados conjuntos, e intercalando ejercicios de terceras, cuartas, quintas y sextas, que a partir de ellos se incluyen en las lecciones. 
Las alteraciones, con dos ejercicios, uno para el sostenido y otro para el bemol, como semitonos diatónicos.

El calderón y la ligadura, y una lección con todo esto y alteraciones. Hay luego un curioso ejercicio de sostenidos: son fragmentos de pocas notas en las que, a modo de Do móvil, se cantan tonos y semitonos entre notas naturales y alteradas. Ejemplo: Sol, La, Si, Do, y luego Mi, Fa , Sol \#, La.

Compás de 2/4: dos lecciones para este compás, la primera de ellas en La menor, sin previa explicación.

Compás de 3/4: además habla aquí de las alteraciones propias y accidentales, y comienza la serie de 3 lecciones dedicadas a aprender este compás, con la tonalidad de Sol mayor, sin haber hablado tampoco nada de tonalidades. En la siguiente lección introduce el puntillo y el doble puntillo, (a los que él llama, punto a la derecha y dos puntos), sin embargo no pone ninguna lección para la práctica del doble puntillo. Ya en la tercera lección de esta serie, aparecen las semicorcheas, y también los términos piano, forte y las otras de este grupo dinámico.

Una especie de resumen, con tres lecciones, en 4, 2 y 3 por 4, en las que además aparece el D. C. y la ligadura de expresión.

Después de esto, una, relativamente, abundante teoría sobre la escala y la composición interválica de los sonidos entre si y entre el primero y los otros. Hay que destacar la explicación que da al por qué de llamar sonidos naturales; explicación fuera de todo lugar en un método de tan poca altura formativa, por dos motivos: porque es meterse en cuestiones de acústica, más propias de niveles bastante más avanzados, y porque además es bastante ininteligible para el neófito. Lo trasladamos literalmente:

\footnotetext{
Está formada por la $8^{a}$ (suponemos aquí la escala ascendente), la $5^{a}$, la $3^{a}$ mayor, la $4^{a}$ justa y la $6^{a}$ mayor, relativa de la tercera menor, cuyos sonidos son los más armoniosos o agradables que se pueden producir, según los físicos. Según los pitagóricos la escala está formada por los sonidos de las 5as ascendentes, Do, Sol, Re, La, Mi, Si acordes o intervalos los más perfectos después del unísono y la $8^{a}$. Del si al fa natural ya no resulta esta armonía y perfección del intervalo; pero la suple la perfección o armonía de la $4^{a}$ justa con su fundamental, do fa. Dados, pues, estos sonidos perfectos de 5as los reúnen formando la Escala natural.
}

Aprovechando la situación de tonos y semitonos en la escala natural, explica la posibilidad de trasladar esto a otras alturas y de formar otras escalas. Y así pre- 
senta la tonalidad de Re mayor, a la que dedica una lección; otra a la de Si bemol mayor y pasa a las síncopas

Síncopas: las explica después de que ya hayan aparecido en la lección anterior, y lo hace diciendo que se ponen a contratiempo, sin definir qué es contratiempo. Una lección para ellas.

A continuación explica la formación de los tonos mayores, y hace una relación de todos en armaduras de sostenidos y de bemoles.

Tresillos: se explican éstos con la figura corchea, con la semicorchea y los seisillos, aunque sólo hay ejemplo con los primeros.

Explica la división de compases regulares, y su posible subdivisión, y pasa el binario simple.

Modo menor: la misma explicación que dio para las escalas mayores, lo hace ahora con las menores y su situación con respecto a las relativas.

Matices: incluye aquí la explicación de los que restan dinámicos, más los signos de articulación.

Sendas lecciones para los compases de $3 / 8$ y $6 / 8$ y pasa a revelar la manera de averiguar las tonalidades según las armaduras. Una lección en Mi bemol mayor (última tonalidad que se ve prácticamente) y otra en el compás de 9/8 sin que previamente haya habido explicación de él.

Termina con una "Recopilación", que es la lección más larga, en la que cambia de armadura, compases y aires.

\subsubsection{VALORACIÓN DE LA EFECTIVIDAD DEL MÉTODO Y DE SU APORTACIÓN A LA ENSEÑANZA.}

Es, como el mismo autor dice, un pequeño compendio muy elemental de solfeo, más que un método, quizás útil para quien quiera tener una ligera información de la escritura y lectura musicales.

No obstante, cae, como muchos de los métodos de corta extensión, en la excesiva precipitación en la presentación de los distintos signos y dificultades.

Totalmente fuera de lugar las explicaciones de acústica. 


\subsection{RESEÑA BIOGRÁFICA DEL AUTOR}

ROGER JUNOI A. Según la Librería musical anticuaria Aria music \& Books, en su página web www.ariarecording.com, es autor de una versión española de la Viuda alegre de Franz Lehar, y también cita su Método práctico de lectura musical y de solfeo, pero parece ser que se hizo una nueva edición posterior a la de 1891, pues cita los volúmenes 2 y 3 en Madrid, Andrés Vidal, s. f. ca. 1920.

\subsubsection{DESCRIPCIÓN DETALLADA DEL MÉTODO.}

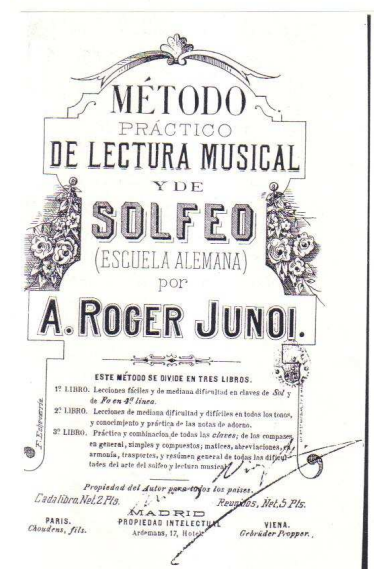

\section{Título del Método}

Método práctico de lectura musical y de solfeo (Escuela alemana), Madrid, Calcografía de F. Echevarría, 1891. Apéndice, página 225.

Un prólogo del editor en el libro primero, no con este título sino con el de "Cuatro palabras del editor", da comienzo al método. Informa que gran parte de las lecciones están tomadas de obras de músicos famosos, como Wagner, Rosini, Beethoven, Mozart, Haydn, Weber, Mendelshon y otros, pero para que el alumno no las aprenda de memoria, el autor ha cambiado el ritmo o variado la melodía. También ha intercalado cantos populares húngaros, eslavos, alemanes y franceses. Que el método está pensado para que un alumno pueda, a partir de los tres meses de su estudio, pasar a la práctica de un instrumento. También dice que el nombre que en principio había dado el autor al método era Escuela completa de lectura musical.

Su método consta de tres libros que analizaremos separadamente. 


\section{LIBRO I}

\section{CUADRO DE INFORMACIÓN GENERAL DEL LIBRO I}

$\mathbf{N}^{\circ}$ de lecciones

126

Extensión de las lec- Desde 8 hasta 66 compases

ciones

Claves empleadas

Tesituras que abarcan

Tonalidades que trata y estudia

Compases que emplea y estudia

Dificultades métricas que contiene

Sol, Fa $4^{\mathrm{a}}$ y mezclas

$\mathrm{Do}_{3} \mathrm{a} \mathrm{Mi}_{5}$

Do M

$4 / 4,2 / 4$ y $3 / 4$
Dificultades de entonación que se encuentran $y$ orden en que se enseñan los intervalos

\section{Armonía utilizada}

Formas que tienen las lecciones

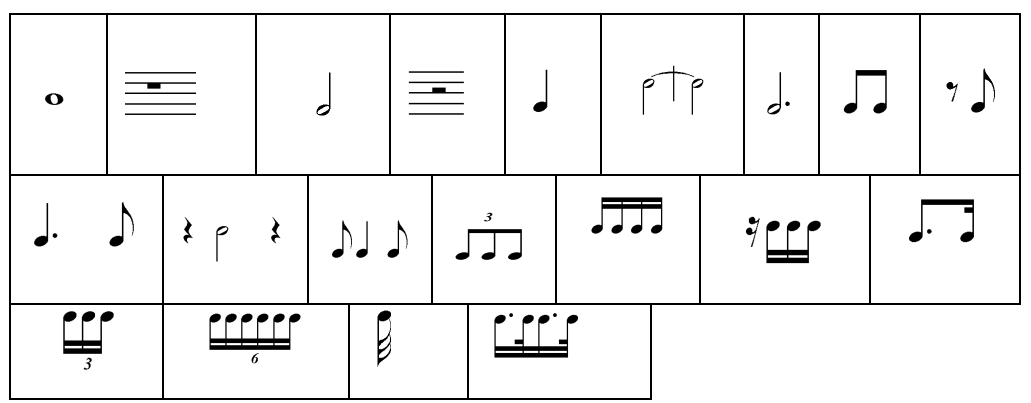

Al principio ninguna, a partir de las alteraciones aparecen algunos intervalos aumentados y disminuidos, intervalos de $9^{\mathrm{a}}$ y $10^{\mathrm{a}}$.

Progresivamente, y con varias lecciones para cada uno, los de $2^{\mathrm{a}}, 3^{\mathrm{a}}, 4^{\mathrm{a}}, 5^{\mathrm{a}}, 6^{\mathrm{a}}, 8^{\mathrm{a}}$ y $7^{\mathrm{a}}$, sin preparación. Semitonos diatónicos, $3^{\text {a }}$ disminuida, otros aumentados y disminuidos. Semitonos cromáticos. Compuestos de $9^{\mathrm{a}}$ y $10^{\mathrm{a}}$

No tiene acompañamiento

La mayoría no tiene ninguna, son como ejercicios, incluso las que podrían tener, como son pequeños fragmentos de composiciones célebres, tampoco tienen. Sí hay algunas con las formas A-A'; A-B-A'-A; A-B; A-B-C; A-B-C-D

No hay

medios o Codas instrumentales

Teoría de la música que incluye
Muy poca, la justa al principio y luego para presentar cada nuevo elemento 


\section{DESCRIPCIÓN DETALLADA DEL LIBRO I}

Después del prólogo del editor, un poco de teoría introductoria, notas musicales, pentagrama o pauta, líneas adicionales, clave de sol, compás de compasillo, líneas divisorias, figura de redonda, escala diatónica e intervalos.

Tres lecciones, que aunque así las numera, son ejercicios de entonación con intervalos de segunda. Compás de compasillo, que es con el comienza.

$\underline{\text { Silencios o pausas, el silencio de redonda: }}$

Una lección alternando redondas y su silencio, también por segundas.

Figura de nota blanca:

Tres lecciones con blancas, redondas y su silencio, siguiendo con intervalos conjuntos.

Intervalos de tercera:

Dos lecciones, primero preparadas y luego unos preparados y otros de salto.

Silencio o pausa de blanca:

Dos lecciones siguiendo con el intervalo de tercera.

Negras:

Cuatro lecciones con ellas, blancas y redondas.

Lecciones para practicar el conocimiento y lectura de varias notas que no se han practicado:

Cuatro lecciones, con las figuras vistas hasta ahora y los intervalos de tercera, pero con notas agudas hasta el $\mathrm{Sol}_{4}$

Intervalos de cuarta:

Cuatro lecciones con las mismas figuras que hasta ahora. 
Roger Junoi, libro I

$\underline{\text { Silencio o pausa de negra: }}$

Con la grafía antigua, cuatro lecciones siguiendo con los intervalos de cuarta.

Ligadura:

Todavía una lección con cuartas para conocer este signo, que aparece formando síncopas muy largas.

Intervalos de quinta:

Nueve lecciones con todos los elementos vistos hasta el momento.

Puntillo:

Dos lecciones, aplicado únicamente a la blanca.

$\underline{\text { Lecciones para practicar el conocimiento y lectura de las notas en las líneas y espacios }}$ adicionales superiores:

Dos lecciones en las que llega la extensión hasta el Do 5 y empleando todo lo conocido.

Corcheas:

Seis lecciones en las que seguimos con intervalos de quinta.

$\underline{\text { Silencio o pausa de corchea: }}$

Una lección en la que, contrariamente a lo que debería ser, es usado el silencio para producir contratiempos cortos.

Intervalos de sexta:

Cinco lecciones, con todo lo usado hasta ahora, incluidos contratiempos y síncopas largas.

Negra con puntillo:

Cinco lecciones, en las que además de este ritmo, se incorporan los términos de la velocidad uniforme, la doble barra de repetición y las casillas de $1^{\mathrm{a}}$ y $2^{\mathrm{a}}$ vez. Ya alguna de estas lecciones son pequeños fragmentos de compositores célebres. 
$\underline{\text { Lecciones para practicar el conocimiento y lectura de las notas escritas en las líneas }}$ adicionales inferiores:

Tres lecciones en las que se llega hasta el Sol 2.

D. C. :

Una lección para ver este signo de repetición.

Del calderón o corona:

Una lección.

De la síncopa:

Aunque ya han aparecido bastante más arriba, es ahora de una forma oficial cuando se explican, con cuatro lecciones, en las que van apareciendo las muy largas, notas partidas, largas irregulares, y breves.

Intervalos de octava:

Una sola lección, pero con abundancia de síncopas breves.

Intervalos de séptima:

Dos lecciones, únicamente con corcheas, negras, blancas y redondas.

$\underline{\text { Clave de Fa en cuarta línea: }}$

Nombre de las notas en esta clave, notas unísonas entre ésta y la de Sol, una lección como lectura de notas, y ya cuatro lecciones, con no mucha dificultad pero con más de la que debiera haber para enfrentarse por primera vez con una clave, contratiempos, negras con puntillo, y lo demás corcheas, negras y blancas.

De los tresillos:

Tres lecciones abundando en esta medida. Ya alterna la clave de Fa con la de Sol.

Semicorcheas:

Tres lecciones. 
Roger Junoi, libro I

$\underline{\text { Silencio o pausa de semicorchea: }}$

Tres lecciones en las que el silencio ocupa diversas partes del tiempo.

Corchea con puntillo:

Tres lecciones.

Compás de dos por cuatro:

Cuatro lecciones con una progresión de dificultad. En la cuarta hay cambios entre las dos claves aprendidas.

Sostenido:

Teoría sobre esta alteración, ejercicios de entonación en los que se forman toda clase de intervalos, escala cromática y cinco lecciones, en las que se utiliza el sostenido formando semitono diatónico.

Compás de tres por cuatro:

Tres lecciones. Ya se emplea el sostenido formando otros intervalos, incluso el de tercera disminuida.

Bemol:

Explicación de esta alteración, ejercicios de entonación en los que se forman toda clase de intervalos, escala cromática ascendente y descendente y seis lecciones en las que se empieza por emplear el bemol formando semitono diatónico, luego mezclando sostenido y bemol y llegando a intervalos aumentados y disminuidos.

Tresillos de semicorchea:

Dos lecciones.

Becuadro:

Dos lecciones, en las, que en su mayor parte, es empleado el becuadro para formar semitonos cromáticos.

En todo momento se siguen mezclando los nuevos elementos con los ya conocidos. 
De los seisillos:

Dos lecciones.

Fusas:

Tres lecciones

$\underline{\text { Silencio o pausa de fusa: }}$

Dos lecciones.

$\underline{\text { Semicorcheas con puntillo: }}$

Dos lecciones.

$\underline{\text { Intervalos: }}$

Explicación de los conjuntos y disjuntos, de los mayores, menores, aumentados y disminuidos. Una tabla con todas las posibilidades de intervalos. Tiene el autor el buen sentido de considerar que todos pueden ser mayores, menores, aumentados y disminuidos, todos; queremos decir que no excluye a las segundas de ser disminuidas, ni a las séptimas de ser aumentadas, y lo que es más notable: califica a las cuartas y quintas de mayores, menores, aumentadas y disminuidas, siendo cada una de ellas distinto intervalo

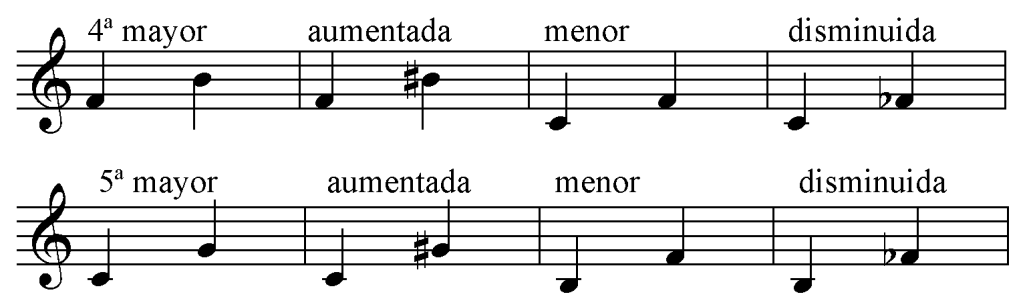

Hay más autores entre esos años, incluso antes, que comparten la idea de que las cuartas y las quintas son mayores y menores, y no justas, Agero, Amorós, Eslava, Moré, Pérez Gascón, Prellezo, pero que además puedan ser aumentadas y disminuidas sin ser unísono de las mayores o menores, solamente hemos encontrado la opinión de este autor, y si decíamos con los otros que suscribíamos íntegramente esa opinión, todavía estamos con Roger, en este asunto, más acorde. 
Práctica de los intervalos:

Dos lecciones con toda clase de intervalos.

Práctica de los intervalos de novena y décima:

Tres lecciones con estos intervalos y las mayores dificultades rítmicas.

Con ellas termina esta primera parte.

\section{LIBRO $2^{\circ}$}

\section{CUADRO DE INFORMACIÓN GENERAL DEL LIBRO $2^{\circ}$.}

$N^{0}$ de lecciones

78

Extensión de las lec- Desde 20 a 90 compases

ciones

Claves empleadas

Tesituras que abarcan

Tonalidades que trata y estudia

Compases que emplea y estudia

Dificultades métricas que contiene

Dificultades de entonación que se encuentran $y$ orden en que se enseñan los intervalos

Armonía utilizada

Formas que tienen las lecciones

Introducciones, Intermedios o Codas instrumentales
Sol y Fa $4^{\mathrm{a}}$

$\mathrm{Do}_{3} \mathrm{a} \mathrm{Do}_{5}$

Todas, empezando por 1 alteración y acabando por 7, alternando las de sostenidos con las de bemoles

$2 / 2,6 / 8,3 / 8,9 / 8,12 / 8$

\begin{tabular}{|c|c|c|}
\hline . & Adornos & $d \ldots \delta$ \\
\hline 8 & $y^{2}$ & $\overline{\overline{1.00 .0}}$ \\
\hline
\end{tabular}

Las anteriores más dobles alteraciones

No hay acompañamiento

A-B-A'; A-B-C; A-B

No hay 
Teoría de la música que incluye
Al principio para explicar las tonalidades, y lo justo cuando aparece un nuevo elemento

\subsubsection{DESCRIPCIÓN DETALLADA DEL LIBRO $2^{\circ}$.}

Explica y muestra con profundidad, al principio, la manera de formarse las distintas tonalidades, sus armaduras, y los tonos relativos.

Y partiendo de nuevo del tono de Do mayor, va pasando por todos, alternando las de sostenidos con las de bemoles, en cuantía de entre 2 y 3 lecciones por tonalidad, introduciendo alguna dificultad más que reseñamos. Va también alternando las dos claves, incluso en alguna lección cambiando entre ellas.

En la segunda lección, seisillos de fusas. Compás mayor o binario, con valores largos. Compás de 6/8, sin demasiadas complicaciones rítmicas. El signo §. Compás de 3/8. Compás de 9/8. Compás de 12/8. Dobles alteraciones.

De las notas de adorno:

Comentamos aparte este capítulo, debido a las distintas opiniones de los autores sobre éstas.

Así como nos mostrábamos totalmente conformes con la opinión de este autor en cuanto a los intervalos, no podemos por menos que decir que ahora con la clasificación de las notas de adorno, no podemos estar más en desacuerdo.

Clasifica éstas en apoyaturas, mordentes, grupetos y trinos, pero después incluye entre las apoyaturas a los mordentes y grupetos, según la siguiente clasificación: Apoyatura simple: ésta y el mordente de una nota Apoyatura doble: mordentes de dos notas Triple apoyatura: grupetos de 3 notas Cuádruple apoyatura: grupetos de 4 notas

Solamente incluye entre los mordentes el signo de abreviatura de mordente a la $2^{\mathrm{a}}$ superior ${ }^{\star}$, y con él ejecuta a la $2^{\mathrm{a}}$ inferior e incluso mordentes de 1 nota.

Y para los grupetos, sólo utiliza el signo $\sim$ y como grupetos posteriores, no existiendo para el autor el grupeto ascendente.

Hay dos lecciones, con doble pentagrama para indicar la melodía con las notas de adorno y el de bajo para representarlas con notas reales. Después siguen 4 lecciones en un solo pentagrama como venía siendo habitual.

Insertamos a continuación ejemplos de todo esto. 
EJEMPLOS DE MORDENTES.
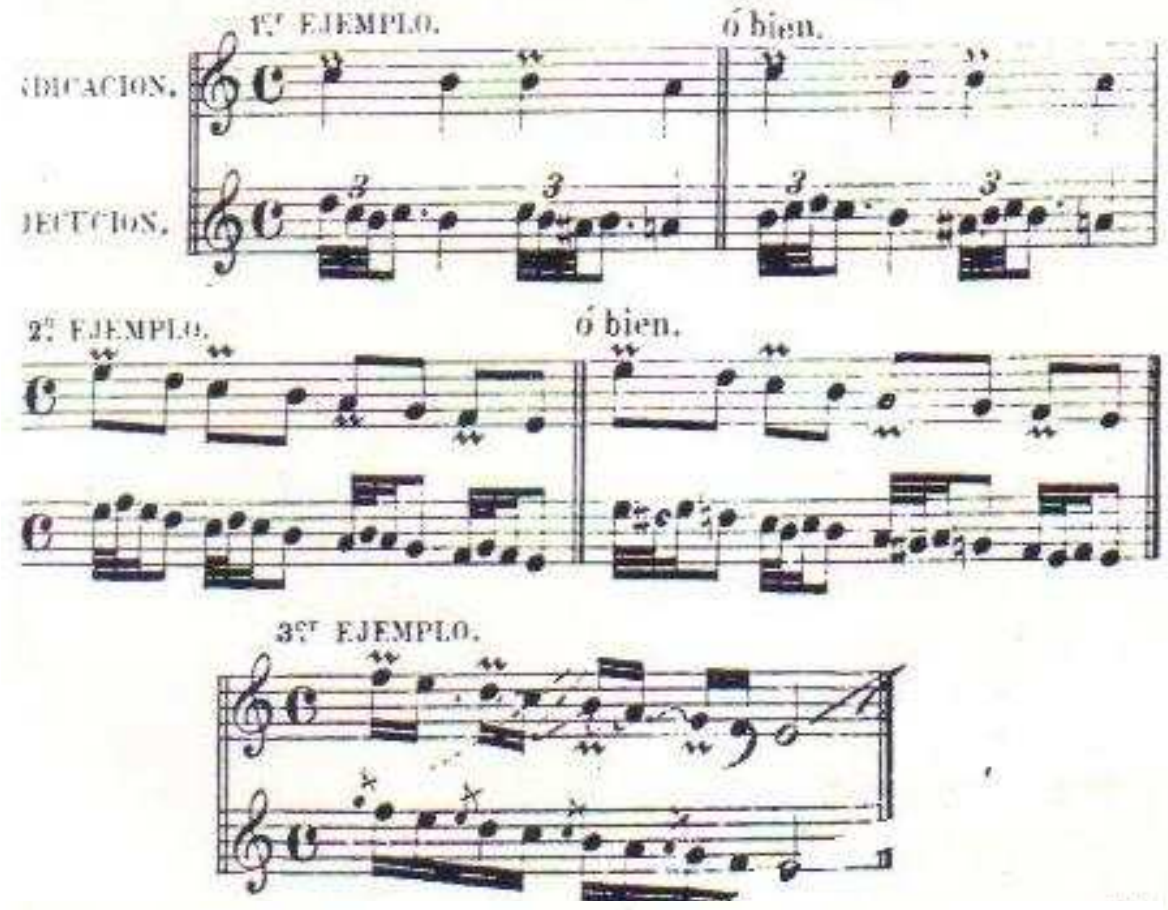

EJEMPLOS DE GRLPETOS.
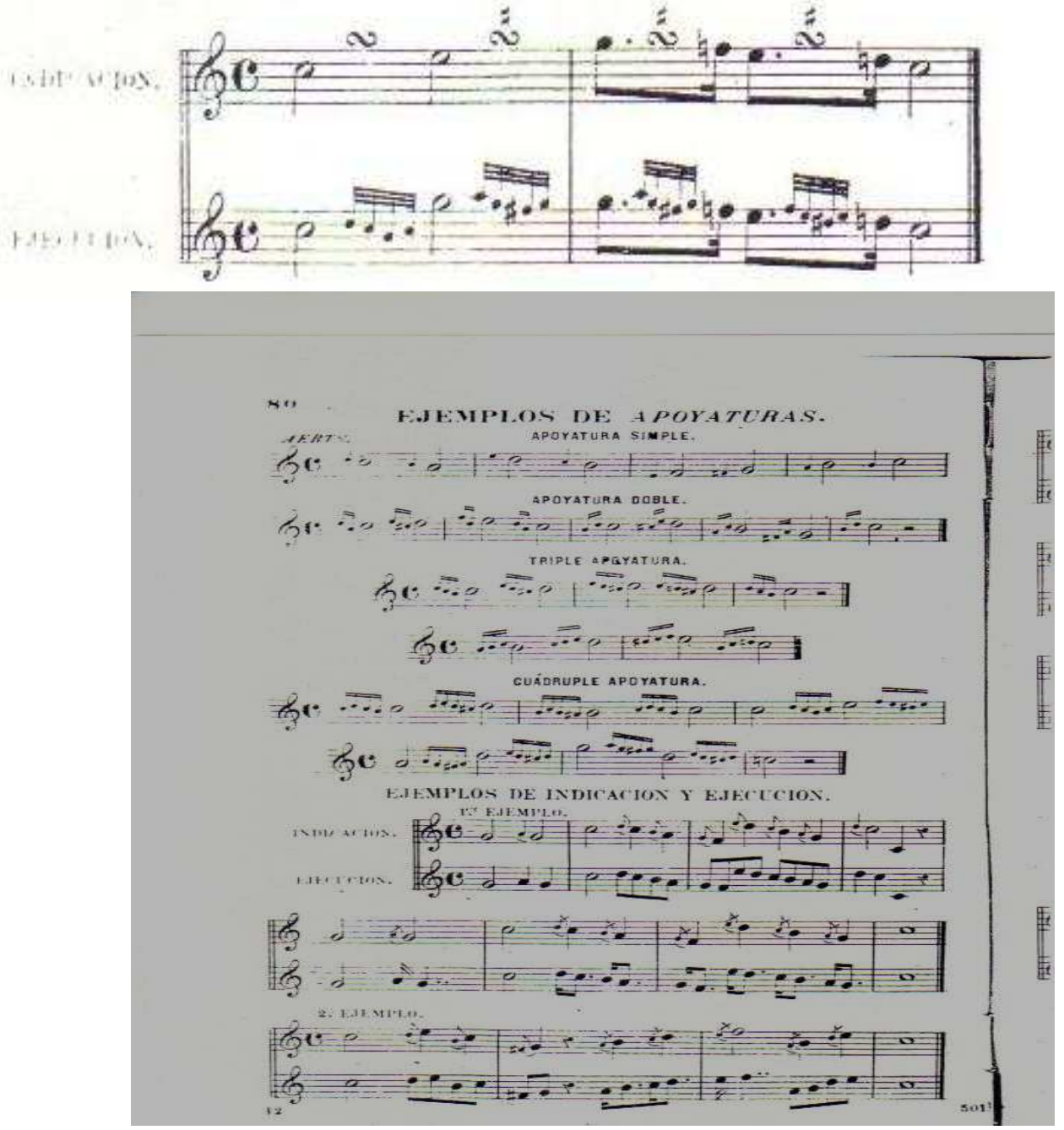
Del segundo puntillo:

Incorpora este signo de prolongación y sigue profundizando en las tonalidades que faltan mezclando todos los elementos aprendidos.

Las últimas lecciones están dedicadas a la semifusa, pausa de semifusa y fusas con puntillo.

\section{LIBRO $3^{\circ}$}

\section{CUADRO DE INFORMACIÓN GENERAL DEL LIBRO $3^{\circ}$.}

$\mathbf{N}^{\circ}$ de lecciones

Extensión de las lec- Entre 18 y 211 compases, exceptuando la última recopilatociones

Claves empleadas

Do $1^{\mathrm{a}}$, Do $2^{\mathrm{a}}$, Do $3^{\mathrm{a}}$, Do $4^{\mathrm{a}}, \mathrm{Fa} 3^{\mathrm{a}}$ y las dos anteriores

Tesituras que abarcan $\mathrm{Do}_{3} \mathrm{a} \mathrm{Si}_{4}$

Tonalidades que trata y estudia

Compases que emplea y estudia

Dificultades métricas que contiene

Dificultades de entonación que se encuentran $y$ orden en que se enseñan los intervalos

Armonía utilizada

Formas que tienen las lecciones

Introducciones, Intermedios o Codas instrumentales

Teoría de la música que incluye
Do M, Mi b M, Si b M, La M, Re M, Sol M, Do m, Do \# m, Fa M, Fa m, Re \# m, Mi m, La b M, Re b M y Mi M

Los anteriores más 4/2, 4/8. 124, 12/16, 3/2, 9/4, 9/16, 2/1, $6 / 4,6 / 16,5 / 4,7 / 4,4 / 1,3 / 1,2 / 1,2 / 8,12 / 2$ y $6 / 2$

Muchas menos que en las anteriores partes. A un nivel de mitad del primer libro, más resto de medidas irregulares y fermatas

Todos los intervalos aumentados y disminuidos. Compuestos hasta de $12^{\mathrm{a}}$.

Enarmonías. $2^{\mathrm{a}}$ disminuida, $4^{\mathrm{a}}$ aumentada, $5^{\mathrm{a}}$ disminuida y $7^{\mathrm{a}}$ aumentada

No hay acompañamiento

A-A'-B-coda; A-B-C-D; A-B; A-B-A'; A-B-A'-C-A',

No tienen

Más que las otras dos partes, pero no tiene una porción específica de teoría. 


\subsubsection{DESCRIPCIÓN DETALLADA DEL LIBRO $3^{\circ}$.}

Este último libro es para conocer todas las claves, todos los compases, los matices y algo del transporte.

Las tonalidades en las que se desenvuelven son las que figuran arriba y por el orden en que están, que son casi todas pero no todas.

Clave de Do en $1^{\mathrm{a}}$ línea:

Siete lecciones, en la tercera ya hace cambios de claves frecuentes entre las tres estudiadas. Intercala teoría de las figuras antiguas, longa y breve, y sus silencios, que al igual que otros autores de ese tiempo, dice se usan para marcar compases de silencio.

\section{DE LAS FIGURAS ANTIGUAS $Y$ DE LOS GOMPASES DE ESPERA}

Antiguamente, y con especialidad en la música religiosa, se usain unas notas cuyas figuras, silencios y valores eran como sigue:

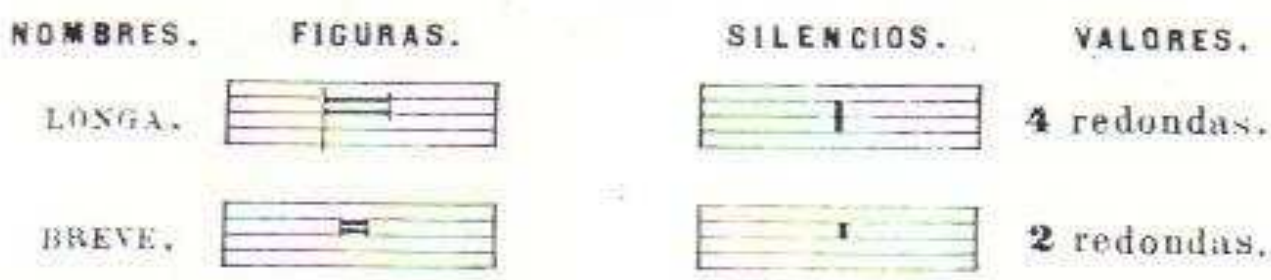

La Longo cayó en desuso despues de inventadas las ineas divisoas, y en la actualidad sólo se usan les silrmasos de Lango para marear impases de espera.

La Breve, tunque ramanente, se usa en los rompases cuya falor es - dos redoudas ó nuí, como en los combranex $\mathbf{1}: \mathbf{3}: \mathbf{i}$. \&.

Tambien se usa el silencio de Brerr para matrar rompases de essra como el de Lonya, $y$ conn éste, sólo en la música exlesiaistica.

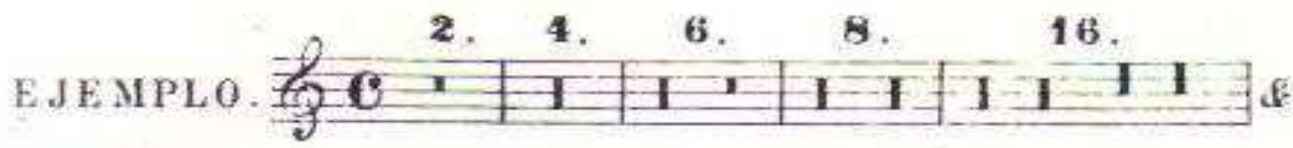

En la música moderna los compases de expera se marean con una bara, encima de la eual se pone el número de los compases.

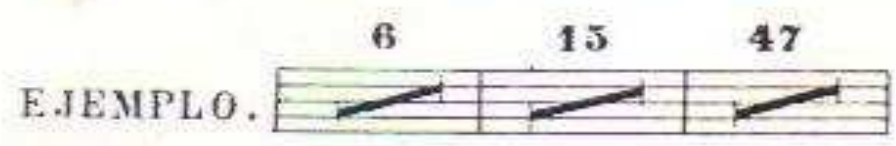

También de la división de los compases en general, que lo hace en compases de 4 partes o tiempos, binarios y ternarios, compases de 3 partes o tiempos binarios y ternarios, y compases de 2 partes o tiempos binarios y ternarios. No les da la denomina- 
ción de compases de subdivisión ternaria; pone ejemplos de todos ellos, y al final nombra los amalgamados 5/4 y $7 / 4$.

Después de esta teoría, sigue con esta clave y lecciones cortas, con compases nuevos, en las que ciertamente, no carga de dificultad.

\section{Clave de Do en $2^{\text {a línea: }}$}

También siete lecciones. Las primeras son de una facilidad enorme, redondas, blancas y negras la primera, negras y corcheas las otras dos, con alguna negra o corchea con puntillo, luego emplea compases nuevos, pero también de fácil ejecución. La última tiene cambios de claves entre las cuatro estudiadas.

\section{Clave de Do en $3^{\text {a línea: }}$}

Ahora son ocho lecciones, también las primeras muy sencillas. Introducción de nuevos compases y la última con cambios entre todas las sabidas.

\section{Clave de Do en $4^{\text {a }}$ línea:}

Nueve lecciones, con la misma tónica que los grupos anteriores.

\section{Clave de Fa en $3^{\text {a línea: }}$}

Ocho lecciones, sigue con la facilidad en las primeras, tampoco se complican mucho las siguientes. La última lleva cambios entre todas las claves, y las dos anteriores son las que sirven para presentar los compases amalgamados.

\section{Valores irregulares:}

Explicación, ejemplos y dos lecciones, con vuelta a la clave de Sol, con lo cual no se hacen muy difíciles.

\section{De la Cadencia:}

Cuatro cortas lecciones para ejecutar alguna fermata, pero con excesivo cambios de clave.

De nuevo una sección teórica con Articulaciones, Abreviaciones, Matices y Movimiento. Las articulaciones las llama picado, ligado, muy picado (al Staccato) y picado 
ligado. En los matices solamente se refiere a los dinámicos. En el movimiento habla también del metrónomo.

Dos lecciones para practicar todo esto. Clave de Sol y poca dificultad.

De la enarmonía:

Comenta éstas, a las que también llama "semitono aparente", y vuelve al concepto de segunda disminuida como intervalo enarmónico. Ejemplos y ejercicios de segundas disminuidas, cuartas aumentadas, quintas disminuidas y séptimas aumentadas. Continua hablando de los tonos enarmónicos y muestra el Círculo de Tonos (lo que hoy llamamos rueda de quintas).

\section{De los transportes:}

No intercala ninguna lección y sigue con teoría, ahora con la del transporte. Explica de una manera muy fácil el mecanismo haciendo partir siempre de la escala o tonalidad de Do, tanto para el cambio de claves como para el de armaduras. Lo que no explica es la mutación que puede haber en las alteraciones accidentales. Pone una frase de ejemplo, transportadas desde un semitono hasta $7^{\text {a }}$ mayor superior, cambia, cuando es necesario las alteraciones accidentales, pero ninguna explicación da al respecto. Remite a su "teoría completa de la música" para mayor información de esta técnica y también a las lecciones fáciles y de mediana dificultad de los libros $1^{\circ}$ y $2^{\circ}$ para su práctica.

Termina con una lección, la más larga, a modo de recopilación, en la que emplea todas las claves, los compases y las tonalidades, a la vez que diversos movimientos. El cambio de las claves es de excesiva frecuencia.

\subsubsection{VALORACIÓN DE LA EFECTIVIDAD DEL MÉTODO Y DE SU APORTACIÓN A LA ENSEÑANZA.}

Muy bien ir introduciendo las primeras figuras de nota manteniendo como distancia entre los sonidos la de tercera, y sucesivamente ir introduciendo más distancias interválicas, no de golpe todas juntas, sino después de ir apareciendo distintos elementos. 
También es una medida adecuada, practicar primero los intervalos de octava que los de séptima, debido a ser estos últimos los de mayor dificultad de entonación entre los simples mayores y menores.

Muy pronto acomete el cambio entre claves.

No obstante, y al menos en la primera parte, se trata de un método bien pensado y distribuido, teniendo en cuenta su edad, a pesar de, en algunos momentos, faltarle la insistencia en cierto tipo de dificultades.

Es una parte atinada la segunda, dentro del estilo del libro, aborda las tonalidades de forma organizada y progresiva, no son muchas las lecciones por cada tonalidad, pero tampoco son muy pocas; sigue con las claves ya sabidas, lo cual facilita el aprendizaje de nuevas dificultades, y no tienen las lecciones, en las que aparece un nuevo compás, mayores dificultades que sus antecesoras.

Lo más criticable, como hemos ya hecho notar, es su opinión sobre la clasificación de las notas de adorno.

Es un volumen bastante completo el tercero, en el que pocas cosas faltan para tener una visión general del solfeo.

Es de valorar positivamente el que las lecciones con nuevas claves sean fáciles de medida y entonación. Lo malo es la mezcla de ellas que es demasiado frecuente, sobre todo en las últimas lecciones, es una cosa bastante generalizada en esa época y en las recientes, pero que sirve más para hacer aborrecer al alumno la disciplina que para utilidad alguna.

En general es un buen método, con los inconvenientes que en la época tenían todos, pero está hecho de una forma progresiva, ordenada, no hay pocas lecciones para practicar cada nueva dificultad, y en general resulta agradable su estudio. 
Roger Junoi, libro 3ํㅜ 


\subsection{RESEÑA BIOGRÁFICA DEL AUTOR}

AMORÓS SIRVENT, Amancio. Agullent 1854 - San Cugat del Vallés (Barcelona) 1926, donde pasaba una temporada con un hijo. Estudió Piano con Roberto Segura, Órgano y Composición, esto último con Giner. Compositor de música religiosa, de la que tiene gran producción, música didáctica y zarzuelas. En 1902 profesor del Conservatorio de Valencia, y de 1919 a 1924 director. Director de número del Centro de cultura valenciana y de la Real Academia de Bellas Artes de San Fernando de Madrid. Fundador de la Biblioteca Musical Valenciana.

Escribió Métodos de solfeo, Teoría general del solfeo en forma de diálogo, Curso elemental de piano; zarzuelas Los dos esclavos, Navegación submarina, El tío sapo; $6 \mathrm{Mi-}$ sas a varias voces y orquesta; Sinfonías y Nocturnos (Loras, 2003, p. 105).

\subsubsection{DESCRIPCIÓN DETALLADA DEL MÉTODO.}

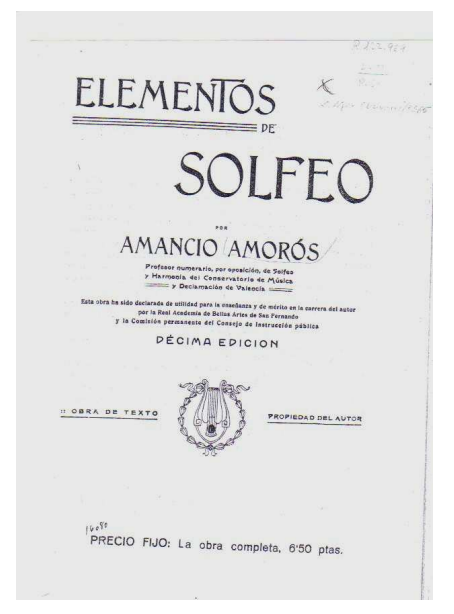

\section{Título del Método}

Elementos de solfeo, $10^{\mathrm{a}}$ edición, s.l., s.f. ${ }^{1}$ Apéndice, página 226.

En la Red de Bibliotecas Universitarias, se encuentra la $3^{\text {a }}$ edición del método, depositada en la Universidad de Alicante

\footnotetext{
${ }^{1}$ PRECIADO, Dionisio. (1978). Don Hilarión Eslava y su "Método completo de solfeo" en Monografía de Hilarión Eslava. Pamplona: Diputación Foral de Navarra, p. 244, cree que fue en el año 1893 que es la fecha que lleva el Dictamen de Pedrell. Y FONTESTAD PILES, Ana. (2005). El Conservatorio de Música de Valencia Antecedentes, Fundación y Primera Etapa (1879 - 1910). Tesis doctoral. Director Vicente Galbis López. Universidad de. Valencia, Departamento de Historia del Arte, p. 394, afirma que la primera edición es de 1890, Imprenta Laviña y Prosper, que lleva un prólogo de Giner; que la edición conteniendo un dictamen de Pedrell, citada arriba, vio la luz tres años después, y que tuvo esta obra muchas ediciones. Por ejemplo en 1914 llevaba añadido al título "de texto en el Conservatorio de Música (Valencia, Tipografía moderna, 1914)”. No obstante creemos que esta edición es posterior a 1911 por el comentario de recuerdo a Giner que hace el autor en el prólogo, habiendo fallecido este compositor en el citado 1911.
} 


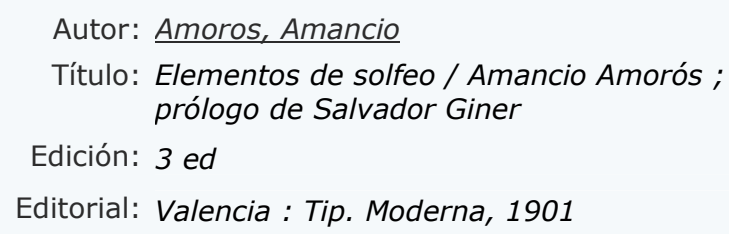

CUADRO DE INFORMACIÓN GENERAL DEL MÉTODO.

$\mathbf{N}^{\mathbf{0}}$ de lecciones

100

Extensión de las lec- Cortas las primeras. Entre 24 y 32 compases una vez se ha ciones metido en materia. Y llega hasta los 55 compases en las finales

Claves empleadas

Tesituras que abarcan

Tonalidades que trata y estudia

Compases que emplea y estudia

\section{Dificultades métricas que contiene}

Dificultades de entonación que se encuentran $y$ orden en que se enseñan los intervalos

\section{Armonía utilizada}

Formas que tienen las lecciones

Introducciones, Intermedios o Codas instrumentales

Teoría de la música que incluye

\section{Sol}

$\mathrm{Do}_{3} \mathrm{a} \mathrm{Fa}_{4}$

Do mayor

$2 / 2,4 / 4,2 / 4,3 / 4$

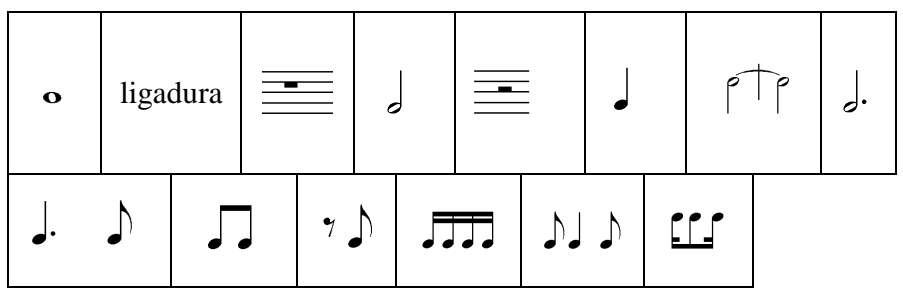

Nada excepcional, todo discurre entre parámetros normales

Grados conjuntos $3^{\mathrm{a}}$ a $8^{\mathrm{a}}$ preparadas y sin preparar; a partir de las sextas, también mezclas con los nuevos intervalos y los anteriores. Semitono cromático y diatónico. Práctica del tono (mediante alteraciones) entre $\mathrm{Mi}-\mathrm{Fa}$ y $\mathrm{Si}-\mathrm{Do} .2^{\mathrm{a}}$ y $3^{\mathrm{a}}$ $\mathrm{M} \mathrm{y} \mathrm{m,} 4^{\mathrm{a}}$ y $5^{\mathrm{a}} \mathrm{m}$ y $\mathrm{M}, 6^{\mathrm{a}}$ y $7^{\mathrm{a}} \mathrm{M}$ y $\mathrm{m}$.

No hay acompañamiento

Son pequeñas formas para la práctica de lo estudiado

No los hay

La básica y mínimamente necesaria 


\section{SECUENCIA}

Empieza con teoría básica: Definiciones, Pentagrama, Claves y Clave de Sol, Notas, Líneas adicionales (todas las explicaciones son breves).

Ejercicios de lectura con las 8 notas

A continuación expone diversas cuestiones, y sobre cada una de ellas verifica una serie de ejercicios de lectura, entonación y/o lecciones, cuyo desarrollo desplegamos detalladamente:

Escala diatónica de Do y distancia entre sus notas, sin explicar qué es tono y semitono

Ejercicios de entonación por grados conjuntos

El compás en general y el binario (que él llama compasillo binario), Figuras (sólo la redonda), Líneas divisorias.

Ejercicios de lectura medida en $2 / 2$. Son muy cortitos, de 1 ó 2 pentagramas y sólo con redondas. ${ }^{1}$

La ligadura:

Dos lecciones cortas con este signo de prolongación.

$\underline{\text { Silencios o pausas (sólo el de redonda) }}$

Dos lecciones cortas con redondas ${ }^{2}$

Ejercicios de lectura

Ejercicios de entonación por grados conjuntos hasta $\mathrm{Fa}_{4}$

La blanca y su equivalencia:

Lecciones cortas con blancas y redondas

\footnotetext{
${ }^{1}$ Antes aconseja que el alumno practique la marcación del compás diciendo 1, 2, y luego sin decirlo. ${ }^{2}$ Da un consejo, que es el de repetir el fragmento comprendido entre la nota anterior y posterior al silencio, con el fin de que el alumno entone la nota posterior al silencio con relación a la anterior. Es un defecto en el que incurren un grupo numeroso de estudiantes. Además comenta que algunos teóricos daban a
} 
El silencio de blanca:

Lecciones cortas con redondas, blancas y sus silencios.

Ejercicios de entonación por terceras preparadas

\section{La negra y su equivalencia:}

Lecciones cortas con estos 3 elementos y la ligadura ${ }^{1}$

Ejercicios de entonación por terceras sin preparar (mezcladas con algunas preparadas)

\begin{tabular}{|c|c|c|}
\hline 66 & "6 & cuartas preparadas \\
\hline “6 & “ & “ $\quad$ sin preparar \\
\hline “ & “ & quintas preparadas por grados conjuntos \\
\hline “ & “ & “ $\quad$ sin preparar \\
\hline “ & “ & sextas preparadas por grados \\
\hline “ & “ & “ $\quad$ sin preparar y mezclas \\
\hline “ & “ & séptimas preparadas por gradas \\
\hline “ & “ & sin preparar y mezclas \\
\hline “ & “ & octavas preparadas por grados \\
\hline “ & “ & “ $\quad$ sin preparar y mezclas \\
\hline
\end{tabular}

Ejercicios de lectura de notas hasta $\mathrm{DO}_{5}$ por arriba y $\mathrm{SOL}_{2}$ por bajo

El compás cuaternario y su equiparación al 2/2

$\underline{\text { Aire o movimiento (sin adverbios) }}$

Síncopas:

Un ejercicio de síncopas largas

El silencio de negra: es singular la forma que adopta

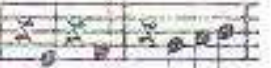

los silencios el nombre de "espera, pausa o media pausa" a los silencios largos, y a los cortos "aspiraciones o suspiros", él propone llamarles "figuras de silencio".

${ }^{1}$ Da los siguientes consejos: subdividir el compás sin más, o sea practicar la subdivisión diciendo 1 y 2 en cada tiempo, luego proceder al solfeo rítmico, después entonando con las subdivisiones, por último sin subdividir.

También aconseja que en adelante se estudien los ejercicios y lecciones en 5 acciones: 1) lectura de notas, 2) entonación no medida, 3) analizar todos los signos, 4) solfeo rítmico y 5) rítmico - melódico. 
Ejercicios con negras, blancas y sus silencios en compás de compasillo

Lección con estas figuras y todos los intervalos simples practicados

El puntillo de aumento o simplemente puntillo:

Lección con los elementos estudiados hasta ahora

La corchea:

Un ejercicio y 1 una lección con estas figuras

El calderón:

Dos lecciones con este signo

El silencio de corchea:

Ejercicios y lecciones con todo lo estudiado, más contratiempos cortos (sin haberlos explicado)

$\underline{\text { Intervalos }}$ con su clasificación en conjuntos y disjuntos, superiores o inferiores (no cita los simples y los compuestos) y su calificación en mayores, menores, aumentados y disminuidos (no nombra los justos)

Alteraciones:

Escala cromática, semitonos cromáticos y diatónicos:

Intervalos mayores y menores con alteraciones:

Doble barra de repetición:

Ejercicios y lecciones con lo estudiado

Empieza en este punto a hacer practicar, mediante alteraciones, la distancia de tono entre las notas MI - FA y SI - DO, y de semitono entre las demás. Una práctica, a nuestro juicio, muy conveniente.

Las lecciones ya empiezan a ser más largas, entre 24 y 32 compases. 
Los ejercicios de entonación empiezan a distinguir la calificación de los intervalos. Ahora son de segunda y tercera mayores y menores, y las lecciones incorporan estos intervalos principalmente

La semicorchea:

Ejercicios de entonación con cuartas y quintas menores y mayores.

Lecciones con estos elementos.

Compás de 2/4:

Ejercicios y lecciones (ya más largas, 55 compases) en las que van entrando síncopas breves y muy breves, y contratiempos.

Compás de 3/4:

Ejercicios de entonación con sextas y séptimas mayores y menores

Lecciones cortas y largas

La última lección, $\mathrm{n}^{\circ}$ 100, es con cambios de compases entre los estudiados y de tempo o movimiento.

Acaba el libro con lecturas de notas en la clave de Fa en $4^{\mathrm{a}}$, en la clave de Sol con notas muy agudas y muy graves, con acordes en ambas claves, muy agudos y muy graves, y con pentagramas de piano con alternancia de notas y acordes en las dos claves.

\subsubsection{VALORACIÓN DE LA EFECTIVIDAD DEL MÉTODO Y DE SU APORTACIÓN A LA ENSEÑANZA.}

Curioso comenzar empleando la ligadura. Bien, o mejor que los anteriores, el tratamiento de la entonación. La progresión en la aparición de figuras de nota es buena y lenta, aunque al final se precipita. Aparece el contratiempo corto sin haber tratado el largo, y la síncopa breve, desde la muy larga, sin haber pasado por la larga.

En fin, con algunas salvedades, es más útil que muchos de los que hasta ahora hemos estudiado. 


\subsection{RESEÑA BIOGRÁFICA DEL AUTOR}

VELÁZQUEZ, Juan. No nos ha sido posible encontrar referencias, ni siquiera pequeñas, a su biografía, a pesar de las muchas fuentes consultadas y requeridas. Según reza en el método este autor era profesor del Colegio del Sagrado Corazón de Sarriá.

\subsubsection{DESCRIPCIÓN DETALLADA DEL MÉTODO.}

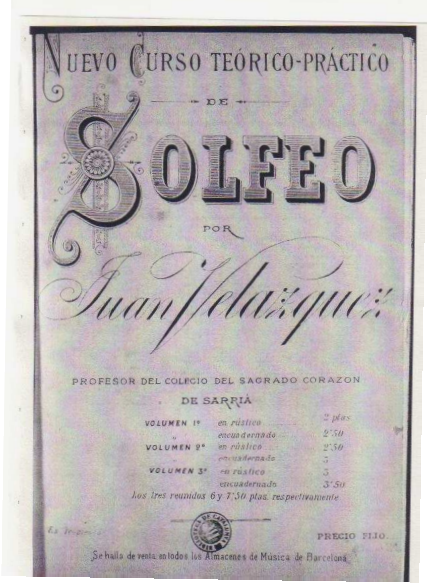

\section{Título del Método}

Nuevo curso teórico-práctico de solfeo, Barcelona, Rafael

Guardia?, 18--? Apéndice, página 227.

\section{$1^{\text {a }}$ Parte}

\section{CUADRO DE INFORMACIÓN GENERAL DE LA PRIMERA PARTE.}

$\mathbf{N}^{\circ}$ de lecciones

91

Extensión de las lec- De 3 a 26 compases ciones

Claves empleadas $\quad$ Sol, únicamente 3 lecciones en Fa en $4^{\mathrm{a}}$

Tesituras que abar- $\quad \mathrm{De} \mathrm{Do}_{3} \mathrm{a} \mathrm{Sol}_{4}$, aunque normalmente se extienden hasta $\mathrm{Mi}_{4}$ can

Tonalidades que tra- Do mayor y La menor

ta y estudia

Compases que em- $\quad 4 / 4,3 / 4,2 / 4,2 / 2,3 / 8,6 / 8,9 / 8$ y $12 / 8$

plea y estudia

\footnotetext{
${ }^{1}$ La imprenta viene referenciada en la información bibliográfica de la Biblioteca de Catalunya, pero ninguna mención hay a ella en el libro. En cuanto al año de edición, también lo supone la dicha información bibliográfica, desde luego antes de 1897, pues hay en la página 2 una mención de la Academia Universal de Ciencias y Artes de Bruselas en la que dice que en sesión de junio de 1897 acordaron concederle al autor el Diploma de Miembro Titular con las insignias de Honor y la Medalla de $1^{a}$ Clase en consideración al mérito de este libro.
} 
Dificultades métricas
que contiene

Dificultades de entonación que se encuentran y orden en que se enseñan los intervalos

Armonía utilizada

Formas que tienen las lecciones

Introducciones, Intermedios o Codas instrumentales

Teoría de la música que incluye

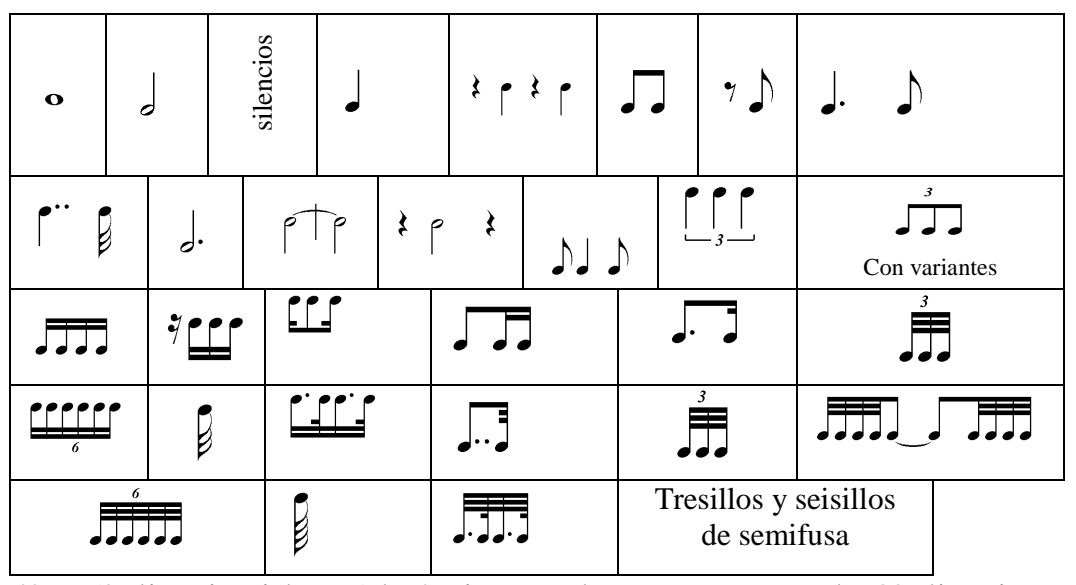

$4^{\mathrm{a}}$ y $5^{\mathrm{a}}$ disminuidas. Algún intervalo compuesto, de $3^{\mathrm{a}}$ disminuida y $2^{\mathrm{a}}$ aumentada

Desde $2^{\mathrm{a}}$ a $8^{\mathrm{a}}$ sin preparar. Semitonos cromáticos y diatónicos. $4^{\mathrm{a}}$ disminuida, $9^{\mathrm{a}}$ menor y $2^{\mathrm{a}}$ aumentada

No lleva acompañamiento

A-A'; A-B-A'; A-B

No tienen

Solamente la indispensable al principio, y luego la necesaria para explicar cada nuevo signo

\section{SECUENCIA}

Comienza con una dedicatoria a su maestro D. Cándido Candi, y con la mención indicada en la nota al pie.

Entra enseguida con la teoría básica para poder comenzar, y lo hace con una bonita definición de Música: es el arte de expresar los sentimientos por medio de la combinación del sonido y del tiempo. Pentagrama, Llave ó Clave, de las que dice que hay varias, pero la principal es la de Sol, y da el nombre de las notas en las líneas y espacios; Líneas Adicionales; Compás, del que dice que el principal es el de cuatro tiempos; Líneas divisorias; Figuras, a las que nombra con las maneras antigua y actual, marcando el valor de cada una en el compás de compasillo, pero sin advertir que estos valores no son absolutos, sino referentes a un determinado compás, y termina la exposición teórica prologal con las Pausas o Silencios. 


\section{Ejercicios de lectura:}

Cuatro de estos ejercicios con la clave de Sol, con notas en las líneas, espacios y ambas cosas.

La escala con redondas, la misma con blancas, y la definición de Intervalo. A partir de ella, lecciones de entonación, con redondas y blancas, de intervalos de $2^{\mathrm{a}}$ a $8^{\mathrm{a}}$ entre notas naturales.

Lecciones, una para cada una, con redondas y su pausa, blancas y su pausa y mezclas de ellas, intervalos todos los naturales. El compás por el que empieza es del que ha hablado en la teoría, 4/4.

\section{Negras:}

Dos lecciones con las que vuelve a colocar los sonidos en la escala.

De los Movimientos:

Nombra 4 de ellos, Lento, Adagio, Andante, Moderato y Allegro, y continua con las lecciones de negra, pero además con su silencio, con los que ya forma contratiempos.

\section{Signos de repetición:}

Explica brevemente la doble barra, el D. C. y el signo $§$ y los hace practicar con dos lecciones, todavía con blancas y negras.

\section{Calderón o punto de reposo.}

Una lección, posterior a su explicación con este signo.

\section{Corcheas:}

Cuatro lecciones introductorias de esta figura, la primera con cuatro corcheas barradas y luego sueltas, las otras con corcheas barradas de dos en dos, y con alguna mezcla de figuras, pero todas ellas melódicamente formando la escala natural. Siguen 3 lecciones con todos los intervalos y mezcla de figuras. La tercera de ellas comienza en anacrusa, y ni mención hace de ello. Prosiguen las corcheas, pero ahora con su pausa, con la que ya forma contratiempos cortos, sin explicar lo que son ni prepararlos. 
Velázquez

Del puntillo y doble puntillo.

Una lección para practicar estos dos signos. Gran barbaridad es acometerlos juntos, y además con una sola lección.

Compás de tres por cuatro:

Cuatro lecciones, la primera solamente con blancas con puntillo, la segunda con blancas y negras.

\section{Compás de dos por cuatro:}

Una sola lección, directamente ya con corcheas.

De los Intervalos y de las Alteraciones:

Para hablar de estas últimas, primero lo hace del tono, semitono y de la situación de éstos en la escala natural. Una vez define las 3 alteraciones, habla de su orden en las armaduras, sin siquiera mencionar la diferencia entre propias y accidentales ni el concepto de armadura.

Una vez que ha explicado, mal y poco, todo esto, dedica una lección, empleando indistintamente los 3 compases estudiados, a practicar el sostenido en cada una de estas notas: Fa, Do, Sol, Re y La, o sea sobre las que no se enarmonizarían con otras naturales, esto es, que introduce la alteración cada vez en una nueva nota sin abandonar las que ya han sido vistas alteradas, y no introduce los sostenidos solamente formando semitono cromático, sino también diatónico e intervalos alterados, incluyendo $4^{\mathrm{a}}$ disminuida. Luego hace lo propio con los bemoles, los va introduciendo sobre distintas notas: $\mathrm{Si}, \mathrm{Mi}, \mathrm{La}, \mathrm{Re}$ y Sol, llegando incluso al intervalo de $9^{\mathrm{a}}$ menor. Acaba haciendo una lección recopilatoria del sostenido y el bemol.

\section{Escalas cromáticas:}

Sin explicar qué son, hay dos lecciones con esta escala empezando por Do, una con blancas y otra con negras.

Escala del modo menor:

Aparece la escala melódica, ninguna otra variación, sin explicación alguna, y le siguen 3 lecciones en La menor. Ya en el resto de esta parte nunca vuelve a aparecer esta tonalidad. 
De los ligados:

Explica qué es la ligadura, y luego dice que hay tres clases de ligados: de dos notas de un mismo nombre, de dos notas de distinto nombre y de varias notas (refiriéndose estas dos últimas evidentemente a la ligadura de expresión, pero no así lo distingue el autor). Después distintas lecciones con ligaduras en distinta combinación: entre blancas, entre negras, entre corcheas, entre notas de distinto nombre (legato entre dos notas) y ligadura entre varias notas (legato de fraseo).

\section{Del Picado.}

Una lección, previa explicación de este signo.

\section{$\underline{\text { Staccato: }}$}

Igualmente que con el picado.

De la síncopa:

Curiosa definición: prolonga el sonido sobre una parte del compás que empezó antes. (Esto no lo entiende cualquiera), encima añade que también se llaman notas a contratiempo. Hay una lección para la síncopa de redonda y blanca, (síncopas muy larga y larga) y otra para la síncopa de negra (síncopa breve).

\section{Del compás mayor o binario:}

Así le llama al 2/2. Y pone 3 lecciones en este compás, una con redondas, blancas y negras, otra con lo mismo más negras con puntillo, y la tercera con corcheas.

De los Tresillos:

Tras la definición, una lección para los de negra, otra para los de corchea y una tercera para añadir la dificultad del silencio de corchea sustituyendo a alguna de las corchas del tresillo.

\section{Semicorcheas:}

Tras una grafía con ellas de 4 en 4, de 2 en 2 y sueltas, varias lecciones, una por cada dificultad, con estas figuras. La primera solamente semicorcheas y negras, la segunda ya mezcla las figuras, y fórmulas vistas hasta ahora; sigue con el silencio de semicorchea, con la ligadura entre dos semicorcheas (formando síncopa muy breve), o 
corchea y semicorchea más la fórmula corchea-dos semicorcheas; la fórmula corchea con puntillo-semicorchea; síncopa muy breve (ahora con otra grafía), tresillo y seisillo de semicorchea.

Compás de 3 por 8 :

Dos lecciones con este compás, la primera más sencilla y con mayor complejidad rítmica la segunda.

\section{Compás de 6 por 8 :}

También dos lecciones procediendo con la misma gradación de las anteriores.

Compás de 9 por 8 :

Igualmente dos lecciones

Compás de 12 por 8 :

Exactamente igual, e igual forma de proceder

\section{Fusas:}

En compás de 4/4 empieza la primera lección dedicada en abundancia a esta figura, le sigue una en 2/4 con el puntillo puesto a la semicorchea, seguida de fusa; continua con otra, de nuevo en $4 / 4$, con la ligadura entre corchea y fusa, semicorchea y fusa y entre dos fusas, formando síncopa súper breve; terminando con una cuarta lección con tresillos y seisillos de fusa.

\section{Semifusas.}

3 lecciones, compás de 4/4, puntillos sobre la fusa, y tresillo y seisillos con estas figuras.

\section{De la Llave de Fa en $4^{\mathrm{a}}$ línea:}

Lectura de notas en líneas, espacios y ambos.

Una lección en compás de $2 / 2$, con redondas, otra con blancas y negras, la tercera ya con corcheas y la cuarta semicorcheas y tresillos de semicorchea, terminando así esta parte. 


\section{$2^{\mathrm{a}}$ Parte}

\section{CUADRO DE INFORMACIÓN GENERAL DE LA SEGUNDA PARTE.}

$\mathbf{N}^{0}$ de lecciones

Extensión de las lec- Entre 15 y 45 compases

ciones

Claves empleadas

Tesituras que abarcan

Tonalidades que trata y estudia

Compases que emplea y estudia

Dificultades métricas
que contiene

Dificultades de entonación que se encuentran $y$ orden en que se enseñan los intervalos

\section{Armonía utilizada}

Formas que tienen las lecciones

Introducciones, Intermedios o Codas instrumentales

Teoría de la música que incluye

59 fácil ejecución.

No hay

No tiene
Solamente Sol y Fa en $4^{\mathrm{a}}$

Iguales que en la primera parte

Todas, empezando de nuevo por Do M y La m, luego todas las de sostenidos, y después todas las de bemoles [hay un error en la relativa de La M, a la que llama Fa m]

Todos los estudiados en la primera parte, y además $2 / 1,3 / 2$, 3/16, 6/4, 6/16, 7/4 (es extraño que aparezca solamente este compás irregular, y no esté primero, incluso que no esté, el de 5/4), 9/4, 9/16, 12/4 y $12 / 16$

Básicamente las mismas que en la anterior parte (que ya eran muchas para ser el primer nivel) Como nuevas tenemos las que se producen como consecuencia de los nuevos compases. Además Notas de Adorno y Valores irregulares desde quintillo a docillo. Las dificultades están muy alternadas, cuando la tonalidad es difícil ésta son menores.

Dobles alteraciones. Enarmonía. Por lo demás todos los intervalos, pero sin llegar a compuestos (que sí habían en la primera), ni a aumentados o disminuidos. Las melodías de

No lleva acompañamiento

Exclusivamente A-B-A'

\subsubsection{DESCRIPCIÓN DETALLADA DE ESTA SEGUNDA PARTE.}

Sin ninguna explicación de lo que es tonalidad, ni nada referente a ella, comienza esta parte dedicando una lección a cada una de las tonalidades referenciadas arriba, 
alternando, no rigurosamente, las claves de $\mathrm{Sol}$ y $\mathrm{Fa}$ en $4^{\mathrm{a}}$, y con los compases que se habían estudiado o practicado en la parte anterior, sin aumentar en nada las dificultades métricas y melódicas, las cuales, las métricas, ya estaban bastante elevadas; ahora debiera haber sido cuando se engrandeciera el nivel de dificultad métrico.

Una vez terminadas todas las tonalidades por orden de armaduras, primero en sostenidos y después en bemoles, aparecen once lecciones dedicadas a las Notas de Adorno, en tonalidades ya vistas, (puesto que todas están ya vistas) son concretamente Fa, Mi bemol, Sol, Re, Do Mi y La bemol, todas mayores, con los compases de 2, 3 y 4 por 4 y el de 6 por 8 , y usando exclusivamente la clave de Sol:

Apoyatura, que la define como unas pequeñas notas en las cuales se apoya la voz antes de pasar a la que sigue, y que le da como valor la mitad de esta nota. O sea que para este autor, la apoyatura no puede tener más o menos valor que la nota a la que adorna. Pero, curiosamente, en el ejemplo de lo que es apoyatura, aparece indistintamente ésta y el mordente de una nota, lo que parece querer decir que para Velázquez es todo lo mismo, sin embargo en las dos lecciones que dedica a esta nota de adorno, solamente se ven mordentes (con la excepción de una sola apoyatura en forma de negra), que para él deben tener como valor la mitad de la nota a la que adornan.

Mordente, escribe que son un grupo de dos notitas que se ejecutan con toda la rapidez posible. Y se escriben normalmente con abreviaturas. Ni distingue si esa abreviatura corresponde a la clase de mordentes a la $2^{\mathrm{a}}$ superior o inferior, ni si las otras especies llevan o no abreviatura. Sin embargo en las dos lecciones en los que aparecen, los hay de todas las clases, incluso los de una nota, los que suponemos querrá que se ejecutasen como apoyaturas.

Grupetos, los divide en de 3 y cuatro notas. Los de 3 notas explica que pueden ser rectos y circulares, que los primeros son rápidos y los segundos se adaptan al género de música, y que éstos se pueden representar con una abreviatura. Explica ésta y pone un ejemplo de escritura con abreviatura, con notas de adorno y trascripción a notas reales. Después hay dos lecciones, y la primera de ellas está escrita en dos pentagramas para transcribir en el de bajo en notas reales las abreviaturas. Alguna vez las pone posteriores a la nota adornada sin haber explicado que pueden ser los grupetos anteriores y posteriores. De los de 4 notas dice que son iguales que los de 3, pero que los circulares toman el valor de la nota anterior, (no pueden tomarla de la que adornan, aunque el estilo de la música así lo pida; tampoco habla de si pueden ser anteriores o posteriores) y también dedica 2 lecciones a ellos. 
Trino, una lección dedicada a este adorno, con abundantes trinos, y un ejemplo previo de ejecución.

Siguen lecciones, una por novedad, dedicadas a las abreviaciones; repeticiones; valores irregulares, en la que en un compás de 4/4 mete grupos desde 5 a 12; enarmonías, en la que a través de la enarmonización del si bemol por el la sostenido pasa de la tonalidad de mi bemol mayor a la de fa sostenido mayor, y vuelve a la primera por enarmonización del do doble sostenido por el re; a algunos signos y términos agógicos y dinámicos y a la fermata.

Procede después a insertar 10 lecciones en los compases que figuran arriba como nuevos en esta parte, a las que encierra bajo el título "compases compuestos poco usados". Desde luego que no comprendemos cómo llama al 2/1, 3/2, 3/16 y 7/4 compases compuestos. Las tonalidades en las que se desenvuelven están entre una y seis alteraciones en la armadura.

Dos lecciones ahora con notas en las líneas adicionales superiores, desde el $\mathrm{La}_{4}$ al Do ${ }_{6}$, sin muchas otras dificultades. Clave de Sol.

Y dos más, ya para terminar esta parte, con notas en las líneas adicionales inferiores, en la clave de Sol desde $\mathrm{Do}_{3}$ a Do 2 , y en la clave de Fa en $4^{\mathrm{a}}$ desde $\mathrm{Sol}_{1}$ a Sol $\mathrm{S}_{-1}$

\section{$3^{\text {a }}$ Parte}

CUADRO DE INFORMACIÓN GENERAL DE LA TERCERA PARTE.

$\mathbf{N}^{\circ}$ de lecciones

Extensión de las lec- Entre 12 y 75 compases

ciones

Claves empleadas

Tesituras que abarcan Como en los anteriores

Tonalidades que trata y estudia

Compases que emplea y estudia

\section{1} de claves más uso
$\mathrm{Fa} 4^{\mathrm{a}}$, Sol, Do $1^{\mathrm{a}}$, Do $2^{\mathrm{a}}$, Do $3^{\mathrm{a}}$, Do $4^{\mathrm{a}}, \mathrm{Fa} 3^{\mathrm{a}}$. Al final mezcla

Casi todas excepto Do \# M, Fa \# M, Mi b m, La b m y $\mathrm{Si}$ b m. Pero sin ningún orden

Todos los simples y compuestos, dentro de los compases de 
Dificultades métricas que contiene

Dificultades de entonación que se encuentran $y$ orden en que se enseñan los intervalos

Armonía utilizada

Formas que tienen las lecciones

Introducciones, Intermedios o Codas instrumentales

Teoría de la música que incluye
Las que ya tenía, abundando en las fusas y semifusas, incluso con tresillos sobre estas figuras, lo que ya hizo en la primera parte. También grupo irregular de 13

Excepto que incide con las enarmonías, no tiene grandes dificultades. Las melodías son agradables
No llevan acompañamiento, excepto la $\mathrm{n}^{\circ} 191$, que es un tema con variaciones

Exclusivamente A- B- A'

No tienen, excepto la última lección a 3 voces que tiene dos acordes para final

No tiene nada

\subsubsection{DESCRIPCIÓN DETALLADA DE ESTA TERCERA PARTE.}

Nos encontramos al principio con 10 lecciones, 2 en clave de Fa en $4^{\mathrm{a}}$, y el resto en la de Sol, que no se sabe muy bien para que están. Quizás como refuerzo de lo anterior; la primera está dedicada en abundancia a adornos, la segunda a tresillos de negra, la tercera y cuarta a abreviaturas, además la tercera cambia de modo (de Fa mayor a menor y vuelta), las que siguen inciden en tresillos de semicorchea, pausa de fusa, grupos irregulares, tresillos de fusa y semifusa y modulación por enarmonía. (La última de estas diez, empieza en Si mayor, modula a Sol bemol mayor y vuelve a la principal)

Después de éstas, comienzan las dedicadas al resto de las 5 claves.

Al conocimiento de cada una de estas claves, que aparecen en el orden citado arriba, dedica cuatro lecciones, con excepción de Fa $3^{\mathrm{a}}$ que sólo tiene tres. Para la de Do en $1^{\mathrm{a}}$ y en $3^{\mathrm{a}}$, hay dos lecciones fáciles y las otras dos más difíciles y con muchas notas de adorno. Para las de Do en $2^{\mathrm{a}}$ y en $4^{\mathrm{a}}$, las cuatro son excesivamente difíciles para haber abordado una nueva clave. Las tres de $\mathrm{Fa}$ en $3^{\mathrm{a}}$ no son demasiado dificultosas.

Se presentan ahora 4 lecciones, de nuevo en la clave de Fa en $4^{\text {a }}$ (que no sabemos a qué viene volver a remachar esta clave), con grandes dificultades métricas.

Prosigue esta parte con lecciones con mezcla de claves: Sol con Do en $1^{\mathrm{a}}$, éstas, más Do en $2^{\mathrm{a}}$, las mismas más Do en $3^{\mathrm{a}}$, todas, más Do en $4^{\mathrm{a}}$, y todas. 
Ya buscando el final, compone una lección en forma de Tema con Variaciones, y a éste le pone acompañamiento de piano. Son dos variaciones rítmicas, la primera tomando la negra de la melodía como la primera de cuatro semicorcheas, y la segunda variación, tomando la negra como la primera de un seisillo de semicorcheas. Otra lección para el cambio de tono (dice él), la que empieza en La menor, y va cambiando en cortos fragmentos a La mayor, Do sostenido mayor, Re bemol mayor, Fa menor, Do mayor, Fa menor, Sol bemol mayor, Si mayor, Mi menor, Mi mayor y de nuevo a La menor para acabar. Una a dúo, en Fa mayor y con el compás de seis por ocho, es una lección casi homofónica, pero dialogada entre las dos voces. Finalmente una a tres voces, también acompañada, más contrapuntística que el dúo, en Si bemol mayor, compás de compasillo y pretensiones de lied.

Termina con una tabla de términos del movimiento y del carácter.

\subsubsection{VALORACIÓN DE LA EFECTIVIDAD DEL MÉTODO Y DE SU APORTACIÓN A LA ENSEÑANZA}

Desde luego era la forma de enseñar en la época, al menos la mayoría.

En las primeras lecciones, ya todos los intervalos de una vez, sin ninguna gradación. Compás, el 4/4, o empezaban con el de $2 / 2$, el de $2 / 4$ no era para la época el más natural.

En cuanto aparece el silencio de negra, se forma el contratiempo largo, sin explicación ninguna, lo mismo con el de corchea. Y como en otros libros, la prisa, a la octava lección los signos de repetición, y en seguida el calderón, sacado de su contexto del resto de signos de prolongación.

Es una barbaridad que en este primer nivel, aparezcan las últimas lecciones con fusas, semifusas, puntillos sobre éstas, tresillos y seisillos con ellas.

Un desastre de método, todo desordenado, con poca insistencia en las dificultades, y aparición de éstas extremadamente prematura.

En la $2^{\mathrm{a}}$ parte, las melodías son bastante agradables y no ofrecen grandes dificultades de entonación.

Está muy bien que se aprendan las distintas tonalidades con las claves de Sol y Fa en $4^{\mathrm{a}}$ 
Velázquez, 3aㅗ parte

Esta parte está bastante completa, pero solamente una lección por dificultad es muy poco, y hay demasiados compases nuevos en un solo curso.

La parte dedicada a Adornos, está fatalmente explicado lo poco que se explica, y con criterios muy discutibles.

En general está mejor esta parte que la primera, sin llegar a ser un método de gran utilidad.

Vista la parte $3^{\mathrm{a}}$, decididamente es un método que nada aporta, aburrido y dentro de los cánones típicos de la mayoría de los de la época. 


\subsection{RESEÑAS BIOGRÁFICAS DE LOS AUTORES}

BRULL AYERRA, A y otros:

BRULL AYERRA, Apolinar. San Martín de Unx (Navarra) 3/7/1845 - Madrid 7/4/1905. Compositor y pianista. Organista en Tafalla y posteriormente profesor del Real Conservatorio de Música de Madrid (Casares Rodicio, en AAVV, 1999, tomo 2, p. 735 y Gómez Amat, 1984, capítulo VI, p. 77).

CANTÓ FRANCÉS, Juan. Alcoy 21/1/1856 - Madrid 17/11/1903. Compositor y director. Profesor repetidor de Armonía en la Escuela Nacional de Música (Casares, en AAVV, 1999, tomo 3, p. 97).

FERNÁNDEZ GRAJAL, Manuel y Tomás. Hermanos. El primero Madrid 5/6/1838 6/2/1920. Compositor y pianista. El segundo Madrid 15/12/1839 - 8/2/1914. Alumno de Albéniz. Profesor de contrapunto y fuga (Alonso, Celsa y G. Iberni, Luís, en AAVV, 1999 , tomo 5 pp. 67 y 68 ).

FONTANILLA MIÑAMBRES, Pedro. Muere en Madrid? 23/7/1931. Pianista, compositor, pedagogo y tratadista. Autor del tratado de armonía Arín y Fontanilla (Iglesias, Antonio, en AAVV, 1999, tomo 5 p. 213)

LLANOS BERETE, Antonio. Madrid 27/9/1841 - 1906. Compositor, profesor y escritor didáctico. Alumno en Madrid de Emilio Arrieta. En 1875 profesor auxiliar de piano en Madrid. Maestro concertador en el Teatro de la Zarzuela y en el Apolo. Director del Orfeón Normal de Madrid. Compositor de óperas y zarzuelas. Autor de un Método de piano y lectura musical (Sanhuesa Fonseca, en AAVV, 1999, tomo 6, p. 943) .

SERRANO RUIZ, Emilio. Vitoria 13/3/1850 - Madrid 9/4/1939. Compositor, pianista, director y profesor. Personaje importante en la música del siglo XIX en España. Profesor auxiliar de solfeo del Conservatorio de Madrid. Llegó a Catedrático de Composición (Cortizo, Ma Encina, en AAVV, 1999, tomo 9 pp. 956 a 961) .

SOS, Antonio. Madrid 24/4/1834 - ? Pianista y compositor. Profesor de solfeo y piano en el Conservatorio de Madrid (Vázquez Tur, Mariano, en AAVV, 1999, tomo 10, p. 31).

I. A. Campo, J. Falcó, J. Jiménez Delgado y P. Hernández no han podido ser localizados en bibliografía alguna. 


\subsubsection{DESCRIPCIÓN DETALLADA DEL MÉTODO}

\section{Título del Método}

Método completo de solfeo, Madrid, José Campo y Castro, s. f. ${ }^{1}$ Apéndice, página 228. El método lleva dos nombres: La primera contracubierta dice Nuevo método de Solfeo, escrito por varios Profesores de la Escuela Nacional de Música y Declamación. A la que sigue otra más artística en forma de retablo, en el que pone en el techo EL PROGRESO MUSICAL, y en el centro Método completo de Solfeo, escrito por A. Brull - I. A. Campo - J. Cantó - J. Falcó - M. Fernández Grajal - T. Fernández Grajal - P. Fontanilla J. Giménez Delgado, P. Hernández - A. Llanos - E. Serrano y A. Sos, profesores de la Escuela Nacional de Música y Declamación.
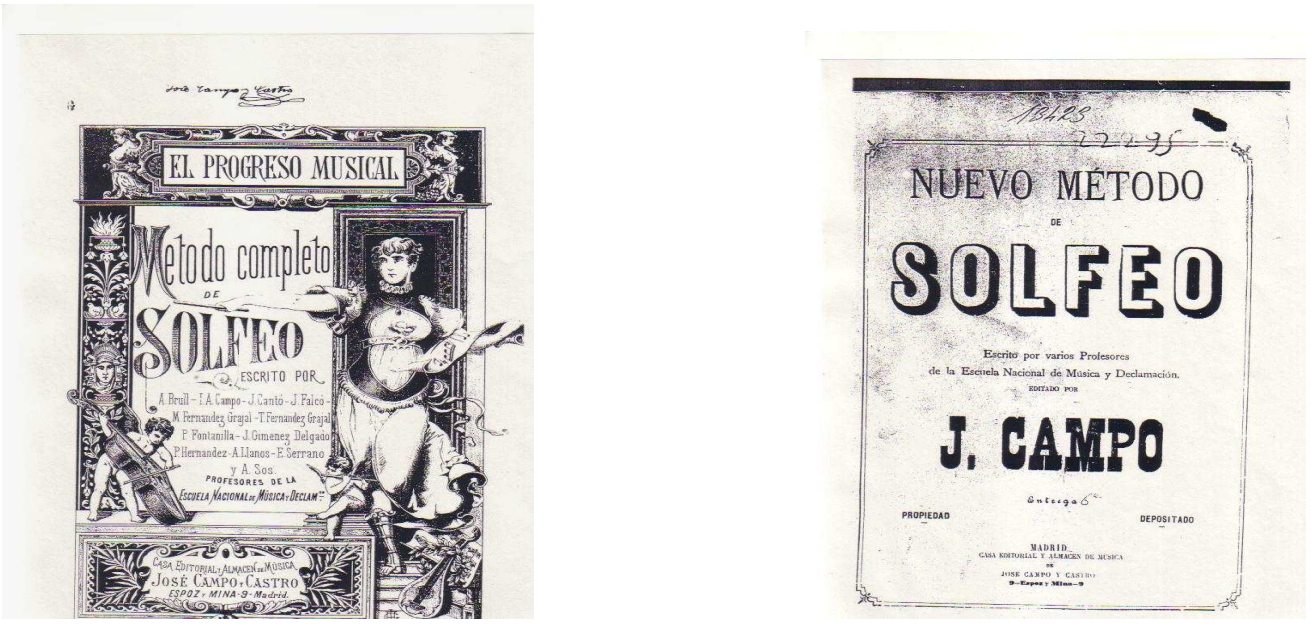

PARTE PRIMERA

CUADRO DE INFORMACIÓN GENERAL DE LA PARTE PRIMERA.

$\mathbf{N}^{\circ}$ de lecciones

44

Extensión de las lec- Desde 12 a 33 compases

ciones

Claves empleadas Sol

Tesituras que abar- $\quad \mathrm{De} \mathrm{Do}_{3} \mathrm{a} \mathrm{Mi}_{4}$, excepcionalmente $\mathrm{Fa}_{4}$

can

Tonalidades que tra- Do mayor

ta y estudia

\footnotetext{
${ }^{1}$ El libro no lleva fecha impresa, pero en la página 1, antes del enunciado "Primera Parte", hay una nota manuscrita, muy poco legible, porque el servicio reprográfico de la Biblioteca Nacional al hacer la fotocopia ha cortado la parte de arriba de este texto, pero se entiende perfectamente "Presentado en .....y al final que no está cortado dice claramente: "en 10 de Marzo de 1898”, siguiendo a esto la firma autógrafa de José Campo y Castro, el editor.
} 


\section{Compases que em- plea y estudia

Dificultades métricas
que contiene

Dificultades de entonación que se encuentran y orden en que se enseñan los intervalos

Armonía utilizada

\section{Formas que tienen las lecciones}

Introducciones, Intermedios o Codas instrumentales

Teoría de la música que incluye
$4 / 4,2 / 4$ y $3 / 4$

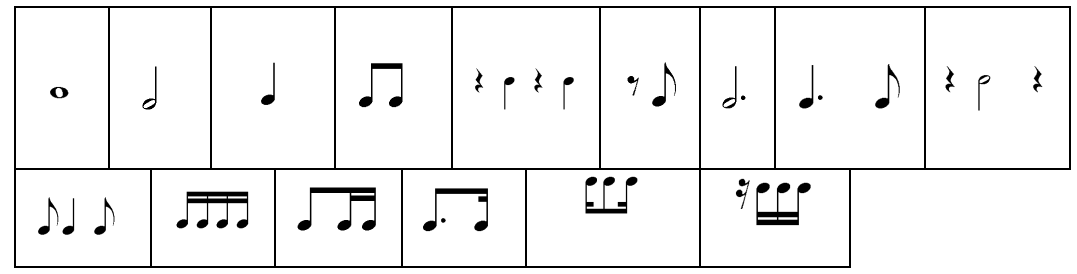

Todos los intervalos naturales de la escala, y alteraciones cromáticas primeramente e intervalos alterados al cambiar de tonalidad. Intervalos compuestos

En general sencillez en la entonación

Desde $2^{\mathrm{a}}$ a $8^{\mathrm{a}}$ preparados y de salto

Romántica y cromática. Todos los acordes de $7^{\mathrm{a}}$, Sexta aumentada, $7^{\mathrm{a}}$ diatónicas sin preparar. Acordes de paso disonantes. $5^{\mathrm{a}}$ aumentada sobre el I Las modulaciones son suaves, a tonos vecinos y normalmente por ciclo de quintas

A-A'; A-B muchas de ellas en forma de antecedente y consecuente, A-B-C; A-B-A'

Tienen introducción 6 lecciones, simplemente unos acordes, o algún bajo. No hay intermedios ni finales.

Muy poca, la estrictamente necesaria para comprender cada nueva dificultad

\section{DESCRIPCIÓN DETALLADA DE ESTA PRIMERA PARTE.}

Comienza por un Prólogo, en el que en síntesis dice que el Solfeo comprende dos partes íntimamente relacionadas, que son la teoría y la práctica. Después de una crítica a las tendencias innovadoras de la época, el editor, que es quien firma este prólogo, anota que este método ha adoptado el sistema de ejercicios prácticos de entonación, medida y escritura, esto último muy importante. También, que se ha tenido muy en cuenta la concisión y exactitud en las definiciones, la claridad en los puntos dudosos, y que en el enlace de las lecciones, cada una sea la consecuencia lógica y progresiva de la anterior. Respecto al acompañamiento de las lecciones, explica que lo hacen manteniendo un bajo cifrado, para quien sepa interpretarlo, y un pentagrama para la mano derecha del piano, que sugiere un acompañamiento acordal, para quien no entienda el 
cifrado armónico. Comenta que todas las dificultades de medida y entonación, se ven en la clave de Sol, lo que da a entender que con las demás ya no hay nada nuevo, si no que se limita a dar a conocer estas claves. Y como se verá, no es cierto. Por último avisa de la inserción, en cada una de las tres partes, de lecciones autografiadas para practicar la lectura a primera vista.

Se trata de la primera edición del después famoso y de larga vida El Progreso Musical, que fue nuevamente editado, por partes, por la Sociedad Didáctico - Musical en 1956. Concretamente, en la primera parte de esta última, figura en su portada y contraportada las siguientes inscripciones: EL PROGRESO MUSICAL, MÉTODO ESPECIAL DE SOLFEO, con acompañamiento de piano y bajo numerado, NUEVA EDICIÓN, escrito y publicado por la Sociedad Didáctico - Musical constituida por Profesores del Real Conservatorio de Música y Declamación de Madrid. En su "Prólogo a la nueva edición", fechado en Septiembre de 1956, dice que se adapta a la Orden ministerial de 30 de mayo de 1955, y no hace sino calcar el viejo Método completo de solfeo, hasta la lección 44 inclusive, añadiéndole, y eso comenta el último párrafo de este prólogo, dos lecciones que estaban en la segunda parte en el antiguo, y algunas lecciones en clave de Fa en $4^{\mathrm{a}}$, concretamente dos, una en Do mayor, con notaciones sencillas y de nueva composición, otra en La menor, también sencilla, trasladada de la segunda parte del método anterior; a las que añade cinco más, que son: una cantiga de Alfonso X el Sabio, una canción de Juan del Encina, y tres Corales de J. S. Bach.

Este método se ha estado usando exclusivamente en la enseñanza oficial y libre, al menos en Valencia, hasta aproximadamente el año 1987, en el que empezó a convivir con otros nuevos, e incluso todavía hay centros que imparten la enseñanza del solfeo valiéndose de él, sobre todo en sus nuevas ediciones; por ello, por lo sobradamente conocido que es, no creemos necesario extendernos en su descripción.

Nos limitaremos a destacar las particularidades de este método: Desde un principio, y ya mientras explica cualquier cuestión teórica, tiene un apartado de "Ejercicio gráfico", con el que pide al alumno que escriba cuestiones relacionadas con lo que se está explicando. También tiene, prácticamente al principio de cada lección, o al menos al comenzar una nueva dificultad, ejercicios de lectura medida, (solfeo rítmico) y lectura entonada con cada uno de los intervalos, preparados por grados y por saltos, y con las alteraciones. 
Otra peculiaridad es el puntillo puesto a una nota que dura más de un compás, o sea, en el compás siguiente, así como una lección dedicada a la nota partida

\section{PARTE SEGUNDA}

\section{CUADRO DE INFORMACIÓN GENERAL DE LA PARTE SEGUNDA.}

$\mathbf{N}^{0}$ de lecciones

41

Extensión de las lec- Entre 20 y 50 compases

ciones

Claves empleadas

Tesituras que abarcan

Tonalidades que trata y estudia

Compases que emplea y estudia

\section{Dificultades métricas que contiene}

Dificultades de entonación que se encuentran $y$ orden en que se enseñan los intervalos

Armonía utilizada

Formas que tienen las lecciones

Introducciones, Intermedios o Codas instrumentales

Teoría de la música que incluye

Igual que en la anterior compases

\author{
Sol, Fa $4^{\mathrm{a}}$, Do $1^{\mathrm{a}}$ y cambios entre ellas
}

Do M, La m, Sol M. Mi m, Fa M, Re m, Re M, Si m, Si b M, Sol m, La M, Fa \# m, Mi b M, Do m

Los de antes más $2 / 2,3 / 8,6 / 8,9 / 8$ y $12 / 8$

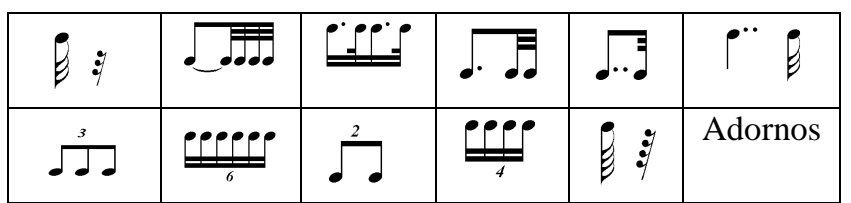

Intervalos mayores y menores alterados. Aumentados, $2^{\mathrm{a}}, 4^{\mathrm{a}}$, $5^{\mathrm{a}}$ y $6^{\mathrm{a}}$. Disminuidos, $3^{\mathrm{a}}, 4^{\mathrm{a}}, 5^{\mathrm{a}}, 7^{\mathrm{a}}$,

Un poco más complicada que en el anterior. Grados alterados y acordes alterados cromáticamente

A-B-C; A-B-C-A'; A-B-C-C': A-B-C; '

Solamente una, la $\mathrm{n}^{\mathrm{o}}$ 2, lleva una introducción rítmica de dos

Al principio en la calificación de intervalos y en las tonalidades. Después cuando aparece alguna novedad. Y casi al final con las notas de adorno 


\subsubsection{DESCRIPCIÓN DETALLADA DE ESTA SEGUNDA PARTE.}

Es exactamente igual, que la conocida segunda parte de este método, editada en 1959. Continúa, como en la anterior parte, con las lecturas medidas, prácticas de intervalos, entonaciones medidas y ejercicios gráficos, a lo que añade escalas y ejercicios de entonación en cada una de las tonalidades.

Al principio hay explicaciones teóricas de: términos del movimiento, clasificación de intervalos (a lo que debería llamar calificación), inversión de éstos y todo lo referente a tonalidad y modalidad.

Cabe criticar la forma de explicar la calificación de intervalos, que es a través de una tabla de los intervalos en la escala diatónica de Do, para que luego se comparen a éstos cualesquiera otros; es una forma torticera y larga para analizarlos. En general está muy poco clara la explicación, dicen: los intervalos menores contienen un semitono menos que los respectivos mayores; los disminuidos uno menos que los menores, y los aumentados un semitono más que los mayores, que en ningún momento dice cuántos tienen cada uno de los mayores. También es ininteligible la definición de Tonalidad: es el conjunto melódico y armónico que debe haber en toda composición musical respecto a un tono establecido. A ver si hay alguien no músico que entiende esto. Y otra cosa curiosa es que llama propia a la escala menor natural, y alterada a la armónica y melódica.

Después hay explicaciones concisas y concretas cuando aparecen nuevas dificultades métricas, compases o claves.

Por último vuelve a ver teoría más extensamente cuando se abordan las notas de adorno, las que clasifica según la teoría más común en la actualidad, apoyaturas, mordentes, trino y fermata, los mordentes en una y dos notas, y a los de 3 y 4 les llaman también grupetos o mordentes circulares. 


\section{PARTE TERCERA}

\section{CUADRO DE INFORMACIÓN GENERAL DE LA PARTE TERCERA.}

$\mathrm{N}^{\mathbf{o}}$ de lecciones

Extensión de las lec- Entre 19 y 83 compases

ciones

Claves empleadas

Do $2^{\mathrm{a}}$, mezclas, Do $3^{\mathrm{a}}$, mezclas Do $4^{\mathrm{a}}$, mezclas, Fa $3^{\mathrm{a}}$, mezclas entre todas.

Tesituras que abarcan Las mismas

Tonalidades que trata y estudia

Compases que emplea y estudia

Dificultades métricas que contiene

Dificultades de entonación que se encuentran $y$ orden en que se enseñan los intervalos

Armonía utilizada

Formas que tienen las lecciones

Introducciones, Intermedios o Codas instrumentales

Teoría de la música que incluye

\section{3}

Mi M, Do \# m, La b M, Fa m, Si M, Sol \# m, Re b M, Si b m, Fa \# M, Re \# m, Sol b M, Mi b m, Do \# M, La \# m Do $b$ M, La b $\mathrm{m}$ y repetición de algunas anteriores. A partir de la mitad del método, también hay cambios de modo y tono.

Los mismos más $2 / 8$ y los irregulares: 7/4, 5/4, 5/8, 10/8. Además en los ejercicios gráficos pide transcribir algunos ejercicios o lecciones a los denominadores 1,2 y 8 para simples o 4 y 16 para compuestos

Ninguna más que sumar a las anteriores, simplemente las que se desprenden de los compases irregulares, y los cambios de clave. Fermata

Dobles alteraciones. Enarmonías

Como en la anterior parte, pero quizás incidiendo en los acordes alterados, además emplea algún acorde de $9^{\mathrm{a}}$

A-B-A'; A-B; A-B-A; A-B-C-A'; A-A'; A-B-C

3 tienen uno o dos compases de introducción. No hay intermedios y codas.

Mucha más que en las anteriores, y casi completa todo lo básico en cuanto a teoría de la música. 


\subsubsection{DESCRIPCIÓN DETALLADA DE ESTA TERCERA PARTE.}

Es exactamente igual que la editada en 1979 ( $3^{\text {a }}$ edición), excepto que aquella incluye 4 lecturas manuscritas de examen del año 1896, y ésta no las lleva.

Hacemos notar la explicación que da el método al compás de 5/8. De entrada dice que vulgarmente se llama zortzico (no todos los cinco por ocho son zortzicos), luego dice que se puede marca en un solo tiempo, o en dos desiguales, y por último alaba la teoría de Eslava (ya comentada por nosotros en el estudio de su método) de convertirlo en un 10/8. La lección que dedica al 5/8, n² 29, la que encabeza con la inscripción "Aire de zortzico, no tiene en absoluto tal aire, ni la métrica corresponde a él; la siguiente la escribe en compás de 10/8 y esa sí tiene aire de zortzico. Seguramente lo hace para confirmar y suscribir la teoría de Eslava en cuanto a este ritmo característico.

Hace una referencia a la música dictada, diciendo que en la primera y segunda parte se debía haber practicado (pero nada de esto se ha visto en ellas), la duración de los sonidos y la entonación, dejando para esta parte el unir ambas cosas. Es un breve comentario a esta parte tan importante de la enseñanza musical, pero es de notar que es el único que lo hace

\subsubsection{VALORACIÓN DE LA EFECTIVIDAD DEL MÉTODO Y DE SU APORTACIÓN A LA ENSEÑANZA}

Es un buen método, progresivo, bastante completo, asequible, fácil de entender, con las tachas pedagógicas de cualquier método de la época, aunque en éste menos que en otros.

Son las melodías más bonitas que en método alguno haya, tienen una musicalidad que hacen que el educando se entregue al estudio de ellas con complacencia.

Sigue siendo la segunda parte, como la primera, un método muy válido, sin embargo las lecciones ya no son todas tan bonitas, empiezan, en esta parte, a ser más duras de estudiar y menos musicales.

No obstante, alabar el que cuando aparecen nuevos compases las dificultades son pequeñas. No así ocurre cuando se empieza a utilizar la clave de Do en $1^{\text {a }}$ línea, que no sólo se afronta con dificultades rítmico - melódicas, sino que se agrava con la inclusión de las notas de adorno. 
La tercera parte ni es tan progresiva como las otras, sobre todo la primera, ni sus lecciones son tan bonitas. Las melodías de este volumen son mucho más rebuscadas y de más difícil entonación.

Por otra parte, las mezclas de claves, barbaridad en la que no es el único método, hacen que aumente considerablemente la dificultad, porque cada nueva clave necesitaría de lecciones sencillas para familiarizarse con ella, por el contrario, con cada una nueva, aparecen a la vez mayores dificultades métricas, de entonación, tonalidades más alteradas y llega al colmo la cuestión con la presentación de la clave de Fa en $3^{\text {a }}$ con compases amalgamados.

No obstante en general es un método muy completo entre los de su tiempo. 
El Progreso Musical, parte tercera 


\subsection{RESEÑA BIOGRÁFICA DEL AUTOR}

PARDÁS Y FONT, Primitivo. Barcelona 8/11/1828 - 20/9/1897. Organista, discípulo de Liszt y Thalberg. En 1845 en Barcelona concertista de piano (Cortés Mir, Francesc, en AAVV, 1999, tomo 8, p. 460).

\subsubsection{DESCRIPCIÓN DETALLADA DEL MÉTODO.}

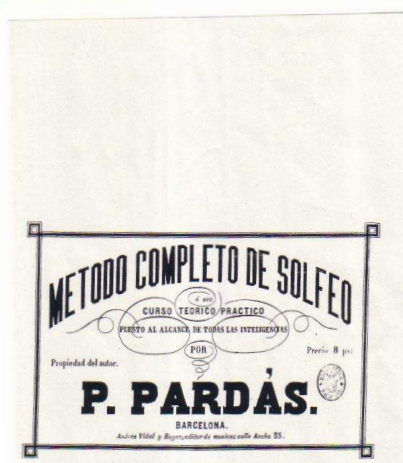

Título del Método

Método completo de solfeo, o sea, Curso Teórico Práctico puesto al alcance de todas las inteligencias, Barcelona, Andrés Vidal y Roger, s. f. ${ }^{1}$ Apéndice, página 229.

Empieza con el prólogo del autor, en el que en resumen, dice que ha pretendido hacer un método fácil y ameno, que evite las prontas deserciones de este estudio.

Presenta tres partes: una teórica, una práctica y una segunda parte.

\section{PARTE TEÓRICA}

Capítulo I.- pentagrama, notas y sus nombres, concepto de intervalo, nombre de las notas en las líneas adicionales.

Capítulo II.- las llaves y el nombre de las notas en todas ellas.

Capítulo III.- las figuras, con su nombre antiguo, su duración en un compás de cuatro partes, los silencios y el puntillo.

Capítulo IV.- compases, que los divide en pares e impares (binarios y ternarios). El compasillo lo cifra solamente con un 4. La manera de marcar el de tres partes dice que es bajo, izquierda y arriba, y también dice que se pueden marchar con la mano o el pie (no imaginamos como marcar con el pie los tiempos arriba). Después los vuelve a dividir en simples y compuestos, siendo los compuestos los de denominador 8. Quizás habla

\footnotetext{
${ }^{1}$ En la portada con la signatura de la Biblioteca Nacional, anterior a la del método, figura al lado del nombre del editor [1864-1900], no sabemos si se refiere a los años en que se estuvo editando el libro, o a los años de funcionamiento de esta editora.
} 
así porque figuran como compuestos los 6,9 y 12 por 8 , pero también el de $3 / 8$ que no tiene nada de compuesto, y nada dice de la posibilidad de 2 ó 4 por 8 . No es fórmula correcta clasificar de compases compuestos atendiendo al denominador. Al hablar de la forma de marcar el compás de 6/8, además de hacerlo como 2 compases de 3/8 o con tres subdivisiones en el formato de 2/4, también dice que puede ser como el de cuatro, dando dos corcheas a la primera parte, una a la segunda, dos a la tercera y una a la cuarta. Eso mismo dice Matías Aliaga, lo que demuestra que hacía la mitad del XIX, ya se practicaba esta manera exacta, en cuanto a la acentuación, de marcar este compás, que nosotros creíamos una invención de los contemporáneos. Al final figura el que llama compás mayor, el 2/2.

Capítulo V.- de los tresillos y seisillos (pocos hablan del resto de valores irregulares). Justifica éstos como una división en tercios o sextos de las figuras de nota, y también figura, aunque muy someramente, alguna combinación.

Capítulo VI.- las alteraciones, las propias y las accidentales (sin darles esas denominaciones) y las dobles. Destacamos que el doble sostenido lo representa *. Capítulo VII.- síncopas con todos los valores.

Capítulo VIII.- notas de adorno, que las clasifica en notita sencilla, notita doble, grupetto, mordente y trino; las dos primeras son los mordentes (para este autor no existe la apoyatura), las abreviaturas de mordentes son la misma para ascendentes y descendentes, esto es, la horizontal $\sim$ para los ascendentes y la misma, más pequeña, para los descendentes; incluye los mordentes entre los trinos, porque llama así a la abreviatura de mordente de dos notas a la segunda superior, o semitrino. De los signos de articulación, solamente menciona el destacado (picado) y el ligado. De la corona o calderón. De las abreviaciones. De las repeticiones, todas ellas. Y acaba con los términos dinámicos y los del movimiento.

\section{PARTE PRÁCTICA}

CUADRO DE INFORMACIÓN GENERAL DE LA PARTE PRÁCTICA. $\mathbf{N}^{\circ}$ de lecciones 109

Extensión de las lec- Entre 4 y 31 compases ciones

Claves empleadas $\quad$ Sol y Fa $4^{\mathrm{a}}$ 


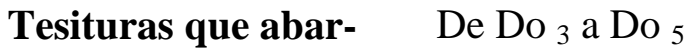

can

Tonalidades que trata Do M

y estudia

Compases que em- $\quad 4 / 4,2 / 4,3 / 4,3 / 8,6 / 8,9 / 8,12 / 8$ y $2 / 2$

plea y estudia

Dificultades métricas que contiene

Dificultades de ento-

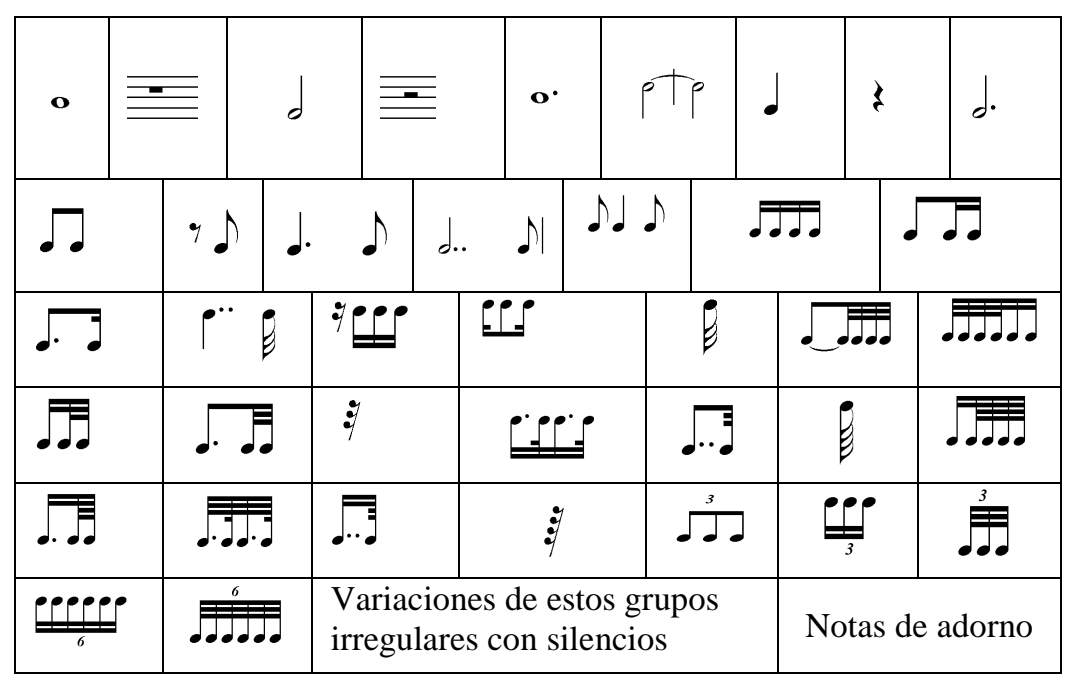

nación que se encuen-

tran

y orden en que se

Ninguna dificultad.

La escala, $3^{\mathrm{a}}, 4^{\mathrm{a}}$ y $5^{\mathrm{a}}$. Semitonos cromáticos, no los diatónicos enseñan los intervalos

Armonía utilizada No hay acompañamiento

Formas que tienen las La mayoría no tiene, son ejercicios métricos con la escala colecciones mo melodía. Otras tienen forma A-A'; A-B-A'

Introducciones, In- No tienen termedios o Codas instrumentales

Teoría de la música Toda una primera parte dedicada a ella que incluye

\section{DESCRIPCIÓN DETALLADA DE LA PARTE PRÁCTICA.}

Comienza por mostrar el nombre de las notas en la clave de Sol, en escala y alternadas; escala para la práctica de la entonación, y ya la primera lección con redondas y sus pausas, en intervalos de tercera, cuarta y quinta.

Con 14 lecciones, llega a la síncopa breve de la siguiente manera: 4 lecciones con blancas, blancas y su silencio, puntillo a la redonda y síncopa de redonda (notas 
partidas). Sigue así con la negra, su silencio, blanca con puntillo; y con la corchea al presentar su silencio, forma de entrada contratiempos; luego el puntillo sobre la negra doble puntillo sobre la blanca y síncopa breve.

A partir de aquí, con las semicorcheas, comienzan una serie de lecciones con doble pentagrama y la misma melodía en ambos, pero la de bajo con contracción rítmica a la mitad con respecto a la melodía superior, por tanto alternan las líneas divisorias pequeña para el pentagrama superior solamente y larga abarcando los dos, puesto que por cada dos compases del de arriba resulta uno bajo.

La secuencia en que aparecen es: corcheas y negras arriba, semicorcheas y corcheas bajo. Negras y corcheas por corchea - semicorcheas y corcheas. Blanca con puntillo seguida de dos corcheas / negra con puntillo - semicorcheas. Blanca, silencio de negra, dos corcheas / negra, silencio de corchea - dos semicorcheas. Negra con puntillo - corchea / corchea con puntillo - semicorchea. Blanca con doble puntillo - corchea / negra con doble puntillo - semicorchea. Blanca, silencio de corchea y 3 corcheas / negra, silencio de semicorchea y 3 semicorcheas. Blanca ligada a la primera de 4 corcheas / negra ligada a la primera de cuatro semicorcheas; síncopa breve / síncopa muy breve. Ocho semicorcheas y dos negras por dieciséis fusas y dos corcheas. Negra, 4 semicorcheas / corchea y 4 fusas. Corchea - dos semicorcheas / semicorchea - dos fusas. Negra con puntillo - dos semicorcheas / corchea con puntillo - dos fusas. Negra, silencio de corchea y dos semicorcheas / corchea, silencio de semicorchea y dos fusas. Corchea con puntillo - semicorchea / semicorchea con puntillo - fusa. Negras con doble puntillo semicorchea / corcheas con doble puntillo - fusa. Pausa de fusa. Ligadura entre blanca y semicorchea / negra ligada a fusa. La misma melodía (escalas ascendentes y descendentes) con fusas y corcheas/semifusas y semicorcheas. Corchea - cuatro fusas / semicorchea - cuatro semifusas. Negra con puntillo - cuatro fusas / corchea con puntillo - cuatro semifusas. Corchea con puntillo - dos fusas / semicorchea con puntillo - dos semifusas. Semicorcheas con puntillo - fusas / fusas con puntillo - semifusas. Corcheas con doble puntillo - fusa / semicorcheas con doble puntillo - semifusa. Semicorchea - dos fusas / fusa - dos semifusas.

Nuevas series de lecciones cuyo patrón es la misma melodía con diferentes ritmos: 3 lecciones con tresillos de corcheas, semicorcheas y fusas. 2 lecciones con seisillos de semicorcheas y de fusas. 3 lecciones con tresillos de corchea, de semicorchea y de fusa, esta vez con combinaciones de dos figuras en los tresillos. 3 lecciones con igual 
progresión, pero utilizando la pausa como sustitución de una nota en el tresillo. Y dos lecciones con pausas en los seisillos.

Notas alteradas.

Catorce lecciones cortas y muy cortas, con sostenidos por grados, bemoles por grados, formando intervalos cromáticos; lo mismo por grados disjuntos y combinación de ambos. No se utiliza el becuadro, y cuando se hace es inadecuadamente, o sea, en forma de precaución sin el paréntesis.

\section{Llave de Fa en $4^{a}$ línea:}

Nombre de las notas en esta clave y dos lecciones, una muy sencilla y la otra ya más complicada, con tresillos, corcheas con puntillo y semicorcheas.

A continuación da a conocer los otros compases que se ven en este método, a razón de 3 lecciones para los de 2/4, 3/4, 3/8, 6/8, 9/8, 12/8 y 2/2, siempre con la sucesión de una fácil, la segunda más complicada y la última muy difícil. Todas ellas en la clave de Fa.

Notas de adorno:

Una lección para cada una de ellas: la apoyatura (notita sencilla), el mordente de dos notas (notita doble), el grupeto ascendente y el grupeto descendente con sus abreviaturas.

Estudio sobre las abreviaciones:

También una lección por cada una de las formas de abreviar: para la abreviatura de corchea, de semicorchea, de corcheas con puntillo a las blancas, de corcheas y semicorcheas con puntillo a las negras.

Estudios sobre la repetición:

Seis lecciones sobre los signos de repetición y una séptima sobre la corona.

Termina con lecciones para notas excesivamente agudas y graves en las dos claves estudiadas. 


\section{$2^{\mathrm{a}}$ Parte}

CUADRO DE INFORMACIÓN GENERAL DE LA SEGUNDA PARTE. $\mathbf{N}^{\circ}$ de lecciones 54

Extensión de las lec- Entre 8 y 40 compases ciones

Claves empleadas

Fa $3^{\mathrm{a}}$, Do $1^{\mathrm{a}}$, Do $2^{\mathrm{a}}$, Do $3^{\mathrm{a}}$, Do $4^{\mathrm{a}}$, y de nuevo las anteriores

Tesituras que abarcan Igual que en la parte anterior De $\mathrm{Do}_{3}$ a Do 5

Tonalidades que trata La m, de nuevo Do M, Sol M, Mi m, Re M, Si m, La M, y estudia Fa \# m Mi M, Do \# m, Si M, Sol \# m, Do \# M, La \# m Fa M, Re m, Si b M, Sol m, Mi b M, Do m, La b M, Fa m, Re b M, Si b m, Sol b M, Mi b m, Do b M, La b m

Compases que emplea Los empleados en la $1^{\mathrm{a}}$ parte, ninguno nuevo y estudia

Dificultades métricas que contiene

Las mismas, más valores irregulares solamente la última lección

Dificultades de entonación que se encuentran $y$ orden en que se enseñan los intervalos

\section{Armonía utilizada}

Formas que tienen las lecciones

Introducciones, Intermedios o Codas instrumentales

Teoría de la música que incluye
Ninguna, intervalos mayores y menores y abundancia de segundas.

No hay acompañamiento

Muchas tienen forma primaria, la mayoría A-A' y alguna AB-A'

No tienen

Nada más al principio para explicar el origen de las tonalidades

\subsubsection{DESCRIPCIÓN DETALLADA DE ESTA SEGUNDA PARTE.}

Unas breves explicaciones de las diferencias entre el modo mayor y el menor, y la necesidad de utilizar alteraciones para igualar las distintas escalas que comiencen por otras notas diferentes a Do o La, seguidas de un esquema con las armaduras de todas las tonalidades. 
Y para empezar con las lecciones, lo hace presentando el resto de claves, y comenzando por la que debía ser la última, Fa en $3^{\mathrm{a}}, 3$ lecciones para conocer y practicar cada una de ellas, según el orden que figura arriba, y utilizando los distintos compases estudiados en la anterior parte.

Continua con el estudio de las distintas tonalidades mayores y menores en el orden indicado arriba, todas las de sostenidos y luego las de bemoles, una lección por cada tonalidad, empleando solamente las claves de Sol y Fa en $4^{\mathrm{a}}$, y todos los compases vistos.

Estudios sobre el cambio de tono:

4 lecciones para ver la modulación a veces transitoria, a veces definitiva: cambio de Re menor a mayor y vuelta; La mayor a Re menor y vuelta; Fa menor a Fa mayor y Mi mayor a Mi menor y de nuevo al principal.

Termina con 6 lecciones en las que hay mezcla de claves, tres claves en una lección y en la sexta todas las claves. Y una más para los valores irregulares hasta oncillos.

\subsubsection{VALORACIÓN DE LA EFECTIVIDAD DEL MÉTODO Y DE SU APORTACIÓN A LA ENSEÑANZA}

Tiene una parte teórica suficiente para afrontar el estudio muy elemental del solfeo, desde luego muy incompleta para cualquier intento de profesionalizarse.

En la parte práctica, se notan a faltar ejercicios de entonación interválica.

Como otros muchos método, tiene demasiadas dificultades de golpe, ¿por qué no poner el silencio de corchea detrás de ella, y luego delante, con el fin de no acometer sin más el contratiempo?

Está bien, sin embargo, utilizar las mismas melodías con distintas duraciones, para demostrar la equivalencia de las distintas figuras y grupos.

Es una primera parte demasiado fatigosa para principiantes, y con escasa práctica e información para formación de profesionales.

Con la segunda parte se completan los conocimientos prácticos necesarios, eso sí, con mucha superficialidad. 
Pardás y Font, $2^{\mathrm{a}}$ parte

Que es un método completo, como su nombre indica, es cierto porque trata de todo un poco, pero, como muchos otros, tan poco de cada cosa que es insuficiente para una buena formación, además de resultar muy difícil la primera parte.

Es, también como muchos, un libro para información de aficionados que pueden llegar hasta donde sus deseos les lleven. 


\subsection{AUTORES VARIOS}

\subsubsection{DESCRIPCIÓN DETALLADA DEL MÉTODO.}

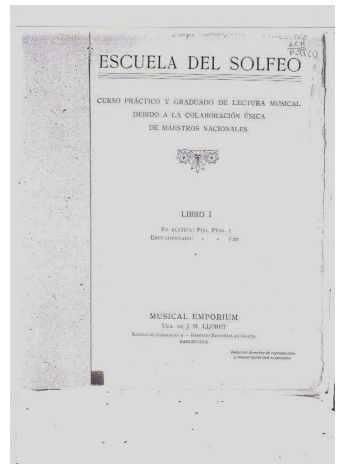

\section{Título del Método}

Escuela del Solfeo. Curso práctico y graduado de Lectura musical debido a la Colaboración única de maestros nacionales. Libro I, Barcelona, Musical Emporium. Vda. de J. M. Llobet, s. f. ${ }^{1}$ Apéndice, página 230.

\section{Autores del LIBRO I}

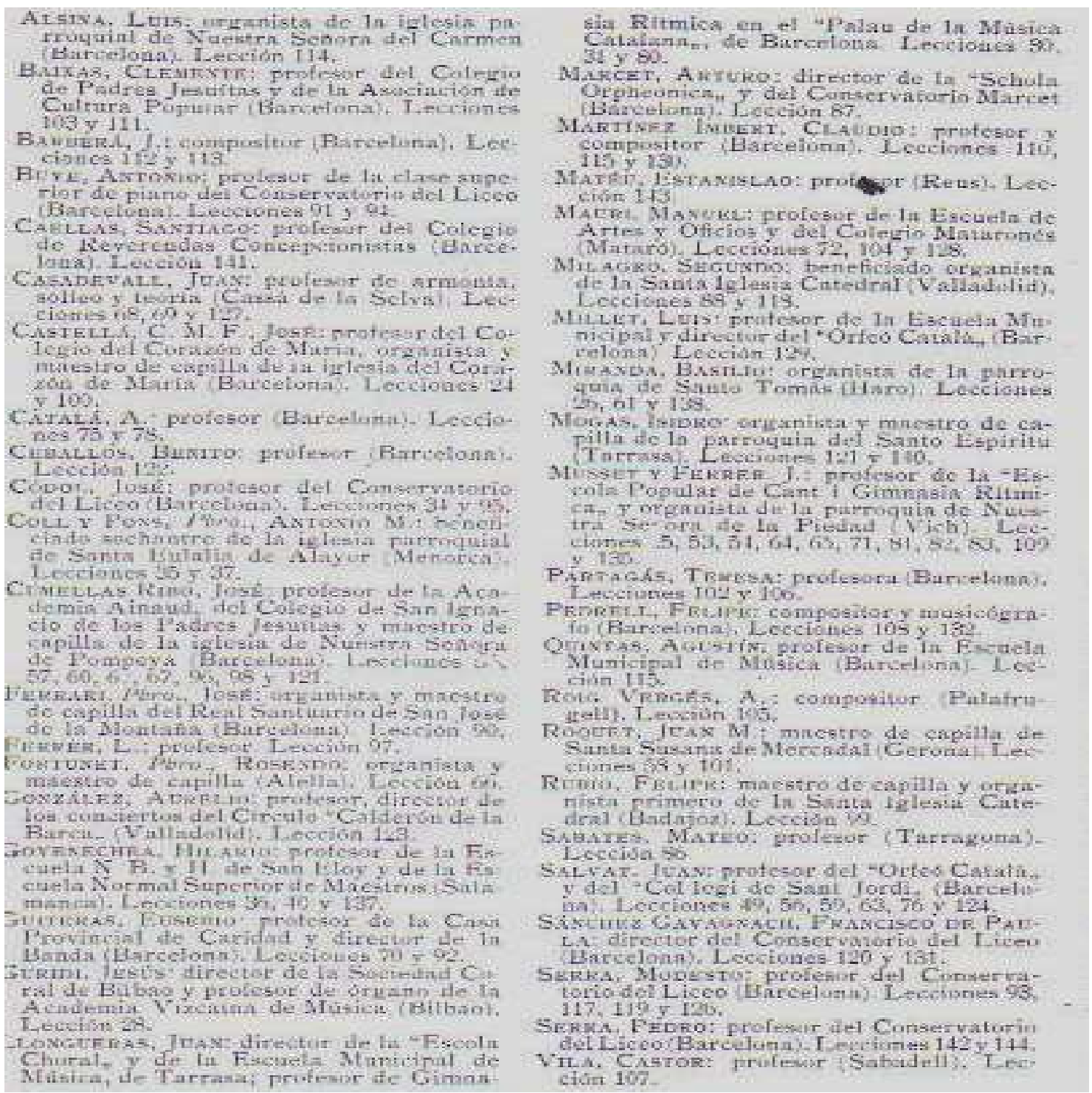

\footnotetext{
${ }^{1}$ El año de media de los distintos autores de este método es 1900, y por eso lo incluimos en este orden, aunque es posible que fuera publicado algunos años después, pero seguramente dentro de los primeros del siglo $\mathrm{XX}$
} 
CUADRO DE INFORMACIÓN GENERAL DEL LIBRO I.

$\mathbf{N}^{\circ}$ de lecciones

Extensión de las lec- De 6 a 80 compases

ciones

Claves empleadas

Tesituras que abarcan

Tonalidades que trata y estudia

Compases que emplea y estudia

Dificultades métricas que contiene

Dificultades de entonación que se encuentran $y$ orden en que se enseñan los intervalos

\section{Armonía utilizada}

Formas que tienen las lecciones

Introducciones, Intermedios o Codas instrumentales

Sol y al final Fa en $4^{\mathrm{a}}$

$\mathrm{Si}_{2} \mathrm{a} \mathrm{Mi}_{4}$

$4 / 4,3 / 4,2 / 2,2 / 4,3 / 8,6 / 8$

DO, RE, MI,

DO, RE, MIFA,

DO, RE, MI, FA, SOL

DO A DO' Dism. A-A'-A',

\section{No tienen ninguna}

Do mayor y al final La menor

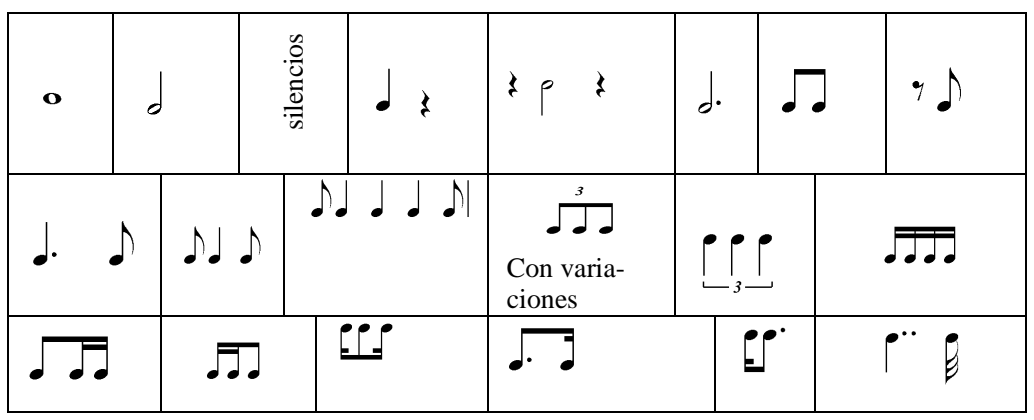

Todos los intervalos diatónicos. Cromatismos, $4^{\mathrm{a}}$ y $5^{\mathrm{a}}$ disminuidas, $2^{\mathrm{a}}, 4^{\mathrm{a}}$ y $5^{\mathrm{a}}$ Aumentadas, $9^{\mathrm{a}}$ Mayor. A partir de la mitad las melodías son complicadas.

Escala. Después 3 notas y progresivamente una más: $2^{\mathrm{a}}$ y $3^{\mathrm{a}}$

“ " $\mathrm{y} 4^{\mathrm{a}}$

DO, RE, MI, FA, SOL, LA, “ “ “ “ “

DO, RE, MI, FA, SOL, LA, SI, “ “ “ “ “ “ $7^{\mathrm{a}} \mathrm{y} 4^{\mathrm{a}} \mathrm{A}$

“ “ “ " "

DO, RE, MI de la octava 4 - DO, SI, LA de la octava 2

De nuevo ejercicios desde $2^{\mathrm{a}}$ a $8^{\mathrm{a}}$. Tetracordos. Pentacordos Semitonos cromáticos y diatónicos, al mismo tiempo $4^{\mathrm{a}}$ y $5^{\mathrm{a}}$

Escala cromática, $2^{\mathrm{a}}$ y $5^{\mathrm{a}}$ Aum. y $9^{\mathrm{a}}$ mayor

Sin acompañamiento de piano

A-A'; A-B-A-B'; A-B-A; A-A'-B-B'; A-B-A'; A-A'B'-A'; A-B-A; A-B-C-A; A-A'-B-A',; A-B; A-B-C-A'; 
Teoría de la música No contiene que incluye

\section{DESCRIPCIÓN DETALLADA DEL LIBRO I.}

En el prólogo (por ellos llamado "proemio") ${ }^{1}$, dicen que las notas van apareciendo por grados sucesivos y no de golpe (como a la sazón se estilaba), también que el alumno debe primero practicar los ejercicios previos a las lecciones hasta su dominio. En el reverso del proemio está la lista de autores que han intervenido en este libro, la cual da una idea de los años de su publicación, probablemente principios del siglo XX.

Es un libro que parte del nivel cero. Comienza con la posición de las notas en clave de Sol, desde el $\mathrm{La}_{2}$ al $\mathrm{La}_{4}$. Después la escala natural ascendente y descendente del modo mayor, indicando la situación de tonos y semitonos.

Ejercicios y lecciones graduadas para la entonación y conocimiento de las notas:

Figuras redondas, notas Do, Re y Mi

Un ejercicio por grados conjuntos e intervalos de tercera.

Un lección con estas notas, 24 compases en $2 / 2$, aunque pone una nota al pie que dice se podrá llevar a 2 o a 4 .

Un ejercicio con las notas Do, Re, Mi y Fa, grados conjuntos, intervalos de tercera y cuarta.

Un lección de 24 compases.

Un ejercicio con las mimas notas más Sol, grados conjuntos, intervalos de tercera, cuarta y quinta.

Un lección de 24 compases

Un ejercicio con las mismas notas pero con figuras de blancas.

Un lección de 32 compases mezclando blancas y redondas; 2 compases de blancas, 2 de redondas; 4 semifrases en forma de pregunta - respuesta.

Un ejercicio, de nuevo con redondas, con las notas de antes más el La, grados conjuntos, intervalos de tercera, cuarta, quinta y sexta.

Un lección de 24 compases con redondas y blancas en forma A - A'.

Un ejercicio añadiendo el $\mathrm{Si}$, intervalos anteriores más la séptima mayor y el tritono.

\footnotetext{
${ }^{1}$ Según CLAVE, diccionario de uso del español actual, proyecto y dirección Concepción Maldonado González, Madrid, Ediciones SM, 1999, página 1486, del griego proóimion (preámbulo)
} 
Un lección de 32 compases en forma de pregunta - respuesta - pregunta -respuesta, como las anteriores muy simétrica y regular

Un ejercicio, llegando ya hasta el Do agudo, grados conjuntos, intervalos de octava y ejercicio de vocalización

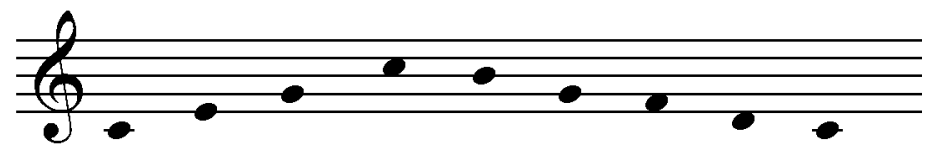

Un lección de 32 compases, irregular y asimétrica

Un ejercicio con Do, Re y Mi agudos, más los anteriores hasta $\mathrm{Sol}_{3}$, intervalos de segunda, tercera, cuarta y quinta.

Dos lecciones de 17 y 32 compases, forma de pregunta - respuesta y A $\mathrm{B}-\mathrm{A}-\mathrm{B}^{\prime}$ respectivamente.

Un ejercicio con Do, Si y La graves, más algunos de los sonidos anteriores hasta $\mathrm{Fa}_{3}$.

Una lección de 32 compases irregular.

Compás de 4/4:

Una lección de 32 compases, redondas y silencios de redonda

Una lección de 16 compases, con blancas y su silencio. Ambas fragmentos de escala.

Lecciones para la práctica de intervalos:

Una para la práctica de cada uno de los intervalos diatónicos, desde segunda a octava, de entre 16 y 24 compases de extensión.

\section{Negras y silencios de negra:}

Un ejercicio en tetracordos ascendentes y descendentes.

Seis lecciones con estos elementos, diversas duraciones, la mayor parte irregulares y asimétricas. En la quinta lección introduce el párrafo o llamada $\$$ y la palabra Fin con una breve explicación a pie de página.

\section{Blancas y negras:}

Dos lecciones con sus silencios, de 15 y 16 compases, irregulares. 
$\underline{\text { Redondas, blancas y negras: }}$

Cuatro lecciones de 16 a 20 compases. Introduce, sin explicarlo, la síncopa larga y también en un fragmento de una de ellas, la ligadura de expresión entre 2 notas.

Compás de 3/4:

Un ejercicio con blancas, negras y blancas con puntillo en el ámbito del pentacordo.

Blancas con puntillo:

Un lección de 16 compases.

\section{Blancas y negras:}

Cinco lecciones de 24 a 37 compases. Inserta el acento, reguladores, matices dinámicos y ligadura de fraseo.

Compás de 2/2:

Redondas:

Una lección con su silencios de 24 compases.

$\underline{\text { Redondas y blancas: }}$

Dos lecciones, una con esta mezcla y sus silencios y otra con sólo blancas.

Negras:

Un ejercicio para practicar estas figuras.

Dos lecciones con sus silencios de 8 y 9 compases.

$\underline{\text { Redondas, blancas y negras: }}$

Dos lecciones, además con sus silencios, de 16 compases.

Compás de 2/4:

Blancas:

Una lección con sus silencios de 32 compases. 
Negras:

Dos lecciones con su silencio de 16 y 20 compases.

Corcheas y silencio de corchea:

Cuatro ejercicios para practicar estos elementos, con el silencio detrás primeramente, y luego formando contratiempos, entonación por fragmentos de escala.

Negras y corcheas:

Cuatro lecciones de 16 a 32 compases. Mete, sin explicación, en la última la anacrusa.

Corcheas en compás de 3/4:

Un ejercicio en fragmentos de escala

Dos lecciones de 26 y 21 compases.

Corcheas en compás de 4/4:

Un ejercicio en forma de escala

Cinco lecciones de 8 a 20 compases.

Corcheas en compás de 2/2:

Dos ejercicios en fragmentos de escala

Dos lecciones de 22 a 24 compases.

Blancas con puntillo en compás de 4/4:

Una lección de 26 compases, mezcla de todas las figuras hasta ahora estudiadas.

Negras con puntillo en el mismo compás:

Un ejercicio con la corchea detrás de la negra con puntillo

Una lección de 27 compases en forma A - B - A'

Una ejercicio con la corchea delante y detrás la negra con puntillo

Una lección de 16 compases. 
$\underline{\text { Redondas y blancas ligadas en compás de 2/2: }}$

Ahora es cuando los autores dicen que se estudia la síncopa regular e irregular, aunque ya se habían practicado sin conciencia de ello.

Hay un ejercicio y una lección con estos elementos en $2 / 2$ y en $4 / 4$, en el último acopla el calderón. Luego hay un ejercicio y una lección con negras ligadas o sea sincopadas. A continuación hay 3 lecciones de 80 y 32 compases en 3/4 las dos primeras y 2/4 la última que son un compendio de lo hasta ahora visto.

Corcheas ligadas:

Una lección de 45 compases en 2/4, la ligadura convierte a las dos corcheas en síncopa irregular y breve.

Negras ligadas con corcheas:

Un ejercicio que convierte a las dos notas ligadas en negra con puntillo

Dos lecciones de 38 y 8 compases, en $2 / 4$ y 4/4; la primera es una célula rítmica que cambia de sonidos, y la segunda tiene la forma $\mathrm{A}-\mathrm{B}$; en esta última presenta, sin decirlo, la síncopa breve.

Un ejercicio para la práctica de esta síncopa y de ella enlazada.

Un lección como resumen de lo anterior, 28 compases de 3/4.

Compás de 3/8:

Tres lecciones de 34, 32 y 49 compases, con síncopas complicadas.

Compás de 6/8:

Un ejercicio para mostrar las distintas combinaciones, máximo corcheas.

Tres lecciones con blancas con puntillo, negras con puntillo, negras y corcheas, 32 y 51 compases.

$\underline{\text { Tresillos de corchea: }}$

Tres ejercicios en fragmentos ascendentes y descendentes.

Dos lecciones de 26 y 16 compases, en 4/4 y 2/4, la primera negras, blancas, negras con puntillo, silencios y tresillos; la segunda todo tresillos. 
Dos ejercicios con tresillos en los que se sustituye una corchea por su silencio en los extremos.

Una lección con estos elementos de 6 compases en 4/4.

Dos ejercicios permutando la corchea central por su silencio y dos corcheas por silencio de negra.

Una lección en 4/4 de 6 compases con estos elementos.

Dos ejercicios sustituyendo dos corcheas por unas negra, e incluso sincopando algunas.

Una lección en 4/4 de 9 compases con estos elementos.

Tres ejercicios alternando corcheas y estos ritmos de tresillo.

Una lección en 4/4 de 17 compases aunando todo lo trabajado en materia de tresillos.

Práctica de las alteraciones:

$\underline{\text { Sostenido al Fa y al Do: }}$

Dos ejercicios abordando las alteraciones por cromatismo y por descenso de semitono diatónico.

Una lección de 4/4, 16 compases, con solamente blancas, negras y sus silencios.

$\underline{\text { Sostenidos el Fa, Do y Sol: }}$

Un ejercicio por semitono diatónico descendente

Una lección en 4/4, 26 compases, las mismas figuras anteriores más corcheas.

$\underline{\text { Sostenido al Sol: }}$

Un ejercicio por semitono diatónico descendente.

Una lección en 2/4 de 40 compases.

Bemol al Si y al Mi:

Un ejercicio por cromatismo descendente y semitono diatónico ascendente.

Cuatro lecciones en 4/4, 3/4 la segunda y tercera y 4/4, 16, 22, 20 y 22 compases, en las que también hay Do sostenido y Fa sostenido. 
Ejercicio cromático con sostenidos:

Un ejercicio con semitonos cromáticos y también diatónicos.

Dos lecciones en 3/4 y 4/4, 29 y 18 compases que contienen cromatismos, pero también saltos de $4^{\mathrm{a}}$ y $5^{\mathrm{a}}$ disminuida.

Ejercicios cromáticos con sostenidos y bemoles:

Un ejercicio principalmente con estos cromatismos, más

Una lección de 2/4, 40 compases, en la que no hay un solo semitono cromático.

Escala cromática de Do mayor ascendente y descendente:

Un ejercicio con esta escala y figuras de blancas.

Una lección de 4/4 y 24 compases, en la que no sólo entran cromatismos, sino segundas aumentadas, sin advertirlo y cuartas aumentadas igualmente sin advertirlo. Coloca sin explicar el D. C.

Ejercicio tonal con los cuatro primeros sostenidos:

Un ejercicio que se desarrolla en la escala de Mi mayor.

Ejercicio tonal con los cuatro primeros bemoles:

Un ejercicio que no se comprende, porque empieza y acaba en Do, pero está en La bemol mayor.

Dos lecciones en 6/8 y 4/4 de 35 y 24 compases respectivamente. Ya los intervalos son dificultosos y las melodías rebuscadas con grandes saltos.

Tresillos de negra:

Dos lecciones en $2 / 2$ de 40 y 46 compases utilizando estos tresillos y sus variaciones rítmicas; intervalos de $5^{\mathrm{a}}$ aumentada y $9^{\mathrm{a}}$ mayor.

Escala de La menor armónica:

Un ejercicio

Escala de La menor melódica:

Un ejercicio

Tres lecciones en 2/4, 3/4 y 2/4 de 26, 60 y 48 compases 
Semicorcheas:

Dos ejercicios en 2/4 con negra y 4 semicorcheas y con 8 semicorcheas.

Una lección en 2/4, 16 compases con negras y semicorcheas.

Tres ejercicios con silencio de semicorchea detrás, delante y sustituyendo la segunda semicorchea.

Una lección en 2/4 de 28 compases.

Tres ejercicios en 3/4 totalmente con semicorcheas uno, otro en 4/4 con negras y semicorcheas y el tercero en $2 / 4$ con la fórmula rítmica corchea y dos semicorcheas y al revés.

Tres lecciones, compases 4/4, 2/4 y 3/4, 13, 24 y 20 compases.

Dos ejercicios en $4 / 4$ con el silencio de semicorchea en diversas subdivisiones, y el otro en 3/4 con síncopas muy breves.

Una lección en 4/4 de 17 compases

Un ejercicio mezcla de todo

Dos lecciones en $4 / 4$ y $2 / 4$ de 7 y 21 compases recopilatorias de todo lo anterior en cuanto a ritmo.

Corcheas con puntillo:

Un ejercicio para practicar la fórmula corchea con puntillo semicorchea

Dos lecciones en 2/4 de 16 compases y la fórmula arriba citada, la segunda lección con más combinaciones rítmicas y en modo hipofrigio griego.

Un ejercicio con la fórmula corchea con puntillo semicorchea y al revés

Un lección en 2/4 de 23 compases en modo dorio griego.

Negra con doble puntillo:

Tres ejercicios, uno para esta duración, otro para practicar el silencio de corchea con puntillo, y el tercero para la práctica del silencio de semicorchea sustitutivo del puntillo en la corchea.

Tres lecciones en $4 / 4$ y $2 / 4$ de 28,32 y 25 compases.

Negras y corcheas ligadas con semicorcheas:

Dos ejercicios con estas medidas

Cuatro lecciones, compases de 4/4 y 3/4, 16, 21, 38 y 41 compases. 
Tresillos de semicorcheas:

Dos ejercicios para esta práctica

Tres lecciones en 3/4 y 4/4 de 22, 18 y 27 compases.

Semicorcheas en compás de 3/8:

Dos lecciones de 32 y 41 compases.

$\underline{\text { Semicorcheas en compás de 6/8: }}$

Tres ejercicios intercalados entre 3 lecciones con las semicorcheas en distinta cantidad, y puestas en diversas subdivisiones.

Cuatro lecciones en 2/4, 4/4 y 2/4, 37, 33 y 53 compases, a modo de recopilación de todo lo anterior, tanto melódico como rítmico.

$\underline{\text { Lecciones para el estudio de la clave de Fa en } 4^{\mathrm{a}} \text { línea: }}$

Posición de las notas desde $\mathrm{Fa}_{1}$ a $\mathrm{Fa}_{3}$.

Tres ejercicios para la lectura de notas, primero correlativas, luego por salto.

Cinco lecciones con redondas, blancas y negras, en Do mayor, compases de $2 / 2,4 / 4$ y $3 / 4,32,16,13,24$ y 52 compases.

Una lección en 4/4 en la tonalidad de La menor, con blancas y negras.

Tres lecciones con corcheas, alteraciones y contratiempos, compases de $3 / 4,3 / 4$ y $4 / 4$.

Una lección en 6/8 de 25 compases.

Dos lecciones en 3/4 con todos los elementos estudiados, 43 y 26 compases. 


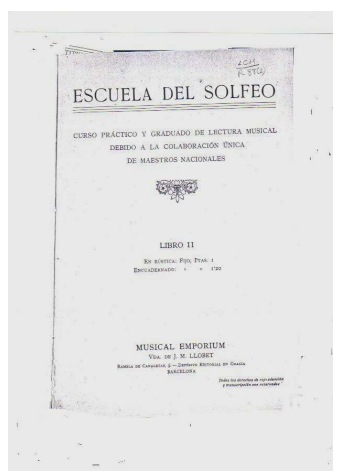

\section{LIBRO II}

\section{Autores del Libro II}

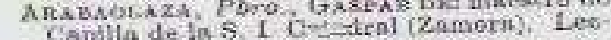
Caphila

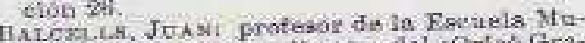

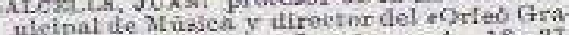

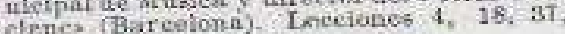

S2 y SL. I. compositos Burcelosay, Lecriones 62 y 75 .

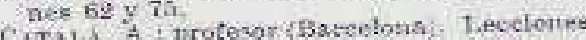
an $x_{2}>23$

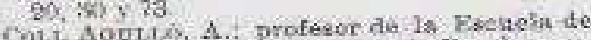

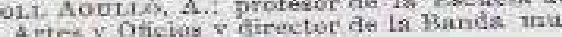
Apted y Oficias s Girector da

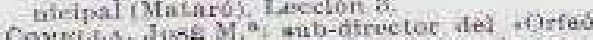

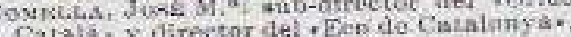
Cataja - y. uirector

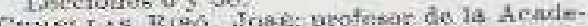

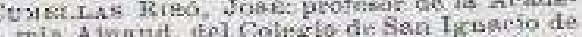

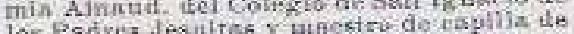

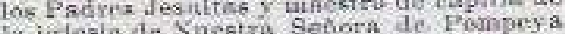

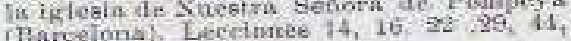
Marceiona:

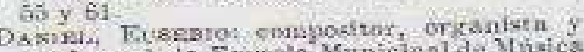

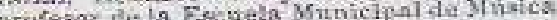

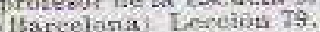

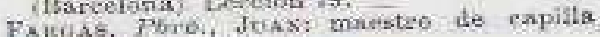

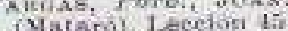

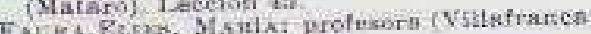

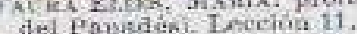

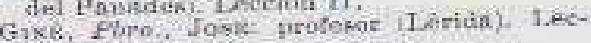
ciùn tad

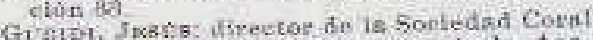
Je zimber y profesos de 6 grom to ta Asa

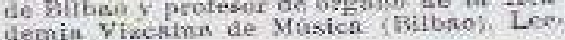
cion 64.

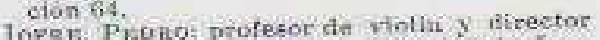
de in Seademia Jofen iBarciesorm) Leecion 58.

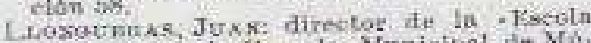

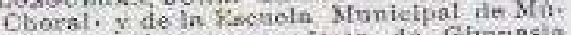

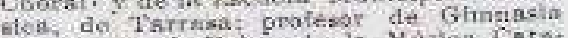
Estrigien en el. Palau dn in Múbien CarnIana., de Bareslowas lacecton. II.

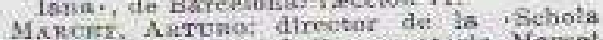

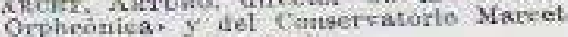
Orphenticas. Y Let $\$ 6$

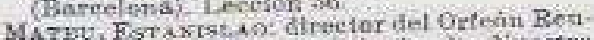
zive lolegio de Xuestru Sencrn de: Pilan y de Nuegtru senori ier la Sencri de: Pitarial. Leveriones 43 y 84

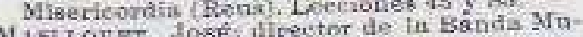
MastiLover, dose nirextor de ti

meipal Snbiscelt. Lecona dis Escrela do Amil, Maxuati protegor Colegio Mrataroné Artes $z$ Otictie y tel Colegio

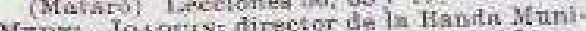

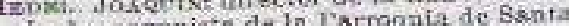

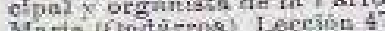

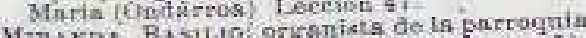

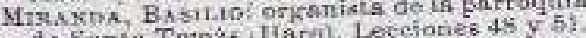

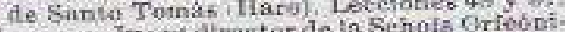

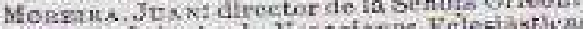

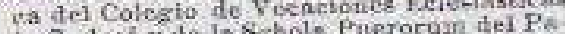

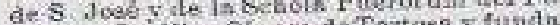

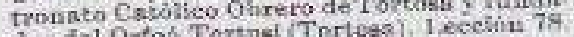

MonzA, Fortakpo; (C. M. F.) protesor (Cerve:

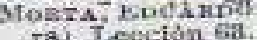

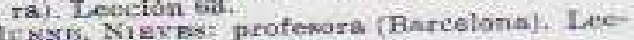
c.lon 00

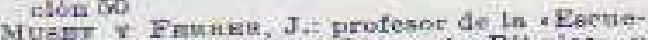
1a Popular de Cant i Glmanala Rttmicen y orgunista de la parroquith de Nuebtea Be-

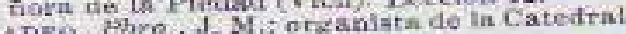
Contonal. Ieedion 72 .

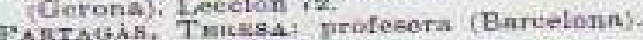
Leccion 41

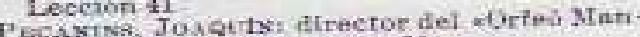

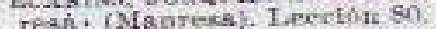

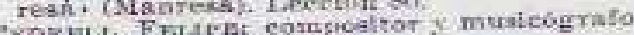
Burelonal Lecelon sh

Briver solfen y tha, Hustarico

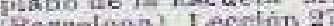

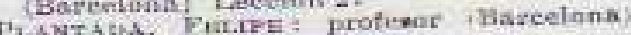
Pr.s.arash a

Leceinin stino InNN M I maestro de ca-

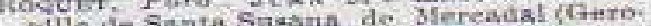
pilli de sirut sus

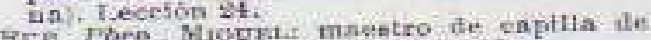
ke Corats. Trectón 99

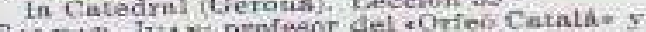

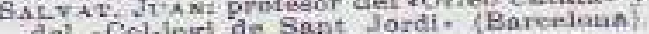
des - Col-jers de

Lecuiones it $\mathrm{X}$ 28.

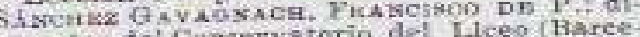
reetor ded Cunertyatoria

Jona), Iecciones 32 y 85 . sublirector de In

Sixemex $r$ 1Pokno, Josic; subdirector de in Academia Sarnkate, tirectno de soctedndes

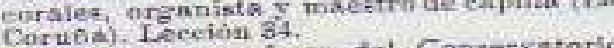

Smen Inowo: profesor det Conservatorto fel Hoes (Barcelona) I eceioner 28 y 40.

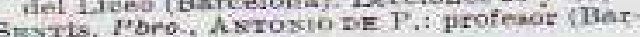
melorin. Lecejon 46

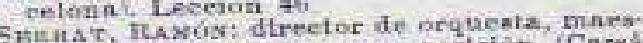

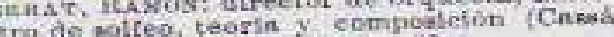
de lo Setvs). Lecelones 10 , 69

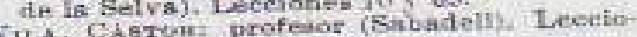

med 21 \% 82 , dridi) Leceiones 7 y 49

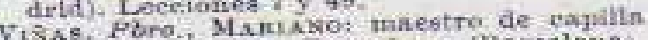
iein Catedral de Bareelena Barcelona. de in Cate 


\section{CUADRO DE INFORMACIÓN GENERAL DEL LIBRO II.}

$\mathbf{N}^{\circ}$ de lecciones

Extensión de las lec- De 16 a 74 compases

ciones

Claves empleadas

Tesituras que abarcan

Tonalidades que trata y estudia

Compases que emplea y estudia

Dificultades métricas que contiene

Dificultades de entonación que se encuentran $y$ orden en que se enseñan los intervalos

Armonía utilizada

Formas que tienen las lecciones

Introducciones, Intermedios o Codas instrumentales

Teoría de la música que incluye

85

Sol y Fa $4^{\mathrm{a}}$ ses $4^{\mathrm{a}}$ y $3^{\mathrm{a}}$ disminuida

No tienen ninguna

No contiene
$\mathrm{Do}_{3} \mathrm{a} \mathrm{Mi}_{4}$ normalmente, y excepcionalmente hasta $\mathrm{Fa}_{4} \mathrm{y}$ Sol ${ }_{4}$. En clave de Fa la misma tesitura para cantarla $8^{\mathrm{a}}$ alta

Mayores y menores desde 1 alteración hasta 4

Los de antes más 9/8, 12/8, 3/2, 6/4 y 9/16

Las anteriores más las que se derivan de los nuevos compa-

$7^{\mathrm{a}}$ disminuida, $2^{\mathrm{a}}$ aumentada, $5^{\mathrm{a}}$ disminuida, doble sostenido,

No hay acompañamiento. A pesar de no haber armonía clara, por el análisis de la melodía se ve que modula a tonos vecinos, y a veces a muy lejanos.

A-B-A'; A-B-A; A-B-C; A-B-C-D; A-B-B'

\subsubsection{DESCRIPCIÓN DETALLADA DE ESTE LIBRO II.}

Este segundo libro está dedicado a la práctica de las tonalidades, desde una hasta cuatro alteraciones, también a la de nuevos compases, compuestos y uno simple, y al final a los cambios de clave entre Sol y Fa en $4^{\mathrm{a}}$ línea

Intercala como lecciones algunas canciones populares y de autores españoles de la polifonía renacentista. 
Tonalidades de Sol mayor y Mi menor:

Escala de Sol mayor y 2 ejercicios de entonación

Cuatro lecciones en claves de Fa, Sol, Fa y Sol alternativamente, compases de 4/4 y 2/4 también alternados, la primera es de Francisco de Peñalosa.

Escala de Mi menor armónica y melódica, 3 ejercicios.

Cuatro lecciones que están en compases de 3/4, 6/8, 2/4 y 3/4; la primera es de Cristóbal Escobar y la cuarta de Felipe Pedrell. Las claves son alternativamente $\mathrm{Fa}$, Sol.

Tonalidades de Re mayor y Si menor:

Escala de Re mayor, 2 ejercicios

Claves de Fa, Sol alternativamente, compases de 2/4, 6/8 y 3/4, la tercera cambia de tonalidad, a Do mayor, aunque muy alterado, y vuelve al principal.

Escala de Si menor y 3 ejercicios

Cuatro lecciones, compases de 2/2, 2/4, 4/4, 2/2. Claves de Fa la primera y Sol las otras tres. La primera es anónima del siglo XV, modal en algunos fragmentos, parece estar en modo deuterus auténtico transportado.

\section{Tonalidades de La mayor y Fa sostenido menor:}

Escala de La mayor y 2 ejercicios, al igual que los anteriores y los siguientes; uno es para entonar la escala con métrica, y el otro para efectuar intervalos, esto es, melodía interválica.

Cuatro lecciones, compases de 6/8, 2/4, 3/4 y 3/8. Claves de Sol las tres primeras y Fa la última. La primera es una canción popular catalana de la colección de J. Pecasins, premiada en la segunda fiesta de la música catalana, la tercera es un baile del siglo XVII de autor desconocido.

Escala de $\mathrm{Fa} \#$ menor y 3 ejercicios, que igualmente a los anteriores y siguientes en modo menor, dos son para las escalas armónica y melódica respectivamente, y el tercero para práctica interválica.

Tres lecciones en compases de 6/8, 3/4 y 6/8. Claves de Sol, Fa y Sol. La última tiene una construcción interesante a modo de pequeños desarrollos del tema, y con una melodía agradable, aunque se complica la métrica. 
Tonalidades de Mi mayor y Do sostenido menor:

Escala de Mi mayor y 2 ejercicios

Cuatro lecciones, compases de 2/4, 3/8, 3/4 y 6/8. Claves de Sol las dos primeras, Fa la tercera y de nuevo Sol la última. La segunda es un baile popular, no dice de qué lugar.

Escala de Do \# menor y 3 ejercicios

Tres lecciones, compases de 2/4, 3/8 y 4/4. Claves de Sol, Fa y Sol respectivamente.

Tonalidades de Fa mayor y Re menor: ${ }^{1}$

Escala de Fa mayor y 2 ejercicios.

Cuatro lecciones, 6/8, 2/2, 4/4, 2/4. Claves de Sol la primera, Fa la segunda y Sol las restantes. La primera es de Sebastián Durón ${ }^{2}$. La segunda introduce el subrayado, dentro de los signos de articulación.

Escala de Re menor y 3 ejercicios

Tres lecciones, 2/4, 2/4 y 6/8. Las dos primeras en clave de Fa y la tercera en la de Sol, ésta con ciertas complicaciones métricas.

\section{Tonalidades de Si bemol mayor y Sol menor:}

Escala de Si b mayor y 2 ejercicios.

Tres lecciones, compases de 3/8. 2/4 y 4/4. Las dos primeras en clave de Fa y la tercera en la de Sol.

Escala de Sol menor y 3 ejercicios

Cuatro lecciones, compases de 4/4, 2/4, 2/2 y 2/4. Claves de Fa y Sol alternativamente. Aparece en la segunda el picado, aunque nada dice de él.

$\underline{\text { Tonalidades de Mi bemol mayor y Do menor: }}$

Escala de Mi b mayor y 2 ejercicios

\footnotetext{
${ }^{1}$ En los grupos de lecciones que figuran en cada uno de los epígrafes por tonalidades, suele emplear una gradación de menor a mayor dificultad.

${ }^{2}$ Guadalajara 1660- Combo-les-Bains 1716, figura fundamental en el teatro lírico español en la época de Carlos II. Según Diccionario de la música española e Hispanoamericana..., tomo 4, p. 575, firmado por Lothar Siemens
} 
Cuatro lecciones, 2/4, 4/4, 3/4 y 3/4. Claves de Sol las dos primeras, Fa la tercera y Sol la cuarta.

Escala de Do menor y 3 ejercicios

Tres lecciones, 6/8, 6/8 y 3/4. Claves de Fa, Sol y Fa.

\section{Tonalidades de La bemol mayor y Fa menor:}

Escala de La b mayor y 2 ejercicios

Tres lecciones en 4/4, 3/8 y 3/4. Claves alternativas de Sol y Fa. La segunda es de Juan del Encina (s. XV).

Escala de Fa menor y 3 ejercicios

Tres lecciones, 6/8, 2/2 y 3/4. Claves de Sol, Fa y Sol.

\section{Lecciones para la práctica de nuevos compases.}

\section{Compás de 9/8:}

Dos ejercicios, el primero con blancas, negras y corcheas; el segundo con corcheas y semicorcheas.

Cuatro lecciones, tonalidades de Do mayor, Sol mayor, Re mayor y Fa \# menor. Claves de Sol la primera, Fa la segunda y Sol las otras dos. La segunda es una canción popular catalana de la colección de J. Pecasins premiada en la segunda fiesta de la música catalana. Como en casi todos los epígrafes, se va aumentando la dificultad desde la primera a la cuarta.

\section{Compás de 12/8:}

Dos ejercicios, el primera con redondas, blancas, negras y corcheas, y el segundo con negras, corcheas y semicorcheas.

Cuatro lecciones, tonalidades de Do mayor, Re mayor, Re menor y Sol mayor. Claves de Sol, Fa la segunda y Sol las otras dos. La tercera es de Jesús Guridi.

\section{Compás de 3/2:}

\section{Un Ejercicio}

Cuatro lecciones, La menor, Fa mayor y Re menor. Claves de Sol y Fa alternativamente. La primera es una canción popular catalana de la colección de Juan Moreira de Tortosa, la segunda es de Escobar (s. XVI), la tercera también popular catalana de la misma colección, aparece sin armadura, y está claramente en Re menor en su 
primer fragmento, la misma tonalidad pero alternando escala natural con armónica en el segundo, y en una mezcla de La menor seguido de deuterus auténtico transportado a La en el tercero y último. La cuarta empieza en Re menor y modula de forma definitiva a su homónimo mayor.

\section{Compás de 6/4:}

Un ejercicio.

Cuatro lecciones en las tonalidades de Fa mayor, Re menor y Sol mayor. Claves de Sol las tres primeras y Fa la última. La primera es de Juan de Anchieta (s. $\mathrm{XV})$. La tercera está en Re menor pero escala natural.

Compás de 9/16:

Un ejercicio.

Tres lecciones en Do mayor, La mayor y Si bemol mayor. Claves de Sol, Fa y Sol.

Lecciones con cambio de claves: (hay una nota al pie que advierte de la no escritura en altura real de las claves).

Hay 9 lecciones en las tonalidades de Do mayor, Mi mayor, La menor, Fa mayor, Sol mayor y Re mayor; compases de 3/4, 2/4, 4/4 y 6/8, cambios frecuentes entre sol y Fa y en su mayoría muy alteradas.

\subsubsection{VALORACIÓN DE LA EFECTIVIDAD DEL MÉTODO Y DE SU APORTACIÓN A LA ENSEÑANZA}

Trata bastante mejor que otros anteriores la entonación.

Aunque no es el ideal, es progresivo y repetitivo en el estudio de los intervalos, si bien se extiende demasiado al llegar hasta muchos aumentados y disminuidos y algunos compuestos. Lástima que las melodías sean muy rebuscadas.

También es progresivo y abundante en la aparición de las figuras de nota y sus combinaciones rítmicas, no obstante también llega a demasiada complicación, pero quizás eso de Libro I no se refiera a un primer curso, sino a un primer tomo. 
Estaría muy bien la segunda parte si hubiera después una tercera, pero no siendo así, el método se queda corto en el estudio del resto de tonalidades y figuras a partir de la fusa.

No es un método que aporte nada, el primer libro es un poco difícil en la métrica, profundiza demasiado para el nivel.

En general encontramos el método difícil, no en su planteamiento, pero sí en algunos de sus desarrollos técnicos, con melodías complejas. 


\subsection{RESEÑA BIOGRÁFICA DEL AUTOR}

VANCELL ROCA, Juan. No hemos podido encontrar ninguna referencia biográfica de este autor. En el libro dice que es maestro normal y profesor de la asignatura en la escuela normal superior de maestros de Barcelona.

\subsubsection{DESCRIPCIÓN DETALLADA DEL MÉTODO.}

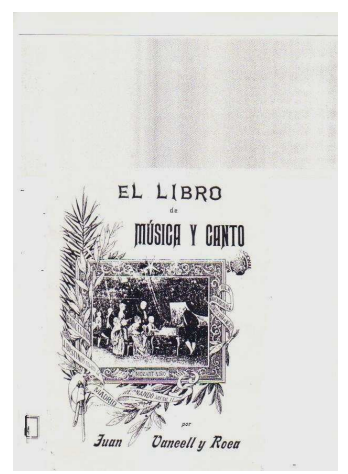

\section{Título del Método}

El Libro de música y canto: tratado de solfeo y cantos escolares: gramática, lectura y escritura musicales simultáneas al alcance de las más pequeñas inteligencias. (Método sintético: Orden cíclico: Procedimientos racionales), Barcelona, Fidel Giró, 1902. Apéndice, página 231.

Primera Parte precedida de unos Preliminares fundamentales.

Hay unas palabras "A los niños" para que accedan con cariño a la música, y otras "A mis comprofesores" agradeciendo su uso y pidiéndoles manifiesten sus deficiencias.

Un "Por vía de prólogo" en el que dice que todos los países, y algunos desde tiempo ha, han incluido la enseñanza de la música y el canto entre las generales, y que en España nos obstinamos en que no es accesible para los niños. Afirma: ...Es indudable que los niños son antes seres sensibles que inteligentes, y que a la sensibilidad hay que dirigirse para despertar su inteligencia. Y se cree que nos es asequible a los niños por que se enseña mal.

Continúa con un "Plan de este libro". Dice que utiliza el método sintético y en el orden lógico, partiendo de un punto, se va agrandando por zonas concéntricas, o sea el orden cíclico... de lo fácil a lo difícil, de lo conocido a lo desconocido, de lo primero a lo segundo. Una cosa que otros ven al final, aquí se ve al principio, el sonido y sus cualidades, pero de un modo práctico y al alcance de los párvulos. Al principio teórico acompaña siempre la aplicación, pero no siempre aplicaciones originales, aprovecha alguna melodía popular que vaya al caso. Otra cosa importante es el comenzar por el compás de 2 y por la figura negra, y lo explica diciendo que es el compás más sencillo, 
el que está más frecuentemente representado en nuestro organismo, y que la negra es la unidad de tiempo y que además con ella desaparece la monotonía que dan las redondas y blancas, que no hay ningún canto que esté constituido así rítmicamente. También incluye ejercicios de aplicación, de escritura, de dictado etc.

\section{Preliminares Fundamentales:}

\section{I.- Música.- Sonidos y ruidos.- Notas:}

Por el procedimiento dialogado, que él llama analítico - sintético, e incluso ejemplos, aborda estas cuestiones. Completa el capítulo con preguntas sobre estos puntos (procedimiento interrogativo, llama él) y con ejercicios de memoria y lenguaje, que son una especie de resumen.

II.- De la llave de Sol.- Notas Sol, La, Si y Do. Para llegar a esto empieza con una línea horizontal, dos, tres, cuatro y cinco, llega al pentagrama, a la clave y las notas. Completa con ejercicios de lectura, procedimiento interrogatorio, ejercicios de escritura, de dictado (entendido éste como oral, no de sonidos) y como en la anterior, de memoria y lenguaje.

III.- Cualidades del sonido.- Del tono. Explica, dialogadamente esto, sigue con ejercicios de entonación (los que sirvieron anteriormente de lectura) y procedimiento interrogatorio.

IV.- De la intensidad, con ejercicios de dictado para escribir sonidos con indicaciones de intensidad.

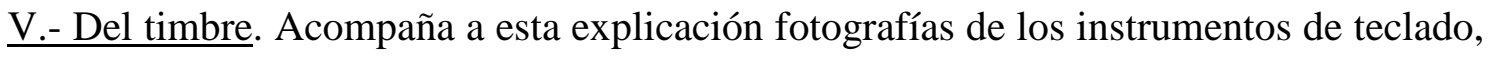
cuerda, viento y percusión. Después ejercicios de memoria de los capítulos III, IV y V. VI.- Del instrumento de la voz. Explicación de los órganos de fonación y resonadores, con dibujos explicativos.

VII.- De la duración. Su unidad de medida.- Del tiempo y del compás. Negra y compás de 2. Todas estas cuestiones, incluyendo el silencio. Y con ejercicios de memoria y lenguaje termina estos preliminares fundamentales. 


\section{PRIMERA PARTE.}

\section{CUADRO DE INFORMACIÓN GENERAL DEL MÉTODO.}

$\mathbf{N}^{\circ}$ de lecciones

202

Extensión de las lec- Entre 2 y 134 compases

ciones

Claves empleadas

Sol

Tesituras que abar- $\quad \operatorname{De~Sol}_{2} \mathrm{a} \mathrm{Sol}_{4}$

can

Tonalidades que tra- Do $\mathrm{M}$ y algunas La $\mathrm{m}$

ta $\mathrm{y}$ estudia

Compases que em-

plea y estudia

Dificultades métricas que contiene

Dificultades de entonación que se encuentran $y$ orden en que se enseñan los intervalos

Armonía utilizada

Formas que tienen las lecciones

Introducciones, Intermedios o Codas instrumentales

Teoría de la música que incluye
2,4 y $3 / 4$

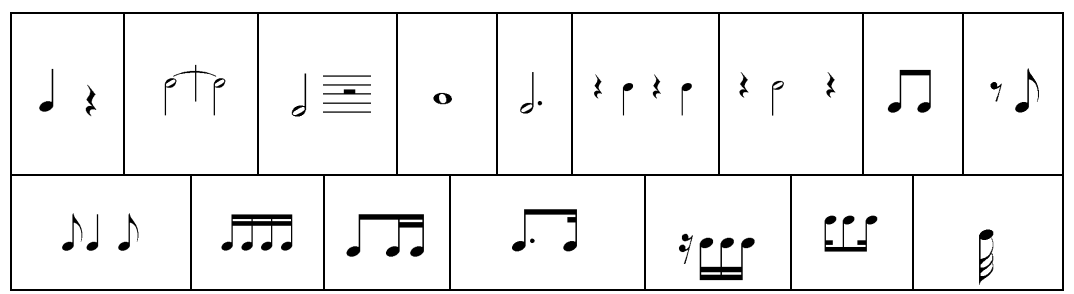

Ninguna

La escala dividida en 2 tetracordos: SOL, LA, SI, DO'/ DO, RE, MI, FA, inmediatos.

Intervalos de $2^{\mathrm{a}}, 3^{\mathrm{a}}$ y $4^{\mathrm{a}} / 5^{\mathrm{a}}, 6^{\mathrm{a}}, 7^{\mathrm{a}}$ y $8^{\mathrm{a}}$. Armónicos

Intervalos mayores y menores. Compuestos hasta $11^{\mathrm{a}}$. Semitonos diatónicos

No hay acompañamiento

No hay formas definidas, son pequeñas lecciones de forma primaria, también cortas canciones populares o de compositores consagrados.

No tienen las lecciones, sí alguna canción que lleva introducción y final.

Bastante, y siempre que hay novedades 


\section{Sección Primera}

\section{I.- Lectura rítmica.- Solfeo.- Vocalización.- Melodía.- Canto:}

Cuatro pequeñas lecciones en compás de 2/4, negras y su silencio (formato antiguo), abarcando el tetracordo Sol, La, Si. Do. Explicación de vocalización y una lección para vocalizar después de haberla solfeado. Concepto de melodía y canción, y una canción con letra. Siempre completa estas unidades con ejercicios interrogatorios, de escritura y de dictado, entendido éste como dictado oral de notas y figuras para escribirlas los alumnos, o sea un ejercicio de escritura o caligrafía al dictado,

\section{II.-Tetracordo de Do:}

Explicación de ello y 4 lecciones, la última con letra, con lo que ya se extiende la melodía a toda la escala.

III.- Escala diatónica y clases de intervalos de tono:

Une los dos tetracordos practicados formando la escala diatónica de Do. Después parte del unísono y va explicando los intervalos, hasta la cuarta inclusive, sólo nombre y dirección. Lo aplica con una lección y una canción.

\section{IV.- Intervalos de $5^{\mathrm{a}}, 6^{\mathrm{a}}, 7^{\mathrm{a}}$ y $8^{\mathrm{a}}$ :}

Ejemplos de éstos y pequeñas lecciones para su aplicación.

V.- Armonía: Dúo e intervalos armónicos.- Del ligado. De la síncopa.

Explicación de los intervalos armónicos y un pequeño dúo homofónico con movimientos contrarios y directos. Explicación de la ligadura y puesta en práctica de ella formando síncopas largas.

VI.- Generación de la blanca.- Expresiones italianas indicadoras del movimiento de la melodía.- Del calderón:

Presentación de esta figura, su silencio, términos de la velocidad uniforme y lección más canción para aplicar todo ello. 


\section{VII.- Eco-.- Canon. Grados e intervalos escala de intensidad:}

Breve explicación y aplicación inmediata, mediante pequeñas lecciones, del canon y el eco. En cuanto a los grados de intensidad, se refiere a la diferencia que hay entre pianísimo y fortísimo. Los intervalos de intensidad, según el autor, son los reguladores. Varias lecciones y canciones con reguladores.

\section{VIII.- Intervalos de tono mayores, menores y justos:}

Explicación de la calificación de los intervalos, considerando las cuartas menores o justas y las quintas mayores o justas. Luego unas tablas abundantes de ejemplos de todos ellos. Lecciones para la práctica de todos.

\section{IX.- Tetracordo de Do $8^{\text {a }}$ alta.- Intervalos compuestos. Acento agudo:}

Explica el tetracordo Do, Re, Mi, Fa a partir del Do agudo, con un dibujo del teclado del piano. El concepto y ejemplos de intervalos compuestos, y en cuanto acento agudo, se refiere al acento propiamente dicho con el vértice hacia arriba.

\section{$\underline{X .-}$ Acentos de compensación y Acento mixto:}

Llama de compensación, a la diferencia de intensidad entre los sonidos, cuando hay un ligado de interpretación entre dos notas; y acento mixto a un pequeño fragmento ligado, donde suele ser más intenso el sonido del medio que el inicial y final, pero también dice que se suele expresar con reguladores. Hay varias lecciones y canciones, como siempre para ilustrarlo y practicarlo. También, aunque no lo indica en el enunciado, expone la síncopa irregular de negra y blanca y la regular de blanca.

$\underline{\text { XI.- Compás cuaternario.- De la redonda. Redondeo o acento mixto del sonido y de la }}$ obra musical:

Explicación del cuatro por cuatro, de la figura redonda, algunas lecciones, canciones; y se refiere al acento mixto de la obra y del sonido, a la mayor fuerza que cobra el sonido, mientras no se indique lo contrario, en la mitad del compás, y en el punto culminante de la obra.

$\underline{\text { XII.- Compás ternario y síncopas regulares e irregulares en el mismo: }}$

Presentación de este compás y también del puntillo, que lo explica como sustitución de la ligadura entre blanca y negra. Varias lecciones y canciones. 
Vancell Roca

XIII.- Del contratiempo en los compases tipos 2, 3 y 4 :

Contratiempos de negra en cada uno de estos compases.

$\underline{\text { XIV.- Tetracordo de Sol } 8^{\mathrm{a}} \text { alta: }}$

Presenta estas notas con el dibujo del teclado del piano, pero no se sabe para qué, solamente hay un ejercicio de lectura con estas notas, ninguna lección posterior (claro que serían harto difíciles de cantar). Sin que lo anuncie, también explica los signos de repetición, y los pone en práctica.

\section{$\underline{\text { Sección Segunda }}$}

$\underline{X V .-}$ Figuras de valores fraccionarios.- De la corchea o fracción mitad.- Tetracordo de Sol $8^{a}$ baja:

Así explica la corchea, y se trabaja en los compases de 2, de 3 y de 4 abundantemente, con lecciones y canciones.

\section{XVI.- Escala de Do $8^{\mathrm{a}}$ baja:}

Conocimiento de estas notas más como lectura que para entonación, aunque hay una lección en esta tesitura.

XVII.- Tonalidad.- Modos mayor y menor antiguo:

Define la tonalidad, con una frase de Fetis (según indica en nota al pie): "relaciones así sucesivas como simultáneas de los sonidos de la escala". Hace un cuadro comparativo de las diferencias entre el modo mayor y el menor antiguo (o sea, la escala natural), y en ese cuadro también pone el nombre de los grados de la escala. Pero anteriormente hace un comentario sobre el carácter alegre del modo mayor contra el triste del menor por la relación de su serie diatónica con el predominio de intervalos menores. No es cierto que haya predominio de intervalos menores, si acaso están en igual proporción; mas no estamos de acuerdo con ese carácter triste que le confiere este autor, al igual que otros muchos profesionales, al modo menor. Quizás tiene una propensión a la intimidad, se adapta mejor que el mayor a la melodía cálida, amorosa, al ambiente recogido, melancólico; pero la intensidad y la agógica pueden hacer perfectamente que una cosa triste se convierta en alegre y viceversa. 
Introduce también aquí el picado, pero la tonalidad y modalidad quedan en este punto, como mera información.

XVIII.- Contratiempo y síncopas regulares e irregulares en corchea:

Hay un amplio tratamiento de estos ritmos.

No hay XIX

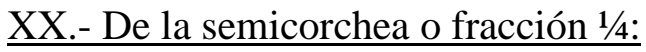

Se practica ésta, su silencio, las fórmulas combinadas corchea - dos semicorcheas y corchea con puntillo - semicorchea.

$\underline{\text { XXI.- Del picado en corcheas: }}$

Práctica tanto del picado como del ligado.

XXII.- Contratiempo y síncopas regulares e irregulares en semicorcheas.- De la fusa:

Silencios de semicorchea en cualquiera de los cuartos de tiempo, síncopas muy breves y la fusa explicada como $1 / 8$ de tiempo.

XXIII.- Escala e intervalos de duración:

Llama así a la relación de las figuras de notas entre si, y por esa relación explica el puntillo y el doble puntillo. También hay en esta unidad, y en alguna de las siguientes, una canción a 3 voces.

XXIV.- Del picado - ligado:

Práctica de esta articulación con canciones, algunas a 3 voces.

$\underline{\text { XXV.- Signos modificadores del tono. Estado subido y estado bajado o sostenidos y }}$ bemoles:

Explicación de las alteraciones y dos canciones formando con éstas semitonos diatónicos, o empleadas en la escala melódica menor. 


\section{$\underline{\text { Capítulo adicional }}$}

$\underline{\text { XXVI.- Del ritmo y de lo bello musical: }}$

Disertaciones sobre el concepto de ritmo, el ritmo en las cualidades del sonido y el ritmo armónico.

\section{CUADROS O CAPÍTULOS RESÚMENES para los repasos CÍCLICO PERCEPTI-} VOS O INTUITIVOS de la teoría razonada que se comprende en esta primera parte de El Libro de Música y Canto.

I.- Del sonido musical en general, su representación gráfica.- Notas:

Pentagrama, llaves, notas, cualidades del sonido. Subdivisión de los signos en Del Tono, De la Duración, De la Intensidad y Signos Varios.

II.- Del Tono:

Clasifica los sonidos en "estado natural", "estado subido" por los accidentes sostenidos y "estado bajado" o bemolizado. Tabla de intervalos simples y compuestos. Tabla de los modos mayor y menor.

\section{III.- De la Duración:}

Tablas de las figuras de nota. Figuras de valores enteros, de valores fraccionarios, figuras simples, figuras compuestas (con puntillo). Signos modificadores de la duración de los valores anteriores: Aumentativos (calderón y puntillo), Diminutivos (picado), Mixtos (picado - ligado). Cuadro de la cantidad de figuras que llenan los compases binarios, ternarios y cuaternarios, de denominador 4 y términos de la velocidad.

IV.- De la intensidad:

Términos dinámicos, contratiempos y síncopas, acentos.

V.- Signos varios:

Los de repetición. 


\subsubsection{VALORACIÓN DE LA EFECTIVIDAD DEL MÉTODO Y DE SU APORTACIÓN A LA ENSEÑANZA}

Es este un libro bastante distinto a los otros. Se fundamenta en verdaderos principios pedagógicos, en el análisis de la realidad del niño, de su capacidad intelectual, de sus intereses en el aprendizaje; y utiliza medios para hacer llegar los conocimientos sin gran esfuerzo.

Por eso comienza con el compás de 2/4, desde Manent en 1860 y Arrieta en 1868, ninguno después ha tenido como primer compás para comenzar a solfear el de $2 / 4$.

Muy progresiva la introducción de las diversas dificultades, y con insistencia en cada una de ellas.

Es un buen método para aprender música en los colegios, o en los conservatorios en sus primeros niveles. No profundiza, y por tanto se queda cortísimo en la enseñanza profesional.

Si hubo una segunda parte, incluso más, en ningún lugar de los que se ha buscado se han encontrado. Por otra parte, nada hace pensar, por lo que dice, en su prólogo que se divida el libro en varias partes, y serían ya demasiadas las dificultades para ser un libro dedicado a niños de corta edad. No comprendemos pues porque indica "primera parte" 
Vancell Roca 


\subsection{RESEÑA BIOGRÁFICA DEL AUTOR}

BRULL AYERRA, Melecio. San Martín de Unx (Navarra) 12-2-1858 - Barcelona 25-3-1923. Compositor para piano de obras fáciles de carácter pedagógico y música de salón (Casares, en AAVV, 1999, tomo 2, pp. 736 y 37). Fue profesor del Real Conservatorio de Madrid (Gómez Amat, 1984, capítulo VI, p. 77).

\subsubsection{DESCRIPCIÓN DETALLADA DEL MÉTODO.}

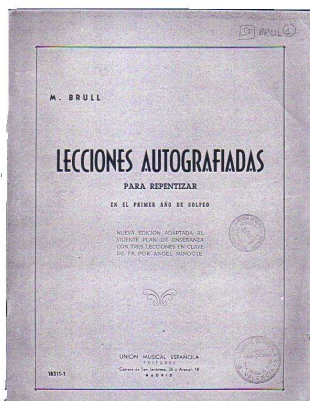

\section{Título del Método}

Lecciones autografiadas para repentizar en el primer año de solfeo (nueva edición adaptada al vigente plan de enseñanza con tres lecciones en clave de Fa, por Ángel Mingote) Madrid, Unión Musical Española, s.f. ${ }^{1}$ Apéndice, página 232.

\section{CUADRO DE INFORMACIÓN GENERAL DEL MÉTODO.}

$\mathbf{N}^{\circ}$ de lecciones 54

Extensión de las 16 a 32 compases

lecciones

Claves empleadas $\quad \mathrm{Sol} \mathrm{y} \mathrm{Fa} 4^{\mathrm{a}}$ las 3 últimas

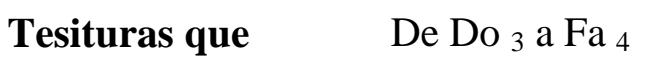

abarcan

Tonalidades que Do mayor y La menor

trata y estudia

Compases que em- $\quad 4,2$ y 3 por 4

plea y estudia

\section{Dificultades métri- cas que contiene}

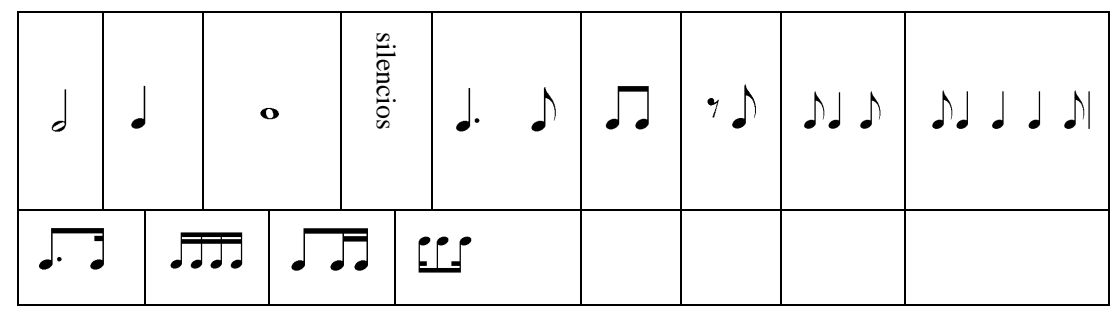

\footnotetext{
${ }^{1}$ La fecha en la que lo incluimos es porque el autor muere en 1923 y dice en el método "plan de enseñanza vigente".
} 
Dificultades de entonación que se encuentran y orden en que se enseñan los intervalos

Armonía utilizada

Formas que tienen las lecciones

Introducciones, Intermedios o Codas instrumentales

Teoría de la músi- No contiene ca que incluye
Intervalos alterados, $2^{\mathrm{a}}$ aumentada, $7^{\mathrm{a}}$ disminuida, $5^{\mathrm{a}}$ disminuida, $4^{\mathrm{a}}$ disminuida. $3^{\mathrm{a}}$ disminuida en los extremos de 3 notas.

Al no ser un método para enseñanza, sino complementario, este es el orden en que aparecen los intervalos

Armonía romántica, con muchas modulaciones, en mayor medida a tonos vecinos, bastantes veces al variante modal, y una vez a vecino en $2^{\circ}$ grado. Utiliza bastante la cadencia plagal minorizada después de la perfecta. Empieza pronto con acordes de $6^{a}$ aumentada y los emplea mucho. También acordes de apoyatura. Algún grado alterado. En la lección 47 modula al tono de la dominante pero menor, y en la 48 a uno lejano

A-B-C; A-A' coda; A-B-coda; A-B-A'; A-A'. Algunas no tienen una forma concreta, son sucesiones de semifrases, más o menos derivadas de la primera o motivo principal

Solamente una tiene introducción de un compás. No tienen ninguna intermedio ni coda

\section{SECUENCIA}

Es un libro dedicado a proporcionar material para repentizar en clase, en el nivel de primer curso, con las dificultades propias de ese curso en los planes de estudios anteriores. Están escritas estas lecciones en dos pentagramas, en forma de partitura de piano, en la que la mano derecha es la melodía que se cantará, y la izquierda es un bajo cifrado que servirá como acompañamiento.

Las 4 primeras lecciones están en compás de 4/4, dedicadas a las figuras de nota blancas, negras y redondas, con sus silencios. Naturalmente clave de Sol. Todos los intervalos naturales y diatónicos.

En las 4 siguientes, 5, 6, 7 y 8, ya encontramos el puntillo en la negra seguido de corchea, las corcheas en grupos de 2 y de 4 , y en la 8 contratiempos y alguna síncopa breve, continua con el mismo compás. Los intervalos ya dejan de ser todos naturales y aparecen las alteraciones, tanto sostenido como bemol, formando en las primeras cro- 
matismos, pero después también intervalos diatónicos alterados e incluso hay ya una segunda aumentada.

En la lección 9 ya se emplean las síncopas enlazadas, la corchea con puntillo y semicorchea y los grupos de semicorcheas, todavía en compás de 4/4

De la lección 10 a la 15 se emplea el compás de 2/4. Ninguna novedad en cuanto a figuras de nota ni a dificultades rítmicas, las mismas de antes más la fórmula corchea con dos semicorcheas. La 11, 12 y 13 están en la tonalidad de La menor, y hay algún intervalo de séptima disminuida, la 14 de nuevo en Do mayor y la 15 en La menor otra vez, en ésta hay un intervalo de $5^{\text {a disminuida. }}$

De la 16 a la 20 están escritas en compás de 3/4, y no se aumenta ninguna dificultad a las ya existentes en sentido rítmico ni melódico.

Desde la 21 a la 40 vuelven a estar en compás de 4/4, cuatro de ellas en La menor y el resto en Do mayor. Ninguna dificultad rítmica se añade, ni tampoco melódica a excepción de un par de veces que aparece una cuarta disminuida.

Lecciones 41 y 42 escritas en compás de 2/4, Do mayor la primera y La menor la segunda. En esta última se utiliza la síncopa muy breve, y en la anterior, también empleada en alguna otra ocasión hay una dificultad melódica, que es comenzar un arpegio melódico con una apoyatura inferior a distancia de semitono, lo que dificulta la entonación de las notas extremas.

Volvemos al compás de compasillo en las lecciones 43, 44 y 45, las tres en la tonalidad de Do mayor. De nuevo aparece la cuarta disminuida.

Las números 46 y 47 de nuevo en 3/4 y Do mayor. En la segunda hay varias síncopas enlazadas, tanto breves como muy breves. Hay aquí una modulación sorprendente, para el contexto total, va a la dominante minorizada.

Las lecciones 48 y 49 vuelven al 4/4 y están ambas en La menor. La primera de ellas tiene una modulación a un tono lejano, aunque se vale de un salto melódico de octava para dulcificar tal paso.

La 50 y 51 en compás de 3/4, La menor la primera y Do mayor la segunda.

Por último están las lecciones números 52, 53 y 54 que introducen la clave de $\mathrm{Fa}$ en $4^{\text {a }}$ línea. Las dos primeras en Do mayor y la última en La menor. Compases de 4/4, 2/4 y 3/4 sucesivamente. Las figuras blancas, negras y corcheas. La segunda tiene demasiadas alteraciones para la poca práctica de la lectura en esta clave. 


\subsubsection{VALORACIÓN DE LA EFECTIVIDAD DEL MÉTODO Y DE SU APORTACIÓN A LA ENSEÑANZA}

Es un libro muy útil para practicar los alumnos en clase el apartado de lectura a primera vista, ya que pone en manos del profesor la posibilidad de, a medida que se va aumentando los conocimientos, ir poniendo en práctica sin previo estudio las dificultades que se van aprendiendo, además de disponer de varias lecturas de una misma dificultad en una misma sesión o clase, lo que evita al docente a poner en el encerado varias lecturas, de lo contrario si la clase es numerosa el último alumno que lea no lo hace a primera vista, sino a enésima vista. 
3.35. AMORÓS SIRVENT, Amancio. Ya hicimos su reseña biográfica al describir su Elementos de solfeo, y analizamos de nuevo métodos de este autor, separados del anterior, por haber también una separación considerable de años en su edición.

\subsubsection{DESCRIPCIÓN DETALLADA DEL MÉTODO.}

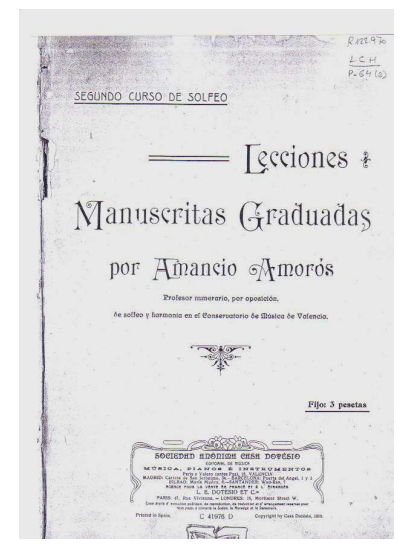

\section{Título del Método}

Lecciones manuscritas graduadas: segundo curso de solfeo, s. 1, (pero sí dice en España), S. A. Casa Dotesio, 1910. Apéndice, página 233.

Son unos métodos no solamente de lecciones, que están manuscritas, y son progresivas, (de ahí su nombre), sino que también hay, ejercicios de lectura de notas y de entonación pura. Al contrario que su primer libro Elementos de solfeo, éste no contiene nada de teoría, remite para ello a sus Nociones teóricas.

Analizaremos cada uno de los cursos por separado.

\section{SEGUNDO CURSO}

\section{CUADRO DE INFORMACIÓN GENERAL DEL SEGUNDO CURSO.}

$\mathbf{N}^{\circ}$ de lecciones

Extensión de las lec- De 10 a 35 compases

ciones

Claves empleadas

Tesituras que abarcan Son extremas, llegan desde un $\mathrm{DO}_{1}$ a $\mathrm{DO}_{5}$

Tonalidades que trata y estudia

Compases que emplea y estudia
Do M, La m, Sol M, Mi m, Re M, Si m, Si b M, Sol m, La M, Fa \# m, Mi b M y Do m

$3 / 4,2 / 2,2 / 4,3 / 8,4 / 4,6 / 8$, cambios entre ellos, $9 / 8,12 / 8$ 


\section{Dificultades métricas que contiene}

Dificultades de entonación que se encuentran $y$ orden en que se enseñan los intervalos

Armonía utilizada

Formas que tienen las lecciones

Introducciones, Intermedios o Codas instrumentales

Teoría de la música que incluye

\begin{tabular}{|c|c|c|c|c|}
\hline$B=$ & צמp & $\xi:$ & $\rho^{\cdots} \Leftrightarrow$ & $\ldots \ldots$ \\
\hline $\begin{array}{l}\text { Cuádruple } \\
\text { puntillo }\end{array}$ & Adornos & 2 & $\stackrel{3}{d 0}$ & $\stackrel{\rho \mu \rho}{=}$ \\
\hline ерер & еререр & & & \\
\hline
\end{tabular}

$7^{\mathrm{a}} \mathrm{M}$ y m, $3^{\mathrm{a}} \cdot 4^{\mathrm{a}}$ y $7^{\mathrm{a}}$ disminuidas, $2^{\mathrm{a}}, 5^{\mathrm{a}}$ y $6^{\mathrm{a}}$ aumentadas Compuestos de $9^{\mathrm{a}}$ y $10^{\mathrm{a}}$ mayores y menores. Cromatismos

En ese orden aparecen los distintos intervalos.

No hay en ninguna acompañamiento

$\mathrm{A}-\mathrm{A}^{\prime} ; \mathrm{A}-\mathrm{A}^{\prime}-\mathrm{A}^{\prime}$; $\mathrm{A}-\mathrm{B}-\mathrm{A}^{\prime}$ la mayor parte, $\mathrm{y}$ algunas de una sola sección

No los hay

No contiene

Comienza con la tonalidad de Do mayor, y su primer ejercicio es la práctica de la escala de esta tonalidad

Ejercicios de lectura de notas en la clave de $\mathrm{Fa} 4^{\mathrm{a}}$ ( 3 ejercicios)

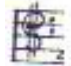

Una lección en esta clave, compás de 3/4, con fusas, alteraciones cromáticas, y modulaciones a tonos vecinos.

Tonalidad de La menor:

Práctica de la escala en sus tres modelos ${ }^{1}$

Doce lecciones de diversa extensión, desde 17 a 35 compases, en clave de $\mathrm{Fa} 4^{\mathrm{a}}$, compases de 2/2,3/4, 2/4 y las últimas 3/8, semicorcheas y su silencio, modulaciones a tonos vecinos en primer y segundo grado. Intervalos aumentados y disminuidos, también compuestos, de novena y décima mayor y menor. Cambios de claves entre Fa y Sol, de compases y de aires, más adelante semifusas, cromatismos, subdivisiones de los compases y doble puntillo, siendo curioso que también utiliza el triple y cuádruple puntillo. Solamente en 1839 Reguart nos habla del cuádruple puntillo, pero sin poner ejem-

\footnotetext{
${ }^{1}$ Muy curioso el nombre que les da a cada una de las variantes de la escala menor: sin modificar (natural), alterada o melódica y propia o harmónica.
} 
plos prácticos, después en 1860, Manent sólo nos habla del triple y en el mismo año, o poco después, Lladó pone ejemplos de triple puntillo, pero no de cuádruple, se vuelve a mencionar el triple (no el cuádruple) en 1888 en Sabatés, y ahora este autor escribe ejemplos prácticos de uno y de otro.
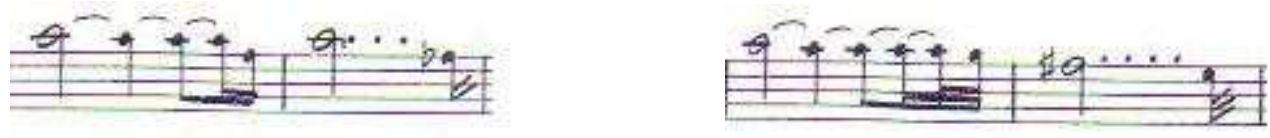

Tonalidad de Sol mayor:

Al igual que al estudiar las tonalidades anteriores, en ésta y todas las sucesivas, siempre comienza con la práctica de la escala, o escalas en sus tres variantes si son tonalidades del modo menor.

Dos lecciones de 13 a 16 compases, una en clave de Sol y otra en clave de Fa, compás binario y $3 / 8$ respectivamente, en las que se encuentran apoyaturas armónicas y muchos cromatismos.

\section{Tonalidad de Mi menor:}

Cinco lecciones de entre 10 y 22 compases, con los elementos estudiados hasta ahora, compases de compasillo, 3/4, surge el de 6/8 (en 2 lecciones). La primera de ellas con valores bastante normales, pero la segunda ya lleva fusas y semifusas, y la última contiene lo que él llama "valores anormales", o sea grupos de valoración irregular, dosillos, tresillos, cuatrillos y seisillos, de distintas duraciones o equivalencias, además de cambios de claves entre Sol y Fa y de compases, de simples a compuestos correspondientes, pero también de $6 / 8$ a $2 / 2$

\section{Tonalidad de Fa mayor:}

Dos lecciones de 15 y 20 compases, compases de 3/8 y 6/8 respectivamente.

\section{Tonalidad de Re menor:}

Dos lecciones de 15 compases, $3 / 4$ y $3 / 8$ respectivamente, la segunda alternando las claves de Sol y Fa

Tres ejercicios de lectura de notas en clave de Do

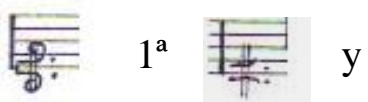

Dos lecciones en esta clave, dentro del grupo de la

tonalidad de Re menor, pero la primera ( $\left.\mathrm{n}^{\circ} 25\right)$ no está en esta tonalidad, sino en Do mayor. La segunda de este bloque la dedica a la práctica de la apoyatura. 
Tonalidad de Re mayor:

Dos lecciones de 23 compases cada una, compases de $2 / 2$ y $6 / 8$, la segunda con cambio de claves entre Sol, Fa y Do $1^{\text {a }}$, con una observación por parte de el autor, la de no respetar la altura real de los sonidos.

Tonalidad de Si menor:

Dos lecciones de 34 y 25 compases, 3/8 y 2/2, la segunda con cambio de claves, e introduce el mordente de una nota de semifusa o cualquier otra.

A todos estos adornos llama Amorós mordentes

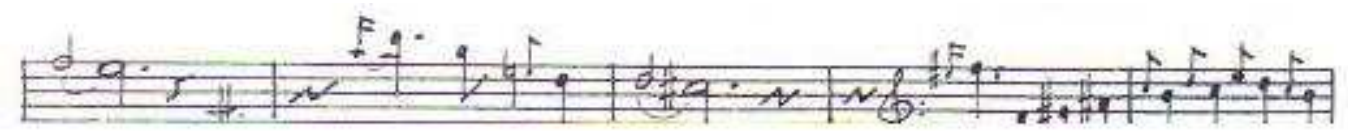

Tonalidad de Si bemol mayor:

Dos lecciones de 23 y 16 compases, 6/8 y 3/4, la segunda incorpora los mordentes de 2 notas. Y siempre va acumulando en las lecciones las dificultades tratadas hasta el momento.

Tonalidad de Sol menor:

Dos lecciones de 26 y 23 compases, $2 / 2$ y 2/4 respectivamente, la segunda contiene mordentes triples (que no son los grupetos establecidos actualmente).

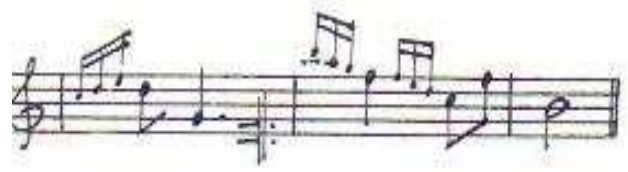

Tonalidad de La mayor:

Dos lecciones, aparece por primera vez el compás de 9/8, y en la segunda de ellas los mordentes cuádruples (que tampoco son los grupetos de 4 notas, como hoy se entienden. Éstos y los anteriores serían llamados ahora "florituras").

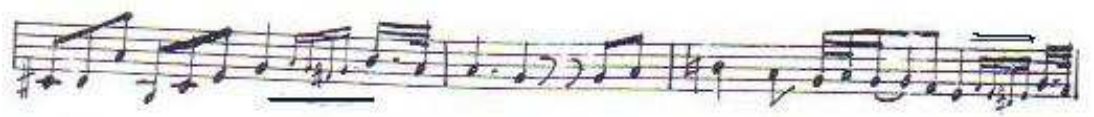




\section{Tonalidad de Fa sostenido menor:}

Dos lecciones de $2 / 4$ y $3 / 4$, la primera con cambio de claves, la segunda con la abreviatura de mordentes de 3 y 4 notas. ${ }^{1}$

Tonalidad de Mi bemol mayor:

Dos lecciones en compás de compasillo la primera y cambio de claves, y 12/8 la segunda (como elemento nuevo)

\section{Tonalidad de Do menor:}

Una lección en compás de 12/8

Termina el libro con 4 lecciones con cambios de compás, aires, claves y modo.

\footnotetext{
${ }^{1}$ Es muy curioso esto de los mordentes triples y cuádruples, quizás debido a un arrastre en el siglo XIX de las inconcrecciones que, en matera de adornos, había en el XVIII. Hemos tratado de aclarar esto buscando en Nociones teóricas de solfeo, primer al tercer curso, de este autor, Valencia, Tipografía Moderna, 1924, y nada aparece al respecto. Sí encontramos explicaciones a este asunto en ALDÁS CONESA, Tomás: Teoría del solfeo $2^{\circ}$ curso, $6^{a}$ edición, Valencia, Profesional edición S. A., s.f., Lección XXIV, pp. 32 y 33 en las que dice que los mordentes pueden ser simples, dobles, triples y cuádruples, que cuando son más de cuatro se les llama "grupetto". Los mordentes de 3 y 4 notas se dividen en rectos y circulares, siendo los rectos por grados conjuntos. Las abreviaturas de mordentes triples son las que se utilizan en la actualidad como abreviaturas de grupetos, y este autor no discrimina si tales abreviaturas son para los mordentes rectos o circulares, y más curioso, incluye el semitrino como mordente cuádruple. Otro autor del mismo tiempo (pues aunque no hay fecha en la publicación de Aldás, tal compositor vivió entre los años 1880 y 1965 , por lo que es muy posible que tal publicación fuera por los años 20 ó 30 del siglo XX), SIMÓ ESCANA VERINO, Bartolomé. (1923). en su Teoría o historia de la Música, Tomo II. Palma de Mallorca: Establecimiento Tipográfico de Guasp, Lección XXIII pp. 67 a 70, abunda en lo mismo que Aldás, sin embargo otro anterior, CABALLERO, Manuel. (1880). en Gramática Filarmónica o Tratado de los Elementos Generales de Música. Palencia: Oficina de José de Orga, Capítulo XV, pp. 29 y 30 llama "grupo" a un mordente de notas, la superior, la de en medio y la inferior, o viceversa y lo mismo de 4 notas (aunque no especifica por cuál nota empezarían), y sus abreviaturas son las eses empleadas hoy en día en los grupetos.
} 


\section{TERCER CURSO}

IERCER CURSO DE SOLFEO

……….......... Leciones

Manuscritas Graduadas

Amancio Amorós

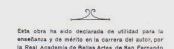

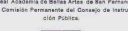

Wxro: mustcal rgpasor

TR. D. S PTAS:

Lecciones manuscritas graduadas: tercer curso de solfeo, Madrid, Unión Musical Española (antes Casa Dotesio), s. f. Apéndice, página 233.

\section{CUADRO DE INFORMACIÓN GENERAL DEL TERCER CURSO.}

$\mathbf{N}^{\circ}$ de lecciones

50

Extensión de las lec- Entre 10 y 64 compases

ciones

Claves empleadas

Do $2^{\mathrm{a}}$, Do $3^{\mathrm{a}}$, Do $4^{\mathrm{a}}$ y Fa $3^{\mathrm{a}}$

Tesituras que abarcan $\quad \mathrm{De} \mathrm{Si}_{1}$ a $\mathrm{La}_{5}$

Tonalidades que trata y estudia

Compases que emplea y estudia

Dificultades métricas que contiene
Mi M, Do \# m, La b M, Fa m Si M, Sol \# m, Re b M, Si b m, Fa \# M, Re \# m, Sol b M, Mi b m, Do \# M, La \# m, Do b M, La b m 2/8, 6/16, 9/16, 4/8, 12/16, 2/1, 6/2, 9/4, 3/2, 4/2, 12/4, 5/8, $7 / 8,10 / 8,14 / 8,5 / 4$

Las mismas que en el anterior volumen, y como nuevas, las propias de los compases que van apareciendo. Además quintillos y septillos. Trino y fermata

Las anteriores, más cromatismos con mayor complejidad, teniendo en el mismo compás una misma nota no consecutiva, con distinta alteración

Enarmonías

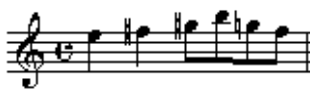

Sin acompañamiento

Las anteriores, más Tema con variaciones

lecciones

Introducciones, Inter- No los hay medios o Codas instrumentales 
Teoría de la música No contiene que incluye

\subsubsection{DESCRIPCIÓN DETALLADA DEL MÉTODO TERCER CUR-} SO.

Es un ejemplar idéntico al anterior, sin teoría, y que sigue las mismas pautas y modos, pero aumentando dificultades y elementos

Comienza con 3 ejercicios de lectura de notas en clave de Do en $2^{\text {a }}$ línea.

A continuación hay 3 lecciones en esta clave, y en las tonalidades de Sol mayor, Sol menor y La mayor, tonalidades ya estudiadas en el anterior volumen, y con compases de 6/8, 3/8 y 12/8, igualmente vistos anteriormente.

A partir de aquí, siguiendo con la forma de presentar las lecciones, vuelve, como en el anterior libro, a hacer bloques de lecciones por nuevas tonalidades que van incorporando sostenidos y bemoles alternativamente

Tonalidad de Mi mayor:

Sigue con la exposición de la escala, o escalas correspondientes, con la aparición de cada tonalidad.

Tres lecciones, la primera compás de 2/4, surge el compás de 2/8 en la segunda y también en la tercera, esta última vuelve a la clave de $\mathrm{Fa} 4^{\mathrm{a}}$

Tonalidad de Do \# menor:

Cuatro lecciones, 4/4, 2/4, como nuevo 6/16 y $2 / 2$, con cambios entre ellos. Incluyen como novedad algunos matices agógicos, como rallentando o ritardando. ${ }^{1}$

$\underline{\text { Tonalidad de La b Mayor: }}$

Cuatro lecciones, 3/4, 9/8 y se presenta 9/16, con cambios. Se intercalan 3 ejercicios de lectura de notas en clave de Do en $3^{\text {a línea. }}$

\footnotetext{
${ }^{1}$ Anteriormente a las lecciones, en la práctica de las escalas, a la "sin modificar" aquí la llama "primitiva"
} 
Amorós Sirvent, tercer curso lecciones manuscritas

Tonalidad de Fa menor:

Cuatro lecciones, 4/4, 12/8 y emerge el de 4/8. Se intercalan 3 ejercicios de lectura de notas en clave de Do en $4^{\text {a }}$ línea. ${ }^{1}$

Tonalidad de Si mayor:

Cuatro lecciones, 2/2 y aparece el compás de 12/16, cambios entre ellos.

$\underline{\text { Tonalidad de Sol \# menor: }}$

Cuatro lecciones, en compases de 9/16 y 3/4, como nuevo el de 2/1. Se interpolan ejercicios de lectura de notas en la clave de Fa en $3^{\text {a línea. }}$

Tonalidad de Re b mayor:

Cuatro lecciones, $3 / 8$ y 2/4, 6/2 como compás nuevo. El compositor hace aparecer aquí por primera vez las enarmonías. Hay cambios de todo, de compás, tonalidades y claves

Tonalidad de Si b menor:

Tres lecciones en compás de 9/8, y como nuevo 9/4

Tonalidad de Fa \# mayor:

Tres lecciones, compás de $2 / 4$ y se muestra el de $3 / 2$, cambios entre todos los elementos.

Tonalidad de Re \# menor:

Dos lecciones en compás de $6 / 2$ y 4/2 como nuevo

Tonalidad de Sol b mayor:

Dos lecciones, compás de 4/2, se insertan como nuevos el compás de 12/4 y el signo $\%$

$\underline{\text { Tonalidad de Mi b menor: }}$

Dos lecciones, 12/4, surgen los compases de amalgama, pero curiosamente no empieza por el $5 / 4$, sino por $5 / 8$

\footnotetext{
${ }^{1}$ Las dificultades métricas y de entonación, a medida que aparecen nuevas claves y compases, y hay mezcla de ambos, no son grandes; en todo caso, son menores que cuando estos elementos estaban más trabajados.
} 
Tonalidad de Do \# mayor:

Dos lecciones en las que ambos compases son nuevos, y siempre dentro ya del grupo de irregulares o amalgamados, en estas dos lecciones son el 7/8 y 10/8 los que da a conocer.

Tonalidad de La \# menor:

Dos lecciones con el compás de 14/8 la primera y 4/4 la segunda, en la que se incorporan como medidas irregulares el quintillo y el septillo.

$\underline{\text { Tonalidad de Do b mayor: }}$

Dos lecciones, compases de 9/8 y 9/4, éstos ya estaban trabajados, e introduce la práctica del trino y la fermata

Tonalidad de La b menor:

Tres lecciones, cada una en un compás, 5/8, 3/4, y 2/2, cambios entre ellos.

Termina con el siguiente diagrama para establecer la relación de las claves entre sí.
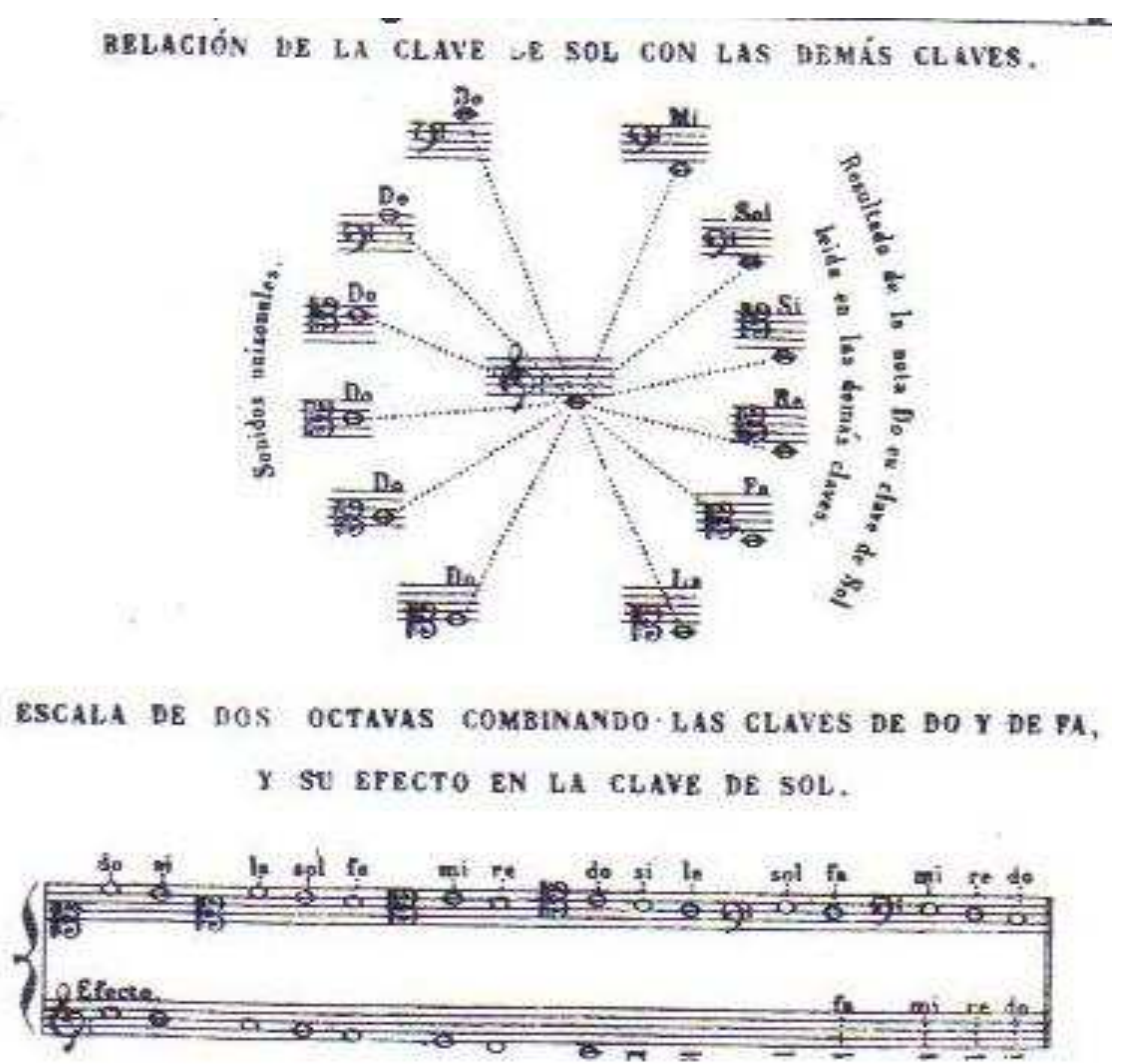


\subsubsection{VALORACIÓN DE LA EFECTIVIDAD DEL MÉTODO Y DE SU APORTACIÓN A LA ENSEÑANZA}

Aunque con diferencia de años, es una continuación del primer método, llamado Elementos de solfeo.

Tiene una buena progresión en la aparición de los distintos elementos y dificultades, aunque debería rebajar las dificultades al aparecer la nueva clave.

Al igual que el primero, es un buen método, mejor que muchos de los anteriormente analizados.

El orden de aparición de los compases en el tercer curso no creemos sea el más apropiado, mejor en el siguiente orden: 12/16, 9/4, 12/4, 2/1, 6/2, 3/2 y 4/2; y los amalgamados mejor haber empezado por los de denominador 4 y pasar después a los de 8 .

Es un buen método, progresivo, completo, trata los elementos imprescindiblemente necesarios para una lectura media de partituras.

Se sitúa en un nivel Elemental alto, es agradable, con no demasiadas y engorrosas dificultades. Aporta en el primer curso los ejercicios preparatorios de lectura, ritmo y entonación, ${ }^{1}$ no así en los siguientes, en los que también podía haber incluido algún ejercicio de solfeo rítmico y de entonación

Ana Fontestad, en su tesis varias veces citada, página 234, menciona otros dos libros: Método elemental de solfeo (1892) y Tratado de solfeo, Valencia, Impr. Manuel Alufre, 1896, pero en ningún archivo lo hemos encontrado, ni ningún otro autor los nombra.

\footnotetext{
${ }^{1}$ FONTESTAD PILES, Ana. (2005). El Conservatorio de Música de Valencia, Antecedentes, Fundación y Primera Etapa (1879 - 1910). Tesis doctoral. Director Vicente Galbis López. Universidad de. Valencia, Departamento de Historia del Arte, p. 397 reseña que tanto Giner en el prólogo de la primera edición, como Pedrell en la segunda alaban la cantidad de ejercicios rítmicos y de entonación que contiene el libro.
} 


\subsection{RESEÑA BIOGRÁFICA DEL AUTOR}

ESPINO IGLESIAS, Felipe. Salamanca 26 - 5 - 1860 - Madrid 12 - 7 - 1916. Estudió inicialmente en la Escuela de Bellas Artes de San Eloy de su ciudad natal. En 1878 ingresó en el Conservatorio de Madrid tras haberse estrenado una ópera suya, Eva, representada para recaudar fondos para su traslado a Madrid. Estudió allí piano y composición. Obtuvo beca para la Academia de Bellas Artes de Roma, y durante unos años viajó por las principales capitales europeas. Al regresar a España organizó el Orfeón salmantino dentro de la Escuela de Bellas Artes de San Eloy, en 1897 obtuvo la plaza de profesor de música en el Colegio de Ciegos y Sordomudos de Madrid, y más tarde la de profesor de Acompañamiento al Piano en el Conservatorio de Madrid. Compuso zarzuelas, óperas, música religiosa y de piano (Sobrino, en AAVV, 1999, tomo 4, pp. 777 y 78).

\subsubsection{DESCRIPCIÓN DETALLADA DEL MÉTODO.}

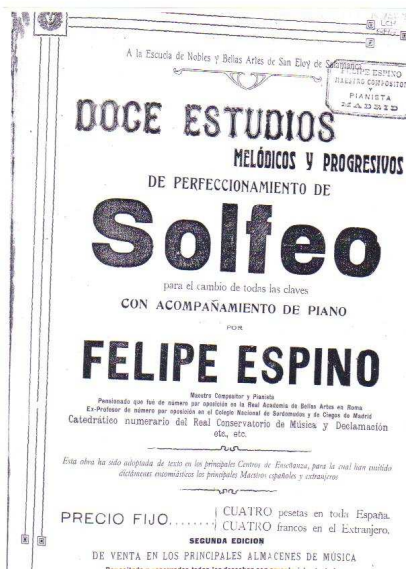

\section{Título del Método}

Doce estudios melódicos y progresivos de perfeccionamiento de solfeo: para el cambio de todas las claves, con acompañamiento de piano. $2^{a}$ edición. Obra dedicada a la Escuela de nobles y Bellas Artes de San Eloy de Salamanca, Madrid, R. Velaso, 1912? ${ }^{1}$ Apéndice, página 234.

Tal como el nombre del libro dice, se trata de estudios en forma progresiva para la práctica exhaustiva de las 7 claves, están en forma manuscrita y llevan acompañamiento de piano.

\section{CUADRO DE INFORMACIÓN GENERAL DEL MÉTODO.}

\section{$\mathbf{N}^{\mathbf{0}}$ de lecciones $\quad 12$}

Extensión de las lec- De 25 a 84 compases ciones Claves empleadas $\quad$ Las 7

\footnotetext{
${ }^{1}$ No sabemos quién supone ni porqué que este es el año aproximado de edición. Así figura en el catálogo de la Biblioteca de Valencia, pero nada hace sospechar esto viendo el libro.
} 
Tesituras que abarcan $\quad \mathrm{Sol}_{2} \mathrm{a} \mathrm{Re}_{4}$

Tonalidades que trata y estudia

Compases que emplea y estudia

Dificultades métricas que contiene

Dificultades de entonación que se encuentran $y$ orden en que se enseñan los intervalos

\section{Armonía utilizada}

Formas que tienen las lecciones

Introducciones, Intermedios o Codas instrumentales

Teoría de la música que incluye
Do M, Do m, Mi M, Si b M, Re \# m Si m, Mi b M, Sol b M, Re m, Re b M, La M Re M, Do \# m. Do \# M, Fa M, Fa m, Fa \# M, La b M

4/4, 3/8, 3/2, 3/4, 5/4, 2/2, 6/8,2/1, 2/4, 12/8, 9/8, 5/8, 9/16, $2 / 8$

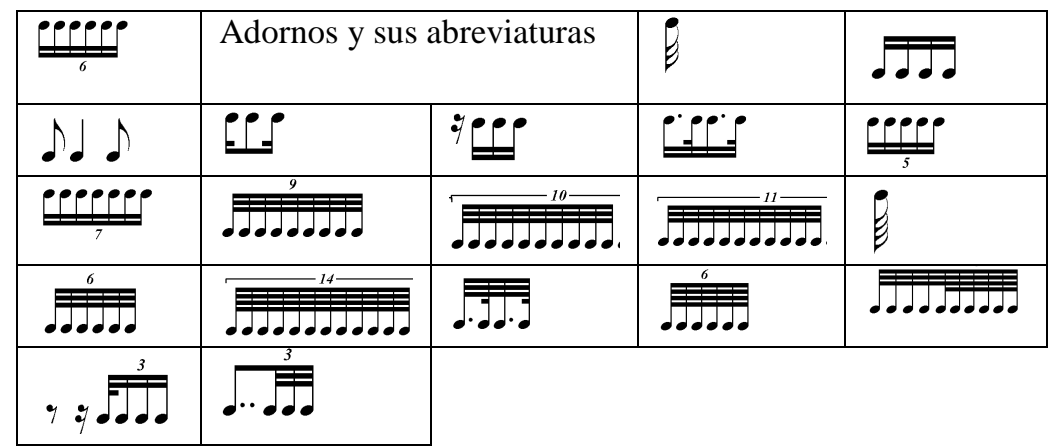

$7^{\mathrm{a}}$ y $8^{\mathrm{a}}$ disminuida, $2^{\mathrm{a}}$ aumentada, enarmonías, $5^{\mathrm{a}}$ y $4^{\mathrm{a}}$ disminuida, $5^{\text {a }}$ aumentada y $3^{\text {a }}$ disminuida.

En general es normal, pero tiene algunas sorpresas. Acordes de $9^{\text {a }}$ mayor de dominante. Acordes de sobretónica. Acordes con $6^{\mathrm{a}}$ y $4^{\mathrm{a}}$ añadidas y la $4^{\mathrm{a}}$ aumentada a modo de acorde de apoyatura. Séptimas sin resolver. Modulaciones generalmente a tonos vecinos, pero hay alguna por enarmonía de sus notas vocales y acompañamiento. Alguna modulación por descenso cromático y alguna a tonos lejanos. Alguna cadencia sobre el VI mayorizado que modula a la subdominante, por tanto utiliza como dominante una $3^{\mathrm{a}}$ superior. Pasajes con indefinición tonal. Acordes pedal. Algún grado alterado. Cadencia final con I-VI-I y el VI rebajado

A-B; A-B-B'; A-B-A'; A-B-C-B'-A; A-B-C-B': A-B-A'C-A'; A-B-A'-A'; Tema y variaciones

No tiene ninguna

No contiene 
$\underline{\mathrm{N}^{\mathrm{o}} 1}$

Extensión. $\mathrm{La}_{2}$ a Do 4 . Tonalidad principal Do mayor, cambiando luego a Do menor y vuelta al principal. Compases de 4/4, 3/8 y de nuevo 4/4. Hay diez cambios de claves. Dificultades métricas normales, solamente en el 3/8 destacar un seisillo de fusas, hay abreviaturas de grupetos. Dificultades melódicas $7^{\mathrm{a}}$ y $8^{\mathrm{a}}$ disminuida.

$\underline{\mathrm{N}^{\circ} 2}$

Extensión, Do 3 a Do 4. Tonalidad Mi mayor. Compases de 3/2 cambio a 3/4 y vuelta al primero. Hay 28 cambios de claves, algunos en cada nota. Dificultades métricas fusas en el 3/4, mordentes y grupetos abreviados. Dificultades melódicas $2^{\mathrm{a}}$ aumentada.

$\underline{\mathrm{N}^{\circ} 3}$

Extensión, $\mathrm{Si}_{2}$ a $\mathrm{Re}_{4}$. Tonalidades de $\mathrm{Si}$ bemol mayor que cambia a $\mathrm{Re}$ sostenido menor por enarmonía con la dominante en una semicadencia, y vuelta a la tonalidad principal por medio del acorde de $5^{\mathrm{a}}$ aumentada sobre el III grado de Re sostenido menor, enarmonizando dos de sus notas (la sostenido y do doble sostenido) por el acorde de Si bemol 7 $7^{\text {a }}$ que modula a Mi bemol Mayor, de ésta a Fa mayor y de ella a Si bemol mayor en un juego de modulaciones frecuentes. Compases de 5/4 en forma amalgamada, 3/4 en la sección que está en Re sostenido menor, y de nuevo 5/4 en la tonalidad principal. Hay 33 cambios de claves, algunas en cada nota o cada tiempo. Dificultades métrica no muchas, semicorcheas, síncopas breves y seisillo en forma de doble tresillo. Dificultades melódicas, enarmonía.

$\underline{\mathrm{N}^{\circ} 4}$

Extensión, $\mathrm{Sol}_{2} \mathrm{a} \mathrm{Do}_{4}$. Tonalidad única Do mayor. Compases de 4/4, 2/2 y 4/4. 32 cambios de claves, varios de esos cambios se producen cada tiempo. Dificultades métricas muy pocas, doble tresillo, una síncopa muy breve, entradas a contratiempo con silencio de semicorchea. Dificultad melódica ninguna.

$\underline{\mathrm{N}^{\circ} 5}$

Extensión, La \# 2 a Do 4 . Tonalidad de Si menor que cambia a Mi menor y vuelve a la primera. Compases de 3/8,6/8 y vuelta a 3/8. 27 cambios de claves, algunos frecuentes. Dificultades métricas normales en el $3 / 8$, un poco más complejas en $6 / 8$, fusas, semicorcheas con puntillo y fusa y viceversa. Dificultad melódica ninguna. 
$\underline{\mathrm{N}^{\circ} 6}$

Extensión, $\mathrm{La}_{2}$ a $\mathrm{Re}_{4}$. Tonalidad Mi bemol mayor. Compases de 2/1, 2/2, $3 / 2$ y 2/4. 62 cambios de clave, muchos de ellos cada tiempo. Dificultades métricas: alguna abreviatura de grupeto, algunas fusas. Dificultades melódicas: enarmonía, $2^{\mathrm{a}}$ aumentada, $5^{\mathrm{a}}$ y $4^{\mathrm{a}}$ disminuida.

$\underline{\mathrm{N}^{\mathrm{o}} 7}$

Extensión, $\mathrm{La}_{2}$ a Do 4 . Tonalidad única, como la anterior, de Sol bemol mayor. Emplea fundamentalmente el compás de compasillo, pero tiene una sección central en la que hay frecuentes cambios de compases, 12/8, 9/8, 6/8, 12/8, 9/8, 6/8, 12/8; después de esta sección vuelve a 4/4 en el que termina. 36 cambios de claves, muchos a cada nota. Dificultades métricas: muchas abreviaturas de grupetos, ${ }^{1}$ abundancia de grupos irregulares, quintillos, septillos, nonillos, diecillos y oncillos; fusas y semifusas. Dificultades melódicas: enarmonías y $5^{\mathrm{a}}$ aumentada.

$\underline{N^{\circ} 8}$

Extensión, $\mathrm{Si}_{2}$ a $\operatorname{Re}_{4}$. Tonalidades de Re menor, Re bemol Mayor, La Mayor, de nuevo Re menor, Si bemol mayor y acaba en Re mayor. Compases de 12/8, 6/8,12/8, $5 / 8$ en ritmo de zortzico, 12/8, 6/8, 4/4, 12/8, 3/8 y 6/8, algunos duran un solo compás. 47 cambios de claves, algunos cada tiempo, aunque hay fragmentos en una sola clave. Dificultades métricas: fusas en el compás de 12/8, en el de 4/4 semifusas y dobles tresillos de fusas, grupos irregulares como quintillos, seisillos, nonillos, y de catorce figuras. Dificultades melódicas: enarmonías varias, muchos cromatismos.

$\underline{\mathrm{N}^{\circ} 9}$

Tesitura, $\mathrm{Si}_{2}$ a $\operatorname{Re}_{4}$. Tonalidades de Do sostenido menor, y su variante modal. Compás único de 3/4. Hay 31 cambios de claves, sin embargo hay más fragmentos sin cambiar de clave que en otras lecciones. Dificultades métricas: fusas con puntillo y semifusas, fórmula con 4 fusas y seisillo de semifusas. Dificultades melódicas, solamente alguna enarmonía.

$\underline{N^{\circ} 10}$

Tesitura, $\mathrm{Si}_{2}$ a $\mathrm{Re}_{4}$.Tiene forma de Tema y variaciones. El tema está en la tonalidad de Fa mayor, compás de 3/4. Hay 7 cambios de clave. Dificultad métrica y meló-

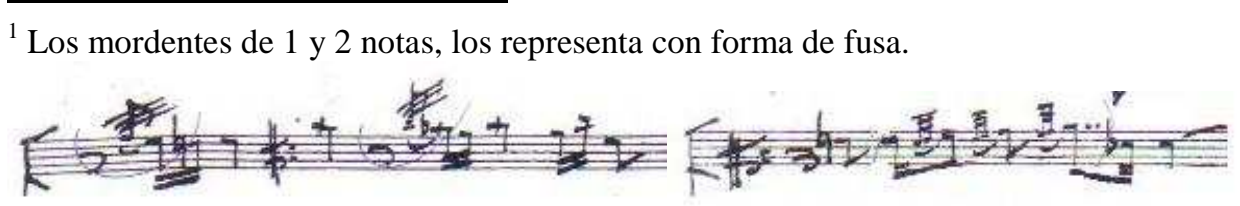


dica ninguna. Variación I, está en la misma tonalidad, cambia al compás también ternario, pero compuesto de 9/8. Solamente utiliza la clave de Do $2^{\mathrm{a}}$. Es una variación ornamental. La Variación II está en Fa menor, compás de 3/8. Única clave Do $3^{\text {a }}$. Es una variación rítmica. Variación III, Fa mayor de nuevo, igualmente compás de 3/8. Empieza en la clave de Do $4^{\mathrm{a}}$, pero ya cambia hacia el final a Fa $3^{\mathrm{a}}$, Do $1^{\mathrm{a}}$, Fa $4^{\mathrm{a}}$, Do $2^{\mathrm{a}}$ y Do $3^{\mathrm{a}}$ y con frecuencia. Es también una variación rítmica. Hay para terminar un Final de 9 compases, mientras que el tema y variaciones son de 16 compases aquel, 16 la primera y segunda y 11 la tercera. Está en el tono principal de Fa mayor, y utiliza el compás de 2/4. Es solamente una coda.

$\underline{N^{\circ} 11}$

Tesitura, $\mathrm{Do}_{3} \mathrm{a} \mathrm{Re}_{4}$. Tonalidades de La mayor, Fa sostenido mayor, Fa mayor y de nuevo a La mayor. Compases de 2/4, 3/4 y vuelta a 2/4. 43 cambios de claves, que no son muchos para lo larga que es la lección; tiene largos periodos sin cambio de clave. Dificultades métricas: en un tiempo silencio de corchea con puntillo - fusa - tresillo de semicorcheas, dobles tresillos de semicorcheas, quintillos de semicorcheas y septillos de fusas. Dificultades melódicas: $2^{\mathrm{a}}$ aumentada, una enarmonía, $3^{\mathrm{a}}$ disminuida. $\underline{\mathrm{N}^{\mathrm{o}} 12}$

Extensión, $\mathrm{Si}_{2} \mathrm{a} \mathrm{Re}_{4}$. Tonalidades de Re sostenido menor, Mi bemol mayor, La bemol mayor, Do menor y Mi bemol mayor. Compases de 4/4, 9/8, 3/8, 9/16, 3/8 y 2/8. Hay 35 cambios de clave, solamente al final cambia con frecuencia, gran parte de la lección tiene periodos en una sola clave, hay quizás menos cambios que en muchas anteriores. Dificultades métricas: doble puntillo en las corcheas con tresillo de fusas, quintillo de fusas. Dificultades melódicas: enarmonías, $4^{\mathrm{a}}, 5^{\mathrm{a}}$, y $7^{\mathrm{a}}$ disminuidas.

\subsubsection{VALORACIÓN DE LA EFECTIVIDAD DEL MÉTODO Y DE SU APORTACIÓN A LA ENSEÑANZA}

Es un libro complementario, no un método. Está hecho con el fin de practicar la lectura de las claves, y de paso ahondar en la medida y la entonación; es por tanto un compendio de los elementos del solfeo, lectura, medida y entonación, ahondando hasta la extenuación en los cambios de clave.

Ya en otros puntos de la tesis comentamos ampliamente este aspecto que ha estado tan en boga en los métodos de solfeo del siglo XX, y que no creemos en absoluto 
Espino

útil, ya que en la práctica profesional jamás se le presentará al músico tal cosa, sí algún cambio esporádico, pero nunca llegar hasta que cada nota esté escrita en una clave. 


\subsection{RESEÑA BIOGRÁFICA DE LOS AUTORES}

ABREU, Avelino. Torroella de Montgrí (Gerona), siglo XIX, profesor y compositor. Estudió armonía en el conservatorio de Barcelona donde fue profesor de Solfeo y Composición (Vega Toscazo, Ana, en AAVV, 1999, tomo I p. 15).

ZAMACOIS SOLER, Joaquín. Santiago de Chile 1894 - Barcelona 1976. Pianista y compositor. Vino a España de muy niño, estudió en el Liceo. Premio de piano en 1911. Estudió composición, premio en 1912, pero estudió por su cuenta los tratados de Gevaert, D’indy, Riemann, Gedalge y Rimsky-Korsakov, y se dedicó al análisis de obras. En 1914 fue profesor de grado elemental en el conservatorio, 2 años después de grado superior. En 1945 fue Director de la Escuela Municipal de Música de Barcelona, que hasta entonces dirigía Lambert y que pasó a llamarse Conservatorio Superior Municipal de Barcelona. Académico correspondiente de San Fernando (Andreu y Sobrino, en AAVV, 1999, tomo 10, p. 1080).

SERRA, Pedro. El tercero de los autores del método que vamos a analizar, pero del que no hemos encontrado ninguna referencia biográfica.

\subsubsection{DESCRIPCIÓN DETALLADA DEL MÉTODO.}

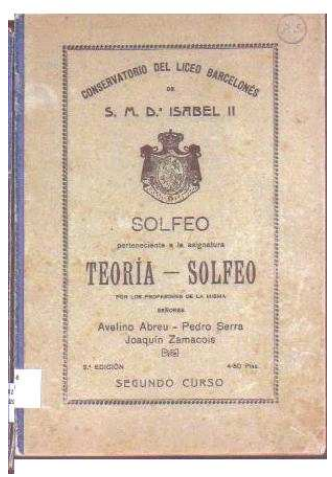

\section{Título del Método}

Solfeo, segundo curso: perteneciente a la asignatura teoría - solfeo, $2^{\text {a }}$ edición, s. 1., s. f. ${ }^{1}$ Apéndice, página 235.

Solfeo, quinto curso: perteneciente a la asignatura teoría - solfeo, $2^{\mathrm{a}}$ edición, s. 1., s. f

El método de Abreu, Zamacois y Serra, alcanzó su 52 edición en 1984, lo que nos da fe de la gran aceptación que este método ha tenido a lo largo de todo el siglo XX.

Hay de estos autores 5 volúmenes o cursos. No hemos podido encontrar los cur$\operatorname{sos} 3^{\circ}$ y $4^{\circ}$, sí el $1^{\circ}$ que está en la Biblioteca Nacional de Cataluña con la referencia TOP $2000-8-324$, pero eso fue después de tener analizados todos los métodos que compo-

\footnotetext{
${ }^{1}$ Aunque en ninguno de los libros figura fecha, lo situamos aproximadamente sobre el 1914 por ser el año en que Zamacois fue nombrado profesor de solfeo de grado elemental.
} 
Dificultades métricas que contiene

Dificultades de entonación que se encuentran $y$ orden en que se enseñan los intervalos

Armonía utilizada

Formas que tienen las lecciones

Introducciones, Intermedios o Codas instrumentales

Teoría de la música que incluye

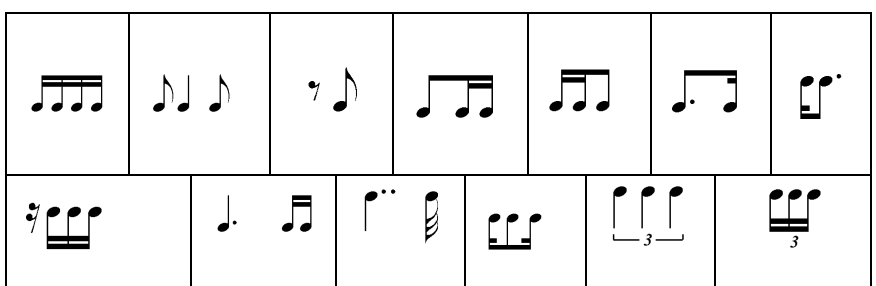

Todos los intervalos aumentados y disminuidos en ejercicios de entonación. En las lecciones, a partir de las distintas tonalidades, aparece alguno de vez en cuando.

Semitonos diatónicos, cromáticos, tonos con alteraciones, aumentados y disminuidos.

Romántica, un tanto sorpresiva. Acordes apoyatura, Acordes de $9^{a}$. Modulaciones a tonos lejanos Algún grado alterado. Alguna modulación sin dominante. A medida que avanzan las lecciones, la armonía es más variada

A-B-A'; A-B-C; A-B; A-A'

No tiene ninguna

Muy poca y concisa

\section{SECUENCIA}

Hay una breve advertencia al comienzo del libro informando que las explicaciones teóricas al comienzo de las lecciones son concisas, por lo que los autores remiten a la Teoría, correspondiente al mismo curso.

Comienza con la aplicación de las alteraciones a ejercicios de entonación en gran número. Primero hay 17 ejercicios con sostenidos, que empiezan por semitonos diatónicos, cromáticos, tonos y van aumentando la dificultad a intervalos aumentados y disminuidos. Siguen otros 17 ejercicios con bemoles, en la misma progresión y dificultades. Continúan con 4 ejercicios mezclando sostenidos y bemoles, en los que se incluyen la escala cromática. Y termina esta serie de ejercicios con 2 para el uso del becuadro. Es una sección de entonación interválica muy completa.

\section{Semicorcheas:}

Inicia con este epígrafe la serie de lecciones. Todas las presenta en dos pentagramas, el superior para la melodía y el de bajo con un acompañamiento en forma de 
Abreu, Zamacois y Serra, segundo curso

bajo cifrado. Arranca partiendo de esta figura de nota en grupos de 4, dentro de compases simples de denominador 4, con la clave de Sol y en la tonalidad de Do mayor. Además de la semicorchea aparecen también síncopas breves y contratiempos. 2 lecciones tratan de esta dificultad

Continúan la serie de lecciones, divididas en los siguientes epígrafes, según la combinación rítmica tratada; todas en la tonalidad de Do mayor, y principalmente en la clave de Sol, con alguna excepción empleando la de Fa en 4a las cuales se indican:

Corchea seguida de dos semicorcheas.- 2 lecciones

Dos semicorcheas seguidas de corchea.- 2 lecciones (la segunda en clave de Fa)

Corchea con puntillo seguida de semicorchea.- 2 lecciones

Semicorchea seguida de corchea con puntillo.- 2 lecciones

1 lección para cada una de estas combinaciones:

$\underline{\text { Silencio de semicorchea delante del grupo }}$

$\underline{\text { Silencio de semicorchea después de la primera }}$

$\underline{\text { Silencio de semicorchea después de la segunda }}$

$\underline{\text { Silencio de semicorchea en el cuarto lugar. }}$

1 lección, en clave de Fa en $4^{\text {a }}$ para cada una de estas combinaciones:

$\underline{\text { Silencio de corchea seguido de dos semicorcheas }}$

$\underline{\text { Silencio de semicorchea en segundo y tercer lugar }}$

Dos semicorcheas seguidas de silencio de corchea.

De nuevo clave de Sol para seguir con estas combinaciones:

Negra ligada a la primera de 4 semicorcheas

$\underline{\text { Silencio de corchea con puntillo seguido de semicorchea }}$

$\underline{\text { Negra con puntillo seguida de dos semicorcheas }}$

Negra con doble puntillo seguida de semicorchea.

Síncopa muy breve, 2 lecciones

(En cada una de ellas se trata casi exclusivamente cada una de estas combinaciones) 
Cinco lecciones dedicadas al resumen de todo lo tratado en las anteriores, es decir, combinaciones de todas las fórmulas rítmicas estudiadas hasta el momento. De ellas una está en clave de Fa en $4^{\text {a }}$.

Compás de 2/2:

Cuatro lecciones para conocer y practicar este compás. La primera en clave de Sol, la segunda en la de Fa, pero con figuras de redonda, blanca, blanca con puntillo negra y sus silencios (muy oportuno para comenzar el estudio de un nuevo compás), la tercera vuelve a la clave de Sol e introduce el tresillo de negra, la cuarta lección la dedica al grupo de 4 corcheas por tiempo, clave de Fa.

Compás de 3/8:

Cuatro lecciones, introduciendo igualmente las dificultades de forma progresiva: negras, corcheas y negras con puntillo; corcheas; combinación de corcheasdos semicorcheas - corchea y la última 6 semicorcheas. La tercera lección lleva clave de Fa.

Tresillos de semicorchea:

Cuatro lecciones, en las que cambia de nuevo a los compases de denominador 4; la última está en 3/8, una de ellas lleva clave de Fa, y también abarca el doble tresillo.

\section{Compás de 6/8:}

Dos lecciones con escasa dificultad rítmica.

\section{Tonalidades:}

\section{Tono de La menor:}

En la lección 43 empiezan las tonalidades. Un ejercicio de entonación previo utilizando solamente la escala melódica.

En la primera lección ya aparece un intervalo de $3^{a}$ disminuida, que hasta ahora, exceptuando los ejercicios del comienzo, no habiase visto ninguno. Son 4 lecciones en total, empleando los compases conocidos, y dedicando cada una de ellas un poco monográficamente a un determinado ritmo. 
Abreu, Zamacois y Serra, segundo curso

Siguen las tonalidades de Sol mayor y Mi menor, con su ejercicio de entonación previo y 4 lecciones dedicadas a cada una. Se emplean todos los compases hasta ahora conocidos, y de vez en cuando se alterna la clave de Sol con la de Fa en $4^{\mathrm{a}}$.

En el turno de la tonalidad de Fa mayor, también se le dedican 4 lecciones, pero en la tercera se presenta el compás de $9 / 8$.

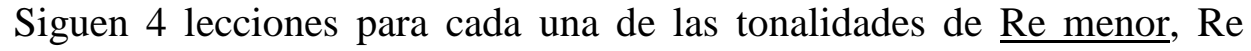
mayor y Si menor. En esta última también sucede que en la tercera surge el compás de $12 / 8$.

Continúan los grupos de 4 lecciones para las tonalidades de $\underline{\mathrm{Si} \text { bemol }}$ mayor, y Sol menor, manteniendo este último compás, aunque la penúltima de esta posterior tonalidad lleva compás de $2 / 2$.

Por último la clave de Do en $4^{\mathrm{a}}$ línea (no vemos el porqué de esta clave y no la de Do en $1^{\mathrm{a}}$, o en todo caso en $3^{\mathrm{a}}$ ). 12 lecciones, en diversas tonalidades, pero ninguna nueva, sino volviendo a las ya practicadas, empiezan en la de Do mayor 3 de ellas, y luego se presentan en Sol mayor, Fa mayor, Re menor, La menor, Re mayor y Mi menor. Se emplean los compases simples primero, y después compuestos que se han estudiado. Y comienzan solamente con redondas para ir poco a poco subiendo de dificultad rítmica: redondas y blancas; blancas y negras; corcheas; puntillos; tresillos y semicorcheas con combinaciones entre las anteriores. 


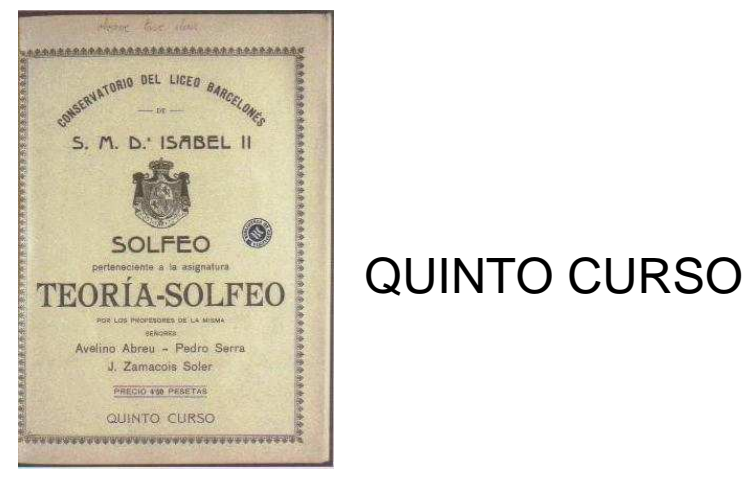

\section{CUADRO DE INFORMACIÓN GENERAL DEL QUINTO CURSO.}

$\mathbf{N}^{\circ}$ de lecciones
61 en total: 30 manuscritas, 17 para la práctica del transporte, y 14 a dos voces solas

Extensión de las lec- Entre 30 y 109 compases las lecciones manuscritas. Entre 18 ciones y 60 compases las dedicadas a la práctica del transporte. Y entre 19 y 77 compases las de 2 voces

Claves empleadas

Las 7 en las manuscritas. Sol, Fa $4^{\mathrm{a}}$, Do $3^{\mathrm{a}}$ y Do $4^{\mathrm{a}}$ en las dedicadas al transporte. Solamente Sol en la tercera sección

Tesituras que abarcan $\quad$ Desde $\mathrm{Si}_{2} \mathrm{a} \mathrm{Mi}_{4}$
Tonalidades que trata y estudia

Compases que emplea y estudia

Dificultades métricas que contiene

Re M, Fa \# m, Fa m, Sol m, Mi m, Do M, Re m, Sol M, Fa M, Mi M, Do m, Re b M, La b M, Mi b M, Sol b M. En las dedicadas al transporte, solamente emplea Do M, Fa M, La m, Re M, Sol M, Do m, y Mi M. En la $3^{\text {a }}$ sección Do M, Re M, Mi b M, Fa M, Sol m, Si b m y Si b M

2,3 у 4/4; 6,9 у 12/8; 3/2, 5/4, 21/8, 4/2, 2/2, 7/4, 5/8, $9 / 8+2 / 4,5 / 4$ y $4 / 8$. En la $2^{a}$ sección solamente 2,3 y $4 / 4$ y en dos ocasiones $6 / 8.3^{\mathrm{a}}$ sección 2,3 y $4 / 4$, solamente las dos primeras llevan el de $2 / 2$.

Como máximo llega a Fusas y combinaciones rítmicas de todo tipo. También medidas irregulares. La mayor parte de las lecciones no presenta grandes dificultades. Las que sí tienen son las dificultades propias de un nivel elevado. En la $2^{\mathrm{o}}$ y $3^{\mathrm{a}}$ secciones las dificultades son elementales

Dificultades de entona- Toda clase de intervalos, pero dentro de un fluir con naturación que se encuentran lidad sin forzarlos. En la $2^{\mathrm{a}}$ y $3^{\mathrm{a}}$ secciones intervalos senciy orden en que se ense- $\quad$ llos ñan los intervalos 
Armonía utilizada

\author{
Formas que tienen las \\ lecciones
}

Introducciones, Intermedios o Codas instrumentales

Teoría de la música que incluye
Romántica. Acordes de $9^{\mathrm{a}}, 7^{\mathrm{a}}$ disminuida, alterados, modulaciones extrañas, resoluciones excepcionales. En la $2^{\mathrm{a}}$ y $3^{\mathrm{a}}$ sección la armonía se hace más sencilla y clásica, modula a tonos vecinos y a homónimos, pero no a lejanos para evitar complicaciones melódicas que dificultarían más el transporte

A-B-A'; A-B-C-D- coda; A-B-A'-A',; A-B-A'-C-A', A-B-C-A'; A-A'-B-C. $2^{\text {a }}$ sección A-A'; A-B; A-B-A'. $3^{\mathrm{a}}$ sección las mismas.

De las manuscritas 12 tienen introducción, y 11 intermedio o intermedios, ninguna tiene coda. En la $2^{\mathrm{a}}$ y $3^{\mathrm{a}}$ secciones no tienen ninguna

Muy poca y concisa

\subsubsection{DESCRIPCIÓN DETALLADA DEL QUINTO CURSO.}

Hay al comienzo, la misma advertencia que en el segundo curso, informando que las explicaciones teóricas al comienzo de las lecciones son concisas, por lo que los autores remiten a la Teoría, correspondiente al mismo curso.

El libro tiene 3 partes diferenciadas, aunque los autores no lo dividen así de forma explícita.

Lo primero que encontramos son 30 lecciones manuscritas, con acompañamiento de piano, empleando todas las claves, en muy distintas tonalidades, compases de utilización común y también otros menos comunes e irregulares, algunas con cambios de compases y de tonalidades, otras que permanecen en la tonalidad y compás inicial, y al final 9 lecciones en las que cambian las claves siempre entre dos de ellas.

1.- Clave de Do $4^{\mathrm{a}}$, Re Mayor, $3 / 4$ cambia a 5/4, y a Fa \# menor, 3/4 y de nuevo Re Mayor.

2.- Clave de Do $2^{\mathrm{a}}$, Fa menor, 3/2, Introducción de 2 compases e Intermedio que es igual a la introducción.

3.- Clave de Sol, Sol menor 4/4, Introducción y 2 Intermedios.

4.- Clave de Sol, Mi menor, 2/4, 4 Intermedios.

5.- Clave de Fa, Do Mayor, 4/4, Introducción. 
6.- Clave de Sol, Fa menor, 21/8 6/8 5/4 21/8 5/4, Fa Mayor. 3/4 Fa menor, 4/4 3/4 4/4 21/8. Los irregulares están en forma amalgamada y sin amalgamar ${ }^{1}$

7.- Clave de Fa $3^{\mathrm{a}}$, Mi menor, 2/4, Intermedio.

8.- Clave de Do $4^{\mathrm{a}}$, Do Mayor, 2/2, Introducción, Intermedio. Acompañamiento contrapuntístico

9.- Clave de Do $1^{\text {a }}$, Mi menor, 6/8, Introducción, Intermedio.

10.- Clave de Do $1^{\mathrm{a}}$, Sol menor, 3/4, Intermedio.

11.- Clave de Do $2^{\mathrm{a}}$, Re menor, 3/4, 4/2.

12.- Clave de Do $3^{\mathrm{a}}$, Re menor, $2 / 4$, Re Mayor, $3 / 4$

13.- Clave de Fa 4ª , Do Mayor, 6/8, 12/8, La Mayor, 9/8, 6/8, Do Mayor, 9/8, 6/8. Introducción.

14.- Clave de $\mathrm{Fa} 4^{\mathrm{a}}$, Sol Mayor, 6/8

15.- Clave de Do $1^{\mathrm{a}}$, Fa Mayor, 3/4, Introducción.

16.- Clave de Fa $3^{\mathrm{a}}$, Sol Mayor, $2 / 4$

17.- Clave de Do $3^{\text {a }}$, Mi Mayor, 7/4 amalgamado, Introducción.

18.- Clave de Fa $3^{\mathrm{a}}$, Sol Mayor, $2 / 4$ que alterna con frecuencia con 3/4, Re menor, Sol Mayor

19.- Clave de Do $3^{\mathrm{a}}$, Fa Mayor, 5/8, Introducción, Intermedio.

20.- Clave de Do $2^{\mathrm{a}}$, Do menor, 2/2, Introducción, Intermedio.

21.- Clave de Do 4a , Mi Mayor, 3/4, Introducción.

En la lección 22 empiezan las lecciones con cambios de clave

22.- Cambios entre Do $3^{\mathrm{a}}$ y Sol, Re b Mayor, $3 / 4$ y 4/4

23.- Sol y Do 4a , Fa Mayor, curioso compás, es un característico compuesto de 9/8 seguido de $2 / 4$. Intermedio

24.- Do $4^{\mathrm{a}}$ y Fa $4^{\mathrm{a}}$, La Mayor, 2/4, Intermedio, 5/4 sin amalgamar y La menor.

25-.Do $3^{\mathrm{a}}$ y Sol, Mi b Mayor, 4/4 alternando con frecuencia con 3/4 y 2/4, Mi Mayor y Mi b Mayor.

26.- Sol y Do $4^{\text {a }}$, Sol Mayor, toda en $2 / 4$

27.- Do $4^{\mathrm{a}}$ y Fa $4^{\mathrm{a}}$, Re b Mayor, 6/8 toda

28.- Sol y Do $4^{\mathrm{a}}$, Re menor, $2 / 4$ toda

29.- Sol y Do $4^{\mathrm{a}}$, Re Mayor, $2 / 4$, Introducción. Tiene una pequeña fermata

\footnotetext{
${ }^{1}$ Significando amalgamados, que llevan la línea intermitente que divide los dos compases que lo forman, y sin amalgamar, que no llevan tal línea y se presentan simplemente como compases irregulares, sin diferenciar claramente una continuidad o sucesión de tiempos siempre igual.
} 
Abreu, Zamacois y Serra, quinto curso

30.- Do $4^{\mathrm{a}}$ y Fa $4^{\mathrm{a}}$, Sol menor, 3/2, 4/8, 3/2.

Sigue a ésta otra sección con otro tipo de lecciones. Están dedicadas a la práctica del transporte, pero únicamente a la segunda mayor superior e inferior (no hay ninguna explicación teórica del transporte).

Son, como se dice en el esquema, 17 lecciones, en general más cortas que las anteriores, compases simples y de los compuestos solamente $6 / 8$ en dos lecciones. Tonalidades hasta 2 alteraciones en la armadura (solamente la última lleva 4). Y claves 4, no utiliza Do en $1^{\mathrm{a}}$ ni en $2^{\mathrm{a}}$ y Fa en $3^{\mathrm{a}}$.

Tienen una muy asequible dificultad métrica, pues en su mayor parte no pasan de blancas, negras y corcheas; a partir de la número 9 se incorporan también semicorcheas, pero por pocas lecciones, enseguida vuelve a la métrica sencilla.

La entonación tampoco es dificultosa, aunque hay algún intervalo aumentado y disminuido, se desenvuelven entre grados conjuntos y algún salto con intervalos propios de la escala, a lo sumo alterados debido a algún cambio de tonalidad.

A ésta le sigue una tercera sección dedicada a lecciones a 2 voces para voces iguales.

Todas en clave de Sol para ambas voces. Compases simples de denominador 4, excepto las dos primeras que están escritas en $2 / 2$. Se emplean preferentemente los ritmos sencillos; las figuras de redonda y blanca en las primeras, corcheas y corcheas con puntillo a partir de la tercera, semicorcheas a partir de la sexta; pero preferentemente blancas, negras y corcheas, algún contratiempo y alguna fórmula combinada, pero todas con muy baja dificultad tanto rítmica como melódicamente.

La $n^{\circ} 7$ alterna la tonalidad menor con su homónima mayor y el compás de 2/4 con el de $3 / 4$.

La $n^{\circ} 9$ cambia con frecuencia entre los compases de 3/4 y 2/4.

Y la penúltima, alterna su tonalidad menor (Si bemol) con la mayor, y deja algún pasaje de una voz sola.

En general son de un estilo polifónico con algún fragmento homófono. 


\subsubsection{VALORACIÓN DE LA EFECTIVIDAD DEL MÉTODO Y DE SU APORTACIÓN A LA ENSEÑANZA}

El segundo curso es muy amplio, comprende elementos del primero y del segundo curso actuales, la progresión de dificultades rítmicas es magnífica, perfectamente graduada y organizada.

Las melodías son muy asequibles, fluyen con facilidad y no se encuentran intervalos rebuscados para ocasionar dificultad por la dificultad.

Es el cuarto método de todos los que hemos estudiado que empieza con el compás de 2/4; Manent, Arrieta con 8 años de distancia, Vancell con 34 años de separación y éste con 12.

Muy didáctico el escalonar las dificultades cada vez que se estudia un nuevo compás.

Lo único censurable es la aparición de la clave de Do en $4^{\mathrm{a}}$, sin haber visto la de $3^{\mathrm{a}}$ ó $1^{\mathrm{a}}$, y habiendo tratado tan poco la de $\mathrm{Fa} 4^{\mathrm{a}}$.

El quinto curso es un libro de perfeccionamiento. Lecciones muy bonitas, parecen lieder o canciones, con un acompañamiento bastante virtuosístico y dialogando con la voz

No están ordenadas siguiendo ningún criterio, ni de dificultad, de progresividad, ni de tonalidades, parece ser que lo están al azar. 
Abreu, Zamacois y Serra, quinto curso 


\subsection{RESEÑA BIOGRÁFICA DEL AUTOR}

LLORCA, Miguel. Villajollosa? + 1926. Compositor y teórico. Estudió en su pueblo. Se fue a Madrid a estudiar Derecho, pero una vez allí se dedicó íntegramente al piano. En 1915 volvió a Villajollosa, donde se dedicó a componer (López Carranza, Ma Cruz, en AAVV, 1999, tomo 6, p. 961).

\subsubsection{DESCRIPCIÓN DETALLADA DEL MÉTODO.}

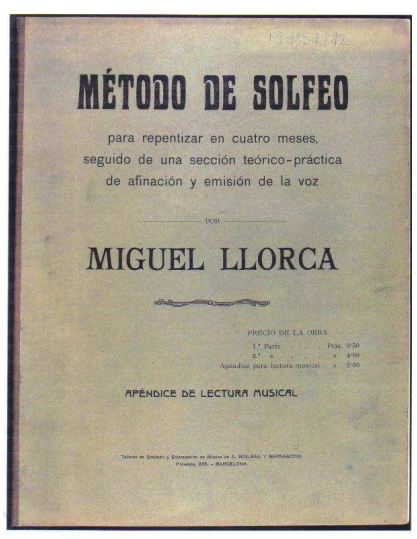

\section{Título del Método}

Método de solfeo, para repentizar en cuatro meses, seguido de una sección teórico práctica de afinación y emisión de la voz, apéndice de lectura musical, Barcelona, A. Boileau y Bernasconi, 1916. ${ }^{1}$ Apéndice, página 236.

Comienza con unas letras del autor, informando que este apéndice tiene el objeto de acostumbrar al alumno a la lectura de notas por salto. Para ello incluye aquí 40 ejercicios sin compasear, con toda clase de intervalos, y acordes arpegiados e invertidos. Y recomienda ejercitar este apéndice durante los meses tercero y cuarto de la enseñanza de su método, dogmatizando que cuando el discípulo consiga leer en 1 hora toda la música de este apéndice, o en 40 minutos la de su segunda parte, ya está en condiciones de afrontar la repentización.

Firma autógrafa del autor al final de este preámbulo

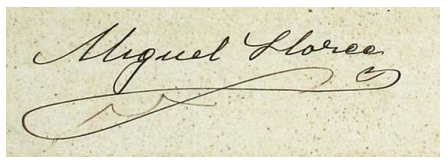

\footnotetext{
${ }^{1}$ Así lo afirma $\mathrm{M}^{\mathrm{a}}$ Cruz López Carranza en la obra arriba citada, sin embargo en el albarán de entrega de la Biblioteca de Cataluña pone año 1900, y en la información bibliográfica de la misma 19--?.

Lo que aquí presentamos es solamente el apéndice. El método tiene además dos cursos, que se encuentran en la Biblioteca Nacional de Cataluña con las signaturas siguientes: $78-\mathrm{FO} / \mathrm{C} 21 / 16$ y $78-\mathrm{FO} / \mathrm{C} 21 / 17$, pero no hemos creído necesario incorporarlos.
} 
CUADRO DE INFORMACIÓN GENERAL DEL MÉTODO.

$\mathbf{N}^{\circ}$ de lecciones

Extensión de las lec- No tienen compases

ciones

Claves empleadas

Tesituras que abarcan

Tonalidades que trata y estudia

Compases que emplea y estudia

Dificultades métricas que contiene

Dificultades de entonación que se encuentran y orden en que se enseñan los intervalos

Armonía utilizada

Formas que tienen las No tienen lecciones

Introducciones, Intermedios o Codas instrumentales

Teoría de la música No contiene que incluye

\section{0}

Sol

$\mathrm{Mi}_{2} \mathrm{a} \mathrm{Mi}_{5}$ ninguna menor

No hay alteración.

No hay

No existen
Do M, Sol M, Fa M, Re M, La M, Si b M, Mi b M. No hay

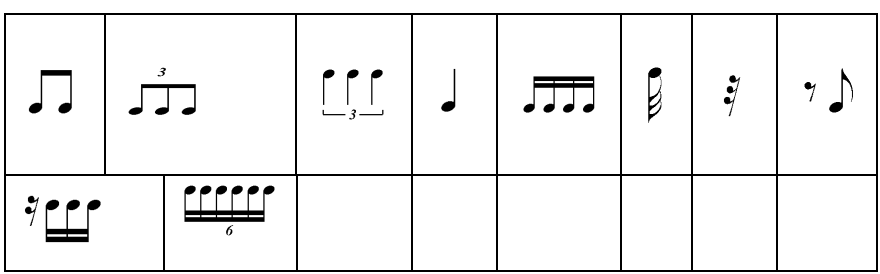

Intervalos totalmente dentro del diatonismo. No hay una sola

Grados conjuntos. $2^{\mathrm{a}}$ y $3^{\mathrm{a}} .3^{\mathrm{a}}, 2^{\mathrm{a}}$ y $4^{\mathrm{a}}$. Arpegios de acordes de $7^{\mathrm{a}} .5^{\mathrm{a}}$ mayor y menor. $8^{\mathrm{a}}$ y arpegios. $6^{\mathrm{a}}$ y $7^{\mathrm{a}}$

\section{Ejercicios del 1 al 5:}

El primero incluye las figuras de corchea, tresillos de corcheas y negras, intervalos por grados conjuntos. El segundo solamente negras, intervalos de segunda y tercera. El tercero, al igual que el primero pero en distinto orden, negras, tresillos de corcheas y corcheas, intervalos de tercera, segunda y cuarta. El cuarto mismas figuras y en el mismo orden que el primero, intervalos de cuarta, tercera, segunda y unísonos. El 
quinto mismas figuras e intervalos, agregando arpegios en forma de bajo de Alberti y de intervalo de séptima en sus extremos.

\section{Ejercicios 6 y $7:$}

En la tonalidad de Sol mayor, mismas figuras que los anteriores. El $n^{\circ} 6$ lleva los mismos intervalos que los de arriba, y añade alguna quinta, incluso menor. El siguiente contiene alguna octava y de nuevo los arpegios de acordes de $7^{\mathrm{a}}$.

\section{Ejercicios 8,9 y 10.}

Tonalidad de Fa mayor. El primero con las mismas figuras de siempre, los intervalos anteriores y arpegios. Los números 9 y 10 ya afrontan las semicorcheas, intervalos los mismos.

\section{Ejercicios 11,12 y 13 :}

Tonalidades de Sol mayor y Re mayor, el primero abunda en los intervalos de quinta; el segundo y tercero en los de sexta y séptima.

Ejercicios números 14 al 20:

El primero en la tonalidad de La mayor, otros 3 en Sol mayor, 1 en Re mayor y de nuevo el 19 en La mayor. Aportan cada uno de ellos una novedad en cuanto a figuras de nota o fórmulas rítmicas; siguiendo el orden numérico nos encontramos con: fusas, tresillos de corchea con las primeras o terceras corcheas ligadas, silencio de fusa, contratiempo de corchea, silencio de semicorchea y seisillo de semicorcheas.

Ejercicios 21 al 25:

Ninguna novedad aportan éstos, exceptuando el $n^{\circ} 23$ que está en la tonalidad de Si bemol mayor, por lo demás insisten en lo ya practicado.

\section{Ejercicios 26 al 32.}

El primero y segundo vuelven a la tonalidad de Do mayor, y abundan más las negras y corcheas, como si volviésemos al principio, aunque también hay seisillos de semicorcheas. El tercero ( $\left.\mathrm{n}^{\mathrm{o}} 28\right)$ ya vuelve a otras tonalidades (concretamente Fa mayor), y sigue con las mismas figuras de nota, añadiendo las fusas. Nada nuevo con los dos siguientes. Y el número 31 sorprende porque es una vuelta total al principio. Do 
mayor y sólo negras. El último, número 32 está en sol mayor y contiene semicorcheas y fusas.

De los números 33 al 40, donde termina el apéndice no aparece ninguna novedad, con la única excepción de la tonalidad de Mi bemol mayor en el ejercicio número 34. Todo lo demás es insistir en lo ya visto.

\subsubsection{VALORACIÓN DE LA EFECTIVIDAD DEL MÉTODO Y DE SU APORTACIÓN A LA ENSEÑANZA}

No es un método, es simplemente un apéndice y por tanto hay que juzgarlo como lo que es, un libro complementario.

Pero de cualquier manera, no vemos en él mucha utilidad; no hay variedad de ritmos, es monotamente insistente en las mismas figuras, no hay fórmulas rítmicas combinadas.

Melódicamente es nulo, puesto que, queriendo que el educando practique los sonidos muy agudos y muy graves, hace que resulten imposibles de cantar. Entonces ¿para qué utilizar distintas tonalidades? y sobre todo ¿para qué dedicar ejercicios monográficamente a un tipo de intervalo, única cosa que está organizada y escalonada? 


\subsection{RESEÑA BIOGRÁFICA DEL AUTOR}

BUXÓ PUJADAS, Tomás. Barcelona 1882 - 1962. Pedagogo y pianista. Estudió en la Escuela Municipal de Música de Barcelona, de la que luego fue profesor, alternando como concertista de piano y música de cámara. Tiene obras didácticas para piano, voz y piano y de cámara (Aviñoa Pérez, Xosé, en AAVV, 1999, tomo 2, p. 814).

\subsubsection{DESCRIPCIÓN DETALLADA DEL MÉTODO.}

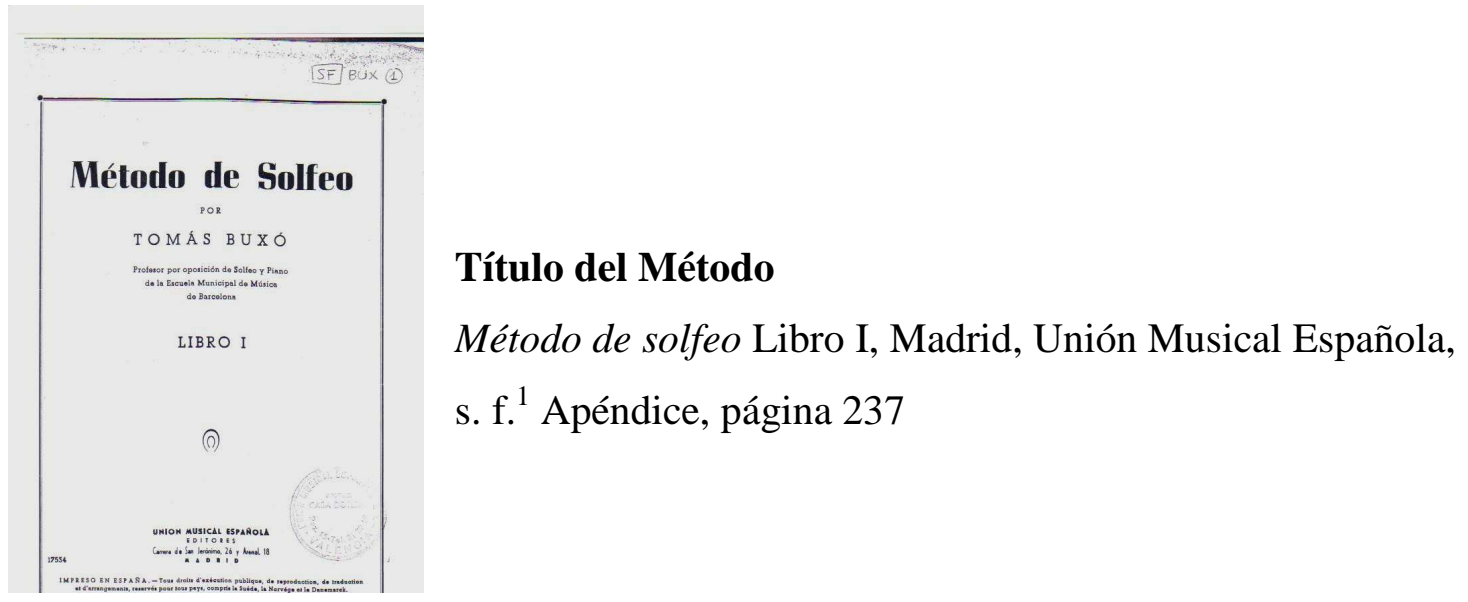

Consta el método de tres libros, que analizaremos separadamente.

\section{PRIMER LIBRO}

\section{CUADRO DE INFORMACIÓN GENERAL DEL PRIMER LIBRO.}

$\mathbf{N}^{\circ}$ de lecciones

Extensión de las lec- 16 a 114 compases

ciones

Claves empleadas

Tesituras que abar-

can

Tonalidades que trata y estudia
Sol y muy al final Fa en $4^{\mathrm{a}}$

De $\mathrm{Si}_{2}$ a Fa $_{4}$, pero más habitualmente hasta $\mathrm{Re}_{\mathrm{o}} \mathrm{Mi}_{4}$

Do mayor en todas las lecciones de clave de Sol. Y en las de clave de Fa, también Do mayor, La menor, 3 en Sol mayor, 33 en Re mayor, 1 en Mi menor y 1 en Fa mayor.

\footnotetext{
${ }^{1}$ El hecho de haberlo colocado al final, siendo que no se sabe su fecha de edición, es simple apreciación, dejándonos guiar por el año de la muerte del autor, que es muy avanzada.
} 
Compases que em- $\quad 4 / 4,3 / 4,2 / 4$ y $2 / 2$

plea y estudia

Dificultades métricas que contiene

Dificultades de ento-

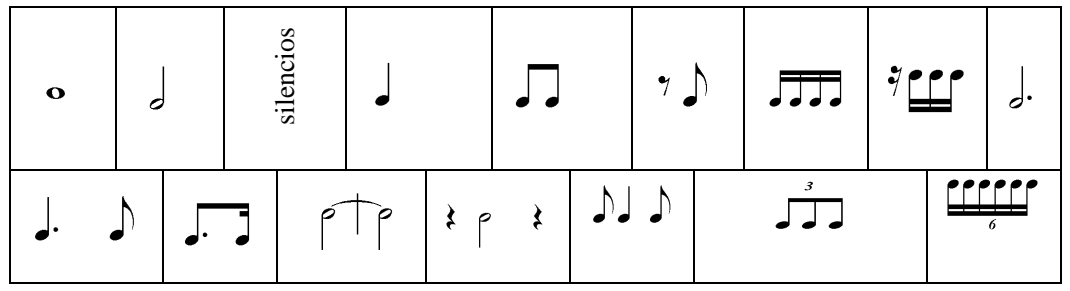
nación que se encuentran y orden en que se enseñan los intervalos

Armonía utilizada

Formas que tienen las lecciones

Introducciones, Intermedios o Codas instrumentales

Teoría de la música No contiene que incluye accidentales formando cromatismos y diatonismos.

$2^{\mathrm{a}}, 3^{\mathrm{a}}, 4^{\mathrm{a}}, 5^{\mathrm{a}}, 6^{\mathrm{a}}, 7^{\mathrm{a}}$, y $8^{\mathrm{a}}$. Semitonos cromáticos y diatónicos

No tienen acompañamiento

Excepto los primeros ejercicios de intervalos, A-B-A', incluso las primeras con negras y blancas, alguna excepción como AB; A-B-C; A-B-A'-C

No tienen ninguna

\section{SECUENCIA}

Comienza más que con lecciones, aunque están numeradas como tales, con una especie de ejercicios introductorios de las figuras de nota y de los primeros intervalos.

Una lección dedicada a las redondas en forma de escala, y otra para las blancas. Desde un principio, y hasta que digamos lo contrario, usa el compás de compasillo.

La tercera y cuarta están dedicadas a la entonación de intervalos de segunda, primero ascendentes y descendentes y luego alternados.

La quinta y sexta lecciones mezcla las blancas con alguna redonda y sigue con intervalos de segunda.

Intervalos de tercera: siguiendo con las anteriores figuras, aborda esta distancia con 4 lecciones, la que sigue es para intercalar el silencio de redonda

Intervalos de cuarta: seis lecciones dedicadas a esta distancia, mezclada con las anteriormente practicadas, con redondas, blancas y sus silencios.

Intervalos de quinta: cuatro lecciones con el mismo tipo de figuras. 
Intervalos de sexta: también cuatro lecciones con las mismas figuras.

Intervalos de séptima: igualmente cuatro lecciones.

Intervalos de octava: tres cortos ejercicios con este intervalo, y un último más largo mezclando todos los simples. Las figuras las mismas que hasta ahora.

Figuras de nota negra: seis lecciones con esta figura y su silencio, comenzando con sonidos por grados conjuntos y separándolos cada vez más.

Dos lecciones para la mezcla de blancas y negras, con sus silencios, y una para la de redondas, blancas y negras.

Figuras de corchea: Una lección cortísima agrupando en dos las corcheas y luego corchea y silencio posterior, formando melódicamente una escala ascendente y descendente. Después 3 lecciones, ya más largas, con corcheas, su silencio y el de negra. Enseguida sitúa el silencio de corchea delante formando el contratiempo corto, a lo que le dedica 3 lecciones, la primera de ellas en forma de escala, y en la siguiente ya introduce, sin ninguna explicación, el párrafo $\$$ y la palabra Fin. El párrafo lo utiliza como

Da Capo, sin indicar “al $\$$ hasta Fin”, solamente pone el signo al final y el Fin en su lugar.

Práctica de valoras en blancas, negras y corcheas: cinco lecciones con esta mezcla y sus silencios.

Figuras de semicorchea: comienza por un corto ejercicio, (aunque él siempre numera como lección, como ya dijimos al comienzo de la explicación) en forma de escala ascendente y descendente con grupos de 4 semicorcheas por tiempo y mezclándolas con corcheas y su silencio. Después dos lecciones con semicorcheas, corcheas y silencio y dos corcheas por tiempo. En seguida afronta el silencio de semicorchea formando contratiempo irregular con un corto ejercicio y 4 lecciones.

El Puntillo: con pobre explicación, como la de los anteriores elementos, y dando valores absolutos, no referidos al tipo de compás que tratamos, aborda aquí este signo de prolongación; primero con 2 lecciones para el puntillo puesto en la blanca, luego otras dos puesto en la negra y 3 puesto en la corchea.

La Ligadura: una lección con ella entre blancas formando síncopas muy largas y regulares; otra lección poniéndola entre negras, formando síncopas largas; dos ponién- 
dola entre corcheas, para formar síncopas breves; y una entre blancas y negras formando síncopas largas irregulares.

Tresillo: tras un ejercicio de dos compases y final en forma de escala, cinco lecciones con todas las dificultades métricas vistas hasta ahora más el tresillo de corcheas. A continuación el seisillo de semicorcheas en forma de dobles corcheas, un ejercicio de 2 compases y una lección. Después el seisillo en forma de doble tresillo también con un ejercicio y una lección.

Compás de 3/4: una lección enteramente con blancas con puntillo, otra con blancas y negras, en la que figura la inscripción ("Canción popular"), una tercera con esto y tresillos de corchea, sigue una con negras y corcheas, una más con negras con puntillo, síncopas, contratiempos y semicorcheas; la que sigue también indica que es una canción popular e incluye el puntillo en la corchea. Viene otra después en la que regresa a la combinación de blancas, negras y corcheas, acabando las lecciones dedicadas al estudio de este compás con la fórmula rítmica corchea y dos semicorcheas, el tresillo de corcheas y el grupo de semicorcheas y su silencio.

Compás de 2/4: una lección dedicada solamente a la blanca; otra con blancas y negras; una tercera, indicando canción popular, con negras y corcheas, otra más que no es canción popular con negras, corcheas, contratiempos y negras con puntillo. Tres canciones populares siguen, dos con los elementos anteriores y una tercera con combinación de corcheas, semicorcheas y corcheas con puntillo. Otra lección con estos ritmos. Otra indicando "Danza popular" en la que también hay síncopas, y una última con casi todos los elementos hasta ahora estudiados.

Compás de 2/2: una lección dedicada enteramente a la redonda, otra a la blanca y redonda y una más a estas dos y las negras.

Los Sostenidos: hay once lecciones para la práctica de esta alteración, formando, casi exclusivamente, semitono cromático, va repartiendo la dificultad de añadir la alteración con la métrica, de manera que empieza con valores largos y va introduciendo los cortos poco a poco. Otra cosa que incorpora a partir de aquí es el "Movimiento o Aire" además de la indicación metronómica (la que curiosamente indica al revés, primeramente la velocidad y luego la figura de nota). Utiliza los tres compases de denominador 4.

Los Bemoles: otro tanto hace con los bemoles, pero en cinco lecciones, y sin llegar más que a corcheas, introduciendo en la última la doble barra de repetición con las casillas de $1^{\mathrm{a}}$ y $2^{\mathrm{a}}$. Ahora utiliza los mismos compases más el de 2/2. 
La clave de Fa en $4^{\mathrm{a}}$ línea: representación del nombre de las notas en las líneas, espacios y en escala (lo que no hace al principio con la clave de Sol). Después una lección con redondas en compás de $2 / 2$, otra en el mismo compás con redondas y blancas y doce lecciones más en las que va cambiando de compases, entre los estudiados, y aumentando las dificultades métricas y melódicas hasta llegar, prácticamente, a las estudiadas con el grueso de lecciones en clave de Sol. 
BI

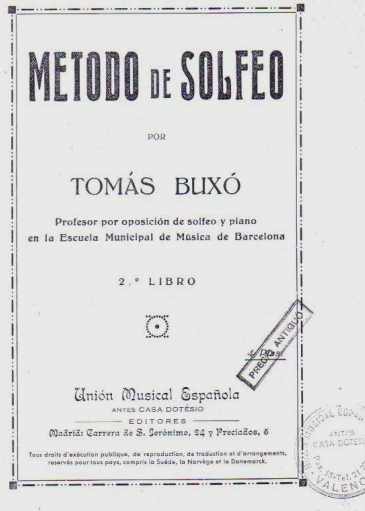

\section{$2^{\circ}$ LIBRO}

\section{CUADRO DE INFORMACIÓN GENERAL DEL SEGUNDO LIBRO.}

$\mathbf{N}^{\circ}$ de lecciones

Extensión de las lec- De 12 a 97 compases

ciones

Claves empleadas

Tesituras que abarcan

Tonalidades que trata y estudia

Compases que emplea y estudia

Dificultades métricas que contiene

Dificultades de entonación que se encuentran $y$ orden en que se enseñan los intervalos

Armonía utilizada

Formas que tienen las lecciones

Introducciones, Intermedios o Codas instrumentales

Teoría de la música que incluye

67 $\mathrm{Sol}_{5}$

No tienen ninguna

No contiene
Sol hasta la lección 41 y Fa en $4^{\mathrm{a}}$ para el resto

$\mathrm{Si} \mathrm{b}_{2}$ a Fa \# 4 , como práctica. De lectura desde $\mathrm{Re}_{2}$ hasta

Sol M, Re M, La M, Mi M, Fa M, Si b M, Do M, La m, Mi m, Si m, Fa \#m, Re m, Sol m

Los anteriores más 3/8, 6/8, 9/8 y 12/8

Afirmación de las anteriores más Fusas

$5^{\mathrm{a}}$ aumentada entre dos notas y entre los extremos de 4 notas, $4^{\mathrm{a}}$ aumentada y $9^{\mathrm{a}}$ menor

Sin acompañamiento. En algunas modula al relativo, y más adelante a algún tono vecino

A-B-C; A-B-A; A-B-A' es la más usada; A-B; A-A'-A', 


\subsubsection{DESCRIPCIÓN DETALLADA DE ESTE SEGUNDO LIBRO.}

Está dedicado este libro a conocer algunas tonalidades, notas muy agudas y muy graves y compases compuestos.

En un principio va agrupando las lecciones por pertenencia a la misma tonalidad.

Tonalidad de Sol mayor:

Escala ascendente y descendente en redondas (sin llegar más que al Mi agudo)

Dos lecciones, la primera en 2/4 en la que indica que es una canción popular; y la segunda que introduce el compás de 3/8 ya con valores de semicorcheas. En el anterior libro varias veces utiliza el párrafo $§$, mal utilizado, como explicamos arriba, y ahora lo emplea también como Da Capo, pero indicando las abreviaturas D. C. Junto al signo $\$$, lo cual es una abundancia de signos de repetición utilizados con el mismo fin y de forma errónea.

\section{Tonalidad de Re mayor:}

Escala ascendente y descendente en redondas.

Tres lecciones en las que comienza con los compases compuestos, primeramente con el de 6/8. La primera exclusivamente con unidades de compás, la segunda con unidades de tiempo y compás y la tercera casi exclusivamente con corcheas (unidades de subdivisión).

\section{Tonalidad de La mayor:}

Escala ascendente y descendente, hasta el fa agudo, utilizando blancas con puntillo.

Tres lecciones, las tres con el compás aprendido anteriormente, la primera combinando corcheas y negras, la segunda semicorcheas casi exclusivamente y la tercera utilizando también corchas con puntillo y síncopas

\section{Tonalidad de Mi mayor:}

Escala ascendente y descendente empleando blancas con puntillo 
Tres lecciones en el compás de 6/8, la primera es, según dice el autor, una canción popular, la segunda utiliza mucho el tresillo de semicorchea en los primeros subtiempos, y la tercera, aunque está en el grupo de la tonalidad de Mi mayor, no está en ella sino en la de Do mayor, y usa mucho el cromatismo.

\section{Tonalidad de Fa mayor:}

Escala ascendente y descendente con blancas con puntillo

Dos lecciones en las que aparece como novedad, dentro de los compuestos, el compás de 9/8. Una primera con unidades de tiempo y compás, y la segunda con unidades de subdivisión mayormente.

\section{Tonalidad de Si bemol mayor:}

Escala ascendente y descendente utilizando blancas con puntillo

Dos lecciones con este compás ya aprendido.

Hay ahora una sección que no es una nueva tonalidad, sino que presenta el compás de $12 / 8$ por primera vez:

Cuatro lecciones en distintas tonalidades. La primera en la que nada más emplea negras, blancas y redondas con puntillos y sigue, como las anteriores en Si bemol mayor; la segunda está en Re mayor, y ya utiliza corcheas; la tercera de nuevo en Si bemol mayor, combinando ya las distintas figuras y la cuarta en Sol mayor empleando ya semicorcheas.

Viene ahora una sección dedicada a aprender a leer las notas representativas de sonidos muy agudos o muy graves.

\section{Lecciones para la práctica de las líneas adicionales superiores:}

Ocho lecciones destinadas a la lectura, a la que vez que entonada, de los sonidos $\mathrm{La}_{5}$ a Sol 6 , teniendo como nota más grave Do ${ }_{4}$. Comienza con blancas y negras, va aumentando progresivamente las dificultades rítmicas, así como las melódicas, sin llegar a verdaderos escollos. Utiliza los compases de 3/4, 2/2 y 2/4, y las tonalidades de Do mayor, Fa mayor, Re mayor, Sol mayor. Dos de ellas, las número 28 y 29, en Fa mayor y Do mayor respectivamente, son canciones populares. 
Lecciones para la práctica de las líneas adicionales inferiores:

Ocho lecciones para la lectura y entonación de los sonidos que van desde el $\operatorname{Re}_{3}$ al $\operatorname{Re}_{2}$, teniendo como nota más aguda $\mathrm{Fa}_{3}$. Igual que en el anterior bloque, empieza con negras y va aumentando con corcheas, semicorcheas y combinaciones. Utiliza los compases de 6/8, 2/4 y 3/8, y las tonalidades de Sol mayor, Do mayor, Fa mayor y Re mayor. Las número 35, 36 y 38, según figura, son canciones populares, y la 40 danza popular.

Empieza ahora una sección, que no anuncia con titulares o epígrafes, o sea no clasifica, de lecciones en clave de Fa en $4^{\mathrm{a}}$ línea

Diez lecciones, utilizando sin orden ni secuencia determinada las tonalidades de Re mayor, Do mayor, Sol mayor, Fa mayor y Mi mayor, y los compases de $6 / 8,4 / 4,2 / 4$ y $3 / 4$. Igual que hace con las anteriores secciones, comienza con muy pocas dificultades rítmico - melódicas y las va aumentando, hasta llegar al tresillo y doble tresillo de semicorchea.

Vuelve ahora a las series de secciones clasificadas por tonalidades, pero ora en modo menor.

\section{Tonalidad de La menor:}

Escala armónica (como hará en todas las siguientes), ascendente y descendente utilizando redondas.

Dos lecciones, la primera en compás de $3 / 8$ en la que ya utiliza tresillos de semicorchea; y la segunda en $2 / 4$, pero complica un poco la rítmica usando tresillos de corchea sincopados.

\section{Tonalidad de Mi menor:}

Escala ascendente y descendente utilizando redondas.

Una sola lección, la más larga, compás de 6/8, tiene como estructura la más utilizada en este método $\mathrm{A}-\mathrm{B}-\mathrm{A}$, pero con subsecciones dentro de cada sección. A tiene a-a'; B b-c-d.

\section{Tonalidad de Si menor:}

Escala ascendente y descendente con redondas. 
Buxó Pujadas, segundo libro

Dos lecciones para trabajar el seisillo de semicorchea. La primera en compás de 3/4, utiliza el seisillo parcialmente, la segunda en 2/4 lo utiliza casi exclusivamente.

$\underline{\text { Tonalidad de Fa sostenido menor: }}$

Escala ascendente y descendente utilizando redondas.

Dos lecciones ambas en $2 / 4$.

\section{Tonalidad de Re menor:}

Escala ascendente y descendente con redondas

Dos lecciones. Una con compás de $2 / 2$, que sigue utilizando el seisillo pero adaptado a este compás. La otra en la que aparecen por primera vez las fusas.

\section{Tonalidad de Sol menor:}

Escala ascendente y descendente con redondas

Una única lección, que tiene 3 secciones distintas en cuanto al ritmo, la primera a base de negras y corcheas, la segunda semicorcheas y fusas y la tercera corcheas con puntillo- semicorcheas. Y es ella la que termina el libro. 


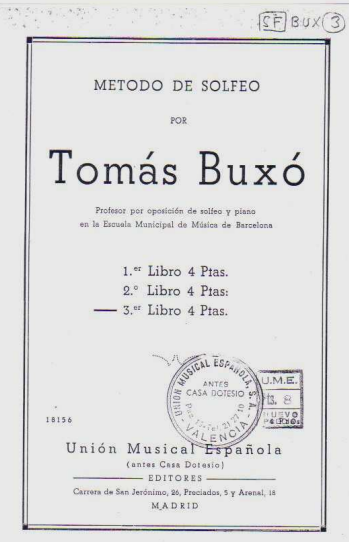

\section{$3^{\circ}$ LIBRO}

\section{CUADRO DE INFORMACIÓN GENERAL DEL TERCER LIBRO.}

$\mathbf{N}^{\circ}$ de lecciones

Extensión de las lec- Desde 8 hasta 253

ciones

Claves empleadas

Tesituras que abarcan $\quad \mathrm{Si}_{2}$ a Sol $_{4}$

Tonalidades que trata Las mismas más Fa m, Do m y Si b m y estudia

Compases que emplea y estudia

Dificultades métricas que contiene

Dificultades de entonación que se encuentran $y$ orden en que se enseñan los intervalos

Armonía utilizada

Formas que tienen las lecciones

Introducciones, Intermedios o Codas instrumentales

Teoría de la música que incluye

\section{2}

Sol, Fa $4^{\mathrm{a}}$, Do $1^{\mathrm{a}}$ y mezcla entre ellas

Los anteriores más 3/2 y 6/4

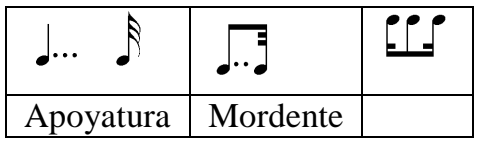

$7^{\mathrm{a}}$ disminuida, $2^{\mathrm{a}}$ aumentada, $3^{\mathrm{a}}$ disminuida, y aunque ya aparecían en el anterior, un uso cada vez más de la $4^{a}$ aumentada. $9^{\mathrm{a}}$ menor y $10^{\mathrm{a}}$ mayor

No tienen ninguna acompañamiento. Ya parece que modulan algunas a tonalidades lejanas

A-B-A'; A-B-C-A

Ninguna posee

No contiene 


\subsubsection{DESCRIPCIÓN DETALLADA DE ESTE TERCER LIBRO.}

Al igual que los anteriores, va agrupando las lecciones bajo algún epígrafe de nuevos conocimientos o formas de estar hechas. En este libro incluye algunas lecciones que son fragmentos de obras de compositores consagrados. Al principio de cada una de ellas figura, o bien T. Buxó cuando son lecciones de él, o el nombre del compositor. ${ }^{1}$

En primer lugar figura la escala cromática con figuras de blancas y redonda para descansar en la mitad y el final.

\section{Doble puntillo:}

Ocho lecciones con esta nueva dificultad rítmica, pero con elementos varios. La primera lleva clave de Fa, tonalidad de La mayor y compás de 4/4, el doble puntillo está añadido a la negra. La siguiente tiene el doble puntillo añadido a la corchea con lo que forma la fórmula rítmica corchea con doble puntillo - fusa, está en Re mayor y lleva el compás de 3/4 y la clave de Sol. La tercera, con la misma clave, está en Fa mayor y compás de compasillo, sin embargo aquí se utiliza muy poco el doble puntillo, se explota mucho más la síncopa breve. A continuación una en compás binario simple, de nuevo clave de Fa, tonalidad de La menor, y con ésta se empieza a utilizar el cambio de tono, pues lo hace a su homónimo mayor en la segunda sección, volviendo al principal al ir a da capo; también es mínimo el empleo del doble puntillo. La quinta sigue con la clave de Fa, compás de compasillo, la misma tonalidad de antes, pero sin cambio; también es poco utilizado el doble puntillo, aunque más que en la anterior. La sexta lección vuelve a la clave de Sol, compás de 2/4, tonalidad de Sol mayor, no aparece en absoluto el doble puntillo, a pesar de estar incluida en ese encabezamiento, si que trata exhaustivamente la síncopa muy breve. Viene otra con la misma clave y compás pero con la tonalidad de Fa mayor; rítmicamente es una mezcla de pasajes tranquilos, otros rítmicos y vuelta al inicial. Y la octava de este epígrafe también está en Fa mayor, y empieza con el mismo compás de 2/4, pero cambia al de 3/4 un solo compás, volviendo al de origen, vuelve a cambiar en el penúltimo compás (iniciando así las lecciones con cambios de compás). La clave que utiliza es Fa y no hay ni un solo doble puntillo. 


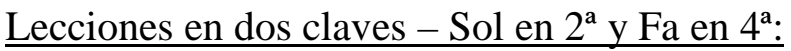

Esta sección comprende 12 lecciones, la mayor parte de ellas fragmentos de compositores consagrados, (que no dice a qué obra pertenecen) y en los que emplea el sistema tan imperante en la época del cambio frecuente y sin sentido de claves. Las lecciones 9 y 10, son del autor, están en Sol mayor y Mi menor respectivamente, y emplea los compases de 2/4 y 3/4 también respectivamente, son de las más cortas del libro. La número 11 es de Wagner, Sol mayor, 4/4; aparece por primera vez, y luego aparecerá más, el silencio de varios compases. La 12 es de Haendel, Si menor y 4/4. La 13 de Mozart, Re mayor, 2/4. Mendelsohn es el autor de la número 14 que está en Fa menor y emplea el compás de 3/8. A Glück le destina la lección 15, 2/4 y La menor. Lección 16 de F. E. Bach que está en la tonalidad de Do menor y en el compás de 3/4. La 17 es de Haydn, La mayor y 2/4. En el lugar 18 pone una nueva lección de él, en la tonalidad de Sol mayor y con el compás de 6/8. En el lugar 19 Locatelli es el compositor de la lección, que está en Do menor y en el compás de 12/8. Y ya la última de esta serie la reserva para J. S. Bach, tonalidad de La mayor y compás de 3/8.

$\underline{\text { Lecciones para la práctica de las líneas adicionales superiores en la clave de } \mathrm{Fa} \text { en } 4^{\mathrm{a}}}$ línea:

Hay ahora una sección, como la tiene el $2^{\circ}$ libro, dedicada a conocer y practicar un poco las notas demasiado agudas y demasiado graves, pero ahora en la clave de Fa. Son 5 lecciones de una dificultad rítmica y melódica sencilla, 2 de ellas canciones populares, una del autor, y las dos últimas son de Glück y Haendel, dedicadas a las notas Do hasta $\mathrm{Si}_{3}$. Tonalidades que emplea La menor, La mayor, Mi bemol mayor y Si menor; y los compases de 3/8, 2/4 y 3/4.

$\underline{\text { Lecciones para la práctica de las líneas adicionales inferiores en la clave de } \mathrm{Fa} \text { en } 4^{\mathrm{a}}}$ línea:

Ahora son 6 lecciones para el estudio de las notas comprendidas desde $\mathrm{Do}_{1} \mathrm{a} \mathrm{Re}_{-1}$, igualmente sencillas, la primera una canción popular, la segunda una danza popular, la tercera de Schumann, las dos siguientes son otras dos canciones populares y la última es del autor. Tonalidades de Sol menor, Fa mayor, Sol mayor y La menor, con los compases de $3 / 4,2 / 2$ y $2 / 4$.

\footnotetext{
${ }^{1}$ Cuando no figura ningún nombre es porque son del autor del libro, cuando es un compositor distinto lo
} 
Buxó Pujadas, tercer libro

Compás de tres por dos:

Dos lecciones de Haendel en Fa mayor y Sol menor, en este compás, utilizando casi exclusivamente blancas, negras y redondas.

De la clave de Do en $1^{\text {a }}$ línea:

Nombre de las notas en las líneas y en los espacios, seguidos de una escala de lectura en esta clave desde el $\mathrm{Si}_{2}$ hasta el $\mathrm{Si}_{4}$

Siete lecciones en las que entra de forma muy suave en el conocimiento de la nueva clave, o sea con unas figuración sencilla, para ir poco a poco complicándola. Hay cuatro canciones populares, una de Mehul, otra del autor y la última de Rameau. Tonalidades de Fa mayor, Do mayor, Re mayor, La mayor, Mi menor y Sol mayor; compases de $3 / 4,4 / 4,6 / 8$ y $2 / 4$.

\section{Compás de seis por cuatro:}

Dos lecciones en este compás y siguiendo con la misma clave, la primera en Si menor, que es del autor, y la segunda en Mi menor siendo su autor Bach.

\section{Apoyaturas:}

Cuatro lecciones. La primera es un minueto de Bach, en Re mayor compás de 3/4, y la segunda es una Gavotta también de Bach, en Do mayor y 4/4; pero la tercera, que es una Mazurka de Chopin, en Si bemol menor y 3/4, ya no tiene apoyaturas, sino mordentes, cosa que el autor no separa ni distingue, y la cuarta es del propio autor, también con mordentes, en la tonalidad de Mi bemol mayor y compás de 2/4.

\section{Lecciones en tres claves - Sol en $2^{\mathrm{a}}, \mathrm{Fa}$ en $4^{\mathrm{a}}$ y Do en $1^{\mathrm{a}}$ :}

Termina el libro con 6 lecciones dedicadas a esta costumbre de la época del cambio frecuentísimo de claves, entre las 3 que ha dado a conocer, al menos no complica este obstáculo con dificultades métricas. Utiliza las tonalidades de Do mayor, Fa mayor, Sol mayor, Re mayor y Si menor; los compases de 3/4, 12/8, 6/8 y 3/8. Son lecciones bastante largas y cada una de un autor: Carissimi, Mendelsohn, Buxó, Mozart, Bach y la última del autor, la más larga y en la que también cambia de tonalidad y de compás hacia la mitad de la lección.

hacemos constar. 


\subsubsection{VALORACIÓN DE LA EFECTIVIDAD DEL MÉTODO Y DE SU APORTACIÓN A LA ENSEÑANZA.}

El primer libro está muy en la línea de los métodos de esa época en cuanto a poca preparación o insistencia en las dificultades iniciales. Aborda demasiado pronto el contratiempo de corchea.

Es muy técnico, pero sus melodías son poco agradables.

Tiene una buena progresión en la aparición de las dificultades métricas, y hay abundante práctica de los intervalos.

Cada vez que presenta un nuevo compás, vuelve a las figuras iniciales y escalona las dificultades, lo mismo cuando aparecen las alteraciones. No así en el apartado de la clave de $\mathrm{Fa}$ en $4^{\mathrm{a}}$, que hay demasiado apresuramiento en aumentar las dificultades.

Tampoco comprendemos a qué viene poner algunas lecciones en las tonalidades de Re M, Sol M, Mi m y Fa M, sin haber explicado las tonalidades, y siendo que de ellas se trata en el siguiente libro.

Encontramos en el segundo libro un vacío de ejercicios rítmicos y de entonación.

No obstante la presentación de las distintas tonalidades la hace sin adentrar demasiado en dificultades rítmico - melódicas, lo cual es beneficioso para el educando, pues es como un repaso de lo anterior, más con las alteraciones propias de cada tonalidad.

La presentación de tonalidades y compases es lógica.

Es muy útil, y poco común, la sección que tiene este segundo libro de lecciones con notas muy por debajo y por encima del pentagrama, que, aunque cantadas octava baja o alta, adiestran al alumno en la lectura de estas notas, cuestión casi siempre eludida.

En el tercer libro está muy bien utilizar canciones, danzas populares, y fragmentos de obras de compositores célebres como lecciones de solfeo, al menos son melodías más atrayentes, aunque no son precisamente las célebres las obras, sino sus compositores.

La sección dedicada a la práctica de las notas agudas de la clave de Fa no parece demasiado práctica, habida cuenta de que tales notas se suelen escribir en la clave de 
Buxó Pujadas, tercer libro

Sol; más útil quizás sean las notas graves de esta clave, aunque también en la práctica se leen utilizando el recurso " 8 a baja".

Muy progresiva la entrada de una nueva clave, aunque no comprendemos por qué ésta y no cualquier otra de las de Do, y por qué no se ven el resto de claves, siendo que ya no hay más libros.

Este tercer nivel se queda corto, omite parte de las notas de adorno también.

En general el método sirve, pero no mucho. 
-4 -

D I S C U S I Ó N 
En este capítulo agrupamos los resultados a que nos han llevado los patrones de comparación, por un lado el de comparar cada método con los programas vigentes en el momento de su edición y por otro cotejándolo con los parámetros y progresiones que consideramos idóneos para el proceso actual de enseñanza/aprendizaje.

De manera que, repartidos en 4 grupos, según la división de épocas que hemos establecido, aparecen, por cada método y parte, dos análisis: el primero se refiere a su GRADO DE AJUSTE CON LOS PROGRAMAS VIGENTES EN EL MOMENTO, y el segundo representa el GRADO DE AJUSTE CON LOS PROCEDIMIENTOS ACTUALES DE ENSEÑANZA/APRENDIZAJE. Todos ellos en el mismo orden que en el punto 3.

En los primeros libros, debido a su antigüedad, solamente se hacen comentarios, pues ni tan siquiera disponemos de programas con los que compararlos, y a partir del método de Reguart, la tabla del GRADO DE AJUSTE CON LOS PROCEDIMIENTOS ACTUALES DE ENSEÑANZA/APRENDIZAJE, se configura en 6 elementos, correspondientes a las categorías que se analizan y en el orden que siempre se exponen: Claves, Tesituras, Tonalidades, Compases, Dificultades métricas y Dificultades melódicas, habiendo una última línea para resumir la cantidad de elementos coincidentes. Desde el método de Pérez Gascón, también la tabla GRADO DE AJUSTE CON LOS PROGRAMAS VIGENTES EN EL MOMENTO, queda configurada de la misma manera.

\section{MÉTODOS ANTERIORES A 1831}

\section{CARRERA}

GRADO DE AJUSTE CON LOS PROGRAMAS VIGENTES EN EL MOMENTO.

Todavía no existían referencias a los contenidos de esta asignatura, no obstante comprándolos con los que veremos de los años 1831 y 32, encaja con los contenidos de la teoría, con la enseñanza del transporte y con la utilización de todas las claves, aunque ya lo hace en el primer curso, y en los programas del 31 es en segundo curso. No encaja con la recomendación de practicar entonación de intervalos, que aquí no la hay.

GRADO DE AJUSTE CON LOS PROCEDIMIENTOS ACTUALES DE ENSEÑANZA/APRENDIZAJE DEL SOLFEO

Ninguno. No puede estar más en desacuerdo con la forma y la progresión de los elementos que es deseable para un aprendizaje accesible, empezando por las claves, 
siguiendo por la tesitura desbordada, tampoco el orden de aparición de las tonalidades es el idóneo, el comienzo con el compás binario simple (lo que veremos luego que hacen muchos) no es nada recomendable, y las dificultades métricas aparecen amontonadas y sin ninguna lógica

\section{LÓPEZ REMACHA}

GRADO DE AJUSTE CON LOS PROGRAMAS VIGENTES EN EL MOMENTO.

$\mathrm{Al}$ igual que en el método anterior, de Carrera, no había programas ni Conservatorio. Si comparamos a los de los años 1831 y 32, encaja con la teoría, con la enseñanza de todas las claves, aunque lo hace presentando todas en un curso, con la enseñanza del transporte y con la práctica de todos los intervalos.

GRADO DE AJUSTE CON LOS PROCEDIMIENTOS ACTUALES DE ENSEÑANZA/APRENDIZAJE DEL SOLFEO

Exceptuando las primeras claves, Sol y Fa en $4^{\mathrm{a}}$, y las primeras tonalidades, Do mayor y La menor, el resto no tiene nada que ver con los parámetros y gradaciones que consideramos idóneos para el aprendizaje

\section{GOMIS}

GRADO DE AJUSTE CON LOS PROGRAMAS VIGENTES EN EL MOMENTO.

Todavía no tenemos programas de la época de su edición para poder comparar su contenido, no obstante encaja con la utilización de todas las claves, pero como los demás, las presenta todas de golpe, y con los contenidos teóricos. No habla del transporte, y está totalmente de acuerdo con la práctica, no intensa, sino intensísima de los intervalos.

\section{GRADO DE AJUSTE CON LOS PROGRAMAS VIGENTES EN EL MO-} MENTO.

Claves

Tesituras

Tonalidades

Compases

Dificultades métricas
Ninguna, excepto, claro está, la primera

No. Más extensa en lo agudo de lo óptimo

Correcto el orden. Se queda cortísimo en la cantidad

Ninguno, no es el orden idóneo

Casi todas si lo consideramos un método de $1^{\circ}$ y $2^{\circ}$ nivel, a excepción de la redonda, que Gomis pone la primera. 
Dificultades melódicas Ninguna

Cantidad de elementos

que encajan

Dos: orden de las tonalidades y de las figuras.

\section{MÉTODOS POSTERIORES A LA FUNDACIÓN DEL RCSMM}

\section{REGUART}

GRADO DE AJUSTE CON LOS PROGRAMAS VIGENTES EN EL MOMENTO.

Coincide con la enseñanza de la teoría, con la de las claves todas, aunque en este libro sea en un solo curso. No coincide con la enseñanza del transporte ni con la práctica de intervalos que aquí no existe.

GRADO DE AJUSTE CON LOS PROCEDIMIENTOS ACTUALES DE ENSEÑANZA/APRENDIZAJE DEL SOLFEO

Claves

Tesituras

Tonalidades

Compases

Dificultades métricas

Dificultades melódicas

Cantidad de elementos

que encajan
Ninguno

No. Exceden con mucho la posibilidad de un/a joven

No. No se estudia ninguna del modo menor

Excepto comenzar con 4/4, podría ser un orden aceptable

Ninguna

Ninguna

Solamente 1. El orden de los compases, y tampoco completamente

\section{ESLAVA}

GRADO DE AJUSTE CON LOS PROGRAMAS VIGENTES EN EL MOMENTO.

De lo poco que se deduce de los documentos arriba expuestos en cuanto a programación, cumple con todos los contenidos, exceptuando que la enseñanza de las claves la hace de forma progresiva, y no agrupadas todas en el $2^{\circ}$ curso. Pero además añade muchísimos contenidos, y los distribuye adecuadamente entre sus diversas partes, de forma que marca un antes y un después. 
GRADO DE AJUSTE CON LOS PROCEDIMIENTOS ACTUALES DE ENSEÑANZA/APRENDIZAJE DEL SOLFEO

Claves

Tesituras

Tonalidades

Compases

Dificultades métricas

Dificultades melódicas

Cantidad de elementos que encajan
En $1^{\circ}$ y $2^{\circ}$ sí. El resto no es el orden más lógico

En $1^{\circ}$ y $2^{\circ}$ son demasiado agudas. En $3^{\circ}$ y siguientes coincide con nuestra propuesta, aunque se queda corto por el registro grave

Sí

En $1^{\circ}$ y $2^{\circ}$ no. En las siguientes partes sí Igual que arriba Igual que arriba

Cuatro en la mitad de contenidos y uno en su totalidad

\section{SOBEJANO}

GRADO DE AJUSTE CON LOS PROGRAMAS VIGENTES EN EL MOMENTO.

Con el que tomamos como existente del año 1831, sólo coincide con la práctica de intervalos. No habla del transporte ni del dictado musical; y las claves, sabiamente, no las agrupa todas en el segundo curso.

Tiene una similitud con el programa desarrollado por Eslava en el primer curso, en cuanto a la clave, la tonalidad y casi las dificultades métricas. No tiene ya ningún parecido con este método el resto de cursos

GRADO DE AJUSTE CON LOS PROCEDIMIENTOS ACTUALES DE ENSEÑANZA/APRENDIZAJE DEL SOLFEO

Claves

Tesituras

Tonalidades

Compases

Dificultades métricas

Dificultades melódicas

Cantidad de elementos que encajan
La primera parte sí, también la $2^{\mathrm{a}}$, no la $3^{\mathrm{a}}$

Ninguna. La primera muy aguda, y las otras dos agudísimas

Sí la primera parte. No las otras dos

Ninguno se ajusta

Ninguna se ajusta

Ninguna se ajusta

Dos y parcialmente

\section{ALIAGA}

GRADO DE AJUSTE CON LOS PROCEDIMIENTOS ACTUALES DE ENSEÑANZA/APRENDIZAJE DEL SOLFEO 
Desde luego con los programas provenientes del 31 , no tiene nada que ver, y con el que origina el método de Eslava tampoco. Es un desarrollo totalmente personal.

GRADO DE AJUSTE CON LOS PROCEDIMIENTOS ACTUALES DE ENSEÑANZA/APRENDIZAJE DEL SOLFEO

Claves

Tesituras

Tonalidades

Compases

Dificultades métricas

Dificultades melódicas

Cantidad de elementos

que encajan
Sí (las 2 primeras)

No, demasiado extensas

No

No

No

No

Una y parcialmente

\section{PÉREZ GASCÓN}

PRINCIPIOS DE SOLFEO Y CANTO

\section{GRADO DE AJUSTE CON LOS PROGRAMAS VIGENTES EN EL MO-} MENTO.

Con el programa que se deduce del año 1831, ninguna similitud o afinidad.

Con el programa que se desprende del método de Eslava, y atendiendo a que este método viene a ser la unión de 2 cursos, las coincidencias y diferencias son:

Claves

Tonalidades

Compases

Dificultades métricas

Dificultades melódicas

Cantidad de elementos que encajan
Coincide casi. Aquí se estudian Sol, $\mathrm{Fa} 4^{\mathrm{a}}$ y Do $1^{\mathrm{a}}$, y en Eslava las mismas más Do $2^{\mathrm{a}}$

Aparecen en el mismo orden que las 10 primeras en Eslava

Coinciden en los simples y compuestos más utilizados, a excepción del orden, que en Eslava aparece 2/4 antes que $3 / 4$, y en éste al revés

Coinciden las primeras figuras, hasta la blanca con puntillo. Después el orden de enseñanza no es el mismo, y este método abarca muchas menos dificultades métricas

Es similar a la progresión de Eslava, pero no se produce aquí el estudio del intervalo de $8^{\mathrm{a}}$ después del de $5^{\mathrm{a}}$, sino que sigue el orden numérico

Cinco pero no en su totalidad 
GRADO DE AJUSTE CON LOS PROCEDIMIENTOS ACTUALES DE ENSEÑANZA/APRENDIZAJE DEL SOLFEO

Claves

Tesituras

Tonalidades

Compases

Dificultades métricas

Dificultades melódicas

Cantidad de elementos que encajan
Sólo en las dos primeras, Sol y

$\mathrm{Fa} 4^{\mathrm{a}}$

Son demasiado agudas desde un principio

No es el mejor orden, aunque es similar

No es el orden adecuado

No es el orden adecuado

No es el orden adecuado

1 y no completamente

MÉTODO DE SOLFEO Y PRINCIPIOS DE CANTO

GRADO DE AJUSTE CON LOS PROGRAMAS VIGENTES EN EL MOMENTO.

Al programa de 1831 solamente se asemeja en la práctica intensiva de todos los intervalos.

Analizamos si tiene alguna similitud con Eslava, encontrando las siguientes:

Claves

Tonalidades

Compases

Dificultades métricas

Dificultades melódicas

Cantidad de elementos que encajan
Coincide en el orden, pero aquí se enseñan menos claves Coinciden casi totalmente. Hay algún pequeño cambio en el orden

Hasta el de 12/8, todo igual, excepto un cambio de orden: el de $3 / 4$, que en este método, aparece antes del de $2 / 4$, y en Eslava, lógicamente, no

Hasta la negra coinciden. Después no. Trata las mismas dificultades, excepto que de las notas de adorno sólo trata la apoyatura, pero en distinto orden, y no llega hasta la semifusa

No coinciden. Aquí la progresión es mucho más pedagógica y completa

Dos casi, uno al $50 \%$ y un tercero en parte

GRADO DE AJUSTE CON LOS PROCEDIMIENTOS ACTUALES DE ENSEÑANZA/APRENDIZAJE DEL SOLFEO.

Claves

Tesituras
Sólo las dos primeras

No. Son muy agudas y desde un principio 
Tonalidades

Compases

Dificultades métricas

Dificultades melódicas

Cantidad de elementos

que encajan
Casi todas

No

No

No del todo, pero hay más coincidencias que con los anteriores

\section{PRELLEZO}

\section{GRADO DE AJUSTE CON LOS PROGRAMAS VIGENTES EN EL MOMENTO.}

Un método tan extraño, lógicamente no se adapta ni se aproxima a ningún programa existente; solamente si lo comparamos al método de Eslava, el orden de aprendizaje de los compases coinciden.

GRADO DE AJUSTE CON LOS PROCEDIMIENTOS ACTUALES DE ENSEÑANZA/APRENDIZAJE DEL SOLFEO.

Claves

Tesituras

No, además, no las practica

Tonalidades

No, son demasiado agudas y graves

Compases

No

No

Dificultades métricas No

Dificultades melódicas No

Cantidad de elementos

que encajan

\section{Ninguna}

\section{VALERO Y ROMERO}

\section{GRADO DE AJUSTE CON LOS PROGRAMAS VIGENTES EN EL MOMENTO.}

De la primera parte:

No encaja con casi nada. Solamente comparándolo con el de Eslava, coinciden las Claves y las Tonalidades.

\section{De la segunda parte:}

Comparándolo con el de Eslava, único existente en el momento, no tiene ningún punto de conexión. 
GRADO DE AJUSTE CON LOS PROCEDIMIENTOS ACTUALES DE ENSEÑANZA/APRENDIZAJE DEL SOLFEO.

De la primera parte:

Claves

Tesituras

Tonalidades

Compases

Dificultades métricas

Dificultades melódicas

Cantidad de elementos

que encajan

De la segunda parte:

Claves

Tesituras

Tonalidades

Compases

Dificultades métricas

Dificultades melódicas

Cantidad de elementos

que encajan
Sí

No, es muy aguda

Sí

No

No

No

Dos

\section{FUNOLL}

GRADO DE AJUSTE CON LOS PROGRAMAS VIGENTES EN EL MOMENTO.

Como seguimos sin tener programas vigentes en el momento, sólo podemos compararlo al supuesto que venimos arrastrando de 1831, al que no se parece en nada; sin embargo si lo comparamos con el método de Eslava, ya tiene algún parecido: La clave que trata Eslava en primer curso es solamente la de Sol, éste también; las tonalidades en Eslava son Do mayor y La menor, y aquí solamente Do mayor; en cuanto a los compases que enseña Eslava y las dificultades rítmicas, no son exactas, pero tienen cierto parecido, solamente hay algún cambio en el orden de presentarlas; finalmente en las dificultades melódicas también se parecen un poco, aunque en el Eslava hay mayor cantidad de intervalos estudiados y practicados.

GRADO DE AJUSTE CON LOS PROCEDIMIENTOS ACTUALES DE ENSEÑANZA/APRENDIZAJE DEL SOLFEO.

Claves

Tesituras

\section{Sí}

No, un poco aguda 
Tonalidades Sí

Compases No

Dificultades métricas No

Dificultades melódicas No

Cantidad de elementos

que encajan Dos

\section{CALVÓ}

GRADO DE AJUSTE CON LOS PROGRAMAS VIGENTES EN EL MOMENTO.

Con las normas para examen de 1831, se asimilan la teoría y la inclusión del transporte. Con el método Eslava, coinciden bastantes más cosas: El orden y aparición de las claves, las tonalidades, y los compases, excepto el orden inicial. Ya no coinciden las dificultades rítmicas, que aquí hay menos combinaciones rítmicas, y tampoco el orden de aparición es igual. El tratamiento de los intervalos no tiene que ver con Eslava.

GRADO DE AJUSTE CON LOS PROCEDIMIENTOS ACTUALES DE ENSEÑANZA/APRENDIZAJE DEL SOLFEO.

Claves

$\mathrm{Si}$

Tesituras

Sí

Tonalidades

No

Compases

No

Dificultades métricas No

Dificultades melódicas No

Cantidad de elementos Dos

que encajan

\section{MANENT}

GRADO DE AJUSTE CON LOS PROGRAMAS VIGENTES EN EL MOMENTO.

Con el libro de Eslava no coincide en nada.

GRADO DE AJUSTE CON LOS PROCEDIMIENTOS ACTUALES DE ENSEÑANZA/APRENDIZAJE DEL SOLFEO.

Claves

Tesituras

Tonalidades

Compases

Dificultades métricas

Dificultades melódicas
No

No, muy aguda

No

Al principio sí, o sea el primero, el resto no.

Las 3 primeras sí, luego no

No 
Cantidad de elementos Una pequeña porción de dos que encajan

\section{MÉTODOS POSTERIORES A 1861}

\section{LLADÓ}

GRADO DE AJUSTE CON LOS PROGRAMAS VIGENTES EN EL MOMENTO.

Claves

Tesituras

Tonalidades

Compases

Dificultades métricas

Dificultades melódicas

Cantidad de elementos que encajan
No, sólo emplea la de Sol

Sí en la primera parte y No en la segunda por ser muy aguda y muy grave

No, emplea todas muy pronto, y en un orden no adecuado

No, el orden no es el mismo

No, el orden es distinto y poco pedagógico

No, apenas trata la entonación

Solamente la tesitura en la primera parte del método

GRADO DE AJUSTE CON LOS PROCEDIMIENTOS ACTUALES DE ENSEÑANZA/APRENDIZAJE DEL SOLFEO.

Claves

Tesituras

Tonalidades

Compases

Dificultades métricas

Dificultades melódicas

Cantidad de elementos

que encajan
No

No, muy agudas

No, orden no adecuado

No

No

No

Ninguno

\section{ARRIETA}

GRADO DE AJUSTE CON LOS PROGRAMAS VIGENTES EN EL MOMENTO.

Del primer año

Claves

Tesituras

Tonalidades

Compases

Dificultades métricas

Dificultades melódicas
Sí

Casi, aunque se queda un poco corta por arriba

Sí

Sí, aunque lógicamente no el orden de aparición

Están dentro del programa

Idem, aunque, al igual que las anteriores, no aparecen en el orden del programa porque no es un método didáctico 
Cantidad de elementos Todos

que encajan

Del segundo año

Claves

Tesituras

No

Tonalidades

Sí

Compases

No, sólo hay alguna

Dificultades métricas

No

Dificultades melódicas

Sí

Sí

Cantidad de elementos Tres

que encajan

\section{$\underline{\text { Del tercer año }}$}

Claves

Tesituras

Tonalidades

Compases

Dificultades métricas

Dificultades melódicas

Cantidad de elementos

que encajan
Sí, excepto que Do en $3^{\mathrm{a}}$ no aparece en todo el libro

Sí

Algunas, no el orden por sus características

No

No

Solamente las dobles alteraciones

Dos, una no del todo, y parte de otra

Del concurso, primer libro

Lógicamente no encaja con ningún programa, puesto que no es un método, sino una recopilación. No obstante en las dificultades métricas y melódicas más avanzadas, se asimila al programa vigente (Eslava) en el tercer curso.

GRADO DE AJUSTE CON LOS PROCEDIMIENTOS ACTUALES DE ENSEÑANZA/APRENDIZAJE DEL SOLFEO.

Del primer año

Claves

Tesituras

Tonalidades

Compases

Dificultades métricas

Dificultades melódicas

Cantidad de elementos

que encajan
Sí

No, un poco aguda

Sí

Casi, si unimos parte del $2^{\circ}$ curso con el $1^{\circ}$

No, demasiada dificultad

Idem

Dos y casi un tercero 
Discusión

$\underline{\text { Del segundo año }}$

Claves

No

Tesituras

No, demasiado agudas y graves

Tonalidades

Casi todas

Compases

Sí

Dificultades métricas

Algunas

Dificultades melódicas

Solamente la $2^{\mathrm{a}}$ aumentada

Cantidad de elementos

que encajan

Una y parte de otras dos

$\underline{\text { Del tercer año }}$

Claves

No

Tesituras

Sí

Tonalidades

Compases

Dificultades métricas

No

Solamente el de $5 / 8$ y los cambios de compás

No

Dificultades melódicas

No

Cantidad de elementos Una y una pequeña parte de otra.

que encajan

Del concurso, primer libro

No procede la comparación por el tipo de libro que es.

\section{OBIOLS}

GRADO DE AJUSTE CON LOS PROGRAMAS VIGENTES EN EL MOMENTO.

Claves

Tesituras

Tonalidades

Compases

Dificultades métricas

Dificultades melódicas

Cantidad de elementos

que encajan
No, además el orden es de lo más extraño

Sí

No, es un raro orden

No

No

No

Uno

\section{ZA/APRENDIZAJE DEL SOLFEO.}

Claves

No

Tesituras

Sí 
Tonalidades No

Compases No

Dificultades métricas No

Dificultades melódicas No

Cantidad de elementos Uno

que encajan

\section{MORÉ Y GIL}

GRADO DE AJUSTE CON LOS PROGRAMAS VIGENTES EN EL MOMENTO.

De la primera parte

Claves

Tesituras

Tonalidades

Compases

Dificultades métricas

Dificultades melódicas

Cantidad de elementos

que encajan

De la segunda parte

Claves

Tesituras

Tonalidades

Compases

Dificultades métricas

Dificultades melódicas

Cantidad de elementos

que encajan

$\underline{\text { De la tercera parte }}$

Claves

Tesituras

Tonalidades

Compases

Dificultades métricas

Dificultades melódicas

Cantidad de elementos

que encajan
Sí

No, se quedan un poco bajas

No, por que no se ve la de La menor

Casi, pero aquí no se incluye el de $2 / 2$

No

No

Una, y casi otra más
No, faltan Do en $1^{\mathrm{a}}$ y $2^{\mathrm{a}}$

No, por bajo es muy grave

Sí

Solamente en los compuestos más usados

No, aquí son mayores

No

Una y parte de otra

No, dos de ellas debieron de tratarse en la $2^{\mathrm{a}}$ parte

Sí

Sí

No

No

Sí

Tres 
De la cuarta parte

Al no tener cuarta parte el programa de Eslava, no podemos compararlo. Lo único que se asimila son los compases irregulares y el estudio de la fermata, que aparecen al final de la tercera parte de Eslava.

No obstante, no es de extrañar que no se adapte en su totalidad al programa establecido hasta entonces con arreglo al método Eslava, ya que este método se convirtió en programa oficial a partir de 1875 .

GRADO DE AJUSTE CON LOS PROCEDIMIENTOS ACTUALES DE ENSENAANZA/APRENDIZAJE DEL SOLFEO.

De la primera parte

Considerando como primera parte, las que figuran en nuestros parámetros como secuencia 1 y 2 juntas.

Claves

Tesituras

Tonalidades

Compases

Dificultades métricas

Dificultades melódicas

Cantidad de elementos

que encajan
No

No, un poco aguda

No

No

No, pero se parecen más que al programa existente

No

Ninguna

$\underline{\text { De la segunda parte }}$

Considerando como segunda parte, las que figuran en nuestros parámetros como secuencias 3 y 4 juntas.

Claves

Tesituras

Tonalidades

Compases

Dificultades métricas

Dificultades melódicas

Cantidad de elementos

que encajan

De la tercera parte

Comparándolo con nuestra secuencia 5

Claves

Tesituras
No

Sí
No

Sí

Casi todas

Sí en los más usados

Casi, aunque aquí son mayores

No, se queda corto

Uno y parte de dos 
Tonalidades

Compases

Dificultades métricas

Dificultades melódicas

Cantidad de elementos

que encajan

$\underline{\text { De la cuarta parte }}$

Solamente el estudio de los compases irregulares encaja con nuestros parámetros en sexta secuencia.

\section{MÉTODOS POSTERIORES A 1875, 1876, 1891 Y 1898}

\section{ABRANTES}

$\underline{\text { De la primera parte }}$

GRADO DE AJUSTE CON LOS PROGRAMAS VIGENTES EN EL MOMENTO.

Claves

Tesituras

No

Tonalidades

No

Compases

Sí

No

Dificultades melódicas No

Cantidad de elementos Uno

que encajan

\section{De la segunda parte}

Claves

Tesituras

No

Tonalidades

Sí

Compases

No

Dificultades métricas No

Dificultades melódicas No

Cantidad de elementos Una que encajan
Sí, aunque aquí hay más que debieron verse en la anterior parte

No, aquí están más rebajadas

Tres 
De la tercera parte

Como esta parte no es más que teoría, lógicamente no puede encajar con ningún programa.

GRADO DE AJUSTE CON LOS PROCEDIMIENTOS ACTUALES DE ENSEÑANZA/APRENDIZAJE DEL SOLFEO.

De la primera parte

Tomando esta primera parte como secuencias 1 y 2

Claves

Sí

Tesituras

No

Tonalidades No

Compases No

Dificultades métricas $\quad$ No

Dificultades melódicas $\quad$ No

Cantidad de elementos Uno

que encajan

$\underline{\text { De la segunda parte }}$

Considerando $2^{\mathrm{a}}$ parte como secuencias 3 y 4

Claves

No

Tesituras

No

Tonalidades $\quad$ No

Compases No

Dificultades métricas No

Dificultades melódicas No

Cantidad de elementos Ninguna

que encajan

De la tercera parte

De cualquier manera, como no es un método para la enseñanza profesional, no puede acoplar con programa alguno existente, ni con planteamientos reglados.

\section{PENELLA}

GRADO DE AJUSTE CON LOS PROGRAMAS VIGENTES EN EL MOMENTO.

Claves

Tesituras

Tonalidades

Compases

Dificultades métricas
No

Sí

No

No

Al principio, y hasta la síncopa larga, casi, después no 
Dificultades melódicas No

Cantidad de elementos Uno, y parte de otro que encajan

GRADO DE AJUSTE CON LOS PROCEDIMIENTOS ACTUALES DE ENSEÑANZA/APRENDIZAJE DEL SOLFEO.

$\begin{array}{ll}\text { Claves } & \text { Sí } \\ \text { Tesituras } & \text { No } \\ \text { Tonalidades } & \text { Sí } \\ \text { Compases } & \text { No } \\ \text { Dificultades métricas } & \text { No } \\ \text { Dificultades melódicas } & \text { No }\end{array}$

Cantidad de elementos Dos que encajan

\section{De BENITO}

$\underline{\text { De la parte primera }}$

GRADO DE AJUSTE CON LOS PROGRAMAS VIGENTES EN EL MOMENTO.

Claves

Tesituras

Tonalidades

Compases

Dificultades métricas

Dificultades melódicas

Cantidad de elementos que encajan

De la parte segunda

Claves

Tesituras

Tonalidades

Compases

Dificultades métricas

Dificultades melódicas

Cantidad de elementos que encajan
No

Sí

No

No

No

Sí en los intervalos, no en los semitonos

Una y parte de otra

No

$\mathrm{Si}$

No

No

No

Sí, excepto enarmonías

Dos 
GRADO DE AJUSTE CON LOS PROCEDIMIENTOS ACTUALES DE ENSEÑANZA/APRENDIZAJE DEL SOLFEO.

De la parte primera

$\begin{array}{ll}\text { Claves } & \text { No } \\ \text { Tesituras } & \text { No } \\ \text { Tonalidades } & \text { No } \\ \text { Compases } & \text { No } \\ \text { Dificultades métricas } & \text { No } \\ \text { Dificultades melódicas } & \text { No }\end{array}$

Cantidad de elementos Ninguna

que encajan

De la parte segunda

$\begin{array}{ll}\text { Claves } & \text { No } \\ \text { Tesituras } & \text { No } \\ \text { Tonalidades } & \text { No } \\ \text { Compases } & \text { No } \\ \text { Dificultades métricas } & \text { No } \\ \text { Dificultades melódicas } & \text { No } \\ & \\ \text { Cantidad de elementos } & \text { Ninguna } \\ \text { que encajan } & \end{array}$

\section{De EGEA}

GRADO DE AJUSTE CON LOS PROGRAMAS VIGENTES EN EL MOMENTO.

Claves

Tesituras

Tonalidades

Compases

Dificultades métricas

Dificultades melódicas

Cantidad de elementos

que encajan
No

No, muy aguda

No, el orden no puede ser más extraño, y el modo menor solamente se estudia con La menor

No

No

Sí

Uno

GRADO DE AJUSTE CON LOS PROCEDIMIENTOS ACTUALES DE ENSEÑANZA/APRENDIZAJE DEL SOLFEO.

Claves No

Tesituras

No

Tonalidades

No 
Compases No

Dificultades métricas No

Dificultades melódicas No

Cantidad de elementos Ninguno

que encajan

\section{SABATÉS}

GRADO DE AJUSTE CON LOS PROGRAMAS VIGENTES EN EL MOMENTO.

Del volumen I

Claves

Tesituras

Tonalidades

Compases

Dificultades métricas

Dificultades melódicas

Cantidad de elementos

que encajan

\section{De la segunda parte}

Claves

Tesituras

Tonalidades

Compases

Dificultades métricas

Dificultades melódicas

Cantidad de elementos

que encajan

$\underline{\text { De la tercera parte }}$

Claves

Tesituras

Tonalidades

Compases

Dificultades métricas

Dificultades melódicas

Cantidad de elementos

que encajan
Sí

Sí, aunque alguna lección sobrepasa el $\mathrm{Mi}_{4}$

Sí

No

No, se queda muy corto

Sí

Cuatro

No

Sí

No, se queda corto

No

No

No

Uno

No

No

No

No

No

Sí

Uno 
Discusión

GRADO DE AJUSTE CON LOS PROCEDIMIENTOS ACTUALES DE ENSEÑANZA/APRENDIZAJE DEL SOLFEO.

Del volumen I

Claves

Sí

Tesituras

Sí

Tonalidades

Sí

Compases

No

Dificultades métricas No

Dificultades melódicas No

Cantidad de elementos Tres

que encajan

$\underline{\text { De la segunda parte }}$

Claves

Sí

Tesituras

Sí

Tonalidades

No

Compases

No

Dificultades métricas No

Dificultades melódicas No

Cantidad de elementos Dos

que encajan

$\underline{\text { De la tercera parte }}$

Claves

Tesituras

No

Tonalidades

No

Compases

No

Dificultades métricas

Cantidad de elementos Ninguna

que encajan

\section{AGERO}

GRADO DE AJUSTE CON LOS PROGRAMAS VIGENTES EN EL MOMENTO.

De la primera parte

Claves

Tesituras

Tonalidades

Compases

Dificultades métricas

Dificultades melódicas
Sí

No, un poco aguda

No

No

No

No 
Cantidad de elementos Una

que encajan

$\underline{\text { De la segunda parte }}$

Claves

Sí

Tesituras

Sí

Tonalidades

No

Compases

Casi, sobra el de $2 / 2$ que debería ir en la $1^{a}$ parte

Dificultades métricas No

Dificultades melódicas

No

Cantidad de elementos

que encajan

Dos y parte de una

De la tercera parte

Claves

Sí

Tesituras

No

Tonalidades

No

Compases

No

Dificultades métricas No

Dificultades melódicas No

Cantidad de elementos Una

que encajan

GRADO DE AJUSTE CON LOS PROCEDIMIENTOS ACTUALES DE ENSEÑANZA/APRENDIZAJE DEL SOLFEO.

De la primera parte

Claves

Sí

Tesituras

No

Tonalidades

No

Compases

No

Dificultades métricas

No

Dificultades melódicas

No

Cantidad de elementos que encajan

Uno

$\underline{\text { De la segunda parte }}$

Claves

No

Tesituras

No

Tonalidades

No

Compases

No

Dificultades métricas

No

Dificultades melódicas

No 
Cantidad de elementos que enca- Ninguno jan

De la tercera parte

Claves No

Tesituras

Sí

Tonalidades

No

Compases

No

Dificultades métricas No

Dificultades melódicas No

Cantidad de elementos Una

que encajan

\section{LLUPART}

GRADO DE AJUSTE CON LOS PROGRAMAS VIGENTES EN EL MOMENTO.

No encaja con ningún programa por que no es un método para el aprendizaje progresivo de elementos, si no un complemento para el canto coral que reúne elementos de los 3 cursos, entonces en vigencia, sin extremar las dificultades, a fin, seguramente, de no entorpecer el ya dificultoso canto a varias voces.

GRADO DE AJUSTE CON LOS PROCEDIMIENTOS ACTUALES DE ENSEÑANZA/APRENDIZAJE DEL SOLFEO.

Por el mismo motivo, no puede encajar con ninguno de nuestros parámetros.

\section{CODINACH}

GRADO DE AJUSTE CON LOS PROGRAMAS VIGENTES EN EL MOMENTO.

Claves Sí

Tesituras Sí

Tonalidades

No

Compases

No (sí si unimos los de 2 cursos)

Dificultades métricas

No

Dificultades melódicas No

Cantidad de elementos Dos

que encajan

GRADO DE AJUSTE CON LOS PROCEDIMIENTOS ACTUALES DE ENSEÑANZA/APRENDIZAJE DEL SOLFEO.

Claves 
Tesituras No

Tonalidades No

Compases No

Dificultades métricas No

Dificultades melódicas No

Cantidad de elementos Uno

que encajan

\section{ROGER}

GRADO DE AJUSTE CON LOS PROGRAMAS VIGENTES EN EL MOMENTO.

\section{$\underline{\text { Del libro I }}$}

Claves No

Tesituras No

Tonalidades Sí

Compases Sí

Dificultades métricas No

Dificultades melódicas No

Cantidad de elementos Dos

que encajan

$\underline{\text { Del libro II }}$

Claves

Tesituras

Tonalidades

Compases

Dificultades métricas

Dificultades melódicas

Cantidad de elementos

que encajan

Del libro III

Claves

Tesituras

Tonalidades

Compases

Dificultades métricas

Dificultades melódicas

Cantidad de elementos

que encajan
No

No

No

Sí, aunque permuta el de $3 / 8$ por el de $6 / 8$

No

No

Uno, con reparos

No

No

No

No

No. Sí coincide con el programa de 1876

No

\section{Ninguno}


Discusión

GRADO DE AJUSTE CON LOS PROCEDIMIENTOS ACTUALES DE ENSEÑANZA/APRENDIZAJE DEL SOLFEO.

\section{Del libro I}

Tomando esta primera parte como secuencias 1 y 2

Claves

Sí

Tesituras

No

Tonalidades

No

Compases

No

Dificultades métricas No

Dificultades melódicas No

Cantidad de elementos Uno

que encajan

Del libro II

Considerando $2^{\mathrm{a}}$ parte como secuencias 3 y 4

Claves

No

Tesituras

No

Tonalidades

No

Compases

Sí, no en el orden que aparecen

Dificultades métricas

No

Dificultades melódicas No

Cantidad de elementos Uno con reparos

que encajan

\section{Del libro III}

Considerando $3^{\mathrm{a}}$ parte como secuencias 5 y 6

Claves

No

Tesituras

No

Tonalidades

No

Compases

No

Dificultades métricas No

Dificultades melódicas No

Cantidad de elementos Ninguno

que encajan

\section{AMORÓS}

Elementos de solfeo

GRADO DE AJUSTE CON LOS PROGRAMAS VIGENTES EN EL MOMENTO.

Claves Sí

Tesituras

No, esta es más recortada

Tonalidades

Sí 
Compases

Dificultades métricas

Dificultades melódicas

Cantidad de elementos

que encajan
No, procede como el de Eslava

No

Sí, incluso lo mejora

Tres

GRADO DE AJUSTE CON LOS PROCEDIMIENTOS ACTUALES DE ENSEÑANZA/APRENDIZAJE DEL SOLFEO.

Claves

Tesituras

Tonalidades

Compases

Dificultades métricas

Dificultades melódicas

Cantidad de elementos

que encajan
Sí

No

Sí

No

No

No

Dos

\section{VELÁZQUEZ}

GRADO DE AJUSTE CON LOS PROGRAMAS VIGENTES EN EL MOMENTO.

$\underline{\text { De la primera parte }}$

Claves Sí

Tesituras No

Tonalidades No

Compases No

Dificultades métricas No

Dificultades melódicas No

Cantidad de elementos Uno

que encajan

De la $2^{\mathrm{a}}$ parte

Claves

No

Tesituras

No

Tonalidades No

Compases No

Dificultades métricas No

Dificultades melódicas No

Cantidad de elementos Ninguna que encajan 
De la $3^{\mathrm{a}}$ parte

Claves No

Tesituras No

Tonalidades No

Compases No

Dificultades métricas No

Dificultades melódicas No

Cantidad de elementos Ninguna

que encajan

GRADO DE AJUSTE CON LOS PROCEDIMIENTOS ACTUALES DE ENSEÑAN-

ZA/APRENDIZAJE DEL SOLFEO.

De la primera parte

Claves $\quad$ Sí

Tesituras No

Tonalidades No

Compases No

Dificultades métricas No

Dificultades melódicas No

Cantidad de elementos Uno

que encajan

De la $2^{\mathrm{a}}$ parte

Claves Sí

Tesituras No

Tonalidades No

Compases No

Dificultades métricas No

Dificultades melódicas No

Cantidad de elementos Uno

que encajan

De la $3^{\mathrm{a}}$ parte

Claves No

Tesituras No

Tonalidades No

Compases No

Dificultades métricas No

Dificultades melódicas No

Cantidad de elementos Ninguna

que encajan 
BRULL y otros

(EL PROGRESO MUSICAL)

GRADO DE AJUSTE CON LOS PROGRAMAS VIGENTES EN EL MOMENTO.

De la primera parte

$\begin{array}{ll}\text { Claves } & \text { Sí } \\ \text { Tesituras } & \text { Sí } \\ \text { Tonalidades } & \text { Sí } \\ \text { Compases } & \text { Sí } \\ \text { Dificultades métricas } & \text { No } \\ \text { Dificultades melódicas } & \text { Sí }\end{array}$

Cantidad de elementos Cinco

que encajan

De la segunda parte

Claves

Sí

Tesituras

Sí

Tonalidades

Sí

Compases

Sí

Dificultades métricas

No en el orden exacto

Dificultades melódicas

Sí

Cantidad de elementos Cinco

que encajan

De la tercera parte

Claves Sí

Tesituras Sí

Tonalidades Sí

Compases Sí

Dificultades métricas No

Dificultades melódicas Sí

Cantidad de elementos Cinco

que encajan

GRADO DE AJUSTE CON LOS PROCEDIMIENTOS ACTUALES DE ENSEÑANZA/APRENDIZAJE DEL SOLFEO.

De la primera parte

Claves Sí

Tesituras No

Tonalidades Sí

Compases No

Dificultades métricas No

Dificultades melódicas No 
Discusión

Cantidad de elementos Dos

que encajan

$\underline{\text { De la segunda parte }}$

Claves No

Tesituras No

Tonalidades No

Compases No

Dificultades métricas No

Dificultades melódicas No

Cantidad de elementos Ninguna

que encajan

De la tercera parte

Claves No

Tesituras No

Tonalidades No

Compases No

Dificultades métricas No

Dificultades melódicas No

Cantidad de elementos Ninguna

que encajan

\section{PARDÁS}

GRADO DE AJUSTE CON LOS PROGRAMAS VIGENTES EN EL MOMENTO.

De la parte primera

Claves No

Tesituras No, son agudísimas

Tonalidades Sí

Compases No

Dificultades métricas No

Dificultades melódicas No

Cantidad de elementos Uno

que encajan

$\underline{\text { De la parte segunda }}$

Claves

No

Tesituras

No

Tonalidades

No

Compases 
Dificultades métricas No

Dificultades melódicas No

Cantidad de elementos Ninguno

que encajan

GRADO DE AJUSTE CON LOS PROCEDIMIENTOS ACTUALES DE ENSEÑANZA/APRENDIZAJE DEL SOLFEO.

De la primera parte

$\begin{array}{ll}\text { Claves } & \text { Non } \\ \text { Tesituras } & \text { No } \\ \text { Tonalidades } & \text { Sí } \\ \text { Compases } & \text { No } \\ \text { Dificultades métricas } & \text { No } \\ \text { Dificultades melódicas } & \text { No } \\ & \\ \text { Cantidad de elementos } & \text { Uno } \\ \text { que encajan } & \end{array}$

De la segunda parte

$\begin{array}{ll}\text { Claves } & \text { No } \\ \text { Tesituras } & \text { No } \\ \text { Tonalidades } & \text { No } \\ \text { Compases } & \text { No } \\ \text { Dificultades métricas } & \text { No } \\ \text { Dificultades melódicas } & \text { No }\end{array}$

Cantidad de elementos Ninguno

que encajan
AAVV
(ESCUELA DEL SOLFEO)
Del libro I
Claves
Sí
Tesituras
Sí
Tonalidades
Sí
Compases
No
Dificultades métricas $\quad \mathrm{No}$
Dificultades melódicas Sí
Cantidad de elementos Cuatro que encajan

GRADO DE AJUSTE CON LOS PROGRAMAS VIGENTES EN EL MOMENTO. 
Del libro II

Claves No

Tesituras Sí

Tonalidades No

Compases No

Dificultades métricas No

Dificultades melódicas Sí

Cantidad de elementos Dos que encajan

GRADO DE AJUSTE CON LOS PROCEDIMIENTOS ACTUALES DE ENSEÑANZA/APRENDIZAJE DEL SOLFEO.

Del libro I

Claves Sí

Tesituras No

Tonalidades No

Compases No

Dificultades métricas No

Dificultades melódicas No

Cantidad de elementos Uno

que encajan

Del libro II

Claves Sí

Tesituras No

Tonalidades No

Compases No

Dificultades métricas No

Dificultades melódicas No

Cantidad de elementos Uno

que encajan

VANCELL

GRADO DE AJUSTE CON LOS PROGRAMAS VIGENTES EN EL MOMENTO.

Claves

Tesituras

Tonalidades

Compases

Dificultades métricas

Dificultades melódicas

Cantidad de elementos que encajan
Sí

No, muy extensas

Sí

No

No

No

Dos 
GRADO DE AJUSTE CON LOS PROCEDIMIENTOS ACTUALES DE ENSEÑANZA/APRENDIZAJE DEL SOLFEO.

Claves Sí

Tesituras No

Tonalidades Sí

Compases No

Dificultades métricas No

Dificultades melódicas No

Cantidad de elementos Dos que encajan

\section{BRULL}

GRADO DE AJUSTE CON LOS PROGRAMAS VIGENTES EN EL MOMENTO.

Claves Sí

Tesituras Sí

Tonalidades

Sí

Compases

Sí

Dificultades métricas No

Dificultades melódicas No

Cantidad de elementos Cuatro que encajan

GRADO DE AJUSTE CON LOS PROCEDIMIENTOS ACTUALES DE ENSEÑANZA/APRENDIZAJE DEL SOLFEO.

Claves

Tesituras

Tonalidades

Compases

Dificultades melódicas No

Cantidad de elementos Dos

que encajan
Sí

No

Sí

No

No

\section{AMORós}

(Lecciones manuscritas graduadas, $2^{\circ}$ curso)

GRADO DE AJUSTE CON LOS PROGRAMAS VIGENTES EN EL MOMENTO.

Del $2^{\circ}$ curso

Claves

Tesituras

Tonalidades

Compases

Dificultades métricas
Sí

No, son muy extremas

Sí

Sí

No, porque algunas ya estaban en el primer método 
Discusión

Dificultades melódicas Sí

Cantidad de elementos Cuatro

que encajan

$\underline{\text { Del } 3^{\circ} \text { curso }}$

Claves

Tesituras

Tonalidades

Compases

Dificultades métricas

Dificultades melódicas

Cantidad de elementos

que encajan
Sí

No, muy extensas

Casi, en los programas vigentes las hay hasta con 6 alteraciones, y aquí llegan a las 7

No

No

Sí

GRADO DE AJUSTE CON LOS PROCEDIMIENTOS ACTUALES DE ENSEÑANZA/APRENDIZAJE DEL SOLFEO.

$\underline{\text { Del } 2^{\circ} \text { curso }}$

Considerando $2^{\mathrm{a}}$ curso como secuencias 2 y 3

Claves

Tesituras

Tonalidades

Compases

Dificultades métricas

Dificultades melódicas

Cantidad de elementos

que encajan
No

No

No

Sí

Sí

No todas, aunque sí algunas

Dos y parte de uno

\section{$\underline{\text { Del } 3^{\circ} \text { curso }}$}

Considerando el tercer curso como secuencias 3,4 y 5

Claves

No

Tesituras

No

Tonalidades

No

Compases

No

Dificultades métricas No

Dificultades melódicas No

Cantidad de elementos Ninguno

que encajan 


\section{ESPINO}

GRADO DE AJUSTE CON LOS PROGRAMAS VIGENTES EN EL MOMENTO. Y CON LOS PROCEDIMIENTOS ACTUALES DE ENSEÑANZA/APRENDIZAJE DEL SOLFEO.

Al tratarse de un libro complementario y no de enseñanza graduada, no puede encajar con ningún programa vigente ni con ningún ideal metodológico. Es un libro que requiere un alto nivel de preparación para poder afrontarlo, y en ese caso servirse de él como elemento de perfeccionamiento. Su nivel sería mucho más que un $3^{\circ}$ curso de los programas que estamos siguiendo y en algunos parámetros, como el excesivo empleo de las claves, más que un $6^{\circ}$ curso actual.

\section{ABREU}

GRADO DE AJUSTE CON LOS PROGRAMAS VIGENTES EN EL MOMENTO.

Del segundo curso

Claves

Tesituras

Tonalidades

Compases

Dificultades métricas

Dificultades melódicas

Cantidad de elementos

que encajan

\section{Del quinto curso}

Siendo un libro complementario y de perfeccionamiento, no puede encajar con ningún programa vigente en aquellos años (además no había quinto curso), ni tampoco con programas u objetivos actuales. Es un libro que reúne lecciones de progreso, práctica del transporte y solfeo a 2 voces, cuestiones ellas que suelen ir en la actualidad por separado en sendos libros.

GRADO DE AJUSTE CON LOS PROCEDIMIENTOS ACTUALES DE ENSEÑANZA/APRENDIZAJE DEL SOLFEO.

Del segundo curso

Claves No

Tesituras 
Tonalidades

Compases

Dificultades métricas

Dificultades melódicas

Cantidad de elementos

que encajan

Del quinto curso
Sí, si consideramos este $2^{\mathrm{a}}$ curso con mis $2^{\circ}$ y $3^{\circ}$

No

No

No

Ninguno, o casi uno

Es válido lo que decimos en el grado de ajuste con los programas vigentes...

\section{LLORCA}

GRADO DE AJUSTE CON LOS PROGRAMAS VIGENTES EN EL MOMENTO Y CON LOS PROCEDIMIENTOS ACTUALES DE ENSEÑANZA/APRENDIZAJE DEL SOLFEO.

Siendo un libro suplementario, exclusivamente de lectura, no puede acoplarse a ninguno de las medidas establecidas ni expresadas como ideales.

\section{BUXÓ}

GRADO DE AJUSTE CON LOS PROGRAMAS VIGENTES EN EL MOMENTO.

Del primer libro

Claves

Tesituras

Tonalidades

Compases

Dificultades métricas

Dificultades melódicas

Cantidad de elementos

que encajan

$\underline{\text { Del segundo libro }}$

Claves

Tesituras

Tonalidades

Compases

Dificultades métricas

Dificultades melódicas

Cantidad de elementos

que encajan
No

Sí

No

No

No

Casi, le falta la preparación en los intervalos

Una y casi dos

No

Sí

No

Sí

No

Sí

Tres 
Del tercero libro

Claves No

Tesituras No

Tonalidades No

Compases No

Dificultades métricas No

Dificultades melódicas No

Cantidad de elementos Ninguno

que encajan

GRADO DE AJUSTE CON LOS PROCEDIMIENTOS ACTUALES DE ENSEÑANZA/APRENDIZAJE DEL SOLFEO.

Del primer libro

Claves No

Tesituras No

Tonalidades No

Compases No

Dificultades métricas No

Dificultades melódicas No

Cantidad de elementos Ninguno

que encajan

Del segundo libro

Claves

No

Tesituras

No

Tonalidades

No

Compases No

Dificultades métricas No

Dificultades melódicas No

Cantidad de elementos Ninguno

que encajan

$\underline{\text { Del tercer libro }}$

Claves

No

Tesituras

No

Tonalidades $\quad \mathrm{No}$

Compases No

Dificultades métricas No

Dificultades melódicas No

Cantidad de elementos Ninguno que encajan 
Discusión 


$$
\begin{gathered}
-5- \\
\text { CONCLUS IONES }
\end{gathered}
$$

INFERENCIAS SOBRE LOS DATOS 


\section{ESTUDIO COMPARATIVO DE LAS ANALOGÍAS Y CONTRAS- TES ENTRE TODOS LOS MÉTODOS. CUADROS ESTADÍSTICOS.}

Una vez analizados y expuestos todos los métodos objeto de este estudio, hacemos en este punto un análisis comparativo entre todos ellos, con objeto de ver en qué se parecen y en qué difieren, extrayendo consecuencias, llegando a conclusiones, presentando incluso aspectos curiosos; y lo hacemos analizando y contrastando los siguientes elementos:

1. Claves empleadas y orden didáctico

2. Tesituras que abarcan las lecciones

3. Tonalidades y modalidades que emplean

4. Compases que enseñan y que utilizan para comenzar la enseñanza

5. Dificultades métricas que se estudian y secuencia

6. Métodos que contemplan las notas de adorno

7. Dificultades melódicas y ejercicios de entonación

8. Opiniones sobre la calificación de los intervalos de $4^{\mathrm{a}}$ y $5^{\mathrm{a}}$

9. Diferentes denominaciones de las escalas menores

10. Tipo de armonía empleada en los métodos.

11. Formas que adoptan las lecciones

12. Cantidad de lecciones que tienen introducción, codas o intermedios instrumentales

13. Métodos que contienen teoría de la música

14. Aspectos curiosos encontrados en algunos métodos

15. Métodos que se hicieron para la enseñanza profesional de la música, y métodos que no se hicieron con ese fin.

16. Consideraciones sobre la utilidad que pudieron tener los métodos examinados en su época.

17. Consideraciones sobre la utilidad actual de los métodos examinados 


\subsection{CLAVES EMPLEADAS Y ORDEN DIDÁCTICO}

USO DE LAS CLAVES.- ${ }^{1}$

\begin{tabular}{|c|c|c|}
\hline AUTOR & AÑO & CLAVES EMPLEADAS Y ORDEN DIDÁCTICO \\
\hline Carrera & 1805 & $\begin{array}{l}\text { Do en } 1^{\mathrm{a}}, \text { Fa en } 4^{\mathrm{a}}, \text { Do en } 4^{\mathrm{a}}, \text { Do en } 3^{\mathrm{a}} \text {, Do en } 2^{\mathrm{a}} \text {, Fa en } 3^{\mathrm{a}} \\
\text { y Sol }\end{array}$ \\
\hline López Remacha & 1815 & $\begin{array}{l}\text { Sol, Fa en } 4^{a} \text {, Do en } 1^{a} \text {, Do en } 2^{a} \text {, Do en } 3^{a} \text {, Do en } 4^{a} \text { y Fa } \\
\text { en } 3^{a}\end{array}$ \\
\hline Gomis & 1826 & $\begin{array}{l}\text { Sol, Do en } 1^{a} \text {, Do en } 2^{a} \text {, Do en } 3^{a} \text {, Do en } 4^{a} \text {, Fa en } 3^{a} \text { y Fa } \\
\text { en } 4^{a}\end{array}$ \\
\hline Reguart & 1839 & $\begin{array}{l}\text { Do en } 1^{a} \text {, Do en } 2^{a} \text {, Do en } 3^{a} \text {, Do en } 4^{a} \text {, Sol, Fa en } 3^{a} \text { y Fa } \\
\text { en } 4^{a} \text {. }\end{array}$ \\
\hline Eslava & 1845 & Sol / Sol y Fa en $4^{\mathrm{a}} / \mathrm{Do} 1^{\mathrm{a}}$, Do $2^{\mathrm{a}}$, Do $3^{\mathrm{a}}$, Do $4^{\mathrm{a}}$ y Fa $3^{\mathrm{a}}$ \\
\hline Sobejano & $1845 ?$ & Sol $/$ Sol y Fa $4^{\mathrm{a}} / \mathrm{Do} 1^{\mathrm{a}}$, Do $4^{\mathrm{a}}$, Do $3^{\mathrm{a}}$, Do $2^{\mathrm{a}}$ y Fa $3^{\mathrm{a}}$ \\
\hline Aliaga & 1847 & Sol, y una sola en $\mathrm{Fa}$ en $4^{\mathrm{a}}$ \\
\hline Pérez Gascón & $1848-1857$ & Sol, Fa $4^{\mathrm{a}}$ y Do $1^{\mathrm{a}}$ \\
\hline Prellezo & 1851 & Sol. Las demás usadas como ficción de claves. \\
\hline Valero y Romero & $1856 ?$ & Sol, / Fa $4^{\mathrm{a}}$. Do $1^{\mathrm{a}}$, Do $4^{\mathrm{a}}$, Do $3^{\mathrm{a}}$, Do $2^{\mathrm{a}}$ y Fa $3^{\mathrm{a}}$ \\
\hline Funoll & $1860 ?$ & Sol \\
\hline Calvó & $1860 ?$ & Sol, Fa. $4^{\mathrm{a}} / \mathrm{Do}$ en $1^{\mathrm{a}}, 2^{\mathrm{a}}, 3^{\mathrm{a}}$ y Fa en $3^{\mathrm{a}}$ \\
\hline Manent & $1860 ?$ & Sol, Do $1^{\mathrm{a}}$, Do $4^{\mathrm{a}}$, Do $3^{\mathrm{a}}$ y Fa $4^{\mathrm{a}}$ \\
\hline Lladó & $1862 ?$ & Sol \\
\hline Arrieta & 1868 a 1891 & Sol / Do $1^{\mathrm{a}}$ y Fa $4^{\mathrm{a}} / \mathrm{Do} 4^{\mathrm{a}},{\text { y Fa } 3^{\mathrm{a}}}$ \\
\hline Obiols & Entre 1868 y $1891 ?$ & Sol $/$ Do $1^{\mathrm{a}}, 2^{\mathrm{a}}, 3^{\mathrm{a}}, 4^{\mathrm{a}}$, Fa $3^{\mathrm{a}}, \mathrm{y} 4^{\mathrm{a}}$ \\
\hline Moré y Gil & 1870 & Sol $/ \mathrm{Fa} 4^{\mathrm{a}} /$ Do en $1^{\mathrm{a}}, 2^{\mathrm{a}}, 3^{\mathrm{a}}$ y $4^{\mathrm{a}}$, Fa en $3^{\mathrm{a}}$ \\
\hline Abrantes & $1879 ?$ & Sol y Fa $4^{\mathrm{a}}$ \\
\hline Penella & 1879 & Sol y Fa $4^{\mathrm{a}}$ unas lecciones \\
\hline Benito & $1880 ?$ & Sol, Fa $4^{\mathrm{a}} / \mathrm{Do} 1^{\mathrm{a}}$, Do $2^{\mathrm{a}}$, Do $3^{\mathrm{a}}$, Do $4^{\mathrm{a}}$ y $\mathrm{Fa}^{\mathrm{a}}$ \\
\hline Egea & 1881 & Sol, Fa $4^{\mathrm{a}} /$ Do $1^{\mathrm{a}}$, Do $2^{\mathrm{a}}$, Do $3^{\mathrm{a}}$, Do $4^{\mathrm{a}}$ y Fa $3^{\mathrm{a}}$ \\
\hline Sabatés & 1888 & Sol y Fa $4^{\mathrm{a}} /$ Do $1^{\mathrm{a}}, 2^{\mathrm{a}}, 3^{\mathrm{a}}, 4^{\mathrm{a}}$ y Fa $3^{\mathrm{a}}$ \\
\hline Agero & Entre 1882 y $1900 ?$ & Sol $/ \mathrm{Fa} 4^{\mathrm{a}}$, Do $1^{\mathrm{a}} / \mathrm{Do} 2^{\mathrm{a}}$, Do $3^{\mathrm{a}}$, Do $4^{\mathrm{a}}$, y Fa $3^{\mathrm{a}}$ \\
\hline Llupart & $1884 ?$ & Sol \\
\hline Codinach & $1890 ?$ & Sol \\
\hline Roger & 1891 & Sol, Fa $4^{\mathrm{a}} /$ Do $1^{\mathrm{a}}$, Do $2^{\mathrm{a}}$, Do $3^{\mathrm{a}}$, Do $4^{\mathrm{a}}$, Fa $3^{\mathrm{a}}$ \\
\hline Amorós & 1890 & Sol \\
\hline Velázquez & $1895 ?$ & Sol, Fa $4^{\mathrm{a}} / \mathrm{Do} 1^{\mathrm{a}}$, Do $2^{\mathrm{a}}$, Do $3^{\mathrm{a}}$, Do $4^{\mathrm{a}}, \mathrm{Fa} 3^{\mathrm{a}}$ \\
\hline $\begin{array}{l}\text { Brull } \\
\text { (El progreso musical) }\end{array}$ & 1898 & Sol $/ \mathrm{Fa} 4^{\mathrm{a}}$, Do $1^{\mathrm{a}} / \mathrm{Do} 2^{\mathrm{a}}$, Do $3^{\mathrm{a}}$, Do $4^{\mathrm{a}}$, y Fa $3^{\mathrm{a}}$ \\
\hline Pardás & Entre 1864 y $1900 ?$ & Sol y Fa $4^{\mathrm{a}} / \mathrm{Fa} 3^{\mathrm{a}}$, Do $1^{\mathrm{a}}$, Do $2^{\mathrm{a}}$, Do $3^{\mathrm{a}}$ y Do $4^{\mathrm{a}}$ \\
\hline $\begin{array}{l}\text { AAVV } \\
\text { (Escuela del solfeo) }\end{array}$ & $1900 ?$ & Sol y un poco de $\mathrm{Fa}^{\mathrm{a}}$ \\
\hline Vancell & 1902 & Sol \\
\hline Brull & $1923 ?$ & Sol y sólo 3 en $\mathrm{Fa} 4^{\mathrm{a}}$ \\
\hline Amorós & 1910 & $\mathrm{Fa} 4^{\mathrm{a}}$, Do $1^{\mathrm{a}} / \mathrm{Do} 2^{\mathrm{a}}$, Do $3^{\mathrm{a}}$, Do $4^{\mathrm{a}}$ y Fa $3^{\mathrm{a}}$ \\
\hline Espino & $1912 ?$ & Las 7 a la vez porque está dedicado a la práctica de ellas \\
\hline Abreu & $1914 ?$ & Sol, Fa $4^{\mathrm{a}} / \mathrm{Do} 4^{\mathrm{a}}$, Do $2^{\mathrm{a}}$, Fa $3^{\mathrm{a}}$, Do $1^{\mathrm{a}}$ y Do $3^{\mathrm{a}}$ \\
\hline Llorca & $1916 ?$ & Sol \\
\hline Buxó & $1920 ?$ & Sol, Fa $4^{\mathrm{a}} / \mathrm{Do} 1^{\mathrm{a}}$ \\
\hline
\end{tabular}

De acuerdo con esta tabla, inferimos los siguientes datos:

\footnotetext{
${ }^{1}$ Todas las referencias a autores están hechas de más a menos antiguo.
} 
Se utiliza exclusivamente la clave de Sol en los métodos de Funoll, Lladó, Llupart, Codinach, Vancell y Llorca.

Únicamente las de Sol y Fa en $4^{\mathrm{a}}$ en los de Aliaga (1 lección), Abrantes, Penella, A.A.V.V. (escuela del solfeo), Brull Ayerra (en 3 lecciones) y Abreu.

Tratan solamente 5 claves: Manent (en orden Sol, Do $1^{\mathrm{a}}$, Do $4^{\mathrm{a}}$, Do $3^{\mathrm{a}}$ y Fa $4^{\mathrm{a}}$ ) y Arrieta (en orden Sol, Do $1^{\mathrm{a}}, \mathrm{Fa} 4^{\mathrm{a}}$, Do $4^{\mathrm{a}}$ y Fa $3^{\mathrm{a}}$ ). Es extraño en este autor que en un solo curso presente tantas claves y, sin embargo, que no las enseñe todas. Es comprensible que puestos a omitir alguna, lo haga con las de Do en $2^{\mathrm{a}}$ y Fa en $3^{\mathrm{a}}$, pero no es nada comprensible que la última en aprender sea la de Fa en $4^{\mathrm{a}}$.

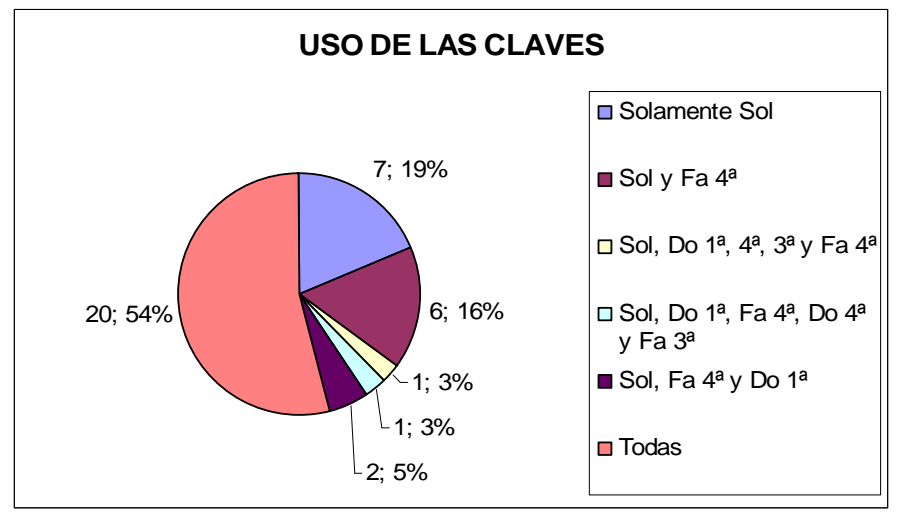

seguir con el resto de claves, se quedaron con la primera en el orden que, como veremos bajo, era el más habitual.

El resto utiliza las 7 claves.

\section{ORDEN EN QUE SE ENSEÑAN LAS CLAVES.-}

Todos los métodos empiezan por la clave de Sol en $2^{\mathrm{a}}$ línea, excepto el de Carrera Lanchares, el más antiguo, y el de Reguart Mestre, editado 34 años después del anterior, que empiezan por la de Do en $1^{\mathrm{a}}$ línea.

El orden de aparición de las claves más utilizado en los diferentes métodos es el siguiente:

\section{Sol, Fa en $4^{a}$, Do en $1^{a}$, Do $2^{a}$, Do $3^{a}$, Do $4^{a}$ y Fa en $3^{a}$.}

Doce métodos siguen este orden de aparición; algunos antiguos, como el de López Remacha, también los de Eslava, Calvó y Moré. Y sobre todo los de finales del XIX: Benito, Egea, Sabatés, Agero, Roger Junoi, Amorós, Velázquez y El Progreso Musical. 
Es de suponer que esta disposición mayoritaria obedece a un doble criterio: el primero, ser las más utilizadas instrumentalmente, y el segundo, seguir el orden de las claves vocales.

Otros métodos, como los de Gomis y Obiols, con 40 años de diferencia uno del otro, siguen otras ordenaciones mucho más minoritarias en la enseñanza de las claves:

$$
\text { Sol, Do } 1^{a} \text {, Do } 2^{a} \text {, Do } 3^{a} \text {, Do } 4^{a}, \mathrm{Fa} 3^{a} \text { y Fa } 4^{a} \text {. }
$$

Lo más extraño e inexplicable es dejar para el final la de Fa en $4^{\mathrm{a}}$ línea. Parecen seguir un criterio de orden numérico o matemático $(1,2,3,4 \ldots)$

Por el contrario los de Sobejano y Valero, aplican una ordenación más acorde a lo que sería una sucesión lógica didácticamente hablando:

Sol, Fa $4^{a}$, Do $1^{a}$, Do $4^{a}$, Do $3^{a}$, Do $2^{a}$ y Fa $3^{a}$.

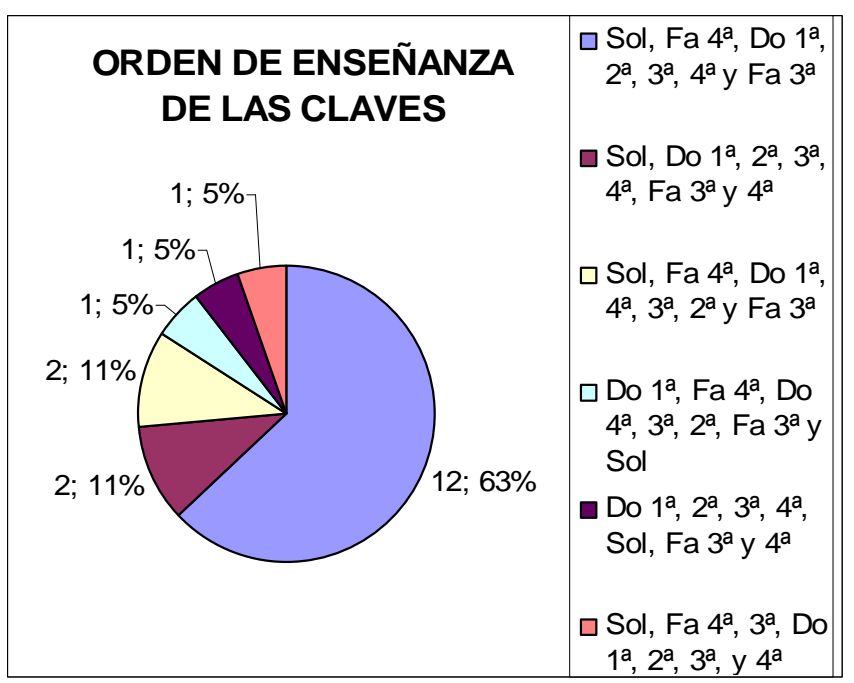

Por último hay tres métodos que utilizan ordenaciones más personales en la enseñanza de las claves:

Carrera Lanchares, que utiliza el siguiente: $\mathrm{Do} \mathrm{I}^{a}, \mathrm{Fa} 4^{a}$, $\mathrm{Do}$ $4^{a}, 3^{a}, 2^{a}, \mathrm{Fa} 3^{a}$ y Sol. Parece lógico el orden de las claves a partir de la de Do en $4^{\mathrm{a}}$, pero empezar por la de Do en $1^{\mathrm{a}}$ y finalizar con la de Sol es, cuanto menos, curioso. Quizás fuera debido a que antiguamente (el método es de 1805) la única clave no utilizada para las voces humanas era la de Sol.

Reguart muestra el siguiente orden: Do $1^{a}, 2^{a}, 3^{a}, 4^{a}$, Sol, Fa $3^{a}$ y $4^{a}$. Este es el más extraño.

Pardás sigue un orden muy similar al estándar, pero con la rareza de situar la clave de Fa en $3^{\mathrm{a}}$, siendo la menos usada, después de la de $4^{\mathrm{a}}$ y antes de las de Do:

$$
\text { Sol, Fa } 4^{a}, \mathrm{Fa}^{a} \text {, Do } 1^{a}, 2^{o}, 3^{a}, y 4^{a} \text {. }
$$

En resumen, de los 19 autores analizados, ninguno sigue un orden lógico de enseñanza de las claves, que sería: primero la de Sol, luego la de $\mathrm{Fa}$ en $4^{\mathrm{a}}$, como claves mayoritarias; a continuación Do en $3^{\mathrm{a}}$ y Do en $4^{\mathrm{a}}$, como más utilizadas por algunos instrumentos, y también para el transporte a distancia de $2^{\mathrm{a}}$; después las no empleadas más que para el transporte, Do en $1^{\mathrm{a}}, 2^{\mathrm{a}}$ y Fa en $3^{\mathrm{a}}$. Únicamente, como decimos más arriba, los métodos de Sobejano y Valero se aproximan a este ideal. 


\subsection{TESITURAS QUE ABARCAN LAS LECCIONES}

\begin{tabular}{|c|c|c|}
\hline AUTOR & AÑO & $\begin{array}{l}\text { TESITURAS QUE } \\
\text { ABARCAN } \\
\text { LAS LECCIONES }\end{array}$ \\
\hline Carrera & 1805 & Do 3 a Sol 4 \\
\hline López Remacha & 1815 & Do 3 a La 4 \\
\hline Gomis & 1826 & Do 3 a Sol 4 \\
\hline Reguart & 1839 & Do 3 a Do 5 \\
\hline Eslava & 1845 & Do 3 a Fa 4 \\
\hline Sobejano & $1845 ?$ & $\begin{array}{l}\text { Do } 3 \text { a Fa } 4 \\
\text { Do } 3 \text { a } \mathrm{La} 4 \\
\text { Do } 3 \text { a Do } 5\end{array}$ \\
\hline Aliaga & 1847 & $\mathrm{La} 2$ a La 4 \\
\hline Pérez Gascón & $1848-1857$ & $\begin{array}{l}\text { Do } 3 \text { a Fa } 4 \\
\text { Si } 2 \text { a Mi } 4\end{array}$ \\
\hline Prellezo & 1851 & $\mathrm{La} 2$ a Fa 5 \\
\hline Valero y Romero & $1856 ?$ & Do 3 a Fa 4 \\
\hline Funoll & $1860 ?$ & Do 3 a Mi 4 \\
\hline Calvó & $1860 ?$ & Do 3 a Mi 4 \\
\hline Manent & $1860 ?$ & Do 3 a Sol 4 \\
\hline Lladó & $1862 ?$ & Do 3 a Fa 4 \\
\hline Arrieta & 1868 a 1891 & $\begin{array}{l}\text { Do } 3 \text { a } \mathrm{Mi} 4 \\
\text { Si } 2 \text { a Fa } 4\end{array}$ \\
\hline Obiols & Entre 1868 y $1891 ?$ & Do 3 a Mi 4 \\
\hline Moré y Gil & 1870 & $\begin{array}{l}\mathrm{Si} 2 \text { a Mi } 4 \\
\mathrm{Si} 2 \text { a Fa } 4 \\
\mathrm{La} 2 \text { a Fa } 4\end{array}$ \\
\hline Abrantes & $1879 ?$ & Do 3 a $\mathrm{Fa} 4$ \\
\hline Penella & 1879 & Do 3 a $\mathrm{Fa} 4$ \\
\hline Benito & $1880 ?$ & Do 3 a Fa 4 \\
\hline Egea & 1881 & Do 3 a La 4 \\
\hline Sabatés & 1888 & Do 3 a Sol 4 \\
\hline Agero & Entre 1882 y $1900 ?$ & Do 3 a Fa 4 \\
\hline Llupart & $1884 ?$ & Sol 2 a Fa 4 \\
\hline Codinach & $1890 ?$ & Do 3 a Mi 4 \\
\hline Roger & 1891 & Do 3 a Mi 5 \\
\hline Amorós & 1890 & Do 3 a Fa 4 \\
\hline Velázquez & $1895 ?$ & Do 3 a Sol 4 \\
\hline $\begin{array}{l}\text { Brull } \\
\text { (El progreso musical) }\end{array}$ & 1898 & Do 3 a Mi 4 \\
\hline Pardás & Entre 1864 y $1900 ?$ & Do 3 a Do 5 \\
\hline $\begin{array}{l}\text { AAVV } \\
\text { (Escuela del solfeo) }\end{array}$ & $1900 ?$ & Si 2 a Mi 4 \\
\hline Vancell & 1902 & Sol 2 a Sol 4 \\
\hline Brull & 1923? & Do 3 a Fa 5 \\
\hline Amorós & 1910 & $\begin{array}{l}\text { Do } 1 \text { a Do } 5 \\
\text { Si } 1 \text { a La } 5\end{array}$ \\
\hline Espino & $1912 ?$ & Sol 2 a $\operatorname{Re} 4$ \\
\hline Abreu & $1914 ?$ & $\begin{array}{l}\text { Do } 3 \text { a Mi } 4 \\
\text { Si } 2 \text { a Mi } 4\end{array}$ \\
\hline Llorca & $1916 ?$ & $\begin{array}{l}\text { Mi } 2 \text { a Mi } 5 \\
\text { Sib } 2 \text { a Fa\# } 4\end{array}$ \\
\hline Buxó & $1920 ?$ & $\mathrm{Si} 2$ a Fa 4 \\
\hline
\end{tabular}


Haciendo el estudio de las tesituras de las lecciones que comprenden los distintos métodos, se observa que hay una gran variedad de ellas, que abarcan desde una extensión prudente y accesible, hasta una desmesurada e imposible de alcanzar por la voz humana.

Predomina, aunque no en un gran porcentaje (22\%), las lecciones cuya tesitura abarca desde el $\mathrm{Do}_{3}$ al $\mathrm{Fa}_{4}$; le sigue con el $14 \%$ aproximadamente las que van de $\mathrm{Do}_{3}$ a $\mathrm{Mi}_{4}$, tesitura que es la que consideramos óptima, como media, para los primeros niveles y edades, siendo la más adecuada para cursos avanzados la de $\mathrm{Sol}_{2}$ a $\mathrm{Fa}_{4}$, la cual sólo tiene un método que la contemple.

De los 67 métodos o partes, habida cuenta que algunas partes repiten extensión, son 55 los que figuran en la relación decreciente de utilización de tesituras que sigue:
$11 \mathrm{Do}_{3}-\mathrm{Fa}_{4}$
$7 \quad \mathrm{Do}_{3}-\mathrm{Mi}_{4}$
$5 \mathrm{Do}_{3}-\mathrm{Sol}_{4}$
$\mathrm{Do}_{3}-\mathrm{La}_{4}$
$\mathrm{Do}_{3}-\mathrm{Do}_{5}$
$4 \mathrm{Do}_{3}-\mathrm{Sol}_{4}$
$3 \quad \mathrm{Si}_{2}-\mathrm{Fa}_{4}$
$\mathrm{Si}_{2}-\mathrm{Mi}_{4}$

$1 \mathrm{Do}_{3}-\mathrm{Mi}_{5}$

$\mathrm{La}_{2}-\mathrm{La}_{4}$

$\mathrm{La}_{2}-\mathrm{Fa}_{4}$

$\mathrm{La}_{2}-\mathrm{Fa} 5$

$\mathrm{Sol}_{2}-\mathrm{Re}_{4}$

$\mathrm{Sol}_{2}-\mathrm{Fa}_{4}$

$\mathrm{Sol}_{2}-\mathrm{Sol}_{4}$

$\mathrm{Mi}_{2}-\mathrm{Mi}_{5}$

$\mathrm{Si} \mathrm{b}_{2}-\mathrm{Fa}_{4}$

$\mathrm{Si}_{1}-\mathrm{La}_{5}$

Tesituras

Do $_{1}-$ Do $_{5}$

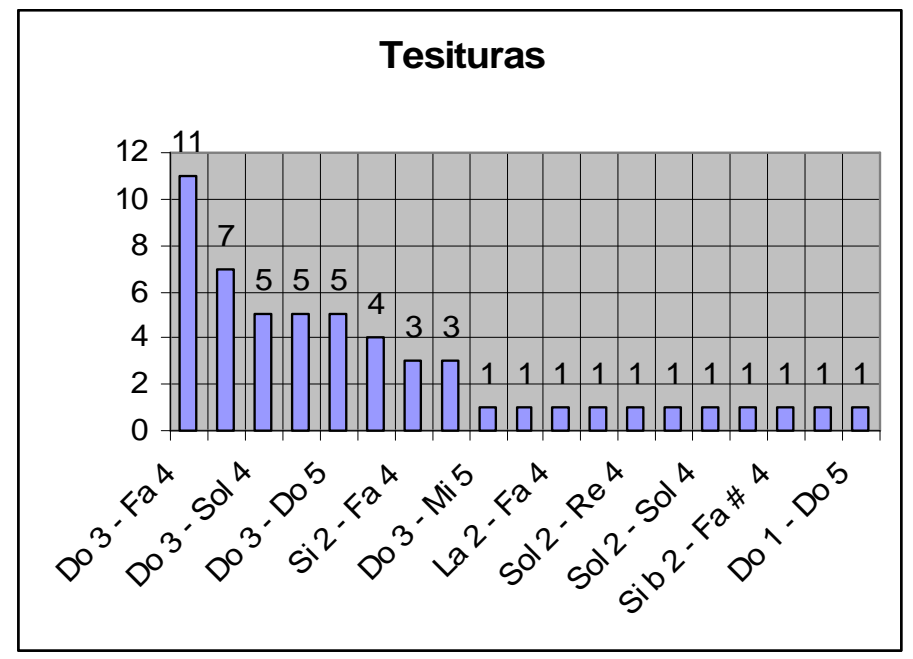

Por tanto, de los 55 métodos reseñados, únicamente 7 cumplen con la tesitura recomendable para los niveles iniciales y nada más que 1 para la considerada perfecta en los niveles avanzados. 


\subsection{TONALIDADES Y MODALIDADES QUE EMPLEAN}

\section{$\underline{\text { Cantidad }}$ \\ 1 Do mayor aparece en 4 \\ Autores}

2 Do mayor y La menor, aparece en 3

$4 \quad$ Las naturales y con 1 bemol

$4 \quad$ Hasta con 1 alteración, sólo las mayores

$7 \quad$ Hasta 3 alteraciones, sólo las mayores

10 Hasta 4 alteraciones, sólo las mayores

10 Hasta 2 alteraciones

12 Hasta 3 alteraciones

14 Hasta 3 alteraciones

14 Hasta 4, incluso bemoles hasta 5; pero faltan muchas menores, incluso La menor

14 Arbitrariamente

16 Hasta 4 alteraciones

16 Todas las mayores solamente

17 Arbitrariamente

18 Hasta 4 sostenidos y 5 bemoles faltando alguna menor

18 Hasta 4 alteraciones, 2

18 Arbitrariamente

19 Arbitrariamente

22 Hasta 5 alteraciones

$24 \quad$ Hasta 5 sostenidos y 6 bemoles

25 Hasta 6 alteraciones, faltando Si b menor

$26 \quad$ Hasta 6 alteraciones se ven en 3

28 Hasta 7 alteraciones faltando las de 7 sostenidos

28 Hasta 7 alteraciones, faltando las de 1 bemol

Todas Las incluyen 8
Funoll, Abrantes, Amorós (en

Elementos de solfeo) y Pardás

Gomis, Vancell y Brull, Melecio

López Remacha

Penella

Llorca

Aliaga

Pérez Gascón en Principios de solfeo y canto

Codinach

Pérez Gascón en Método de solfeo y principios de canto

Arrieta

Egea

Carrera

Reguart

Buxó

Valero

Agero y Escuela del solfeo

Espino

Abreu

Sobejano

Prellezo

Obiols

Eslava, Moré y Benito

Pardás

Amorós Lecciones manuscritas progresivas $2^{a}$ y $3^{a}$

Calvó, Manent, Lladó, Sabatés (aunque en la $3^{\text {a }}$ parte), Llupart, Roger, Velázquez y El Progreso musical

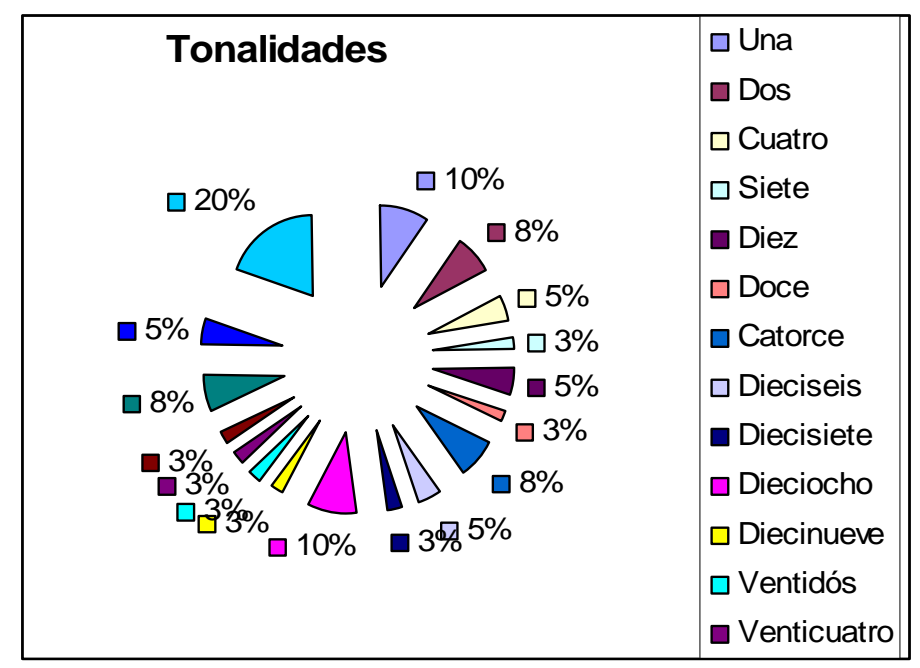




\subsection{COMPASES QUE ENSEÑAN Y QUE UTILIZAN PARA}

COMENZAR LA ENSEÑANZA.

\begin{tabular}{|c|c|c|c|}
\hline AUTOR & AÑO & $\begin{array}{l}\text { COMPÁS } \\
\text { POR EL } \\
\text { QUE } \\
\text { EMPIEZA }\end{array}$ & $\begin{array}{l}\text { ¿TRATA } \\
\text { TODOS } \\
\text { LOS BÁSICOS? } \\
*\end{array}$ \\
\hline Carrera & 1805 & $2 / 2$ & No, $5 \mathrm{~S}$ y $1 \mathrm{C}$ \\
\hline López Remacha & 1815 & $4 / 4$ & No, $5 \mathrm{~S}$ y $2 \mathrm{C}$ \\
\hline Gomis & 1826 & $4 / 4$ & Sí y más \\
\hline Reguart & 1839 & $4 / 4$ & No, $4 \mathrm{~S}$ y $1 \mathrm{C}$ \\
\hline Eslava & 1845 & $2 / 2$ & Sí y muchos más \\
\hline Sobejano & $1845 ?$ & $4 / 4$ & Sí y más \\
\hline Aliaga & 1847 & $4 / 4$ & Sí \\
\hline Pérez Gascón & $1848-1857$ & $2 / 2$ & Sí \\
\hline Prellezo & 1851 & $2 / 2$ & Sí y más \\
\hline Valero y Romero & $1856 ?$ & $4 / 4$ & Sí \\
\hline Funoll & $1860 ?$ & $4 / 4$ & No, $3 \mathrm{~S}$ \\
\hline Calvó & $1860 ?$ & $4 / 4$ & No, falta $12 / 8$ \\
\hline Manent & $1860 ?$ & $2 / 4$ & Sí y más \\
\hline Lladó & $1862 ?$ & $4 / 4$ & Sí y más \\
\hline Arrieta & 1868 a 1891 & $2 / 4$ & Sí y más \\
\hline Obiols & Entre 1868 y $1891 ?$ & $4 / 4$ & Sí y más \\
\hline Moré y Gil & 1870 & $4 / 4$ & Sí y más \\
\hline Abrantes & 1879? & $4 / 4$ & Sí \\
\hline Penella & 1879 & $4 / 4$ & No, $4 \mathrm{~S}$ y $1 \mathrm{C}$ \\
\hline Benito & $1880 ?$ & $2 / 2$ & Sí \\
\hline Egea & 1881 & $4 / 4$ & Sí \\
\hline Sabatés & 1888 & $4 / 4$ & Sí \\
\hline Agero & Entre 1882 y $1900 ?$ & $2 / 2$ & Sí y más \\
\hline Llupart & $1884 ?$ & $4 / 4$ & Sí y más \\
\hline Codinach & $1890 ?$ & $4 / 4$ & No, falta $12 / 8$ \\
\hline Roger & 1891 & $4 / 4$ & Sí y más \\
\hline Amorós & 1890 & $2 / 2$ & No, $4 \mathrm{~S}$ \\
\hline Velázquez & $1895 ?$ & $4 / 4$ & Sí y más \\
\hline $\begin{array}{l}\text { Brull } \\
\text { (El progreso musical) }\end{array}$ & 1898 & $4 / 4$ & Sí y más \\
\hline Pardás & Entre 1864 y $1900 ?$ & $4 / 4$ & Sí \\
\hline $\begin{array}{l}\text { AAVV } \\
\text { (Escuela del solfeo) }\end{array}$ & $1900 ?$ & $4 / 4$ & Sí y más \\
\hline Vancell & 1902 & $2 / 4$ & No, $3 \mathrm{~S}$ \\
\hline Brull & 1923? & $4 / 4$ & No, $3 \mathrm{~S}$ \\
\hline Amorós & 1910 & - & Sí y más \\
\hline Espino & $1912 ?$ & $4 / 4$ & Sí y más \\
\hline Abreu & $1914 ?$ & $2 / 4$ & Sí y más \\
\hline Llorca & 1916? & No hay & - \\
\hline Buxó & 1920? & $4 / 4$ & Sí y más \\
\hline
\end{tabular}

* $\mathrm{S}=$ a compases simples. $\mathrm{C}=\mathrm{a}$ compases compuestos. 
Enseñan todos los compases básicos, tanto simples como compuestos... 8

No enseñan como mínimo los compases básicos. . . . . . . . . . . 9

Enseñan todos los compases básicos y algunos más, la mayoría. . . . . . 18 ${ }^{1}$

Comienzan a presentar lecciones o ejercicios con el compás:

. Mayoritariamente con el de 4/4, 25 de ellos.

. Con el de 2/2 lo hacen 7: Carrera, Eslava, Pérez Gascón, Prellezo, Benito, Agero y Amorós

. Con el de 2/4 son 4 quienes así comienzan: Manent, Arrieta, Vancell y Abreu . Hay uno, Llorca, que no utiliza compases.
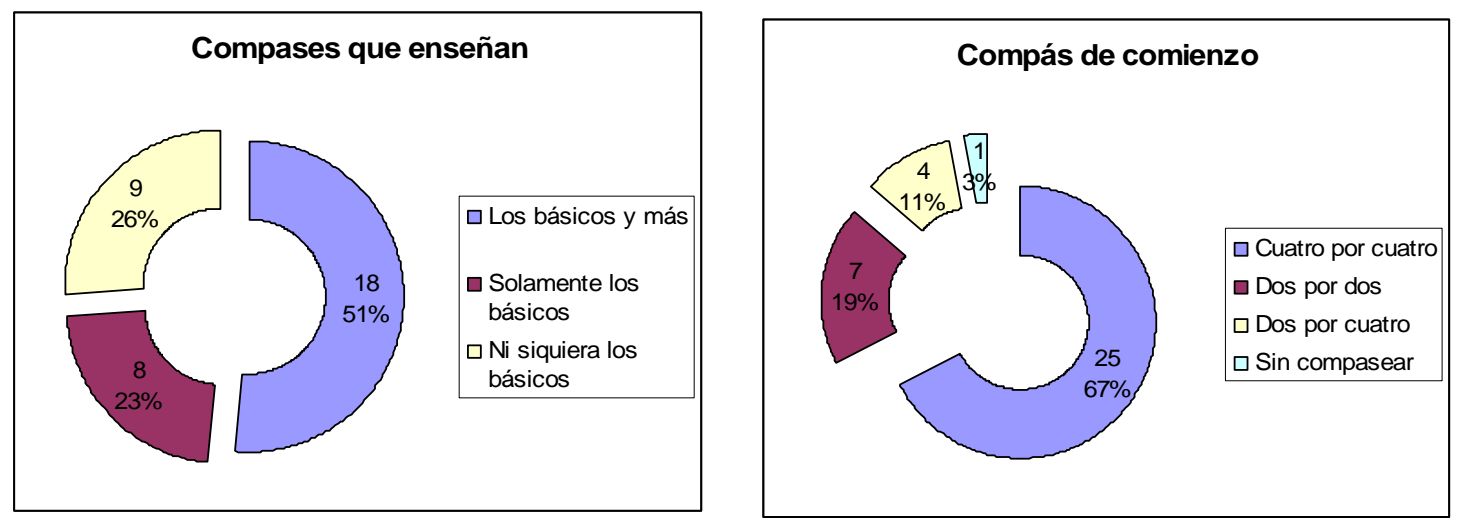

Como se observará, solamente 4 comienzan el aprendizaje del solfeo con el compás de $2 / 4$, que es lo idóneo, dos de ellos ya en el siglo XX, con una diferencia de 12 años: Vancell y Abreu, pero lo que habría que destacar es el caso de Manent, que en 1860 ya optó por comenzar con este compás.

\footnotetext{
${ }^{1}$ Consideramos básicos simples: 2/4, 3/4 y 4/4. Básicos compuestos: 6/8, 9/8 y 12/8
} 


\subsection{DIFICULTADES MÉTRICAS QUE SE ESTUDIAN Y SECUENCIA}

Consecuente con el patrón de comparación de este punto, explicado en el 2. 4. 3, exponemos esta tabla:

AUTOR

Carrera

López Remacha

Gomis

Reguart

Eslava

Sobejano

Aliaga

Pérez Gascón

Prellezo

Valero

Funoll

Calvó

Manent

Lladó

Arrieta

Obiols

Moré

Abrantes

Penella

Benito Cosme de

Egea

Sabatés

Agero

Llupart

Codinach

Roger Junoi

Amorós (1890)

Velázquez

Brull

(El progreso musical)

Pardás

Escuela del solfeo

Vancell

Brull Ayerra

Amorós (1910)

Espino

Abreu
MÁXIMO DE

DIFICULTAD

Hasta

Semifusa

Semicorchea

Fusa

Semifusa

Todas

Semifusa

Fusa

Fusa

Semifusa

Semifusa

Semicorchea

Fusa

Semifusa

Todas

Todas

Semifusa

Todas

Fusa y grupos irregulares

Fusa

Semifusa y grupos irregulares

Fusa y grupos irregulares

Todas

Fusa y grupos irregulares

Semicorchea

Semicorchea

Todas

Semicorchea

Todas

Todas

Todas

Fusa

Fusa

Semicorchea

Todas

Semifusa y grupos irregulares

Fusa y grupos irregulares

\section{FORMA DE INTRODUCIRLAS}

En tromba

Progresiva. No idónea

Progresiva. Casi idónea

(los adornos demasiado pronto)

Progresiva. No idónea

Progresiva. Casi idónea

Progresiva. No idónea

Progresiva. No idónea

Progresiva. Idónea

Disgregada

Progresiva. Idónea

Progresiva. Casi idónea

Progresiva. No idónea

Progresiva. Casi idónea

En tromba

No ha lugar. Es un método especial

Progresiva. Casi idónea

Progresiva. Idónea

Progresiva. Casi idónea

Progresiva. Casi idónea

Progresiva. Casi idónea

Progresiva. No idónea

Progresiva. Casi idónea

Progresiva. No idónea

Disgregada

Disgregada

Progresiva. Casi idónea

Progresiva. Casi idónea

Disgregada

Progresiva. Casi idónea

Disgregada

Progresiva. Casi idónea

Progresiva. Casi idónea

Progresiva. No idónea

Disgregada

En tromba

No ha lugar. Es un método complementario 
Dificultades métricas que se estudian

$\begin{array}{lll}\text { Llorca } & \text { Fusa } & \text { No ha lugar. Es un apéndice } \\ \text { Buxó } & \text { Fusa } & \text { Progresiva. Idónea }\end{array}$

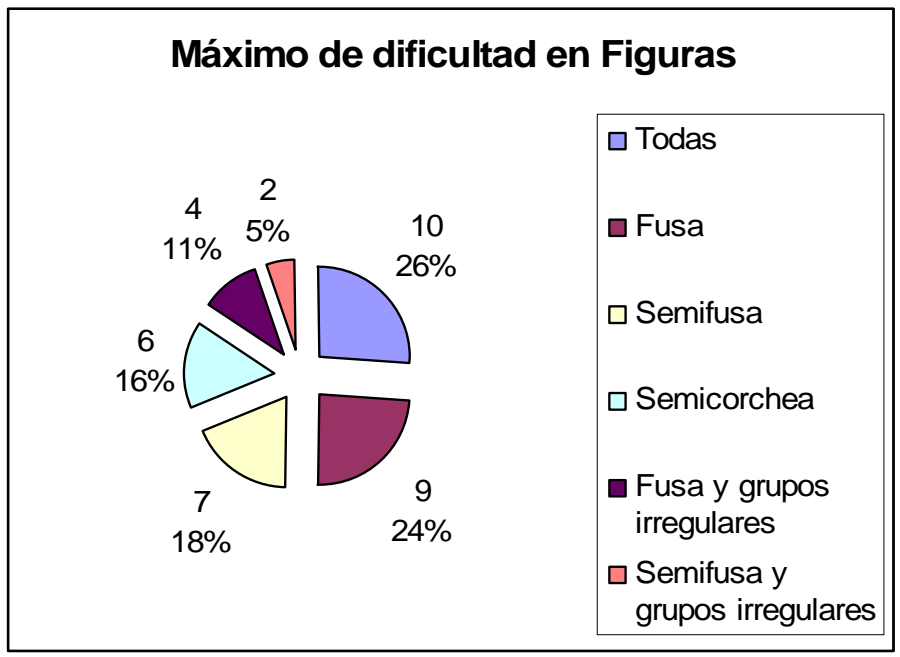

\section{Forma de introducir las dificultades}

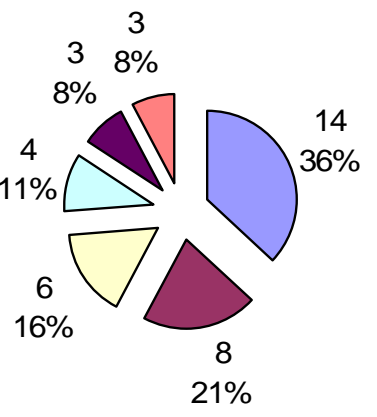

$\square$ Progresiva. Casi idónea

$\square$ Progresiva. No idónea

$\square$ Disgregada

$\square$ Progresiva. Idónea

$\square$ En tromba

a Fuera de análisis 


\subsection{MÉTODOS QUE CONTEMPLAN LAS NOTAS DE ADORNO.}

Presentamos a continuación un análisis de las notas de adorno que aparecen en los distintos métodos, el modo de definirlas, agruparlas y tratarlas.

LÓPEZ REMACHA: Llama apoyaturas a éstas y a los mordentes de 1 nota, llama mordentes a los grupetos de 3 notas, sólo los anteriores.

ESLAVA: Agrupa todas las notas de adorno conocidas en dos tipos: las que nos apoyamos sobre ellas al ejecutarlas, y las que se ejecutan hiriendo o mordiéndolas pasajeramente. Según Eslava, al primer grupo pertenecen la apoyatura y la doble apoyatura; al segundo el mordente, grupo, medio grupo, círculo y semicírculo. No aclara cuál es la descripción de cada una de ellas.

SOBEJANO: Las divide en apoyaturas, que son éstas y los mordentes de 1 y 2 notas, y mordentes, que son los grupetos de 3 notas anteriores y su abreviatura. Similar a López Remacha.

PRELLEZO: Llama mordentes a unas notas en formas de semicorchea, sin barrar; apoyatura a la apoyatura armónica, y la define de manera bien difícil: una nota que forma parte del compás, y cuyo tiempo de duración está con la inmediata siguiente en la proposición de 2 a 1 o de 4 a 5..., y que debe ocupar la parte "sensible" del compás, o sea la fuerte; grupeto a dos, tres o cuatro pequeñas notas en forma de fusas barradas, afirma que para los de 3 y 4 notas se utiliza el signo $\sim$ sin que nombre siquiera el descendente, y los utiliza anteriores, posteriores y cuando los sitúa arriba de la nota principal, es para que sean de 4 notas.

VALERO habla así de los adornos: Mordentes de 1, 2 y 3 notas. Tomando su valor de la nota siguiente, los de una nota, y de la siguiente los de dos y tres si la nota anterior no es de mayor duración, en cuyo caso lo toman de ella. Los grupetos son siempre de cuatro notas y su duración siempre la toman de la nota que los antecede. 
MANENT: Llama apoyatura a ésta y al mordente de una nota, pero dice que éste es rápido, también apoyatura, pero doble, a los mordentes de dos notas, y grupetos a los de 3 y 4 ; pero nada más explica.

LLADÓ: Denomina apoyatura a ésta y a los mordentes de una y dos notas. A los de una los representa con una barra y con dos. Grupeto a los de 3 o más notas. Dice que toman el valor de su nota o de la anterior, según el gusto del ejecutante.

OBIOLS: Incluye entre las apoyaturas los mordentes rectos, entre los mordentes las abreviaturas de grupetos, y como grupetos, a los que llama "Grupos", solamente a los rectos ascendentes y descendentes.

MORÉ Y GIL: Los dividen en apoyaturas y mordentes, y éstos de una, dos, tres y cuatro notas, también rectos ascendentes y descendentes.

EGEA: Designa apoyatura simple a ésta y al mordente; doble a los mordentes de 2 notas. Los grupetos los define como lo hacemos en la actualidad. Llama cifras de mordentes o grupos cifrados a las abreviaturas de grupetos y apoyaturas de extensión a mordentes de dos notas con intervalos separados tipo floritura.

SABATÉS: Apellida apoyatura lenta a la auténtica apoyatura. Apoyatura rápida al mordente de una nota. Apoyaturas dobles a los mordentes de 2 notas, tanto rectos como mixtos. Mordentes a los mordentes a la segunda superior o inferior y a su abreviatura. Grupetos rectos y circulares, de 3 y 4 notas con sus abreviaturas.

ROGER JUNOI: Llama apoyatura simple a ésta y al mordente de una nota. Apoyatura doble a los mordentes de dos notas. Triple apoyatura a los grupetos de 3 notas. Cuádruple apoyatura a los grupetos de 4 notas.

Solamente incluye entre los mordentes al signo de abreviatura de mordente a la $2^{\mathrm{a}}$ superior $\rightsquigarrow$, y con él ejecuta a la $2^{\mathrm{a}}$ inferior e incluso mordentes de 1 nota.

Y para los grupetos, sólo utiliza el signo $\sim$ tanto anteriores como posteriores, no existiendo para el autor el grupeto ascendente. 
AMORÓS: Solamente cita la palabra mordente, pero son dobles, triples y hasta cuádruples, y no son estos últimos precisamente los grupetos de 3 ó 4 notas. Es similar a lo que manifiesta Moré, pero sin incluir la apoyatura.

VELÁZQUEZ: Apoyatura, la define como unas pequeñas notas en las cuales se apoya la voz antes de pasar a la que sigue, y que le da como valor la mitad de esta nota., aparece indistintamente ésta y el mordente de una nota, lo que parece querer decir que para Velázquez es todo lo mismo.

Mordente, escribe que son un grupo de dos notitas que se ejecutan con toda la rapidez. posible. O sea que para él no los hay de una nota.

Grupetos, los divide en de 3 y cuatro notas. Los de 3 notas explica que pueden ser rectos y circulares, que los primeros son rápidos y los segundos se adaptan al género de música, y que éstos se pueden representar con una abreviatura. No dice si pueden ser anteriores o posteriores

De los de 4 notas indica que son iguales que los de 3 , pero que los circulares toman el valor de la nota anterior.

EL PROGRESO MUSICAL: Solamente habla de los mordentes. A los de 2 notas a la $2^{\mathrm{a}}$ superior e inferior, los califica en semitrino ascendente y descendente. Directos ascendentes y descendentes a los rectos. Circulares a los mixtos.

PARDÁS: notita sencilla, notita doble, grupetto, mordente y trino; las dos primeras son los mordentes (para este autor no existe la apoyatura), las abreviaturas de mordentes son la misma para ascendentes y descendentes, esto es, la horizontal $\sim$ para los ascendentes y la misma, más pequeña, para los descendentes; incluye los mordentes entre los trinos, porque llama así a la abreviatura de mordente de dos notas a la segunda superior, o semitrino.

BUXÓ: no distingue entre apoyaturas y mordentes. En la explicación de su libro hay una franja verde al final en la que dice que al parecer en la época no había mucho acuerdo. 
Es llamativo que entre tantos autores y con diferencias históricas que van desde el año 1805 al 1920, algo más del siglo, hayan tantos contrastes en esta materia. Ya en una nota al pie en el estudio de Lecciones manuscritas graduadas, $2^{\circ}$ curso de Amancio Amorós, comentamos algo de esta cuestión, refiriéndonos al arrastre de los diferentes criterios en las notas de adorno en el XVIII, pero es que, como se puede observar, esas diferencias se arrastraron todo el XIX y parte del XX.

Solamente hay 4 autores en los que se asimila el criterio sobre estas notas, son López Remacha, Sobejano, Manent y Lladó, los métodos de los dos últimos son del mismo año, los anteriores tienen una diferencia de 30 años, e igualmente 30 con los dos últimos. De cualquier forma, a lo largo de un siglo los criterios sobre las notas de adorno han sido dispares.

Hay una cosa en la que varios métodos coinciden, que es en llamar apoyatura al mordente de una nota, y hasta el de dos.

\begin{tabular}{|l|l|l|}
\hline AUTOR & PARTES & $\begin{array}{l}\text { IINCLUYEN } \\
\text { ADORNOS? }\end{array}$ \\
\hline Carrera & 1 & No \\
\hline López Remacha & 1 & Sí \\
\hline Gomis & 1 & No \\
\hline Reguart & 1 & No \\
\hline Eslava & 4 & Sí \\
\hline Sobejano & 3 & Sí \\
\hline Aliaga & 1 & No \\
\hline Pérez Gascón & 2 iguales & No \\
\hline Prellezo & 1 & Sí \\
\hline Valero y Romero & 2 & Sí \\
\hline Funoll & 1 & No \\
\hline Calvó & 1 & No \\
\hline Manent & 1 & Sí \\
\hline Lladó & 2 & Sí \\
\hline Arrieta & 4 & No \\
\hline Obiols & 1 & Sí \\
\hline Moré y Gil & 4 & Sí \\
\hline Abrantes & 2 & No \\
\hline Penella & 1 & No \\
\hline Benito & 2 & No \\
\hline Egea & 1 & Sí \\
\hline Sabatés & 3 & Sí \\
\hline Agero & 3 & No \\
\hline Llupart & 1 & No \\
\hline Codinach & 1 & No \\
\hline Roger & 3 & Sí \\
\hline Amorós & 1 & Sí \\
\hline Velázquez & 3 & Sí \\
\hline $\begin{array}{l}\text { Brull } \\
\text { El progreso musical) }\end{array}$ & 3 & Sí \\
\hline Pardás & & Sí \\
\hline AAVV & 2 & No \\
\hline & 2 & \\
\hline & & \\
\hline
\end{tabular}




\begin{tabular}{|l|l|l|}
\hline (Escuela del solfeo) & & \\
\hline Vancell & 1 & No \\
\hline Brull & 1 & No \\
\hline Amorós & 2 & No \\
\hline Espino & 1 & No \\
\hline Abreu & $2($ de 5$)$ & No \\
\hline Llorca & 1 & No \\
\hline Buxó & 3 & Sí \\
\hline
\end{tabular}

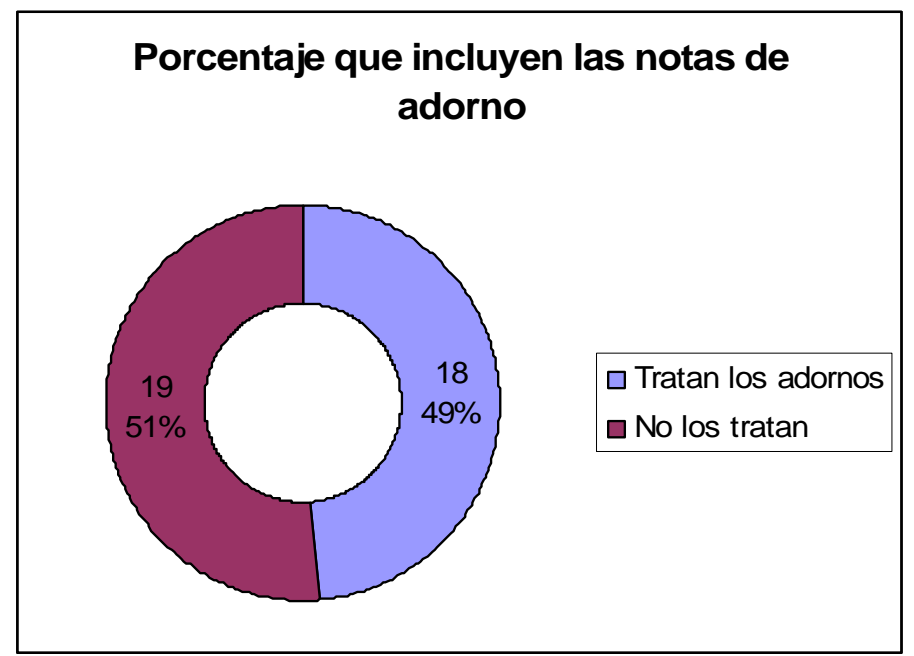




\subsection{DIFICULTADES MELÓDICAS Y EJERCICIOS DE ENTONACIÓN:}

Aproximadamente la mitad de autores desarrollados, y no en todos los volúmenes, plantean dificultades melódicas de cierta importancia en sus lecciones, como son intervalos aumentados y disminuidos, cromatismos, enarmonías, saltos interválicos fre-

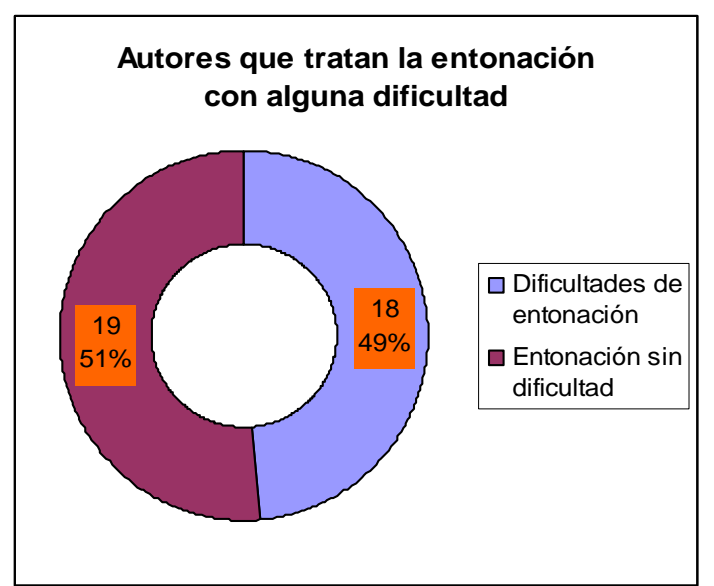
cuentes, incluso intervalos compuestos; y estos autores son: Eslava, en su $2^{\mathrm{a}}$ y $3^{\mathrm{a}}$ parte; Pérez Gascón en su Método de solfeo y principios de canto; Manent; Lladó; Arrieta; Obiols; Moré, en su $3^{\mathrm{a}}$ y $4^{\mathrm{a}}$ parte; Benito en la $2^{a}$ parte; Agero; Roger; Velázquez: $D i$ dáctico Musical; Escuela del Solfeo; Brull, Melecio; Amorós en Lecciones manuscritas; Espino; Llorca en su $2^{\circ}$ libro y Buxó también en su $2^{\circ}$ libro.

De todos ellos, los que mayores dificultades de entonación introducen son Eslava y, sobre todo, Arrieta.

Pero no todas las dificultades tienen la misma justificación; los hay que parece que el objetivo sea poner la dificultad por la dificultad, mientras otros plantean dificultades melódicas porque son necesarias para construir una buena melodía, generosa y con musicalidad. Estos son: Eslava, cuyas melodías tienen una gran musicalidad. Pérez Gascón, con melodías muy atractivas. Valero. Funoll. Lladó en su $2^{\mathrm{a}}$ parte. Llupart. Velázquez $2^{a}$ parte. A.A.V.V. Didáctico Musical, creemos que son las melodías más bonitas que método de esa época lleve, y Abreu.

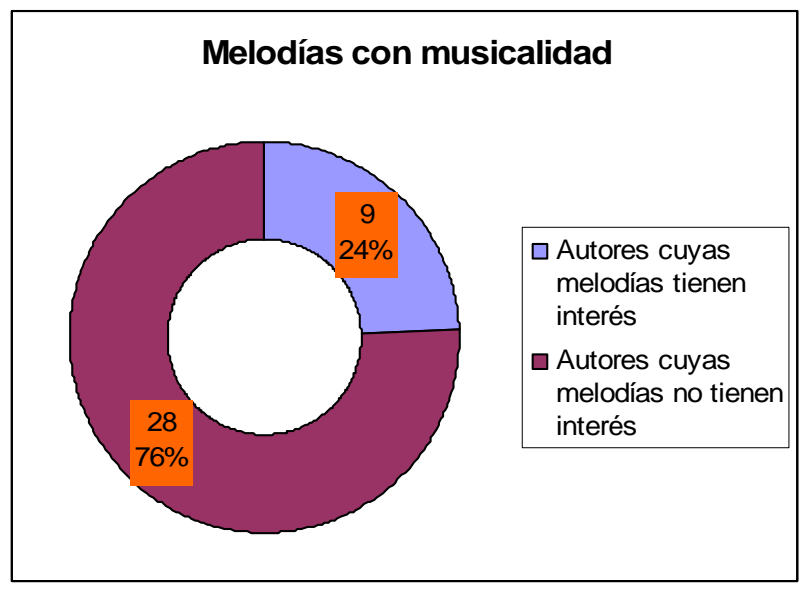




\subsubsection{INTERVÁLICA: MÉTODOS QUE INCLUYEN EJERCICIOS DE ENTONACIÓN}

\begin{tabular}{|c|c|c|}
\hline AUTOR & AÑO & $\begin{array}{c}\text { AUTORES QUE } \\
\text { INCLUYEN EJERCICIOS } \\
\text { DE ENTONACIÓN }\end{array}$ \\
\hline Carrera & 1805 & no \\
\hline López Remacha & 1815 & no \\
\hline Gomis & 1826 & sí \\
\hline Reguart & 1839 & no \\
\hline Eslava & 1845 & sí \\
\hline Sobejano & $1845 ?$ & sí \\
\hline Aliaga & 1847 & sí \\
\hline Pérez Gascón & $1848-1857$ & sí \\
\hline Prellezo & 1851 & sí \\
\hline Valero y Romero & $1856 ?$ & sí \\
\hline Funoll & $1860 ?$ & sí \\
\hline Calvó & $1860 ?$ & sí \\
\hline Manent & $1860 ?$ & sí \\
\hline Lladó & $1862 ?$ & sí \\
\hline Arrieta & 1868 a 1891 & no \\
\hline Obiols & Entre 1868 y $1891 ?$ & sí \\
\hline Moré y Gil & 1870 & sí \\
\hline Abrantes & $1879 ?$ & no \\
\hline Penella & 1879 & sí \\
\hline Benito & $1880 ?$ & sí \\
\hline Egea & 1881 & sí \\
\hline Sabatés & 1888 & sí \\
\hline Agero & Entre 1882 y $1900 ?$ & sí \\
\hline Llupart & $1884 ?$ & no \\
\hline Codinach & $1890 ?$ & sí \\
\hline Roger & 1891 & sí \\
\hline Amorós & 1890 & sí \\
\hline Velázquez & $1895 ?$ & sí \\
\hline $\begin{array}{l}\text { Brull } \\
\text { (El progreso musical) }\end{array}$ & 1898 & sí \\
\hline Pardás & Entre 1864 y $1900 ?$ & sí \\
\hline $\begin{array}{l}\text { AAVV } \\
\text { (Escuela del solfeo) }\end{array}$ & $1900 ?$ & sí \\
\hline Vancell & 1902 & sí \\
\hline Brull & $1923 ?$ & no \\
\hline Amorós & 1910 & no \\
\hline Espino & $1912 ?$ & no \\
\hline Abreu & $1914 ?$ & no \\
\hline Llorca & $1916 ?$ & sí \\
\hline Buxó & $1920 ?$ & sí \\
\hline
\end{tabular}




\begin{tabular}{|c|c|c|c|}
\hline \multicolumn{4}{|c|}{$\begin{array}{l}\text { DIVISIÓN EN } 4 \text { GRUPOS DE LOS AUTORES QUE INCLUYEN EJERCI- } \\
\text { CIOS DE INTERVALOS DE ENTONACIÓN }\end{array}$} \\
\hline \multirow[t]{10}{*}{ I. L. $\sin$} & I. L. con & P. I. con & P. I. sin \\
\hline & & Gomis & \\
\hline & & & Eslava \\
\hline & Sobejano & & \\
\hline & Aliaga & & \\
\hline & & & Pérez Gascón \\
\hline & Prellezo & & \\
\hline & Valero & & \\
\hline & Funoll & & \\
\hline & Calvó & & \\
\hline \multicolumn{4}{|l|}{ Manent } \\
\hline \multicolumn{4}{|l|}{ Lladó } \\
\hline \multicolumn{4}{|l|}{ Obiols } \\
\hline & Moré y Gil & & \\
\hline \multicolumn{4}{|l|}{ Penella } \\
\hline & De Benito & & \\
\hline & De Egea & & \\
\hline \multicolumn{4}{|l|}{ Sabatés } \\
\hline & Agero & & \\
\hline \multicolumn{4}{|l|}{ Codinach } \\
\hline \multicolumn{4}{|l|}{ Roger } \\
\hline & Amorós & & \\
\hline \multicolumn{4}{|l|}{ Velázquez } \\
\hline & $\begin{array}{l}\text { Brull (El } \\
\text { progreso } \\
\text { musical) }\end{array}$ & & \\
\hline \multicolumn{4}{|l|}{ Pardás } \\
\hline & & $\begin{array}{l}\text { Escuela del } \\
\text { solfeo }\end{array}$ & \\
\hline Vancell & & & Llorca \\
\hline Buxó & & & \\
\hline
\end{tabular}

I. L. $\sin =$ Intervalos lineales sin preparación

I. L. $\operatorname{con}=$ Intervalos lineales con preparación

P. I. con $=$ Intervalos personalizados con preparación

P. I. $\sin =$ Intervalos personalizados sin preparación

De los métodos estudiados, hay 28 autores que incluyen ejercicios para la práctica interválica, y 9 que no.

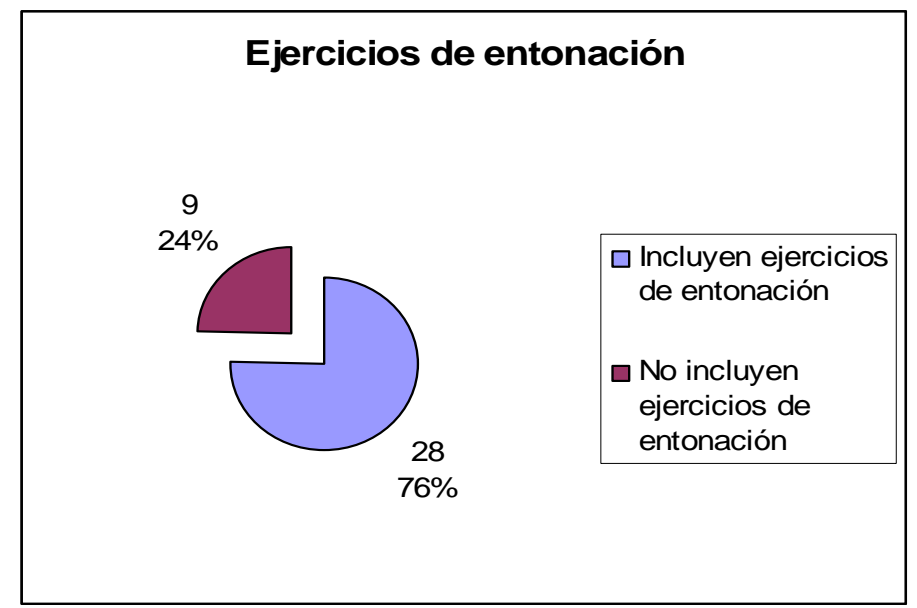


Los 28 que incluyen estos ejercicios, los hemos dividido en 4 grupos:

a) los que se limitan a poner ejercicios desde $2^{\mathrm{a}}$ a $8^{\mathrm{a}}$ sin preparación (intervalos lineales sin preparación "I. L. sin";

b) quienes proceden de la misma manera, pero con preparación (intervalos lineales con preparación "I. L. con";

c) aquellos que personalizan los intervalos, o sea que tratan por separado cada uno de ellos, incidiendo en algunos o en todos y en un orden más o menos apropiado para la mayor penetración del alumno en la entonación; en este grupo también hay quienes los hacen preparándolos ("P. I. con”).

d) o sin la preparación (personalización de intervalos sin preparación "P. I. sin")

Son mayoría los que se limitan a exponer los intervalos unos tras otros sin más. Minoría quienes tratan cada uno de ellos, que es lo verdaderamente pedagógico, y dentro de esto hay más que preparan los saltos, que es lo más adecuado, que quienes no lo hacen.

Después de analizados, quedan como sigue:

\section{Forma de presentar los ejercicios}

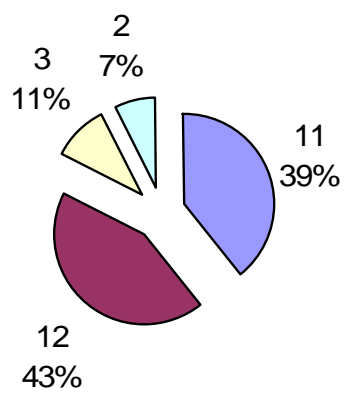

I. L. $\sin =11$, con la particularidad de que el método de Codinach sólo llega hasta la $6^{\mathrm{a}}$ y el de Pardás hasta la $5^{\mathrm{a}}$, el resto los obvian.
I. L. $\operatorname{con}=12$
P. I. $\sin =3$
P. I. $\operatorname{con}=2$ 


\subsection{OPINIONES SOBRE LA CALIFICACIÓN DE LOS INTERVALOS DE CUARTA Y QUINTA.}

En un orden cronológico, de más a menos antiguo, hay 8 autores, de entre los que incluyen teoría en su método, que califican los intervalos de cuarta y quinta como mayores y menores y no como justos, son los siguientes:

$\begin{array}{lll}\begin{array}{ll}\text { AUTOR } \\ \text { Eslava }\end{array} & \begin{array}{l}\text { ANO DEL LIBRO } \\ \text { ONESERVACIONES }\end{array} & \begin{array}{l}\text { OBSER } \\ \text { En la explicación detallada de este método ya } \\ \text { mencionamos nuestro acuerdo con tal teoría }\end{array} \\ \text { Pérez Gascón } & 1857 & \begin{array}{l}\text { También hacemos ahí un pequeño comentario al } \\ \text { respecto }\end{array} \\ \text { Moré } & 1870 & \\ \text { Amorós } & 1890 & \\ \text { Roger Junoi } & 1891 & \\ \text { Agero } & 1900 ? & \text { Las llama menor o justa y mayor o justa } \\ \text { Vancell } & 1902 & \end{array}$

Ocho autores que van desde mitad del siglo XIX a principios del XX, lo que da una ligera idea de que esta calificación de las cuartas y quintas no era una cosa puntual, una teoría aislada, sino que estaba bastante generalizada.

\subsection{DIFERENTES DENOMINACIONES DE LAS ESCALAS MENORES.}
AUTOR
AÑNO DENOMINACIÓN
Eslava
1845 A la armónica "escala propia" y a la escala melódica "escala menor", y también escala menor con alteración.
Pérez Gascón
1857 No les da nombre alguno, sino que dice que se alteran los gra- dos $6^{\circ}$ y $7^{\circ}$ cuando sube, y que también conviene practicar la escala menor sin el $6^{\circ}$ grado alterado
Moré
1870 "Escala de La natural modo menor" a la armónica
Amorós
1890 Sin modificar (natural), alterada o melódica y propia o harmó- nica
Brull (El pro- 1898 Propia a la natural y alterada a las armónica y melódica 


\subsection{TIPO DE ARMONÍA EMPLEADA EN LOS MÉTODOS}

\begin{tabular}{|c|c|c|c|}
\hline AUTOR & PARTES & $\begin{array}{c}\text { ¿LLEVA } \\
\text { ACOMPAÑAMIENTO? }\end{array}$ & ARMONÍA UTILIZADA $^{1}$ \\
\hline Carrera & 1 & Sí & Clásica \\
\hline López Remacha & 1 & Sí & Clásica \\
\hline Gomis & 1 & Sí & Clásica \\
\hline Reguart & 1 & No & \\
\hline Eslava & 4 & Sí & Alterada \\
\hline Sobejano & 3 & Sí & Clásica \\
\hline Aliaga & 1 & No & \\
\hline Pérez Gascón & 2 iguales & No & \\
\hline Prellezo & 1 & No & \\
\hline Valero y Romero & 2 & Sí & Clásica \\
\hline Funoll & 1 & No & \\
\hline Calvó & 1 & Sí & Clásica \\
\hline Manent & 1 & Sí & Clásica \\
\hline Lladó & 2 & Sí & Clásica \\
\hline Arrieta & 4 & Sí & Alterada \\
\hline Obiols & 1 & Sí & Romántica \\
\hline Moré y Gil & 4 & Sí & Alterada \\
\hline Abrantes & 2 & No & \\
\hline Penella & 1 & No & \\
\hline Benito & 2 & No & \\
\hline Egea & 1 & Sí & Romántica \\
\hline Sabatés & 3 & No & \\
\hline Agero & 3 & No & \\
\hline Llupart & 1 & Sí & Romántica \\
\hline Codinach & 1 & No & \\
\hline Roger & 3 & No & \\
\hline Amorós & 1 & No & \\
\hline Velázquez & 3 & No & \\
\hline $\begin{array}{l}\text { Brull } \\
\text { (El progreso musical) }\end{array}$ & 3 & Sí & Alterada \\
\hline Pardás & 2 & No & \\
\hline $\begin{array}{l}\text { AAVV } \\
\text { (Escuela del solfeo) }\end{array}$ & 2 & No & \\
\hline Vancell & 1 & No & \\
\hline Brull & 1 & Sí & Romántica \\
\hline Amorós & 2 & No & \\
\hline Espino & 1 & Sí & Romántica \\
\hline Abreu & $2(\mathrm{de} 5)$ & Sí & Romántica \\
\hline Llorca & 1 & No & \\
\hline Buxó & 3 & No & \\
\hline
\end{tabular}

Lo primero que destaca, a la vista de la tabla, es que un gran porcentaje de métodos no incluyen acompañamiento en sus lecciones, lo cual indica que para muchos de los autores no era importante lo que nosotros consideramos fundamental y se considera imprescindible en la actualidad $^{2}$, que, a excepción de los ejercicios rítmicos, tanto

\footnotetext{
${ }^{1}$ Extractada de los cuadros de información general de los métodos.

${ }^{2}$ En las oposiciones a profesor de lenguaje musical dos de las pruebas son acompañar una lección al piano con acompañamiento realizado y con bajo cifrado.
} 
ejercicios de entonación como lecciones, deben ser acompañadas siempre o en algún momento, pues es lo que más contribuye a entronizar en el alumno el sentido tonal.

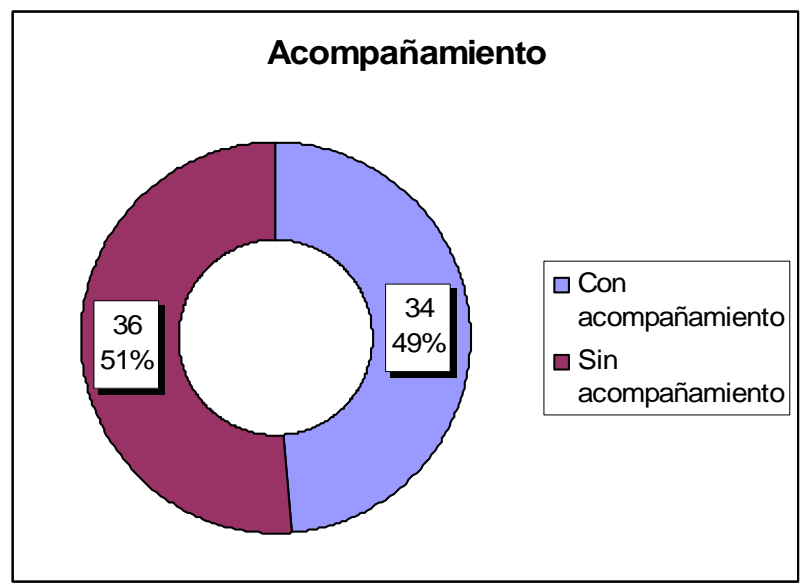

dividiéndola en 3 grupos:
De los 70 métodos o partes analizados, 32 no incluyen acompañamiento y 38 sí. Entre los que no lo incluyen hay métodos de todos los años de edición, no es una exclusiva de los más remotos.

Se ha analizado el arquetipo de armonía empleada en los 38 métodos que incluyen acompañamiento,

Armonía clásica, armonía romántica y armonía alterada, siendo mayoría los que tienen una armonía simple, sencilla y clásica. Naturalmente entre ellos están los más antiguos, pero también los hay con este tratamiento entre los de finales del XIX y principios del XX.

El grupo cuyas lecciones están armonizadas dentro de una armonía más avanzada y elaborada, calificada por nosotros de romántica, es el que sigue en cantidad, el primero en poder calificarse así es la $3^{\text {a }}$ parte de Eslava, después ya no hay otros hasta llegar a los de Arrieta, y el resto a partir de éste.

Son minoría los que llevan una armonía que puede considerarse alterada, por la cantidad de cromatismos, grados de la escala alterados, acordes con notas añadidas, resoluciones excepcionales u otros procedimientos armónicos más modernos, y los encontramos a partir de los métodos de Moré y Gil.

Resumiendo, hay 20 métodos que llevan una armonía clásica, 13 con una romántica y 5 con una armonía alterada.

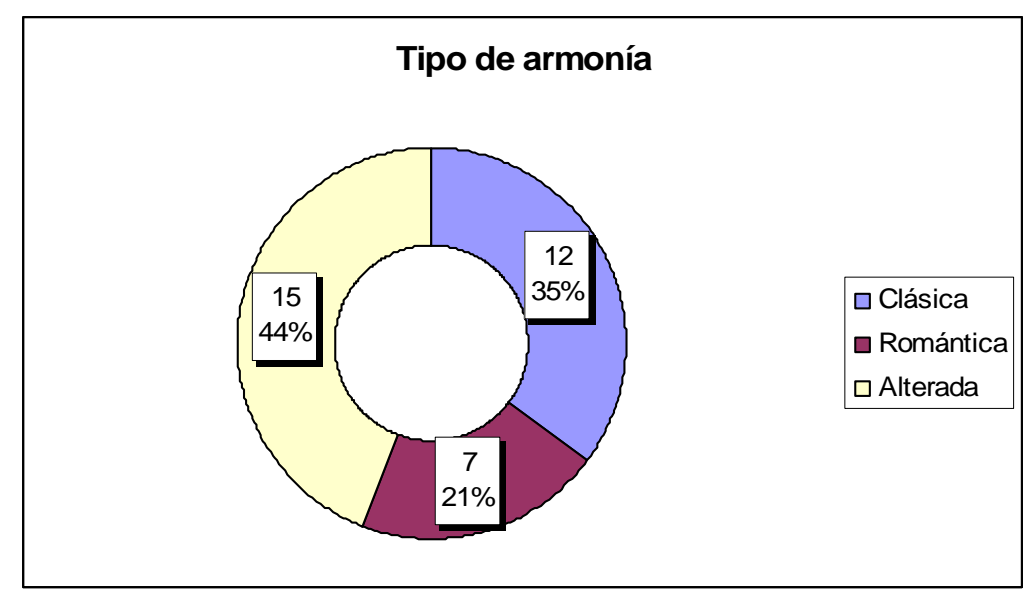




\subsection{FORMAS QUE ADOPTAN LAS LECCIONES}

En los distintos métodos hemos visto las combinaciones formales más variopintas, desde la ausencia de forma, pasando por las formas primarias, monofrase, las bipartitas, tripartitas, cuatripartitas, de 5 y hasta de 6 secciones.

Como bipartitas encontramos las formas A - B, la mayoritaria, y la A - A'.

Entre las tripartitas están A - B - C; A - B - A’ la mayoritaria, no sólo entre éstas, sino entre todas; A - A' - A'”; A - B - A; A - A' - B y A - B - B'.

Cuatripartitas son A - B - C - D; A - B - B' - B' '; A - B - A' - C; A - B - C $\mathrm{A}^{\prime} ; \mathrm{A}-\mathrm{B}-\mathrm{A}^{\prime}-\mathrm{A}^{\prime}$; $\mathrm{A}-\mathrm{B}-\mathrm{A}^{\prime}-\mathrm{A} ; \mathrm{A}-\mathrm{B}-\mathrm{C}-\mathrm{C}^{\prime} ; \mathrm{A}-\mathrm{B}-\mathrm{A}-\mathrm{B}^{\prime} ; \mathrm{A}-\mathrm{A}^{\prime}-\mathrm{B}-$ B'; A - A' - B - A'; A - B - C - A ; A - A' - B - A' ; A - B - C - B' y A - A' - B $\mathrm{C}$, todas ellas minoritarias, pero habiendo más cantidad de la forma $\mathrm{A}-\mathrm{B}-\mathrm{C}-\mathrm{D}$.

Algunas de 5 partes A - B - A' - C - A''; A - B - c - B' - A y solamente una de 6 partes $\mathrm{A}-\mathrm{B}-\mathrm{A}^{\prime}-\mathrm{C}-\mathrm{B}-\mathrm{C}$.

También hay alguna, muy pocas, con el formato de Tema y Variaciones.

De entre todas, la preferida de la mayor parte de estos compositores es la forma lied ternario A - B - A', le sigue la forma binaria A - B, luego, a no mucha distancia, la ternaria A - B - C; ya a más distancia la binaria A - A', y la ternaria A - B - A. Las demás aparecen menos veces.

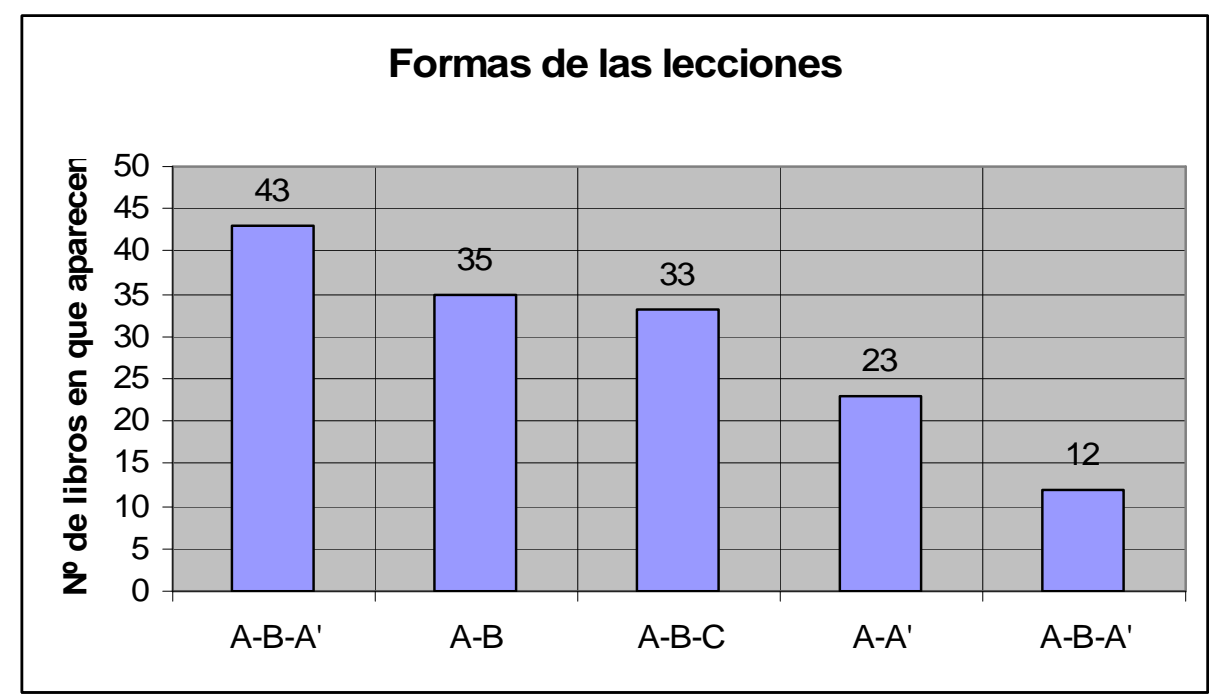




\subsection{CANTIDAD DE LECCIONES QUE TIENEN INTRODUCCIÓN, CODAS O INTERMEDIOS INSTRUMENTALES}

De los 70 métodos o partes examinados, la mayoría no tiene ninguna lección con introducciones, intermedios, ni codas, lo que demuestra una cierta carencia de musicalidad. No es que sea condición indispensable que los lleven, pero una introducción prepara al solfista para entrar en la altura debida, y un intermedio le hace descansar; si alguna se completa con una coda final, se logra que las lecciones tengan un diálogo y se conviertan en algo más que pura rutina lectora.

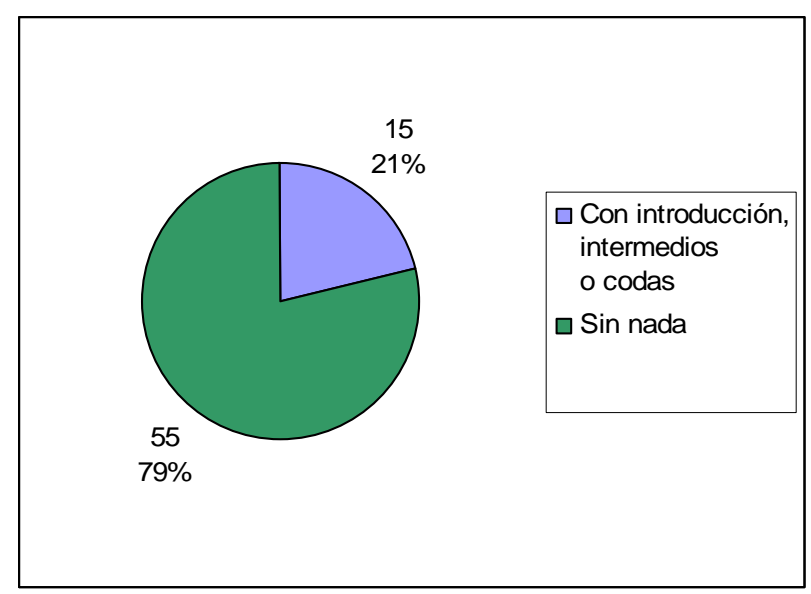

De entre los métodos que tienen alguno o varios de estos pequeños pasajes, encontramos mayoritariamente los que tienen alguna introducción, que son ciento cuarenta y una lecciones entre todos los métodos. Cincuenta y dos llevan algún tipo de final o coda al piano. Y treinta y siete contienen algún corto intermedio.

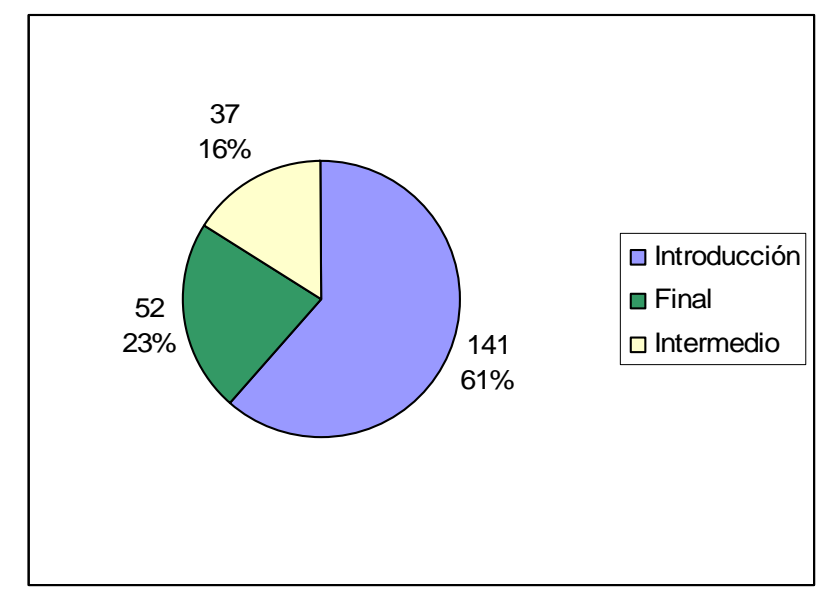




\subsection{MÉTODOS QUE CONTIENEN TEORÍA DE LA MÚSICA}

Son la mayoría los que contienen algo, bastante o mucho de lecciones teóricas, concretamente 46 contra 24 que nada de ella incluyen.

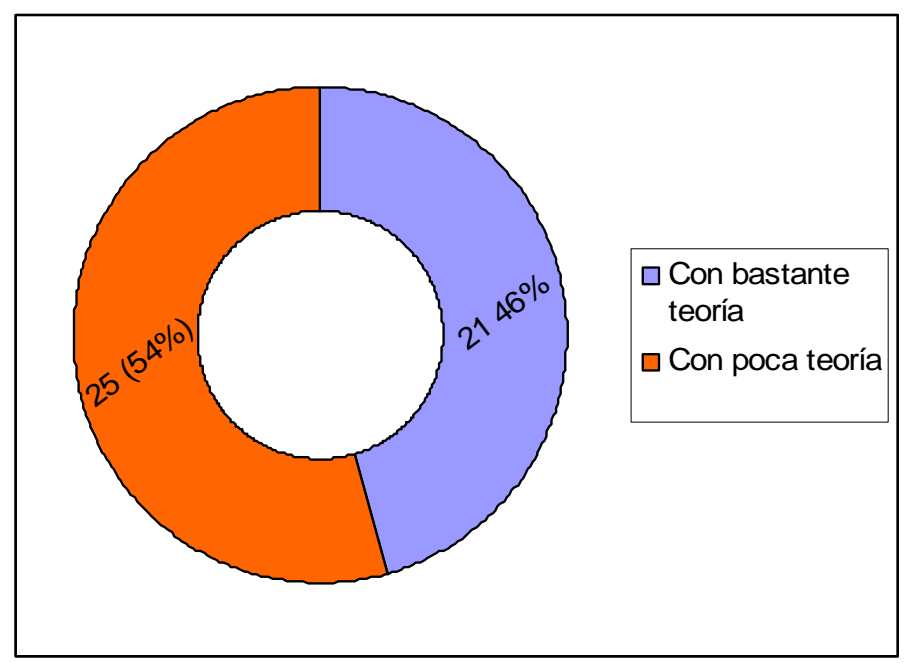

De entre los 46 métodos que insertan teoría, 21 tienen mucha o bastante, 25 tienen poca o muy poca, la básica o imprescindible.

Ya nos manifestamos en el punto 3 sobre la idea de que la teoría debe ir en libro aparte, y no anteponerse a la práctica. Está bien que un libro de solfeo contenga la teoría indispensable para poder interpretar los signos, pero nada más.

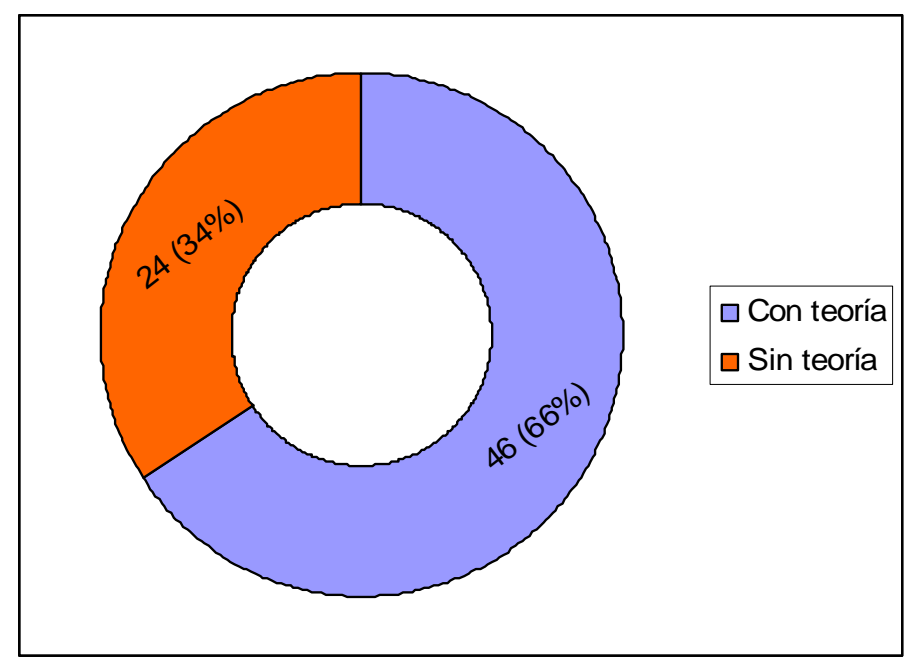




\subsection{ASPECTOS CURIOSOS ENCONTRADOS EN ALGUNOS MÉTODOS}

\section{NOMBRES DE LAS FIGURAS Y SILENCIOS.-}

Los 4 primeros métodos analizados y expuestos (Carrera, López Remacha, Gomis y Reguart) todavía usan la denominación renacentista y barroca para las figuras de nota (esto es, semibreve, mínima, semínima, corchea, semicorchea, fusa y semifusa). Eslava es el primero en utilizar la denominación actual, cambiando la semibreve por redonda, la mínima por blanca y la semínima por negra; no así con las corcheas y siguientes, como más abajo explicamos.

Sin embargo, autores posteriores, y bastante posteriores, casi hasta final del siglo XIX, estuvieron utilizando la denominación antigua, y algunos emplearon las dos.

Por orden de más a menos antiguo son los siguientes quienes adoptaron, después de Eslava, la denominación antigua de las figuras de nota: Sobejano (1845?), Aliaga (1847), Pérez Gascón (1852), Valero (1856?) emplea las dos denominaciones, Funoll (1860?) también emplea las dos maneras, Calvó (1860?), Lladó (1860?), Obiols (1868), Egea (1881) y Velázquez (1895?) también las llaman de las dos maneras y por último Pardás (1900?) aún utiliza la denominación antigua.

Respecto a las semicorcheas, fusas y semifusas, Eslava las denomina "dobles corcheas", "triples corcheas" y "cuádruples corcheas". Valero solamente emplea la denominación de "dobles corcheas" para las semicorcheas. Funoll igual que Eslava. Penella (1879) igual que Valero. Y Agero (1900?) como Eslava y Funoll.

Como se ve, todavía en 1900 no había una unidad de criterio en estas denominaciones.

Otra cosa, también a destacar, es la forma del silencio de negra. En el primer método analizado (Carrera Lanchares) encontramos una forma tan personal que no se presenta en ningún otro, quizás por ser manuscrito. Pero ya en el siguiente (López Remacha) lo vemos con la forma del actual de corchea al revés, figura que otros muchos autores reproducen: Gomis, Reguart, Eslava, Sobejano, Aliaga, Pérez Gascón, Prellezo, Valero y Funoll. Es Calvó i Puig (1860?, quizás 1900) el primero en utilizar el formato actual del silencio de negra. 
Otros autores cuyas ediciones son posteriores (o quizás anteriores, según explicamos en nota al pie del enunciado del libro de Calvó) como Obiols, Moré y Penella lo representan con la forma antigua.

Después del método de Calvó, y con las excepciones indicadas arriba (que bien podrían ser anteriores), en todos aparece con el formato actual. Sin embargo, de nuevo, algunos otros métodos con toda seguridad posteriores, vuelven a representarlo con la forma antigua. Son los de Agero (1900), Codinach (1890?), Roger (1891), Amorós (1890), Pardás (1864?, quizás 1900) y Vancell (1902).

Como se puede observar, estos últimos, todos alrededor de finales del XIX, más otros editados por esas fechas no empleaban esa forma. A partir de 1902 ya ninguno de los métodos estudiados vuelve a representar el silencio de negra con su figuración antigua.

\section{LOS DOBLES, TRIPLES Y CUÁDRUPLES PUNTILLOS.-}

Una cuestión ya comentada en el estudio de los métodos de Amancio Amorós (1910), pero que sintetizamos de nuevo aquí, es el que se refiere al triple y cuádruple puntillo.

Ya en el método de Salvador Reguart (1839) nos habla el autor del triple y cuádruple puntillo, sin poner ningún ejemplo ni lección que los contenga. Después Manent i Puig (1860?), casi 20 años después, nos vuelve a hablar, sólo hablar, pero nada más que del triple puntillo. Joaquín Lladó (mismo año aproximadamente) ya pone ejemplos de triple puntillo. Mateo Sabatés Estaper (1888), vuelve a mencionar el triple puntillo, pero sin utilizarlo en ninguna lección. Y es Amorós (1910), quien sí utiliza en algunas lecciones el triple y cuádruple puntillo,

\section{MANERAS DE MARCAR LOS COMPASES SEGÚN ALGUNOS AUTORES.-}

Reguart

Para el ternario, el primero bajo, el segundo a la izquierda y el tercero arriba; y para el cuaternario, bajo, izquierda, derecha y arriba.

Prellezo

Para el compás ternario dos movimientos hacia abajo y uno hacia arriba, para el binario uno bajo y otro arriba, para el cuaternario, dos abajo y dos arriba 
Calvó

No siendo igual entre los maestros el modo de dar los tiempos con la mano, lo dejamos a su voluntad, prefiriendo empero el que en compás de tres o cuatro tiempos se batan los dos primeros.

Obiols

Compasillo $1^{\circ}$ y $2^{\circ}$ tiempo bajo (uno a continuación del otro, como una subdivisión del mismo tiempo), $3^{\circ}$ hacía arriba inclinado a la derecha y el $4^{\circ}$ más arriba en la misma dirección. El de 3 bajo, izquierda y arriba.

Pardás

El 6/8 como 2 de 3/8 La manera de marcar el de tres partes dice que es bajo, izquierda y arriba, y también dice que se pueden marchar con la mano o el pie.

Algo que aprendimos ya maduros e introducidos en nuestra actividad profesional, y que creíamos producto de estudios modernos respecto a la métrica y a la dirección de orquesta, es la manera de marcar el compás de 6/8 subdividido. Esto es, marcando un cuaternario, normalmente dos subtiempos abajo, uno a la izquierda, el cuarto y quinto a la derecha y el sexto arriba, aunque, según la distribución de figuras, puede ser de otra manera, pero casi siempre dentro del marcaje cuaternario.

Pues bien, esto ya lo recomendaba Matías Aliaga en 1847, después Nicolau Manent (1860?), más tarde en 1888 Mateo Sabatés y en 1895 Primitivo Pardás. Los 3 últimos están más o menos dentro de una misma época, pero el primero, Aliaga, en 1847 ya prefería esta manera de marcar el 6/8, que en la actualidad es la más usada. Solamente 4 de entre los 70 métodos vistos enseñan a marcar así este compás, pero es sorprendente que después de ellos ninguno más lo vuelve a exponer así, y en época más reciente se ha vuelto a lo que creíamos una técnica actual de dirección.

\section{FALTAS DE ORTOGRAFÍA.-}

Hemos encontrado muchas palabras que, de acuerdo con el Diccionario de la Real Academia Española de la Lengua, serían hoy faltas de ortografía, y no sólo hoy, sino bastantes años atrás. No podemos juzgar si en los años en que fueron escritos estos libros sería correcta o no la escritura de estas palabras, por que no es nuestra especialidad ni el motivo de esta tesis, simplemente nos limitamos aquí a exponerlas como una rareza al día de hoy. 
Eran muchos los que no usaban la "x", obviaban los acentos en palabras agudas o esdrújulas, cambiaban la "j" por "g" y la "v" por "b".

Las siguientes están extraídas de los métodos de Hilarión Eslava, más extraño aun siendo clérigo, tenido por hombre culto, una personalidad en España. Tal vez no había reglas ortográficas muy precisas:

compas, estraña, ademas, mas, devil, notava, brebe, tubiera, ageno, hai, ecsiste, voi, ecsigir, vuelben, muger, baritono

Y éstas son otras varias encontradas en distintos métodos:

espresión, sesta, estrangero, espresa, decisibo, dibidir, sectimas, dibiden, lleban, á bisto, vinario, magestuoso, mui, raia, frequente, logica, ayre, quales, fixando, baxa. 
Métodos para la enseñanza profesional y para la no profesional

\subsection{MÉTODOS QUE SE HICIERON PARA LA ENSEÑANZA PRO- FESIONAL DE LA MÚSICA Y MÉTODOS QUE NO SE HICIERON CON ESE FIN.}

Hacemos aquí dos columnas con los nombres de los autores que hemos estudiado, separados por la utilidad que creyeron darle a sus métodos sus creadores.

MÉTODOS DEDICADOS A LA ENSENANZA PROFESIONAL

López Remacha

Gomis

Eslava

Sobejano

Pérez Gascón (aunque también los hizo pensando en la enseñanza general)

Prellezo

Valero y Romero

Funoll

Calvó

Manent

Lladó

Arrieta

Obiols

Moré

Benito Cosme de

Egea

Sabatés

Agero

Llupart

Roger Junoi

Amorós

Velázquez

Brull (El Progreso musical)

AAVV (Escuela del solfeo)

Brull Ayerra

Amorós

Espino

Abreu

Llorca

Buxó
MÉTODOS DEDICADOS A LA ENSEÑANZA NO PROFESIONAL

Carrera

Reguart

Aliaga

Abrantes

Penella

Codinach

Pardás

Vancell

Muchísimos más (algo más del 75\%) eran los que se dedicaban a la enseñanza del solfeo para los Conservatorios o Escuelas de Música, y un porcentaje mucho menor (menos del 25\%) dedicados a quienes quisieran acceder a una pequeña información en los principios del lenguaje musical 


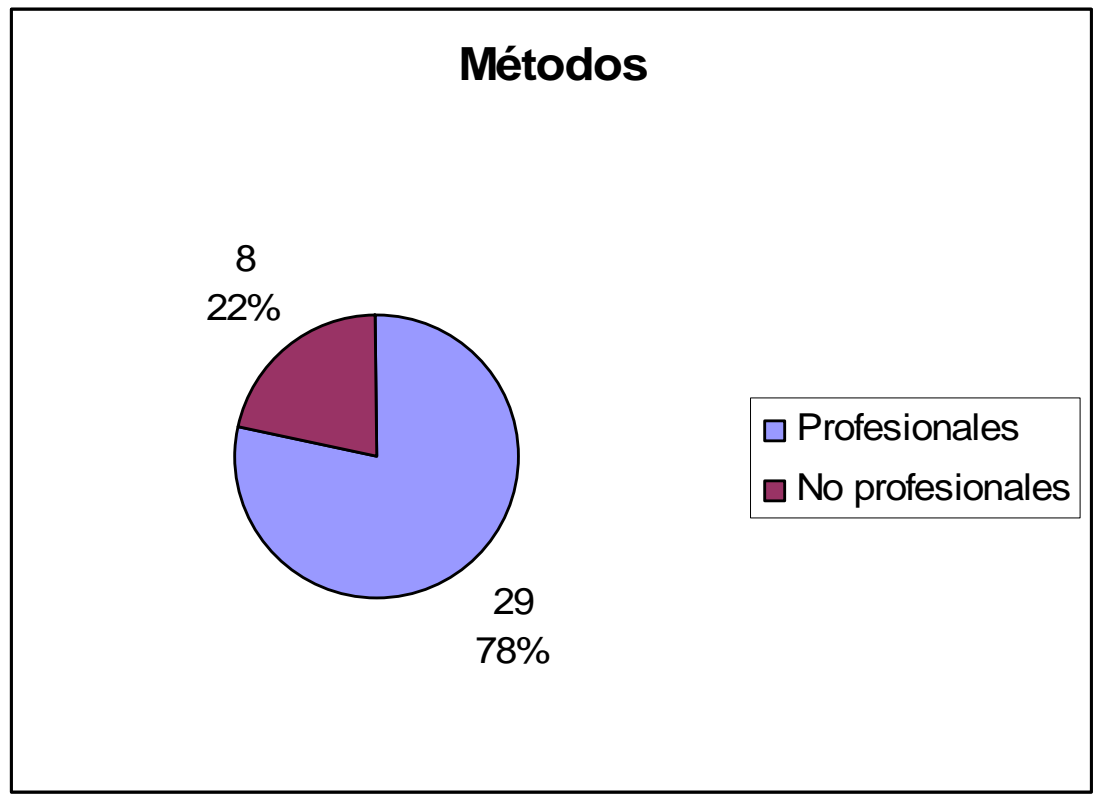


5.16. CONSIDERACIONES SOBRE LA UTILIDAD QUE, A NUESTRO JUICIO, PUDIERON TENER LOS MÉTODOS EXAMINADOS EN SU ÉPOCA.

\begin{tabular}{|l|l|}
\hline \multicolumn{1}{|c|}{ AUTOR } & VALÍA DE SUS MÉTODOS \\
\hline Carrera & Nada \\
\hline López Remacha & Nada \\
\hline Gomis & Aceptable \\
\hline Reguart & Nada \\
\hline Eslava & Sí \\
\hline Sobejano & Aceptable \\
\hline Aliaga & Nada \\
\hline Pérez Gascón & Sí \\
\hline Prellezo & Nada \\
\hline Valero y Romero & Nada \\
\hline Funoll & Aceptable \\
\hline Calvó & Nada \\
\hline Manent & Nada \\
\hline Lladó & Sí \\
\hline Arrieta & Nada \\
\hline Obiols & Nada \\
\hline Moré y Gil & Sí \\
\hline Abrantes & Nada \\
\hline Penella & Nada \\
\hline Benito & Nada \\
\hline Egea & Nada \\
\hline Sabatés & Nada \\
\hline Agero & Nada \\
\hline Llupart & Sí \\
\hline Codinach & Sí \\
\hline Roger & Sí \\
\hline Amorós & Sí \\
\hline Velázquez & Nada \\
\hline $\begin{array}{l}\text { Brull } \\
\text { (El progreso musical) }\end{array}$ & Sí \\
\hline Pardás & Nada \\
\hline $\begin{array}{l}\text { AAVV } \\
\text { (Escuela del solfeo) }\end{array}$ & Nada \\
\hline Vancell & Sí \\
\hline Brull & Sí \\
\hline Amorós & Sí \\
\hline Espino & Sí \\
\hline Abreu & Sí \\
\hline Llorca & Nada \\
\hline Buxó & Aceptable \\
\hline & \\
\hline
\end{tabular}


Autores cuyos métodos, con más o menos reparos, consideramos que pudieron ser útiles para la enseñanza, y métodos poco o nada provechosos.

ÚTILES

Gomis

Eslava

Sobejano

Pérez Gascón

Funoll

Lladó

Moré

Llupart

Codinach

Roger Junoi

Amorós

Brull (El progreso musical)

Vancell

Espino

Brull Ayerra

Abreu

Buxó
NO ÚTILES

Carrera

López Remacha

Reguart

Aliaga

Prellezo

Valero y Romero

Calvó

Manent

Arrieta

Obiols

Abrantes

Penella

Benito Cosme de

Egea

Sabatés

Agero

Velázquez

Pardás

AAVV (Escuela del solfeo)

Llorca

Son algo más los poco eficaces que los que podían, aunque fuera en su época, ser de interés. Concretamente 20 contra 17.

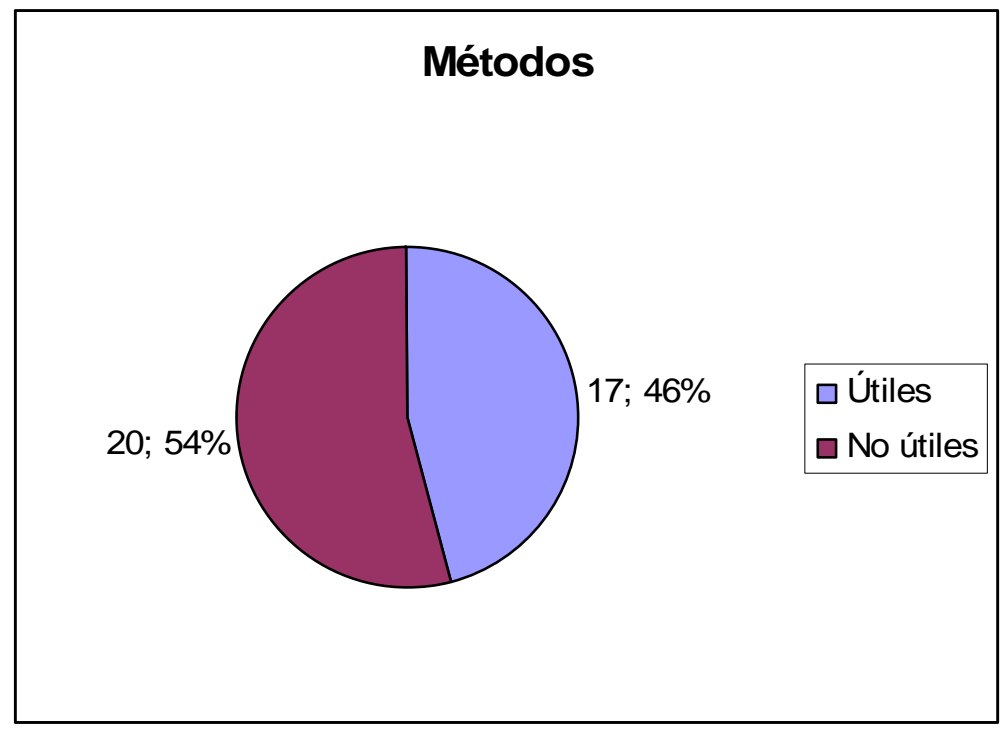




\subsection{CONSIDERACIONES SOBRE LA UTILIDAD ACTUAL DE LOS MÉTODOS EXAMINADOS}

PORCENTAJES DE COINCIDENCIA DE LOS MÉTODOS CON LOS PROGRAMAS VIGENTES EN CADA MOMENTO Y CON LOS PARÁMETROS ESTABLECIDOS POR NOSOTROS COMO ÓPTIMOS EN EL PROCESO DE ENSEÑANZA/APRENDIZAJE ACTUAL DEL SOLFEO.

\begin{tabular}{|c|c|c|}
\hline AUTOR & $\begin{array}{l}\text { Porcentaje de coincidencia con pro- } \\
\text { gramas }\end{array}$ & $\begin{array}{l}\text { Porcentaje de coincidencia } \\
\text { con parámetros actuales }\end{array}$ \\
\hline Carrera & $25 *$ & 0 \\
\hline López Remacha & 50 & 10 \\
\hline Gomis & 50 & 33 \\
\hline Reguart & $10^{1}$ & 10 \\
\hline Eslava & 100 & 50 \\
\hline Sobejano & 17 & 17 \\
\hline Aliaga & 0 & 10 \\
\hline Pérez Gascón & $* * 1^{\circ} 83 / / 2^{\circ} 50$ & $1^{\circ} 10 / / 2^{\circ} 33$ \\
\hline Prellezo & 5 & 0 \\
\hline Valero y Romero & $1^{\circ} 33 / / 2^{\circ} 0$ & $1^{\circ} 33 / / 2^{\circ} 0$ \\
\hline Funoll $^{2}$ & 45 & 33 \\
\hline Calvó & 75 & 33 \\
\hline Manent & 0 & 10 \\
\hline Lladó & $85^{3}$ & 0 \\
\hline Arrieta & $1^{\circ} 100 / / 2^{\circ} 50 / / 3^{\circ} 38 / / 4^{\circ} 67$ & $1^{\circ} 58 / / 2^{\circ} 33 / / 3^{\circ} 20 / / 4^{\circ} 0$ \\
\hline Obiols & 17 & 17 \\
\hline Moré y Gil & $1^{\circ} 20^{4} / / 2^{\circ} 20 / / 3^{\circ} 50$ & $1^{\circ} 0 / / 2^{\circ} 20 / 73^{\circ} 50$ \\
\hline Abrantes & $1^{\circ} 17 / / 2^{\circ} 17 / / 3^{\circ} 20$ & $1^{\circ} 17 / / 2^{\circ} 0 / / 3^{\circ} 33$ \\
\hline Penella & 20 & 33 \\
\hline Benito & $1^{\circ} 20 / / 2^{\circ} 33$ & $1^{\circ} 0 / / 2^{\circ} 0$ \\
\hline Egea & 17 & 0 \\
\hline Sabatés & $1^{\circ} 67 / / 2^{\circ} 17 / / / / 3^{\circ} 17$ & $1^{\circ} 50 / / 2^{\circ} 33 / / 3^{\circ} 0$ \\
\hline Agero & $1^{\circ} 17 / / 2^{\circ} 40 / / 3^{\circ} 17$ & $1^{\circ} 17 / / 2^{\circ} 0 / / 3^{\circ} 17$ \\
\hline Llupart & 0 & 0 \\
\hline Codinach & 33 & 17 \\
\hline Roger & $1^{\circ} 33 / / 2^{\circ} 10 / / 3^{\circ} 0$ & $1^{\circ} 17 / / 2^{\circ} 10 / / 3^{\circ} 0$ \\
\hline Amorós & $1^{\circ} 50 / / 2^{\circ} 67 / / 3^{\circ} 50$ & $1^{\circ} 33 / / 2^{\circ} 40 / / 3^{\circ} 0$ \\
\hline Velázquez & $1^{\circ} 17 / / 2^{\circ} 0 / / 3^{\circ} 0$ & $1^{\circ} 17 / / 2^{\circ} 17 / / 3^{\circ} 0$ \\
\hline $\begin{array}{l}\text { Brull } \\
\text { (El progreso musical) }\end{array}$ & $1^{\circ} 83 / / 2^{\circ} 83 / / 3^{\circ} 83$ & $1^{\circ} 33 / / 2^{\circ} 0 / / 3^{\circ} 0$ \\
\hline Pardás & $1^{\circ} 17 / / 2^{\circ} 0$ & $1^{\circ} 17 / / 2^{\circ} 0$ \\
\hline $\begin{array}{l}\text { AAVV } \\
\text { (Escuela del solfeo) }\end{array}$ & $1^{\circ} 67 / / 2^{\circ} 33$ & $1^{\circ} 17 / / 2^{\circ} 17$ \\
\hline Vancell & 33 & 33 \\
\hline Brull & 67 & 33 \\
\hline Amorós & $1^{\circ} 50 / / 2^{\circ} 67 / / 3^{\circ} 50$ & $1^{\circ} 33 / / 2^{\circ} 40 / / 3^{\circ} 0$ \\
\hline Espino & 0 & 0 \\
\hline Abreu & $1^{\circ} 50 / / 2^{\circ} 0$ & $1^{\circ} 10 / / 2^{\circ} 0$ \\
\hline Llorca & 0 & 0 \\
\hline Buxó & $1^{\circ} 20 / / 2^{\circ} 50 / / 3^{\circ} 0$ & $1^{\circ} 0 / / 2^{\circ} 0 / / 3^{\circ} 0$ \\
\hline
\end{tabular}

\footnotetext{
${ }^{1}$ Una pequeña parte de todos los elementos

${ }^{2}$ El primer método, de entre los analizados, posterior a la ley Moyano (ley de educación de 1857)

${ }^{3}$ La mitad del primer elemento

${ }^{4}$ Un poco más de un elemento
} 
* Coincidencia de elementos:

$$
\begin{aligned}
& 1=17 \% \\
& 2=33 \% \\
& 3=50 \% \\
& 4=67 \% \\
& 5=83 \% \\
& 6=100 \%
\end{aligned}
$$

** $1^{\mathrm{a}}=$ primera parte o primer libro del método en cuestión

$$
\begin{gathered}
2^{\mathrm{a}}=\text { segunda parte } \\
3^{\mathrm{a}}=\text { tercera parte, etc. }
\end{gathered}
$$

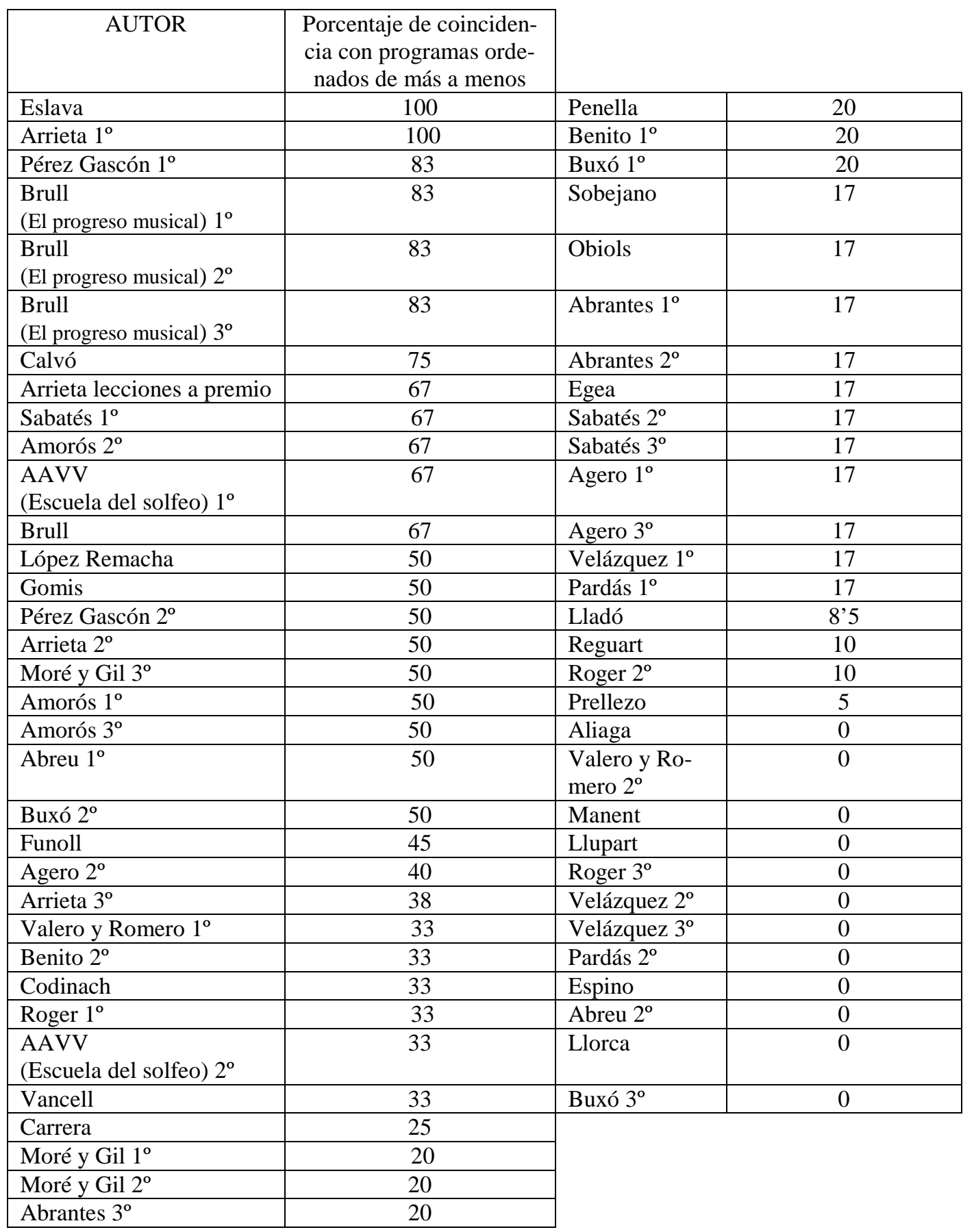


Resumen del "Grado de ajuste con los programas vigentes en el momento" de los distintos métodos analizados.

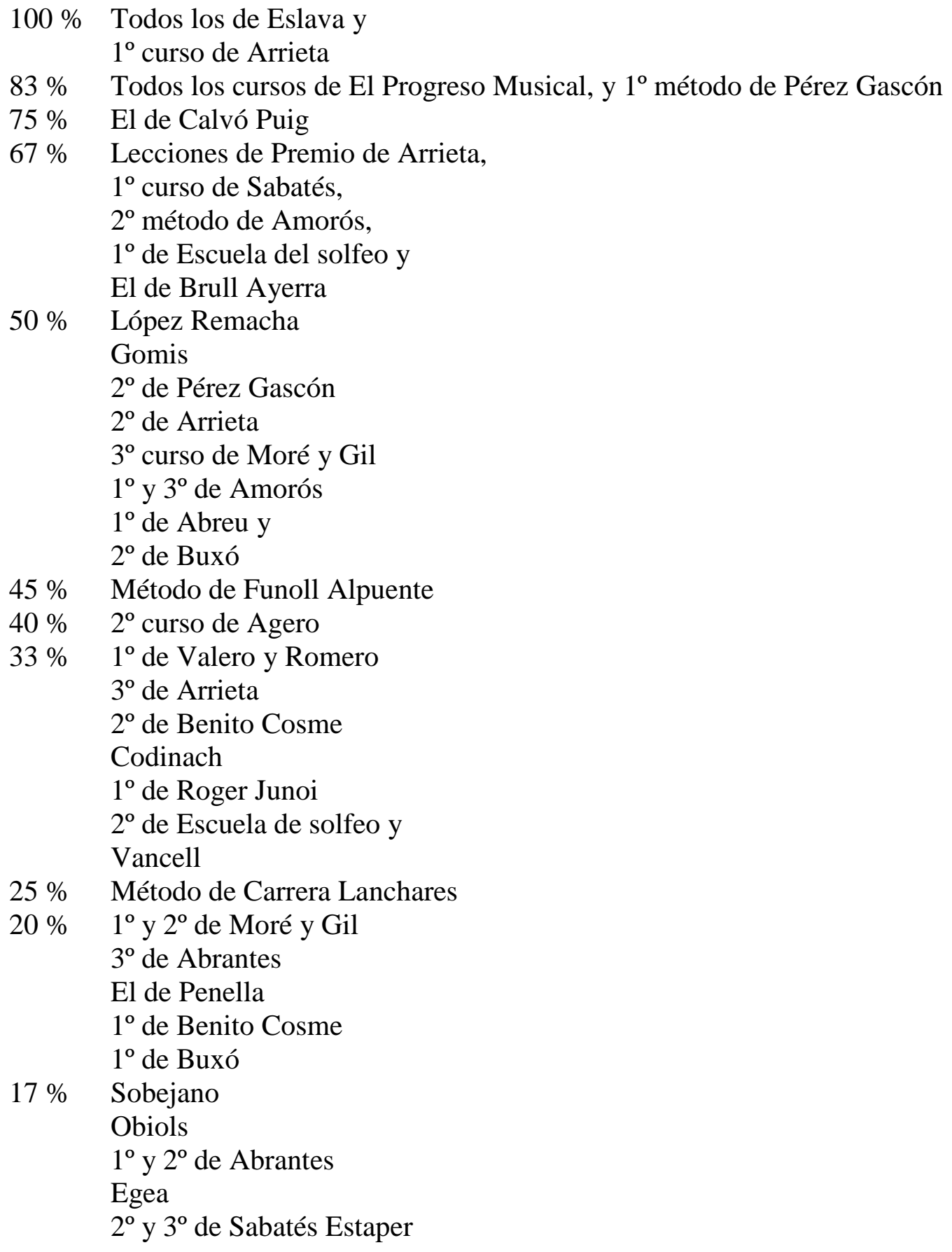

Solamente dos coinciden al 100\% con los contenidos que se consideraban idóneos en la época, y nueve están al 50\% con ellos.

Hemos de tener en cuenta que la ley de Instrucción Pública "Ley Moyano", es de 1857, y hemos analizado métodos anteriores a esa fecha; además esta ley no dictó normas para la enseñanza de la música, por lo que cada cual hizo lo que creyó más oportuno, u obró a su libre albedrío 


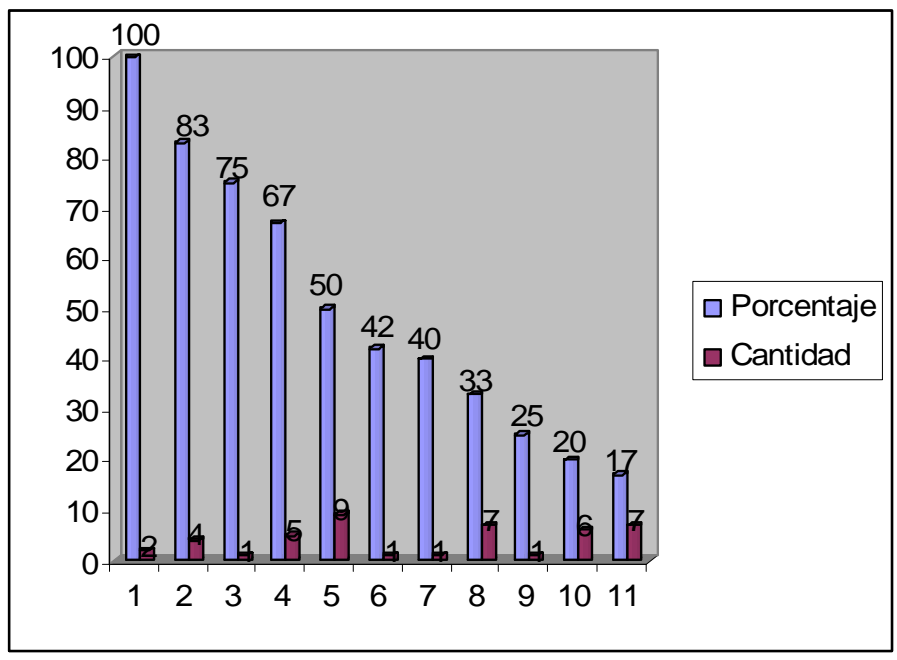

PORCENTAJE DE COINCIDENCIA CON LOS PARÁMETROS Y GRADACIONES DE LOS DISTINTOS ELEMENTOS MUSICALES CONSIDERADOS ÓPTIMOS EN LA ACTUALIDAD.

\begin{tabular}{|c|c|c|c|}
\hline AUTOR & $\begin{array}{l}\text { Porcentaje de coinci- } \\
\text { dencia con los paráme- } \\
\text { tros idóneos ordenados } \\
\text { de más a menos }\end{array}$ & & \\
\hline Arrieta $1^{\circ}$ & 58 & Velázquez $2^{\circ}$ & 17 \\
\hline Eslava & 50 & Pérez Gascón $1^{\circ}$ & 10 \\
\hline Sabatés $1^{\circ}$ & 50 & López Remacha & 10 \\
\hline Moré y Gil $3^{\circ}$ & 50 & Abreu $1^{\circ}$ & 10 \\
\hline Amorós $2^{\circ}$ & 40 & Reguart & 10 \\
\hline $\begin{array}{l}\text { Brull } \\
\text { (El progreso musical) } 1^{\circ}\end{array}$ & 33 & Roger $2^{\circ}$ & 10 \\
\hline Calvó & 33 & Aliaga & 10 \\
\hline Brull & 33 & Manent & 10 \\
\hline Gomis & 33 & $\begin{array}{l}\text { Brull } \\
\text { (El progreso musical) } 2^{\circ}\end{array}$ & 0 \\
\hline Pérez Gascón $2^{\circ}$ & 33 & $\begin{array}{l}\text { Brull } \\
\text { (El progreso musical) } 3^{\circ}\end{array}$ & 0 \\
\hline Arrieta $2^{\circ}$ & 33 & $\begin{array}{l}\text { Arrieta lecciones a } \\
\text { premio }\end{array}$ & 0 \\
\hline Amorós $1^{\circ}$ & 33 & Amorós $3^{\circ}$ & 0 \\
\hline Funoll & 33 & Buxó $2^{\circ}$ & 0 \\
\hline Valero y Romero $1^{\circ}$ & 33 & Agero $2^{\circ}$ & 0 \\
\hline Vancell & 33 & Benito $2^{\circ}$ & 0 \\
\hline Abrantes $3^{\circ}$ & 33 & Carrera & 0 \\
\hline Penella & 33 & Moré $1^{\circ}$ & 0 \\
\hline Sabatés $2^{\circ}$ & 33 & Benito $1^{\circ}$ & 0 \\
\hline Arrieta $3^{\circ}$ & 20 & Buxó $1^{\circ}$ & 0 \\
\hline Moré y Gil $2^{\circ}$ & 20 & Abrantes $2^{\circ}$ & 0 \\
\hline $\begin{array}{l}\text { AAVV } \\
\text { (Escuela del solfeo) } 1^{\circ}\end{array}$ & 17 & Egea & 0 \\
\hline Codinach & 17 & Sabatés $3^{\circ}$ & 0 \\
\hline Roger $1^{\circ}$ & 17 & Lladó & 0 \\
\hline $\begin{array}{l}\text { AAVV } \\
\text { (Escuela del solfeo) } 2^{\circ}\end{array}$ & 17 & Prellezo & 0 \\
\hline Sobejano & 17 & Valero y Romero $2^{\circ}$ & 0 \\
\hline Obiols & 17 & Llupart & 0 \\
\hline Abrantes $1^{\circ}$ & 17 & Roger $3^{\circ}$ & 0 \\
\hline Agero $1^{\circ}$ & 17 & Velázquez $3^{\circ}$ & 0 \\
\hline
\end{tabular}


Consideraciones sobre la utilidad de los métodos

\begin{tabular}{|l|l|l|l|}
\hline${\text { Agero } 3^{\mathbf{0}}}$ & 17 & Pardás 2 $^{\mathbf{0}}$ & 0 \\
\hline${\text { Velázquez } 1^{\mathbf{0}}}^{\text {Pardás } 1^{\mathbf{0}}}$ & 17 & Espino & 0 \\
\hline & 17 & Abreu 2 & 0 \\
\hline & & Llorca & 0 \\
\hline
\end{tabular}

Resumen del "Grado de ajuste con los procedimientos actuales de enseñanza/aprendizaje del solfeo".

\begin{tabular}{|c|c|c|c|}
\hline $58 \%$ & $1^{\circ}$ de Arrieta & $10 \%$ & $1^{\circ}$ de Pérez Gascón \\
\hline \multirow[t]{3}{*}{$50 \%$} & Todos los de Eslava & & López Remacha \\
\hline & $1^{\circ}$ de Sabatés Estaper & & $1^{\circ}$ de Abreu \\
\hline & $3^{\circ}$ de Moré y Gil & & Reguart Mestre \\
\hline \multirow{2}{*}{$40 \%$} & $2^{\circ}$ de Amorós & & $2^{\circ}$ de Roger Junoi \\
\hline & & & Aliaga y \\
\hline \multirow[t]{13}{*}{$33 \%$} & El Progreso Musical & & Manent \\
\hline & Calvó & $0 \%$ & El Progreso Musical $2^{\circ}$ y $3^{\circ}$ \\
\hline & Brull Ayerra & & Solfeo para premio de Arrieta \\
\hline & Gomis & & $3^{\circ}$ de Amorós y \\
\hline & $2^{\circ}$ de Pérez Gascón & & $2^{\circ}$ de Buxó \\
\hline & $2^{\circ}$ de Arrieta & & \\
\hline & $1^{\mathrm{o}}$ de Amorós & & \\
\hline & Funoll & & \\
\hline & $1^{\circ}$ de Valero y Romero & & \\
\hline & Vancell & & \\
\hline & $3^{\circ}$ de Abrantes & & \\
\hline & Penella y & & \\
\hline & $2^{\circ}$ de Sabatés Estaper & & \\
\hline \multirow[t]{2}{*}{$20 \%$} & $3^{\circ}$ de Arrieta & & \\
\hline & $2^{\circ}$ de Moré y Gil & & \\
\hline \multirow[t]{9}{*}{$17 \%$} & $1^{\circ}$ y $2^{\circ}$ de Escuela de solfeo & & \\
\hline & Codinach & & \\
\hline & $1^{\circ}$ de Roger Junoi & & \\
\hline & Sobejano & & \\
\hline & Obiols & & \\
\hline & $1^{\circ}$ de Abrantes & & \\
\hline & $1^{\circ}$ y $3^{\circ}$ de Agero & & \\
\hline & $1^{\circ}$ y $2^{\circ}$ de Velázquez y & & \\
\hline & $1^{\circ}$ de Pardás & & \\
\hline
\end{tabular}


Ninguno coincide al $100 \%$ con nuestros planteamientos, es natural, hay cerca de doscientos años de diferencia en la visión pedagógica, el que más está en el 58\%, y de los que más abundan, trece, coinciden al 33\% con nuestros parámetros, e incluso hay 5 que no concuerdan en absoluto

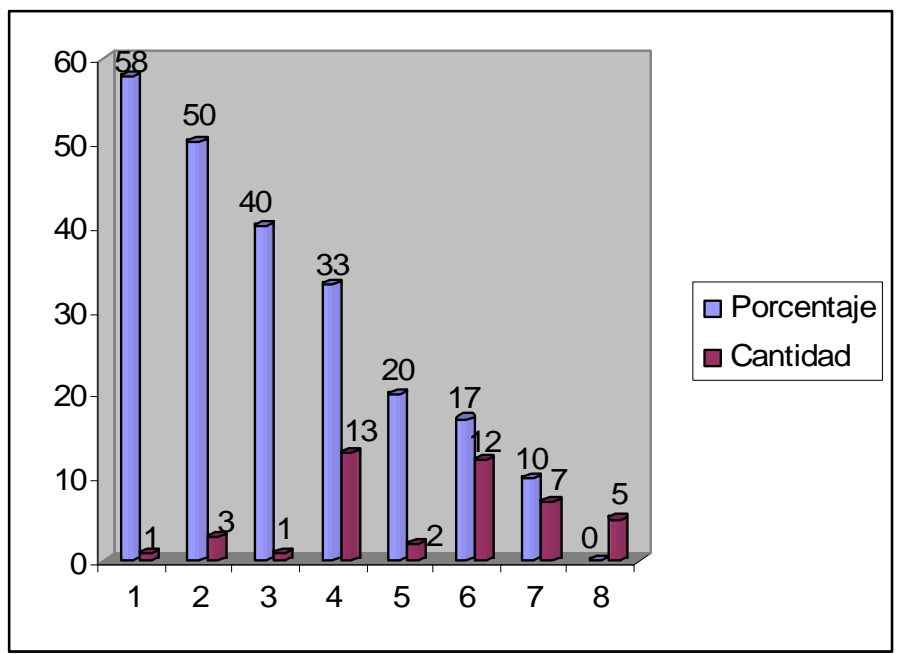


- 6 -

\section{CONCLUSIONES DEFINITIVAS \\ Y RECOMENDACIONES}


Conclusiones definitivas 
Por último, una vez analizados los métodos de autores españoles del período estudiado, procede exponer aquí las conclusiones a las que llegamos a través de la observación del estudio comparativo de todos ellos.

Siguiendo el método empleado en toda la tesis para analizar los contenidos de los distintos libros de solfeo, y expuesto en el punto 2, dividiremos las conclusiones en:

1. Claves y orden en que se enseñaban

2. Tesituras que abarcaban las lecciones en esos años

3. Cuántos enseñaban todas las tonalidades practicadas y por cuál se comenzaba

4. Qué compases mayoritariamente se practicaban y en qué orden

5. Dificultades rítmico - métricas que se estudiaban

6. Las notas de adorno en estos libros

7. Los ejercicios de entonación

8. Métodos con musicalidad

9. Métodos con acompañamiento al piano de las lecciones

10. Métodos que contienen, o no, teoría de la música y en qué grado de acierto

11. Deducciones de la coincidencia o no de cada uno de los métodos con los programas vigentes en cada momento y con los parámetros establecidos por nosotros como óptimos para el aprendizaje de la materia.

12. Conclusiones definitivas sobre la bondad o imperfecciones de los métodos y de la enseñanza del solfeo en general en la época circundada.

\section{Claves y orden en que se enseñaban:}

La gran mayoría de los métodos enseñaba las 7 claves, había extrañas excepciones, y no las enseñaban todos aquellos métodos que constaban de una o dos partes, estaban dedicados a una enseñanza "amateur" o simplemente eran métodos demasiado elementales para incluir todas ellas.

En cuanto al orden en que se enseñaron, tiene primacía la clave de Sol y luego la de Fa en $4^{\text {a }}$ línea, lo cual es perfectamente explicable, y aun hoy día se sigue haciendo así, pero respecto a las de Do, hacerlo siguiendo un orden numérico no tienen explicación. Quizás empezar por la de Do en $1^{\mathrm{a}}$ línea fuera una consecuencia de tener que emplearla más tarde, si se estudiaba armonía, debido a la costumbre que había, hasta hace pocos años, de trabajar la armonía y el contrapunto con las 4 claves que se consideran naturales para las voces. Pero es que la de Do en $2^{\text {a }}$ no se usa en el cuarteto de voces 
mixtas. Es por lo que lo más lógico hubiese sido: Do en $4^{\mathrm{a}}$, porque así los instrumentistas que estudiasen instrumentos barítonos - bajos, que la emplean en sus registros agudos, ya la practicaban; después en todo caso la de Do en $1^{a}$, por lo explicado arriba; a continuación Do en $3^{\mathrm{a}}$ por la misma causa, y también por los alumnos que estudiasen viola; y por último Do en $2^{\mathrm{a}}$, que no tiene más uso que el del transporte. Acabando, como hacían casi todos, con $\mathrm{Fa}$ en $3^{\mathrm{a}}$ que tampoco sirve más que para el transporte.

Cualquier otro orden de los que se emplearon es totalmente absurdo y fuera de de cualquier planteamiento pedagógico.

\section{Tesituras que abarcaban las lecciones en esos años:}

Solamente un $14 \%$ de los métodos mantienen sus lecciones en un tesitura abarcable por alumnos/as cuya voz no está formada ni tienen técnica vocal (Do ${ }_{3} \mathrm{a} \mathrm{Mi}_{4}$ ), y un $22 \%$ en una tesitura, que quizás para los primeros niveles sea un poco aguda, pero que también se puede considerar aceptable ( $\mathrm{Do}_{3} \mathrm{a} \mathrm{Fa}_{4}$ ), y nada más un método que mantenga una tesitura en sus lecciones, para los niveles avanzados, que consideramos buena ( $\mathrm{Sol}_{2} \mathrm{a} \mathrm{Fa}_{4}$ ). La mayoría, $62 \%$, emplean extensiones que son demasiado agudas, demasiado graves, las dos cosas, o simplemente imposibles de cantar, y aquí no están incluidas las lecciones o métodos que están dedicados a conocer las notas en tesituras propias de instrumentos con el fin de practicarlas sin entonar.

Si el propósito de estas lecciones de amplia extensión de voz era el de practicar también la lectura de notas fuera del pentagrama, para luego reconocerlas en los instrumentos, deberían haber sido lecciones simplemente rítmicas y no rítmico - melódicas.

\section{Cuántos enseñaban todas las tonalidades practicadas:}

Solamente ocho de los autores expuestos incluyen lecciones en todas las tonalidades practicadas. En un principio se podía pensar que son los que abarcan 3 ó 4 partes en su método, pero no es así; algunos de los que extienden su método hasta 3 partes no incluyen el estudio de todas las tonalidades (Buxó, Agero, Moré y Eslava), sin embargo sí las hacen practicar otros autores con un sólo volumen (Calvó, Manent y Llupart).

Y el orden en que se enseñaban, en algunos casos, también es poco lógico. Como se puede ver en el punto 5. 3. los hay que solamente incluían las modalidades mayores, o que no se veían todas las menores, incluso hay quien las hace aparecer de forma totalmente arbitraria. 
Un método completo debe poner en práctica todas las tonalidades y en orden creciente de alteraciones en la armadura, alternando las de sostenidos, en los modos mayor y menores, con las de bemoles. Y ya vemos que esto no era así en todos los casos, aunque sí en la mayoría.

\section{Qué compases mayoritariamente se practicaban y por cuál se comenzaba:}

La mayoría hacían trabajar los simples y compuestos más utilizados y también otros de menor empleo (51\%), habiendo un porcentaje del $26 \%$ que ni siquiera incluye los compases básicos en su método.

En cuanto al compás elegido para iniciar al estudiante, como se ve en el punto 4.4, el $67 \%$ lo hace con el de compasillo, gran mayoría por tanto partidaria de que este sea el compás con que se iniciaran los estudiantes. Otros (19\%) lo hacen más difícil, empleando el compasillo ordinario, dos por dos, como compás inicial de los estudios de solfeo, lo que es mucho más complicado; es mucho más comprensible este compás después de haber practicado el de compasillo por su similitud en cuanto a figuras de nota. Y tan sólo un pequeño porcentaje (11\%) eligieron el compás de dos por cuatro para empezar, lo que hoy constituiría una total aberración, ya que nadie pone en duda que el compás de dos tiempos es el más sencillo de los compases.

Los que proceden de la forma mayoritariamente expuesta, luego siguen con el de dos por dos, tres por cuatro, o al revés; le suele seguir dos por dos y tres por ocho, y luego ya los compases compuestos, que suelen ir en el orden del 6, 9 y 12 por ocho; a partir de ahí ya otros compases, si los incluyen, terminando con los amalgamados, los pocos métodos que los contienen.

\section{$\underline{\text { 5. Dificultades rítmico - métricas que se estudiaban: }}$}

La mayor parte abarcan el máximo de dificultades que la extensión de su método permite; los que las incluyen todas es por que tienen tres o cuatro partes, y los que se van quedando en otros niveles de dificultad es porque su método no tiene tanta extensión. En este punto casi todos proceden de forma lógica.

No hay tanta coincidencia en cuanto a la forma de introducir estas dificultades, aunque son mayoría (68\%) quienes lo hacen de forma progresiva, aunque más o menos idónea. 


\section{Las notas de adorno en estos libros:}

Ya se ha visto en las anteriores estadísticas que prácticamente la mitad de los autores incluían en sus métodos las notas de adorno (49\% sí, $51 \%$ no).

Imaginamos que la causa de que ese $51 \%$ no trate este contenido es la corta extensión de su método, dicho de otra forma, observamos que ese porcentaje corresponde, casi completamente, a los autores que sólo publicaron métodos con una única parte. Al no profundizar mucho en dificultades, es lógico que los adornos no fueran incluidos en sus contenidos.

Hay algunas pocas excepciones, métodos con 2 partes que sí podían haber contenido esta cuestión, son el de Cosme de Benito, Escuela del solfeo, los libros manuscritos de Amancio Amorós, el de Avelino Abreu (que tiene 5 partes) y los de Emilio Arrieta, que aunque no son métodos pedagógicos, sino recopilaciones de ejercicios de examen, podrían haber presentado en sus lecciones alguna o algunas de las notas de adorno.

Lo que sí es destacable, es que de esa casi mitad de autores que enseñan los adornos, solamente haya coincidencia de criterios en cuatro, habiendo, como hay, tanta distancia en el tiempo.

\section{Los ejercicios de entonación:}

Son mayoría quienes aplican ejercicios de entonación, previos a las lecciones de solfeo, o intercalados entre ellas, pero gran minoría quienes los tratan por separado en un orden pedagógico, e incidiendo en los que son básicos. Y ninguno tiene abundancia de esta práctica.

Un orden pedagógico sería el que figura en nuestro punto 2. "Parámetros y gradaciones de los distintos elementos..."

\section{Métodos con musicalidad:}

Ya hemos expuesto en el 5.7 que de entre todos los autores expuestos, solamente nueve destacan por la musicalidad de sus melodías, Eslava, Pérez Gascón, Valero, Funoll, Lladó en su $2^{\mathrm{a}}$ parte, Llupart, Velázquez $2^{\mathrm{a}}$ parte, A.A.V.V. Progreso musical y Abreu.

Tan solo un $24 \%$ de los autores estudiados podríamos decir que hicieron lecciones que tenían cierta musicalidad. No llega por tanto a la cuarta parte de los autores estudiados. 
Estos datos nos hacen deducir que contados músicos se preocuparon por que la enseñanza del solfeo fuera agradable y estimulante, tratando de infundir diletantismo a los futuros músicos o practicantes de música. Fernando Delgado García, al final de su tesis doctoral sobre la formación del músico en España, hace una referencia a Alfonso G. Aijón, de su artículo "El actual Conservatorio de Madrid. Es apremiante necesidad su total reforma” en Aria, Año I, no 4, (1956), p. 27 que dice:

Solfeo: tal y como hoy se exige, es un obstáculo en el que se quedan muchas veces los buenos músicos, dada la aridez y la falta de musicalidad del programa. Creemos que las Cantatas de Bach o canciones de nuestro olvidado folklore, por ejemplo, son más valiosas en arte y pedagogía que las monótonas lecciones de la "Didáctica",

\section{Métodos con acompañamiento al piano de las lecciones:}

Una ligera minoría de los métodos analizados llevan acompañamiento para sus lecciones (49\%), y las lecciones "a capella" no es una exclusiva de los métodos más antiguos, sino que en toda la época analizada los hay que no llevan acompañamiento.

Como ya hemos comentado anteriormente, indica que muchos músicos no veían la gran necesidad de acompañar al educando con un instrumento polifónico, privándole del acceso a la cuadratura musical, al sentimiento tonal y armónico de la música, al mantenimiento de la altura tonal y a la interpretación individual y en grupo. La práctica de las lecciones "a capella", sólo puede hacerse cantando el profesor primero y después el alumno, o cantando ambos a la vez. $\mathrm{O}$ en el peor de los casos dejando al alumno a su libre albedrío la altura absoluta de los sonidos, la velocidad y el mantenimiento del pulso.

Una parte menor de las armonizaciones se realizaban con estilos bastante clásicos y tradicionales, y la mayoría fueron los que acompañaban con una armonía cromática, alterada o en definitiva evolucionada.

Está bien que los acompañamientos de las lecciones de solfeo, como materia ésta básica y primeriza, sean, al menos al principio, muy tonales y sencillos, tanto rítmica como armónicamente; aunque también es provechoso que a medida que la dificultad aumenta, se vaya complicando o enriqueciendo, no en exceso, el ritmo y la armonía.

\footnotetext{
${ }^{1}$ DELGado GARCíA, Fernando. (2003). Los Gobiernos de España y la Formación del Músico (1812 - 1956), Tesis doctoral, Sevilla, Universidad de Sevilla, Departamento de Teoría e Historia de la Educación y Pedagogía Social, p. 724.
} 
10. Métodos que contienen, o no, teoría de la música y en qué grado de acierto:

Son suficiente mayoría los métodos que incluyen algo o bastante teoría (66 \%), y aunque no es nuestro tema principal, nos pronunciaremos respecto al grado de acierto en que están tratadas las cuestiones teóricas que cada cual expone, haciendo un resumen de lo que argumentamos en la exposición de cada libro.

Esa mayoría de $66 \%$ de los métodos, corresponde a 26 de los 37 autores estudiados; de esos 26, solamente 11 consideramos que, exceptuando alguna discrepancia, exponen la parte teórica de forma clara, universal, pedagógica y apropiada al nivel que se enseña, estos autores son: Eslava, Sobejano, Pérez Gascón, Moré, Abrantes, Penella, de Benito, Codinach, Roger, Amorós y Vancell.

De los otros 15 , hay 8 a los que solamente se les puede aducir algún comentario crítico: Aliaga, hace extrañas y singulares denominaciones. Valero, curiosas definiciones y alguna explicación confusa. Funoll, alguna definición y clasificación curiosas. Calvó, enrevesada y amontonada manera de explicarla. Egea, agrupaciones y clasificaciones extrañas de los signos. Velázquez, mal y poco explicada la teoría, y mal clasificados algunos signos. El Progreso Musical, explicaciones poco claras. Pardás, incompleta y en algunos casos errónea.

Finalmente, hay 7 con bastantes deficiencias en la parte teórica: López Remacha, es de difícil comprensión. Reguart, desorganizada, incompleta, con descripciones e indicaciones singulares. Prellezo, erudita, enrevesada y escasa. Manent, nefasta. Lladó, tiene lagunas en las explicaciones. Obiols, escueta, con lagunas enormes, conceptos y explicaciones que pueden dar lugar a equívocos. Agero, desorganizada y precipitada.

La conclusión es que tampoco la teoría, cuando estaba incluida en los métodos, se enseñaba de la mejor manera posible en un gran porcentaje.

11. Deducciones de la coincidencia o no de cada uno de los métodos con los programas vigentes en cada momento y con los parámetros establecidos por nosotros como óptimos para la enseñanza/aprendizaje de la materia:

A pesar de que hasta 1861 no hubo unos programas definidos para la asignatura de solfeo, ni para ninguna otra, ya desde la fundación del Conservatorio de Madrid, hubo pautas sobre las materias a enseñar y su división en etapas. En realidad el programa oficial siempre fue, más o menos, el que comprende los contenidos del Método completo de solfeo de Hilarión Eslava. 
Pues como hemos visto en el punto 5.16, solamente el método de Eslava y únicamente el primer curso de Emilio Arrieta, coinciden totalmente con los programas establecidos, siendo que el único Conservatorio reconocido como oficial durante el siglo XIX y gran parte del XX era el de Madrid, por tanto no habían otras enseñanzas musicales oficiales, y sí las habían libres, y ambas tenían que ceñirse a la única oficial.

Hay dos métodos más, El Progreso Musical, y el primer método de Pérez Gascón que se adaptan en el $83 \%$ de su contenido. Uno, el de Calvó Puig, llega al $75 \%$. Cinco están al $67 \%$. Y la mayor cantidad, nueve, se acoplan al $50 \%$ con los programas que se consideraron oficiales, habiendo incluso siete, que solamente se adaptan al $17 \%$. ¿Qué deducimos de estas cifras?, pues que cada cual iba a su libre albedrío. Descartando aquellos que intentaron hacer una metodología nueva o experimental, el resto, la gran mayoría, desarrollaron sus contenidos, el orden de enseñanza de ellos y la división por etapas de la manera que les pareció más oportuna.

En cuanto al porcentaje de los que se adaptan a los parámetros que nosotros hemos considerado óptimos para la enseñanza del solfeo, parámetros que están fundados en nuestras propias experiencias como alumnos, luego como profesores, en las de muchos otros profesionales y en las teorías de los grandes pedagogos relacionados en el punto 2, ya se habrá observado en el punto 5.17 que absolutamente nadie llega al 100 $\%$, los que más, tres, se quedan al $50 \%$, estando la mayor cantidad, trece, al 33\%, nada más que un tercio de los contenidos y progresión de ellos que creemos más pedagógicos. Ya decimos en este punto 5.17 que nos separan casi dos siglos de experiencias en la enseñanza y en su visión; pero la deducción, a la vista de estas cifras, sigue siendo que cada quien tomaba el camino que creía unilateralmente mejor, sin pararse a pensar en las posibles consecuencias de una mediocre enseñanza, ni consultar con las directrices que habían ya trazado algunos de los grandes pedagogos de la historia de la enseñanza musical.

12. Conclusiones definitivas sobre la bondad o imperfecciones de los métodos y de la enseñanza del solfeo en general en la época circundada.

En este último apartado, postrero de la tesis, insertamos, a modo de resumen, una tabla con la síntesis de cada uno de nuestros comentarios en el epígrafe "Valoración de la efectividad del método y de su aportación a la enseñanza" que cierra el estudio del total de cada uno de los métodos. 


\begin{tabular}{|c|c|}
\hline AUTOR Y MÉTODO & VALORACIÓN \\
\hline $\begin{array}{l}\text { Rudimentos de Música } \\
\text { Solfeo Práctico (Se- } \\
\text { gunda Parte) }\end{array}$ & $\begin{array}{l}\text { La clasificación de los signos y elementos musicales es arbitraria y desorde- } \\
\text { nada. El orden de aprendizaje de las claves es de lo más peculiar, lo mismo } \\
\text { que la manera que van apareciendo las distintas tonalidades. } \\
\text { En general no es un método nada completo, útil, ni acertado. }\end{array}$ \\
\hline López Remacha & $\begin{array}{l}\text { De difícil comprensión las exposiciones teóricas. En cuanto a la práctica, en } \\
7 \text { lecciones, y cortas, llegamos ya a las notas de adorno, habiendo pasado } \\
\text { por contratiempos y síncopas, lo cual es exagerado y nada pedagógico, a } \\
\text { medida que se adentra en las otras claves, aumenta la duración y la dificul- } \\
\text { tad rítmica, hasta llegar a la de Fa en } 3^{\text {a }} \text { línea, que son las más largas y difí- } \\
\text { ciles. } \\
\text { No podemos juzgar si fue útil en aquel tiempo. }\end{array}$ \\
\hline $\begin{array}{l}\text { Mèthode de Solfège et } \\
\text { de Chant, } 1^{\mathrm{a}} \text { parte }\end{array}$ & $\begin{array}{l}\text { Un desatino es enseñar en último lugar la clave de Fa en } 4^{\text {a }} \text { línea; el método } \\
\text { se titula "método de solfeo y de canto", y si no es sólo de canto, sino princi- } \\
\text { palmente de solfeo, la clave de Fa en } 4^{\text {a }} \text { le hace falta al alumno mucho antes } \\
\text { que las demás. } \\
\text { No es un mal método, pero tampoco es lo que su fama le precede, hay } \\
\text { que considerar que es uno de los primeros, tiene cosas buenas y otras } \\
\text { no tanto. }\end{array}$ \\
\hline Reguart Mestre & $\begin{array}{l}\text { La teoría no puede estar más desorganizada e incompleta, amén de utilizar } \\
\text { descripciones e indicaciones de lo más singulares. } \\
\text { Todo él es muy insuficiente, antipedagógico y lamentable. Ni es sencillo } \\
\text { ni se aprende con facilidad la música, como dice su título; lo que sí es } \\
\text { corto, pero no por ello sencillo, y menos, útil para aprender. }\end{array}$ \\
\hline $\begin{array}{l}\text { Método completo de } \\
\text { solfeo }\end{array}$ & $\begin{array}{l}\text { Es de gran ingenio repetir algunas lecciones o transcribirlas con otro com- } \\
\text { pás u otro ritmo, porque es una demostración de la interrelación de los com- } \\
\text { pases, las figuras y el aire. Nos parece, sin embargo, muy poco adecuado el } \\
\text { comenzar las lecciones en la clave de Fa en } 4^{\text {a }} \text {, con figuraciones y dificulta- } \\
\text { des métricas avanzadas. } \\
\text { Muy positivo el estudio de lecciones en, prácticamente, todos los compases } \\
\text { existentes, incluso algunos de los irregulares más utilizados. La tónica de } \\
\text { rebajar las dificultades melódicas al presentar una nueva clave es loable, } \\
\text { pero no las rítmicas que también entorpecen mucho, o quizás más, la lectura } \\
\text { de una clave con la que no se tiene familiaridad. También nos parece útil } \\
\text { comparar tonalidades desconocidas con armaduras abundantes, con otras ya } \\
\text { conocidas de menor cuantía en sus armaduras. } \\
\text { Vienen a completar la formación del nuevo músico la serie de lecciones a } 2 \\
\text { voces en las que se practican todas las claves importantes, los compases más } \\
\text { usados, y se repasa todas las dificultades rítmicas tratadas a lo largo de los } \\
\text { métodos; } \\
\text { En general es un buen método, con sus defectos como todos, pero, sal- } \\
\text { vando las costumbres de su época, afronta todas las cuestiones solfísti- } \\
\text { cas, no deja nada en el aire, no va de pasada por ninguna dificultad, sin } \\
\text { ser tampoco exhaustivo, está bien calculada la progresión de las dificul- } \\
\text { tades, abunda en consejos para el enseñante que juzgamos muy oportu- } \\
\text { nos, y sobre todo tiene musicalidad. }\end{array}$ \\
\hline $\begin{array}{l}\text { Sobejano Ayala } \\
\text { Escuela de solfeo, } \\
\text { según el estilo moder- } \\
\text { no }\end{array}$ & $\begin{array}{l}\text { Está muy comprimida la enseñanza, sobre todo la práctica, de cada nueva } \\
\text { dificultad; la progresión de ellos es adecuada. } \\
\text { En general es un método casi completo. Las melodías no son muy musi- } \\
\text { cales, incluso en las dos partes últimas, algunas son verdaderos ejerci- } \\
\text { cios gimnásticos. No obstante para su antigüedad es aceptable. }\end{array}$ \\
\hline
\end{tabular}




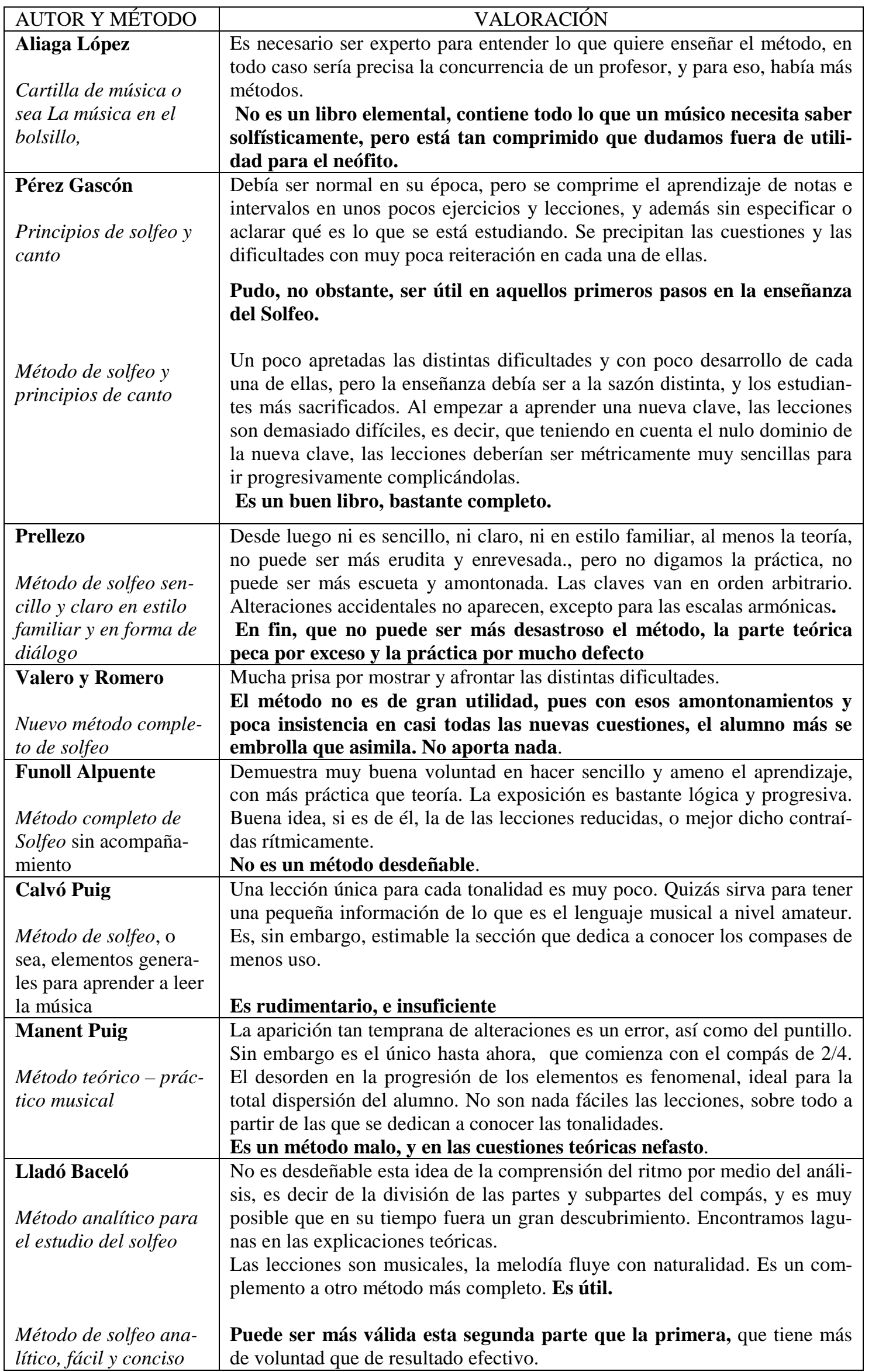




\begin{tabular}{|c|c|}
\hline AUTOR Y MÉTODO & VALORACIÓN \\
\hline $\begin{array}{l}\text { Arrieta } \\
\text { Solfeos autografiados }\end{array}$ & $\begin{array}{l}\text { Debieron ser buenos alumnos los que pasaban esta prueba, si es que la pa- } \\
\text { saban, pues las lecciones son harto difíciles, poco musicales y enrevesadas; } \\
\text { haciendo falta un verdadero esfuerzo para estudiarlas. } \\
\text { No aportan nada y más bien creemos que puede hacer desistir a quien se } \\
\text { inicie en esta disciplina sin excesiva predisposición. }\end{array}$ \\
\hline $\begin{array}{l}\text { Obiols Tramullas } \\
\text { Método de solfeo }\end{array}$ & $\begin{array}{l}\text { Hay una o dos lecciones para practicar cada dificultad. Las melodías no son } \\
\text { difíciles, pero insustanciales. La teoría escueta, eso podría ser adecuado, } \\
\text { pero además con lagunas enormes, conceptos y explicaciones que dan lugar } \\
\text { a equívocos. } \\
\text { Es un método al que le faltan pocas cosas, pero pesado e inservible, y de } \\
\text { todo punto contrario a la pedagogía. }\end{array}$ \\
\hline $\begin{array}{l}\text { Moré y Gil } \\
\text { Método completo de } \\
\text { solfeo }\end{array}$ & $\begin{array}{l}\text { La dificultad métrica es quizás fuerte demasiado pronto. Lo que nunca tiene } \\
\text { exceso de dificultad es la melodía, postura ésta elogiable, ya que al alumno } \\
\text { se le quita al menos una dificultad, y no pequeña, y se le hace menos árida } \\
\text { la materia. } \\
\text { El orden de exposición de las claves no nos parece el correcto. Siguen un } \\
\text { proceso ordinal y no de mayor a menor uso. Cada vez que aparece una nue- } \\
\text { va clave, las lecciones debieran ser de menor dificultad rítmica y melódica, } \\
\text { e ir progresando éstas; pero no siempre lo hacen así, por el contrario sólo lo } \\
\text { hacen poquísimas veces. } \\
\text { En general es un buen método, como todos, tiene sus defectos y caren- } \\
\text { cias, pero es bastante completo. }\end{array}$ \\
\hline $\begin{array}{l}\text { Abrantes Bello } \\
\text { Método de solfeo abre- } \\
\text { viado }\end{array}$ & $\begin{array}{l}\text { Nos parece exagerada la aseveración del autor de que estudiando la primera } \\
\text { parte es suficiente para un músico amateur. Sí que es cierto que las dificul- } \\
\text { tades básicas están todas contempladas, pero muy poco reiteradas; es dema- } \\
\text { siado escueto. } \\
\text { La segunda parte, y la teoría de la tercera, completan un poco la cortedad de } \\
\text { la primera, pero sigue siendo un método muy primario e insuficiente a todas } \\
\text { luces. Las tonalidades no existen, y muchas cuestiones se ven de paso sin } \\
\text { ahondar en ellas. } \\
\text { En definitiva no es útil para los aficionados ni para los profesionales. }\end{array}$ \\
\hline $\begin{array}{l}\text { Penella } \\
\text { Principios de solfeo }\end{array}$ & $\begin{array}{l}\text { Es un libro muy escueto, posiblemente por el alumnado al que estaba desti- } \\
\text { nado, no encaminado en absoluto al terreno profesional. Sirve como } \\
\text { aproximación al solfeo, al conocimiento teórico de sus signos, y a la lectura } \\
\text { musical muy elemental. } \\
\text { No obstante está carente de cualquier línea pedagógica. }\end{array}$ \\
\hline $\begin{array}{l}\text { De Benito } \\
\text { Método completo de } \\
\text { Solfeo en Compendio }\end{array}$ & $\begin{array}{l}\text { Está todo muy comprimido, como ya hemos comentado con otros métodos. } \\
\text { En su prólogo dice que está pensado para niños y jóvenes; son precisamente } \\
\text { ellos quienes necesitan una progresión adecuada del aprendizaje y abundar } \\
\text { en cada uno de los nuevos problemas que se van presentando. } \\
\text { Las lecciones son francamente feas y aburridas. }\end{array}$ \\
\hline $\begin{array}{l}\text { De Egea } \\
\text { Método de Solfeo o } \\
\text { nuevo Arte de la Músi- } \\
\text { ca }\end{array}$ & $\begin{array}{l}\text { Como muchos otros de la época, se precipita la puesta en práctica de ritmos } \\
\text { y figuras, que deben esperar un tiempo de maduración. } \\
\text { Es bastante completo para su corta extensión. } \\
\text { No es útil. }\end{array}$ \\
\hline $\begin{array}{l}\text { Sabatés Estaper } \\
\text { Solfeo: curso completo }\end{array}$ & $\begin{array}{l}\text { Lo que tiene de positivo es que hay muchas lecciones para ejercitar una } \\
\text { misma dificultad. Por lo demás es carente de todo interés musical, sus me- } \\
\text { lodías son insípidas, la mayor parte son la misma frase con cambios de } \\
\text { dirección. Sólo se practica un compás. } \\
\text { Entre las dos partes hacen una. No nos agrada el orden de consignar los } \\
\text { compases compuestos. } \\
\text { La tercera parte tiene un poco más de nivel, pero sigue siendo insuficiente } \\
\text { una lección para cada dificultad, y menos una para cada clave. } \\
\text { En general un método insustancial y de escasa utilidad. }\end{array}$ \\
\hline
\end{tabular}




\begin{tabular}{|c|c|}
\hline AUTOR Y MÉTODO & VALORACIÓN \\
\hline $\begin{array}{l}\text { Método completo de } \\
\text { solfeo: dividido en tres } \\
\text { partes }\end{array}$ & $\begin{array}{l}\text { No puede estar más desorganizada y precipitada la teoría. Las alteraciones, } \\
\text { antes de conocer ritmos de corcheas, semicorcheas y fórmulas combinadas, } \\
\text { es otro disparate, al que se le suma el agolpamiento de dificultades. Sin } \\
\text { embargo es muy útil la forma de realizar los ejercicios de entonación. } \\
\text { La segunda y tercera parte está mejor pensada que la primera, no hay tanta } \\
\text { precipitación en el abordaje de las distintas dificultades y la progresión de } \\
\text { los diferentes elementos es, dentro de los parámetros de la época, más lógi- } \\
\text { ca. } \\
\text { Pero en general, un método poco afortunado e inservible para } \\
\text { aficionar a un educando. }\end{array}$ \\
\hline $\begin{array}{l}\text { Llupart Alverni } \\
\text { Escuela de Conjunto. } \\
\text { Treinta solfeos a tres } \\
\text { voces iguales }\end{array}$ & $\begin{array}{l}\text { Sus melodías son bonitas, discurren entre intervalos sencillos, no tienen } \\
\text { grandes saltos, sus ritmos no son difíciles, por lo que es agradable su estudio } \\
\text { y ejecución. Muy cuidado el contrapunto. Es lástima que no lleve acompa- } \\
\text { ñamiento, ya que a capella es más dificultosa la entonación. } \\
\text { Es un buen método, aunque es complementario. }\end{array}$ \\
\hline Nociones de solfeo & $\begin{array}{l}\text { Quizás útil para quien quiera tener una ligera información de la escritura y } \\
\text { lectura musicales. No obstante, cae, como muchos de los métodos de corta } \\
\text { extensión, en la excesiva precipitación en la presentación de los distintos } \\
\text { signos y dificultades. } \\
\text { Es, como el mismo autor dice, un pequeño compendio muy elemental de } \\
\text { solfeo, más que un método. }\end{array}$ \\
\hline $\begin{array}{l}\text { Roger Junoi } \\
\text { Método práctico de } \\
\text { lectura musical y de } \\
\text { solfeo,(Escuela alema- } \\
\text { na) }\end{array}$ & $\begin{array}{l}\text { Es una medida adecuada practicar primero los intervalos de octava que los } \\
\text { de séptima, debido a ser estos últimos los de mayor dificultad de entonación } \\
\text { entre los simples mayores y menores. Acomete muy pronto el cambio entre } \\
\text { claves. } \\
\text { Aborda las tonalidades de forma organizada y progresiva. Lo malo es la } \\
\text { mezcla de claves, que es demasiado frecuente, sobre todo en las últimas } \\
\text { lecciones. } \\
\text { Presenta los inconvenientes que en la época tenían todos, pero está hecho de } \\
\text { una forma progresiva, ordenada, con abundantes lecciones para practicar } \\
\text { cada nueva dificultad, y en general resulta agradable su estudio. } \\
\text { Se trata de un método bien pensado y distribuido. En general es un } \\
\text { buen método. }\end{array}$ \\
\hline $\begin{array}{l}\text { Amorós Sirvent } \\
\text { Elementos de solfeo }\end{array}$ & $\begin{array}{l}\text { Curioso comenzar empleando la ligadura. Bien, o mejor que los anteriores, } \\
\text { el tratamiento de la entonación. La progresión en la aparición de figuras de } \\
\text { nota es buena y lenta, aunque al final se precipita. } \\
\text { Con algunas salvedades, es más útil que muchos. }\end{array}$ \\
\hline $\begin{array}{l}\text { Velázquez } \\
\text { Nuevo curso teórico- } \\
\text { práctico de solfeo, }\end{array}$ & $\begin{array}{l}\text { Todo desordenado, con poca insistencia en las dificultades, y aparición de } \\
\text { éstas extremadamente prematura. } \\
\text { Las melodías son bastante agradables y no ofrecen grandes dificultades de } \\
\text { entonación. } \\
\text { La segunda parte está bastante completa, pero solamente una lección por } \\
\text { dificultad es muy poco; en general está mejor esta parte que la primera, sin } \\
\text { llegar a ser un método de gran utilidad. } \\
\text { Decididamente un método que nada aporta, aburrido. }\end{array}$ \\
\hline
\end{tabular}




\begin{tabular}{|c|c|}
\hline AUTOR Y MÉTODO & VALORACIÓN \\
\hline $\begin{array}{l}\text { Brull Ayerra y otros } \\
\text { Método completo de } \\
\text { solfeo } \\
\text { El Progreso Musical }\end{array}$ & $\begin{array}{l}\text { Es un buen método, progresivo, bastante completo, asequible, fácil de en- } \\
\text { tender, con las tachas pedagógicas de cualquier método de la época, aunque } \\
\text { en éste menos que en otros. Son las melodías más bonitas que en método } \\
\text { alguno haya, tienen una musicalidad que hacen que el educando se entregue } \\
\text { al estudio de ellas con complacencia. } \\
\text { Sin embargo las lecciones de la segunda parte ya no son todas tan bonitas. } \\
\text { La tercera parte ni es tan progresiva como las otras, sobre todo la primera, } \\
\text { ni sus lecciones son tan bonitas. Las melodías de este volumen son mucho } \\
\text { más rebuscadas y de más difícil entonación. Por otra parte, las mezclas de } \\
\text { claves, hacen que aumente considerablemente la dificultad. } \\
\text { Es un método muy válido, muy completo entre los de su tiempo. }\end{array}$ \\
\hline $\begin{array}{l}\text { Pardás Font } \\
\text { Método completo de } \\
\text { solfeo, o sea, Curso } \\
\text { Teórico Práctico pues- } \\
\text { to al alcance de todas } \\
\text { las inteligencias }\end{array}$ & $\begin{array}{l}\text { Es un método completo, como su nombre indica, porque trata de todo un } \\
\text { poco, pero, como muchos otros, tan poco de cada cosa que es insuficiente } \\
\text { para una buena formación, además de resultar muy difícil la primera parte. } \\
\text { Se notan a faltar ejercicios de entonación interválica. Está bien, sin embar- } \\
\text { go, utilizar las mismas melodías con distintas duraciones, para demostrar la } \\
\text { equivalencia de las distintas figuras y grupos. } \\
\text { Es demasiado fatigoso para principiantes, y con escasa práctica e in- } \\
\text { formación para formación de profesionales. }\end{array}$ \\
\hline $\begin{array}{l}\text { AAVV. } \\
\text { Escuela del Solfeo } \\
\text { Libro I }\end{array}$ & $\begin{array}{l}\text { Trata bastante mejor que otros anteriores la entonación. Aunque no es lo } \\
\text { ideal, es progresivo y repetitivo en el estudio de los intervalos, lástima que } \\
\text { las melodías sean muy rebuscadas. Se queda corto en el estudio del resto de } \\
\text { tonalidades y figuras a partir de la fusa. } \\
\text { No es un método que aporte nada, difícil, no en su planteamiento, pero } \\
\text { sí en algunos de sus desarrollos técnicos, con melodías complejas. }\end{array}$ \\
\hline $\begin{array}{l}\text { Vancell Roca } \\
\text { El Libro de música y } \\
\text { canto }\end{array}$ & $\begin{array}{l}\text { Es este un libro bastante distinto a los otros. Se fundamenta en verdaderos } \\
\text { principios pedagógicos. Por eso comienza con el compás de } 2 / 4 \text {. Muy pro- } \\
\text { gresiva la introducción de las diversas dificultades, y con insistencia en cada } \\
\text { una de ellas. } \\
\text { Es un buen método para aprender música en los colegios, o en los con- } \\
\text { servatorios en sus primeros niveles. }\end{array}$ \\
\hline $\begin{array}{l}\text { Brull Ayerra, M. } \\
\text { Lecciones autografia- } \\
\text { das }\end{array}$ & $\begin{array}{l}\text { Es un libro muy útil para practicar los alumnos en clase el apartado de lectu- } \\
\text { ra a primera vista. }\end{array}$ \\
\hline $\begin{array}{l}\text { Amorós Sirvent } \\
\text { Lecciones manuscritas } \\
\text { graduadas: }\end{array}$ & $\begin{array}{l}\text { Al igual que el primero, es un buen método, mejor que muchos de los ante- } \\
\text { riormente analizados. Trata los elementos imprescindiblemente necesarios } \\
\text { para una lectura media de partituras. Es agradable, con no demasiadas y } \\
\text { engorrosas dificultades. } \\
\text { Es un buen método, progresivo y completo. }\end{array}$ \\
\hline $\begin{array}{l}\text { Espino } \\
\text { Doce estudios melódi- } \\
\text { cos y progresivos de } \\
\text { perfeccionamiento de } \\
\text { solfeo: }\end{array}$ & $\begin{array}{l}\text { Es un libro complementario, no un método. Está hecho con el fin de practi- } \\
\text { car la lectura de las claves, y de paso ahondar en la medida y la entonación; } \\
\text { es por tanto un compendio de los elementos del solfeo. }\end{array}$ \\
\hline Abreu & $\begin{array}{l}\text { La progresión de dificultades rítmicas es magnífica, perfectamente graduada } \\
\text { y organizada. Las melodías son muy asequibles, fluyen con facilidad y no se } \\
\text { encuentran intervalos rebuscados para ocasionar dificultad por la dificultad. } \\
\text { Lecciones muy bonitas, parecen lieder o canciones, con un acompañamiento } \\
\text { bastante virtuosístico y dialogando con la voz. } \\
\text { Es un libro de perfeccionamiento. }\end{array}$ \\
\hline
\end{tabular}




\begin{tabular}{|l|l|}
\hline AUTOR Y MÉTODO & \multicolumn{1}{c|}{ VALORACIÓN } \\
\hline Llorca & $\begin{array}{l}\text { No hay variedad de ritmos, es monotamente insistente en las mismas figu- } \\
\text { ras, no hay fórmulas rítmicas combinadas. }\end{array}$ \\
& $\begin{array}{l}\text { Un libro complementario, pero de cualquier manera, no vemos en él } \\
\text { mucha utilidad. }\end{array}$ \\
\hline Buxó & $\begin{array}{l}\text { Poca preparación o insistencia en las dificultades iniciales. Es muy técnico, } \\
\text { pero sus melodías son poco agradables. Tiene una buena progresión en la } \\
\text { aparición de las dificultades métricas, y hay abundante práctica de los inter- } \\
\text { valos. } \\
\text { Utiliza canciones, danzas populares, y fragmentos de obras de compositores } \\
\text { célebres como lecciones de solfeo, al menos son melodías más atrayentes, } \\
\text { aunque no son precisamente célebres las obras, sino sus compositores. } \\
\text { En general el método sirve, pero no mucho. }\end{array}$ \\
\hline
\end{tabular}

La síntesis de esta tabla, por tanto es la siguiente:

De entre los treinta y siete autores investigados, hay casi una paridad en cuanto a nuestro juicio sobre la valía de su o sus métodos, aunque es un poco mayor la consideración negativa. Resultan 17 entre los que consideramos buenos, útiles y/o aceptables, y 20 los que nos parecen poco útiles, rudimentarios, insuficientes...

De entre los 17, encontramos 13 métodos buenos, completos, útiles, bien pensados y distribuidos, son sus autores: Eslava, Pérez Gascón, Lladó, Moré y Gil, Llupart, Codinach, Roger Junoi, Amorós, AAVV. (El Progreso Musical), Vancell, Brull Ayerra, Espino y Abreu.

Y 4 que calificamos de aceptables, o que se encuentra en ellos alguna enseñanza válida, son los autores: Gomis, Sobejano, Funoll y Buxó.

El resto estimamos que son poco servibles, poco acertados, que no tienen una línea pedagógica interesante, o simplemente no aportan nada.

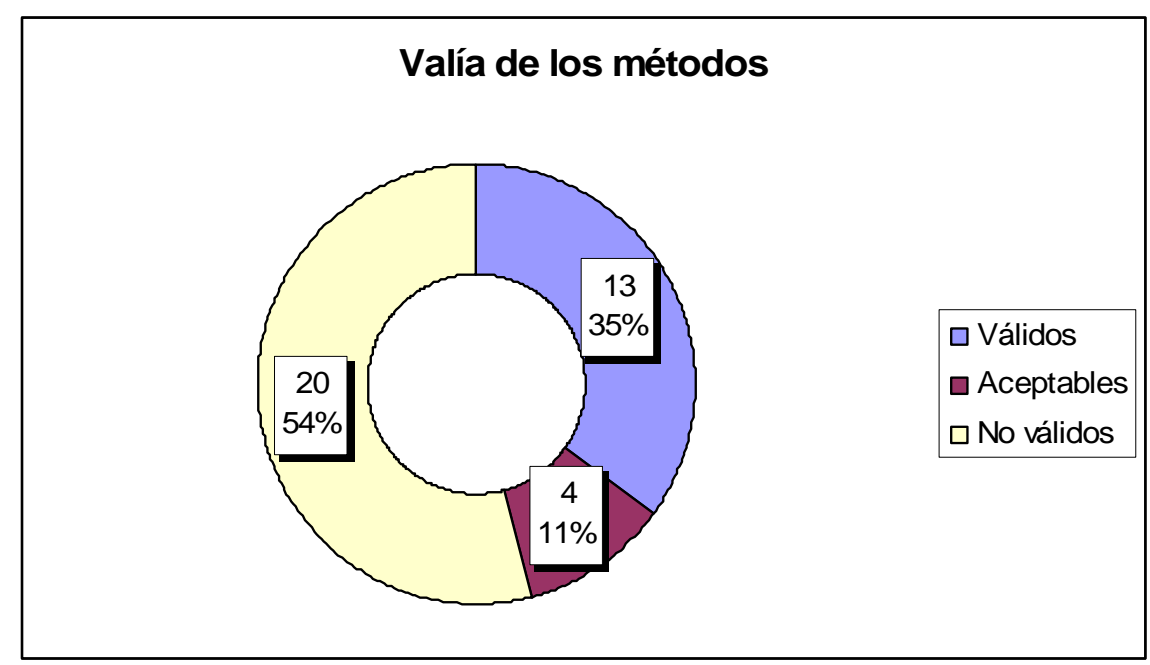


Resumen extractado de las consecuencias extraídas de este estudio:

a) El orden de aprendizaje de las claves no era el correcto.

b) Las tesituras en un porcentaje mayoritario eran excesivas, sino incantables.

c) Las tonalidades no siempre se enseñaban todas, ni en el orden racional; pero en este punto la mayoría si lo hacía como creemos que es debido.

d) La mayoría incluía en sus métodos los principales compases. En lo que casi había unanimidad era en presentar como compás inicial de los estudios el compasillo. Producto de un escasa reflexión o de proceder de forma rutinaria, cada cual hacía lo que había visto hacer a sus antecesores.

e) Los límites de dificultades rítmicas son lógicos en casi todos los autores, y también en la mayoría la introducción de ellas progresivamente.

f) Las notas de adorno formaban parte de la enseñanza de la mayoría de métodos con más de un volumen o parte, pero las discrepancias en cuanto a su nombre, uso y ejecución eran generales.

g) No se concedía apenas importancia a la práctica de la entonación, no considerando el dominio de la interválica como fundamental y básico.

h) La musicalidad en las lecciones brillaba por su ausencia en la gran mayoría. La aridez, simpleza o acrobacias melódicas era predominante en ese periodo.

i) Una pequeña mayoría no acompañaba las lecciones. Es una carencia no justificable. La armonía de los que tenían acompañamiento solía ser clásica y tradicional, al menos en las primeras cotas, lo que es bastante admisible, y en otros niveles más avanzada.

j) La teoría, los métodos que la incluían, tampoco era, mayoritariamente, un ejemplo de pedagogía.

k) Los métodos en su gran mayoría no se adaptaban a programas establecidos ni a metodologías experimentadas como idóneas.

1) Aproximadamente el $50 \%$ de los métodos publicados aportaban poco o nada a la enseñanza.

La última deducción y conclusión es que el solfeo nunca se enseñó, en su generalidad, adecuadamente, que no se hizo ningún caso a las enseñanzas de los grandes pedagogos, que siempre se hizo de él una asignatura ardua, que se aprende por obligación para olvidarla al poco tiempo, e incluso estaríamos por decir que aun hoy día se enseña con grandes deficiencias. 
Trasladamos, para acabar, y reafirmar esta, nuestra, opinión, literalmente la de Lorenzo Serrallach:

...El estudio del Solfeo fue siempre árido debido, en parte, a las características de lo que trata de representar (sonido y duración) y, por otra parte, a la escasez de verdaderos maestros de solfeo; materia ésta que todos se consideraban capaces de enseñar apenas tenían algunas nociones.

...Es muy común, casi general, que se enseñe mal el Solfeo, que no se eduque el oído y que se enseñe más por la representación que por el reconocimiento auditivo...

Tras este estudio analítico, dejamos los caminos abiertos a nosotros mismos, o a otros investigadores para posteriores trabajos. Labores que pueden ser: el análisis pedagógico de los métodos de solfeo del resto del siglo XX, métodos españoles, métodos franceses, belgas, métodos extranjeros que han tenido una implantación importante en España; métodos que se han utilizado en el Conservatorio de Valencia, y/o en otros Conservatorios. También, quizás, métodos anteriores al siglo XIX, si es que los había.

Tratados de teoría de la música de autores españoles, en el período tratado aquí o más amplio. Tratados de teoría de la música de autores extranjeros con traducción e implantación en España: cuestiones que enseñan, cursos en que se dividen, orden en que enseñan los temas, idoneidad en la redacción, en los ejemplos, si insertan o no ejercicios prácticos de las cuestiones tratadas, u otros aspectos pedagógicos.

Libros de Dictado musical, igualmente españoles y/o extranjeros: planteamientos didácticos, divisiones entre dictado melódico, rítmico y rítmico - melódico, su adecuación a los distintos niveles de la enseñanza. Dictados a dos y tres voces: su iniciación y progresión de las dificultades.

También, quizás, a estudios sobre libros o tratados complementarios al solfeo, la teoría musical o el dictado musical; y libros que tratan el verdadero significado de la denominación de la asignatura "lenguaje musical"; esto es, aquellos que engloban, solfeo, teoría, dictado, análisis, elementos primarios de la armonía y estructura o formas musicales; junto con improvisación y repentización.

\footnotetext{
${ }^{1}$ SERRALLACH, Lorenzo. (1953). Historia de la Enseñanza Musical. Buenos Aires: Ricordi Americana S. A., pp. 193 y 214.
} 
Conclusiones definitivas

638 


\section{BIBLIOGRAFÍA}

\section{REFERENCIAS BIBLIOGRÁFICAS}

AAVV. (1999). Diccionario de la Música española e Hispanoamericana. Director y coordinador general Emilio Casares Rodicio, Madrid: SGAE.

AAVV. (1990). Primer Congreso Nacional de la Enseñanza del Solfeo. Las Palmas de Gran Canaria del 9 al 11 de octubre de 1989. Madrid: Editorial Música 2000.

ALONSO GONZÁLEZ, Celia. (1992). Canción y Sociedad en la España Decimonónica: 1800-1874. Tesis Doctoral. Director Emilio Casares Rodicio. Universidad de Oviedo, Departamento de Historia y Artes.

ARAVAL. (1995). Lenguaje musical 1. Libro del profesor. Método activo para el nivel inicial de Educación Primaria y grado elemental de Conservatorios y Escuelas de Música. Director Salvador Seguí. Madrid: Unión Musical.

(1993). Temas de lenguaje musical: Lectura rítmica y entonación. Director Salvador Seguí. Valencia: Piles.

(1994). Temas de lenguaje musical: Solfeo expresivo. Director Salvador Seguí. Valencia: Piles.

(1996). Lenguaje musical 2. Libro del profesor. Método activo para el nivel inicial de Educación Primaria y grado elemental de Conservatorios y Escuelas de Música. Director Salvador Seguí. Valencia: Piles.

(1997). Lenguaje musical 3. Libro del profesor. Método activo para el nivel inicial de Educación Primaria y grado elemental de Conservatorios y Escuelas de Música. Director Salvador Seguí. Valencia: Piles.

(1997). Lenguaje musical 4. Libro del profesor. Método activo para el nivel inicial de Educación Primaria y grado elemental de Conservatorios y Escuelas de Música. Director Salvador Seguí. Valencia: Piles.

(1999). Lenguaje musical 6. Curso Segundo de Grado Medio. Libro del profesor: Método activo para el primer ciclo de grado medio en Conservatorios y Escuelas de Música. Director Salvador Seguí. Valencia: Piles.

BARCELÓ AMORÓS, José Luís. (2001). Lenguaje musical: Entonación. Curso cuarto. Metodología de acuerdo con la LOGSE. Valencia: Piles.

BARRIO, Adelino. (1975). Tratado de entonación- Madrid: Real Musical.

(1987). Iniciación Musical. Madrid: Musicinco.

(1987). Tratado de solfeo: ejercicios, lecciones y terminología musical. Madrid: Musicinco.

(1988). La modulación en el solfeo. Madrid: Musicinco, S. A.

(1990). Teoría de la entonación y práctica de ejercicios musicales.

Madrid: Real Musical, D. L.

CANDELA ROMÁN, Rebeca. (2005). "Nuevo método para la enseñanza musical”, I + E Revista Digital “Investigación y Educación”, ISSN 1696 - 7208, número 14 de enero. 
CALVO PASCUAL, M. Araceli y MARTín SÁNCHEZ, Manuela. (2005). “Análisis de la adaptación de os libros de texto de ESO al currículo oficial, en el campo de la química en Enseñanza de las Ciencias, Departamento de Didáctica de las Ciencias Experimentales. Facultad de Educación. Universidad Complutense de Madrid. Centro de Formación del Profesorado.

DELGADO GARCÍA, Fernando. (2003). Los Gobiernos de España y la Formación del Músico (1812 - 1956), Tesis doctoral, Sevilla, Universidad de Sevilla, Departamento de Teoría e Historia de la Educación y Pedagogía Social.

FONTESTAD PILES, Ana. (2005). El Conservatorio de Música de Valencia. Antecedentes, Fundación y Primera Etapa (1879 - 1910). Tesis doctoral. Director Vicente Galbis López. Universidad de. Valencia, Departamento de Historia del Arte.

GALBIS LÓPEZ, Vicente. (1998). La Música Escénica en Valencia: 1832-1868. Del Modelo del Antiguo Régimen a la Organización Musical. Tesis Doctoral. Director Emilio Casares Rodicio. Universidad de Valencia, Departamento de Historia del Arte.

GÓMEZ AMAT, Carlos. (1984) Teóricos y tratadistas. La enseñanza musical. El piano y el órgano. Los instrumentos. En Pablo López de Osaba (Dir). Historia de la música española - 5 - siglo XIX (Cap. XXI). Madrid: Alianza Editorial.

GÓMEZ MENDOZA, Miguel Ángel. (s.f.). “Análisis de contenido cualitativo y cuantitativo: Definición, clasificación y metodología".S. L. Disponible en web:

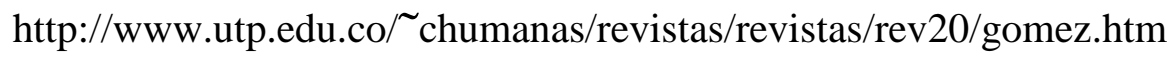

JORQUERA JARAMILLO, María Cecilia. (2004). "Métodos Históricos o Archivos en Educación Musical", Revista Electrónica de LEEME (Lista Europea de Música en la Educación), n 14, noviembre. Disponible en web: http://musica.rediris.es

LÓPEZ DE ARENOSA, Encarnación; OLIVER, Ángel y PILDAIN, Joaquín. (1988). Lenguaje musical 2. Madrid: Real Musical.

(1988). Lenguaje musical II. Madrid: Real Musical.

(1989). Lenguaje musical 3. Madrid: Real Musical.

(1989). Lenguaje musical III. Madrid: Real Musical.

(1990). Lenguaje musical; preparatorio. Madrid: Real Musical.

(1990). Lenguaje musical 1, $5^{\text {a }}$ edición. Madrid: Real Musical.

(1994). Lenguaje musical. Madrid: Real Musical.

LORAS VILLALONGA, Roberto. (1998). Aspectos Teóricos del Lenguaje Musical. Valencia: Rivera Mota S. L.

(2003). La Asociación de Profesores Músicos de Santa Cecilia desde su fundación a 2002. Valencia: Mare Nostrum.

LLONGUERAS, Juan. (1942). El ritmo en la educación y formación general de la infancia. España: Editorial Labor S. A., Biblioteca de Iniciación Cultural.

MAYOR IBÁÑEZ, Amando, DE PEDRO CURSÁ, Dionisio. (1994). Cuadernos de lenguaje, $1 A, 1 B, 1 C$. Villaviciosa de Odón: Real Musical, D. L. 
(1995). Cuadernos de lenguaje, 2A, 2B, 2C. Madrid: Real Musical, D. L. (1995 - 1996). Cuadernos de lenguaje, Grado medio, 1A, 1B,1C. Villaviciosa de Odón: Real Musical, D. L.

(1996). Cuadernos de lenguaje, Grado elemental 3A, 3B, 3C. Villaviciosa de Odón: Real Musical, D. L.

(1997). Cuadernos de lenguaje, Grado elemental 4A, 4B, 4C. Villaviciosa de Odón: Real Musical, D. L.

NAVARRETE PORTA, Ana María. (1994). El lenguaje de la música .l Madrid: Sociedad Didáctico Musical.

(1996). El lenguaje de la música 2. Madrid: Sociedad Didáctico Musical.

NAVARRETE PORTA, Ana María, MORENO-BUENDÍA, Manuel. (1993). El lenguaje de la música 3. Madrid: Sociedad Didáctico Musical.

(1994). El lenguaje de la música 4. Madrid: Sociedad Didáctico Musical.

ORIOL DE ALARCÓN, Nicolás. (2005) "La música en las enseñanzas de régimen general en España y su evolución en el siglo XX y comienzos del XXI", Revista Electrónica de LEEME (Lista Europea de Música en la Educación), no 16, noviembre. Disponible en web: http://musica.rediris.es

PÉREZ GIL, Manuel. (1989). "Proyecto de Notación musical de Jean Jacques Rousseau", en Cuadernos Didácticos de Música $n^{\circ}$ 5. Valencia: Piles.

Pedagogía Musical, diferentes sistemas metodológicos (inédito).

PORTA, Luís y SILVA, Miriam. (2003). "La investigación cualitativa: El Análisis de Contenido en la investigación educativa". Universidad Nacional de Mar del Plata. Disponible en web: http://www.uccor.edu.ar/paginas/REDUC/porta.pdf

PRECIADO, Dionisio. (1978). Don Hilarión Eslava y su "Método completo de solfeo" en AAVV, Monografía de Hilarión Eslava. Pamplona: Diputación Foral de Navarra.

RUEFF, Jeanine. (1964). Étude d'intervalles, Dix huit leçons de solfège en clés de sol et de fa melangées: avec acompagnamnet de piano. París: Alphonse Leduc.

SALDONI, Baltasar. (1868-1881). Diccionario biográfico-bibliográfico de Efemérides de músicos españoles, tomos I al IV. Madrid: Imprenta a cargo de D. Antonio Pérez Dubrull.

SANCHO GARCÍA, Manuel. (2003). El Sinfonismo en Valencia durante la Restauración (1878-1916). Tesis doctoral. Director Francisco Bueno Camejo. Universidad de Valencia, Departamento de Historia del Arte.

SARGET ROS, María Ángeles; BELTRÁN ROMERO, Marcelo y MOLTÓ ROMERO, María Ángeles. (1993). Lenguaje musical 1: Metodología de acuerdo con la LOGSE. Valencia: Piles.

(1994). Lenguaje musical 2: Metodología de acuerdo con la LOGSE. Valencia: Piles. (1995). Lenguaje musical 3: Metodología de acuerdo con la LOGSE. Valencia: Piles. (1996). Lenguaje musical 4: Metodología de acuerdo con la LOGSE. Valencia: Piles. 
SEGUÍ, Salvador; CARBONELL, Juan Miguel y MONTESINOS, Eduardo. (19851999). Ars Solfandi: Modena aportación metodológica, cursos primero al sexto. Valencia: Piles.

SCHOLES, Percy A. (1984). Diccionario Oxford de la Música, $2^{\mathrm{a}}$ edición. Barcelona: Edhasa/Hermes/Sudamericana.

SERRALLACH, Lorenzo. (1947). Nueva Pedagogía Musical. Buenos Aires: Ricordi Americana S. A. E. C.

(1953). Historia de la Enseñanza Musical. Buenos Aires: Ricordi Americana S. A.

SOPEÑA IBÁÑEZ, Federico. (1967). Historia crítica del Conservatorio de Madrid. Madrid: MEC, D. G. de Bellas Artes.

VALENZUELA REMOLINA, Miguel Arturo. (s.f.). Reflexiones acerca de las asignaturas de solfeo y Adiestramiento auditivo en la Escuela Nacional de la UNAM Universidad Nacional de México. Disponible en la web: http://www.biblioteca.org.ar./autor.asp?texto=v (Bibliotecas Rurales Argentinas).

ZAMACOIS, Joaquín. (1973). Temas de Pedagogía Musical. Barcelona: Ediciones Quiroga.

\section{OBRAS DIDÁCTICAS ANALIZADAS}

AAVV. (s. f.) Escuela del Solfeo, Curso práctico y graduado de Lectura musical, debido a la colaboración única de maestros nacionales. Libro I y Libro II. Barcelona: $\mathrm{Mu}-$ sical Emporium. Vda. de J. M. Llobet.

ABRANTES BELLO, Joaquín. (s.f. ${ }^{1}$ ). Método de solfeo abreviado $3^{\text {a }}$ edición. Madrid: Calcografía de B. Eslava.

ABREU, Avelino, SERRA, Pedro y ZAMACOIS, Joaquín. (s. f.)

Solfeo, segundo curso, perteneciente a la asignatura Teoría - Solfeo, $2^{\mathrm{a}}$ edición. s. 1.

Solfeo, quinto curso, perteneciente a la asignatura Teoría - Solfeo. s. 1.

AGERO, Feliciano. (1900 ca. $\left.{ }^{2}\right)$. Método completo de solfeo: dividido en tres partes. Madrid: sin ed.

ALIAGA LÓPEZ, Matías. $\left(1847^{1}\right)$. Cartilla de música o sea La música en el bolsillo. Madrid: Imp. De Alejandro Gómez Fuentenebro.

\footnotetext{
${ }^{1}$ s/ AAVV. (1999). Diccionario de la Música española e Hispanoamericana..., p. 11, tomo 1, artículo firmado por A. V. T. este libro estuvo publicado en el año 1879.

${ }^{2}$ Según indica el catálogo de la Biblioteca Nacional. Pero el Diccionario de la Música española..., tomo 1, p. 85, artículo firmado por $\mathrm{M}^{\mathrm{a}}$ Antonia Virgili Blanquet, dice que el método es de 1882.
} 
AMORÓS, Amancio. (s.f.). Elementos de solfeo, $10^{\text {a }}$ edición. s. 1. (suponemos que la edición sería después de 1911, por el comentario que hace en la p. 2 a Giner ${ }^{2}$ (S. f.). Lecciones manuscritas graduadas, segundo curso de solfeo. s. 1., (pero sí dice en España), S. A: Casa Dotesio.

(1910). Lecciones manuscritas graduadas, tercer curso de solfeo. Madrid: Unión Musical Española (antes Casa Dotesio).

ARRIETA, Emilio. (s.f. ${ }^{3}$ ) Solfeos autografiados, Colección de todas las lecciones inéditas, primer año. Madrid: Unión Musical Española.

(S.f.). Solfeos autografiados, segundo año. Madrid: Unión Musical Española. (S.f.). Solfeos autografiados, tercer año. Madrid: Unión Musical Española.

(S.f.). Solfeos autografiados, Concursos, primer libro. Madrid: Unión Musical Española.

BENITO, Cosme José de. (s.f. $\left.{ }^{4}\right)$. Método completo de Solfeo en Compendio. s. 1.

BRULL AYERRA, A; CANTÓ FRANCÉS, J.; FERNÁNDEZ GRAJAL, M.; FONTANILLA MIÑAMBRES, P.; LLANOS BERETE, A.; SERRANO RUÍZ, E.; SOS, A.; CAMPO, I. A.; FALCÓ, J.; JIMÉNEZ DELGADO, J. y HERNÁNDEZ, P. $\left(\right.$ s. f. $\left.^{5}\right)$. Método completo de solfeo. Madrid: Li. Palacios.

BRULL, M. (s.f.). Lecciones autografiadas para repentizar en el primer año de solfeo (nueva edición adaptada al vigente plan de enseñanza con tres lecciones en clave de Fa, por Ángel Mingote). Madrid: Unión Musical Española.

BUXÓ, Tomás. (s.f.). Método de solfeo Libro I. Madrid: Unión Musical Española.

(S.f.). Método de solfeo $2^{\circ}$ Libro. Madrid: Unión Musical Española.

(S.f.). Método de solfeo $3^{\circ}$ Libro. Madrid: Unión Musical Española.

CALVÓ I PUIG, Bernat. (s.f. ${ }^{6}$ ). Método de solfeo, o sea, elementos generales para aprender a leer la música. Barcelona: Juan Budó, grabador de música.

\footnotetext{
${ }^{1}$ Según el catálogo de la Biblioteca Nacional, y PRECIADO, Dionisio: Don Hilarión Eslava y su "Método completo de solfeo" en Monografía de Hilarión Eslava..., 1978, p. 239, en 1851 se publicó una $3^{\text {a }}$ edición de este método, pero con el nombre de El más barato de los solfeos ó sea La música puesta al alcance de todas las inteligencias y fortunas, también en Madrid, pero por el editor Casimiero Martín, seguía teniendo las mismas 85 páginas, pero medía un poco más, $18 \mathrm{~cm}$.

2 PRECIADO, Dionisio. (1978). Don Hilarión Eslava y su "Método completo de solfeo" en Monografía de Hilarión Eslava..., p. 244, cree que fue en el año 1893 que es la fecha que lleva el Dictamen de Pedrell.

3 s/ AAVV. (1999). Diccionario de la Música española e Hispanoamericana..., en la p. 756 Tomo I, dice que estuvo el total de esta obra editada entre 1868 y 1891.

${ }^{4}$ En la cubierta de las fotocopias enviadas por el servicio de reprografía de la Biblioteca Nacional, donde figura la signatura del libro, añaden a las referencias [S. 1.]: [s. n. ], [ca. 1880].

5 El libro no lleva fecha impresa, pero en la página 1, antes del enunciado "Primera Parte", hay una nota manuscrita, muy poco legible, porque el servicio reprográfico de la Biblioteca Nacional al hacer la fotocopia ha cortado la parte de arriba de este texto, pero se entiende perfectamente "Presentado en ...... al final que no está cortado dice claramente: "en 10 de Marzo de 1898”, siguiendo a esto la firma autógrafa de José Campo y Castro, el editor.

${ }^{6}$ En el catálogo de la Biblioteca de Cataluña figura como año de publicación 18--?, en el albarán de entrega del documento 1900. PRECIADO, Dionisio. Op. citada, p. 242 pone 1860, pero quizás no hablemos del mismo libro, pues Preciado le llama "Curso completo de solfeo o elementos teórico-prácticos para aprender a leer la música”. Lo cierto es que en el libro no figura año ninguno.
} 
CARRERA y LANCHARES, Fray Pedro. (1805). Rudimentos de música: divididos en cinco instrucciones que facilitan la más pronta inteligencia para el uso de los caballeros seminaristas del real seminario de nobles. Madrid: Imp. de Don Josef [sic] Doblado.

(1815). Solfeo práctico (segunda parte) metódicamente formado según el orden de las instrucciones anteriores para el uso de los caballeros seminaristas del real seminario de nobles. Madrid: Imp. de Álvarez.

CODINACH, Carmelo. (s.f.). Nociones de solfeo. Jerez: Tip. P. Del Carmen.

EGEA, Pedro María de. (1880). Método de Solfeo o nuevo Arte de la Música. S. 1.

ESLAVA, Hilarión. (s.f. ${ }^{1}$ ). Método completo de solfeo, $2^{\mathrm{a}}$ edición. Madrid: Lit. de Peant Car ${ }^{\mathrm{a}}$.

ESPINO, Felipe. $\left(1912 ?^{2}\right)$. Doce estudios melódicos y progresivos de perfeccionamiento de solfeo: para el cambio de todas las claves, con acompañamiento de piano. $2^{\mathrm{a}}$ edición. Obra dedicada a la Escuela de nobles y Bellas Artes de San Eloy de Salamanca. Madrid: R. Velaso.

FUNOLL Y ALPUENTE, Francisco. (s.f.). Método completo de Solfeo sin acompañamiento. Madrid: U. M. E.

GOMIS, José Melchor. (s. f. ${ }^{3}$ ). Mèthode de Solfège et de Chant, $1^{\mathrm{a}}$ parte. París: Masus.

LÓPEZ REMACHA, Miguel. (1815). MELOPEA Instituciones de canto y de armonía para formar un buen músico y un perfecto cantor. Madrid: Impr. que fue de Fuentenebro.

LLADÓ BARCELÓ, Joaquín. (1860 ó 62. ${ }^{4}$ ). Método analítico para el estudio del solfeo, compuesto y dedicado a S.A.R. el Serenísimo Príncipe de Asturias. Barcelona: Juan Budó.

$[1868]^{5}$. Método de solfeo analítico, fácil y conciso. Barcelona: Juan Budó.

\footnotetext{
${ }^{1}$ AAVV. (1999). Diccionario de la Música española e Hispanoamericana..., p. 750, tomo 4, el firmante del artículo José Luís Ansorena, afirma que el método fue editado el año 1845, y que el autor en su introducción manifiesta que fue escrito en Sevilla en 1837 [así es en cuanto al año, pero nada hemos leído referente a la ciudad. ¿Porqué no puedo ser en Burgo de Osma donde Eslava fue Maestro de Capilla y empezó a enseñar solfeo?]. Dionisio Preciado. (1978). Don Hilarión Eslava y su "Método completo de solfeo" en Monografía de Hilarión Eslava..., pp. 246 a 251 afirma que el método comenzó siendo editado por entregas en Madrid en 1845, y que existe un manuscrito sin fecha ni lugar que lleva por título Método de Solfeo de Don Hilarión Eslava, Maestro de Capilla, no de la Capilla Real, por lo que puedo ser este el embrión de su Método cuando estaba en Sevilla o quizás en Burgo de Osma.

${ }^{2}$ No sabemos quién supone ni porqué que este es el año aproximado de edición. Así figura en el catálogo de la Biblioteca de Valencia, pero nada hace sospechar esto viendo el libro.

${ }^{3}$ Aunque en la contestación y comentario de Rossini a Gomis que está al principio del libro, figura la fecha de 24 de enero de 1826, y PRECIADO, Dionisio: op. citada, p. 235 así lo indica.

${ }^{4}$ ÍBIDEM, p. 242, figura 1860, y esa es la fecha que lleva el informe, insertado al principio del libro, que emiten destacados músicos; pero en la cubierta figura (y parece ser manuscrita) la fecha de 1862.

${ }^{5}$ Esta fecha no está impresa, sino, entre corchetes, manuscrita, pero dentro, al final de la página XVI, sí que figura impresa la fecha de 8 de noviembre de 1868.
} 
LLORCA, Miguel. (19--- $\left.{ }^{1}\right)$. Método de solfeo, para repentizar en cuatro meses, seguido de una sección teórico práctica de afinación y emisión de la voz. Barcelona: A. Boileau y Bernasconi.

LLUPART ALBERNI, Carlos. (1884 ó posterior ${ }^{2}$ ). Treinta solfeos a tres voces iguales. Barcelona: Amorós.

MORÉ y GIL. (s. f. ${ }^{3}$ ). Método completo de solfeo adoptado como texto en la Escuela Nacional de Música y Declamación (Conservatorio) y en todas las principales Academias, Seminarios y Colegios. Madrid: U. M. E.

OBIOLS Y TRAMULLAS, Marià. (18--?). Método de solfeo, 23ª ed. Barcelona: Andrés Vidal y Roger.

PARDÁS Y FONT, Primitivo. (s. . . ${ }^{4}$ ). Método completo de solfeo. Barcelona: A. Vidal y Roger.

PENELLA, Manuel. (1879). Principios de solfeo: escritos para la clase de música de las escuelas de artesanos de Valencia, $3^{\text {a }}$ ed. Valencia: Imp. de J. Peydró.

PINILLA Y PASCUAL, José. (s.f.). Egercicios [sic] de entonación y medida aplicables a todos los métodos de solfeo. Madrid: Bonifacio Eslava.

PÉREZ GASCÓN, Pascual. (1852). Principios de solfeo y canto para uso de los alumnos del Colegio Real de S. Pablo de Valencia. Valencia: copia de la $2^{\mathrm{a}}$ edición; copiado en 1854. Edición manuscrita. ${ }^{5}$

(1857). Método de solfeo, principio de canto: aplicables en las escuelas y colegios. Valencia: Lit. de N. Sanchis. Edición manuscrita ${ }^{6}$

PRELLEZO, Mariano de. (s. f. ${ }^{7}$ ). Método de solfeo sencillo y claro en estilo familiar y en forma de diálogo. Madrid: Casimiro. Martín.

\footnotetext{
${ }^{1}$ Así lo afirma Ma Cruz López Carranza en la página 961, tomo 6 de AAVV. (1999). Diccionario de la Música española e Hispanoamericana... Sin embargo en el albarán de entrega de la Biblioteca de Cataluña pone año 1900, y en la información bibliográfica de la misma 19--?.

${ }^{2}$ En el catálogo de la Biblioteca de Cataluña así aparece. En el libro no figura en absoluto la editorial Amorós, sino Lit. Plaza del Rey 6, Barcelona, ni tampoco el año. Éste quizás sea una deducción por los años que figuran en las primeras páginas dentro del juicio crítico que esta obra ha merecido..., que son 1883 y 1884.

${ }^{3}$ Aunque PRECIADO, Dionisio (1978). Don Hilarión Eslava..., p. 243 da como probable 1870.

${ }^{4}$ En la portada con la signatura de la Biblioteca Nacional, anterior a la del método, figura al lado del nombre del editor [1864-1900], no sabemos si se refiere a los años en que se estuvo editando el libro, o a los años de funcionamiento de esta editora.

${ }^{5}$ PRECIADO, Dionisio: op. citada, p. 240 figura 1848 como año de edición de la primera.

${ }^{6}$ Esa es la fecha que figura en la catalogación de la Biblioteca Valenciana, pero quizás sea una deducción, debido a la fecha que lleva el dictamen del Real Conservatorio de Música y Declamación, firmado por Ventura de la Vega, Vice-Protector, que es en Madrid, 27 de octubre de 1857, pero para que se pudiera emitir este dictamen, el método ya estaba impreso, por lo que debió editarse antes. También en PRECIADO, Dionisio, obra citada, p. 240, figura este año como fecha de edición de este método.

${ }^{7}$ En este ejemplar no consta fecha alguna, pero en el catálogo de la Biblioteca Nacional, la obra total, o sea, el Curso completo de música teórico-práctica: por un método sencillo y claro, en estilo familiar y en forma de diálogo, figura el año 1851 y otra editorial, también de Madrid, Martínez y Minuesa. También lo confirma PRECIADO, Dionisio: obra citada, p. 240.
} 
REGUART MESTRE, Salvador $\mathrm{M}^{\mathrm{a}}$. (1839). Elementos musicales. Método sencillo para aprender exactamente y con facilidad de Música. Barcelona: F. Vallés.

ROGER JUNOI, A (1891). Método práctico de lectura musical y de solfeo. Madrid: Caleografía de F. Echevarría.

SABATÉS ESTAPER, Mateo. $\left(1888{ }^{1}{ }^{1}\right)$. Solfeo: curso completo. Barcelona: Rafael Guardia.

SOBEJANO Y AYALA. José de. (s. f. ${ }^{2}$ ). Escuela de solfeo, según el estilo moderno, dedicada a la juventud española. Madrid: B. Wirmbs.

VALERO, José y ROMERO, Antonio. (18-- $\left.?^{3}\right)$. Nuevo método completo de solfeo. Madrid: Antonio Romero.

VANCELL ROCA, Juan. (1902). El Libro de música y canto: tratado de solfeo y cantos escolares: gramática, lectura y escritura musicales simultáneas al alcance de las más pequeñas inteligencias. Barcelona: Fidel Giró.

VELÁZQUEZ, Juan. (18--? $\left.{ }^{4}\right)$. Nuevo curso teórico-práctico de solfeo, $4^{\mathrm{a}}$ ed. Barcelona: Rafael Guardia?

\footnotetext{
${ }^{1}$ Según AAVV. (1999). Diccionario de la Música española e Hispanoamericana, p. 516, tomo 9, firmado por Ramón Sobrino, pudo estar publicado alrededor de este año.

${ }^{2}$ En el catálogo de la Biblioteca Nacional pone con interrogante 1820, ello no sería posible si su vida transcurrió entre 1819 y 1885 como figura en el dicho catálogo; sí lo sería si vivió entre 1791 y 1857 y es el José Soberano Ayala que aparece en Diccionario de la Música española e Hispanoamericana, tomo 10, p. 11, firmado por Emilio Casares, y en Diccionario Saldoni, tomo III p. 151. PRECIADO, Dionisio. (1978)Don Hilarión Eslava..., p. 239 indica: ca, 1845.

${ }^{3}$ Según AAVV, op. citada, Tomo 10, pp. 675 y 676, firmado por Vicente Galbis, se llama Nuevo método general de solfeo, y cree que pudo estar publicado hacia 1857 [Desde luego en el libro pone Nuevo método completo de solfeo y no general]; y PRECIADO, Dionisio: obra citada, asienta que fue en el año 1856.

${ }^{4} \mathrm{La}$ imprenta viene referenciada en la información bibliográfica de la Biblioteca de Catalunya, pero ninguna mención hay a ella en el libro. En cuanto al año de edición, también lo supone la dicha información bibliográfica, desde luego antes de 1897, pues hay en la página 2 una mención de la Academia Universal de Ciencias y Artes de Bruselas en la que dice que en sesión de junio de 1897 acordaron concederle al autor el Diploma de Miembro Titular con las insignias de Honor y la Medalla de $1^{\text {a }}$ Clase en consideración al mérito de este libro.
} 


\section{OBRAS DIDÁCTICAS Y TÉCNICAS CONSULTADAS}

ABELlán AlCARAZ, A. Ginés. (1979). Solfeo manuscrito. Madrid: Unión Musical Española.

ALAIN, Olivier. (1969). L'harmonie, deuxième édition mise a tour. París : Presses Universitaires de France.

ALDÁs CONESA, Tomás. (s.f.). Teoría del Solfeo, $2^{\circ}$ curso, $6^{\text {a }}$ edición. Valencia: Profesional Edición S. A.

ALIAGA, ? (1847). Cartilla de música, o sea, la música en el bolsillo. Madrid: Imprenta de don Alejandro Gómez Fuentenebro.

BARCELÓ AMORÓS, José Luís. (2001). Lenguaje musical. Ritmo, Primero de Grado Medio. Madrid: Real Musical.

BARRIO, Adelino. (1988). La modulación en el solfeo. Madrid: Musicinco S. A.

BECKER, Georges. (1934-1936). Cours complète de Solfège en huit volumes. París: Alphonse Leduc, Co.

BLANQUER PONSODA, Amando. (1975). Técnica del contrapunto. Madrid: Real Musical, S. A.

(1989). Análisis de la Forma Musical (Curso teórico- analítico). Valencia: Piles.

BOBADILLA, Emilio. (1893). Solfeo: crítica y sátira. Madrid: Imp. de Manuel Tello.

CABALLERO, Manuel. (1880). Gramática Filarmónica o Tratado de los Elementos Generales de Música. Palencia: Oficina de José de Orga.

CAPLAROLS Y MARUÑS, Pedro Pablo. (1825). El maestro y discípulo de música. Método breve y fácil de elementos generales de música, útiles y necesarios a todos los que quieran aprender este bello arte, arreglados al estilo moderno, con definiciones claras y fundamentales y copiosidad de ejemplos para mayor ilustración. Barcelona: Imp. de José Torner.

CHAILlEy, J: y CHALLAN, H. (1947). Théorie Complète de la Musique, $1^{\circ}$ volumen. París: Alphonse Leduc.

DE ARABAOLAZA Y GOROSPE, Gaspar. (1927). Lecciones Teóricas de Solfeo,. Zamora: Imp. y Lib. Hijo de M. Rodríguez.

D'INDY, Vincent. (1897-1907). Cours de Composition Musicale, 4º Vol. París : Durand.

GEDALGE, André. (1987). Trattato della Fuga. Milán: Edizioni Curci. Versión italiana de Renato Parodi, título del original Traité de la Fugue, París, Enoch \& Cie., 1952.

GOMAR, José Mª (1956). Teoría de la música, primer curso. Valencia, (sin editorial). 
IBARRA, José. (1958). Método práctico de Solfeo, con acompañamiento de piano, cuarto curso (superior) solfeo artístico. Madrid: Editorial Música Moderna.

LA RUE, Jan. (1989). Análisis del estilo musical. Barcelona: Labor.

LAZ. (1941-1943). Método graduado de solfeo, Libro I al V. Barcelona: Boileau, co.

LEMOINE, Henry. (1910). Solfeo de los solfeos. Paris: Bruselas: Henry Lemoine.

LORAS VILLALONGA, Roberto. (2003). Lecciones de solfeo a 2 y 3 voces. Salvador Giner. Valencia: Rivera Editores.

LORAS VILLALONGA, Roberto; MEDINA SENDRA, Dolores A. y JORDÁ TORRES, ma Cristina. (2001). Aspectos Teóricos del Lenguaje Musical Vol. 2 y Vol. 3. Valencia: Rivera Mota S. L.

LLACER PLA, Francisco. (1982). Guía analítica de formas musicales para estudiantes. Madrid: Real Musical, S. A.

MARTÍ PUCHADES, Eduardo. (1996). Lenguaje Musical Artístico. Valencia: Piles. (1997). Lenguaje Musical Artístico II. Valencia: Piles. (1998). Lenguaje Musical Artístico III. Valencia: Piles.

PIRFANO, Pedro. (1975). 34 Lecciones de Soleo a todos los niveles, (melódico - rítmicas) con acompañamiento de piano. Madrid: Unión Musical Española.

PISTON, Walter. (1987). Armonía. Barcelona: 2001 Idea Books, S. A., colección Idea Música, director de la colección Juan José Olives, traducción Juan Luís Milán, título del original Harmony, Nueva York, W. W. Norton \& Company.

RIEMAN, Hugo. (1927). Bajo cifrado. Barcelona: Labor (1928). Fraseo Musical. Barcelona: Labor

(1950). Composición Musical. Manual de la teoría de las formas musicales, $3^{\mathrm{a}}$ edición. Barcelona: Labor

ROCA Y BISBAL, Juan Bautista. (1837). Gramática musical dividida en catorce lecciones. Obra utilísima paral os que quieren aprender la música; resumen para los que la saben e introducción para todos los métodos. Barcelona: (sin editorial).

RUIZ MANZANARES, Jacinto. (s.f.). Nociones de Harmonía. Madrid: Unión Musical Española.

SANUY, Monserrat y GONZÁLEZ SARMIENTO, Luciano. (1969). Orff - Schulwerker, Música para niños. Madrid: U. M. E.

SIMÓ ESCANAVERINO, Bartolomé. (1923). Teoría e historia de la Música. Tomo II Palma de Mallorca: Establecimiento Tipográfico de Guasp. 
SOCIEDAD DIDÁCTICO MUSICAL. (s.f.). El Progreso Musical, Partes primera a tercera. Madrid: Sociedad Didáctico Musical, S. A.

SPEARDERO, R. (19--?). Breve complemento de Solfeo. Barcelona: A. Boileau y Bernasconi.

TORRE BERTUCCI, José. (1947). Tratado de contrapunto. Buenos Aires: Ricordi Americana S.A.E.C.

TURINA Joaquín. (1931). Tratado de Composition Musicale, 4 Vol. París: Schola Cantorum.

VELASCO DE VELASCO, Manuela. (1907). Apuntes musicales: primero, segundo y tercer año de solfeo: nociones sobre la manera de escribir la música dictada: conocimientos preliminares de armonía. Guadalajara: Imp. Del Colegio de huérfanos de la Guerra.

WILLEMS, Edgar. (1954). Le rythme musical. Rythme, Rythmique et Métrique. París : Ed. P. U. F. res: Eudeba.

(1976). La preparación musical de los más pequeños. Buenos Ai-

ZAMACOIS, Joaquín. (1982). Curso de formas musicales, 5ª edición. Barcelona: Labor, S. A.

(1986-1989). Tratado de Armonía, Libro I, 11ª edición, Libro

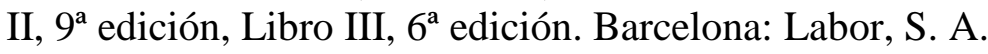

\section{OTRAS OBRAS Y ARTÍCULOS CONSULTADOS}

AAVV. (1999) CLAVE, diccionario de uso del español actual, proyecto y dirección Concepción Maldonado González. Madrid: Ediciones SM.

AAVV. (1926). Enciclopedia Universal Ilustrada Europeo - Americana. Madrid: Espasa Calpe S. A.

AAVV. (1980). The new Grove Dictionay Music \& Musicians, director de la obra Stanley Sadie. Londres.

BOLETÍN MUSICAL DE VALENCIA. (1898). $\mathrm{n}^{\circ}$ 165, de 30 agosto. ESCUELA NACIONAL DE MÚSICA. Programas oficiales de Solfeo y Piano. (Biblioteca Valenciana).

COUTURE - DIABET. (1987). Salvat Universal diccionario enciclopédico. Barcelona: Salvat Editores S. A.

DÍAZ, Maravillas y LLORENTE, Joxean. (1998). "El lenguaje musical en la escuela de música" en Eufonía. Didáctica de la Música, n 11, año IV, abril. Barcelona: Graó. 
ECO, Humberto. (1988). Cómo se hace una tesis, veintidós edición. Barcelona: Editorial Gedisa, S. A. Título del original italiano: Come si fu una tesi di laurea, Tascabili Bompiani, 1977.

ESCUELA NACIONAL DE MÚSICA Y DECLAMACIÓN. (1891). PROGRAMA OFICIAL DE LA ENSEÑANZA DE SOLFEO. Madrid: Imprenta de José M. Ducazcal. (Biblioteca del Conservatorio Superior de Música de Madrid).

ESPAÑA. INSTRUCCIÓN PÚBLICA. (1876). MEMORIA presentada por la ESCUELA DE MÚSICA Y DECLAMACIÓN en la Exposición Internacional de Filadelfia. Madrid: Imprenta y Fundición de J. Antonio García. PROGRAMA de la enseñanza de Solfeo, con las materias y estudios que comprenden cada año de los tres de que consta. (Biblioteca del Conservatorio Superior de Música de Madrid).

GIRADLES, Andrea. (1998). "Desde el sonido a el símbolo y a la teoría" en Eufonía. Didáctica de la Música, nº 11, año IV, abril. Barcelona: Graó.

HODGES, Donald A. (1992). Universidad de Texas, en San Antonio, EEUU, "Adquisición de habilidades de lectura musical" en Hanbook of research on music teaching and learning, New Cork, Richard Colwell - Schirmer books.

Instrucciones para el buen desempeño de las enseñanzas y para el régimen y disciplina del Real Conservatorio de Música y Declamación. Las firma el Director Ventura de la Vega, en Madrid a 30 de enero de 1861. (Biblioteca del Conservatorio Superior de Música de Madrid).

JORQUERA JARAMILLO, María Cecilia. (s.f.). Lectoescritura musical: fundamentos para una didáctica., Centre d'Educació Musical de Terrasa. Disponible en web: http://musica.rediris.es

LORAS VILLALONGA, Roberto. (2007). El Patriarca de la música valenciana. Valencia: Editorial de la UPV.

MINISTERIO DE FOMENTO. INSTRUCCIÓN PÚBLICA. (1892). MEMORIA acerca de la ESCUELA NACIONAL DE MÚSICA Y DECLAMACIÓN DE MADRID.

Escrita para ser presentada en la EXPOSICIÓN UNIVERSAL DE LA MÚSICA Y DEL TEATRO que ha de verificarse en Viena en el año de 1892. Madrid: Imprenta de José M. Ducazcal. (Biblioteca del Conservatorio Superior de Música de Madrid).

PROGRAMA DE SOLFEO dentro del Programa de las enseñanzas de la Escuela Nacional de Música y Declamación, a fecha de 1 de agosto de 1875 en Madrid. Firmado por Emilio Arrieta (todo él manuscrito imposibilitado de fotocopiar). Biblioteca del Conservatorio Superior de Música de Madrid.

ROUGNON, Paul. (1945). La música y su historia, resumen histórico. Buenos Aires: Caymi.

WOLFE, Joe. (1997).Cómo escribir una tesis de grado? traducido por PARIENTE, José; adaptado por VERA, Raúl, 1999. S. L. Disponible en web: http://www.monografías.com y http://www.abcdatos.com/tutoriales/apuntes 